DE GRUYTER

SAUR

\title{
LIBRARIES, ARCHIVES AND MUSEUMS AS DEMOCRATIC SPACES IN A DIGITAL AGE
}

Edited by Ragnar Audunson, Herbjørn Andresen, Cicilie Fagerlid, Erik Henningsen, Hans-Christoph Hobohm, Henrik Jochumsen, Håkon Larsen and Tonje Vold 
Libraries, Archives and Museums as Democratic Spaces in a Digital Age 


\section{Current Topics in Library and Information Practice}




\section{Libraries, Archives and Museums \\ as Democratic Spaces in a Digital Age}

Edited by

Ragnar Audunson, Herbjørn Andresen, Cicilie Fagerlid, Erik Henningsen, Hans-Christoph Hobohm, Henrik Jochumsen, Håkon Larsen, and Tonje Vold 
ISBN 978-3-11-062954-5

e-ISBN (PDF) 978-3-11-063662-8

e-ISBN (EPUB) 978-3-11-063281-1

ISSN 2191-2742

DOI https://doi.org/10.1515/9783110636628

\section{(cc) BY-NC-ND}

This work is licensed under the Creative Commons Attribution-NonCommercialNoDerivatives 4.0 International License. For details go to http://creativecommons.org/licenses/by-nc-nd/4.0/.

\section{Library of Congress Control Number: 2020942338}

\section{Bibliographic information published by the Deutsche Nationalbibliothek}

The Deutsche Nationalbibliothek lists this publication in the Deutsche Nationalbibliografie; detailed bibliographic data are available on the Internet at http://dnb.dnb.de.

(c) 2020 Ragnar Audunson, Herbjørn Andresen, Cicilie Fagerlid, Erik Henningsen, Hans-Christoph Hobohm, Henrik Jochumsen, Håkon Larsen, Tonje Vold, published by Walter de Gruyter GmbH, Berlin/Boston

This book is published with open access at www.degruyter.com.

Typesetting: le-tex publishing services $\mathrm{GmbH}$, Leipzig

Printing and binding: CPI books $\mathrm{GmbH}$, Leck

www.degruyter.com 


\section{Acknowledgments}

The research on which the contributions in this anthology is based would not have been possible to undertake without the generous research grant our project received from the KULMEDIA program of The Research Council of Norway. We take this opportunity to express our gratitude to the council for their support.

We would also like to express our gratitude to colleagues from the international LIS community who volunteered to peer review the chapters in this volume, thereby contributing in important ways to the quality of the papers presented in this book.

Our gratitude also goes to the respondents who took the time to fill in questionnaires and take part in qualitative interviews, all the LAM-organizations who opened their doors to us and the users who accepted our presence when doing our observations.

Oslo/Tromsø/Uppsala/Borås/Copenhagen/Potsdam/Chur/Budapest

November 20, 2019

The ALMPUB research team 



\section{Contents}

\section{Acknowledgments - V}

Ragnar Audunson, Herbjørn Andresen, Cicilie Fagerlid, Erik Henningsen, Hans-Christoph Hobohm, Henrik Jochumsen, and Håkon Larsen

1 Introduction - Physical Places and Virtual Spaces:

Libraries, Archives and Museums in a Digital Age - 1

\section{Part I: Policies}

Kerstin Rydbeck and Jamie Johnston

2 LAM institutions: a Cross-country Comparison of Legislation and Statistics on Services and Use - 25

Erik Henningsen and Håkon Larsen

3 The Digitalization Imperative: Sacralization of Technology in LAM Policies — 53

Roger Blomgren

4 The Institutions Go Digital -73

\section{Sigrid Stokstad}

5 Norwegian National Policies for Digitalization in the LAM Sector Imperative and Implementation — 91

Máté Tóth

6 Organization and Funding of Digitization in the Visegrád Countries — 111

Andreas Vårheim, Roswitha Skare, and Sigrid Stokstad

7 Institutional Convergence and Divergence in Norwegian Cultural Policy: Central Government LAM Organization 1999-2019-133

\section{Part II: Professions}

Ragnar Audunson, Hans-Christoph Hobohm, and Máté Tóth

8 LAM Professionals and the Public Sphere - 165 
Herbjørn Andresen, Isto Huvila, and Sigrid Stokstad

9 Perceptions and Implications of User Participation and Engagement in Libraries, Archives and Museums - 185

Roswitha Skare

10 Like, Share and Comment! The Use of Facebook by Public Libraries and Museums: A Case Study from Troms $\varnothing$, Norway - 207

Kjell Ivar Skjerdingstad

11 Reading Between the Shelves - the Library as Perspective in Life and Profession -225

\section{Part III: Users}

Andreas Vårheim, Henrik Jochumsen, Casper Hvenegaard Rasmussen, and Kerstin Rydbeck

12 The Use of LAM Institutions in the Digital Age - 247

Hans-Christoph Hobohm

13 Libraries and Democracy in Germany.

As Perceived by the Public in Contrast to the Professionals - 271

Cicilie Fagerlid

14 Democratic Coexistence, Tiny Publics and Participatory Emancipation at the Public Library 285

Tonje Vold and Sunniva Evjen

15 Being, Learning, Doing: A Palace for the Children? - 305

Geir Grenersen

16 Libraries and the Sámi population in Norway - Assimilation and Resistance - 325

Erik Henningsen and Håkon Larsen

17 The Joys of Wiki Work: Craftsmanship, Flow and Self-externalization in a Digital Environment — 345

The Authors -363

Index -367 
Ragnar Audunson, Herbjørn Andresen, Cicilie Fagerlid, Erik Henningsen, Hans-Christoph Hobohm, Henrik Jochumsen, and Håkon Larsen

\title{
1 Introduction - Physical Places and Virtual Spaces: Libraries, Archives and Museums in a Digital Age
}

\begin{abstract}
The research that will be presented in this book documents a seeming paradox: in spite of massive digitalization of our everyday lives, libraries, archives, and museums are heavily used as physical spaces and meeting places. The role of LAM-institutions as physical spaces seems to be increasing. Does the massive digitalization we are experiencing lead to a growing need for and appreciation of physical spaces and meeting places?
\end{abstract}

In what direction is our digitalized society steering? Are we heading towards more democracy and more community, due to the forms of crowdsourcing new technologies open up for (Landemore 2013)? Will digitalization lead to increased participation, collaboration, transparency, and thus a deepening and widening of democracy and community, or will it rather result in technologically advanced ways of "talking to ourselves" in increasingly closed circuits of communication or "echo chambers" (Sunstein 2001), i.e. in isolation instead of more community? Will digitalization create new platforms for public discourse and communication between citizens and between citizens and government, or will it result in degradation of public discourse, with mockery and harassment taking the place of rational and respectful arguments? Will it empower citizens or facilitate increased surveillance and a transfer of power from citizens to the state and giant corporations like Google, Facebook and Amazon (Braman 2007)?

From these remarks it might appear that we are standing at a crossroad and that our digitalized society is heading towards the realization of either a dark or a bright vision of the future. However, the contradictory tendencies we have highlighted should not necessarily be treated as dichotomies or mutually excluding scenarios. The development of our digitalized society can be seen rather as multidirectional. It might, for example, simultaneously lead to increased state and corporate surveillance power and increased empowerment of citizens. Developments in the digitalized society might also follow different paths related to the dilemmas and challenges described above. This underscores the scope of opportunities that exists at this juncture for various kinds of actors to influence the direction of development of the digitalized society. To create knowledge and understanding that can help us realize the positive potentials of digitalization and avoid the threats is therefore of fundamental importance. 
In order to shed light on the possible contributions of LAM institutions to the solving of these challenges, this book will address the following questions:

- How is the balance between the digital and analogue roles of LAM institutions, as meeting places and providers of knowledge and information? Is it useful, or even possible, to distinguish between the digital and the analogue, or do they constitute one socio-material reality?

- To what extent do LAM institutions in their policies and practices open for forms of digital user participation?

- What political visions of LAM-institutions as democratic public spaces are currently articulated by European governments and how does digitalization feature in these visions?

- How do professionals in the LAM fields perceive their institutions' roles as democratic public spaces in a digital age?

- What characterizes the public's uses of libraries, archives, and museums in the digital age? What roles do these institutions play in the different life spheres of their users? How do modes of usage shape and form for example libraries and how do new trends in design of libraries change, shape, and form use?

\section{Our Point of Departure}

Libraries, archives and museums have traditionally been institutions empowering their users by providing equal access to knowledge, culture, and information of vital importance. ${ }^{1}$ This holds true even in the present situation, characterized by the ubiquity of the digital. Today, large sections of the population in European countries relate to digital platforms and digital communication in their professional lives, at home, in their social life, and leisure time activities etc. Whereas other institutions of the public sphere, such as printed newspapers, have experienced a dramatic decline in use in recent years, this has not been the case for LAM-institutions. Today, in many European countries, libraries and museums are still used by approximately 50 percent of the population. Our overriding question, then, is: how do these institutions function as public spaces in the digitalized society? Can these institutions be instrumental in realizing what we in another context called "a civilized information society" (Audunson 2001) and what roles do they play in ongoing transformations of the public sphere described above? Such questions are at the base of the studies that are presented in this book.

1 All libraries have traditionally had this role. In this project, however, we will focus upon public libraries. 
As participants of the research project "The ALM-Field, Digitalization and the Public Sphere" (ALMPUB), ${ }^{2}$ the contributors to the book have carried out a broad range of studies of libraries, archives, and museums, in various European countries. The ALMPUB-project comprises research from the Nordic countries as well as from Germany, Hungary, and Switzerland. ${ }^{3}$ A common thread to the studies that have been carried out as a part of the project is a probing of the changing roles of LAM-institutions as public spaces. The book will approach this subject matter from three principal angles: through inquiries into national policies pertaining to LAM-institutions, through inquiries into the professions that belong to these institutions, and through inquiries into the public or users of the institutions.

When engaging with these questions, the contributors to the book depart with an understanding of LAM-institutions as complex public spaces. On the one hand, these are governmental institutions and managed in accordance with the administrative procedures of public bodies. As such, they are instruments for the implementation of central and local governments' cultural and educational policies. On the other hand, libraries, archives, and museums are institutions whose roles and operations to varying degrees are shaped by the interests and needs of their users, or by "the people". Put differently, LAM-institutions are meeting places for the public where the public have played a vital role in setting the agenda and defining their purposes as meeting places. One of the major conclusions from our ethnographic studies of public libraries is that these are multifunctional spaces. In libraries visitors move smoothly and without friction between different roles and life spheres. During one and the same visit they can act in the roles of students, citizens, friends, next of kin etc. (Aabø and Audunson 2012). Fagerlid's ethnographic studies from several local branches of the Oslo public libraries presented in this book dig deeper into the findings of Aabø and Audunson from 2012.

2 In the project we used the acronym ALM, as this is common in Norway. In this book we will, however, use the acronym LAM when referring to the three institutions, as this is common in the international scholarly literature.

3 The selected countries are all undergoing similar processes related to digitalization and globalization but represent different contexts which might be fruitful when studying LAM institutions in relation to the public sphere. Internationally, the Scandinavian countries are regarded to represent a Nordic model and have taken up the responsibility of laying the infrastructural foundations for the public sphere (See Engelstad, Larsen and Rogstad 2017; Larsen 2018). Hungary has, in spite of its socialist past, since the 1970s-1980s developed its public library system according to Scandinavian and Anglo-Saxon ideals (See Audunson 1996; Audunson 1999). Now, Hungarian politics have embarked upon a nationalistic course, which might be relevant for our research questions. In Germany, running costs per capita for public libraries are much lower than in the Scandinavian countries; for example only one fifth in Denmark. Switzerland has its particular public sphere-traditions with frequent referendums. 
Another point of departure for the contributors to the book is an understanding of LAM-institutions as democratic public spaces. This should hardly come as a surprise to readers familiar with academic or political debates on LAM-institutions. Over the last years, the notion that libraries, archives, and museums contributes to democracy in important ways has been foregrounded in cultural policy debates and, increasingly, LAM-institutions have come to profile themselves in this capacity. In the Nordic countries, where many of the studies featured in this book have been carried out, this line of thinking has been elevated into an important - if not the most important - political legitimation for public finance of institutions of the cultural sector. As far as libraries are concerned, this is reflected in recent changes in library legislation in Norway, Sweden, and Finland, focusing upon the libraries' role as meeting place and arenas for debate (Norway), institutions promoting the free formation of opinion (Sweden), and active citizenship and democracy (Finland). We find similar trends within the museum field and the archives field. The topic of the Norwegian national meeting for museums in 2019 was Democracy, Digitalization and Bildung. But is this focus on the LAM institutions' democratic role first and foremost a Nordic phenomenon? In one of the chapters, based on a survey with representative samples of the adult population in all our countries, Hobohm compares German versus Scandinavian attitudes to libraries as institutions promoting democracy.

Our aim in the chapters that follow is to develop analytical accounts of LAMinstitutions' roles as democratic public spaces that go beyond the idealised discourses that are currently in circulation. In doing so, we take as our starting point the fundamental criticism voiced by Paul Jaeger et al. (2013); namely that discussions on the relationship between libraries and democracy lack empirical evidence. According to Jaeger, these discourses tend to proclaim the institutions' role as democratic public spaces more than documenting it. More specifically, the contributors will attend to this task through empirical and theoretical specification of the entailments of LAM-institutions roles as democratic public spaces. Rather than simply affirming that LAM-institutions fulfil important democratic roles, we seek to explicate whether and in what ways they come to fulfil these roles. As a part of this endeavor, we seek also to specify ongoing changes to these roles that are brought on by digitalization, from different empirical and theoretical perspectives.

\section{Libraries, Archives and Museums as Institutions - a Historical Perspective}

Libraries, archives, and museums are organizations and they belong to institutionalized fields. Our study object is the institutions of library, archives, and museum. We are studying changes within these individual institutions (in the 
singular), as well as the institutions seen as a cluster (LAM). Our actual empirical studies are of actors operating within or at the border of the institutions. We study professionals employed within concrete archives, libraries, and museums (organizations), we study individual users of the offering of such organizations, and we study the cultural policies related to libraries, archives, and museums. In the policy studies, the authors have analyzed concrete policies related to both the institutions in the abstract, and to concrete organizations, such as the national library or the national archive. When wielded together, the individual studies provide an understanding of ongoing changes within the institutions of library, archives, and museum. ${ }^{4}$

Libraries, archives and museums have developed historically as institutions from common roots (Given and McTavish 2010). They are all closely linked to the nation building project of the eighteenth and nineteenth centuries, which needed museums and libraries to document the national culture and archives to establish efficient administrative and governmental procedures; they are linked to the age of enlightenment which needed institutions to spread knowledge also to lay people; they are linked to the growth of the bourgeois public sphere, also in the late eighteenth and early nineteenth centuries and they are linked to the development of modern universities according to the norms of Humboldt. Modern science and the search for knowledge presupposed institutions where academics could have access to the works of other academics, thus contributing to establishing a system of scholarly communication. In some instances, they made up one integrated organization. The British Museum was the library where Karl Marx in the middle of the nineteenth century was sitting when writing Capital. The British Library was singled out as an independent institution as late as 1973.

Libraries, archives, and museums have in common that they have been important institutions of the public sphere of modern societies. More specifically, libraries, archives, and museums are similar in that they take on four important roles: they are memory institutions guarding our collective and public memory, our cultural heritage. As memory institutions, they provide knowledge and cul-

\footnotetext{
4 According to American sociologist W. Richard Scott, "Institutions comprise regulative, normative, and cultural-cognitive elements that, together with associated activities and resources, provide stability and meaning to social life" (Scott 2014, 56). This definition can be directly applied to the institutions under analysis in our book: most people know what a library, an archive, or a museum is and what one usually does when present at one, simply by hearing the word spoken in a sentence (cultural-cognitive). Most of us think that these institutions should be public and accessible, as part of our democracy (normative). These institutions are regulated in certain ways by public bodies though cultural polices (regulative). Due to the cultural-cognitive, normative, and regulative aspects of our institutions, they tend to be similar across national borders.
} 
tural expressions to large sections of the population. Libraries, archives, and museums have exerted and continue to exert as agents of popular enlightenment, and they have a role as local meeting places and arenas of participation in public space.

Even though there are important commonalities between libraries, archives, and museums and in spite of them frequently being subsumed under the joint category of memory institutions, they are simultaneously constituted as separate institutional fields via for example institution specific educational programs, institution specific professional organizations, conferences, journals, institution specific legislation etc. This institutionalization of a library, and an archival and a museum field might demarcate the LAM-institutions from each other. Vårheim, Skare and Stokstad's analysis of the rise and fall of the Norwegian LAM authority in this volume illustrates this.

Realizing the public potential in artefacts carrying knowledge and cultural content otherwise locked in private collections and securing public access to these collections is in many ways the basic idea and raison d'être of libraries, archives, and museums. They have actively strived to reach all segments in society and mediate the content of their collections to all social strata. Taking libraries as an example, the American library historian Wayne Wiegand documents how public libraries from the very start served as arenas integrating also groups who did not have access to other public sphere arenas, e.g. workers, women and teens. ${ }^{5}$ As a corollary of this, libraries, archives, and museums have been public meeting places open to wide sections of the populace. A wide range of meetings and debates open for all took place in libraries already in the first decades of the twentieth century and Wiegand documents how the public from early on had an influence over the agenda of their local library. The role of libraries in their communities, e.g. the balance between popular fiction on one hand and high-quality fiction and non-fiction on the other, were always a negotiated compromise between the librarians and the citizens of the community the library in question served (Wiegand 2015).

When the modern idea of public librarianship was implemented in European countries, it was naturally moulded and adapted to different national contexts, for example the impact of the popular movements in Sweden, the broad movement of popular colleges in Denmark, the struggle for independence from Sweden in Norway, and, in all the Nordic countries, the dominating position of the social democratic welfare state from 1945 and onwards. In Germany, Hungary, and Switzerland, other national trends and traditions had impact on the implementation of

5 The integration of colored people is more doubtful. In the southern states of the US, public libraries were also segregated. 
the public library model in particular and the development of LAM institutions in general. For example, in Germany the dominating party in establishing the German welfare state in the first decades after WW2 was CDU, a relatively conservative Christian-Democratic Party (van Kersberger 1995), as opposed to the social democratic parties of the Scandinavian countries, which kept socialism as a programmatic vision well into the latter half of the 1970 s. $^{6}$

The modern concept of a public library was in Norway implemented by Haakon Nyhuus, library director in Oslo from 1898 onwards. In the years immediately preceding the appointment of Nyhuus, annual circulation in Oslo's public library varied between 20,000 and 30,000 per year, i.e. from 0.09 to 0.13 volumes per inhabitant. In 1900, when Nyhuus had been in office for two years, that figure had exploded into 310,000, i.e. 1.2 volumes per inhabitant. In 1915 that figure had more than doubled to 660,000 volumes, i.e. 2 volumes per inhabitant yearly. These figures illustrate the crucial role of the library in integrating ordinary people - women as well as men, workers as well as middle class, youngsters as well as adults - in the public and that libraries have been important in establishing a literary public sphere.

Museums were vital in creating one basis for a unified national discourse a national and cultural identity - by giving citizens access to the national cultural heritage. Early museum collections were first established for facilitating scientific enquiry, and not primarily for public access. In the nineteenth century, museums were also used as instruments for creating one basis for a unified national discourse, a national and cultural identity. To this end, museums of cultural heritage and history of industries and the like have developed collections in order to preserve buildings and other cultural heritage objects which were about to disappear from the rural scene and modern way of life. Exhibitions open to the public had partly other origins than the endeavors of creating museum collections, such as oddities, entertainment events, or the world exhibitions from the mid-nineteenth century onwards. Museums as places for exhibitions and dissemination of knowledge to the public followed suit. The Norwegian Folk Museum was established in 1894, and Bergen Museum established the first permanent building for exhibitions in Norway in 1897. In modern society, most museums combine a scientific approach with preservation of heritage and outreach activities. Their mission as institutions for the public can be taken for granted.

6 In spite of these differences, there were fundamental similarities. Haakon Nyhuus, the Norwegian public library pioneer, and Szabo Ervin, who implemented the modern public library concept in Hungary early in the twentieth century, never communicated as far as we know. Nevertheless, they had the same reform ideas and implemented the public library ideas stemming from the United States at approximately the same time (Audunson 1996). 
Archives and the archivist profession deal with what is sometimes called the secondary value of archival materials. The primary value is to evidence actions and events. The secondary value is as information and heritage and is often able to shed light on aspects of past events beyond the intended purpose of the records. The archivist profession has traditionally been regarded as an auxiliary profession to the historians. Early dissemination activities have been directed towards the professional community, such as printed editions of transcribed ancient diplomas. Since the early twentieth century, there has been a modest expansion of the user communities to include amateur historians and genealogists. However, the threshold for finding and interpreting old handwritten materials remained too high for the larger public. Reaching out to the general public is therefore, generally speaking, a more recent aspiration for archives than for libraries and museums. Access to archival materials, and outreach as part of the archivists' professional repertoire, has predominantly expanded to the general public and gained momentum through digitalization of much sought sources. Outreach programs and physical events prepared by archival institutions may not necessarily be a direct result from digitalization as such, but their recent growth have likely been stimulated by the increased demand and visibility instigated by the archives' digital presence.

The development of libraries, archives, and museums has not been a unilateral top-down process structured by governmental and professional authorities. Popular movements have also been active in establishing and running libraries, archives, and museums. In the Nordic countries, public libraries in their formative years were closely associated with democratic popular mass movements such as the trade union movement, the temperance movement the folk high school movement, and countercultural movements representing the linguistic, cultural, and religious periphery against the elites of the centre. Voluntary work and the effort of local enthusiasts have often been important in creating and running local museums. Although archives at a national level are relatively strictly regulated and governed via law and governmental authorities, local enthusiasts and local associations such as local history associations have often been instrumental in establishing local history archives, as have popular mass movements such as the labour movement and the temperance movement.

Focusing upon libraries, Söderholm and Nolin identify three historical waves of community engagement. In the early twentieth century, during the first wave, the focus was upon literacy and public education, the second wave in the late 1960s and 1970s focused upon "radical” grassroots work for targeted social inclusion, while the third wave which took off around 2000, and still lasts, focuses upon community hubs, open social space, and diversity (Söderholm and Nolin 2015, 253). In an adapted form, these three waves are probably also valid for mu- 
seums (see for example Simon 2010) and - with some hesitations - for archives as well. The upsurge in interest in genealogical research and, not least, the upsurge in interest in local community research is reflected in the high number of participants in the local history wiki which Erik Henningsen and Håkon Larsen present in one of the chapters in this volume. In accordance with Söderholm and Nolin, these processes should be viewed as cumulative or sedimentary. In the transition from one historical wave to another, the focus and values of the former wave is not left behind or replaced by new values but becomes an integrated part of an extended social role. Literacy and public education, for example, remain important elements in the social role of the LAM-institutions even today.

\section{Theoretical Perspectives}

From this brief historical account, it should be clear that one reason for describing libraries, archives, and museums as "democratic" public spaces is that they contribute to the empowerment of people. To provide broad sections of the population access to information, knowledge, and cultural expressions has been - and continues to be - a core mission of LAM-institutions. By gaining access to these resources, people become better equipped to exert citizenship and in other ways to participate in society. A survey undertaken in our six partner countries (Norway, Sweden, Denmark, Germany Hungary, Switzerland) clearly documents that libraries as well as museums and archives are used in these ways today. As documented in another publication from the ALMPUB-project, a high proportion of the users that responded to the survey reported that libraries, archives, and museums sometimes or often are important sources for accessing citizenship relevant information - information regarding their rights and obligations as citizens, keeping themselves generally updated as citizens, informing themselves in issues they are particularly interested in as citizens, and making decisions as citizens. Here we find the highest proportion among the users of archives, where more than 60 percent report that they access such information in archives (Audunson et.al. 2019b). However, when we describe libraries, archives, and museums as democratic public spaces in this book, this points beyond the roles these institutions take on as (publicly accessible) repositories of information, knowledge, and cultural expressions. It points also to the institutions' role as arenas of public action and interaction. How can this aspect of LAM-institutions' roles as democratic public spaces be grasped theoretically?

When dealing with this question it is essential to sort (scientific) explanation and analysis from political legitimation. Public libraries, archives, and museums differ when it comes to their legitimating purposes. A national art museum is there 
to document the national art heritage and promote knowledge and experience related to that. A natural history museum is there to document the development of the natural history and promote knowledge and experiences related to that. Archives are there to document decision-making processes, administrative procedures, and case handling of public institutions. Public libraries, however, tend to have more porous legitimations related to a multiplicity of life spheres and policy areas. The public library, therefore, although a remarkably durable institution, tends to have its raison d'être continuously questioned. Documenting its value is challenging (Huysmans and Oomes 2013). A range of justifications have been offered seeking to connect libraries with trending topics relating to their respective social context: they may be "media-lending facilities", "information facilities", "agencies for freedom of opinion and information", "learning centres and educational institutions", "cost centres with high return on investment", "analogous places in digital dematerialisation" or, more recently, "communicative places for democratic opinion formation". This results in evolving justifications linked to current trends which seek to explain why libraries exist, generally while convincing funding bodies of their legitimacy. The most striking aspect of these arguments - even as they actually appear in mission statements, strategy papers, and library laws - is their fundamentally normative nature.

Policy often lacks the kind of empirical underpinning that could provide arguments based on current practice or its historical development with facts. Alternatively - or additionally - no theoretical justification has been developed by any discipline - political science, economics, sociology, anthropology etc. - capable of providing the well-argued conceptual framework for analysis and thought required to explain why the library institution is actually needed, and why it seems to have continuously endured despite all adversities during all time periods and in all forms of society and institutions. ${ }^{7}$ The normative framing of the library's role is particularly noticeable in library laws, which also serve as an excellent barometer for observing social cycles and cultural contexts. Here, "social integration enabling democratic participation" ${ }^{\prime}$ is mentioned with increasing frequency. In

7 This prompted leading representative of the American Library Association (ALA) Michael Gorman (2015) - to take just one prominent example - to express his astonishment that, 15 years after the first edition of his famous "manifesto" "Our Enduring Values", the library (be it "public" or "academic") has yet to lose its importance despite the emergence of so many technical upheavals and innovations (from Google to smartphones and social media) in recent years. It continues to demonstrate its "enduring values", especially in critical periods which Gorman links explicitly to the role of libraries in democracy. However, his evidence remains anecdotal and is taken as an article of faith (cf. Marci-Boehnke 2019).

8 E.g. in one German State Library Law we read: "Sie [Bibliotheken] sind Orte der Wissenschaft, der Begegnung und der Kommunikation. Sie fördern den Erwerb von Wissen und damit die 
Europe's Nordic countries, the extent to which culture and library legislation assigns libraries a responsible and active role in democracy is striking (see page 3 earlier; see also Audunson et al. 2019b). ${ }^{9}$

Habermas' Structural Transformation of the Public Sphere (1989[1962]) has had a strong and lasting impact in the Nordic countries. The book was translated and reviewed relatively early in the Nordic countries, while Anglo-American discussion around the "public sphere" began much later due to a delayed translation into English. Perhaps this also explains Habermas' late, but in recent years all the more hotly disputed, reception in international library science (e.g. Buschman 2003, 2019; Jaeger and Burnett 2010; Vårheim et al. 2019; Audunson et al. 2019a). Habermas views the free opinion forming, non-hierarchical discourse and bourgeois public sphere, which he observed at the beginning of the eighteenth century in the "communities" of the municipal cafés and reading societies, as the prerequisite and basis for democracy. In contrast to Michel Foucault (2005[1966]), he does not focus on libraries as places for the formation of a democratic public sphere or indeed even as "special places" (Foucault's heterotopia). It should be noted that the Anglo-American discourse of library science has yet to incorporate many of the other French reactions to the Habermasian theses on democratic consensus-culture which may cast a different light on some current, rather less consensual (some say democracy-damaging (Helbing 2015)) excesses in the digital public sphere (see Huzar 2013; Lyotard 1988; Rancière 1999).

Even if theoretical discussion of the political role of libraries was on the increase long before David Lankes (2011), empirical research on libraries and the public sphere is limited (Widdersheim and Koizumi 2016). So far, only a few studies have yielded concrete research results in the spirit of evidence-based librarianship (Booth and Brice 2004). Alex Byrne has established a clear correlation be-

\footnotetext{
gesellschaftliche Integration und demokratische Teilhabe.” §1 LBibG des Landes RheinlandPfalz (19.11.2014) (translated quotation: "They [libraries] are places of science, interaction and communication. They promote the acquisition of knowledge, thus enabling social integration and democratic participation.")

9 The fact that this idea is actually a well-established claim within library science can be seen in this quotation of the German librarian Hans P. Schuhböck dating from the 1980s, which continues to be cited internationally: "A yet-to-be-undertaken attempt to derive the function of the library from the characteristics of a democratic society would have to take the two sides of the relationship between society and state in modern society as its starting point: welfare state and popular sovereignty, with the democratic public sphere mediating between state and society" (Schuhböck 1983, 222 translated from German). Jürgen Habermas' habilitation thesis "Strukturwandel der Öffentlichkeit" ("Structural transformation of the public sphere”, 1989[1962]) was important for making the concept of the public sphere central to democratic theory, with its ideal of a "domination-free discourse" (for a critic from a digital age perspective, see Han 2013).
} 
tween the democratic maturity of a country and the existence and use of libraries worldwide. Based on the "Democracy Index" of the Economist Intelligence Unit (EIU) and the Library Map of the World of the IFLA, he even postulates a "symbiotic relationship" between libraries and democracy. The correlation coefficient is particularly high when political participation of users is accounted for, and less when controlling only for the mere existence of a library infrastructure.

Michael Widdersheim (2018) has applied methodically sound case studies with solid empirical foundations to investigate how public libraries develop into different political cultures over a long period of time. On this basis, he formulates a "political theory of library development" that describes the requisite and adequate factors for change in public libraries. Like all publicly financed infrastructure, libraries' development - i.e. their adaptation to the changes in society and its supporting institutions - is governed by a cycle of political decisions. Libraries can be said to perform best (and achieve successful development) when they demonstrate responsiveness by reacting to external developments, even if in the normative framing of their funding bodies these have yet to be implemented specifically to libraries. Interesting conceptual analyses from Michael Widdersheim and Masanori Koizumi have been able to illustrate the recent diversity of development in the field of research "Libraries and Democracy" (Widdersheim and Koizumi 2016).

The abovementioned survey from our six partner countries clearly confirms that libraries as well as museums and archives offer services and are used as public spaces along the lines of Habermas' theory of the public sphere. ${ }^{10}$ Here, a substantial proportion of the users of libraries, archives, and museums report that they have attended public meetings, lectures, and debates at these institutions (Audunson et.al. 2019b). Ethnographic studies from public libraries undertaken as a part of the ALMPUB project also highlight the role public libraries take on as arenas for respectful discourse, but not necessarily with an aim of reaching a common opinion. ${ }^{11}$ Thus, in Fagerlid's study of social reading circles at libraries, similarities appear between these groups (that mainly consist of women) and the

\footnotetext{
10 According to Habermas (1989[1962]), the public sphere is a sphere in-between and independent of the private sphere, the market, and the state. In the public sphere, citizens come together to discuss issues of common interest and a public opinion can be formed. The public sphere is a sphere where rationality prevails, and the participants are committed to the value of the better arguments. It is an open sphere, where participants meet on an equal footing - as citizens - not according to rank and status in a hierarchical system.

11 Our research indicates that the Habermasian understanding of the public sphere as an arena for forming a public opinion rather should be rephrased as an arena for forming public opinions, i.e. stressing the plural. Through a civilized and respectful public discourse, we refine the opin-
} 
literary salons of the early days of the developing bourgeois public sphere. However, as a framework for understanding what goes on between people at libraries, archives, and museums, Habermas' theory on the public sphere has clear limitations. In part, this is due to the theory's strong dualistic and rationalistic leanings that give little credence to the emotional, affectual, and sensuous aspects of experience and communication. Rather than rational minds in minimalist bodies like the Habermasian subjects (Gardiner 2004, 31), people visit museums and libraries as gendered, socially situated, experiential, and affective human beings. In daily life, rational and emotional, individual and social, private and public needs and concerns often blur. For example, a lonely elderly man reads the newspapers every day in the library in order to stay informed or to be among people. In our survey among professionals in the three fields (Audunson, Hobohm, and Toth, this volume), respondents in particular from the museum field were of the opinion that creating emotional involvement and engagement via the museums' exhibitions was more important than providing a background for a rational discourse via neutrally curated exhibitions striving for balance.

Furthermore, while the ambition to facilitate a salon public features prominently in policy discourses in the LAM-field, and in the event-programming of libraries, archives, and museums, the survey indicates that this is accorded low priority by users as well as professionals. Here, users rank the libraries' role as arenas for public discourse close to the bottom among 12 reasons legitimizing the use of scarce public resources for upholding a library service. Although an overwhelming majority of librarians, archivists, and museum professionals report that arranging public meetings and debates are important parts of the service portfolio in their respective institutions, they rank these activities relatively low compared to other reasons for upholding their service.

The findings referred to above on libraries as democratic meeting places illustrate the importance of side effects (Elster 1981). The role of libraries as meeting places and democratic spaces plays a prominent role in library policies and strategic documents. But the users frequenting a library, an archive, or a museum do not frequent an abstract "meeting place." They go for an experience, to find a book, to work, to relax, to search for a piece of information they need in their everyday lives, to read newspapers, to listen to an author or to be with others - in short, they visit the library to satisfy individual needs and interests. The library's role as a democratic community-building meeting place is a side effect. Nevertheless, in our qualitative observations, as well as our survey, we find that libraries are important places for a variety of meetings and encounters.

ions we started out with, and we learn to respect and accept the opinions of others, but we do not - maybe we should add hopefully not - develop a, in the sense of one, common opinion. 
Another theoretical angle we will rely on to grasp LAM-institutions' roles as democratic public spaces is to view these as arenas for the formation of a culture of civility. This directs us to a cluster of theories that are less concerned with the formation of public opinion than with the multiplex forms of interactions that go on between people at public places and the skills or competence in dealing with social and cultural complexity they acquire through these experiences. Thus, according to Sennett $(1977,2009)$, the public realm is to be considered a place where strangers meet and where they can become part of a culture of civility. To Sennett, the public realm is a forming space where people are developed as tolerant citizens. Sennett can be read as delivering a defence for re-establishing social conventions, which best can be relearned in the public space, whether in the street, in the café or in cultural institutions such as libraries, archives, and museums. The re-establishing of the social conventions is not to be looked upon as a sort of rigid armour to hide or enclose the subject, but on the contrary as a condition for people to enjoy the company of each other at the same time as they are protected against more unfortunate inclinations of others (Rasmussen, Jochumsen, and Skot-Hansen, 2013). Strauss (1960), Lofland (1973), and Klinenberg (2018) make similar arguments regarding the civic skills people acquire from participation in public places, including libraries and museums. These skills are essential prerequisites for a well-functioning democracy in societies characterized by social divisions and cultural diversity. That LAM-institutions are arenas for the formation of skills of civility has been well documented in previous research (Audunson 2001) and the fruitfulness of this approach is confirmed by qualitative and quantitative studies undertaken as a part of the ALMPUB-project. In the survey that was carried out within the framework of the project, we found that among the users of libraries, 40 per cent of the respondents reported having entered in contact with strangers, for example via short conversations, and every fourth library user reported such contact with strangers belonging to a group different from themselves, e.g. a different age group, a different ethnic group (Audunson et al. 2019b).

A third theoretical angle we rely on in the chapters that follow is to consider LAM-institutions as arenas for the formation of community. This directs us to theories that may overlap considerably with Sennett and the other writers listed above, but that differ in that they give less emphasis to the formation of skills of civility than to the ways in which people may enter into communities and attach a sense of "home" to public places. In his book The Great Good Places - Cafés, Coffee Shops, Bookstores, Bars, Hair Salons and Other Hangouts at the Heart of a Community, the American sociologist Ray Oldenburg describes, analyzes, and praises the different places where people can gather, put aside the concerns of home and work, and hang out for the pleasures of good company and lively conversation. 
Nevertheless, according to Oldenburg these places are not without a more serious meaning as they actually are the heart of a community's vitality and the grassroots of a democracy (Oldenburg 1989). Oldenburg names these places "third places", contrary to "first" and "second places", which are respectively home and work. Unfortunately, according to Oldenburg the third places have been declining in postwar USA.

The prevailing successful paradigm of the library as a "third place" is, on the one hand, indicative of the current "state" of society and its search for a community in the digital world (Stalder 2018) beyond the intimate private sphere and the world of work governed by outside forces (Oldenburg's first and second places). In view of the issues which clearly extend beyond these two spheres, there is a growing awareness that participation in the processes of civil society can no longer only take place passively behind (television) screens, and that more than the fourth estate of journalism is needed (Fichtelius et al. 2018). On the other hand, current trends speak for themselves: new third places (such as co-working spaces and maker spaces) are emerging but their effects and even causes are difficult to measure. In empirical terms, it remains unclear why libraries are now being promoted by politicians in line with the described current trends of third place development and the support of a civic public sphere. ${ }^{12}$

Library professionals have widely adopted the concept of "third places". Our research, both the quantitative surveys and the observational studies, document that libraries do function as third places. Thus, Evjen and Vold, who have studied a dedicated branch for children and youngsters between 10 and 15 years of age in an Oslo public library, conclude in their chapter in this volume that this branch first and foremost functions as a third place. This is interesting taking into consideration that Oldenburg himself does not consider libraries as third places as they are often too big and too purposive. Nevertheless, the comprehensive articulation of "third places" in library circles has undoubtedly helped to create greater focus on the library as meeting- or community space when rearranging old libraries or building new. What is particularly interesting in this context is that we have witnessed, during the last decade, an increased interest from museums to become "third spaces", inviting users to stay longer and engage with each other (Tate 2012). Our studies, however, indicate that the concept of third places, although important, is too narrow to grasp the complexity of the library's role in the same sense as we have argued that the public sphere concept also is too narrow. Library use is simultaneously linked to the users' private lives, i.e. first place,

12 Danish library policy seems to be the exception which proves the rule here: the frequently imitated example of the municipal library of Aarhus DOKK1 reveals exactly how successful evidencebased library development can be (Jochumsen 2018). 
to work and education, i.e. second space, and to community, i.e. third space. We need concepts and approaches that can grasp this complexity and should refrain from perspectives narrowing it down.

Participation, user empowerment, and community orientation are often key elements of observed paradigm changes in the professional fields of LAM. Let it be called "New Librarianship" (Lankes 2011) new currents of archival thinking (MacNeil and Eastwood 2017) or "New Museology" (McCall and Gray 2013). Especially in New Librarianship, the concept refers to the cybernetical (i.e. digital) foundation of knowledge in society: only via an interaction of information agents, a "conversation", may knowledge occur in a community (Lankes 2011). This reflects quite well the conception of our digital age by the Swiss media scientist Felix Stalder (2018), who defines "digitality” by its three dimensions: algorithmicity, referentiality, and community.

Change versus stability is a central issue in the research on which this book is based. How do technological changes induce change and do the role and social mission of the LAM institutions change or remain stable when exposed to digital changes? Institutional approaches are fruitful when discussing such processes. When Henningsen and Larsen analyze policy documents on digitalization of LAM-institutions in Norway (this volume) and coin the term "digitalization imperative", they are, among other things, identifying institutional isomorphic processes. When Vårheim, Skare, and Stokstad (this volume) use historical institutionalism to analyze the rise and fall of the ALM-authority in Norway between 2003 and 2009, they are identifying encultured and institutionalized norms and standards promoting or prohibiting convergence.

\section{Libraries, Archives, and Museums in the Digital Age}

Technology changes the way we live and permeates every life sphere. The ubiquity of online searching is a fundamental characteristic of our way of living (Haider and Sundin 2019). Digitalization has fundamentally affected the public's media use. The proportion reading traditional newspapers and watching traditional television has fallen dramatically. Many have foreseen that also LAM-institutions will lose ground due to digitalization. According to Nicholas (2012), digitalization leads to a situation where people do not need librarians (or archivists or museum professionals) as intermediaries. Via the Internet, we have all direct access to the resources, which in the pre-digital era were guarded by librarians, archivists, and museum professionals.

The omnipresence of digital technologies and their supplanting of traditional physical meeting places is, however, not unambiguous. In spite of Massive Open 
Online Courses (MOOCs) and digital learning platforms, universities are very preoccupied with physical campus development - a seeming paradox in a situation where it is technologically possible to complete a degree without setting your foot on campus. Universities, in spite of this, continue to invest billions and billions in physical campus development, while in their rhetoric being preoccupied with what they term "digital transformation". A similar trend is in evidence in the LAMfield in the Nordic countries and other parts of Europe. In parallel with the massive digitalization, large investments have been made in recent decades in museum and library buildings, often of a spectacular nature. To take one example, through ongoing developments of the seaside parts of the city centre of Oslo, this area is about to become plastered with monumental buildings housing cultural institutions. This and other trends in the cultural sector prompt the question of whether digitalization and the ubiquity of social media create a newfound appreciation of our need for physical meeting places. Is there a dialectic at work here, whereby the increasing digitalization of everyday experience heightens the awareness of the value of tactile experiences and face-to-face human communication?

This question, which is perhaps one of the most important coming out of our research, serves as a reminder of the critique of "telepresence" Hubert Dreyfus formulated in On the Internet (2009[2001]). Here, he argued that digitally mediated experience is not only inferior to face-to-face communication when it comes to learning and skills acquisition, but more broadly as a vehicle of human engagement with the world. What is lost on the Internet, according to Dreyfus, is embodied experience and engagement with people and things. With this loss of bodily involvement, we lose the sense of risk and vulnerability that attaches to our engagements in the real world, the sensitivity to shared moods that make social situations matter to us and, ultimately therefore, the sense of being connected to reality. To live one's life on the Web, Dreyfus notes, may be attractive to people because it is a path of least resistance that relieves them from the vulnerability and commitment of real world involvements with people and things, but at the same time "this lack of passion necessarily eliminates meaning as well" (137). Thus, on this account, if one is to live a meaningful life, one would have to embrace "our embodied involvement in the risky, moody, real world" (120). If one accepts this argument, the expectation follows that the massive digitalization of everyday life that has occurred in recent years would probably engender a widespread appreciation of, or need for, experiences of face-to-face human interaction and experiences of real physical places.

The findings of the ALMPUB-project support this assumption. Based on our research we can conclude that libraries, archives, and museums are heavily used also in our digital age and that they first and foremost are used as physical spaces, not digital. Contrary to the prophesies of the vanishing of libraries, archives, 
and museums, these institutions have not suffered the same fate as for example newspapers. A survey undertaken within the framework of this project in the six partner countries confirms that particularly libraries and museums are used by a majority of the population and that physical visits dominate, although physical use is combined with the use of digital services. The proportion of the population that report having visited a museum over the last 12 months has not been reduced since the 1990s and the proportion visiting libraries and using them as meeting places seems to be increasing. In Norway, Sweden, Denmark, and Hungary, a clear majority of the respondents have used libraries one time or more in the preceding 12 months. In Germany and Switzerland, the percentage of users is not very far from 50 (Audunson et al. 2019b). These figures are in line with most surveys measuring library use. A majority in all the countries have visited a museum one time or more, whereas the proportion using archives at least one time per year varies around 20 in all the countries. The most important difference in use patterns between libraries and museums, which also our research confirms, is that a significantly larger proportion of library users visit the library frequently $-3-4$ times per year or more often - compared to users of museums.

In addition to LAM-institutions' strong position as physical meeting places, libraries, archives, and museums have gone digital. They have made their content accessible via digital platforms, having developed digitally based forms for user participation and digitally based platforms for communication with the public. New arenas for public life have emerged within and across LAM-institutions, e.g. in the form of crowdsourcing or voluntary digital work. Thus, in one of the chapters of this book, Henningsen and Larsen show how a local history wiki site operated by the Norwegian National Library has become a vehicle for public expressions by local history enthusiasts with a broad following. Skare has done a case study on the use of social media as a platform for communication between libraries and museums and their public. Her cases are the public library and two museums in the city of Tromsø in northern Norway.

Vårheim, Rasmussen, Jochumsen, and Rydbeck document in another chapter in this volume that although a substantial proportion of the users of libraries, archives, and museums report having used digital services during the last year, the dominating way of contacting libraries and particularly museums is via physical visits. Archives deviate from libraries and museums with a much higher proportion of the users reporting visiting the archive via Internet. Use of digital services supplement, thus, physical visits and are seldom, with archives as an exception, related to accessing content. In libraries, the dominating use is related to administering one's lending activities and in museums to checking opening hours and programs. Users of archival digital services more frequently report hav- 
ing accessed and read content digitally, for example church registers and local newspaper archives.

\section{The Structure of the Anthology}

In the following 16 chapters researchers from the ALMPUB-project will dig deeper into the problems touched upon in this introductory chapter by discussing the main findings from ALMPUB's sub projects. The anthology is organized into three parts. In the first part we focus upon policies with a main focus on those related to digitilization of the LAM field. The second part of the book contains contributions focusing upon the LAM professions. How do librarians, archivists, and museum professionals perceive their and their institutions' role as public spaces in a digital age? The third part of the book has the users as its focus area. With the exception of two chapters, the contributions in this part analyze the role libraries play in the lives of their users. One chapter in this part has a LAM perspective and one studies users in an evolving digital public space - the local history wiki.

\section{References}

Aabø, S. and R. Audunson. "Use of Library Space and the Library as Place". Library \& Information Science Research, 34, no. 2, 138-149, 2012. https://doi.org/10.1016/j.lisr.2011.06. 002.

Audunson, R. Change Processes in Public Libraries. A Comparative Project Within an Institutionalist Perspective. Doctoral dissertation, Oslo: Oslo University College, 1996.

Audunson, R. "Between Professional Field Norms and Environmental Change Impetuses. A Comparative Study of Change Processes in Public Libraries". Library and Information Science Research, 21, no. 4, 523-552, 1999.

Audunson, R. "Folkebibliotekenes rolle i en digital framtid. Publikums, politikernes og bibliotekarenes bilder (The Role of Public Libraries in a Digital Future. The Perceptions of the Public, the Politicians and the Librarians)". In Audunson, Ragnar and Niels Windfeld Lund (eds), Det sivilserte informasjonssamfunn, pp. 206-224. Bergen: Fagbokforlaget, 2001.

Audunson, R., S. Aabø, R. Blomgren, S. Evjen, H. Jochumsen, H. Larsen, C. H. Rasmussen, A. Vårheim, J. Johnston, and M. Koizumi. "Public Libraries as an Infrastructure for a Sustainable Public Sphere: A Comprehensive Review of Research". Journal of Documentation, 75, no. 4, 773-790, 2019.

Audunson, R., S. Aabø, R. Blomgren, H.-C. Hobohm, H. Jochumsen, M. Khosrowjerdi, R. Mumenthaler, K. Schuldt, C. H. Rasmussen, K. Rydbeck, M. Toth, and A. Vårheim. "Public Libraries as Public Sphere Institutions. A Comparative Study of Perceptions of the Public Library's Role in Six European Countries”. Journal of Documentation, 75, no. 6, 1396-1415, 2019.

Audunson, R., H.-C. Hobohm, and M. Toth. "LAM Professionals and the Public Sphere: How do Librarians, Archivists and Museum Professionals Conceive the Respective Roles of their Institutions in the Public Sphere?". In Audunson, R., H. Andresen, C. Fagerlid, E. Hen- 
ningsen, H.-C. Hobohm, H. Jochumsen, H. Larsen, and T. Vold (eds), Libraries, Archives and Museums as Democratic Spaces in a Digital Age. Berlin: De Gruyter Saur, 2020.

Booth, A. and A. Brice (eds). Evidence-based Practice for Information Professionals. A handbook. London, 2004.

Braman, S. Change of State. Information, Policy and Power. MIT Press, 2007.

Buschman, J. E. Dismantling the Public Sphere: Situating and Sustaining Librarianship in the Age of the New Public Philosophy. Westport, 2003.

Buschman, J. E. "The Public Sphere Without Democracy: Some Recent Work in LIS". Journal of Documentation, 2019. https://doi.org/10.1108/JD-06-2019-0115.

Byrne, A. “Democracy and Libraries. Symbol or Symbiosis?”. Library Management, 39, no. 5, 284-294, 2018.

Dreyfus, H. On the Internet. New York: Routledge, 2nd edn, 2009.

Elster, J. "States That are Essentially By-products". Social Science Information, 20, no. 3, 431473, 1981.

Engelstad, F., H. Larsen, and J. Rogstad. "The Public Sphere in the Nordic Model”. In Engelstad, F., H. Larsen, J. Rogstad, and K. Steen-Johnsen (eds), Institutional Change in the Public Sphere: Views on the Nordic Model. Berlin: De Gruyter Open, 2017.

Evjen, S. and T. Vold. "Being, Learning, Doing: A Palace for the Children? A Tween's Library Seen from the Users' Perspectives”. In Audunson, R., H. Andresen, C. Fagerlid, E. Henningsen, H.-C. Hobohm, H. Jochumsen, H. Larsen, and T. Vold (eds), Libraries, Archives and Museums as Democratic Spaces in a Digital Age. Berlin: De Gruyter Saur, 2020.

Fagerlid, C. "Democratic Coexistence, Tiny Publics and Participatory Emancipation at the Public Library”. In Audunson, R., H. Andresen, C. Fagerlid, E. Henningsen, H.-C. Hobohm, H. Jochumsen, H. Larsen, and T. Vold (eds), Libraries, Archives and Museums as Democratic Spaces in a Digital Age. Berlin: De Gruyter Saur, 2020.

Fichtelius, E., E. Enarson, K. Hansson, et al. "Den femte statsmakten. Bibliotekens roll för demokrati, utbildning, tillgänglighet och digitalisering”. Stockholm, Malmö, 2018.

Foucault, M. “Die Heterotopien. Zwei Radiovorträge [7. und 21. Dezember 1966]”. Frankfurt am Main, 2005[1966]. (French-German, bilingual edition).

Gardiner, M. E. "Wild Publics and Grotesque Symposiums: Habermas and Bakhtin on Dialogue, Everyday Life and the Public Sphere". The Sociological Review, 52, no. 1, 28-48, 2004.

Givens, L. M. and L. McTavish. "What's Old is New Again. The Reconvergence of Libraries, Archives and Museums in the Digital Age". Library Quarterly, 80, no. 1, 7-32, 2010.

Gorman, M. "Our Enduring Values Revisited. Librarianship in an Ever-Changing World". Chicago, 2015.

Habermas, J. The Structural Transformation of the Public Sphere: An Inquiry Into a Category of Bourgeois Society. Cambridge: Polity Press, 1989[1962].

Haider, J. and O. Sundin. Invisible Search and Online Search Engines. The Ubiquity of Search in Everyday Life. London: Routledge, 2019. https://doi.org/10.4324/9780429448546.

Han, B.-C. Digitale Rationalität und das Ende des kommunikativen Handelns. Berlin: Merve, 2013.

Helbing, D. The Automation of Society is Next: How to Survive the Digital Revolution. North Charleston, SC: Createspace, 2015.

Henningsen, E. and H. Larsen. "The Digitalization Imperative: Sacralization of Technology in LAM Policies”. In Audunson, R., H. Andresen, C. Fagerlid, E. Henningsen, H.-C. Hobohm, H. Jochumsen, H. Larsen, and T. Vold (eds), Libraries, Archives and Museums as Democratic Spaces in a Digital Age. Berlin: De Gruyter Saur, 2020. 
Henningsen, E. and H. Larsen. "The Joys of Wiki Work: Craftsmanship, Flow and Selfexternalization in a Digital Environment”. In Audunson, R., H. Andresen, C. Fagerlid, E. Henningsen, H.-C. Hobohm, H. Jochumsen, H. Larsen, and T. Vold (eds), Libraries, Archives and Museums as Democratic Spaces in a Digital Age. Berlin: De Gruyter Saur, 2020.

Hobohm, H.-C. "Libraries and Democracy in Germany. As Perceived by the Public in Contrast to the Professionals". In Audunson, R., H. Andresen, C. Fagerlid, E. Henningsen, H.-C. Hobohm, H. Jochumsen, H. Larsen, and T. Vold (eds), Libraries, Archives and Museums as Democratic Spaces in a Digital Age. Berlin: De Gruyter Saur, 2020.

Huysmans, F. and M. Oomes. "Measuring the Public Library's Societal Value”. IFLA Journal, 39, no. 2, 168-177, 2013.

Huzar, T. J. "The Public Library, Democracy and Rancière's Poetics of Politics”. Information Research, 18, no, 3, 2013. http://InformationR.net/ir/18-3/colis/paperC15.html.

Jaeger, P. T. and G. Burnett. "Information Worlds. Social Context Technology and Information Behavior in the Age of the Internet”. New York, 2010.

Jaeger, P. T., U. Gorham, J. C. Bertot, et al. "Democracy, Neutrality, and Value Demonstration in the Age of Austerity”. The Library Quarterly, 83, no. 4, 368-382, 2013.

Jochumsen, H. "How to Qualify the Debate on the Public Library by the Use of ResearchDeveloped Tools". Bibliothek - Forschung und Praxis, 42, no. 2, 344-350, 2018.

van Kersberger, K. Social Capitalism. A Study of Christian Democracy and the Welfare State. New York: Routledge, 1995.

Klinenberg, E. Palaces for the People. How to Build a More Equal and United Society. London: the Bodly Head, 2018.

Landemore, H. Democratic Reason: Politics, Collective Intelligence and the Rule of the Many. Princeton: Princeton University Press, 2013.

Lankes, R. D. The Atlas of New Librarianship. Cambridge, Mass.: MIT Press Association of College \& Research Libraries, 2011.

Larsen, H. "Archives, Libraries and Museums in the Nordic Model of the Public Sphere". Journal of Documentation, 74, no. 1, 187-194, 2018.

Lofland, L. A World of Strangers: Order and Action in Urban Public Space. Waveland Press, 1973.

Lyotard, J.-F. The Differend: Phrases in Dispute. Manchester: Manchester Univ. Press, 1988.

MacNeil, H. and T. M. Eastwood (eds). Currents of Archival Thinking. Santa Barbara, California: Libraries Unlimited, 2nd edn, 2017.

Marci-Boehnke, G. “Media Literacy und Librarians Beliefs. Wie Einstellungen auf das Professionalitätsverständnis wirken”. In Hauke, P. (ed.), Öffentliche Bibliothek 2030. Herausforderungen - Konzepte - Visionen, pp. 311-322. Bad Honnef, 2019.

McCall, V. and C. Gray. "Museums and the 'new Museology': Theory, Practice and Organisational Change”. Museum Management and Curatorship, 29, no. 1, 1-35, 2013. https: //doi.org/10.1080/09647775.2013.869852.

Nicholas, D. “Disintermediated, Decoupled and Down, Cilip Update”. http://ciber-research.eu/ download/20120501-CILIP_Update_March_2012_pp29-31.pdf, 2012.

Oldenburg, R. The Great Good Places - Cafés, Coffee Shops, Bookstores, Bars, Hair Salons and Other Hangouts at the Heart of a Community. New York: Marlowe \& Company, 1989.

Rancière, J. Disagreement: Politics and Philosophy. Minneapolis: Univ. of Minnesota Press, 1999. 
Rasmussen, C. H., H. Jochumsen, and D. Skot-Hansen. "Biblioteket som mødested - Sociologisk legitimitet og inspiration fra byplanlægningen”. Nordisk Tidsskrift for Informationsvidenskab og Kulturformidling, 2, no. 1, 51-59, 2013.

Schuhböck, H. P. "Die gesellschaftliche Funktion von Bibliotheken in der Bundesrepublik Deutschland. Zur neueren Diskussion nach 1945". In Bibliothek. Forschung und Praxis, 7, no. 3, 203-222, 1983.

Scott, W. R. Institutions and Organizations: Ideas, Interests, and Identities. Los Angeles: Sage, 4th edn, 2014.

Sennett, R. The Fall of Public Man. London: Penguin Books, 1977.

Sennett, R. "Quant. The Public Realm". https://www.richardsennett.com/site/senn/templates/ general2.aspx?pageid=16\&cc=gb, 2009. Accessed 19.03.2019.

Simon, N. The Participatory Museum. Santa Cruz: Museum 2.0, 2010.

Söderholm, J. and J. Nolin. "Collections Redux: The Public Library as a Place of Community Borrowing”. The Library Quarterly, 85, no. 3, 244-260, 2015.

Stalder, F. The Digital Condition. Newark: Polity Press, 2018.

Strauss, A. "Spatial Representation and the Orbits of City Life". Sociological Quarterly, 1, no. 3, 167-180, 1960.

Sunstein, C. R. Republic.com. Princeton, N.J.: Princeton University Press, 2001.

Tate, N. B. “Museums as Third Places or What?". Museums \& Social Issues, 7, no. 2, 269-283, 2012.

Vårheim, A., R. Skare, and N. Lenstra. "Examining Libraries as Public Sphere Institutions: Mapping Questions, Methods, Theories, Findings, and Research Gaps”. Library \& Information Science Research, 41, no. 2, 93-101, 2019.

Vårheim, A., C. H. Rasmussen, H. Jochumsen, and K. Rydbeck. "The Use of LAM-institutions in the Digital Age". In Audunson, R., H. Andresen, C. Fagerlid, E. Henningsen, H.-C. Hobohm, H. Jochumsen, H. Larsen, and T. Vold (eds), Libraries, Archives and Museums as Democratic Spaces in a Digital Age. Berlin: De Gruyter Saur, 2020.

Vårheim, A., R. Skare, and S. Stokstad. "Institutional Convergence and Divergence in Norwegian Cultural Policy: Central Government LAM Organization 1999-2019”. In Audunson, R., H. Andresen, C. Fagerlid, E. Henningsen, H.-C. Hobohm, H. Jochumsen, H. Larsen, and T. Vold (eds), Libraries, Archives and Museums as Democratic Spaces in a Digital Age. Berlin: De Gruyter Saur, 2020.

Widdersheim, M. M. “A Political Theory of Public Library Development”. Libri, 68, no. 4, 269289, 2018.

Widdersheim, M. M. and M. Koizumi. "Conceptual Modelling of the Public Sphere in Public Libraries”. Journal of Documentation, 72, no. 3, 591-610, 2016.

Wiegand, W. A. Part of Our Lives: A Peoples History of the American Public Library. Oxford: Oxford University Press, 2015. 
Part I: Policies 

Kerstin Rydbeck and Jamie Johnston

\section{LAM institutions: a Cross-country Comparison of Legislation and Statistics on Services and Use}

\section{Introduction}

Many factors influence the ability of libraries, archives, and museums (LAM) to fulfil their role as public sphere institutions. This chapter aims to give an overview of the current situation of LAM institutions in the partnering countries of the ALMPUB research project by reviewing the legislation and the national statistics on services and use. The overarching purpose is to provide a background for the following chapters written by researcher partners from the participating countries. The countries included in the project are Norway, Sweden, Denmark, Germany, Switzerland, Hungary, and to some extent Iceland and Poland, which were not part of the initial research team.

This chapter has separate sections on libraries, archives, and museums. These sections include overviews of the purpose statements in the legislative acts in the participating countries, the methods used to collect national statistics, and the national statistics on services and use across the countries. Lastly, a broad comparison is made of the LAM institutions in the summarizing discussion.

The collection of national LAM statistics presents various methodological challenges when attempting to make comparisons across countries; however, these challenges can also be seen as a part of the result. The aims and focus differ widely across countries and across the three sectors. The statistics gathered, or not gathered, have implications about what is deemed important as well as about whether the respective sectors can be regarded as part of a common field of practice. The statistics and information about LAM legislation in the eight countries are presented in Table 2.1 (see appendix). Unless otherwise indicated, the information in the text is based on Table 2.1. Links to legislative documents and national statistics are included in the reference list.

\section{Public Library Legislation}

The International Federation of Library Associations and Institutions (IFLA) defines a public library as “an organization established, supported and funded by 
the community, either through local, regional or national government or through some other form of community organization. It provides access to knowledge, information and works of the imagination through a range of resources and services and is equally available to all members of the community" (The Public Library Service 2001). This definition can be seen as describing the core functions of public libraries, however many libraries have taken on an expanded role as a result of their own initiative or of country-specific legislation.

Public libraries are legislated to a far greater degree than archives and museums. Of the participating countries, Norway, Sweden, Denmark, Iceland, Poland, and Hungary have library laws, whereas only Germany and Switzerland do not. In Germany, some of the federal states have legislation that describes the role of public libraries, but without any statutory duty, funding requirements or regulation of mission fulfillment. Public libraries are defined as non-compulsory municipal services. The first of the 16 German states (Bundesländer) to establish a library law was Thüringen in 2008. This was preceded by a law in 1969 that established the mission of the national library, which was revised after the reunion in 2006. Switzerland does not have a library law at any level of government. Combination libraries appear to be more common in Switzerland than in the other participating countries. This prevalence of combination libraries may complicate attempts to establish public-library specific legislation.

The social missions or purposes stated in the library laws vary across the different countries. Democracy and the formation of an educated and informed citizenry are central themes in all the library laws in the participating countries. In Norway, the purpose of libraries is to promote information, education, and other cultural activities and serve as independent meeting places and arenas for discussion and debate; thus, the law can be seen as primarily focusing on the fostering of an inclusive and informed public discourse or sphere. Furthermore, it is stated in the Norwegian Public Library Act (2013) that library materials should be free to anyone living in the country, which can be interpreted as the promotion of equality and equal opportunity. Lastly, it states that the individual library must emphasize quality, versatility, and timeliness in its offerings to children and adults and make the materials and services known, which can be understood as tasking libraries to serve and represent all groups in society.

The Swedish Library Act (2013) applies to all types of libraries. The law states that libraries shall promote the development of democratic society by contributing to the dissemination of knowledge and the freedom of opinion. Furthermore, it states that libraries are to promote literature and interest in education, information and research, and cultural activities in general. Lastly, it states that library activities should be available to everyone, thus including the promotion of equality and inclusivity. 
Danish Library Act (2000) states the purpose of public libraries is to promote information, education, and cultural activity by making available books, periodicals, talking books, and other suitable material, such as recorded music and electronic information resources, including Internet and multimedia and videos. Libraries also shall promote municipal and government information and information about society in general; thus, the law can be seen as focusing on the promotion and support of citizenship and an informed citizenry. Furthermore, it states that the objective of the public libraries shall be achieved by observing quality, comprehensiveness, and topicality in the selection of materials, and that these criteria alone must be the decisive factors and not any religious, moral, or political views of the staff. The obligation to be impartial can be seen to relate, again, to the library's role in the promotion and establishment of equality and inclusivity; thus democracy.

The Libraries Act of Iceland (2013) applies to all types of libraries and states that the common goal of libraries is to equalize access to culture and knowledge through the provision of diverse collections and information in various forms and the promotion of cultural and scientific activities, education, lifelong learning, work life, Icelandic language, reading for pleasure, and information literacy. It also states that emphasis should be placed on libraries' collections reflecting as many views as possible. Collectively, this can be seen as supporting democracy through equality and and inclusion.

The Polish Library Act (1997) in Chapter 5 on public libraries states that public libraries are to meet the educational, cultural, and information needs of the general public and participate in the dissemination of knowledge and culture as well as preserve the national heritage by organizing and providing access to Polish works. The premise that libraries are for everyone and that they are to provide information and preserve the cultural heritage again relates to the promotion of equality and inclusion.

The Hungarian Library and Museum Act (1997) states that the institutions' aims are the preservation of national cultural traditions and those of national and ethnic minorities, their worthy continuation, improving the staffing, intellectual and economic conditions for community and individual general cultural activities, and promoting value-oriented activities aimed at improving citizens' quality of life. It also states that freedom of access to information for all is a fundamental condition for the functioning of the information society and the democratic constitutional state, thus explicitly establishing libraries and museums as fundamental to democracy. This is the only law that combines museums and libraries together, which can be seen as giving them a shared social role and possibly as placing them within a common sector. 
Access to information is stated in each of the acts, however, only the library acts in Hungary and Sweden state the promotion of democracy as part of the social mission or role of public libraries, although the promotion and provision of access to information, culture, knowledge or a combination of these things can be seen as relating to the basic democratic principles of enlightened citizens and freedom of expression. Sweden is the only country that includes the promotion of active citizenship, though it is implied in the Danish law with the libraries' role in the promotion of municipal and government information and information about society in general.

All laws state something concerning the preservation or promotion of culture and cultural activities, however, Iceland, Hungary, and Poland are the only countries that explicitly state the preservation or promotion of the national language or culture; in Iceland, it is the Icelandic language and in Poland and Hungary, it is the national heritage. All the library laws require municipalities in the respective countries to offer a public library service. In some cases, municipalities can offer library services jointly with another municipality or type of library, such as a school or university library. The legal obligation for all municipalities to provide a library service can be seen as a high degree of structural support for their role as culture and information promoting institutions; however, there are many other factors that influence it, which can be seen in the statistics on services and use.

\section{Public Library Statistics}

Statistics provide a broad picture of whether the public funds invested in a library service lead to the desired results, for example, regarding the number of library visits or books loaned per year. Accordingly, there is an international ISO standard for library statistics that was developed in collaboration with IFLA ("ISO 2789:2013”). The fact that municipalities generally run the public libraries in the participating countries makes the collection of national statistics easy and, accordingly, almost all of the countries collect statistics that include all municipal library services regardless of size.

There are two exceptions, Iceland and Switzerland. In Iceland, the collection of statistical data pertaining to the LAM institutions was discontinued due to cuts in government spending after Iceland's financial crisis of 2008-2011. The main libraries in the different regions continued to collect statistics on their services and use. These are presented in Table 2.1. In Switzerland, the library statistics only include municipalities with 10,000 inhabitants and above. Some of the libraries are combination libraries, both public libraries and state (canton) libraries. The 
municipalities included in the national statistics represent a little over a third of Swiss libraries and these libraries are mainly located in the most densely populated areas. Consequently, the Swiss figures in Table 2.1 only give an approximate picture of the library services in the country and need to be interpreted with caution.

There are two other discrepancies in the statistics. The figures in Table 2.1 are all based on the 2017 library statistics; however, some of the figures from Denmark are not available for 2017 so figures for 2015 are used instead. The German figures only include participants in a voluntary survey; smaller libraries may be not included. To summarize, the differences noted above in the statistical data mean that the figures are not completely comparable. The figures do provide an overview of the situations in the participating countries and this allows for general comparisons across the countries.

\section{Public Libraries: Services and Use}

According to the figures in Table 2.1, Iceland is the country that allocates the most resources per capita for public libraries, followed by Denmark and Sweden; Switzerland comes forth and Norway fifth. However, Norway's figure only includes the resources for media and staff, which means that in reality the amount allocated is actually higher because the costs for and associated with the library premises need to be added in order to obtain a fully comparable figure.

Iceland stands out, not only because of its total resources per capita for public libraries, but also for the high number of physical access points and physical items per inhabitant. The relatively high figures may be in part a result of the low population density; each municipality must offer a library service, but there are fewer people per library service. The high total resources per capita may also be a result of the relatively high cost associated with the provision of public library services in the country. It is more costly to ship materials and other resources to Iceland than to countries located in mainland Europe. Salaries are also relatively high. The high figures for total running costs, number of access points and physical items per inhabitant may also indicate that Iceland gives a high level of priority to its library services.

The total number of library employees and items per inhabitant are relatively high in Poland and Hungary. Poland spends the least amount on library resources and staffing and Hungary the third lowest. The relatively high number of staff and physical items per inhabitant yet relatively low expenditure is likely a result of there being relatively lower salaries and cost of materials (e.g. book prices) in these two countries than in many of the other countries. 
Germany has the second lowest running costs per capita although the general levels of income are quite high. This means that the relatively high expenditures associated with staffing, compared to those in Poland and Hungary, yet low running costs must be balanced in some way. Consequently, Germany shows low figures for the number of full-time employees per 1,000 inhabitants, the number of physical service points per 1,000 inhabitants, and the number of physical items per inhabitant. The number of on-site visits per inhabitant is relatively low, however, Germany's figures regarding e-resource downloads (e.g. e-books) are high compared to other countries, with the exception of Denmark, although figures are not available for all countries. Public libraries in these two countries may have better solutions for downloading e-books and audiobooks than in the other countries. For example, in Denmark there are national agreements between the publishing houses and the public library sector. These types of agreements do not exist in the other countries or only to a limited extent, which makes the loaning of e-books more difficult for public libraries and may result in fewer downloads.

Intensity of library use can be obtained by comparing the number of borrowed items and library visits per capita with the numbers of physical items, employees, and physical access points. Accordingly, people in the Nordic countries appear to use their libraries more intensively than in the other countries, especially in comparison to library use in Hungary and Poland. Some ambiguity remains regarding the intensity of library use in Switzerland due to the way library statistics are collected in the country. However, the figure for the number of borrowed items is very high in relation to the figures for the number of physical items and number of visits per inhabitant in comparison to the Nordic countries, which suggests that the Swiss use their libraries just as or more intensively.

Hungary comes in second after Iceland for the most physical access points per inhabitant, which is still about three times more than in the other Nordic countries, yet Hungary has comparatively few library visits and loans per inhabitant. For example, Hungary's figures for library visits and loans are about a third of the Danish figures. Hungary's high number of service points per inhabitant may result from the administrative division of its municipalities. The country has more than 3,000 municipalities and more than half of them have less than 1,000 inhabitants. All municipalities regardless of size are required to provide a public library service that is operated by the county library. Interestingly, this relatively dense system does not result in intensive use.

Norway and Sweden have low population densities, though not to the same degree as Iceland. Low population density may result in a higher number of physical access points in relation to inhabitants so that the distance to the library does 
not hinder or prevent use. This is especially important in the rural areas where winter road conditions and limited transportation services can disrupt or prevent travel. For example, Sweden has almost twice as many access points per inhabitant as Germany even though Germany has almost ten times the population density as Sweden. This means each library in Sweden has a service area approximately five times as large as the service area of a German library. The number of physical access points per inhabitant in Norway is lower than in Sweden; however, the figure in Norway does not include library boats, buses and small service points. Interestingly, the Nordic countries have many more on-site visits than the other four countries, though no figure is available for Iceland.

To summarize, the figures suggest that the public library as a physical place is of greater importance in the Nordic countries than the other countries. Do the libraries in the Nordic countries offer more on-site services than libraries in the other participating countries? Do the results imply that in the Nordic countries there is a higher level of trust in libraries than in the other countries? How do these differences reflect the public libraries' role in supporting local public spheres? These questions will be reflected upon and addressed in other chapters of this anthology.

\section{Museum Legislation}

The International Council of Museums (ICOM) defines a museum as "a non-profit, permanent institution in the service of society and its development, open to the public, which acquires, conserves, researches, communicates and exhibits the tangible and intangible heritage of humanity and its environment for the purposes of education, study and enjoyment" ("ICOM Definition of a Museum").

Six of the eight participating countries have legislation governing museums; Germany and Norway do not. In Denmark, the stated purpose of the law (2013) is to promote museum work and cooperation with a view to safeguarding Denmark's cultural and natural heritage and securing access to and knowledge of this heritage and its interaction with the rest of the world. Through collection, registration, conservation, research, and communication, museums are tasked with working for the safeguarding of Denmark's cultural and natural heritage, illustrating cultural, natural, and art history, expanding the collections and documentation within their respective areas of responsibility, making the collections and documentation accessible to the general public, making the collections and documentation accessible for research, and communicating the results of such research. 
The Swedish Museum Act (2017) states museums are to contribute to society and its development by promoting knowledge, cultural experiences, and free opinion formation. The law tasks museums with three areas of responsibility. The first, concerning public activities, is that exhibitions and other public activities at a museum shall be knowledge-based and characterized by versatility and openness and shall be accessible to all and adapted to the different conditions of the users. The second, concerning knowledge formation, is that museums shall contribute to research and other knowledge building, among other things by having high competence in its subject area. The third, concerning collection management, is that museums shall actively manage their collections to achieve the objectives of the business.

Icelandic Museum Act (2011) tasks museums with the preservation of Iceland's cultural and natural heritage, ensuring that it is returned unspoiled to future generations, providing access to it and contributing to increased knowledge of the heritage and understanding of its connection to the outside world. The act tasks museums with the collection, registration, preservation, research, exhibitions, and other media to safeguard Iceland's cultural and natural heritage, highlight the country's cultural, natural, and artistic history, strengthen its collection and source collection within its special field, and make its collection and archives accessible to the public and scholars. Furthermore, museums should aim to enhance the quality of life of human beings by fostering understanding of the evolution and status of culture, art, nature or science and aim to ensure the comprehensiveness of their collections. Museums are to operate in the public interest, must be open to the public, and are not for profit.

The Polish Museum Act (1996) states that a museum is a non-profit organizational unit with the aim collecting and preserving tangible and intangible natural and cultural heritage. Furthermore, museums are to inform about the values and contents of their collections, promote fundamental values of the Polish and world history, science and culture, develop cognitive and aesthetic sensitivity, and provide access to the collected holdings.

The Hungarian Library and Museum Act (1997) states, as previously indicated, that the institutions are tasked with the preservation of national cultural traditions and those of national and ethnic minorities, their worthy continuation, improving the staffing, intellectual, and economic conditions for community and individual general cultural activities, and promoting value-oriented activities aimed at improving the quality of life of citizens. Lastly, as stated previously, libraries and museums are to promote the freedom of access to information for all, as it is a fundamental condition for the functioning of the information society and the democratic constitutional state. 
The goals of the Swiss Museums and Collections Act (2010) is to safeguard the important movable cultural property of Switzerland, raise awareness of the cultures of Switzerland, provide museums and collections with a strong identity, collaborate and support other museums, and contribute to the attraction of Switzerland as a place of training and research, economic center, and tourist destination. The Act tasks museums with the preservation of the tangible and intangible heritage, the development of collections with other museums, acquisition of artifacts, presentation themes relating to Swiss society, culture and identity through exhibitions and publications, and promotion of public access to culture.

The mediation and preservation of cultural heritage can be seen as the focus of the museum laws. Cultural heritage may not appear to relate directly to democracy and the public sphere, however, understanding and critical reflection of the cultural heritage is essential for the facilitation of democratic processes. Understanding the past social, economic, and cultural realities forms the basis for decision-making and planning, hence the ability to reflect critically upon cultural heritage underlies democratic processes. Tasking museums with the mediation of cultural heritage is the way the museum laws can be seen to support and connect to democracy and the public sphere. Interestingly, Sweden tasking museums with supporting free opinion formation, versatility, and openness and Iceland tasking museums with ensuring the comprehensiveness of their collections hints at a more inclusive approach, whereas the other countries simply focus on preserving and mediating the cultural heritage.

The Danish and Icelandic laws emphasize the need to relate the cultural heritage to the rest of the world, which may reflect the greater interconnectedness of the world. This may also have something to do with the size of the countries, as Denmark and Iceland are countries with the smallest populations out of the countries with museum laws. Surprisingly, only Hungary includes something in its law about the need for inclusion of minority groups' heritage into the national heritage. Poland's inclusion of the need to "promote fundamental values of the Polish and world history" is ambiguous; does the promotion of world values imply the relation of Poland's cultural heritage to the rest of the world? Does it imply European or Western values, or a broader field?

The promotion and provision of access to information, culture, knowledge, or a combination of these things relate to the basic democratic principles of enlightened citizens and freedom of expression. All the museum laws task the country's museums with making their collections accessible, which can be related back to one of the fundamental values of democracy and the public sphere: equality. However, unlike libraries, not all municipalities or other administrative divisions are 
required to provide a museum service, though museums are commonly found in communities of all sizes, which will be discussed in detail in the next section.

\section{Museum Statistics}

The museum statistics in Table 2.1 are from national sources in the participating countries or from the European Group on Museum Statistics (EGMUS). As previously stated, there are no official statistics available for Iceland; however, data from 2015 were published in a preliminary study on cultural statistics in the Nordic countries. The study was done on behalf of The Nordic Council of Ministers (Kulturstatistik $i$ Norden 2017). These statistics are used in Table 2.1.

Less statistical data are available for the museums than for public libraries, although there is an international ISO standard also for Museum statistics ("ISO 18461:2016"). Funding for museums is often complex and originates from a variety of resources, both public and private. For example, some museums are owned and run by foundations or private entities, but receive public funding. Not all municipalities or other administrative divisions are required to provide a museum service. Interestingly, anybody can start a private business open to the public that aims at displaying a collection of artifacts and call it a museum. There are many local, private owned, and very small museums run by NGOs that are built and rely on voluntary work. This variation in ownership makes it difficult to collect information for national statistics. Consequently, providing a reliable and comprehensive picture of the museum sector is difficult.

The difficulty in obtaining statistics on museums means that the figures in Table 2.1 regarding the number of museums in each country must be interpreted with caution. For example, the statistics for Sweden and Norway only include institutions with professional employees working in positions corresponding to at least one Annual Work Unit (AWU). Museums are not obliged to provide statistics on their operations and use; some provide statistics on a voluntary basis while others do not. In Sweden, for example, it is estimated that about 25 percent of the museums with at least one AWU are not included in the national statistics (Museer 2017 2018, 3).

Despite the ISO Standard for museum statistics, the categorization of museums based on ownership, management, and types of collections differs between the countries and four of the countries do not provide any statistics at all about their collections. This is the reason why there is no information about the collections in Table 2.1. The lack of statistics makes international comparisons very difficult and also makes it difficult to discuss the museum sector in relation to the rest of the LAM field. 


\section{Museums: Services and Use}

The large number of museums in Germany stands out in relation to the other countries, something which may be explained by the fact that Germany has the largest population. The larger population may make possible the provision of and maintenance of museums and museum collections to a greater degree than in the countries with smaller populations. There are also many local museums in Germany, some publicly owned and others privately. A larger proportion of these small, local museums might be included in the statistics than in the other countries. This may be because there is no restriction in Germany, unlike in Sweden and Norway, that only museums with at least one AWU can be included in the national statistics. The institute responsible for the German museum statistics also aims to include all museums, even the very small local museums. The German statistics are still not complete. Twenty-five percent of the museums have not provided statistical data, which means that they are only included in the figure for the total number of museums, but none of the other figures (Statistische Gesamterhebungen den Museen der Bundesrepublik Deutschland für das Jahr 2017, 3).

Private museums are the most common in all countries except Hungary, where publicly run local and regional museums form the largest group. Norway, Sweden, and Poland are the only countries that provide information about running costs. The figures show that the difference in staff density between the countries is small, while there is a huge difference regarding running costs. In Norway, the cost is $94 €$ per inhabitant per year, while in Hungary it is only one fourth of that $(23 €)$. The Polish figures for running costs also appear to be low, though the figures are not completely comparable to the others. The explanation is likely the same as for the staff density in the public libraries. The labor costs are lower in Poland and Hungary than in the other countries, which means that the two countries can spend significantly less money on their museums and still maintain the same staff density. There are no figures from Germany on running costs or staff density, which would have been interesting due to the high number of museums.

Libraries and archives provide access to their collections, but are generally not involved in the interpretation of the content. Contrarily, museums have a strong focus on the interpretation and mediation of their exhibitions, which forms the basis for their public activities. However, not all countries collect statistics on their annual number of exhibitions, and the existing figures are not entirely comparable. The available figures show that Germany is first, which is not surprising considering the high number of museums reported. The figure for Poland, which is second, is also relatively high and well above the figure for Norway, which is third. 
Some museums have entrance fees while archives and libraries generally do not. It would be valuable to see in the museum statistics whether there is a correlation between the proportion of museums with free entry and the number of visits per capita; however, information about entry fees is not included in Table 2.1 because only two countries provide figures. The lack of data here may be because it is complicated for museums to collect statistical data. For example, museums may charge for some arrangements and exhibitions or not for others. Groups, such as children and the elderly, may receive free entry while other groups are required to pay. Currently, many of the museums at the national level in Sweden offer free entry as a result of a parliamentary decision in 2016 that aimed at increasing visits and citizens' overall engagement in cultural activities ("Fri entré infört vid 18 statliga museer.”). In 2019, the Swedish Agency for Cultural Policy Analysis published an evaluation showing that the museums that introduced free admission increased their visiting numbers significantly compared to those that did not (Besöksutveckling för de centrala museerna 2018, 5).

Iceland reports 7.9 museum visits annually per capita, which a very high number in comparison to the other countries. Denmark reports 2.9 and is followed by Sweden and Norway with 2.8 and 2.1 visits respectively. Hungary and Poland are the lowest here with 1.1 visits per capita, which is surprising as Poland has a high number of exhibitions annually; this implies a low number of visitors per exhibition. The figures show that the Nordic countries have high visiting figures in relation to the other countries. This is a similar pattern of use as previously reported for public libraries.

Tourism likely affects the number of visits. Tourists seldom visit archives or public libraries, but they often visit museums, thereby boosting visitor numbers. This is a likely explanation for Iceland's extremely high figure for annual visits per capita. In 2017, Iceland had 7.7 million foreign visitors with at least one overnight stay, which is 23 times the population. In comparison, Germany had about as many foreign visitors as the population and Poland had just under half as many visitors as residents (“Tourism Statistics 2017”).

The national statistics offer little regarding how the digital and online opportunities and resources have affected the collections, services, and use of museums in the respective countries. The Hungarian museum statistics provide some basic figures showing that 56 percent of the museums in Hungary have access to the Internet and that 28 percent use computers for visitors' information purposes ("EGMUS: Complete Data", Hungary 2017). The Swedish museums collect data on the number of unique visits to museum websites (Museer 2017 2018). Norway gives some information about the digitization of museum collections and reports the 
number of visits to Digitaltmuseum.no, which had double the visits in 2017 as 2015 (“Statistikk for museum 2017”).

\section{Archival Legislation}

The word archive has several meanings, of which two are of particular importance for this chapter. First, an archive refers to a collection of primary source records generated by an individual, family or private or public organization; records that have been selected for permanent or long-term preservation due to their cultural, historical or evidentiary value. Second, the word archive refers to an institution with the responsibility to organize, preserve, store, and make accessible archival material (Pearce-Moses 2005, 30). The use of the word archive in this chapter mostly relates to the second definition, therefore, the term "archival institution" will be used. Publicly run archival institutions typically focus on material generated by authorities and public organizations at the national, regional or local level. However, some of the publicly run archival institutions also keep private archives; for example, materials on NGOs, churches, private enterprises, estates, families, and individuals. Privately run archival institutions differ. Many are small, local endeavors built partly or totally by volunteer efforts. Some archival institutions are open to the general public while others restrict access for various legal or cultural reasons.

All the countries participating have archival laws requiring the provision of national archives and the archival laws all have similar purposes related to the preservation of documents of cultural and legal nature and, to varying degrees, making them accessible. The Norwegian Archive Act (1992) states that the purpose of the act is to ensure that archives containing significant cultural or research value or those containing legal or important administrative documentation are preserved and made available for posterity. The Swedish Archive Act (1990) states that archives are part of the national cultural heritage and that they must be preserved, organized, and maintained in order to fulfill the right to access public documents; the need for information pertaining to legal and administrative matters; and the needs of the research.

The Danish Archive Act (2008) states that the purpose of the National Archives is to ensure the preservation of archival records that are of historical value or serve as evidence pertaining to administrative or legal matters that are of importance to citizens and authorities; to ensure the possibility of discarding non-conservation worthy public records in cooperation with the authorities covered by the Act; to 
make archives available to citizens and authorities, including for research purposes; to guide citizens and authorities in the use of archives; and to carry out research and disseminate research results. The Icelandic Public Archives Act (2014) states that the objective of the Act is to safeguard the creation, conservation, and safe handling of public records with a view to protecting the rights of the citizens and the interests of the administration, and ensuring the preservation of the Icelandic people's history.

A common theme running through the archival acts in the Nordic countries is an emphasis on ensuring access to citizens; however, moving away from the Nordic countries to Germany and Switzerland, the emphasis is placed on the carrying out of research, specifically academic research. The German Federal Archives Act (2017) states that the task of the Federal Archives shall be to conserve, utilize, and exploit federal archive material for academic purposes. It shall ensure access to federal archive material while safeguarding private and public interests. However, many of the German states also have archival acts ("Archivrecht/ Archivgesetze"). For example, the act of Thüringen states that everyone has the right to use archival material in public archives (§ 16). The Swiss Federal Act on Archiving (1999) states in the principles section that federal documents that are valuable for legal, political, economic, historical, social or cultural reasons shall be archived and that archiving makes a contribution towards legal certainty and to the continuous and efficient management of administrative activities. In particular, it forms the basis for historical and sociological research.

Hungarian Archive Act (1995) tasks archives with ensuring that current records of public agencies are processed, classified, and made accessible for the administration and public and that current records of any agency or private persons are preserved and made available for posterity in public or open private archives, or as protected archival documents. The law clarifies that the free access to data of public interest and freedom of scientific research be realized together with the protection of fundamental constitutional rights related to personality and to personal data and protection of state secrets, official secrets or business confidential data (Hungarian Archive Act, Section 1). Hungary is one of the few countries that, in the purpose statement, emphasizes the balance between the granting of access and the protection of personal data and confidential state matters. The German Federal Archives Act is the only other act that touches upon this balance in its purpose statement: that archives "shall ensure access to federal archive material while safeguarding private and public interests” (§3). This balance in granting access and protection of personal and state matters might be seen as limitations, albeit necessary and important, when considering how archives can support an informed public discourse and foster the formation of a public sphere. 
The Polish Act on the National Archive Resource and Archives (1983) states that the national archives are to preserve the "materials old" serving as important sources of information pertaining to the historical activities of the Polish State, its bodies, and other State organizational units and its relations with other countries, the development of political, social and economic, professional and religious life, the organization and the development of science, culture and art, as well as on the activities of the local government units and other local organizational units in the past and produced today. The Polish act is the only act to note the role of archives in the development of social and economic life and activities in the political, social, cultural, scientific, economic, professional, and religious realms of society, thus implying an active role that goes beyond preservation and ensuring access.

To summarize, the focus of the archival laws in all of the participating countries is the preservation of and accessibility to historical documents and artifacts. The documentation of the past and accessibility to that documentation ensures citizens', or in some cases scholars', ability to obtain the information needed for understanding and making sense of the present, which is necessary for informed decision-making and the protection of rights, though in some situations access may be limited for the protection of individuals and concerning confidential state matters.

\section{Archival Statistics}

The American Society of Archivists developed a set of principles and guidelines for the collecting of archival statistics, which were approved in 2018, and an ISO standard for archive statistics is in the initial stage of development (Standardized Statistical Measures and Metrics for Public Services in Archival Repositories and Special Collections Libraries, 2017; “ISO 18461:2016”). Currently, no internationally accepted statistical measures exist for archives and little statistical information is available from the participating countries.

Norway and Denmark are the only countries collecting national archival statistics comparable to the statistics collected on libraries. The Norwegian statistics include 61 national, regional, and local archival institutions, and the Danish about 500 national, city, and local archives (Statistikk for arkivinstitusjoner og arkiv i bibliotek og museum 2017, 2018; Statistikdokumentation for Arkiver 2017, 2018). Information is given about the number of full-time employees in national, regional, and local archival institutions, number of visits, written requests for archival documents, and collection growth. The Norwegian statistics include figures about total running costs and the digitization of archival material, while the 
Danish statistics include the number of voluntary workers (Statistikk for arkivinstitusjoner og arkiv i bibliotek og museum 2017, 2018; “Arkiver”). Hungary also has national statistics but unfortunately they were not accessible for the ALMPUB project. None of the other participating countries has comprehensive statistics of the archival sector. Poland and Sweden collect statistical data regarding their national archives, which includes the main and branch locations (Sprawozdanie $z$ działalności Naczelnego Dyrektora Archiwów Państwowych oraz archiwów państwowych w 2017 r., 2018; Kulturstatistik i Norden, 2017, Table 7).

The dearth of national statistics for the archival sector makes comparisons impossible. The figures in Table 2.1 must be considered with caution. Information about the number of state owned national archival institutions is readily available, but information about the number of regional and local archival institutions and for privately run institutions is extremely difficult to find. For example, in Poland, many regional and local archives, such as city archives, are formally parts of the national archive ("Resources in Poland: 1.1 Archives"). The number of archival institutions might be considerably higher than is presented in Table 2.1. To complicate matters further, private archival institutions are generally not covered by archival legislation and many of them are small and sometimes depend on volunteer work. Denmark is exceptional in that it collects statistical data from about 500 different archival institutions, many of them local (Statistikdokumentation for Arkiver 2017, 2018, 4).

Why are there no international standards for archival statistics and why are almost no statistics collected? There is no obvious answer. However, archival institutions have not had the same focus on serving the public, offering cultural experiences or mediating their collections, as have public libraries and museums. Historically, the archival institutions focused primarily on preservation of materials for local, regional, and national governance, management and administration. Researchers also became an important target group more recently. As previously noted, support for administrative and scholarly activities is still strongly emphasized in archival legislation, however the focus has shifted. Currently, the material preserved in the archival institutions is regarded primarily as part of the cultural heritage and the archival acts in all the countries, with exception of the German and Swiss federal acts, strongly emphasize the responsibility to fulfill citizens' right to access public documents. To what extent do citizens access archival documents? How do they do it, through on-site visits or through digital media? Is staffing sufficient to respond to user requests and to manage the rapidly expanding collections? A better, more comprehensive collection of statistics could provide answers to these questions.

There are now ongoing discussions in some countries about improving the archival statistics and an ISO standard is being developed. An official report about 
the archival sector is currently underway in Sweden and will be presented in December 2019. Suggestions on how to organize the collection of archival statistics will be included in this report ("Kommittédirektiv: Översyn av arkivområdet: Dir 2017:106.”).

\section{Archives: Services and Uses}

As a result of the lack of data, it is impossible to draw any overall conclusions about the services and use of archival institutions in the participating countries. Statistics from the national archives could be compared across some of the countries. However, this will say little about LAM institutions' roles as public spheres. The regional and - most of all - the local archives need to be included if that dimension should be taken into account and in order to make comparisons with public libraries and museums. For example, and of relevance to the public sphere, some countries have many private archives connected to local history. In Sweden, many of these regional or local archival institutions are organized as NGOs. They preserve local archival material from a wide spectrum of organizations connected to civil society, for example political, temperance, religious, and ethnic organizations, and the archives work in close cooperation with their member organizations.

Finally, although no conclusions can be drawn about services and use of archival institutions based on archival statistics, one of the surveys of the ALMPUB project that focused on the use of LAM institutions amongst the public presents some data in this respect. The results are discussed in other chapters of this anthology.

\section{Final conclusions}

Public libraries, archival institutions, and museums work with the acquisition, organization, preservation, retrieval, and mediation of information, though they historically have focused on different types of materials. Their collections form parts of our cultural heritage and the LAM-institutions are often referred to as society's collective memory - as “memory institutions". Their work is determined largely by cultural and educational policy decisions and is considered to be of great importance from a democratic perspective. Consequently, their roles as public sphere institutions have many similarities, but can archives, libraries, and museums be considered as a common field of practice, based on the results in this chapter? 
This study has shown that the legislation pertaining to libraries, archives, and museums varies greatly between the participating countries and between the three types of institutions. Library legislation generally came first and in several of the countries as early as the 1920s, when modern public libraries started to develop. Archive laws were established significantly later, in most countries during the 1980s or 1990s, and museum legislation in many cases after the turn of the millennium. There are some exceptions. Norway does not have a museum law yet. The Sweden Library Act (1997) was established relatively late. This may be due to the state, through the conditions for the state grants to public libraries that were introduced as early as 1905, setting frameworks for library services. Hungary has had legislation for all three institutions since the late 1920s.

The federal states of Germany and Switzerland differ from the other countries as the LAM institutions are regulated only partly by federal legislation. There are national archival laws, focusing on federal archival material, a federal law regulating the role of the German national library, and Switzerland has a museum law. Neither Switzerland nor Germany has a federal library law defining the roles and terms of public libraries, as do the other participating countries. It is also important to emphasize that there are many private archives and museums in all countries that are not covered by the legislation. This variation in institutional legislation brings into question how, and to what extent, LAM legislation impacts the activities offered by public libraries, museums, and archival institutions. For example, do public libraries receive more money if there is a law? Would there be fewer if they were not mandated by law? We do not have the answers to these questions, but present important topics for future research to address.

In addition to legislation at the national level, the so-called participatory turn or paradigm that has taken place more broadly in the cultural sector, especially at the policy level, is also important to mention. An in-depth discussion of it is out of the scope of this chapter, but will be addressed in later chapters and is highly relevant for the future of the LAM institutions and their role(s) as public sphere institutions. The cultural sector, within which the LAM institutions are subsumed, has shifted from the experience paradigm to a participatory paradigm (Grøn and Gram 2019). This development of an increasingly participatory culture is one that embraces a bottom-up approach to collection and service provision that facilitates interaction and creation of content by users rather than a top-down approach based on the provision of culture created or collected by professionals (Deodato 2014; Roued-Cunliffe and Copeland 2017).

This has resulted in an emphasis on providing greater support for diversity of expression and the inclusion of marginalized discourses, which has been argued as necessary for achieving a comprehensive and robust public sphere (Fraser 2010). This focus can be seen already in some of the library laws, such as Nor- 
way's that tasks libraries with being meeting places and arenas for dicussion and debate and possibly Sweden and Iceland's museum laws that mandate openness, versitality, and comprehensiveness respectively. Many of the other laws, across the three sectors, can be seen to open up for bottom-up approaches as many of them focus on equal opportunity for expression and the inclusion of diverse perspectives.

On the European level, the Council of the European Union requested a report to identify innovative approaches to the governance of all forms of cultural heritage (e.g. tangible, intangible, digital) that involves stakeholders from all realms of society. This resulted in a collective effort by experts from 27 European countries to create a handbook for professionals and led to the publication of Participatory Governance of Cultural Heritage; Report of the OMC (Open Method of Coordination) Working Group of Members States' Experts; European Agenda for Culture; Workplan for Culture 2015-2018. The participatory governance approach has been used as a working method in the field of culture since 2017 in the framework of the European Agenda for Culture. Of the participating countries in the ALMPUB project, Switzerland, Norway and Iceland are not member states in the EU; however, Norway, for example and in addition to its library law, has relatively new cultural policy goals based on a bottom-up approach (Meld St. 8 (2018-2019) Report to the Storting (white paper), 2019). The creation of this report and the incorporation of participatory governance as a working method suggest that the participatory paradigm is gaining momentum within the European context.

Looking forward, this new participatory turn may facilitate the formation of a more unified LAM sector, but it may also create tensions as these intitutions have historically been characterized by top-down approaches and, as publicly funded insitutions, may experience pressure to carry out state agendas. This is a growing concern as nationalist ideas have grown in strength all over Europe in recent years and a raging debate has arisen, particularly in Poland and Hungary, about the nationalist orientation of cultural policy and an increased ideological control of cultural institutions. An important question is how this development will affect the LAM field. As we could see, Hungary has a very dense network of local public libraries compared to most of the other ALMPUB countries, because of its numerous small municipalities. Publicly run local and regional museums are the most common in Hungary, although most of them are private in the other countries. To what extent will these publicly run local ALM institutions be expected to serve as the government's tool in the disseminating of a nationalist cultural policy at the local level and to what extent could that affect their public access to free information?

This study has also shown that the collection of statistics is very different when it comes to archives, libraries, and museums. For example, there are no 
national archival statistics except for Norway and Denmark. Norway is the only country that has had a common governmental agency aimed at the development of the whole LAM field. "ABM-utvikling” existed between 2003 and 2009 and will be discussed and analyzed in two other chapters of this anthology. However, it is an interesting question, whether Norway's complete statistics could be explained by the fact that for a period there was a clearer focus on LAM as a common field than in many other countries.

Finally, the main purpose of the ALMPUB project has been to study LAM institutions' role as public spheres in the age of digitalization. A few of the participating countries give some information in their statistics about the digitization of collections and use of digital media in museums. Most of the countries present figures about the downloading of e-books in public libraries. Norwegian archival statistics present figures about the digitization of archival material. Other than these statistics, the statistics are still focused on traditional media and give very limited information about digital media, services and use. This leaves us with the question of how the LAMs can (or will) employ digitalization and ICT in their role as public sphere institutions, or, in the face of increased online activity, will the institutions' ability to facilitate physical meetings and discussions be the way in which they break through online echo chambers and filter bubbles and nurture the dialogue necessary for the realization of a robust and inclusive public sphere?

\section{References}

\section{LAM-legislation}

Act LXVI of 1995 on Public Records, Public Archives, and the Protection of Private Archives [Hungary]. Accessed August 22, 2019. https://www.ecoi.net/en/file/local/1067797/227_ tmpphpFMFCXI.pdf.

Act CXL. of 1997 on the Protection of Cultural Goods, Museum Institutions, Public Library Services and Community Culture [Hungary]. Accessed August 22, 2019. https://net.jogtar.hu/ jogszabaly?docid=99700140.TV.

"Archivrecht/Archivgesetze." Arkivschule Marburg. Accessed August 22, 2019. https://www. archivschule.de/DE/service/archivrecht/.

Danish Archive Act. Accessed August 22, 2019. https://www.retsinformation.dk/forms/r0710. aspx?id=183862.

Danish Library Act. Accessed August 22, 2019. https://www.retsinformation.dk/forms/r0710. aspx?id=145152.

Danish Museum Act. Accessed August 22, 2019. https://kum.dk/english/services/legislation/ archives-museums-and-cultural-heritage/museum-act/.

German Federal Archives Act. Accessed August 22, 2019. https://www.bundesarchiv.de/EN/ Navigation/Meta/About-us/Legal-Bases/Federal-Archives-Act/federal-archives-act.html. 
Icelandic Library Act. Accessed August 22, 2019. https://www.government.is/media/menntamala raduneyti-media/media/frettir2014/Thyding-bokasafnalog-april-2015-Lokagerd-a-vef.pdf.

Icelandic Museum Act. Accessed August 22, 2019. https://www.althingi.is/lagas/nuna/2011141. $\mathrm{html}$.

Icelandic Public Archives Act. Accessed August 22, 2019. https://skjalasafn.is/files/docs/ ThePublicArchivesAct-in-Iceland-No-77-2014.pdf.

Norwegian Archive Act. Accessed August 22, 2019. https://lovdata.no/dokument/NL/lov/199212-04-126.

Norwegian Public Library Act. Accessed August 22, 2019. https://lovdata.no/dokument/NL/lov/ 1985-12-20-108.

Polish Act on the National Archive Resource and Archives. Accessed August 22, 2019. https: //www.global-regulation.com/translation/poland/3354040/the-act-of-14-july-1983-onthe-national-archive-resource-and-archives.html.

Polish Library Act. Accessed August 22, 2019. https://www.portaloswiatowy.pl/organizacjapracy/ustawa-z-27-czerwca-1997-r.-o-bibliotekach.-tekst-jedn.-dz.u.-z-2018-r.-poz.-57416532.html.

Polish Museum Act. Accessed August 22, 2019. http://prawo.sejm.gov.pl/isap.nsf/DocDetails. xsp?id=WDU19970850539.

"Stand der Entwicklung in den Bundesländern." Deutscher Bibliotheksverband. Accessed August 22, 2019. https://www.bibliotheksverband.de/dbv/themen/bibliotheksgesetze/bundeslae nder/stand-der-entwicklung.html.

Swedish Archive Act. Accessed August 22, 2019. https://www.riksdagen.se/sv/dokument-lagar/ dokument/svensk-forfattningssamling/arkivlag-1990782_sfs-1990-782.

Swedish Library Act. Accessed August 22, 2019. https://www.riksdagen.se/sv/dokument-lagar/ dokument/svensk-forfattningssamling/bibliotekslag-2013801_sfs-2013-801.

Swedish Museum Act. Accessed August 22, 2019. https://www.riksdagen.se/sv/dokumentlagar/dokument/svensk-forfattningssamling/museilag-2017563_sfs-2017-563.

Swiss Federal Act on Archiving. Accessed August 22, 2019. https://www.admin.ch/opc/en/ classified-compilation/19994756/index.html.

Swiss Museums and Collections Act. Accessed August 22, 2019. https://www.global-regulation. com/translation/switzerland/2974889/rs-432.30-federal-law-of-june-12\%252c-2009-onthe-museums-and-collections-of-confederation- $\% 2528$ law-on-museums-and-collections $\%$ 252c-cml\%2529.html.

\section{Other material}

“A Magyarországi Könyvtárak Statisztikai Adatai [Statistical Data of Hungarian Libraries].” n.d. Könyvtári Intézet [The Library Institute]. Accessed October 12, 2019. http://www.ki.oszk. hu/informacioszolgaltatas/magyarorszagi-konyvtarak-statisztikai-adatai.

“Archives of Hungary." Association of Hungarian Archivists. Accessed October 12, 2019. http: //www.archivportal.hu/en/archives-of-hungary/.

“Arkiver." Statistics Denmark. Accessed October 12, 2019. https://www.statistikbanken.dk/ 10391.

Årsredovisning 2017 för riksarkivet. Stockholm: Swedish National Archives, 2018. https: //riksarkivet.se/Media/pdf-filer/Riksarkivet-arsredovisning-2017.pdf. 
Besöksutveckling för de centrala museerna 2018: redovisning av regeringsuppdraget "Besöksutveckling för vissa statliga museer 2018" 2019-05-02. Stockholm: Swedish Agency for Cultural Policy Analysis, 2019. https://kulturanalys.se/wp-content/uploads/2019/05/ Besoksutveckling-for-de-centrala-museerna-2018_v2.pdf.

Bibliotek 2017: offentligt finansierade bibliotek. Stockholm: National Library of Sweden, 2018. https://www.kb.se/download/18.42b0ca55163848cb4b5227/1531819095573/ Biblioteksstatistik_2017.pdf.

“Culture in 2017." Statistics Poland. Accessed October 12, 2019. https://stat.gov.pl/obszarytematyczne/kultura-turystyka-sport/kultura/kultura-w-2017-roku, 2,15.html.

“Data of Museums 2000-." Hungarian Central Statistical Office. Accessed October 12, 2019. https://www.ksh.hu/docs/eng/xstadat/xstadat_annual/i_zkk005b.html.

Deodato, J. “The Patron as Producer: Libraries, Web 2.0, and Participatory Culture”. Journal of Documentation, 70, no. 5, 734-758, 2014.

“EGMUS: Complete Data." EGMUS - European Group of Museum Statistics. Accessed October 12, 2019. https://www.egmus.eu/nc/en/statistics/complete_data/.

“European Countries by Population.” Worldometers. Accessed October 12, 2019. https://www. worldometers.info/population/countries-in-europe-by-population/.

European Union. Participatory Governance of Cultural Heritage: Report from the OMC (Open Method of Coordination) Working Group of Member States' Experts: European Agenda for Culture; Workplan for Culture 2015-2018. Luxembourg: Publications Office of the European Union, 2018. https://apo.org.au/sites/default/files/resource-files/2018/04/aponid189996-1238346.pdf.

Fraser, N. "Rethinking the Public Sphere: A Contribution to the Critique of Actually Existing Democracy (1992)". In Gripsrud, J. and M. Eide (eds), The Idea of the Public Sphere: A Reader, pp. 127-149. Lanham, MD: Lexington Books, 2010.

"Fri entré infört vid 18 statliga museer”. Swedish Government. Accessed October 12, 2019. https://www.regeringen.se/artiklar/2016/02/fri-entre-infort-vid-18-statliga-museer/.

Grøn, R. and L. K. Gram. "Deltagelsens paradoks - samlingens rolle i den brugerinddragende formidling". The Nordic Journal of Cultural Policy, (2), 2019.

"Héraðsskjalasöfn [Regional Archives]." National Archives of Iceland. Accessed October 12, 2019. https://skjalasafn.is/heradsskjalasofn.

"Historisk statistikk for folkebibliotek, 2017." National Library of Norway. Accessed October 12, 2019. https://kunnskapsbase.bibliotekutvikling.no/statistikk/statistikk-for-norskebibliotek/folkebibliotek/historisk-statistikk-for-folkebibliotek/.

"ICOM Definition of a Museum." ICOM - International Council of Museums. Accessed October 12, 2019. http://archives.icom.museum/definition.html.

“ISO 2789:2013, International Library Statistics." International Organization for Standardization. Accessed October 12, 2019. https://www.iso.org/obp/ui/\#iso:std:iso:2789:ed-5:v1: en.

“ISO 18461:2016, International Museum Statistics." International Organization for Standardization. Accessed October 12, 2019. https://www.iso.org/obp/ui/\#iso:std:iso:18461:ed-1: v1:en.

"ISO/CD 24083, Information and Documentation - International Archives Statistics." International Organization for Standardization. Accessed October 12, 2019. https://www.iso.org/ standard/77765.html. 
“Kommittédirektiv: Översyn av arkivområdet: Dir 2017:106." Swedish Government. Accessed October 12, 2019. http://www.sou.gov.se/wp-content/uploads/2018/03/ Kommittédirektiv-Översyn-av-arkivområdet-för-delning.docx.pdf.

Kulturstatistik i Norden: en förstudie. Stockholm: Kulturanalys Norden, 2017. https:// kulturanalysnorden.se/wp-content/uploads/2017/04/kulturstatistik-i-norden.pdf.

Meld St. 8 (2018-2019) Report to the Storting (white paper): The Power of Culture. Summary. Oslo: Norwegian Ministry of Culture. https://www.regjeringen.no/contentassets/ 9778c28ab1014b789bbb3de0e25e0d85/en-gb/pdfs/stm201820190008000engpdfs.pdf.

“Museen 2017." Bundesamt für Statistik [Switzerland]. 2017. Accessed October 12, 2019. https: //www.bfs.admin.ch/bfs/de/home/statistiken/kultur-medien-informationsgesellschaftsport/kultur/museen.html.

Museer 2017. Stockholm: Swedish Agency for Cultural Policy Analysis, 2018. https:// kulturanalys.se/wp-content/uploads/2018/06/museer-2017-webb.pdf.

Museer i Norden. Stockholm: Kulturanalys Norden, 2018. https://kulturanalysnorden.se/wpcontent/uploads/2018/06/Museer-i-Norden-webb_NY.pdf.

“Museums.” Statistics Denmark. Accessed October 12, 2019. https://www.dst.dk/en/Statistik/ emner/kultur-og-kirke/museer-og-kulturarv/museer.

“Öffentliche Bibliotheken Gesamtstatistik, Kerndaten 2017.” DBS - Deutsche Bibliotheksstatistik. Accessed October 12, 2019. https://wiki1.hbz-nrw.de/pages/viewpage.action?pageld= 99811337\&preview=/99811337/311230480/oeb_bund_2017.pdf.

“Öffentliche Bibliotheken in den Städten (Gemeinden Ab 10,000 Einwohnern): Daten 2017." Bundesamt für Statistik [Switzerland]. Accessed October 12, 2019. https://www.bfs.admin. $\mathrm{ch} / \mathrm{bfs} / \mathrm{de} /$ home/statistiken/kultur-medien-informationsgesellschaft-sport.assetdetail. 5746971.html.

Pearce-Moses, R. A Glossary of Archival and Records Terminology. Chicago: The Society of American Archivists, 2005. http://files.archivists.org/pubs/free/SAA-Glossary-2005.pdf.

“Public Libraries." Statistics Denmark. Accessed October 12, 2019. https://www. statistikbanken.dk/10391.

“Real GDP per Capita [2017]." Eurostat. Accessed October 12, 2019. https://ec.europa.eu/ eurostat/databrowser/view/sdg_08_10/default/table?lang=en.

"Resources in Poland: 1.1 Archives." School of Advanced Study, University of London. Accessed October 12, 2019. https://port.sas.ac.uk/mod/book/view.php?id=1887\&chapterid=2022.

Roued-Cunliffe, H. and A. Copeland. Participatory Heritage. London: Facet, 2017.

Sprawozdanie z Działalności Naczelnego Dyrektora Archiwów Państwowych Oraz Archiwów Państwowych w 2017 r. [Report on the Activities of the Polish State Archives in 2017]. Warsaw: General Directorate of State Archives, 2018. https://www.archiwa.gov.pl/files/ SPRAWOZDANIE_2017.PDF.

Standardized Statistical Measures and Metrics for Public Services in Archival Repositories and Special Collections Libraries. Society of American Archivists \& Association of College and Research Libraries, 2017. https://www2.archivists.org/standards/standardizedstatistical-measures-and-metrics-for-public-services-in-archival-repositories.

“Statistik der schweizer Städte 2019." Bundesamt für Statistik. 2019. Accessed October 12, 2019. https://www.bfs.admin.ch/bfs/de/home/statistiken/kataloge-datenbanken/ publikationen.assetdetail.8086839.html.

Statistikdokumentation for Arkiver 2017. Copenhagen: Statistics Denmark, 2018. https://www. $\mathrm{dst.dk/da/Statistik/dokumentation/statistikdokumentation/arkiver.}$ 
Statistikdokumentation for Museer 2017. Copenhagen: Statistics Denmark, 2018. https://www. dst.dk/da/Statistik/dokumentation/statistikdokumentation/museer.

Statistikk for arkivinstitusjoner og arkiv i bibliotek og museum 2017. Oslo: Arkivverket, 2018. https://www.arkivverket.no/arkivutvikling/tall-og-data-statistikk/arkivstatistikken-amb/ tall-og-analyser-fra-2017\#!\#block-body-2.

Statistikk for museum 2017. Oslo: Arts Council Norway, 2018. https://www.kulturradet.no/ documents/10157/4c3ab521-3498-4c80-8942-413b205bdeba.

Statistische Gesamterhebungen den Museen der Bundesrepublik Deutschland für das Jahr 2017. Berlin: Institut für Museumsforschung, 2018. https://www.egmus.eu/fileadmin/ national_Data/German_Publications/mat72.pdf.

The Public Library Service: IFLA/UNESCO Guidelines for Development. IFLA Publications 97. München: Saur, 2001. www.ifla.org/files/assets/hq/publications/archive/the-publiclibrary-service/publ97.pdf.

“Tourism Statistics 2017.” Eurostat. Accessed October 12, 2019. https://ec.europa.eu/eurostat/ statistics-explained/index.php?title=Tourism_statistics.

Verband deutscher Archivarinnen und Archivare (ed.). Archive in Deutschland, Österreich und der Schweiz: Adressenverzeichnis 2017-2018. Münster: Ardey, 2017.

The authors wish to thank Henrik Jochumsen, Casper Hvenegard Rasmussen, Andreas Vårheim, Ragnar Audunson, Hans-Christoph Hohbom, Karsten Schuldt, Máté Tóth, Ágústa Pálsdóttir, and Anna Mierzecka for information about LAM legislation and statistics from their respective countries and for constructive and insightful comments on the text. 


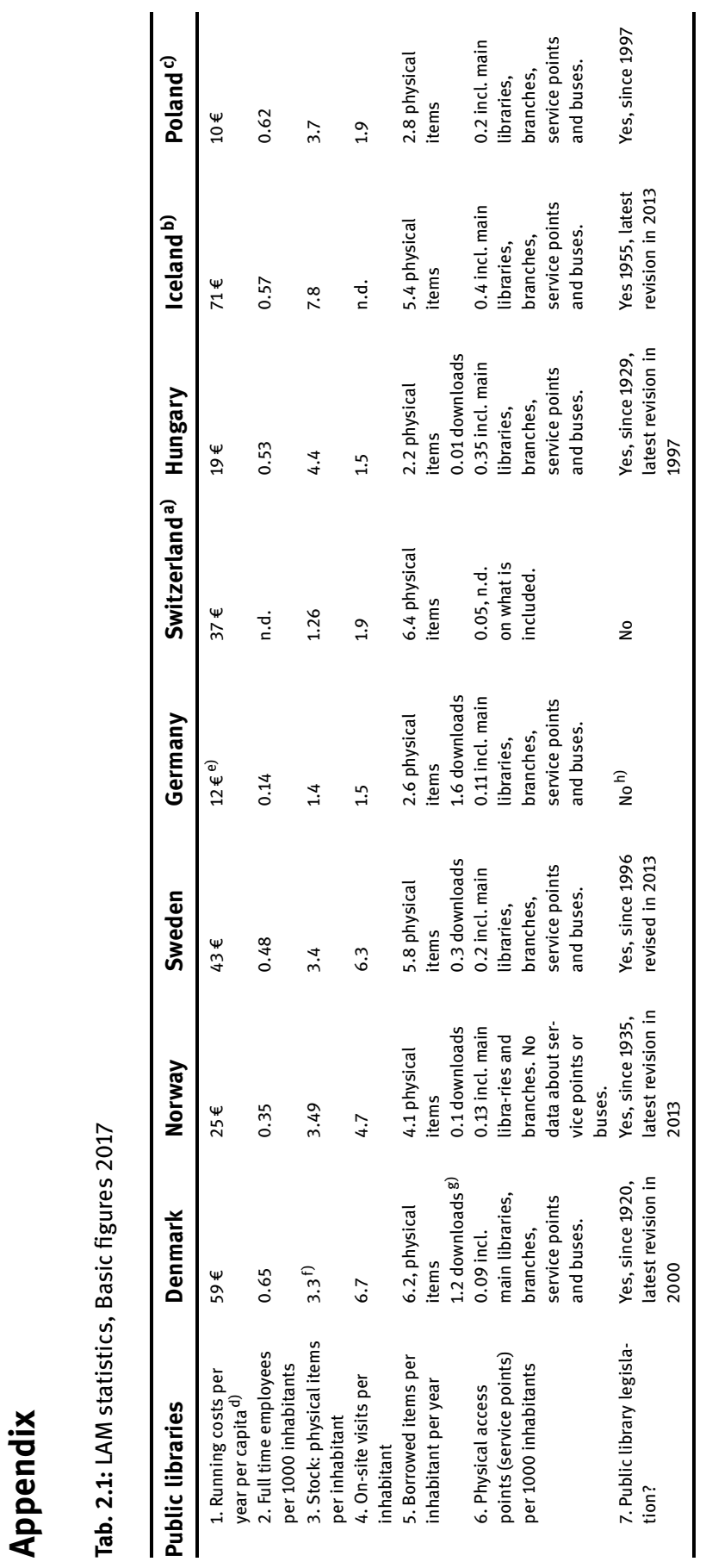




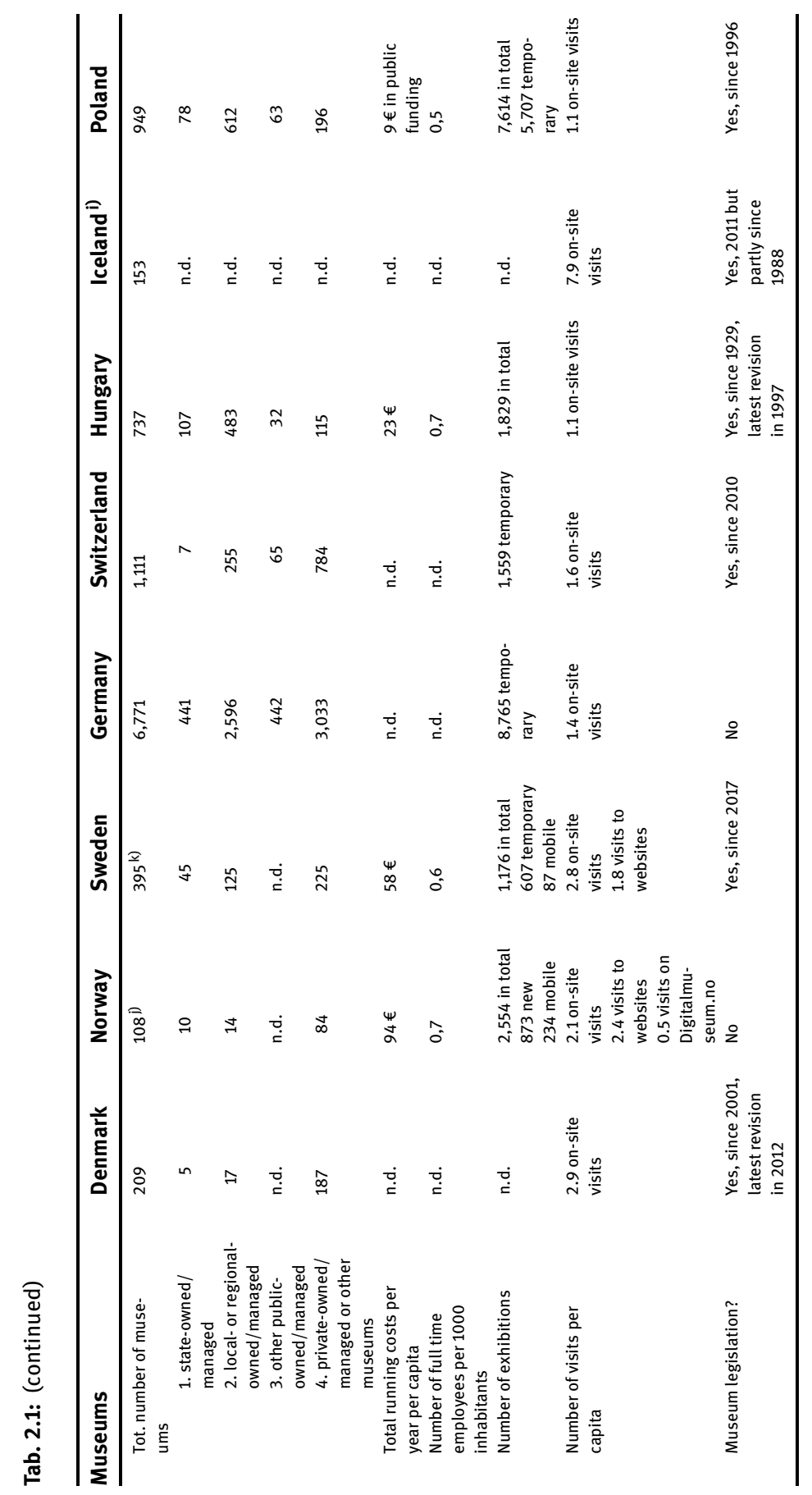




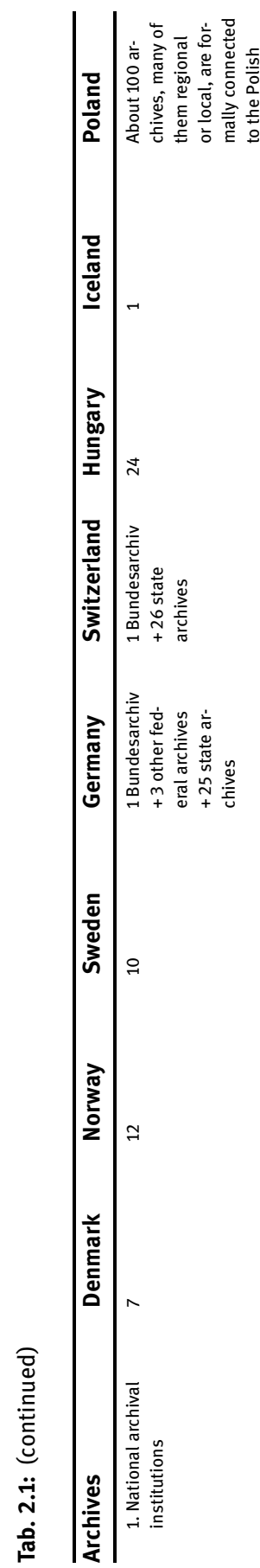

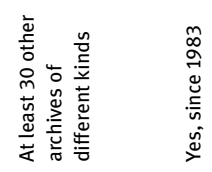

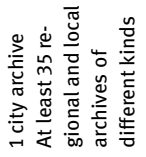

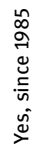

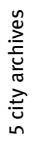

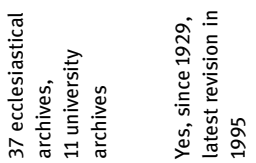

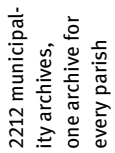

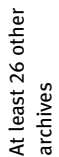

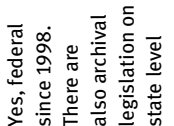

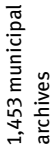

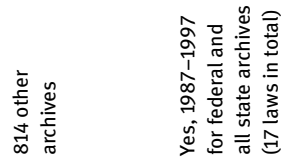

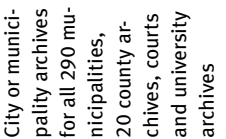

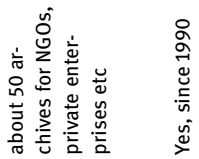

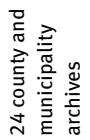

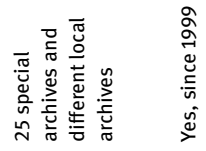

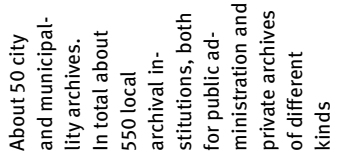

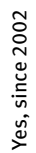
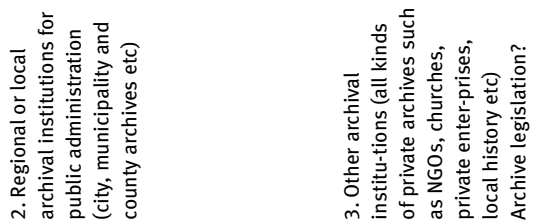


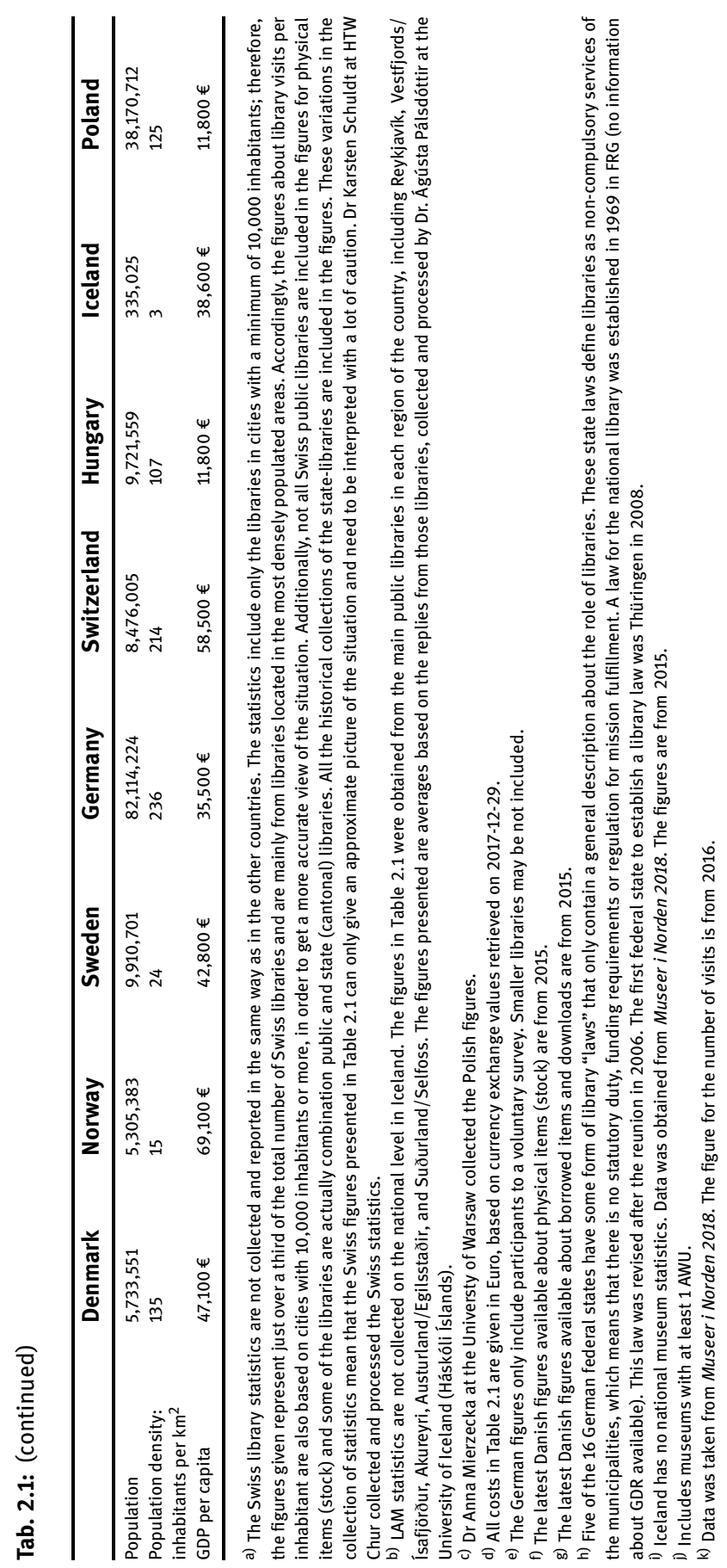




\section{Erik Henningsen and Håkon Larsen \\ 3 The Digitalization Imperative: Sacralization of Technology in LAM Policies}

\section{Introduction}

In most Western countries, cultural policy is at base a matter of public funding of the culture sector, and hence a question of money. At the same time, this is a domain of policy that is heavily invested with ideas that explain and justify the need for public expenditure on the culture sector. European cultural policies have for several decades been legitimized with reference to specific overarching ideas, being activated by policy actors and managers in cultural organizations. These ideas have guided the development of policies, as well as functioned as the normative grounds on which policies have been based. Some of the ideas are normative principles (e.g. universal access to culture, the right to participation, freedom of expression), while others are concerned with emergent trends of social, cultural, and technological development (e.g. globalization, cultural diversity). Since the mid-twentieth century onwards, notions of democratization of culture, cultural dissemination, and cultural participation has guided the formulation of cultural policies in Western Europe. In the 1990s as well as the 2000s globalization and cultural diversity became important overriding concepts in cultural policy discourses. Since the turn of the century, digitalization has emerged as another guiding concept in the formulation of cultural policies, or as what we will refer to as a "policy imperative".

In accordance with dictionary definitions, "imperative" is an authoritative command or call for action. Here, one may think also of Kant's "categorical imperative", which refers to an ultimate and universally applicable moral principle or rule of action. When we talk of policy imperatives in this chapter it denotes the fact that ideas may take on the commanding force of an imperative, regardless of their objective or normative validity. This imperative force may be short- or long lived and restricted to certain groups or domains of social action. More specifically, we use the concept of policy imperatives in reference to ideas that take on the character of self-explanatory and universally binding calls for action within a given field of policy. These are ideas actors within the policy field can openly reject or protest only at the risk of being perceived as irresponsible, foolish or morally corrupted. By virtue of this, the ideas become obligatory reference points in the formulation of policies and organizing concepts in policy discourses. Today, digitalization is 
perhaps the most central concept to be found in cultural policy discourses (as well as in many other domains of policy) and a concept that cannot be overlooked by any actor that wants to be a serious contributor to cultural policy discourse. Reflections on the actual and potential significance of digital technology is not only part of every contemporary discussion of the future of cultural organizations, but policy actors have themselves been striving to promote the "digital society". ${ }^{1}$

Our aim in this chapter is to investigate how digitalization has attained the role as policy imperative within the culture sector and how the imperative is influencing contemporary discourses on cultural policy. In doing so, we will pay specific attention to the role the concept of digitalization plays in policies related to libraries, archives, and museums (LAM-organizations). Because we want to make a case analysis covering all relevant policy documents, we have chosen to limit our analysis to one particular country, Norway. ${ }^{2}$ To study the role of digitalization in LAM-policies and its emergence as a policy imperative within this field, we have analyzed all relevant policy documents issued by state authorities within the LAM-sector since the time around the turn of the century. By studying these documents, we can trace the history and development of the discourse on digitalization of the LAM-sector. We will investigate when digital technology became a topic within the discourse and when it achieved the status of an imperative influencing every discussion on the future of LAM-organizations.

Digitalization is a significant force of change in contemporary society, and this applies as much to the culture sector as to other sectors of society. Digital technologies have profoundly changed the workings of cultural industries over the past years and it is safe to assume that they will continue to do so in the years to come. However, it would be mistaken to infer from this that the emergence of digitalization as a policy imperative within the culture sector is simply a natural response to technological circumstances. As already pointed out, there are several competing concepts that might have taken digitalization's place as policy imperative, and digitalization is of varying salience to actors within the culture sector.

To be able to understand how digitalization has attained the role of a policy imperative within this field of cultural policy, we will show that one must take several types of cultural processes into consideration. First, digitalization's ascendancy into a policy imperative can be viewed as a process of imitation or "mimetic

1 The Norwegian white paper on preserving and disseminating cultural heritage was framed with the intention to contribute to the development of the digital society (St.meld., nr. 24 (20082009)).

2 As we are both experts on Norwegian cultural policy, and have a lot of knowledge on the actual policies, the key actors of the sector, and the political and bureaucratic traditions, the choice became obvious to us. 
isomorphism" (DiMaggio and Powell 1983). Such processes can occur at various levels of organization, including at the international level. According to Dahl and Helseth (2006, 268-269), imitation of policies from other countries has been one of the principal mechanisms shaping Norwegian cultural policy. As we will demonstrate, this applies to the case of digitalization as well. Second, to understand its role as a policy imperative in the LAM policy field, one must consider the conceptual framing of the discourse on digitalization, and in particular the diagnostic and prognostic visions that structure the discourse (cf. Lakoff and Johnson 1980; Snow and Benford 1988). Proceeding along these lines, we will show how digitalization at varying moments emerges as a potential threat to the continued existence of actors within the sector or as a utopian promise of future prosperity.

Even though the analysis of mimetic processes, and of the conceptual framing of discourses on digitalization, can take us some distance toward understanding how digitalization is constituted as a policy imperative in the LAM-field, to arrive at a fuller understanding of how digitalization attains the role of policy imperative it is necessary to take a third type of cultural process into consideration, namely that of sacralization. By this, we are referring to the process whereby objects through mystification get invested with sacredness. Sacred objects are kept at a safe distance from profane elements and their importance gets confirmed trough actors engaging in ritual practice (Durkheim 1995[1912]). As a sacred object, digitalization has become mystified, distanced from the practical aspects of transforming analogue objects to digital form. Digitalization is perceived as an external force to social relations, dictating action on the part of actors working within the sector. As a sacred object in cultural policy discourse, digitalization can serve as an effective policy imperative.

Compared with such cultural industries as the news media or the music industry, digitalization is less of an acute question of economic survival to the actors working within the LAM-sector. In most European countries, LAM-organizations rely heavily on public funding and are not in need of inventing new business models in order to survive under circumstances brought on by digitalization. When these organizations take actions related to ongoing processes of digitalization, e.g. by making collections accessible online, it is more a matter of choice and persuasion than a dictate of practical necessity. For these reasons, the case of LAMpolicies can be assumed to bring out in clear view cultural processes involved in the emergence of digitalization as a policy imperative. 


\section{Cultural Heritage and Digitalization in Norwegian Cultural Policy}

Discourses on digitalization have been around for several decades, but as a discursive topic in the Norwegian LAM-policies it is relatively recent. In policy documents pertaining to this field from the 1980s and early 1990s there is barely a mentioning of the topic. However, as is demonstrated by our study, in the period from the late 1990s until the present, digitalization was firmly put on the agenda in discourses on LAM-organizations. In this section, we briefly discuss the main findings from our study of Norwegian state issued policy documents that deal with cultural heritage and digitalization. The corpus of documents under consideration includes all Norwegian white papers related to the subject, which comprises a total of seven documents, written over a time span of 14 years (1999-2013). In addition, we have also studied two reports written by experts on the request of the Ministry of Culture. Information on the documents making up the data for this study is presented in Table 3.1. To allow the reader to trace the emergence of digitalization as a discursive topic within the LAM-field, the documents will be briefly presented in a chronological manner, before we analyze them as a cluster.

The green paper "Museum, Diversity, Memory, Meeting-place” (NOU, 1996:7) was presented to the Ministry of Culture in 1996 and has been a reference point for policy discussions on museums in Norway up until this day. The report highlights the relevance or utility of museums to society ("samfunnsnytten") and their potentialities as meeting places or "dialogue institutions". While the term digitalization is not employed in the report, it features discussions on the use of information and communication technologies (ICT) in museums, and the concept of the "information society" is central to the reports' explication of museums' potential roles as a dialogue institution.

The concept of the information society is accorded an important role as well in the first Norwegian white paper that deals specifically with digitalization and the cultural heritage field, as is indicated by the title "Sources of Knowledge and Experience. On Archives, Libraries and Museums in an ICT-age ..." (St.meld., nr. 22 (1999-2000)). The white paper affirms the main arguments of the preceding green paper, while accentuating the significance and value of cultural heritage organizations' responsiveness to "users" and users' access to knowledge and information. An important difference between the two documents is that whereas the discussions of the green paper implicitly affirms the uniqueness of museums as organizations, the white paper highlights the shared identity of libraries, archives, and museums as "cultural heritage organizations". For these reasons, the white paper has become known colloquially as the "LAM-paper". 
Tab. 3.1: "List of documents studied."

\begin{tabular}{|c|c|c|c|}
\hline Year & Title (Norwegian/English) & $\begin{array}{l}\text { Place of } \\
\text { publication }\end{array}$ & $\begin{array}{l}\text { Type of } \\
\text { document }\end{array}$ \\
\hline 1996 & $\begin{array}{l}\text { NOU 1996:7: Museum, mangfald, minne, møtestad/ } \\
\text { Museum, Diversity, Memory, Meeting-place }\end{array}$ & $\begin{array}{l}\text { Oslo: Ministry } \\
\text { of Culture }\end{array}$ & $\begin{array}{l}\text { Green } \\
\text { paper }\end{array}$ \\
\hline 1999 & $\begin{array}{l}\text { St.meld. nr. } 22 \text { (1999-2000) Kjelder til kunnskap og } \\
\text { oppleving. Om arkiv, bibliotek og museum i ei IKT-tid } \\
\text { og om bygningsmessige rammevilkår på kulturom- } \\
\text { rådet/Sources of Knowledge and Experience. On } \\
\text { Archives, Libraries and Museums in an ICT-age, and } \\
\text { on Housing Infrastructure in the Culture Sector }\end{array}$ & $\begin{array}{l}\text { Oslo: Ministry } \\
\text { of Culture }\end{array}$ & $\begin{array}{l}\text { White } \\
\text { paper }\end{array}$ \\
\hline 2003 & $\begin{array}{l}\text { St.meld. nr. } 48 \text { (2002-2003) Kulturpolitikk fram mot } \\
\text { 2014/Cultural Policy Toward } 2014\end{array}$ & $\begin{array}{l}\text { Oslo: Ministry } \\
\text { of Culture and } \\
\text { Church Affairs }\end{array}$ & $\begin{array}{l}\text { White } \\
\text { paper }\end{array}$ \\
\hline 2006 & $\begin{array}{l}\text { Kulturarven for alle - digitalisering i abm- } \\
\text { sektoren/Cultural Heritage for All - Digitalization } \\
\text { in the LAM-sector }\end{array}$ & $\begin{array}{l}\text { Oslo: LAM- } \\
\text { Development }\end{array}$ & $\begin{array}{l}\text { Directorate } \\
\text { report }\end{array}$ \\
\hline 2009 & $\begin{array}{l}\text { St.meld. nr. } 24 \text { (2008-2009) Nasjonal strategi for } \\
\text { bevaring og formidling av digital kulturarv/National } \\
\text { Strategy for Maintenance and Dissemination of Digi- } \\
\text { tal Cultural Heritage }\end{array}$ & $\begin{array}{l}\text { Oslo: Ministry } \\
\text { of Culture and } \\
\text { Church Affairs }\end{array}$ & $\begin{array}{l}\text { White } \\
\text { paper }\end{array}$ \\
\hline 2009 & $\begin{array}{l}\text { St.meld. nr. } 23 \text { (2008-2009) Bibliotek. Kunnskap- } \\
\text { sallmenning, møtestad, og kulturarena i ei digital } \\
\text { tid/Libraries. Knowledge Common, Meeting Place } \\
\text { and Cultural Arena in a Digital Age }\end{array}$ & $\begin{array}{l}\text { Oslo: Ministry } \\
\text { of Culture and } \\
\text { Church Affairs }\end{array}$ & $\begin{array}{l}\text { White } \\
\text { paper }\end{array}$ \\
\hline 2009 & $\begin{array}{l}\text { St.meld. nr. } 49 \text { (2008-2009) Framtidas museum. For- } \\
\text { valtning, forskning, formidling, fornying/Museum of } \\
\text { the Future. Administration, Research, Dissemination, } \\
\text { Renewal. }\end{array}$ & $\begin{array}{l}\text { Oslo: Ministry } \\
\text { of Culture and } \\
\text { Church Affairs }\end{array}$ & $\begin{array}{l}\text { White } \\
\text { paper }\end{array}$ \\
\hline 2012 & $\begin{array}{l}\text { Meld.St. nr. } 23 \text { (2011-2012) Visuel kunst/Visual } \\
\text { Arts }\end{array}$ & $\begin{array}{l}\text { Oslo: Ministry } \\
\text { of Culture }\end{array}$ & $\begin{array}{l}\text { White } \\
\text { paper }\end{array}$ \\
\hline 2012 & Meld.St. nr. 7 (2012-2013) Arkiv/Archive & $\begin{array}{l}\text { Oslo: Ministry } \\
\text { of Culture }\end{array}$ & $\begin{array}{l}\text { White } \\
\text { paper }\end{array}$ \\
\hline
\end{tabular}

The next state issued policy document that featured discussions on digitalization and the cultural heritage sector is a so-called "culture report". Since the 1970s, Norwegian governments have, at intervals of about a decade, presented white papers that make broad assessments of developments within the culture sector and signals future directions for the country's cultural policies. The document “Cultural Policy Toward 2014" (St.meld., nr. 48 (2002-2003)) was presented 
by the Ministry of Culture to the Parliament in August 2003. While the topic of cultural heritage is relegated to a subchapter only, the document affirms the continued importance of digitalization in the LAM-sector as well as the goals and priorities formulated in the preceding LAM-paper. More specifically, "Cultural Policy Toward 2014" affirms the recommendation from the LAM-paper that a status report should be produced on issues related to digitalization and the LAM-sector, and further that the report should be a responsibility of the newly established directorate LAM-development (ABM-utvikling [NO]). ${ }^{3}$

In response to this recommendation, the report "Cultural Heritage for All Digitalization in the LAM-sector" (ABM 2006) was published by the directorate three years later. The report affirms goals formulated in previous documents regarding the importance of users' access to information and knowledge from LAMorganizations. It also details the various categories of users LAM-organizations may relate to. For the most part, the document deals with technical challenges related to digitalization and the allocation of tasks and responsibilities between actors in the LAM-sector.

In April 2009, the Ministry of Culture presented the white paper "National Strategy for Maintenance and Dissemination of Digital Cultural Heritage" (St.meld., nr. 24 (2008-2009)), often referred to as the "digitalization paper" by actors in the LAM-sector. While the aims and purposes of the white paper are parallel to those of the report issued by LAM-development, it is couched in a more visionary tone and introduces several concepts that were novelties within this domain of policy. The vision underlying the ICT-policy for the culture sector, it is stated, is to "make as much as possible of the collections available to as many users as possible. The collections should be searchable and available across the whole of the LAM-sector, and the content should be disseminated in a user-friendly manner” (St.meld., nr. 24 (2008-2009), 9). Inspired by policy documents from other sectors, the white paper introduces the concepts of "digital society", "digital common", and "knowledge common". References are also made to Paragraph 5 of Article 100 (the freedom of speech article) of the

3 The establishment of this directorate in 2003 was a material outcome of the LAM-paper from 1999, and a creation of the Ministry of Culture and the Ministry of Church Affairs, Education and Research. The directorates' mission was to administer and develop issues related to all three types of organizations. Following a re-organization, the directorate ceased to exist already in 2011, with archival and museum issues being directed to the Arts Council, and the library issues directed to the National Library (see Vårheim, Skare, and Stokstad, this volume, for more on ABM-utvikling). 
Norwegian Constitution, which states that "the state authorities shall create conditions that facilitate an open and enlightened public discourse". ${ }^{4}$

A white paper on libraries and digitalization, entitled "Libraries. Knowledge Common, Meeting Place and Cultural Arena in a Digital Age” (St.meld., nr. 23 (2008-2009)), was also presented in 2009. The paper is set in the perspectives of the previously mentioned documents, arguing that "the technological development challenges the libraries at the same time as it opens for innovation" (St.meld., nr. 23 (2008-2009), 29). The user perspective is prevalent in the document. It notes how new digital services are developed with the users in mind, instead of the organizations or the experts. At the same time, the white paper addresses a number of challenges related to 1) administering information in a responsible manner, 2) the amount of time it will take to digitize collections, and 3) issues related to digital access among different social strata - (the "digital divide").

A third white paper titled the "Museum of the Future" (St.meld., nr. 49 (20082009)) was presented by the Ministry of Culture to the Parliament in 2009. Tasks related to making digitalized catalogues accessible for a wider audience are highlighted in the document. It is stated that " $[t]$ he catalogues were originally only intended for the scientists and other employees at the museums, and it is a big challenge to present catalogues in a form that can function for different types of users" (St.meld., nr. 49 (2008-2009), 149). In the paper, a distinction is made between making collections accessible and disseminating the content to a wider audience. It is argued: "While making the collections accessible is about providing access to the material and objects in the museums, dissemination is about actively adapting content, form, message, and choice of channels etc. to specific target groups. There is a big leap from digital accessibility to digital dissemination" (St.meld., nr. 49 (2008-2009), 156).

The use of digital technology for dissemination purposes has remained an important topic in the cultural policy discourse on LAM-organizations. In a white paper on the visual arts (Meld.St., nr. 23 (2011-2012)) from May 2012, many examples of successful usage of digital technology as part of dissemination strategies were presented. The document points towards the democratizing aspects of technological advances. Some challenges related to the preservation of digitally produced art are also addressed (Meld.St., nr. 23 (2011-2012), 180). The most recent white paper dedicated to issues related to LAM-organizations and digitalization

4 This so-called "infrastructural requirement" of the Constitution entails that the state shall ensure that citizens are given access to information and given an opportunity to take part in public discourse (NOU, 1999:27; Rønning 2016). The state is obliged to provide the citizens with positive freedom (Berlin 2013[1969]; Engelstad, Larsen, Rogstad, and Steen-Johnsen 2017). 
was presented before the Parliament by the Ministry of Culture in November 2012 (Meld.St., nr. 7 (2012-2013)). The discussions in this white paper, which has the title "Archive", are confined mostly to technical aspects related to archiving and dissemination. ${ }^{5}$

\section{The Emergence of the Digitalization Imperative in Norwegian LAM Policies}

Having introduced the chain of documents where the policy discourse on digitalization and LAM-organizations is manifested we will now draw out more clearly the contours of this discourse. We have seen that from the mid-1990s to the mid2000s digitalization went from a secondary concern into a principal topic of LAMpolicy discourse. In the course of this period, digitalization was no longer seen as a contextual factor that should be "taken into account" when addressing other more pressing matters, but emerged as a development that must be addressed in its own right and that calls for immediate responses from all actors that belong to the sector. Digitalization became a policy imperative. It is noticeable in this regard that, unlike discourses on digitalization in other sectors of policy, this accentuation of the importance ascribed to digitalization did not necessarily take the form of a rhetorical escalation. The policy documents under consideration are generally couched in a tone of sobriety and geared towards the practical implications of digitalization within the sector. In most cases, the documents contain a section that affirms the goals for digitalization policies, and that point to potential dangers and future rewards that may ensue from this. Having stated these goals and visions, the documents move on to lengthy discussions on the allocation of practical tasks and responsibilities between the actors in the sector.

We have seen also that the emergence of digitalization as a policy imperative in these documents coincided with several other discursive developments. One such coincidence is the emergence and solidification of libraries, archives, and museums - or the cultural heritage field - as a discrete conceptual and organizational entity, or what is referred to as the convergence of the LAM-field in other chapters of this book. One may point to several reasons for the emergence and solidification of "the LAM" around this time. However, as is explicated

5 In November 2018 the Government presented a new "culture report" covering cultural policy in general (Meld.St., nr. 8 (2018-2019)). In the white paper, the Government anchors the legitimacy of cultural policies on its importance for freedom of speech. LAM is addressed within this frame. As our investigation was concluded prior to the publication of this document, it does not make up part of our data. 
in the "LAM-paper” from 1999 (St.meld., nr. 22 (1999-2000)), this development was in part predicated on perceived implications of digitalization. Digitalization and the opportunities it entailed for users' access to online collections, it is argued in the whitepaper, reduces the differences in modum operandi between libraries, archives, and museums. At the same time, the document notes that the many technical challenges the organizations face when implementing the digitalization agenda necessitate a greater degree of cooperation and coordination between libraries, archives, and museums.

Another coincidence we have heeded to is the rise to prominence of "the user" in LAM-policy discourse. The user-perspective is highlighted in all documents under consideration. Whereas the principal tasks of cultural heritage organizations was previously seen to lie in the preservation of objects, and in the provision of "top-down" popular education to the public, it is argued in the documents that these tasks are now to be found in the organizations' interactive relations to users. The principle task lies in the organizations' responses to users' variegated needs and interests for information and knowledge, and intellectual and emotional experiences. This concern with interactive relations between cultural heritage organizations and users is by no means a new development in the cultural heritage sector, or a development that comes into being as a result of digitalization. Rather, digitalization paves the way for an accentuation and redefinition of the user-perspective, as it allows one to envisage new opportunities for the democratization of LAM-organizations. This may be specified as a straightforward matter of users' digital access to the collections of LAM-organizations, or as new forms of dissemination associated with digitalization, or as a matter of a digital reconfiguration of boundaries between users and experts. We will return to this topic in a later section.

Thus, the emergence of digitalization as a policy imperative took place in conjunction with the emergence of the LAM-sector as a discrete entity and with a heightened emphasis on the user-perspective in policy discourse on LAMorganizations. While these observations provide us with a background understanding of the discourse on digitalization and LAM-organizations, they do not clarify what forms of cultural processes account for the elevation of digitalization into a policy imperative in this field. To arrive at answers to this question we must look more carefully at the makeup of this discourse and, as we have indicated above, we will do so in three analytical steps. A first step to understand the emergence of digitalization as a policy imperative is to consider processes of institutional isomorphism. 


\section{Step 1: Mimetic Processes and Cultural Policies}

In their seminal article, DiMaggio and Powell $(1983,147)$ argues that the engine of organizational rationalization has shifted, as "structural change in organizations seems less and less driven by competition or by the need for efficiency. Instead, (...) organizational change occur as the result of processes that make organizations more similar without necessarily making them more efficient”. A driving force in such processes of institutional isomorphism, DiMaggio and Powell make clear, is organizational actors striving for legitimacy by way of projecting images of themselves as up to date organizations onto their environments. Early adopters of organizational innovations are likely to be driven by a desire to enhance efficiency and competitive advantages, they note. However, as an innovation proliferate within an organizational field a threshold is reached, "beyond which adoption provides legitimacy rather than improves performance" (DiMaggio and Powell 1983, 148). The neo-institutional perspective has been applied widely to account for organizational change within the culture sector in various countries. Publicly funded culture organizations are characterized by having complex and contradictory goal structures, with pressures coming from the funders, the art worlds, and the citizens at large (Larsen 2016, chp. 1). Given that institutional isomorphism is engendered under conditions of uncertainty and ambiguity, culture organizations are prone to engage in such processes.

DiMaggio and Powell highlight coercive isomorphism, normative pressures, and mimetic processes as mechanisms that engenders institutional isomorphism. When it comes to understanding the emergence of digitalization as a policy imperative in the LAM-field, the mechanism of mimetic processes is particularly relevant. In their historical account of state cultural policy in Norway since 1814, Dahl and Helseth (2006, 268-269) highlight imitation as one of the mechanisms that has shaped this domain of public policy over time. Many, if not most, of the cultural policy objectives and measures that have been introduced by the Norwegian government have been modelled on existing arrangements in other countries, according to Dahl and Helseth. While imitation can be assumed to be important for cultural policy everywhere, such processes can be expected to be particularly prominent in small and peripheral countries, such as Norway. A recent testimony to such imitation, where a "downloading" of concepts and language extracts from international policy documents entered into the formulation of national policies, is found in the Norwegian government's efforts to promote cultural diversity and the rights of minorities in the domain of cultural policy (Henningsen, Berkaak, and Skålnes 2010).

A similar tendency is evident in the discourse on digitalization in the Norwegian LAM-field. A backdrop to many of the arguments presented in the white 
papers and reports under consideration in this study is an understanding that in other countries policies dealing with digitalization are already in place and that to "catch up" with this new reality is an impending task of Norwegian LAM-organizations. Several of the documents include quotations from UNESCOdocuments and other international sources that underscore the need for development of policies to tackle the challenges and opportunities posed by digitalization in the LAM-sector. However, mimetic processes are not restricted to imitation of cultural policy elements from the international arena. In several of the documents reference is made to policy initiatives, concepts, and goals that originate from other domains of public policy, such as the industry and commerce sector, the communications sector, and the research and education sector. A further source of imitation in these documents is other subsectors within the culture sector that have developed more elaborate policies on digitalization for reasons of practical necessity, such as the commercial music industry and the news media. While the documents make few explicit references to policies from these subsectors, they exhibit a tendency to adopt the vocabulary established here, as indicated by the use of such terms as "information”, “access”, "users”, and "platforms".

In accordance with the neo-institutional perspective, one may view the elevation of digitalization into a policy imperative in the LAM-sector as a result of mimetic processes leading to institutional isomorphism. Even though this is a plausible analysis, it does not by itself account for the special priority that is ascribed to digitalization when compared to other developments that are seen to impinge on the policy field. Why is it that digitalization acquires the role of a policy imperative, at the expense of other emergent developments? From what sources is the sense of urgency that accrues to the topic of digitalization in the LAM-field derived? To deepen the understanding of the emergence of digitalization as a policy imperative within the LAM-field, a second analytical step is in order, which is to look more closely at the mobilizing aspects of the discourse and the potential dangers and rewards that are evoked here. More specifically, this invites a consideration of the discursive framing of the topic of digitalization in the documents under consideration.

\section{Step 2: The Epochalist Framing of the Discourse on Digitalization and the LAM-sector}

Framing refers to conceptual structures - metaphors, images, narratives - that are evoked in communication about a phenomenon and that impress a simplified understanding of the phenomenon onto communication participants (Bateson 1972; Goffman 1974; Lakoff 2010). Framing analysis has been applied to explain the mo- 
bilizing powers of discourses espoused by social movements, by demonstrating how such discourses provide adherents with compelling diagnostics of their current grievances and with utopian prognostic visions of the future (cf. Henningsen and Jones 2013; Snow and Benford 1988). When it comes to contemporary discourses on digitalization, a consideration of their epochalist framing is particularly relevant. Epochalism is a discursive form that describes and explains social change based in dichotomized schemes of periodization, e.g. by accentuating the contrast between the "analogue" culture of the past and the "digital" culture of the future (du Gay 2003). In other words, it is a form of discursive framing that highlights a sense of the present as moment of historical rupture, where an established "old" order of society is rapidly giving way to an emerging "new" order of society. By evoking fear-inducing images of the future along with images of potential future prosperity, du Gay (2003) notes, epochalist discourses may take on a hortatory or mobilizing role, as urgent calls for action.

As Kaufmann and Jeandesboz (2017) point out, such epochal visions are a pervasive feature of contemporary discourses on "the digital" in many domains of policy. This applies to academic as well as popular discourses, which tend generally to be ripe with declarations about the era-defining and transformative consequences of digitalization. A similar tendency is detectable in the discourse on digitalization in the LAM-field. The epochalist framing is revealed most clearly in the titles of some of the white papers, which allude to the present as an "age" of digitalization ("Sources of Knowledge and Experience: On Archives, Libraries and Museums in an ICT-age”, "Libraries: Knowledge Common, Meeting Place and Cultural Arena in a Digital Age"), and in the use of concepts such as "information society" and "digital society" in the documents. Furthermore, such a frame is revealed in the documents' highlighting of the potential dangers and rewards of digitalization.

One set of dangers associated with digitalization evoked in the documents are those of fragmentation and an overload of information. While digitalization creates infinite possibilities for users to access information, it is argued, users may lack the competence and means required to access information; they may become overwhelmed by the masses of information at hand, disoriented because of the fragmented nature of digital information, and may be misled by false information. This affirms the need for LAM-organizations as authorities that can ensure quality (truthfulness, authenticity, relevance) of knowledge and information. It affirms also the need for LAM-organizations that, through dissemination and interactive relations with users, can provide guidance on how to access knowledge and place information in contextual frameworks that foster learning and critical thinking. Thus, when the dangers and dystopian tendencies associated with digitalization are highlighted in the documents, LAM-organizations are simultaneously posited 
as a "counterweight" (as one documents puts it) to the present and future dangers of digitalization.

On the other hand, the documents appeal to utopian desires aroused by digitalization, by pointing to its potential as a means of realizing overarching policy goals of democratization of access to culture within the context of LAM-organizations. Above, we have noted the heightened emphasis on the userperspective in the discourse on digitalization and LAM-organizations. Here, digitalization's role as a tool of democratization may refer simply to enhanced access to cultural products for everyone, as people may now increasingly access the collections of LAM-organizations by way of electronic devices and regardless of their physical location. In a slightly different manner, it may refer to possibilities for the fulfilment of constitutional requirements relating to freedom of information and expression (NOU 1999:27; Rønning 2016), and hence to promote deliberative democracy. Democratization can further refer to the new possibilities for popular participation made possible by digital technology. By paving the way for the prosumer role (Ritzer, Dean, and Jurgenson 2012; Toffler 1980) and interactive relations that transcend boundaries between experts and users, digitalization can be viewed as a democratizing force (see also Henningsen and Larsen, this volume). Thus, when the documents highlight the utopian potentialities of digitalization within LAM-organizations, they also highlight a potential remedy for the historical failures of LAM-organizations in truly realizing their goals of universal access to culture.

As this serves to indicate, a consideration of the epochalist framing of the discourse on digitalization and the LAM-field can be a useful means of understanding the emergence of digitalization as a policy imperative. More specifically, this line of analysis can help us understand the sense of urgency that attaches to discourses on digitalization and their power and persuasiveness as calls for immediate action. However, while this is a line of analysis that is supported by research from other sectors of society, there are reasons to caution against placing too much weight on it in the context we are dealing with. Above, we noted how the discourse on digitalization in the LAM-field for the most part is couched in a tone of sobriety, with the documents containing discussions of a range of specified technical processes and procedures related to production, dissemination, storage, and consumption of cultural material. Digitalization is thereby dissolved into many opportunities for technical improvements and a host of practical tasks to be completed if actors of the sector are to reap these rewards. When talked about in this way, digitalization is effectively demystified and emerges as an integral feature of everyday life in LAM-organizations. While the documents under consideration clearly evoke the widespread epochal discursive frame, it would be misleading to say that this permeates the discourse on digitalization and the LAM- 
field. If we are to arrive at a satisfactory understanding of the cultural processes that enter digitalization's makeup as a policy imperative a further analytical step is called for.

\section{Step 3: The Sacralization of Digital Technologies in Cultural Policies}

In order to flesh out this argument, we must return to one of the documents in the chain of whitepapers and reports presented above. The report "Cultural Heritage for All" (ABM 2006) was the first among these documents that was devoted exclusively to the topic of digitalization. The report is highly symptomatic of the sober tone of the discourse on digitalization and LAM-organizations, where visionary talk is kept at a bare minimum, apart from the mentioning of the possibility of increased user access to collections. At no point does the document halt to ask whether or how the massive task of bringing LAM-organizations up to date with the possibilities of digital technology is justified. Rather, this circumstance is treated as a self-explanatory fact and a point of departure for the report's unending "to do-list" of practical tasks related to the digitalization agenda. In this way, the report attests more firmly than any of the other documents under consideration to the imperative role that is attached to digitalization. While the report almost completely refrains from placing digitalization into a narrative frame, digitalization nevertheless emerges as an object of reverence and an object that dictates action by its mere mentioning.

What is suggested by these observations is that there is a form of mystification at work in the discourse on digitalization in the LAM-field. This does not take the form of a utopian/dystopian narrative of epochal change; rather it is a tendency of sacralization. In Durkheim's discussion on religion as a system of beliefs, special weight is placed on the concepts of the sacred and the profane, as the two worlds into which all "real or ideal things that men conceive of" are placed in religious thought (Durkheim 1995[1912], 34). When we say that digitalization is sacralized in the context of LAM-policy discourse, the implication is that it is classified in this manner, and thus set apart from the world of profane things. To suggest that technology or a process of technological development can be subject to sacralization along these lines is consistent with Durkheim's explication of the concept of the sacred. While the category of the sacred often include gods or high-ranking values and ideas, for Durkheim it is not confined exclusively to objects that are believed to be entrusted with supernatural powers, nor does it necessarily imply beliefs about a hierarchy of beings or values. The sacred, as defined by Durkheim, may potentially include any form of object or idea. In accordance with his account, 
the essential characteristic of the sacred is the absolute separation of the category from the category of the profane, as incommensurate worlds. From this premise, it follows that a universal feature of religious thought and action (i.e. ritual) is its concern with the regulation of the boundary between these two worlds, ensuring that the sacred is not colluded with the profane.

In line with Durkheim's discussion, we can talk of sacralization as a cultural process without activating the full range of his theory of religion. Religion, Durkheim argues, occurs when several beliefs about the sacred combine into a system of beliefs, and when the beliefs and practices in question are associated with a moral community or church. However, as Durkheim makes clear, beliefs about the sacred can exist also in separation from religion, as in the case of individualized magical practices and beliefs, or in the case of rituals that continue to exist in society as remnants of vanished religions. Sacralization can thus be viewed as a cultural process that precedes religion. This notion of sacralization can be further substantiated with reference to Graeber's (2005) discussion of the phenomenon of fetishism, the process whereby people come "to view objects they have created or appropriated for their own purposes as alien powers imposed on them". To Graeber $(2005,427)$, fetishism is a form of proto-religious belief, or "a god under construction", which may take various forms. Fetishism, he argues, is certain forms of beliefs and practices that arise in connection with "social creativity", or the emergence of new social arrangements. It is a way in which human agents deal with such novelties and convert them into conceptually manageable features of the worlds they inhabit.

Graeber's understanding of fetishism is, in several respects, broader than Marx's (1906) concept of commodity fetishism. In Graeber's rendering, fetishism is not confined to modern capitalist society. Rather, it is a potential feature of all kinds of social formations, which may or may not involve alienation or mystification. At the one extreme, Graeber shows that fetishism may simply consist in the recognition that emergent social arrangements exert power over people that enter into them, in which case there is hardly reason to speak about mystification at all. ${ }^{6}$ At the other extreme, fetishism can take the form of an unquestioned belief that, for instance, "the laws of the market" makes up a system that is "natural, immutable, and therefore completely outside any possibility of human interventions" (Graeber 2005, 429). To relate to technology (or more specifically, to digitalization) as a force that is external to the world of social relations and that

6 As Graeber notes in this regard: "If fetishism is, at root, our tendency to see our own actions and creations as having power over us, how can we treat it as an intellectual mistake? Our actions and creations do have power over us. This is simply true" $(2005,431)$. 
somehow impinges on this world from the outside would be an example of an equivalent form of fetishism. In our view, the latter forms of fetishisms can more precisely be termed sacralization, due to the form of mystification they involve. In these cases, social phenomena (the market, technology) are relegated conceptually to a world that is over and beyond the mundane everyday world of those affected by them.

Digitalization has increasingly become subject to sacralization during the course of its introduction into the Norwegian policy discourse on LAM-organizations. This trajectory is contradictory to Benjamin's (1969[1935]) famous theory, where cultural objects become demystified and lose their aura due to introduction of new technology. However, this is not an unambiguous tendency of the digitalization discourse in the LAM-field. While digitalization at times is subject to sacralization in the policy documents, there is also an opposite tendency of demystification to be found. Again, Graeber's (2005) discussion of fetishism can be illuminating in this regard, as he challenges the view of fetishism as a permanent state of misconception of reality that works its way wholly "behind the backs" of people. Reviewing various ethnographic examples, he notes how persons who exhibit fetishized beliefs about rituals and ritual objects at other times often demonstrate demystified understandings of the social nature of the same phenomena. It is only when fetishism is turned into a theology that the alternation between mystification and demystification is brought to a halt, Graeber argues. Transferred to our empirical case, this point alert us to how the discourse on digitalization in the LAM-field alternates between moments of mystification and moments of demystification. More specifically, this observation resonates with Alexander's (2003[1993]) cultural theory of the computer, which highlights that the new technology started out as a mystified and sacred object, then gradually developing into an object treated as both sacred and profane.

"Whereas contact with the sacred side of the computer is the vehicle for salvation, the profane side threatens destruction", writes Alexander (2003[1993], 191). We also find such a binary code to be present in our analysis of technological discourse. As digitalization has become the overall imperative for cultural policies in the twenty-first century, digital technology is seen both as a challenge for the existing structure of culture industries and as a potential for realizing such important policy goals as democratization and inclusion. Digital technology is an object onto which policy actors and managers of cultural organizations can project utopian dreams for the future, as well as dystopian views of destruction. The LAM-organizations are safely tied to the sacred side of this binary. By being a sacred object in the discourse, digitalization is approached by policy actors and managers of cultural organizations in a ritualistic manner when promoting and legitimating LAM cultural policies. In the policy discourse on cultural heritage, 
technology is being approached as a democratizing tool for inclusion, as well as a vehicle for progress and modernization. To be anti-technology in this discourse is to be anti-modern and anti-civil, which is a tough position to defend in powerful ways in a modern democracy.

\section{Conclusion}

Our starting point in this chapter was the observation that the generation of cultural policy tends always to revolve around certain ideas and concepts that take on the character of policy imperatives. At present, we noted, the concept of digitalization has such a commanding role in cultural policy discourse, and more specifically in the policy discourse on Norwegian LAM-organizations. Our aim in the chapter has been to throw light on the question of how and by what forms of cultural processes digitalization is constituted as a policy imperative within this field. In order to identify cultural processes that contribute to the "digitalization imperative", we have examined policy documents from the late 1990s and onward that deal with digitalization and the LAM-field. As the analysis has shown, there are several processes that can account for the concept of digitalization achieving the status of policy imperative in the LAM-field. We have highlighted mimetic processes and the epochalist framing of the discourse on digitalization as two such forms of cultural processes. These are relevant and plausible lines of analysis when it comes to digitalization's constitution as a policy imperative in the LAMfield (as well as in other policy fields), but they do not by themselves provide us with a satisfactory understanding of this phenomenon. To gain a fuller understanding of the cultural processes at work, a third analytical step was called for. In this final step, we considered how digitalization's role as a policy imperative could be the outcome of a process of sacralization.

Even though the analysis in this chapter is limited to a particular policy field in one country, it is our opinion that this line of analysis can have a much broader applicability when it comes to understanding discourses on digitalization throughout the culture sector, as well as in other domains of policy. The concept of policy imperative can be an important tool for a general understanding of the generation and regeneration of cultural policy. In a recent historical study of the Norwegian Arts Council, Fidjestøl (2015) notes that state cultural policy is always founded on the "ulterior values" of the time. Our discussions in the previous pages can be seen as an attempt to add substance and specificity to this claim. As an overarching imperative for cultural policies, digitalization has become a powerful trope for actors performing legitimacy (Larsen 2016), irrespective of policies or whether the technology is approached as sacred or profane. LAM-policies are safe on the 
sacred side of the binary code of technology discourse, leading actors promoting policies to emphasize such aspects as democratization, inclusion, and participation when legitimizing the importance of digitalization for the cultural heritage sector. Through mimetic processes, epochal framing and sacralization, digitalization has become a policy imperative influencing every discussion on the future of the culture sector.

\section{References}

ABM. Kulturarven til alle - digitalisering i abm-sektoren. Oslo: ABM-utvikling, 2006.

Alexander, J. C. "The Sacred and Profane Information Machine”. In Alexander, J. C. (ed.), The Meanings of Social Life, pp. 179-192. Oxford: Oxford University Press, 2003[1993].

Bateson, G. Steps to an Ecology of Mind. London: Jason Aronson Inc, 1972.

Benjamin, W. "The Work of Art in the Age of Mechanical Reprodcution (H. Zohn, Trans.)". In Arendt, H. (ed.), Illuminations. New York, NY: Schocken Books, 1969[1935].

Berlin, I. "Two Concepts of Liberty". In Isiah Berlin. Four Essays on Liberty. Oxford: Oxford University Press, 1969.

Dahl, H. F. and T. Helseth. To knurrende løver: kulturpolitikkens historie 1814-2014. Oslo: Universitetsforlaget, 2006.

DiMaggio, P. J. and W. W. Powell. “The Iron Cage Revisited: Institutional Isomorphism and Collective Rationality in Organizational Fields". American Sociological Review, 48, no. 2, 147-160, 1983.

du Gay, P. “The Tyranny of the Epochal: Change, Epochalism and Organizational Reform”. Organization, 10, no. 4, 663-684, 2003.

Durkheim, E. The Elementary Forms of Religious Life. New York, NY: Free Press, 1995[1912].

Engelstad, F., H. Larsen, J. Rogstad, and K. Steen-Johnsen. "Introduction: The Public Sphere in Change. Institutional Perspectives on Neo-corporatist Society". In Engelstad, F., H. Larsen, J. Rogstad, and K. Steen-Johnsen (eds), Institutional Change in the Public Sphere: Views on the Nordic Model, pp. 1-21. Berlin: De Gruyter Open, 2017.

Fidjestøl, A. Eit eige rom. Norsk kulturråd 1965-2015. Oslo: Samlaget, 2015.

Goffman, E. Frame Analysis: An Essay on the Organization of Experience. New York, NY: Harper and Row, 1974.

Graeber, D. "Fetishism as Social Creativity. Or, Fetishes are Gods in the Process of Construction". Anthropological Theory, 5, no. 4, 407-438, 2005.

Henningsen, E., O. A. Berkaak, and S. Skålnes. Mangfoldsåret: Muligheter og motsigelser i politikken for et flerkulturelt kulturliv. Oslo; NIBR, 2010.

Henningsen, E. and P. Jones. “'What Kind of Hell is This!' Understanding the Mungiki Movement's Power of Mobilisation”. Journal of Eastern African Studies, 7, no. 3, 371-388, 2013.

Henningsen, E. and H. Larsen. "The Joys of Wiki Work: Craftsmanship, Flow and Selfexternalization in a Digital Environment". In Audunson, R., H. Andresen, C. Fagerlid, E. Henningsen, H-C. Hobohm, H. Jochumsen, H. Larsen, and T. Vold (eds), Libraries, Archives and Museums as Democratic Spaces in a Digital Age. Berlin: De Gruyter Saur, 2020.

Kaufmann, M. and J. Jeandesboz. "Politics and 'the Digital': From Singularity to Specificity". European Journal of Social Theory, 20, no. 3, 309-328, 2017. 
Lakoff, G. "Why it Matters How we Frame the Environment”. Environmental Communication, 4, no. 1, 70-81, 2010.

Lakoff, G. and M. Johnson. Metaphors We Live By. Chicago, IL: University of Chicago Press, 1980.

Larsen, H. Performing Legitimacy: Studies in High Culture and the Public Sphere. Switzerland: Palgrave Macmillan, 2016.

Marx, K. Capital: A Critique of Political Economy. New York, NY: The Modern Library, 1906.

Meld.St. (nr. 8 (2018-2019)). Kulturens kraft: Kulturpolitikk for framtida. Oslo: Kulturdepartementet.

Meld.St. (nr. 7 (2012-2013)). Arkiv. Oslo: Kulturdepartementet.

Meld.St. (nr. 23 (2011-2012)). Visuell kunst. Oslo: Kulturdepartementet.

NOU (1996:7). Museum, mangfald, minne, møtestad. Oslo: Kulturdepartementet.

NOU (1999:27). 'Ytringsfrihet bør finde sted'. Forslag til ny § 100. Oslo: Justis- og politidepartementet.

Ritzer, G., P. Dean, and N. Jurgenson. “The Coming of Age of the Prosumer”. American Behavioral Scientist, 56, no. 4, 379-398, 2012.

Rønning, H. “On Press Freedom and Other Media Freedoms”. In Carlsson, U. (ed.), Freedom of Expession and Media in Transition: Studies and Reflections in the Digital Age, pp. 43-51. Gothenburg: Nordicom, 2016.

Snow, D. A. and R. D. Benford. “Ideology, Frame, Resonance, and Participant Mobilization”. In Klandermans, B., H. Kriesi, and S. G. Tarrow (eds), From Structure to Action: Social Movement Participation Across Cultures. Greenwich, CT: JAI press, 1988.

St.meld. (nr. 22 (1999-2000)). Kjelder til kunnskap og oppleving. Om arkiv, bibliotek og museum i ei IKT-tid og om bygningsmessige rammevilkår på kulturområdet. Oslo: Kulturdepartementet.

St.meld. (nr. 23 (2008-2009)). Bibliotek. Kunnskapsallmenning, møtestad og kulturarena i ei digitial tid. Oslo: Kultur- og kyrkjedepartementet.

St.meld. (nr. 24 (2008-2009)). Nasjonal strategi for bevaring og formidling av digital kulturarv. Oslo: Kultur- og kirkedepartementet.

St.meld. (nr. 48 (2002-2003)). Kulturpolitikk fram mot 2014. Oslo: Kultur- og kyrkjedepartementet.

St.meld. (nr. 49 (2008-2009)). Framtidas museum. Forvaltning, forskning, formidling, fornying. Oslo: Kultur- og kirkedepartementet.

Toffler, A. The Third Wave. New York, NY: William Morrow \& Co, 1980.

Vårheim, A., R. Skare, and S. Stokstad. "Institutional Convergence and Divergence in Norwegian Cultural Policy: Central Government LAM Organization 1999-2019”. In Audunson, R., H. Andresen, C. Fagerlid, E. Henningsen, H-C. Hobohm, H. Jochumsen, H. Larsen, and T. Vold (eds), Libraries, Archives and Museums as Democratic Spaces in a Digital Age. Berlin: De Gruyter Saur, 2020. 



\section{Roger Blomgren \\ 4 The Institutions Go Digital}

\section{Introduction}

These are revolutionary times. What many forecasters have long predicted is happening now. All industries and all businesses are affected by these changes. Old power structures are collapsing, business models are being turned on their heads, and it is increasingly difficult to find one's way in this new world. (Fichtelius 2016) Libraries - hubs in the knowledge and information society - find themselves in these changes. However, what is a book today? Moreover, what will a library become? What should it be? (ibid.)

The above was proclaimed by the chairman of the Swedish library strategy group which was assigned by the Swedish government to investigate and recommend future library policies. Another example of statements dealing with the effects of digitalization can be found in the Swedish commission For digitalization in time (För digitalisering i tiden). In their inquiry report (SOU 2016, 89) this is described as the most revolutionary process since industrialisation and can, according to the report, support the development of a democratic and sustainable welfare society, which we currently think is hardly possible. Digitalization also implies, according to the report, new needs and conditions for individuals and society, for companies and the public sector, as well as for working life and education. It also affects the essential elements of society: growth and sustainability, welfare and equality, security and democracy (ibid).

In another words, this is something that will change our lives in every sense. Even if we want to, we can not escape from it. This obviously also includes government authorities, institutions and organisations as well as their roles and missions. In the commission report it is claimed that it is crucial not only for Sweden to prioritize progress in digitalization in order to avoid falling behind and risk becoming an average and innovatively unimpressive country within EU and business, but also in order to reach equality in society (SOU 2016, 85,13).

As apparent in the statements above, this is a concept that describes a "revolution" in society. Two Norwegian researchers have used the word "imperative" to characterise digitalization as a central concept in the cultural policy field. By imperative, they mean "an authoritative command or call for action to describe the influences on daily life, democracy, welfare society and society as a whole" (Henningsen and Larsen, this volume). Policy imperative is seen as self-explanatory ideas and universally binding calls for action within a given field of policy. Politi- 
cal systems have to deal with digitalization, and the main question is thus in what way?

Digitalization can also be described as a deterministic idea. In philosophy, determinism can signify that the state of the universe at any subsequent time is entirely determined. Human actions can be seen as part of the universe, and it follows that humans cannot act otherwise than as they do; free will is impossible (Lübcke 1988, 111). In Media and Communication Science, the concept "magic bullet theory" that was introduced in the 1930s can be characterized as a determinist conception. The main idea was that messages directly from the media were wholly accepted by the receiver as the independent variable that could explain people's opinions and behaviour per se (Boyd-Barrett and Newbold 1997). In sum: digitalization as a concept and phenomenon, in these interpretations, suggests that society, citizens, and political institutions can only react and adapt their actions to this new phenomenom in a deterministic way.

The aim of this chapter is to examine and problematize how digitalization has been interpreted in policy documents in the cultural sector, here limited to its role and function in archives, libraries, and museums (LAM) in Sweden. The question is what happens when this concept moves and are interpreted by different authorities in the LAM-sector? I have no intention of either carrying out a historical overview or a systematic study. Instead, focus in this chapter is on problematising digitalization as a concept, as it is employed in different kinds of policy documents from 1980 to 20019. The empirical material consists of Public Inquiry reports (SOU), propositions from the government, strategy documents, and documents from governmental bodies.

Even if this chapter is limited to studying policy documents, it is important to note that digitalization has changed citizens' cultural habits. According to the report, Swedes and the Internet (Svenskarna och internet 2018), this can be described as a gamechanger. Nearly everybody has access to the internet in today's Sweden. According to the report all young people under 26 years of age use YouTube, nearly 97 per cent of the population between 16-25 years of age listen to music on the streaming service Spotify, and 37 per cent of the population listen to audio books or read e-books. Figures have almost doubled since 2015. Nearly every third internet user (32 per cent) watches movies and videos over the internet daily; almost double the number since 2015 and more than three times as much since 2014, when daily video viewing on the Internet began to increase seriously. This is a significant shift affecting citizens' cultural habits. Not only has cultural consumption changed, but also information seeking habits, according to the report. Today 97 per cent of the population search for information on the internet, 61 per cent google every day, while 85 per cent use Wikipedia, 39 per cent weekly. More than half of 12 to 15 -year-olds use Wikipedia every week. People use 
commercial e-books and audio services to a greater degree than before and search for them on their own. This has traditionally been one of the core missions of libraries and therefore meeting this competition from commercial forces presents a great challenge for the future (ibid.).

\section{The Problem/Theoretical Inputs}

One fruitful way to understand and explain how institutions such as libraries, museums, and archives interpret digitalization and how this in turn influences policy recommendations is through the theoretical lens of historical institutionalism, which can be seen as an approach to studying politics. In addition to being a historical approach, historical institutionalism is distinguished from other social science approaches by its attention to real world empirical questions and to the ways in which its institutions structure and shape political behaviour and outcomes (Steinmo 2008).

One fundamental idea in historical institutionalism is that institutional settings have a significant impact and determine agenda setting in this policy area. Institutions include both formal and informal rules that structure the relationship between individuals in various units of the polity and economy (see Rothstein 1998). These settings tend to strengthen over time and established strong institutional relations and ideas of what is considered "the right way", to talk about museums, archives, and libraries as well as views on which agents should set the agenda. In historical institutional theory the concept path - dependency is often used to describe this phenomenon (Pierson 2000). Here, ideas have an important function as mental maps or common frameworks of meaning, guiding the practices of actors and influencing people's preferences in what they see as a proper political solution. Ideas can also play an important role in explaining both reinforcement and change relating to institutions; the so-called formative moments (Rothstein 1998; Legro 2000). Individuals in organizations use, in other words, ideas and beliefs as tools for interpreting the world. The starting point is that digitalization is an example of influence exerted to the fore mostly through exogenous rooted ideas that impact strongly on the public debate. These kinds of ideas have been conceptualized by researchers as zeitgeist, paradigmatic ideas, public philosophies, and ideas on higher abstract levels (Börjesson 2018; Mehta 2013; Berman 1998/2011). Keynesianism, Neo-liberal ideas, and New Public Management are examples of other schools of thought concepts and ideas that have influenced policy agenda. Paradigmatic ideas, a Kuhnian expression, according to Metha (2013), can shift the directions and boundaries of debate and change the political landscape. When this occurs a policy window opens, with new actors 
becoming involved and new fissures created (ibid). New ideas can thus act as catalysts, or new perspectives, entailing that "reality" or the phenomenon in focus is understood in a new way (Karlsson 2003, 68; Rothstein 2003, 69).

In this chapter this phenomenon is exemplified by policies and organisational settings on Swedish national level in the LAM- sector and which are rooted in traditions from the seventeenth century. The Swedish National Archive (Riksarkivet) was founded in 1618 and has archived documents since the Middle Ages. The Swedish National Heritage Board (Riksantikvarieämbetet RAÄ) was founded in 1632 and has since then been Sweden's central administrative agency in the area of cultural heritage. Moreover, in the library sector, The National Library of Sweden (Kungliga Biblioteket, KB) has an even more extensive history and, since 1661, has also been regulated by the law on legal deposits.

Focus here is on what happens when old institutional settings are challenged by the imperative of digitalization as a policy concept. Which factors influence attitudes to digitalization and how do different fields choose to implement this concept in their policy documents? The main question posed is if this has fundamentally changed institutional settings or if institutions responsible for implementation have merely adapted to digitalization in support of their ordinary activities.

\section{A Historical View - the Information Concept is Introduced}

One of the first times digitalization, or in this case information technology and data, was paid attention to in Swedish cultural and library policy was in the Information Technology Official Investigation (Informationsteknologiutredningen) initiated by the Swedish government (Statens offentliga utredningar, SOU 1981, 45)) in 1978. In the government guidelines for the inquiry the challenge was to discuss the role and function of new technologies in the framework of the new state cultural policy objectives formulated in 1974 , to which the minister responsible for cultural policy wrote:

Technical achievements raise crucial issues: Who will control this new media? In what ways can the emergence of new media promote the political objectives of, among other things, the expansion of freedom of expression that has been granted by Parliament (Riksdag) (Dir 1978:75 in SOU 1981, 145, 225 f.).

In the commission's report, both threats and opportunities afforded by new technology were discussed. The threat was that new media could increase citizen passivity and that they would be isolated among devices in their homes. They would 
then, according to the commission, be an easy target for commercial forces' efforts to feed them with entertainment violence and programs without cultural or social value rather than for communication between people (ibid.,132 ff.). New media, (text-tv and data-tv) could also become an instrument for decentralization by providing opportunities for two-way communication directly with different authorities, for each holder of a tele-data device. However, one important recommendation was that society should not allow new technology to be run by commercial forces. Telecommunication databases should be set up by governmental bodies, the state, county councils, municipalities, universities etc. for providing information on education, consumption etc. (ibid., $136 \mathrm{ff}$.).

The government guidelines and the inquiry report can be understood as a belief in the state's power to control and steer new technology in order to fulfil cultural policy objectives, both for minimizing the damage caused by commercial forces and by using steering instruments such as organizational control and planning. These optimistic ideas are in line with conceptions prevailing in the 1960s and 1970s era of social engineering when the welfare state engineering played a prominent part in Swedish policy and which was also reflected in the new direction of cultural policy (SOU 1972, 66).

This was ushered in by the introduction of a state department for Cultural Affairs in the mid-1970s. It was inspired by the predominant and contemporary political belief in rationalism and planning as crucial concepts. There was a widely-held and optimistic view that the community, through political solutions and steering, could be controlled and planned (SOU 1997, 57, 45). However, as history has shown, efforts to stop or control the emergence of commercial radio, television, and the progress of the Internet failed.

In the mid-1990s, the question of digitalization was highlighted in the report The Direction of Cultural Policy (Kulturpolitikens inriktning 1995, 84). One proposal was to create databases for the cultural area, Culture Network Sweden, that would increase access to the collective knowledge and information of cultural institutions. (ibid.). This was also the theme of a public inquiry under the name of IT in the Service of Culture that started their work in 1995 (SOU, 1997, 14). Their starting point was an ambition to strengthen possibilities for citizens to participate in art and culture by providing greater access to leading institutions such as libraries, museums, and archives through IT (Dir 1995, 129).

In the report IT in the Service of Culture (IT i kulturens tjänst 1997, 14, 269), the central theme was how cultural institutions with the support of IT could stimulate participation in cultural life and increase accessibility much to the excitement of the cultural institutions concerned: "We believe that it is of great importance that people get to know and are given the opportunity to share our cultural heritage as well as culture that is being created in Sweden today." (ibid., 219). Through the in- 
ternet, it would become possible to take part in physically remote activities, thus supporting the "decentralisation objective" that was essential to cultural policy after 1974. It was proposed that every cultural institution should use IT to make them more accessible, and the way of reaching this objective was to initiate Cultural Network Sweden (SOU 1997, 14, 219).

Apart from rhetorical statements and proposals, digitalization was perceived as crucial to collaboration within LAM (ABM) and between state authorities, such as the National Library of Sweden, The National Heritage Board, The Swedish National Archives, National Museum, and the Council for Cultural Affairs, when they started their work in 1992. Even if collaboration had a longer history, the introduction of databases, and not least the Internet, there was a greater impetus for new forms of collaboration. Issues on electronic access and digital preservation and the opportunities for streamlining the activities of cultural institutions and making their knowledge banks and skills more accessible from a national perspective came now into focus (ibid., 152).

In sum, digitalization as a "game changer" in society had not yet reached LAM-institutions. From the early 1980s to the late 1990s the idea of controlling technical development was viewed optimistically and it was mostly perceived of as a technical tool. There would be no need to change institutional settings. Instead, ideas about digitalization's transformative power were used to strengthen the institutions' historical objectives of increasing citizens' opportunities for engaging with products and services produced by institutions in the cultural sector and for coordinating work between cultural institutions. It was left up to each institution to decide which parts of their collections to digitize (SOU 1997, 14, 22). The role of citizens was to accept what the institutions valued as high quality and the "right" kind of Swedish heritage. This, in turn, is something that has characterized cultural policy in Sweden since the 1930s (Blomgren 2017). The policy recommendations for the cultural institutions' work with digitalization were in some ways similar to the so-called broadcast model that privileges one-to-many communication. In the center there are institutions with experts functioning as gatekeepers, checking and formulating what is being told. In the periphery there are recipients who use and interpret what is made available and communicated in different ways (Axelsson 2015, 13).

Notably, the latest review above was completed in the late 1990s. Much has happened in the 20 years that have passed since then, especially in the field of digitalization and with the breakthrough of social media, Facebook, YouTube, smartphones etc. The Internet Foundation in Sweden (IIS) states in its report Swedes and the Internet 2017 that virtually all Swedes have access to the internet in their homes (Davidsson and Thoresson 2017). Digitalization is an integral part of soci- 
ety in 2019, it's in everyone's hand, although no-one could have known that in the 1990s. Has this development changed policy and strategies in the LAM-sector?

\section{Digitalization in the LAM sector - Some Current Examples}

In this section, the purpose is to use current and different national documents to exemplify and discuss how digitalization as a concept is interpreted by authorities who are politically liable. It should be once more emphasized that I do not intend to draw any general conclusions about current policy; the aim is to problematize, exemplify, and discuss how digitalization as a concept is treated in official reports and governmental proposals. In the first section, I will discuss, on a general level how and in what sense this as a phenomenon is interpreted and what challenges it imposes on the LAM-sector. In the second section, I discuss how digitalization is implemented in terms of strategies in the sector. Even here I emphasize that this is not a study of de facto implementations, but of the ideas on which implementation plans and strategies are founded in the chosen texts.

\section{The Challenges of Digitalization in the Cultural Heritage Sector - Some Current Examples}

The first example is from the cultural heritage sector in general and the role of museums specifically. In 2015, the investigation inquiry New Museum policy (Ny museipolitik) was presented. Digitalization was explicitly discussed in five pages, in the 350-page long report. This may seem remarkably little with regard to the present stage of the development in the field. However, in these five pages digitalization is presented as a magic bullet, a paradigm changer, which also was highlighted in the Digitalization commission report (SOU 2015, 89). In the heritage sector, according to the report, there is a growing awareness that this not only adds a dimension to the institutions, but also in a more profound way changes conditions in a society where everyone has increasing and seemingly boundless access to information, entertainment, and social contacts on the Internet (ibid., 230). It is foremost young people who are active, and they participate in different digital communities that are shaped by the member's interests regardless of where they live in the world. Participants interact and share their views with others, where socially beneficial initiatives are created collectively. In the report they notice the divided idea of a producer and consumer is thus abolished; you are both a producer and a consumer, often called prosumer. Convergence, participant or network cultures have been used to describe the complex relationships between information 
dissemination and participation. In the broadcast model, the social refers to the public and the citizens. In convergence and participatory cultures, social refers to social life in terms of peer-to-peer relationships (ibid., 232).

This phenomenon will also, according to the report, challenge the museum's traditional expert position which is legitimized by distinct subject areas and a strong research focus. When new expectations challenge its traditional functions this will have both positive and negative effects. According to the report, knowledge institutions need to be open to users' needs, questions, and their own knowledge to a greater extent than before (SOU 2015, 89). Another vital task is social platforms. For people to participate digitally, there must also be information to retrieve, as well as experiences of testing and communication. This will be an excellent question for the museums and will create new expectations and conditions for the museums in their role as knowledge intermediaries (ibid., $232 \mathrm{f}$.).

The challenges are also recognized in the proclamations about digitalization that are introduced this chapter, namely as the game changer that will lead to profound changes in the sector. This is radically different from the approach that characterized the view of digitalization that evolved after the late 1990s.

\section{The Challenges for Libraries}

For the library sector, ideas about digitalization and how libraries will be affected can be traced in the reports concerning the Swedish National Library Strategy from 2015-2019. In 2015, the Swedish government assigned the Royal Library the task of proposing long-term goals and strategies, based on the provisions of the Library Act, for promoting collaboration and quality development throughout the public library system (The National Library Strategy). The assignment includes, among other things, highlighting the role and conditions of librarian culture, the role of libraries in promoting the position of literature, the democratic dialogue, freedom of opinion, and citizen ability to evaluate sources of information. It also includes in the assignment the expansion of technology and libraries' role in creating equality of access for all citizens (Ku2014/01693/KI, Ku2015/00747/KI).

In their first report, The Fifth Estate (Den femte statsmakten), one of their main tasks was to discuss how digitalization affects Swedish libraries. It is important to note that this report mainly has the function of an "external analysis". However, it still reflects ideas and opinions in this field about what is considered the essential work of the library sector. A new challenge for libraries, according to the commission, is defending democratic values that today are threatened by Donald Trump. Russia has a president who spreads confusion and propaganda with the help of net-trolls and Sweden has far right forces that act as news brokers for spreading 
hatred and prejudice. Google search works by using secret algorithms to provide people with the information and worldview they assume the user wants. Digitalization has, according to the report, formed a society open to fake news, filter bubbles, and similar which can be a threat to democracy (Den femte statsmakten 2017). The library has, according to the report, an important democratic mission as a democratic infrastructure, providing an independent arena that pushes enlightenment and education ideals in the era of digitalization. It should be an independent arena free from commercial special interests focusing on citizens and the development of democracy (Stakston 2017, 43).

The commission report From Words to Action (2018) discusses commercial search services such as Google, with everything they entail in terms of privacy infringement, commercialism, political governance, manipulation, filter bubbles, and secret algorithms for ordering information (ibid., 41). This development threatens to render libraries irrelevant if they are unable to respond to users' searches for knowledge and reading experiences online. However, such threats can motivate libraries to work towards making their activities more relevant for citizens. Another threat is filter bubbles spread by commercial operators or attempts to spread propaganda. Finding truth on the internet is difficult and libraries have a responsibility to challenge fake-news. In March 2019, the final report The Treasury of Democracy (Demokratins skattkammare) was presented (National Library of Sweden 2019). The report reiterated that the library system should provide guidelines on critical evaluation of information sources (källkritik/kildekritikk) and information searching as well as information on algorithms and filter bubbles and how they can contribute to a fragmentation of the public conversation leading to reduced confidence in basic facts. The libraries are assigned to support citizens in developing adequate media and information literacy (MIL) (ibid.).

\section{Summary}

A common feature in the texts above is that digitization poses a greater challenge than merely converting and making artifacts and books available online, which had until recently dominated policymaking in the LAM-sector. The so-called broadcast model according to which producers can determine what is to be made available to the public is questioned with reference to the shift in consumption behaviors occasioned by digitalization. Other external events that have occurred in recent years include how digitalization has formed a society open to fake news, filter bubbles, and secret algorithms which threaten democracy. Digitalization, as presented here, is an exogenous rooted idea that impacts strongly on the public debate, and not only in the LAM-sector, as shown in the introduction to this chap- 
ter. These new ideas about digitalization can be conceptualized as a new zeitgeist or paradigmatic ideas that, according to Metha (2013), can shift the directions and boundaries of debate and change the political landscape (Börjesson 2018; Mehta 2013; Berman 1998/2011). The main question is if and how institutions with their historical traditions are now being forced to rethink their role and institutional setting in formative ways in order to meet new challenges? Can these new ideas act as a catalyst or can they change perspectives entailing that "reality" or is the phenomenon in focus understood in new ways (Karlsson 2003, 68; Rothstein 2003, 69)?

\section{However, When it Comes to Concrete Measures for the Institutions...}

As discussed above in public investigations and strategies for the LAM-field, digitalization is something that will greatly influence this sector. What policy recommendations can then be found in the policy proposals to meet these changes? There seems to be a wide gap between what is seen as the challenge of digitalization as a game changer and the concrete policy recommendations that are emphasized in documents.

\section{What was Proposed for the Heritage Field?}

In the government proposition Heritage Policy (Kulturarvspolitik) (2016/17:116) following the public investigation (SOU 2015, 89), the government notes that cultural heritage institutions should be at the forefront when it comes to digital interactions. If people are to retain an interest in a common cultural heritage then the state cultural institutions should exploit the possibilities of digitalization for the promotion of co-creation and citizen commitment. Broadband expansion, the increased use of smartphones, and new digitally-based teaching methods in schools have created entirely new conditions for the meeting between the cultural heritage and various target groups and users in other sectors of society (Prop. 2016/17: 116, $182 \mathrm{f}$ ). Digitalization has been seen as an essential tool for cultural heritage institutions to meet their goals for cooperation both within the respective cultural sectors and for increasing interest in the interplay between archives, libraries, and museums. One important task was to link the mediation of information between them, as well as facilitating search and ways of releasing the potential of cultural heritage information as a resource throughout society (ibid., 183). Here we recog- 
nize the argument that was highlighted in the mid-1990s that digitalization is an authoritative policy instrument to fulfil the cultural policy objectives.

In the proposition the National Archives (Riksarkivet) were concerned about being assigned to organize the Media Conversion Center as a shared resource for the mass digitalization of cultural heritage materials (ibid., 187). The National Library and the Swedish Film Institute were to jointly investigate and submit proposals in order to increase collaboration on the digitization of audiovisual material (ibid., 189). The National Heritage Board was given the task of coordinating and supporting the work on digitization, digital preservation, and digital mediation in the cultural heritage sector. All these assignments had, as an overall objective, to distribute and secure the availability of the "heritage" to citizens.

Digisam, a platform where state actors together create standard solutions that are needed for gaining access to a digitized and useful cultural heritage, were given an important role in coordinating, managing, developing, and disseminating national guidelines for digitization, digital preservation, and the digital mediation of cultural heritage (ibid., 186). Digisam started their work in February 2011; the purpose was to bring about greater coordination of the ongoing digitization work being carried out by the relevant institutions on heritage material. In their work, Digisam had been developing an information infrastructure with open information sources and joint services, standards, and terminologies.

Against this background, the government emphasized that Digisam had a vital role in creating the conditions for making the cultural heritage a matter for everyone and also that they had a lot to gain from this, by supplying new information and opportunities for rationalizing work processes (ibid.). There was no discussion in the proposition about digitalization and how it affects citizens' cultural habits; it was mainly treated as a "technical solution". A clear example of this can be found in a report from Digisam 2014, where they describe digitalization:

Digitalization means here, in addition to the transmission of information, efforts to make digital materials as used and as useful as possible and to secure digital information, data and metadata for the future. (Digisam 2014, 4)

This ambition became the official recommendation within this sector in their policymaking strategies. In reports from The National Library and the Swedish Film Institute (2018) Digitalization of Audio-visual Collections (Digitalisering av audiovisuella samlingar) presented proposals on how cooperation between them could strengthen the digitalization of audio-visual material within LAM-sector and make their work more efficient (Konstenius 2018). 
The ideas of digitalization as a game changer and the challenges emerging in the prosumer-era that were highlighted in the previous section for museums and archives are totally absent here. Instead, policy proposals are influenced by a technocratic approach focusing on converting and making artefacts and books available online, and which had hitherto dominated policymaking in the LAMsector. The ideas of the so-called broadcast model in which producers decided what to digitalize for the citizen had been institutionalized in the late 1990s and still had "power" over policymakers. These new ideas about digitalization as a game changer did not change the already rooted perspective in these institutions.

\section{And in the Library Strategy?}

In the library strategy, it was noted that digitalization had created a platform for Trump, Putin, and fake news and created filter bubbles for citizens as we mentioned in the previous section. What kind of policy recommendations were then proposed to meet these challenges in the final report The Treasure Trove of Democracy, Proposals for a National Strategy for Libraries (KB 2019)? In the report digitalization is said to be one of the greatest change driving factors in current society.

Sweden shall - on the basis of its IT policy objectives - be the best in the world at using the opportunities inherent in digitalization. The Government is working to ensure that this contributes to sustainable growth, employment and a socially cohesive society. Libraries have a crucial role to play here. (ibid, 12).

Six strategic reforms to strengthen the library were presented in the report (2019); one of them was about national library services. The goal was to "make as much information and literature as possible freely and digitally available to everyone" (ibid., 37).

In the rhetoric of the strategy group, it is argued that the collective knowledge of humanity needs to be accessible, transparent, and processable through public digital services and this is essential for a democratic society. It was thought that users would easily be able to access the library's resources through an overall search function. The rhetoric from the Digisam-report is intact concerning institutionalized ideas about digitalization. The aim is that Sweden over a ten-year period "should digitize most of the material that has been published in the country" (ibid., 21). This was necessary as "in order to preserve our democratic society, the mental cultivation of our population and scientific research, humanity's aggregate knowledge needs to be accessible, open and processable using common digital services.” (ibid., 21). According to the authors, this requires a three-track national plan: systems for demand-driven digitization, identifying what needs to be preserved, and which collections to digitalize more methodically (for example 
newspapers). Norway's work in this sense is used as a good example for Sweden (ibid., 21).

In the specific reform proposals the future development of National Library Services was highlighted, i.e. systematic work for "the conservation of the information found in books, newspaper and analogue to digital format" (ibid., 24). This work is to be done with the support of the entire library system and the entire LAM sector, for example within the framework of Digisam, work for an open information infrastructure of information sources, shared services, standards and terminologies, and moreover, to finally make the libraries' collections available through several channels and with technology (ibid).

In sum, proposals to meet the challenges posed by the likes of Putin, commercial internet algorithms, and fake news were not highlighted here. Digitalization seems not to be the imperative for the sectors' concrete work; it is instead availability, the citizens' "democratic" right to see what the producing units are offering. The primary purpose is to increase accessibility for the people to get in touch with what the actual institutions, here the National Library and other libraries, define as valuable. These are the same proposals that were present in earlier proposals and which underlay the strong institutional ideas about the role of LAM-institutions vis-a-vis digitalization that was current in the early 1990s. The technocratic approach focusing on converting and making artifacts and books available online, organized by the so-called broadcast model, still dominated policymaking. The ideas about digitalization as a game changer did not challenge the already rooted perspectives of these institutions.

In the strategy report they proposed that the National Library should be granted 90 million Swedish crowns for their work with digitalization. In institutional terms the National Library strengthened its institutional framework by promoting itself as the most fitting organisation to implement digitalization (ibid., 38).

\section{Summary and Conclusions}

In this chapter, the aim was to discuss, with some chosen examples, how digitalization has been interpreted in policy documents in the archive, library, and museum sector in Sweden. What happens when this imperative concept moves and is interpreted in the different authorities in the LAM-sector? The point of departure was that this is an example of a phenomenon that is influenced by foremost exogenously rooted ideas that have a significant impact in the public debate. This is also an example of paradigmatic ideas that could shift the directions and boundaries of the debate and change the political landscape (Metha 2013). 
These kinds of ideas could function as new lenses through which to view "reality", allowing the phenomenon to be understood in a new way (Karlsson 2003, 68; Rothstein 2003, 69). The main question is if digitalization has, through new ideas, fundamentally changed institutional settings, or if institutions responsible for implementation have merely adapted to this concept that supports their ordinary activities.

The result, as shown, was that even if there was a discussion about the challenges digitalization entails there are no traces of these kinds of opinions in the policy recommendations. No strategies to meet the changes that digitization has generated in the form of changing cultural habits, information seeking, and filter bubbles were presented. The historical institutional perspective here provides some insight into why the digitalization of the LAM-sector did not become a game changer.

One explanation is that the LAM - institutions or the governmental bodies in general, neither can control development caused by digitization that was described above, nor create new institutional settings to meet these challenges. In the first public inquiry (1981:16), one important statement was that society should not pass on new technology (telecommunications databases) to commercial forces but to control it through governmental bodies, the state, county councils, municipalities, universities (ibid.,136 ff.). There was a rash of a widespread optimistic view about the possibilities of controlling and planning society that was common in those days (Blomgren 2018; SOU 1997, 57). However, these plans to control the new technology, such as the introduction of satellite television in the late 1980s, failed. The increasing development of internet and digitalization that has characterized the last 20 years is, in a liberal democracy, hard to control and steer. Digitalization can be viewed as a deterministic force that society has had to adapt to. This also emerged in ideas expressed by the IT-commission (SOU, 2016: 89). The absence of policy measures in the strategies proposed the can be explained by the facts that different stakeholders realized that the official authorities cannot steer or control this development.

A second explanation is the gap between what is said, on the general rhetorical level, where it is not acknowledged that implementation must necessarily follow from what is proposed. The overall objectives of cultural and library policy have mostly a symbolic political significance. Cultural policy objectives of promoting universal access to cultural heritage or of promoting civic, democratic influence over cultural policy are not perceived to have a real and binding character. This may be because the goals are perceived as impossible to fulfil by cultural policy actors or that they are used solely for the purpose of legitimation (Henningsen and Blomgren 2017). Digitalization can now also be included in these objectives that are primarily used to legitimate the sector. That digitalization 
creates filter bubbles; alternative facts have in the library sector a vital role in policy documents and among politicians in legitimizing libraries' essential role in society. Other examples of concepts often highlighted in contemporary policy documents are social inclusion, democracy, and sustainability, which also represent symbolic values in creating the sector's legitimacy in relation to other policy sectors.

A third explanation that can explain the gap between the challenges of digitalization and policy proposals can be found in the institutional settings in this policy sector, as discussed in the theoretical paragraph. The sector's institutional arrangement, in the Nordic countries, as well as in most other liberal states, is influenced by ideas about the autonomy of the arts and artists. Vague and cautious government policy grants considerable power to the institutions and organizations to implement policy themselves (Blomgren 2007a, 2007b). These segmented structures of autonomy were established long before the digitalization era, and the actors involved are fundamentally skeptical of policy decisions that challenge the existing institutional settings. One strategy is to protest and try to influence leading politicians not to implement reforms that threaten institutional settings (Blomgren and Johannisson 2018). Another strategy is to interpret, in this case, digitalization, to fit in with the institution's ordinary tasks as an essential policy instrument. The policy proposals about the aim of digitalization have been interpreted as an instrument for increasing accessibility for the people to get in touch with the high arts and Swedish cultural heritage. In this work, the institutions have strengthened their role and mission and become an example of a classical cultural policy objective which assumes that the state's primary task is to support good quality art products and ensure that they are made available to citizens (Blomgren 1998, 2012; Bennich-Björkman 1991). The power to define good art and valuable cultural heritage lies with centrally positioned institutions. Recipients or "cultural consumers" would no longer have significant influence over what can be considered good or valuable. The baseline is to construe the audience as an uninformed mass who can be formed with the help of LAMinstitutions.

Can this raise a discussion about LAM-institutions' legitimacy in the future? One problem is that if these institutions are fixed in an old traditional cultural policy, and citizens become less and less interested in taking part in officially financed and sanctioned policy activities such as library lending, museum activities, film and theatre performances etc., what will happen to them in the future? Even if citizens do not participate in these activities to the same extent any more, they are not passivated but are active in other platforms, YouTube, Facebook etc. in the digitalized arenas, as noted in the beginning in this chapter. There is a significant shift that has and is still affecting citizens' cultural and information seek- 
ing habits. If this development continues, there may be a risk that these institutions become obsolete and lose their legitimacy.

However, the role of the LAM-institutions in a society characterized by the ubiquity and dominance of digital services and platforms can also be characterized as a rhetorical problem. Local libraries, with limit budgets, cannot act as fake news hunters; museums and other heritage institutions cannot compete with YouTube, Facebooks groups and so on, as little as they can change citizens' cultural habits. The problem arises when policymakers', something which can also be identified in other policy areas, central argument for supporting LAMinstitutions focuses on objectives, such as increased democracy, or stopping fake news instead of focusing on the institutions' fundamental tasks.

\section{References}

Axelsson, B. Mellan kataloger och sociala medie. Medborgarna och kulturarvsinsitutionerna på nätet. Rapport från en förstudie. FoU-publikation från Riksantikvarieämbetet, 2015.

Bergman, S. The Primacy of Politics. New York: Cambridge University Press, 2006.

Berman, S. "Path Dependency and Political Actions: Reexamining Responses to the Depression". Comparative Politics, 30, 379-400, 1998.

Blomgren, R. Staten och filmen - svensk filmpolitik 1909-1993. Hedemora: Gidlund förlag, 1998. (doktorsavhandling).

Blomgren, A.-M. and R. Blomgren. "Det ostyrbara pastoratet. Teaterpolitikens nätverk”. Forskningsrapport 02:03, Trollhättan: Högskolan i Trollhättan/Uddevalla, 2002.

Blomgren, R. "Den onda, den goda och den nyttiga - filmen, kulturindustrin och regionerna”. Högskolan Väst HV:s forskningsrapportsserie 2007:01, 2007.

Blomgren, R. “Att styra eller styras. Från kulturpolitiska visioner till konstpolitisk vardag”. $i$ Nordisk kulturpolitisk tidskrift, Nr. 2/2007 (s. 40-59), 2007.

Blomgren, R. "Social Engineering and Cultural Policy - Theoretical and Empirical Reflexions from Swedish Cultural Policy in a Historical Perspective". The International Journal of Cultural Policy, 2017.

Blomgren, R. and J. Johannisson. "Failures in Swedish Cultural Policy, and Why Cultural Policy Research Does not Seem to Care". Paper presented at the 10th International Conference on Cultural Policy Research (ICCPR 2018), Tallinn, August 21-25, 2018.

Boyd-Barret, O. and C. Newbold (eds). Approaches to Media. New York: Arnold, 1997.

Börjesson, A. (R)evolutionära idéer: Förändringar i svensk sjukförsäkringspolitik. Göteborg: Göteborgs universitet, 2018.

Davidsson, P. and A. Thoresson. Svenskarna och internet 2017: undersökning om svenskarnas internetvanor. Redaktör: Matti Palm, 2017.

Digisam. "Digitalt bevarande vid kulturarvsinstitutioner. Nulägesanalys och framtida behov". Diarienummer: RA 06-2014/4911, 2014.

Fichtelius, E. “Låt biblioteken bidra till ökad digital kompetens”. Svenska Dagbladet, 2016. https://www.svd.se/lat-biblioteken-bidra-till-okad-digital-kompetens. 
Fichtelius, E., E. Enarsson, H. Hansson, J. Klein, and C. Persson. Den femte statsmakten: Bibliotekens roll för demokrati, utbildning, tillgänglighet och digitalisering. Stockholm: Kungliga biblioteket, 2017.

Fichtelius, E. "Swedish Libraries. The Current Situation”. Scandinavian Library Quarterly, 49, no, 4, 2016.

Fichtelius, E. “Massdigitalisera Sveriges kunskaps- och kulturarv". Dagens Nyheter, 7/3-19, 2019. https://www.dn.se/debatt/massdigitalisera-sveriges-kunskaps-och-kulturarv/.

Fichtelius, E., C. Persson, and E. Enarson. Demokratins skattkammare: förslag till en nationell biblioteksstrategi. Stockholm: Kungliga biblioteket, Nationell biblioteksstrategi, 2019.

“Från ord till handling, på väg mot en nationell biblioteksstrategi”. Utkast, Kungliga Biblioteket, 2018.

Henningsen, E. and R. Blomgren. “Organisere for organiseringens skyld, Kultursamverkansmodellen og organisasjonsreformenes rolle i nordisk kulturpolitikk". Nordisk kulturpolitisk tidskrift, 20, no, 1-2, 2017.

Henningsen, E. and H. Larsen. "The Digitalization Imperative: Sacralization of Technology in LAM Policies”. In Audunson, R., H. Andresen, C. Fagerlid, E. Henningsen, H-C. Hobohm, H. Jochumsen, H. Larsen, and T. Vold (eds), Libraries, Archives and Museums as Democratic Spaces in a Digital Age. Berlin: De Gruyter Saur, 2020.

Hovlin, K. and M. Nemlander. Ökad digitalisering av offentligt finansierad kultur i Sverige. Kulturrådet, 2016.

Karlsson, L. Konflikt eller harmoni?: individuella rättigheter och ansvarsutkrävande I svensk och brittisk sjukvård. Göteborg: Centrum för forskning om offentlig sektor (CEFOS), 2003.

Konstenius, G. “Digitalisering av audiovisuella samlingar. Förslag på hur ökad samverkan kan effektivisera digitalisering av audiovisuellt material inom ABM-området”. Svenska Filminstitutet Dnr. SFI-2018-537-2, Kungliga Biblioteket. Dnr. 1.1.5-2018-120.

Legro, J. “The Transformation of Policy Ideas". American Journal of Political Science, 44, 419432, 2000.

Lübcke, P. (ed.). Filosofilexikonet. Sockholm: Forum, 1988.

March, J. G. and J. P. Olsen. Rediscovering Institutions. New York: The Free Press, 1989.

Mehta, J. "How Paradigms Create Politics: The Transformation of American Educational Policy, 1980-2001”. American Educational Research Journal, 50, no. 2, 285-324, 2013.

National Library of Sweden. "The Treasure Trove of Democracy. Proposals for a National Strategy for Libraries”, 2019.

Pierson, P. “Increasing Returns, Path Dependence, and the Study of Politics”. American Political Science Review, 95, no. 2, 251-267, 2000.

Rothstein, B. "Political Institutions: An Overview”. In Goodin, R. E. and H-D. Klingemann (eds), A New Handbook of Political Science. Oxford: Oxford University Press, 1998.

Rothstein, B. Sociala fällor och tillitens problem. Stockholm: SNS, 2003.

Rothstein, B. Politik som organisation. Stockholm: SNS, 2010.

"Sex strategiska reformer för stärkta bibliotek Bilaga till Demokratins skattkammare. Förslag till en nationell biblioteksstrategi”. https://www.kb.se/download/18. 6e28c3bf1694cc0bf9e21c/1551950675660/Reformpaket_nationell_biblioteksstrategi.pdf, 2019.

SOU. Nya medier, informationsteknologiutredningen. Stockholm: Liber förlag, 1981. (44).

SOU. Kulturpolitikens inriktning. Fritze: Stockholm, 1995. (84).

SOU. IT i kulturens tjänst. Fritze: Stockholm, 1997. (14). 
SOU. “Ny museipolitik". (89). https://www.regeringen.se/contentassets/ a7f58685a4964dbfb276541303516196/ny-museipolitik-sou-201589.pdf, 2015.

SOU. "För digitalisering I tiden". (89). https://www.regeringen.se/4af25c/contentassets/ f7d07b214e2c459eb5757cea206e6701/sou-2016_89_webb.pdf, 2016.

Stakton, B. "Från sagor till cyberpunk. Mediers utveckling och med borgarnas utbildnings behov". i (Fichtelius m.fl). Den femte statsmakten. https://www.kb.se/samverkan-ochutveckling/biblioteksutveckling/nationell-biblioteksstrategi.html, 2017.

Steinmo, S. "What is Historical Institutionalism". In Porta, D. and M. Keating (eds), Approaches and Methodologies in the Social Sciences. Cambridge University Press: Cambridge, 2009.

"Svenskarna och internet 2018". Internetstiftelsen. www.svenskarnaochinternet.se. 


\section{Sigrid Stokstad}

\section{Norwegian National Policies for Digitalization in the LAM Sector - Imperative and Implementation}

\section{Introduction}

In a press release in October 2019, the Ministry of Culture stated that the National Budget for 2020 represented a historic commitment to the National Archives, and more specifically to the start-up of the development of national joint solutions for preservation and dissemination of digital archives (Ministry of Culture 2019). Similar objectives were identified in a white paper from 1999 about the LAM institutions in a digital age (Ministry of Culture 1999). Why is the development of solutions still in a start-up phase, 20 years later?

Digitalization in the LAM sector has been regarded as a prerequisite for enhancing the public-sphere infrastructure and strengthening the roles and functions of LAM institutions, and it has been an imperative for decades. But digitalization as imperative has some difficult aspects, such as the tendency to sacralization (Henningsen and Larsen, this volume) and other factors that make the concept unclear when it comes to implementation (Blomgren, this volume). What shall be implemented, how, by whom, and at which costs?

The concept of digitalization may include many different aspects, such as digital access to collections, the use of social media, strengthening of digital skills among the inhabitants, and increased user contribution. This is a study of the implementation of two aspects of digitalization in the LAM sector in Norway: digitization of analogue material and long-term preservation of born-digital materials. The aim is to deepen the understanding of the national policies in this field. These policies may not be fully formulated in white papers and other policy documents; they should also be regarded in light of the implementation policy and the steps that may or may not be taken in order to realize the objectives expressed at a more abstract level. The study may also contribute to a better understanding of the mechanisms of governing the LAM sector in general.

The scope of this study is LAM institutions for which the Ministry of Culture has state responsibility that are regarded as central for achieving the digitalization imperative. This includes the National Library for the library sector and the National Archives for the archives sector. For the museum sector, the Arts Council 
Norway is central, but otherwise, each museum must be seen independently. We bring in museums, public libraries, and municipal archives when necessary for the study. The temporal scope of the study starts with the white paper on LAMinstitutions in a digital age, Stortingsmelding 22 (1999-2000) (Ministry of Culture 1999) and ends with the Norwegian National Budget 2018 (Ministry of Finance 2017). This period is characterized by high ambitions on digitalization and varying results, which are high on some areas, such as the National Library's digitization of analogue material, and low on other areas, especially the digitization of analogue material in museums and archives and long-term preservation of borndigital materials in general. It is a rather long period during which digitalization took important steps forward elsewhere, and it is of importance to analyze why the development in the LAM institutions did not keep up with this development in important matters.

The aspects of digitalization that are the subjects of this study illustrate two challenges of digitalization: firstly, realizing the potential of the new technology that became available in order to augment the dissemination of cultural heritage artefacts and documents in a new and radical way, giving the public electronic access to the collections of the cultural heritage institutions. Secondly, decreasing a danger that follows digitalization - a possible loss of born-digital materials due to lack of capacity to maintain long-term preservation.

\section{Theoretical Approach and Methodology}

Archives, libraries, and museums share important qualities and functions, and there is a tradition of seeing LAM institutions as a whole, as an entity. At the same time, the LAM institutions vary substantially, in tasks and authority as well as organizational structure. The implementation of the policies will be analyzed in light of this formal structure. The starting point is that national policies must be seen as three-folded, consisting of objectives, implementation, and results. The implementation is seen in light of the juridical framework of the relation between the national authorities and the LAM-institutions. This framework varies extensively between the three sectors when it comes to the means of implementation available to the national authorities. The ambition is to identify the action of the national authorities, and not only their rhetorical grip, and subsequently try to explain why the journey from visions to results in many aspects has been long, and why results are yet to be achieved.

A "forward mapping" strategy of implementation studies begins with statements of intent from the Parliament or the King in Council, and proceeds through more specific steps to define what is expected of implementors at different levels, 
such as regulations and administrative actions. At the bottom of the process, it states an outcome (Elmore 1979). Along with administrative actions come other factors such as political actors and the interplay between them and technological solutions. In this study, our starting point is the statement of intent from the national authorities and the outcome as it is assessed by the Auditor General (Auditor General 2017). A top-down oriented study has some weaknesses, such as the assumption that policymakers control the organizational, political, and technological processes that affect implementation (Elmore 1979). Nevertheless, the main actors of the LAM sector are public bodies or private institutions that are publicly financed. The use of formal means of implementation in order to achieve political objectives is worth analyzing, even if their impact might be limited for several reasons.

The study is based on document studies and interviews. We have conducted four semi-structural interviews in the Ministry of Culture, the National Archives, The National Library, and the Arts Council Norway. The document study is based on white papers, national budgets, letters of allocation, and reports from the Auditor General. It starts with a white paper on LAM-institutions in a digital age from 1999 (Ministry of Culture 1999), and goes via a national strategy for digital preservation and dissemination of cultural heritage (Ministry of Culture 2009) and the scope of the report on digitalization of the cultural heritage, which covered the years up to 2015 (Auditor General 2017), and ends with the National Budget of 2018 (Ministry of Finance 2017).

White papers are the starting point for identifying national objectives. They are drawn up when the Government wishes to present matters to the Parliament that do not require a decision. It is expected that they form a basis for future steps of implementation, such as law bills or budget allocations. White papers are substantial for the development in public institutions, especially within the state hierarchy, but their role outside the state government is more limited, as they are not legally binding instruments in their own capacity. Here, white papers will be used in order to identify the objectives of the national authorities concerning digitalization in LAM-institutions.

We can distinguish between hard and soft means of implementation, or "hard and soft law" of implementation. Here, hard means of implementation will be identified as law, administrative instruction, and budget allocations. The hard means of implementation have directly binding effects. Law, instruction, and budget allocations do not necessarily have such implications, that depends on the wording and the character of each provision. For instance, an initial section about the purpose of a law will normally not establish any rights or duties, an administrative instruction of vague character has only a limited authority, and allocations that do not come with clear guidelines for the use of the money and reporting re- 
quirements may lead to the realization of various purposes. Soft means of implementation may first of all be of pedagogical nature, such as information work and system development that may facilitate digitalization activities. The use of the information or the systems that are made available is not mandatory.

This study is based on a legal approach to the governing of the LAM sector. This emphasis on the formal structure and the hard means of implementation is of course not the only possible approach to the questions that are raised, and the value of the findings has some limitations. Formal structure and hard means of implementation are not the only factors that have impact on the development of public bodies. Bottom-up initiatives, co-creation, and contract-based structures with private or public parties are examples of structures which may be of special interest concerning digitalization in LAM institutions. The digitalization processes may also have cultural and social aspects that fall outside the scope of this formal approach. Nevertheless, the formal structure and the hard means of implementation establish a framework for the institutions and means of implementation for the national authorities. In view of the lack of results in important matters, which was clearly identified over years, it is reasonable to highlight a formal approach, this being done as a supplement to other possible approaches.

The results of the national policies may be difficult to measure, and the ambition is not to contribute with new research in the matter. The results identified in the last report from the Office of the Auditor General are the basis for the description of the results achieved up to 2015 (Auditor General 2017).

\section{The Imperative and the Results}

The white paper from 1999 identified main challenges for the government for the next decades concerning LAM institutions in a digital age (Ministry of Culture 1999). Here, we focus on two major objectives that are identified in the white paper: firstly, making as much as possible of the analogue/physical contents in the institutions' collections digitally available to the public, and secondly, ensuring long-term preservation of born-digital materials (14). The challenges of ensuring long-term preservation of born-digital archive materials from public bodies was emphasized in the white paper, with the danger of losing the records along with changes of technical equipment and software specifically mentioned. It was already clear that important documentation from public bodies was lost. According to the white paper, it is worth mentioning that the National Archives had solutions for receiving and long-term preservation, but was lacking capacity and needed more staff in order to handle the transition from paper-based to digital administrative procedure. 
The objectives and the challenges were known, but when the government presented a new white paper on digitalization in the LAM sector almost ten years later, important elements were still waiting to be realized. The National Library was at the forefront concerning digitization of analogue material. The National Archives' digitized material in the Digital Archive was popular among users, whereas the museums were considered as having digitized the smallest amount of analogue material (the University museums were a possible exception). The digitalization activity in the LAM sector was still considered to be in the start-up phase (Ministry of Culture 2009).

Another eight years later, the Auditor General concluded that the majority of the collections of Norwegian cultural institutions was yet to be digitized. According to the report, the potential consequences of this could be considerable ( $\mathrm{Au}$ ditor General 2017). The investigation conducted by the Auditor General showed that only the National Library had made progress in line with the digitalization report (Ministry of Culture 2009). The National Library had digitized most of its entire collection of books. Around 30 percent of artefacts in museums had been digitized, while 27 percent of museums believed that it would take more than 20 years to get up to date. The National Archives had digitized around two percent of its analogue material.

"Progress to date cannot be said to be in line with the Storting's overall goal of the best possible access to as many cultural heritage artefacts as possible”, said Auditor General Per-Kristian Foss. Users only had access to around half of the material that had been digitized in the archive and museum sectors online. The investigation showed that this stemmed primarily from the fact that records of the materials were incomplete. No sector could be said to disseminate the digital material sufficiently. The Auditor General pointed at the Ministry of Culture, stating that the Ministry had not actively managed the digitalization work, as digitalization did not have a high profile in the management dialogue, and there was little evidence that the results were being evaluated or followed up.

The biggest challenge within the archive sector was handling born-digital materials. The National Archives had stated that they were facing major challenges here. Nevertheless, there were few signs that the ministry had taken the initiative to overcome this problem during the period covered by the audit:

Materials from previous phases in the history of electronic documents represent an important part of Norwegian cultural heritage, which could soon be lost unless more is done. There is a risk that archives will be lost to posterity if they are not converted to modern technical solutions. (Auditor General, 2017) 
According to the digitalization report, the long-term storage of archive materials was so competence- and resource-intensive that the National Archives and the National Library should work both with each other and with the museum sector to bring about a solution. No such collaboration had been established during the audit period. The lack of common solutions meant that most museums had no arrangements for the long-term archiving of digitized materials.

We have seen major changes in the management of born-digital archives materials during the years after 2015, and the cooperation between the institutions has taken steps forward. Nevertheless, there are still challenges. It was not until 2018 that the Ministry of Culture explicitly asked the National Archives, by means of the annual letter of allocation accompanying the budget allowances, to produce a plan for the process of converting analogue archives to digital preservation (Ministry of Culture 2017, Chapter 7.5). And similarly, in 2018, the Ministry asked the Arts Council Norway, the National Library, and the National Archives to cooperate in identifying the needs for long-term preservation of digital material and recommend solutions. This idea from the policy document from 1999 was not yet realized.

The last white paper from the Ministry of Culture points at the fact that analogue material is preserved unless it gets damaged, while digital material may get lost if it is untouched. The importance of maintaining digital material is highlighted (Ministry of Culture 2018). A commission to propose a new Archives Act has recently pointed at the fact that the Archives Act has not been adjusted to the effects of the digital transformation (NOU 2019, 9).

Long-term preservation of digital archives in the municipalities was subject to an investigation from the Auditor General in 2010 (Auditor General 2010). In 2018, eight years later, there were still 54 percent of the municipalities who had never tried to export data from their record management system. There had been almost no change since the investigation from 2009 (NOU 2019, 9, punkt 21.3.4).

Imperatives formulated in white papers are widely discussed within the LAM institutions, and formulations from such documents often justify further developments. Why were these imperatives not enough to achieve the objections concerning digitalization? Here, we will investigate whether the formal structure of the LAM institutions and the hard means of implementation may explain the mismatch between the imperative and the implementation. 


\section{The Implementation}

\section{Actors and Tasks}

“The LAM sector" consists of many different actors with different roles: here we focus on the Ministry of Culture, which is at the top, and at the national level we also find the National Archives, the National Library, and the Arts Council Norway. But in addition to this, we have local and regional institutions and even some other national institutions, and there are private actors that play important roles.

The LAM institutions have different tasks. The National Archives' main tasks are preservation and dissemination of archive material from public agencies in state government, municipalities, and county authorities. The duty of preservation and dissemination corresponds with the tasks of libraries and museums in their respective areas. When it comes to digitization of analogue material, there are obvious similarities between the different institutions. They all have analogue (or physical) objects in their collections that must be scanned, photographed or in other ways converted to a digital platform. The digital information must be organized in a systematic way before it may be disseminated to the public. There are however, important differences between the original materials. The digitization of books in the National Library may be done in an "industrial way", and subsequently be disseminated to the public, on condition that the copyrights are respected. Archive materials often materialize in "cases" where parts of the material may be subject to confidentiality or personal data protection. The possibilities of using industrial working operations are limited. In museums, the artefacts are of very different kinds, and they are rarely suitable for putting into a scanning machine.

Long-term preservation of born-digital materials may also lead to quite different challenges in the different sectors. Here, we will have a special focus on the electronic records of public bodies. There is a distinct quality of public archives that "everyone" has the right to access, due to the right to information from public authorities according to Art. 100 in the Constitution and the Freedom of Information Act. Parties also have a right to information according to the Public Administration Act. In addition to this, the National Archives has a role as public authority. According to the Archives Act, the Director General of the National Archives is responsible for supervision of archival work conducted in government entities, county authorities, and municipalities. The National Archives may require information about the archive system and access to it, and may impose a duty to correct circumstances that are in violation of the Archives Act and regulations (Archives Act, Section 7 and 8). Furthermore, the Director General of the National Archives 
has the authority to set general rules and to pass special resolutions. The general rules issued by the Director General are laid down in a separate regulation.

We do not find any public authority equivalent to this in libraries or museums. The National Library has the authority to make decisions in cases concerning legal deposit of material published in Norway according to the Act on Mandatory Deposits for Published material and regulation pursuant to the act, but the authority does not go as far as the National Archives' authority to supervise and set general rules. The Public Libraries Act states that the task of public libraries is to promote the dissemination of information, education and other cultural activities through active dissemination and by making books and other media available for the free use of all the inhabitants of Norway. Furthermore, they are to be an independent meeting place and arena for public discussions and debates (Section 1). Museums do not have their own act applying to their activities.

Preservation and dissemination of born-digital materials is of special relevance for the National Archives. Whereas the responsibility lies with the public bodies for the creation and the preservation and dissemination during the first years, the National Archives is nevertheless responsible for supervision, guidance, and decisions according to the Archives Act and regulations.

Seen in light of these differences concerning actors and tasks, we would suppose that the implementation strategies for digitalization would be different. Nevertheless, there has been a tendency to regard common approaches as the solution for the institutions in the LAM sector. Here, we will take a step backwards and map the means of implementation available before we describe how they have been used.

\section{Means of Implementation for National Authorities}

National policies may be implemented in many different ways. One way is just simply to tell what the national authorities want, and then it will be up to the different actors to achieve the objectives in their respective areas. This is often done in a white paper. There are also pedagogical means of implementation. On the other hand, implementation may be carried out by using hard means of implementation, such as law, administrative instruction, and budget allocations. The use of hard means of implementation is the scope of our study.

Whereas the report from the Office of the Auditor General focuses on the organization of digitalization within the LAM institutions and the management dialogue maintained by the Ministry of Culture, we will here take a step backward and analyze the means of implementation available and the way in which they 
are used from a top-down perspective. Given that the expectations of digitalization were not met, what could the Ministry of Culture have done?

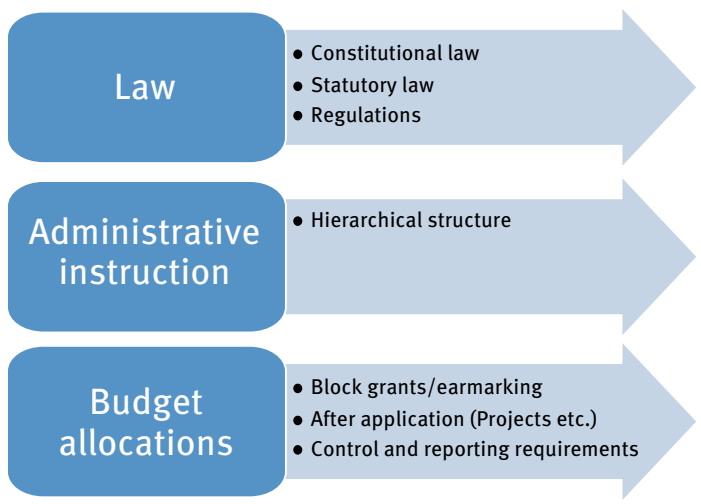

Fig. 5.1: Binding means of implementation

The three levels of law in the figure illustrate that legal obligations may be established by different bodies and procedures. Constitutional law must be adopted by the Parliament according to special procedures and a majority of 2/3 (The Constitution art. 121). Statutory law is also adopted by the Parliament, but according to quicker procedures and simple majority (The Constitution art. 76-79). Regulations may be adopted by the government or subordinate bodies on the condition that a statutory law allows so. A law provision may give rights or duties to private parties as well as public authorities. Laws and regulations are binding for everyone, including state administration, counties, municipalities, companies etc.

Administrative instruction within the hierarchy of state government is part of our constitutional system according to the Constitution Art. 3. The King in Council is on the top. Powers may be delegated to ministries, which in turn may delegate further to subordinated bodies. Within this hierarchical system, instructions may be used to govern subordinated bodies unless a law provision says something else. Such instructions are legally binding (Eivind Smith 2017, 232). The power of administrative instruction only applies within the hierarchy. State administration may not instruct counties and municipalities without a specific law provision.

When an administrative body is given allocations according to the National Budget, it is obliged to use the money as decided according to a regulation concerning the National Budget (Bevilgningsreglementet 2005). This is why budget allocations are regarded as a "hard" means of implementation. There are nevertheless different techniques of allocating money, and they give various degrees 
of choice for the recipient. Allocations to the municipalities are mainly done by "block grants", which have no specification of the use of the money except for the duty to fulfill legal obligations. If the allocation is earmarked, the money must be spent for a specified purpose. Many allocations are organized as "pots", from which different actors can apply for money for specific purposes. Then the duty to use the money for the given purpose arises only if an actor chooses to apply. The governing effects of allocations also depend on the level of control and reporting which follows the money.

The administrative organization of the archives sector shows that administrative instruction may be used as means of implementation of national policies from the Ministry of Culture and down to the National Archives. The hierarchical line is interrupted when it comes to private archives as well as municipal, inter-municipal, and county authority archives. Local self-government for municipalities (and county authorities) excludes administrative instruction from state administration, and instruction must be based on specific law provisions (including regulations). If for instance the Ministry of Culture wants changes in the electronic records management in municipalities, it may use administrative instruction in an indirect way, by giving instructions for the supervision activities of the National Archives. It may also give funding for relevant projects in the municipalities. Otherwise, it is obliged to use law and regulations. If we look to the organization of the library sector, the instruction line stops similarly at the National Library.

In the museum sector, however, the possibilities of administrative instruction towards the operative functions are excluded. The Arts Council Norway is responsible for allocation of funds from the state to the museums. Arts Council Norway works to develop the museum sector in Norway and advises the government in museum matters. A major responsibility is ensuring that the museums supported by the Ministry of Culture operate and develop in line with approved policy in this field. The main focus areas include developing sector-specific standards, statistics, and skills, as well as digital access to collections via open platforms. The council is appointed and financed by the Ministry of Culture, but administrative instruction is restricted by a provision in a specific law concerning the Arts Council Norway (Kulturrådsloven 2013, Section 5). There is, however an instruction line from the Ministry to the administrative part of the Arts Council. The museums are independent legal subjects organized as foundations, intermunicipal companies, and limited liability corporations. The government may have a role of appointing the board, being represented as member of the board or as owner, but there is no direct line of instruction as we find within the hierarchical organization of state administration.

There are, accordingly, important differences between the sectors when it comes to using administrative instruction as a means of implementation. The 
Ministry of Culture may use this means more extensively towards the archives services than towards museums. In other words, if the Ministry wants to govern actively, they have better formal possibilities in the archive sector than in the museum sector.

Archives, libraries, and museums are subject to quite different legal frameworks. The legal framework of the archive sector is detailed, and this legal structure opens up for implementing change by amendments in law or regulations. The legal framework of the libraries is less specific. Since there is no act concerning museums, but an act concerning the purpose and organization of the Arts Council Norway which establishes the Art Council as a professional independent body independent from the Ministry, the legal framework impedes rather than opens up for implementation of national policy in the museum sector.

The National Archives and the subordinated bodies are financed by their own chapter for archival purposes in the budget proposed by the Ministry of Culture. Municipal and county archives are financed by the respective local and regional authorities, which are obliged to fulfill their archival duties according to law and regulations. This means that the Ministry of Culture may give directions for implementation of national policies in the budget documents to the National Archives, but not to the municipal and county archives. It also means that the ministry does not have the authority to decide the level of financing for local and regional archives.

The National Library is financed by another chapter in the budget proposed by the Ministry of Culture, and the ministry may give directions in the budget document. As for the archive sector, municipal and county libraries are financed by their respective local and regional authorities. The National Library has a pot for grants to specific activities from which libraries may apply for financing. These grants give the National Library a possibility to influence the activities in the local libraries.

The museums which take part in the national network for museums are financed by their own chapter in the budget proposed by the Ministry of Culture. Relevant County authorities and municipalities are responsible for financing a part of the costs of the regional or local museums. It is specifically mentioned in the budget proposal that the objectives of the institutions shall be defined by the institutions themselves. In addition to this, the Art Council has a pot for museum development. Governing of the museums is mainly based on budget allocations and the control- and reporting regime and the management dialogue that is established. 


\section{How Have the Powers Been Used?}

We have seen that the possibilities of using hard means of implementation vary between the LAM institutions. The Ministry of Culture is free to take initiatives towards other ministries, the King in Council, and the Parliament, and the means of implementation available are not fixed forever. There could for instance have been developed stronger law provisions concerning digitalization, and the financial mechanisms could have been strengthened.

The interview data and the budget processes indicate that the development of the National Library's digitization of analogue material has been conducted through a close connection between the institution and the Ministry of Culture. The objective has been clear, and the practical implications and the costs have been concrete and measurable. It seems that the objectives have been achieved by an interplay between a bottom-up initiative, administrative instruction, and budgets. The situation where a "digitization factory" was established after the closedown of an iron plant in Mo i Rana might have contributed to favorable budget allocations to the new activity.

When it comes to the museums, the picture is more complicated. Firstly, there is the high number of institutions in which the realization of the objectives should take place, which makes any implementation of policies challenging. During the scope of this study, we have had a museum consolidation process, which means that the structure of the museums is changed. The conditions have been challenging to the institutions during this process, and the digital development should be regarded in light of this (Olav Aaraas, presentation at Kulturrådet: Digitaliseringsmeldingen åtte år etter, 24.04.2017, unpublished). More important here is the lack of means of implementation from the central level. There has been no tradition for law provisions on duties for museums. On the contrary, the principle of arm's length has been important for the relation between museums and government. There has not been any possibility of direct administrative instruction. And in addition to this, the financing of the digitalization processes has mostly been conducted by the possibility to apply for project financing.

In the National Archives, the possibilities of governing through hard means of implementation are wide, but it seems nevertheless as though the Ministry has been reluctant to use them actively. The financing of the digitization of analogue material was limited; for example, scanning machines were financed by external actors, which meant that the scanning activities depended on external initiatives rather than internal strategies (interview, National Archives, 05.09.2017). Longterm preservation of electronic records was challenging, and it seems as though the interplay between bottom-up initiatives from the National Archives and the 
Ministry was not optimal, as the Ministry was waiting for digitalization strategies from the National Archives.

Here, we will concentrate on the implementation of the long-term preservation of electronic records from public bodies. The Auditor General has done investigations of the preservation and accessibility of electronic records in state agencies and municipalities, and has stated that the work of the Ministry of Culture and the National Archives in this field has not been sufficient. This was illustrated when the white paper from 2000 pointed at the fact that preservation of and accessibility to electronic archive materials were main challenges, and that important archive material in municipalities was lost (Ministry of Culture 1999). Budgetary funding of NOK 62 million to electronic archives over a period of five years was proposed in this report, but eventually it was not given priority in the annual budgets. The National Archives had for a long time pointed at a need for new statutory law in this matter, but this initiative was not followed up until 2016. The management dialogue connected to the National Budget did for many years not address the digitalization challenges actively.

The Ministry of Culture and the National Archives have increased their efforts in this field after 2015. It has for a long time been an understanding that the duty of the public bodies to have management systems for their electronic records should be clarified in statutory law. The provisions of the Archives Act of 1992 have not been regarded as satisfactory. It was however not until 2016 that the Ministry of Culture established a committee to propose a new Archives Act. The work on new regulations started in 2015 and is currently finished, whereas a new Archives Act is still in the process. The supervision activities, especially those concerning electronic records in municipalities, have been increased lately.

There have been digitalization ambitions at the national level, and public bodies have digitized their work to a very large extent. But the questions regarding management of the electronic records have somehow been neglected for quite a long period. Here, we investigate further the role of the National Archives and the Ministry of Culture in the management of electronic records. This is a field where archives separate from libraries and museums, as archives have specific responsibilities according to law.

The fact that the Auditor General found that more than 200 case management systems from state authorities were out of use without arrangements for preserving the information illustrates that materials from the previous phases in the history of electronic documents can soon be lost unless more is done. The National Archives had informed the Auditor General that there might be several thousands of archives from the last 20 years in state administration waiting to be transferred to the National Archives. The Auditor General pointed out that there was a risk that archives would be lost to posterity if they were not converted to modern technical 
solutions. More recently, the supervision of state administration and municipalities by the National Archives has revealed that the municipalities especially fail to actively ensure that digital information is preserved. (National Archives 2018)

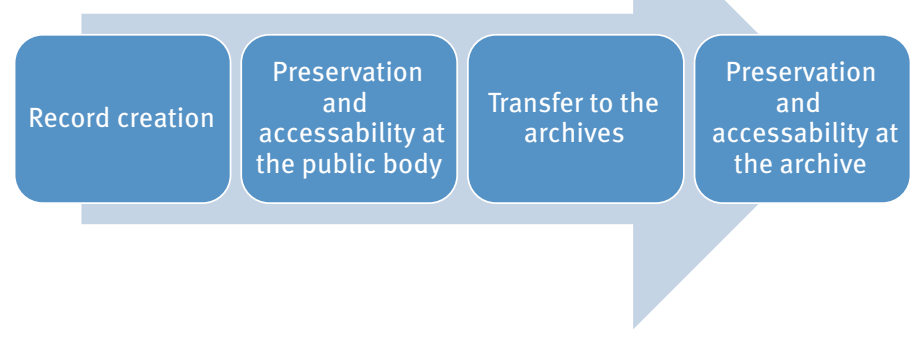

Fig. 5.2: Management of electronic records

There are major challenges to all the stages in this simplified picture of the management of electronic records. Firstly - what should be included in the record management system? Secondly, in what kind of system shall the registration happen? Then the question is whether the management system at the public body is capable of preservation of the record, and whether the agency can retrieve the record when needed. After several years, the record must be transferred to an archive institution. This is complicated, as the record management system at the public body must be open for such transfer and the archive must be able to receive the records in a suitable system. Then, the questions of how to maintain the information on a long-term basis remain.

The authorities became aware of these challenges many years ago. The National Archives started to receive electronic records in the middle of the 1980 s. Then the amount of electronic records exploded as the public agencies digitized their correspondence and their own working processes. The National Archives is responsible for the long-term preservation and availability of electronic records from state agencies, whereas the municipal archives are responsible for the longterm preservation and availability of the electronic records from the municipalities.

But the National Archives is also responsible for information to and supervision of the records management of all public bodies according to the Archives Act. The director general of the National Archives also has some regulation authority in this field, among other tasks to establish a standard for management of electronic systems (Noark). The Ministry of Culture is responsible for the develop- 
ment of statutory law in this field, and also has some regulation authority. It has the power to instruct the National Archives, but not the municipal archives. The national budget process might be used as a way of instruction towards state agencies. The municipal grants are however usually given as block grants. According to this, statutory law, regulations, supervision, information, and budgets are elements that might be important for the management of electronic records in public bodies.

The Ministry of Culture might instruct the National Archives, but does not have this authority towards ministries, directorates, and other parts of state administration which are not subordinated to the Ministry. The King in Council, or the respective ministers, may however instruct within the scope of their authority. There are major coordination challenges between the different branches of state administration and between state administration and municipalities. The Ministry of Culture and the National Archives are nevertheless key factors for the development of management of electronic records in state agencies and municipalities.

The means of implementation available have not been used in an active way by the Ministry and the higher authorities at national level during the scope of this study. Long-term preservation of born-digital materials from public bodies was a major challenge. Important steps have been taken lately, but there is still a risk that important parts of information that shall be available according to the law will be lost to posterity.

\section{Discussion - From Imperative to Implementation}

The national authorities have had a common approach to the implementation of the digitalization imperative in the LAM institutions. This study shows that there is reason to be more specific in this approach and regard the different institutions independently. The differences in organization, tasks and the formal framework are important, even if they are all cultural heritage institutions.

Digitalization was the reason for both establishing and liquidation of the common institution ABM-utvikling (Norwegian Archive, Library, and Museum Authority), which existed from 2003 to 2010 (Skare, Stokstad, and Vårheim 2019; Vårheim, Skare and Stokstad, this volume). This institution was expected to take common steps towards digitalization in the LAM institutions, but did not meet this expectation at the time when the tasks were reorganized to different LAM institutions. One explanation might be that digitalization demands processes that should be maintained by the different sectors independently, and that cooperation should be anchored at each institution. The Norwegian Archive, Library, and 
Museum Authority was subordinated to the Ministry of Culture, but it did not have any hard means of implementation towards the other LAM institutions. It seems as though there has been an idea of common solutions to common challenges in this field, which has not corresponded well with the formal framework and the realities. The common approach has been time consuming without important results.

It also seems that the parties outside the LAM institutions have been neglected. The need for formal framework, supervision, and guidance to the public bodies that produce the electronic records is of importance. The National Archives and the Ministry seemed for many years to regard their responsibility as starting when the records were transferred to the archives, but the possibilities for and costs of long-term preservation and dissemination is to a large extent dependent on the quality of the archive production, which is going on outside this scope. It is not unnatural that the Ministry of Culture is reluctant to take responsibility for the records management in other ministries and their subordinated bodies, neither in the municipalities and counties. But such a reservation means that there might be no authority to govern this field. During recent years, the Ministry of Local Government and Modernization has taken the lead in developing digitalization strategies, but there may have been a lack of responsibility at the national level for an important part of the scope of this study.

Another major aspect of the implementation results must be seen in light of the technological challenges of long-term preservation of born-digital materials. These challenges are important, and there is reason to ask if anybody else would have known better how to start the digitalization processes. An underestimation of the technological challenges might nevertheless explain why the resources allocated to the matter were not sufficient.

The lack of priority to important aspects of digitalization in the LAM sector might also be explained by a weak understanding of the importance of these processes to the public sphere. We may illustrate this with some reflections on the Constitution Art. 100, which regulates the freedom of expression. One aspect of this concept is the right to information from public bodies, and in our perspective, it is reasonable to emphasize paragraph five, which states that everyone has a right of access to documents of the State and the municipalities. In addition to this, the article has since 2004 consisted of a provision on public-sphere infrastructure, saying that it is the responsibility of the authorities of the state to create conditions enabling an open and enlightened public debate (paragraph 6). The state authorities have extensive leeway in carrying out this duty, and digitalization is not mentioned neither in the wording nor in the preparatory work of the paragraph. The white paper on a national strategy for digital preservation and dissemination of cultural heritage from 2009 (Ministry of Culture 2009, 15.) refers to 
this constitutional provision, emphasizing that an effective policy for digitalization of the cultural heritage contained in archives, libraries, and museums may strengthen the role of these institutions. It seems however that this constitutional provision has not been regarded as instigating a strong duty to realize the digitalization imperative.

When it comes to the digitization of analogue material in the National Archives, it should also be mentioned that there might be a mismatch between the objectives expressed in the white papers and the objectives that have actually been part of the policy implementation. The leading principle of the priorities within the National Archives, which has also been expressed to the Ministry, was to digitize on demand, based on the needs of important stakeholders. These were in reality the genealogy organizations (interview, National Archives, 05.09.2017).

The interplay between the Ministry and the LAM institutions is of great importance for the realization of objectives. The budget process and the letters of allocation are top-down oriented, but the institutions are expected to contribute to the development of their activities. A lack of initiatives from the bottom may explain why the imperative is not implemented. The report from the General Auditor gives the impression that the Ministry has been waiting for solutions and proposals from the LAM institutions. This bottom-up perspective is effective in many relations, but it seems as though the challenges of digitalization, especially in the archives, demand a more active hand from above.

But in addition to this, we find a policy of "implementation at a distance" when it comes to cultural institutions. Implementation of digitalization policies concerns technical, organizational, and economical matters more than cultural activities, and effective implementation demands a willingness to engage in such matters. The principle of arm's length is clearly expressed concerning museums and the Arts Council Norway. We do not find similar expressions concerning libraries and archives. However, there is a possibility that a tradition for nongoverning of cultural activities is transferred between sectors and institutions under the same Ministry. The lack of achievements when it comes to digitalization in the LAM institutions may be seen as a result of a lack of implementation policies. The national authorities have expressed that they want digitalization, but the questions of what, by whom, how, when, and at which costs are not answered.

Preservation of and access to public authorities' records are key factors for the infrastructure for an open and enlightened public discourse. Public bodies are working on digital platforms, and the medias' and individuals' possibilities to see what public bodies do depend on the management of electronic records. Preservation of and access to digital material is a prerequisite for the maintenance 
of the Freedom of Information Act and the right of parties to acquaint themselves with documents, in their cases according to the Public Administration Act.

The study of the implementation of the national policies for digitalization in the LAM sector in Norway shows that the role of the LAM-institutions for the public sphere has some unclear aspects. Digitalization has opened up very important parts of the collections for the public, but it has also entailed a risk that borndigital materials will be lost, material that is essential for the right of information from public agencies. Digitalization has a huge potential for efficiency, but reaching this efficiency has costs. The priority of resources to digitalization processes within the LAM sector has been varying, and it is difficult to see systemized priorities for the LAM sector during the scope of this study.

The lack of priority of management of electronic records tells us that there has also been a lack of policy concerning the public sphere in the Ministry of Culture, in the National Archives, and in many public agencies in state administration and municipalities. The insecurity of access to the records of the public agencies means that digitalization has decreased the freedom of information, which is in itself a crucial factor for the public sphere. The Ministry of Culture has a special responsibility for this. It is reasonable to ask whether the duty to establish an infrastructure for an open and enlightened public debate has been fulfilled and whether the right to documents from State and municipalities has been respected. The recent development, and especially the commitment to these tasks in the National Budget for 2020, shows that there has been a change, and that there is reason to be more optimistic about the future than this retrospective study would indicate.

\section{References}

Act on Mandatory Deposits. Lov om avleveringsplikt for allment tilgjengelege dokument (pliktavleveringslova) (LOV-1989-06-09-32).

Archives Act. Lov om arkiv (arkivlova) (LOV-1992-12-04-126).

Auditor General. Riksrevisjonens undersøking av digitalisering av kulturarven. 2017 (Dokument 3:4 (2016-2017).

Auditor General. Riksrevisjonens undersøkelse av arbeidet med å sikre og tilgjengeliggjøre arkivene i kommunal sektor. 2010 (Dokument 3:13 (2009-2010)).

Bevilgningsreglementet. Bevilgningsreglementet. (FOR-2005-05-26-876).

Blomgren, R. “The Institutions Go Digital”. In Audunson, R., H. Andresen, C. Fagerlid, E. Henningsen, H-C. Hobohm, H. Jochumsen, H. Larsen, and T. Vold (eds), Libraries, Archives and Museums as Democratic Spaces in a Digital Age. Berlin: De Gruyter Saur, 2020.

Constitution of the Kingdom of Norway. Kongeriket Norges grunnlov (LOV-1814-05-17).

Elmore, R. F. "Backward Mapping: Implementation Research and Policy Decisions". Political science quarterly, 94, no. 4, 601-616, 1979. 
Freedom of Information Act. Lov om rett til innsyn i dokument i offentleg verksemd (offentleglova) LOV-2006-05-19-16, 2016.

Henningsen, E. and H. Larsen. "The Digitalization Imperative: Sacralization of Technology in LAM Policies". In Audunson, R., H. Andresen, C. Fagerlid, E. Henningsen, H-C. Hobohm, H. Jochumsen, H. Larsen, and T. Vold (eds), Libraries, Archives and Museums as Democratic Spaces in a Digital Age. Berlin: De Gruyter Saur, 2020.

Ministry of Culture. "Kjelder til kunnskap og oppleving. Om arkiv, bibliotek og museum i ei IKT-tid og om bygningsmessige rammevilkår på kulturområdet”. (St.meld. nr. 22 (19992000)), 1999.

Ministry of Culture. “Nasjonal strategi for digital bevaring og formidling av kulturarv". (St.meld. nr. 24 (2008-2009)), 2009.

Ministry of Culture. “Arkivverket - statsbudsjettet 2018 - tildelingsbrev”. (Letter, case file no. 2017/1056-6), 2017.

Ministry of Culture. “Kulturens kraft - kulturpolitikk for framtida”. (Meld. St. nr. 8 (20182019)), 2018.

Ministry of Culture. “Statsbudsjettet 2020: Historisk satsing på Arkivverket”. (press release). https://www.regjeringen.no/no/aktuelt/historisk-satsing-pa-arkivverket/id2671080/ visited 01.11.19, 2019.

Ministry of Finance. "The National Budget 2018”. (Prop. 1S (2017-2018)), 2017.

National Archives. https://www.arkivverket.no/nyheter/tilsyn-avdekket-200-lovbrudd-i-2017, visited 27.11.18, 2018.

NOU. “Fra kalveskinn til datasjø - Ny lov om samfunnsdokumentasjon og arkiver”. (9), 2019.

Public Administration Act. Lov om behandlingsmåten i forvaltningssaker (forvaltningsloven) (LOV-1967-02-10).

Public Library Act. Lov om folkebibliotek (LOV-1985-12-20-108).

Skare, R., S. Stokstad, and A. Vårheims. “ABM-utvikling og avvikling: institusjonell konvergens og divergens i kulturpolitikken”. Nordisk kulturpolitisk tidsskrift, no. 2, 231-256, 2019.

Smith, Eivind. Konstitusjonelt demokrati. Bergen: Fagbokforlaget, 2017.

Vårheim, A., R. Skare, and S. Stokstad. "Institutional Convergence and Divergence in Norwegian Cultural Policy: Central Government LAM Organization 1999-2019”. In Audunson, R., H. Andresen, C. Fagerlid, E. Henningsen, H-C. Hobohm, H. Jochumsen, H. Larsen, and T. Vold (eds), Libraries, Archives and Museums as Democratic Spaces in a Digital Age. Berlin: De Gruyter Saur, 2020. 



\section{Organization and Funding of Digitization in the Visegrád Countries}

\section{Introduction}

“Europe's cultural heritage, both tangible and intangible, is our common wealth - our inheritance from previous generations of Europeans and our legacy for those to come. It is an irreplaceable repository of knowledge and a valuable resource for economic growth, employment and social cohesion. It enriches the individual lives of hundreds of millions of people, is a source of inspiration for thinkers and artists, and a driver for our cultural and creative industries. Our cultural heritage and the way we preserve and valorise it is a major factor in defining Europe's place in the world and its attractiveness as a place to live, work, and visit.” (European Commission 2014)

These few sentences from the European Commission's Communication from 2014 mirrors the European Commission's view on our common cultural heritage that needs to be digitally reproduced, provided via digital services and preserved for future generations. The charge is laid to cultural institutions of the European Union member states.

Digital technologies mean new opportunities for museums, archives and libraries to fulfil their historic mission: providing people with information and cultural heritage content and giving access to the published knowledge. Digital technologies have also changed the way of the consumption of cultural content and moreover breathed new life into artefacts. The European Union intends to take a very significant role in developing common ways of collecting, processing and protecting the cultural assets related to the European nations' heritage. Europe has historically one of the oldest, most diverse and richest heritages in the world and therefore all European countries, the European Commission, the European Union member states and their institutions have important responsibility for ensuring the preservation of cultural content.

In this article I will analyze how Visegrád countries implemented the European Commission's recommendations on digitization and digital preservation related to organization and funding issues into their cultural policies.

The Visegrád Four (V4) term refers to four Central and Eastern European countries, Czech Republic, Hungary, Poland and Slovakia, which - based on their common historical, economic and cultural background - form an alliance within the European Union. The Visegrád name is derived from the 1335 Congress of Visegrád 
where the Bohemian, Hungarian and Polish kings (John I of Bohemia, Charles Robert of Hungary and Casimir III of Poland) agreed on the creation of new commercial routes in the Castle of Visegrád in Hungary. After the fall of Communism on 15 February, 1991, three heads of states from Czechoslovakia, Hungary and Poland signed an agreement on cooperation in different areas. After the dissolution of Czechoslovakia, the former Visegrád Triangle became the Visegrád Four.

The socio-political development of the four countries in the twentieth century is very similar. The life behind the iron curtain, the change of the communist regimes, the transition period and finally joining the European Union hand in hand on 1 May, 2004 all represent the countries' common destiny. Now the alliance has a growing importance both in political and economical terms within the European Union. The states in many respects make up an opposition with the European Union. This opposition may also be linked to former cultural experiences if we take the approach of migration crisis as an example. Tracing back the history of V4 cooperation to 1335 we can find the antitype of this opposition to the Western neighbors as the kings met in Visegrád to find new commercial routes to bypass the city of Vienna.

Though after the 1989 political turn the V4 countries lagged behind in economic terms, very innovative solutions have been elaborated in the field of promotion of digital culture. Hungary in particular had strong traditions in the field of digitization before the country's EU membership. We can mention a great pioneer within computer science, John von Neumann, whose name referred to an early example of digital libraries in the end of 1990. One of the Neumann digital library and multimedia center's innovations was that it offered unlimited access to the masterpieces of contemporary national literature based on mutually profitable agreements between authors or copyright holders and the Hungarian government. The institution beat the path to online services of digitally reproduced copyright protected material.

The V4 represents a continuously strengthening group of countries with common values, a strong identity that is occasionally expressed opposite to the mainstream European Union opinions and ideas. Analyzing the cultural heritage field, many questions have emerged. Is this opposition present in the implementation of digitization policies too? How is the common historical, economic, social background reflected in the implementation of EU recommendations in the field of cultural heritage? How does the common characteristics of V4 countries appear in the field of digitization policies?

The paper has two main objectives.

1. Firstly, I shortly present the European Commission's recommendations (European Commission 2011) related to organization and funding that aims to 
supports the member states in developing and implementing national policies related to digitization and digital preservation in the cultural field.

2. Based on the latest national progress reports that the countries are obliged to submit to the European Commission I will analyze how Visegrád countries (Czech Republic, Hungary, Poland and Slovakia) implemented the European Commission's recommendations related to organization and funding of digitization of cultural material and digital preservation into their national policies.

Do we find reflections of the V4 countries' common platform and common background in the way they approach the digitization of the cultural heritage or are these processes first and foremost directed by technological groups of experts more loosely coupled to the common platform and history of the V4 countries?

\section{Digitization Policies}

The Digital Single Market Strategy is a high-level policy framework launched by the European Commission in 2015. It covers several policy actions, coordination and funding mechanisms that support - among others - the member states' cultural policies in the fields of digitization, online accessibility and digital preservation of cultural material. The strategy is based on the development of three key pillars (access, environment and economy/society). Digital developments from business to culture fall under this common framework shaped by the DSM strategy (European Commission 2015). Presently, this strategy defines the framework of the digitization of cultural heritage in the EU.

Three policy levels can be identified.

1. European Commission;

2. European Union member states;

3. Cultural Heritage Institutions of EU member states.

Between the different policy levels several connections, links can be found.

\section{European Commission}

Within the European Commission, the Directorate General for Communications Networks, Content and Technology is responsible for the issues related to digital cultural heritage. Several actions and activities have been made to exchange knowledge and to harmonize digitization policies on a European level. The fol- 
lowing three areas supervised by this directorate have key importance in shaping of the European Union cultural policies.

1. One important activity is the operation of the Expert Group on Digital Cultural Heritage and Europeana for the member states, which primarily aims to function as a forum for knowledge exchange (European Commission 2017). Its predecessor was the Member States Expert Group (MSEG) on Digitisation and Digital Preservation which was established with the aims of monitoring progress of the implementation of European Union recommendations and exchanging information and good practices of member states' policies and strategies on the digitization and online accessibility of cultural material and digital preservation (European Commission 2015).

2. Another important policy action was the issue of a recommendation that provides proposals for organization and funding of digitization activities in the member states, harmonizing legal regulations (digitization of public domain and in-copyright material) on a European level, which contains suggestions related to the contribution to Europeana and recommendations regarding digital preservation of cultural content (European Commission 2011). This recommendation changed a former one that was published in 2006 (European Commission 2006).

3. The third important policy area is the Europeana that represents the political vision on the presentation of the European cultural heritage and at the same time is a useful tool for retrieving cultural heritage objects through borders and sectors. Europeana was initiated by six heads of states (France, Germany, Hungary, Italy, Poland and Spain), led by Jacques Chirac president of France in 2005 who wrote a letter to Jose Manuel Barroso in which they proposed the launch of a common digital library of Europe that would virtually present Europe's rich cultural heritage; it started on 20 November, 2008 (European Commission 2008).

More actions could also be mentioned, but the above mentioned three points represent some very tangible and visible areas.

\section{European Union Member States}

The European Commission gives member states a free hand in how to implement the different paragraphs of the recommendation into practice, but expects each to submit a progress report in every second year in which the national governments describe their activities related to the recommendations. The national progress reports are available on the European Commission's portal and make it possible 
to reveal the various approaches that the different member states follow in cultural policies (European Commission 2017). Though the EU recommendation is not binding, every member state follows or at least takes this into account on various levels during policy actions.

\section{Cultural Heritage Institutions of Member States}

The cultural heritage institutions also define their own policies following the requirements of national governments' legislation. The organizations often refer directly to EU recommendations and policies and the above mentioned DCHE expert group also partly consists of representatives who are working in the cultural heritage institutions that suggests that a direct link between EU and institutional level policies also exists. On the other side, another chapter of this book reveals that although goals and policies are formulated at governmental or a higher level, those goals and policies are not implemented by the institutions (Stokstad, this volume).

\section{Method}

The paper is based on document analysis. The main source for policy documents is the portal of the European Commission's Directorate General for Communications Networks, Content and Technology where the above-mentioned recommendation (European Commission 2011) and every current policy document are available.

Former reports can also be found, but I only focused on the last submitted ones that apply to the 2015-2017 period. Every report is based on the same form that contains open and closed-ended questions. Within the first paragraph (Organization and funding) the respondent has to describe the present system and organization of digitization of cultural material. The reports contain references to past actions also, to make the current situation understandable. Therefore, the analysis of former reports would not add more value to this paper.

The organization and funding part - following the structure of the recommendation - contains the following themes:

1. Progress on planning and monitoring the digitization of cultural material
a) Planning digitization
b) Monitoring digitization

2. Progress on partnerships between cultural institutions and private sector

3. Progress on making use of Structural Funds

4. Progress on ways to optimize the use of digitization capacity and achieve economies of scale 
The European Commission's Directorate General for Communications Networks, Content and Technology makes consolidated reports every second year where they summarize the main conclusions derived from the member states' documents (European Commission 2018). I used this consolidated report as well where it provided additional contextual information.

Altogether, five documents were analyzed: firstly, the Commission Recommendation of 27.10.2011 on the digitization and online accessibility of cultural material and digital preservation (European Commission 2011) and then the latest 2015-2017 progress reports on the implementation of the recommendation from the four countries (Czech Republic, Hungary, Poland and Slovakia).

\section{Digitization Recommendations of the European Commission on Organization and Funding}

Recommendations of the European Commission to member states related to strategic approaches are listed under the "Digitisation: organisation and funding" chapter of the document as follows:

1. further develop their planning and monitoring of the digitisation of books, journals, newspapers, photographs, museum objects, archival documents, sound and audiovisual material, monuments and archaeological sites (hereinafter 'cultural material') by:

a) setting clear quantitative targets for the digitisation of cultural material, in line with the overall targets mentioned under point 7 , indicating the expected increase in digitised material which could form part of Europeana, and the budgets allocated by public authorities;

b) creating overviews of digitised cultural material and contributing to collaborative efforts to establish an overview at European level with comparable figures;

2. encourage partnerships between cultural institutions and the private sector in order to create new ways of funding digitisation of cultural material and to stimulate innovative uses of the material, while ensuring that public private partnerships for digitisation are fair and balanced, and in line with the conditions indicated in the Annex;

3. make use of the EU's Structural Funds, where possible, to co-finance digitisation activities in the framework of regional innovation strategies for smart specialisation;

4. consider ways to optimise the use of digitisation capacity and achieve economies of scale, which may imply the pooling of digitisation efforts by cultural institutions and crossborder collaboration, building on competence centers for digitisation in Europe. (European Commission 2011)

The setting up of quantitative targets is a clear message, though in case we expect comparable figures (see point “ $b$ ”) across Europe, this recommendation requires a two-sided mechanism in which national and joint European efforts should also be made. The "overall targets mentioned under point 7 " emphasize the importance of 
reuse of cultural content for commercial and non-commercial purposes to exploit the huge potential that digitization offers regarding the revitalization of cultural artefacts. The setting up of qualitative targets is not mentioned here but in the progress reports one can find references to them. In the age of mass digitization qualitative targets seem as - or even more - important as quantitative ones.

Planning and monitoring based on hard data is a quite evident requirement in every controlling and management activity. Making the progress and results of digitization quantifiable is quite difficult as different measures can be defined. To support the member states' activities to collect statistically valid data on digitization and digital preservation, one of the key objectives of the European ENUMERATE project was "the creation, promotion and development of a statistically-valid open methodology for surveying the digitisation, use, preservation and associated costs of cultural heritage materials in Member States in order to develop an effective methodology for measuring digitisation”. (Poole, 2014)

There is a growing demand from the users' side for digitized content, which means exploitable business opportunities to profit-oriented companies. If private and public partners can harmonize their interests in the use of digitized content, synergies can be created that may result in better utilization of public moneys by involving extra human capacities, creativity or financial contribution. Ensuring "fair and balanced" cooperation is even a more difficult challenge. In the last reporting period European Commission has concluded that although the number of public private partnerships is growing only a few examples are available all over Europe (European Commission 2018).

The Structural Funds are important tools in the European Union's Regional Policies that function as a direct way of supporting member states' digitization policies. Generally, the poorer regions are eligible for more funding as the purpose of this tool is reduce regional disparities in the territories of the European Union. As most regions of the V4 countries fall into the most underdeveloped parts of the EU, the use of Structural Funds is a unique possibility for all of these states. When the analyzed reports were written, member states were in the middle of the 2014-2020 programming period. The fields and purposes in which the funds can be used depend on the programs prepared by the member states and accepted by the European Union.

Regarding pooling of digitization activities, most of the member states set up national aggregators that may have different functions that vary all over the countries. The term "competence center" is not defined in the recommendation and according to the progress reports most member states satisfy this recommendation by setting up aggregators; this can be cross-domain or domain specific depending on the sectors covered (e.g. libraries, museums, archives, audio-visual institutions). According to a recent survey, national aggregators' common missions are: 
1. Giving access to cultural heritage objects; 2 . Promoting resources and cultural heritage of their country; 3 . Setting up quality standards and creating high quality data and metadata (Truyen 2019). Further roles can be played that depend on the organization of digitization in the certain country.

The recommendation is obsolete in many ways, leading to the European Commission deciding to revise it with the active participation of member state experts and cultural heritage institutions (Fernandes 2019).

\section{Results}

In this section I will present the organization and funding of digitization in the Visegrád countries according to the information collected from the latest (2017) progress reports (European Commission 2017).

\section{Czech Republic}

Digitization of cultural heritage is an important part of the Czech cultural policy. This aim is presented in several upper and lower level policy documents.

1. State Culture Policy for 2015-2020 (with the view to 2025);

2. Culture Content Digitisation Strategy for 2013-2020;

3. Integrated Strategy of the Support of Culture to 2020;

4. Libraries Development Concept for 2011-2015 including digitization of libraries; and

5. Libraries Development Concept for 2017-2020 including digitization of libraries.

Digitization activities in the cultural field is financed by the Ministry of Culture that launched two national projects focusing on the digitization of: 1. rare documents, manuscripts and old prints; and 2. endangered material (monographs and periodicals) published after 1800. Both projects set up quantitative targets. Regarding rare documents, manuscripts and old prints, the project allows the digitization of 200 documents and approximately $60-80,000$ pages, while from post-1800 documents of about 550,000 pages can be digitized annually all over the country.

A central aggregator, Manuscriptorum, is responsible for the presentation of old documents collected from the participating institutions, while modern material is aggregated by Czech Digital Library (Lhoták 2016). According to the Eu- 
ropean recommendations, public-private partnerships (PPP) are launched with Google for the mass digitization of old prints.

European Union funding sources were also used for digitization in the Czech Republic. The National Digital Library (NDK) Project was co-financed from the European Union Integrated Operational Programme and from the budget of the Ministry of Culture. Since 2015 about six million pages have been digitized. All content is available via the Kramerius system, which also ensures the long-term preservation of endangered documents.

Endangered documents have priority in digitization in the Czech Republic. A central heritage management body, the Central Register of Cultural Heritage of the Czech Republic, is responsible for the selection of the listed cultural heritage. The register is managed by the National Heritage Institute.

Regarding public private partnerships, the Czech National Library could report a long-standing and successful cooperation with Google for the digitization of old printed books. The project started in 2011 and at the time of the progress report was still operating. Since 2014, the National Library of Czech Republic prepared the documents that are digitized and made available in the Google Digitization Centre. Altogether, 150,000 books have been published digitally as a result of this cooperation.

Concerning qualitative and quantitative targets, the biannual progress report mentions that under the national level of digitization "it is the interest of each memory institution to plan, budget, and routinely digitize at least those documents whose lifetime is limited and / or that their condition requires immediate rescue." On this lower level neither quantitative nor qualitative targets have been set. Regarding the Czech National Library as an example digitization is a continuously running process in which the institution can estimate the number of digitized items or pages.

A central Digitization Register is established to avoid unwanted duplications in the library fields. This mechanism saves financial resources and makes the progress of digitization more effective.

\section{Hungary}

The Hungarian progress report mentions several strategic documents that deal with digitization activities.

1. The Digital Nation Development Programme

2. Digital Well-being Programme

3. Digital Education Strategy

4. Public Collections Digitisation Strategy 
The documents are related to different levels. The Digital Nation Development Programme is a top-level government strategy that targets the digitalization of the citizen services in many different fields. The aim of this is to create a digital ecosystem that supports private companies and individuals in exploiting the possibilities of the digital change. The Digital Education Strategy and the Public Collections Digitisation Strategy are also parts of this program of which the latter defines the tasks of the cultural institutions for the 2017-2025 period. All institutional strategies and the strategies of the different domains should be derived from the Public Collections Digitisation Strategy.

The progress report mentions the European Digital Agenda as a top-level European framework that defines the expectations for every member state in the field of digitization. According to the report all of the abovementioned strategies are aiming to harmonize with this European initiative. The public collections are identified as authentic content providers of the knowledge-based society that have a unique role in providing other sectors with cultural content. The strategy is service-oriented and emphasizes content providing instead of preservation purposes.

The Public Collections Digitisation Strategy describes the framework of aggregation appointing aggregators in each sector. The National Széchényi Library is responsible for the aggregation of documents digitised in libraries, the Hungarian National Museum for museum content, the Hungarian National Archive for archival material and the Hungarian National Film Archive for movies and audiovisual material. The Forum Hungaricum Nonprofit Ltd., the successor of the former Hungarian National Digital Archives - MANDA (that functioned as a national aggregator in a previous era until 2016) is responsible for other content not covered by libraries, museums, archives and audiovisual institutions.

The present system - defined in the Public Collections Digitisation Strategy is building on former initiatives performed by institutions with a national scope. The progress report mentions one example. The National Centre for Museology and Museum Information which operates as a department of the Hungarian National Museum launched the MuseuMap aggregation service for materials digitized in Hungarian museums in 2014. This portal can function as a base for further development of museum aggregation activities. This was the main cause for appointing the Hungarian National Museum as a museum aggregator in Hungary. On the archival field it was also obvious that the Hungarian National Archive should function as national aggregator as organizationally it covers all of the former county archives. The National Inventory Project aims to create a joint portal for public collections material that ensures a common search interface both for end users and institutions. This portal will function as a top-level layer for aggregating content digitized in public collections. 
There are no real public-private partnerships launched in Hungary in the field of digitization of cultural heritage. One example is mentioned in the progress report in which a private company is involved in digitization activities. The company provides capacities and expertise for developing services based on cultural heritage objects. National funds are available for cultural heritage institutions that can be used for digitizing the objects from their collections by a private company. It profits twice from this cooperation, once when they are paid for digitization and once when the digitized content is sold to institutions or individuals.

Regarding qualitative targets, a group of experts has been set up called Public Collections Digitisation College, which colligates the efforts of the different sectors. This group is responsible for elaborating common guidelines that ensure the quality and interoperability of digitized resources all over the library, museum and archival fields. Aggregator institutions are also developing standards, vocabularies and guidelines for their own fields of interest. A good example for guidelines is the "White book" that is developed in the library field and contains metadata and quality requirements for ensuring interoperability and harmonization of services.

Concerning quantitative targets, the Public Collections Digitisation Strategy have set up a very ambitious goal intending to complete the digitization of 50\% of the documents compared to all documents to be digitized, and to make them accessible through the online search interface of the National Inventory Project. Another quantitative target was set up to support the realization of the Digital Education Strategy. The number of available digital curricula based on the material provided by public collections should increase by $40 \%$ until 2025 .

The European Union Structural Funds are used only for developing services. The implementation of the strategy is primarily financed by Hungarian governmental funds. An example that the progress report mentions is the National Library System project of the National Széchényi Library that functions as a complex development program for library digitization that contains the development of infrastructure, performing digitization, creating new services, elaborating standards and launching thematic portals.

\section{Poland}

The digitization of cultural heritage is part of several strategic documents in Poland. These strategies constitute the framework for all digitization activities in Poland.

1. Strategy for Responsible Development to 2020 - with the perspective to 2030 .

2. Strategy of Social Capital Development 2020 
3. Strategy of Digitisation of national archives resources for years 2017-2022

4. Programme of Digitisation of culture goods and collecting, storing and sharing digital objects in Poland 2009-2020

The first is the highest level strategy adopted in 2017 and contains the description of tasks in six respective areas (qualifying, defining, implementing strategic activities; digitization process; long-term storage of digital documents; creating a national repository system; providing access to digitized cultural material; cooperation between different sectors). The Social Capital Development Strategy constitutes a broader context of digitization defining activities related to digital culture in general. The national archives strategy is focusing on the network of state archives, while the last program contains the development of the national framework of digitization of cultural heritage.

Leading institutions were selected as competence centers for digitization of documents in each particular area. The national library functions as a competence center responsible for the digitization of library materials, the National Heritage Board for historical monuments, the National Digital Archives for archival documents, the National Institute of Museology and Collection Protection for museum objects and the National Film Archive - Audiovisual Institute for audiovisual materials.

The competence centers have been defined in a former Long-term Government Programme (Culture+ 2011-2015). They have been existing since 2016 and are responsible for various professional activities. These institutions store the copies of digitized documents and they have further different roles too, from organizing and realizing trainings to ensuring consultancy and professional guidance and updating standards in the field of digitization.

Digitization projects are partly financed from national sources via open calls and tenders and partly from the European Union Structural Funds. An example for the latter that the progress report mentioned was the Digital Poland Programme, priority axis II. E-administration and open government, specific objective 4. Increasing the availability and use of public sector information (Submeasure 2.3.2. Digital sharing of cultural resources) that costed more than 100 million EURs and was financed from European Union Regional Development Fund. Most of the digitization activities were financed from national sources in the different sectors. The cultural heritage institutions could apply for financial support. The report lists all successful projects of which we can mention some examples.

In Krakow's Closer to culture project intended to digitize the representative collections of one of the oldest and largest museums in Poland, the Polish Film Institute realized a project aimed to digitally reconstruct and digitize Polish films, documentaries and animations and provide access to all forms of distribution 
(cinema, television, Internet, mobile devices) and preserve Polish film heritage for future generations. The National Library of Poland launched a project for the digitization of and providing access to Polish national heritage from The National Library and Jagiellonian Library collections. The competence centers' budget was also defined by national sources.

According to the progress report, the Ministry of Culture and National Heritage of Poland has not received any information on public-private partnerships targeting digitization and or related services though - they think - such cooperation would be fruitful for the cultural heritage sector.

Quantitative targets haven't been set up on a national level, and the individual - competing - projects have to define the numbers of documents or pages that should be digitized within the project period. Qualitative objectives are defined by the Ministry of Culture and National Heritage. All beneficiaries should declare that the digitized material would be compliant with the cataloguing practices and standards defined in the different sectors (Catalogue of Practices and Standards of Digitisation of Library Facilities, Catalogue of Practices and Standards of Digitisation of Museum Facilities, Catalogue of Practices and Standards of Digitisation of Audiovisual Materials, Catalogue of Practices and Standards of Digitisation of Archive Materials, Catalogue of Practices and Standards of Digitisation of Historical Monuments).

The competence centers have a key role in the development of guidelines for the institutions. An example that can be mentioned here is the National Library of Poland that elaborated the Digitising Literature Handbook, which contains the quality requirements, recommendations and good practices that should be followed during mass digitization of written heritage. The same projects have been implemented in other sectors by the competence centers of the certain field.

\section{Slovakia}

Slovakia performs quite well among the Central and Eastern European countries in the mass digitization of cultural material. The use of EU structural funds is especially exemplary in that it made very complex and industrial-scale projects possible regarding the printed heritage (Kováčik 2017).

The Slovak Republic performs digitization of cultural material under the framework of the Development and Renewal of the National Infrastructure of Repository Institutions Priority Axis of the EU Structural Funds Informatisation of Society Operational Programme. The program aims to contribute to an inclusive information society and facilitate the development of a knowledge-based economy. The priority axis' objective on the one hand is to improve acquisition, 
processing, protecting and providing digitized cultural content, and on the other hand is to develop the infrastructure of the memory institutions functioning on a national level.

Three cross-domain infrastructural projects have been implemented that are dealing with the joint development of Slovak cultural institutions. These projects are focusing on the interoperability of information systems, long-term preservation of digitized content and developing tools for launching new services. The priority axis contains six domain specific digitization projects that are targeting the digitization of content of ALM (archives, libraries and museums) institutions. The aim of these projects is to create digital library, archive, gallery, museum, collection of monuments and audio-visual documents. The digitization projects also cover both the tangible and the intangible cultural heritage (e.g. folk dances, songs, customs etc.)

While implementation was financed by the European Union Structural Funds, the sustainability period is coordinated and funded from the budget of the Ministry of Culture of the Slovak Republic and cultural institutions. Every participating cultural institution has their own plan for digitization that ensures the sustainability of results achieved by using up European Union financial sources.

The Slovak progress report answered negatively to the question "have cultural institutions in your country entered into PPPs (including also partnerships with non-EU partners) for digitization or for facilitating the access to digital cultural heritage?"

According to the last progress report, quantitative targets have been set for each domain (e.g. Digital Library and Digital Archives set up a target of 2.52 million objects to digitize from the Slovak National Library and Slovak National Archives, the Slovak National Gallery and other Slovak galleries contributing to the Digital Gallery with 100,688 digitized objects.) All together, 3.09 million objects should have been digitized, which - at the end of the implementation period was exceeded by more than $30 \%$.

The quality of digital content and services is ensured by "manuals" elaborated for specific domains. These documents are based on European recommendations, contain requirements for resolution, metadata etc. and are obligatory for all projects funded from European sources. These manuals ensure the common standards for storage in central digital archives and for presentation on the national portal called Slovakiana.

The national cross domain aggregator, the National Cultural Center, was responsible for the realization of a national project that targeted the development of the Central Application Infrastructure and Registry which is a system for pre- 
senting every kind of digitized cultural material both on a national level and on Europeana. Using this system was a pre-condition for the approval of any digitization project in the country. The digitized items are registered centrally. The mechanism was developed to avoid unwanted duplications in the library field.

Digitization activities are hosted in specialized national digitization worksites for each domain. Printed library documents are digitized in the Digitisation Centre of the Slovak National Library, the paintings and statues in the Slovak National Gallery. This centralized approach simultaneously ensures the economies of scale and safeguards the quality of outputs

\section{Discussion}

The policy recommendations of the European Union allow for very wide possibilities for the member states for the implementation. In this paper I analyze how the different paragraphs related to organization and funding have been implemented in four Central and Eastern European countries (Czech Republic, Hungary, Poland and Slovakia) according to the progress reports that the national governments should submit in every second year to the European Commission. In this paragraph I compare the countries' systems in planning and monitoring, financing and capacity optimizing following the reports structure.

\section{Aims of Digitization}

What we can observe in the different strategic approaches appearing in the progress reports is that the aims of digitization vary from one country to another. While for example Hungary has a very strong orientation toward service delivery and generally digital well-being, the Czech Republic strongly focuses on old prints, rare documents and the long-term preservation of vulnerable cultural heritage materials. While in Poland responsible development and social capital appear in strategy documents, in Slovakia the effective use of Structural funds and high quantity of digitized material based on cross sectoral cooperation seem to be the main aspirations.

It seems that the common platform of V4 states regarding their historical background and cultural orientations do not mean that they would formulate the aims of digitization in the same way. 


\section{Planning and Monitoring}

Strategic planning and development in the field of digitization is in place in all four Visegrád countries. Every country has national strategy on digitization of cultural material, while Poland and Czech Republic reported having also domain specific initiatives for planning. It is only Slovakia that has a national funding program too, though according to the answers to open ended questions it is obvious that the extended use of European Union sources made financial planning necessary. In comparison to other European Union member states where only 19 out of 27 (the United Kingdom has not submitted the report for this period) reported having a national digitization strategy, the Visegrád countries seem very conscious regarding planning of professional activities (European Commission 2017). It is common in all four countries that the current system of digitization is heavily reliant on the national libraries, museums and archives which have a key role in organizing and performing digitization.

Quantitative targets are set up in every country though various approaches are followed in the different states. Hungary defined a target value in percentage in comparison with all content to be digitized. Slovakia defined target numbers of documents regarding each project of the different domains financed from European Union Structural Funds. In the Czech Republic and Poland centrally defined target values are not existing, and therefore the institutions are primarily responsible for planning the volume of digitization. There is no information about the effectiveness of the different approaches.

Qualitative targets are realized via manuals or standards in all countries. The main objective of setting such targets is to ensure semantic and technical interoperability between different levels of services (institutions, national cross-domain or domain-specific aggregators, contribution to Europeana). According to the reports, the following of standards and guidelines is a prerequisite for receiving financial support for the projects from national budgets.

In the Czech Republic and Slovakia there are national schemes for monitoring progress in the digitization of cultural material, while such a mechanism is lacking in Poland and Hungary. The former Czechoslovak states established national registers for monitoring purposes, while in other countries national institutions have to trace the progress of digitization. Avoiding unwanted duplication of digitized documents is a central argument for creating registries and following progress of digitization.

Participating in the data collections performed by the ENUMERATE network is an important contribution to a European-level monitoring mechanism. Three countries - Czech Republic, Hungary and Poland - reported that they encouraged and supported the participation of cultural institutions in the ENUMERATE 
surveys for the establishment of a European-level overview of digitization data. As far as Slovakia is concerned, it may have a clear correspondence with the low response rate to Enumerate questionnaires in the 2015-2017 period. In 2015 only three institutions responded, while in 2017 there was none that did (Nauta Heuvel 2015; Nauta - Heuvel - Teunisse 2017).

\section{Partnerships Between Cultural Institutions and Private Sector}

Only two countries reported any kind of cooperation between private and public partners. In the Czech Republic the national library collaborates with the Google Digitisation Centre while in Hungary a small company cooperates with libraries, museums and archives in order to produce and provide digitized content. The biggest challenge regarding public private partnerships is to find mutually advantageous ways for cooperation, because while the companies are interested in making profit, the cultural institutions - adjusted to their historic mission - insist on free access to information and cultural assets. On the other side, the huge technical capacities that big companies can ensure makes cooperation an attractive solution.

According to the consolidated report, the partnership launched by the Czech National Library is quite typical in other member states also: "Main reported PPPs are between national libraries and technology companies - most often involving multi-nationals such as Google and ProQuest (publisher) that are known to have a vested interest in text based content" (European Commission 2018). National libraries in Austria, Germany, Italy and the Netherlands are also involved in PPP cooperation with Google, and the Bibliothéque National de France with ProQuest.

\section{The Use of Structural Funds}

With the exception of Hungary all Visegrád countries reported that they used European Union Structural funds for financing digitization activities to various extents. This financial source is a unique possibility that can be used according to the predefined program that member states present to the European Union. In Hungary, the Structural Funds can be used for the development of services of institutions, but not for the digitization of analogue collections. Despite the negative answer in the Hungarian progress report, Hungary also used Structural Funds on a certain extent, but solely for developing services based on electronic sources and building technical capacities. 
When considering the entire European landscape, only two thirds of Member States reported making use of EU Structural and Investment Funds for the programming period 2014-2020. The ratio is much higher in Central and Eastern Europe. The preparations of the next programming period of 2021-2027 are underway which gives member states the possibility to make new considerations based on experiences in this period.

\section{Optimizing Capacities}

The optimization of capacities is a necessity for effective digitization and it can be conducted in several ways: by setting up national cross-domain or domain specific competence/digitization centers; by launching shared services or facilities at a national level or across borders; by starting other types of national or crossborder collaboration initiatives. Centralization efforts are quite typical in Central and Eastern Europe and according to the consolidated report all over Europe as well. All together 18 member states reported designated digitization and competence centers (European Commission 2018). While the recommendation clearly communicates competence centers (which emphasizes human skills and capacities), on the other hand it is obvious that digitization efforts are much more dependent on aggregators. The term "competence center" is present only in the Polish progress report of the analyzed four.

All Visegrád countries operate an aggregation mechanism, though the maturity of these systems is on a varied level. On one side of the scale is Hungary where a former system - in which one national aggregator was appointed - was recently changed into a complex, two-layered aggregation approach in which four domain specific aggregators collect digitized content and present on a common portal. The whole system is under development and exists only in plans. On the other side of the scale is Slovakia, which has a long-standing, well-functioning system with huge national institutions as domain-specific aggregators.

It is common in every Visegrád country that national institutions are responsible for pooling digitization capacities and efforts. These institutions are functioning as competence centers, as digitization centers and they are the main contributors to Europeana.

Regarding the organization and funding, several countries mention the priorities of digitization. The clear orientation toward services can be observed in Hungary, Slovakia and Poland. In Hungary the Public Collections Digitisation Strategy is explicitly service-oriented, giving priority to the digitization of content that caters immediate user needs. On the other side, the digital preservation of endangered material has the highest priority in the Czech Republic. 


\section{Conclusion}

The European Commission's recommendation on digitization and digital preservation and the progress reports that the European Union member states should submit every second year on the implementation of the recommendation let us make comparisons between digitization practices of European countries. The paper focused on the issues related to organization and funding that are key topics of the reports. The recommendation was issued eight years ago, in 2011. Despite the relatively long time passed since its publication, the key points seem still highly relevant and up to date as far as the organization and funding issues are concerned.

We could observe several similarities in the analysis of the latest progress reports. These similarities can be regarded as typical Central and Eastern European features in organizing digitization. The most striking similarities concerning organization are the following.

The strong intention toward pooling digitization capacities is very typical in Central and Eastern Europe. All analyzed countries are building on existing national institutions as aggregators and/or competence centers.

Regarding funding of digitization there are also common features. The extensive use of structural funds is especially important in these countries, which have a much lower economic power than their Western counterparts within the European Union. Perhaps this easily obtainable financial source makes these countries less ingenious in elaborating new funding mechanisms. Accordingly, we can find fewer examples for public private partnerships than in other European Union member states.

We could find differences as well. One example is the setting of quantitative targets which is very different in the Visegrád countries. On one side of the scale is Poland and the Czech Republic leaving the definition of targets to institutions, while on the other side is Hungary where very ambitious targets have been set centrally. Slovakia follows a third approach by setting numeric targets as indicators for European Union financed projects.

We presumed earlier that due to some similar cultural, political and economic background the countries' policymakers found analogous solutions that on the one hand fit to the European Commission's recommendation and on the other hand reflect the needs and potentials of the analyzed countries. We have not found reflections to the V4 countries' common platform and common background in the way they approach the digitization of the cultural heritage. We found that these processes are first and foremost directed by technological solutions. The countries followed different paths related to the aims of digitization of cultural heritage. 


\section{References}

European Commission. "Commission Decision of of 27 February 2006 Setting up a High Level Expert Group on Digital Libraries". Official Journal of the European Union, 49, 2006, 3233, 2019. Accessed August 30, 2019. https://eur-lex.europa.eu/legal-content/EN/TXT/ PDF/?uri=0J:L:2006:046:FULL\&from=EN.

European Commission. "Commission Recommendation of 24 August 2006 on the Digitisation and Online Accessibility of Cultural Material and Digital Preservation". Official Journal of the European Union, 236, 2006, 28-30, 2019. Accessed August 30. https://eur-lex. europa.eu/legal-content/EN/TXT/PDF/?uri=CELEX:32006H0585\&from=EN.

European Commission. "Council Conclusions of 20 November 2008 on the European Digital Library EUROPEANA”. Official Journal of the European Union, 319, 2008, 18-19, 2019. Letöltés dátuma August 30, 2019. forrás. https://eur-lex.europa.eu/legal-content/EN/TXT/ $\mathrm{PDF} /$ ?uri=CELEX:52008XG1213(04)\&from=EN.

European Commission. "Commission Recommendation of 27.10.2011 on the Digitisation and Online Accessibility of Cultural Material and Digital Preservation". Official Journal of the European Union, 283, 2011, 39-45, 2019. Accessed August 23, 2019. https://eurlex.europa.eu/legal-content/EN/TXT/PDF/?uri=CELEX:32011H0711\&from=EN.

European Commission. "Towards an Integrated Approach to Cultural Heritage for Europe". July 22, 2014. Brussels. Accessed August 23, 2019. https://ec.europa.eu/assets/eac/culture/ library/publications/2014-heritage-communication_en.pdf.

European Commission. "A Digital Single Market for Europe: Commission sets out 16 Initiatives to Make it Happen”. May 6, 2015. Brussels. Accessed August 23, 2019. https://europa.eu/ rapid/press-release_IP-15-4919_en.htm.

European Commission. "2017 National Reports on Digitisation, Online Accessibility and Digital Preservation”. October 20, 2017. Accessed August 26, 2019. https://ec.europa.eu/digitalsingle-market/en/news/2017-national-reports-digitisation-online-accessibility-anddigital-preservation.

European Commission. "Commission Decision of 7.3.2017 Setting up the Expert Group on Digital Cultural Heritage and Europeana”. March 7, 2017. Brussels. Accessed August 23, 2019. http://ec.europa.eu/information_society/newsroom/image/document/201742/commission_decision_dche_D19B28A2-BCEE-B2D6-81F1AA9FB3CE377C_47767.pdf.

European Commission. Cultural Heritage: Digitisation, Online Accessibility and Digital Preservation - Consolidated Progress Report on the implementation of Commission Recommendation (2011/711/EU) 2015-2017. Luxembourg: European Commisssion - Directorate General for Communications Networks, Content and Technology, 2018.

Fernandes, M. "Presentation on the Current State of Progress and Next Steps in the Process of Evaluating the Recommendation". Presentation at 6th Meeting of Expert Group on Digital Cultural Heritage and Europeana. European Commission. Luxembourg, 2019.

Heuvel, W.-G. v. Survey Report on Digitisation in European Cultural Heritage Institutions 2015. The Hague: Europeana, 2015. Accessed August 27, 2019. https://pro.europeana.eu/files/ Europeana_Professional/Projects/Project_list/ENUMERATE/deliverables/ev3-deliverabled1.2-europeana-version1.1-public.pdf.

Kováčik, J. “The National Project Digital Library and Digital Archives: Mass Digitisation of Printed Cultural Heritage Materials in Slovakia”. Alexandria, 27, no. 3, 163-174, 
2017. Accessed August 27, 2019. https://journals.sagepub.com/doi/full/10.1177/ 0955749018763720.

Lhoták, M. "The Czech Digital Library - Aggregation and Dissemination of Digital Content From the Czech Libraries". In Libraries V4 in the Decoy of Digital Age: Proceedings of the 6th Colloquium of Library and Information Experts of the V4+ Countries, pp. 345-351. Brno: Moravská zemská knihovna, 2016.

Poole, N. “MSEG ENUMERATE Workshop”. Luxembourg: European Commission, 2014. Accessed August 26, 2019. https://ec.europa.eu/digital-single-market/en/news/13th-meetingmseg.

Stokstad, S. "Norwegian National Policies for Digitalization in the LAM Sector -Imperative and Implementation". In Audunson, R., H. Andresen, C. Fagerlid, E. Henningsen, H-C. Hobohm, H. Jochumsen, H. Larsen, and T. Vold (eds), Libraries, Archives and Museums as Democratic Spaces in a Digital Age. Berlin: De Gruyter Saur, 2020.

Teunisse, G. J.-W.-S. Europeana DSI 2 - Access to Digital Resources of European Heritage Deliverable - D4.4 Report on ENUMERATE Core Survey 4. The Hague: Europeana, 2017. Accessed August 27, 2019. https://pro.europeana.eu/files/Europeana_Professional/Projects/ Project_list/ENUMERATE/deliverables/DSI-2_Deliverable\%20D4.4_Europeana_Report\% 20on\%20ENUMERATE\%20Core\%20Survey\%204.pdf.

Truyen, F. "Common Culture Capacity Building. Presentation at 5th Meeting of Expert Group on Digital Cultural Heritage and Europeana”. European Commission. Luxembourg: Letöltés dátuma, August 26, 2019. https://ec.europa.eu/digital-single-market/en/news/fifthmeeting-european-commissions-expert-group-digital-cultural-heritage-and-europeanadche. 



\title{
Andreas Vårheim, Roswitha Skare, and Sigrid Stokstad \\ 7 Institutional Convergence and Divergence in Norwegian Cultural Policy: Central Government LAM Organization 1999-2019
}

\section{Introduction}

[T] he advent of electronic sources of information and their ever-increasing volume and variety will require a major redefinition and integration of the role of archives, museums, and research libraries. It is my point of view that the distinction between all of these apparently different types of institutions will eventually make little sense. (Rayward 1998, 207).

Rayward's prediction describes expectations in the LAM (libraries, archives, and museums) field that technological change and digitalization would produce coordination gains and institutional mergers over time. In Norway, The Norwegian Archive, Library and Museum Authority (ABM-utvikling - Statens senter for arkiv, bibliotek og museum), from here on referred to as $A B M-u$, was established in 2003. The digitization of documents such as books, journals, archival material and museum objects, and with this increasing similarity in working methods between the sectors was an essential argument in the process leading up to the creation of ABM-u:

\begin{abstract}
The commonality between the three sectors is even stronger through the growing use of information and communication technology (ICT) both in the organization and management of collections and materials and in the dissemination work towards the public. In addition, the three types of institutions increasingly handle digital material, either in the form of digitized representation of other original material, or material that already exists in digital form. This may lead to the working methods becoming more similar, and it is natural to consider how closely the coordination potential can develop so that users can have the easiest possible access to combined services. (St.meld. nr. 22 (1999-2000), 2). ${ }^{1}$
\end{abstract}

1 The quotations from Norwegian public documents have been translated by the authors of this chapter.

Note: The chapter builds on and develops material previously published by the authors (Skare, Stokstad and Vårheim 2019; Vårheim, Skare and Lenstra 2019), and is partly a translation of one of the articles (Skare, Stokstad and Vårheim 2019). 
In 2007, ABM-u was reorganized on the basis of an evaluation carried out by Statskonsult. ${ }^{2}$ The evaluation was to "assess the appropriateness of the current organization of ABM- $u$ and outline possible alternatives" (Statskonsult 2006, foreword). In 2010, the central government administration of the LAM (libraries, archives, and museums) sector was reorganized and ABM- $\mathrm{u}$ was discontinued (St.meld.nr. 20 (2009-2010)). This should lead to "a better and more focused work on the digital challenges of the future in the archives, libraries and museums" (St.meld. nr. 20 (2009-2010), 3).

ABM-u's short-lived existence appears as a long-drawn-out reorganization process. In short, $\mathrm{ABM}-\mathrm{u}$ was created, evaluated, reorganized, re-evaluated, reorganized, and discontinued within seven years. In the years before, during, and after ABM- $\mathrm{u}$, the LAM task portfolio was distributed within different institutional frameworks. It is noteworthy that a central governmental agency was closed seemingly painlessly in just under eleven months.

This article raises the question of why ABM- $u$ was not continued as a cultural policy instrument for the LAM sector. The question provides a basis for elucidating conditions for state governance in the cultural heritage area, contributing to the academic and professional discussion of organizational and governance models in the public sector and reorganization processes in Norwegian public administration. Also, the chapter is a contribution to the international literature on institutional convergence in the LAM field. Convergence in the LAM sector concerns co-location, forms of collaboration, and digitalization. The article describes the process from the establishment of ABM- $u$ in 2003 to reorganization and closure in 2010. An underlying and central issue in the process was the importance of digitizing cultural heritage and whether a separate coordination body was appropriate to achieve this.

The concepts of digitization, digitalization, and digital transformation are often confused. Warner and Wäger $(2019,328)$ provide an overview of definitions of the three concepts ranging from the change in technology and changing socio-technical systems to the transformation of the business models and institutions. Digitization means " $\mathrm{t}$ ] he encoding of analog information into digital format. Digitization makes physical products [e.g., artifacts] programmable, addressable, sensible, communicable, memorable, traceable and associable" (Yoo, Henfridsson, and Lyytinen 2010, 725). Digitalization is defined as “[a] sociotechnical process of applying digitizing techniques to broader social and institutional contexts that render digital technologies infrastructural” (Tilson, Lyytinen, and

2 Statskonsult was until 2008 the Norwegian government directorate for administrative development, and then merged into a larger agency; see note 5. 
Sørensen 2010, 749). Digital transformation involves "the changes digital technologies can bring about in a company's business model, which result in changed products or organizational structures or in the automation of processes" (Hess, Matt, Benlian, and Wiesböck 2016, 124).

We analyze and discuss the change processes in the central government LAM organization engaging historical institutional theory and a policy studies approach and primarily examine public documents such as annual reports, White Papers, consultation statements, budget proposals, letters of assignment, and evaluation reports. The 20 years of digital and institutional development since 1999 is in focus.

\section{Theory: Institutional Convergence}

\section{LAM: Organizational Focus}

In a comprehensive two-part review article on different models for library-museum collaboration, Warren and Matthews conclude that the literature in the field is limited in scope and that the findings to a small extent provide a basis for saying what factors influence whether collaborative measures in the cultural organizational field are successful (Warren and Matthews 2018a; 2018b). The main focus of the article is what the authors call physical convergence between libraries and museums, that is, merging and co-location, but also weaker forms of collaboration such as partnerships, integration in the sector, and project collaboration are described and discussed.

Since the 1990', within information science and media studies, it is the digital revolution, where different types of documents are given digital representations that makes the concept of convergence relevant. The extent to which the concept of convergence is equally fruitful in the study of organizational change in the LAM sector, in the study of organizational change in general, or as a basis for institutional development in the public sector, is unclear.

Studies of organizational change in the LAM sector, including the change process $A B M-u$ underwent, are interesting for the LAM sector with a view to future policy formulation processes. The lack of studies of organizational change in the LAM sector as such makes the case study of the change processes in ABM- $u$ interesting as a basis for generating hypotheses and as part of theory development processes about organizational change and policy change in information and cultural heritage institutions. 


\section{LAM Convergence}

In this article, we focus on institutional convergence. Convergence means that phenomena are moving towards each other, approaching each other, and becoming more similar to each other. The term existed in the analog world, but in the twenty-first century it is increasingly used by researchers and in public documents, also in the LAM field. This increase is most evident regarding the emergence of electronic and digital media and digitalization. Digitization would cause - it was expected - that all the documents we surround ourselves with will eventually be retrievable in the same digital format, and that the differences between formats and media will, therefore, disappear: "Digitization makes the signals themselves equal, regardless of what kind of information or communication they represent. As a result, it was assumed that convergence would take place." (Fagerjord and Storsul 2007, 19).

The merging of institutions, co-location, and collaboration are often used as synonymous terms for convergence when LAM institutions are in focus. As mentioned at the outset, it is envisaged that digitization will lead to more similarities between the various institutions and that this would increase cooperation on technological solutions. An example is an article "From coexistence to convergence" (Duff et al. 2013), which is based on interviews with employees of five "converging" LAM institutions in Canada and New Zealand. The concept of convergence is not used in the research questions of the project, but collaboration. Warren and Matthews (2018a; 2018b) highlight other concepts that signal collaboration between institutions such as "cooperation, partnership and integration" (Warren and Matthews 2018a, 1). The authors point out that physical convergence has been seen as "an innovative answer to the increasing challenges and demands faced by cultural heritage institutions" (Warren and Matthews 2018a, 1), while digital convergence is cited as a starting point for initiatives that have led to collaboration in the LAM sector (Warren and Matthews 2018a, 2).

Given and McTavish find that "libraries, museums, and archives could overlap in terms of political function and physical space" $(2010,8)$ in the nineteenth century, while today's motivation for increased collaboration and convergence may differ. The authors mention the various educational programs in the LAM sector and state that as long as they do not overcome the boundaries between disciplines, "real boundaries to collection, management, preservation, and access of materials remain" (Given and McTavish 2010, 23). Duff et al. find four factors that motivate LAM convergence processes: better user services; better scholarly support; better use of new technology; and cost savings (Duff et al. 2013, 6). 
The motivation for the establishment of ABM- $u$ was first and foremost characterized by the first factor, the ability to give users better and easier access. Digitalization was the main tool in this process.

\section{Institutional Theory Perspectives and LAM Convergence}

How can we understand and explain the LAM institutional change processes in relation to technological change and digitalization? The standard explanation has been that convergence in digital technology leads to convergence at the institutional level. Given that digitalization causes convergence of document forms, simply put, that everything in analog format is transformed into a digital file format, this means that LAM institutions and LAM policies will also necessarily converge. As we have seen above, this is a widespread view among researchers and policy actors. However, whether and how institutional convergence results from convergence in technology is a comprehensive and complex empirical research question and requires analysis from a wide range of theoretical and methodological approaches. To gain further knowledge, future studies of change processes in LAM governance require a comparison between countries and cultural policy regimes. This chapter hopes to inspire such an effort by examining institutional change processes in the LAM field in the Norwegian central government.

In the Norwegian context, attempts were made to merge the LAM institutions, but it was a short-term affair. Institutions diverged in spite of digital convergence. Convergence as a consequence of digitalization was central when ABM- $u$ was established, but both changing international institutional environments and central government institutional relationships need to be considered as important drivers. It remains to describe how and why the institutional change process that involved ABM-u's rise and fall took place.

\section{Transformative Institutional Change}

Institutional theories, whether rational, sociological, or historical, have all been better at explaining stability than change (Thelen and Conran 2016). One leading theory within historical institutionalism views institutional development as path-dependent with long stretches of stability (equilibria) interrupted by sudden exogenous shocks (punctuations) (Krasner 1988). These external shocks mean a wholesale change of institutional structures unrelated to former institutional regimes. This theory of punctuated equilibria originated in paleontology and evolutionary biology. Thus, the dramatic events in the history of the earth could be read from the fossil record (Eldredge and Gould 1972; Gould and Eldredge 1977). 
Path-dependent institutional development theories allow actors little leeway for variation, particularly in change processes. Gradual change happens in the form of routine adaptations. The main task of institutions becomes reproducing stable equilibria in the long periods between punctuations caused by exogenous shocks, also known as critical junctures (Lipset and Rokkan, 1967). In crises, actor choice can turn development trajectories. The paradox is that "real" institutional change is caused by circumstances external to actors and is not itself institutionally constricted (Thelen and Conran 2016), while social actors more or less relate to rules and are constricted by rules (Ostrom 1990). This implies that critical junctures do not involve social actors.

However, if we stick to the simple notion that institutional change in most cases is initiated by social actors that to some extent are bound by rules and institutions, this makes institutional change more of an ongoing process rather than a rare revolutionary event and paves the ground for a range of gradualist change perspectives. Also, real-world examples, as the AMB-u change process, seem to indicate that gradualist change beyond path-dependence occurs, even significant structural change, without a general understanding of paradigmatic change. The changes in the Norwegian LAM field are examples of transformative change - major change, but over time.

From a gradualist perspective of historical institutionalism, it is reasonable to surmise that institutions converge and diverge and can show relative stability over long stretches of time. If we want to explain institutional change, we need to adapt the theoretical toolbox according to the phenomena and processes we observe, and not the other way around. This simple reasoning is the basis for most historical institutionalists: institutions vary, they structure politics, but they do not by themselves determine outcomes or the path of history (Steinmo 2008; Thelen 1999). Actors follow rules, and they can be more or less rational, altruistic, and habitual (rule-following) in their behavior. This openness to variation also applies to institutional change processes and outcomes.

Institutions are socially created and, as such, not perfect. Creators of institutions are faced with the usual limitations on rational decision making. A gap between the expectations of institutional designers of what can be achieved through institutional design and reorganization and the actual results achieved through implementation on the ground is almost necessarily present (Pressman and Wildavsky 1984).

As is known from the classics of organizational theory, actors cannot have an overview of all alternative outcomes of policies due to limited access to information and limited cognitive capacity (Simon 1947). Actors are subject to bounded rationality (Simon 1947), and therefore follow standard operating procedures (i.e. rules) (March and Simon 1958). Furthermore, different groups that are affected 
by institutional change have different interests that inspire unclear compromises and blocking strategies (Cyert and March 1963). Actors play with or against existing rules, and this transpires over time, throughout the life of organizations. Institutions have built-in structural conflicts and may owe their existence to lines of conflict, as do most political institutions.

Institutions allocate resources and exercise power. Losers come back and find ways to use institutions that serve their cause. Over time, the "terrain" may change (e.g. new technology), and the impact of institutional rules and policies may be quite different than initially thought (Pierson 2004). A particularly relevant approach for understanding policy change and institutional change in government organizations is based on the theory that "policies make politics" (Schattschneider 1935; see also Hacker and Pierson 2014). Political decisions and policies have different outcomes for different actors - interest groups - some are winners, and others lose. New policies can change the terrain in the form of new rules and instructions. One strategy among stakeholders, therefore, is to try to influence policymakers before new policies are adopted, or try to mobilize for changing policies/ rules after adoption or try to influence or block implementation.

This description of processes of institutional change shows that the period between revolutionary changes can be dramatic enough. Hacker, Thelen, and others have shown how gradual changes can have transformative effects through special institutional mechanisms (Mahoney and Rueschemeyer 2003; Hacker 2004; Streeck and Thelen 2005; Mahoney and Thelen 2010; Thelen and Mahoney 2015; see also Vårheim 2001; Vårheim 2007; Vårheim, Skare and Lenstra 2019). This perspective is quite different from the theory of sudden exogenous shocks and path dependence where change comes from the outside and is abrupt, with actors having little agency. In a gradualist perspective, on the other hand, change can come from within, change can be gradual, and internal actors have agency in shaping the impact of change processes. The understanding of how gradual institutional change adds up to the transformation of institutions is the basis for the transformative model of institutional change.

\section{Mechanisms of Transformative Institutional Change}

This transformative change perspective within historical institutionalist theory considers mechanisms by which institutions change over time. These mechanisms include the following.

Conflicting institutional logics and time of origin. Institutions are children of their time and display different vulnerabilities. Public libraries and opera houses were established during different historical epochs and subjected to different cultural policy regimes. In the digital age, both institutions are challenged by the 
new media. Still, when it comes to government funding, it is comparatively easier to advocate the cause of libraries because of the legitimacy created by the democratization of culture that has taken place since the era of princely benefactors.

Institutional reproduction and change. The factors that make institutions durable are also their Achilles heel. For example, stable public funding of LAMs is easier to sustain in social democratic regimes until neoliberal agendas appear. The effects of austerity become more difficult to endure than in liberal regimes, where existing systems of private donations and patronage could alleviate unwanted state budget cuts.

Conversion. Conversion means that institutions, rules, or policies change through the processes of applying, using, interpreting, or implementing rules or frameworks over time. Supreme court decisions are prime examples. Another example could be a possible outcome resulting from the implementation of the Norwegian Public Libraries Act describing public libraries in the role of "independent meeting-places and arenas for public conversation and debate" (Ministry of Culture 2014). For public libraries, one strategy of adapting to this new statute could be to hold on to and redefine the traditional programs of book circles and author meetings so they fit the categories of the new policy, rather than venture into the more unfamiliar territory of facilitating debate arenas or structuring events for, say, groups focused on recreational pursuits like music, fitness, or crocheting.

Layering and drift. Layering and drift are strategies for institutional or policy change intentionally employed by actors, and both mechanisms have been extensively studied. Drift describes a situation when rules and policies are kept the same (change is blocked e.g. by the opposition), while contextual change makes outcomes different (Hacker 2004). One example is when universal welfare benefits are paid to clients staying in another country with a lower cost of living, as from Norway to Eastern and Central European countries. Another example involves technological change, e.g. when Norwegian library users cannot access library e-books on the most popular digital devices - Kindle e-readers - and thus are constricted from universal access. Relating to the present study, during $\mathrm{ABM}-\mathrm{u}$ 's tenure and the following years, digitization processes are becoming increasingly important, and this could mean that the National Library as the most prolific "digitizer" becomes an even more central player in the LAM field.

Layering means that new institutional structures, rules, or policies are put on top of existing structures, rules, or policies (Schickler 2001). Layering is much used when a change of existing structures, rules, or policies is opposed and cannot be achieved outright. Over time, layering can produce the intended outcomes. The Norwegian central government institution for the LAM sector was established 
while not including the National Library and the National Archives in ABM- $u$ and letting them go about their business as usual. This institutional configuration can be interpreted as a government layering strategy focused on gradual integration of the National Library and the National Archives into ABM-u over time (Vårheim, Skare, and Lenstra 2019), but one that ultimately failed, with the dissolution of the central government LAM institution.

\section{$A B M-u$ in an International Perspective}

The creation of $A B M-u$ was proposed at a time when major technological changes were taking place. It was envisaged that the similarities between the LAM institutions would be greater because of digitalization, and give users easier and increased access to information and knowledge. This line of thinking did not arise unaffected by developments in other countries. The establishment of ABM- $u$ in Norway appears to be in close connection with international trends. Around the turn of the millennium, several European countries created similar constellations (which the LAM White Paper devotes an entire chapter to): "Particularly worth noting is that many countries, but in various ways, have worked on issues or taken organizational steps crossing the traditional dividing lines between archive, library and museum” (St.meld. nr. 22 (1999-2000), 9).

The LAM White Paper highlights the Nordic countries and the developments in the Netherlands, the United Kingdom, and Canada. Sweden had already from 1991 a collaborative group for archives, libraries, and museums, while in 1996, Denmark was the first country to establish a network of cultural institutions as a gateway to shared internet-based information. In 2002, Denmark established Kulturarvstyrelsen (the National Heritage Board), which was responsible for administering the legislation and taking care of government tasks within cultural preservation and museums. In 2012, Kulturarvstyrelsen was merged with the Kunststyrelsen (Danish Arts Agency) and Styrelsen for Bibliotek og Medier (Danish Agency for Library and Media) to Kulturstyrelsen (Danish Agency for Culture) (Nielsen 2019).

The United Kingdom planned "to establish a new body for archives, libraries and museums, called the Museums, Libraries and Archives Council (MLAC)" (St.meld. nr. 22 (1999-2000), 145). In the United Kingdom, too, the emphasis is placed on "how the use of ICT leads to challenges and potential that are increasingly the same for the three sectors" (St.meld. nr. 22 (1999-2000), 146). The MLAC existed from 2000 to 2011 when libraries and museums were transferred to the Arts Council ("Museums and libraries formally transfer to Arts Council England,” 2011; “Museums, Libraries and Archives Council,” 2019). 
In Canada, ever since the National Library of Canada was established in 1953, it has worked closely with the National Archives. Since 1967, the institutions had been partially co-located with common technical and administrative functions (St.meld. nr. 22 (1999-2000), 146).

Both co-locations of LAM institutions with shared functions and the creation of new bodies appear to be a trend around the turn of the millennium. We also see this in countries not mentioned in the LAM White Paper, such as the US and Australia. Institutions such as the Institute of Museum and Library Service (IMLS) ${ }^{3}$ in the United States (established 1996) and the Collection Council in Australia (20042010) (cf. Warren and Matthews 2018a, 6) were established in these countries to coordinate activities in the LAM area and to encourage collaboration through grants. Although the concept of "convergence" is not always found, an important reason for this trend of establishing national LAM institutions is that technological advances lead to more and more similarities between the institutions and that they want to take this into account in the organization of LAM services, and also because of the possible efficiency gains:

International developments, particularly in Australia, the USA, and Canada, demonstrate a trend for cultural legislative frameworks that promote cross-sector collaboration, potentially driven by a need to make efficiency savings alongside recognition of the common ground shared by libraries, archives, and museums. (Warren and Matthews 2018a, 6)

This LAM trend was reflected in research efforts related to LAM institutions, for example, in the publishing of theme numbers of three leading journals in each of their disciplines, Archival Science, Library Quarterly, and Museum Management and Curatorship in 2008. Based on a common "call for papers," 14 articles were published (Marty 2008).

\section{ABM-u: Creation, Evaluation, Reorganization, Liquidation}

\section{The Creation of $A B M-u$}

In St.meld. nr. 22 (1999-2000) Sources of Knowledge and Experience - About Archives, Libraries, and Museums (the LAM White Paper), it was proposed to initiate research work with the aim of forming a new joint professional body for the three sectors of archive, library, and museum (cf. Section 8 of the White Paper).

3 IMLS purpose is to "advance, support, and empower America's museums, libraries, and related organizations through grantmaking, research, and policy development” (https://www.imls.gov/ about/mission). 
Based on new information technology and digitalization (St.meld. nr. 22 (19992000), 20-22), and with this potential for increased cooperation to the benefit of the users, the new body should exploit the opportunities for coordination and collaboration, but also develop the particularities of the sectors:

The aim of the White Paper is thus to create conditions that can give rise to the full use of the potential for coordination and collaboration that lies between archives, libraries and museums [... . Collectively, they should be able to provide better services to society (St.meld. nr. 22 (1999-2000), 2).

The body was supposed to take care of sector-specific and cross-sectoral tasks and become a cross-sectoral entity, and in the process, it also became a crossministerial agency. The original proposal in the LAM White Paper was to merge the Museumsutvikling (Norwegian Museum Authority) with the Statens bibliotektilsyn (National Library Inspection agency). The new, merged agency should also have sufficient competence to handle tasks in the archive area and should be placed under the Ministry of Culture. When processing the Church, Education, and Research Ministry's White Paper Do your duty - Claim your right (St.meld. nr. 27 (2000-2001)) in the Standing Committee of the Storting (the legislative assembly) for Church, Education, and Research matters, the committee "expected" (decided) that the National Libraries Service (Riksbibliotekstjenesten) for research libraries should be included in the new body (Innst. S. nr. 46 (2000-2001), 14).

In the state budget for 2002, the Storting endorsed the proposal to establish $\mathrm{ABM}-\mathrm{u}$. In addition to the already mentioned White Papers and committee reports, other key documents were the evaluation of the National Library Inspection agency and the Norwegian Museum Authority (see Ministry of Culture 2001a), and the report TverrsAMBand (Ministry of Culture 2001b) from the ministerial working group for IT and other cross-sectoral issues within libraries, archives, museums, and comments on this report from LAM sector bodies and organizations. Both the availability and dissemination of digitized material are mentioned in the report as important arguments for the establishment of ABM-u:

\footnotetext{
Digitalization makes it possible not only to reach new user groups but also to compile the material in ways that provide new knowledge and experience. Both facilitation and use require competence in several areas. Effective access to material that is distributed among archives, libraries, and museums, respectively, also demands organizational and professional collaboration (Ministry of Culture 2001b, 17).
}

Many of the comments on the report are positive, but point out areas that are not mentioned in the report or that require increased financial resources. However, it is worth noting that some key players saw little benefit from the establishment of a joint LAM body. While the National Library points out its competences and that 
it is "a 'mini-LAM' in itself" (Brev fra Nasjonalbiblioteket til Kulturdepartementet av 16.11.01), the National Archives considers "that the measures and recommendations promoted by the working group on institutionalized measures, or which can be interpreted as recommendations on such measures across the LAM sectors, is not convincingly justified" (Brev fra Riksarkivaren til Kulturdepartementet av 10.07.01, ref. 01/3593 A. $008 \mathrm{JH}$ ). The National Archives also believes "that the similarities between the institutions in the LAM sector, in general, are overstated in the report, and some proposed measures seem unnecessary" and that "no new national superstructures are needed."

ABM- $u$ appears to be a body wanted by the ministry and received with somewhat limited enthusiasm from the sectors concerned. At the same time, according to the project description, $\mathrm{ABM}-\mathrm{u}$ was not only obliged to establish good forms of cooperation with the sectors but was given "the main responsibility for quickly establishing the necessary dialogue” (DIFI-rapport 8 2008, appendix $5^{5}$ ). In the statutes for ABM-u, laid down by the Ministry of Culture on March 6, 2003, this is further specified in Section 3: " $\mathrm{ABM}-\mathrm{u}$ shall cooperate professionally with the National Archives and the National Library and adapt its activities in accordance with the competence and functions that these institutions have." (DIFI-rapport 2008, appendix 4). The Director of ABM-u shall "facilitate the good cooperation of $A B M-u$ with all actors involved with the institution” (DIFI-rapport 2008, appendix 4).

\section{Organization of ABM-u in 2003}

Cross-sectoral thinking is underscored in the original description of ABM-us organizational model:

It is assumed that $\mathrm{ABM}-\mathrm{u}[\ldots]$ is organized according to functional and not sector-specific criteria, so that a real joint body is created, and not just a loose superstructure over three relatively independent specialist departments for each of the sub-sectors (DIFI-rapport 2008, appendix 3).

4 The Agency for Public Management and eGovernment (DIFI) is "the specialized body for the Ministry of Local Government and Modernization; and the Ministry of Trade, Industry and Fisheries in the fields of management, organization, public procurement and digitalisation in the public sector" (https://www.difi.no/om-difi). From 2008 Statskonsult was included in DIFI.

5 The report has seven attachments: 1) Overview of the interviewees; 2) Interview guide; 3) Project description from 2002; 4) Statutes for ABM-u; 5) Mandate for ABM- $u$ in the interim year 2002; 6) Statutes of the Board of Directors; 7) Graphic representation of the LAM sectors. 
Here we see that the idea of one joint organization of tasks that applies across sectors was strong. It reflects the expectations of convergence not only in terms of technological solutions but also in the organization. As a result, ABM- $u$ was organized with three departments: administration, information, and development departments. The department for development was divided into three professional groups for archives, libraries, and museums, respectively, with "three managers placed on the same hierarchical level, where the managers had the responsibility of personnel management for the employees in their own professional group, while the priorities and issues that applied to the entire department had to be decided jointly” (DIFI-rapport 2008, 15).

At the same time as ABM- $u$ was to meet the sector-specific needs, the institution also had to work with developing strategies and activities across the three sectors. Besides, the ABM White Paper "saw a need for a package of initiatives that will address tasks that are common to archives, libraries, and museums and thus encourage closer cooperation between the sectors" (St.meld. nr. 22 (1999-2000), 168).

$\mathrm{ABM}-\mathrm{u}$ was assigned responsibility for a strategy that, on the one hand, should be cross-sectoral, but on the other hand should not come at the expense of the three sectors' professional domains. The creation of a new body, rather than collaboration between the existing agencies, should ensure the necessary coordination. It was emphasized by the Standing Committee for Church, Education, and Research matters that it was important to look at experiences from other countries and that all three LAM sectors were "equated in terms of professional competence” (Innst. S. nr. 46 (2000-2001), 16).

\section{Evaluation and Reorganization in 2006}

In 2006, ABM-u's organization was evaluated (Statskonsult 2006). The report concludes that the LAM organizational model of the ABM- $u$ had not impaired the sector-specific tasks, while the development of sector-wide tasks had received less attention. This indicates that little convergence had taken place so far. The report also states that "the board has a weak position, among other things because the ministry has the direct management responsibility for the activity" (Statskonsult 2006, 1). The report states about collaborative relations:

The establishment of a new cross-sectoral body meant that ABM-u touched on the areas of expertise and responsibilities of the existing institutions - the National Archives and the National Library. The new body had a challenge in clarifying the division of roles, initiating professional collaboration, operating in gray zones, establishing territory, etc. (Statskonsult 2006, 25). 
Furthermore, the report says about the three-tier leadership of the Development Department:

It is not unexpected that such a constellation with three leaders is problematic and encounters dissatisfaction. However, this should not be seen as a criticism of the three department heads, but of the organizational structure, they form part of. The three directors are recruited from each sector, they are set to lead their respective professional groups, and their portfolio is more or less dominated by sector-specific tasks, while at the same time they form one joint management structure. By others, they will easily be perceived primarily as sector representatives, and they will meet with similar role expectations. In our opinion, this is not a structure that promotes cross-sectoral initiatives, but a structure that is used for territorial defense (Statskonsult 2006, 29).

The report, therefore, proposes two alternative models for organizing ABM- $u$, the first according to sector and the second according to function (cf. Statskonsult 2006, 37-40). The strengths and weaknesses of the two models are discussed, but Statskonsult does not recommend a specific model:

The question must be assessed in particular based on the potential for and interest in increased application of the cross-sectoral perspective vs. the need for a multi-sectoral approach to remain dominant (cf. Section 5.1). The issue can also be considered in a temporal perspective, for example, that it is currently considered most realistic to organize with sector as the main structure, but that in the longer term it may be relevant to switch to function as the main structure if the cross-sectoral perspective becomes more prominent and widespread in the LAM sector (Statskonsult 2006, 40).

The organizational model that was chosen is sector-based, but a department for digital LAM issues is also established, a unit working across the sectors:

[the] three-headed leadership of the Development Department [...] dissolved, and the department was divided into three units: the departments for archive development, library development, and museum development. The information department was split into two units: the digital LAM department and a smaller information department. (ABM-utvikling årsmelding 2007, 44).

Thus, convergence was still relevant in the field of digitalization. The increased focus on digitalization issues by establishing a separate department can seem as a significant change. According to information from Lars Egeland (Head of the Information Department from 2003-2006), the former Information Department was already working primarily on tasks related to the development of digital solutions such as kulturnett.no and Norsk digitalt bibliotek (NDB: the Norwegian Digital Library) (Egeland 2019). The Digitalization Working Group was established within ABM-u in 2004 as part of the project "Norwegian Digital Library" and de- 
livered the report Kulturarven til alle (Cultural Heritage to All, ABM-skrift 32) ${ }^{6}$ in July 2006. The creation of the digital department in ABM- $u$ can, therefore, be seen as a follow-up of already existing work tasks and methods but increased the visibility of digitalization issues. Still, the cross-sectoral digitalization initiative was overshadowed by an increased organizational focus on the sectors. In 2007, ABM$\mathrm{u}$ received NOK 3 million for digitization purposes earmarked for the museum sector, while the same amount went directly to the National Library and the National Archives and their digitization work.

\title{
New Evaluation in 2008
}

Already in the year following the 2007 reorganization, the Ministry of Culture commissioned another evaluation of ABM- $u$ to be conducted by the Agency for Public Management and eGovernment (DIFI). The mandate for the evaluation was to

\begin{abstract}
analyze how ABM- $\mathrm{u}$ has implemented the cultural policy and the LAM sectors' professional intentions that formed the basis for the institution put forward in the ALM White Paper, and in the corresponding proposal from the Storting and the statutes of the institution. Based on the analysis, the evaluation will present proposals for possible changes and further development of ABM- $u$ as the state agency for archives, libraries, and museums (DIFI-rapport 2008, 2).
\end{abstract}

The DIFI survey was to form the basis for

- $\quad$ an assessment of the strategic and organizational choices made when ABM$\mathrm{u}$ was established and how the work has evolved in relation to the intentions that formed the basis for the establishment

- an overall assessment of ABM-u's interface with other relevant institutions, in particular with regard to the adequate assignment of tasks and possible reassignment of tasks (DIFI-rapport 2008, 3).

Since the transfer of library tasks to the National Library the following year means that ABM- $u$ will be discontinued, it is worth noting that the DIFI evaluation should map the division of the LAM areas of responsibility and possible transfer of responsibilities. The report provides a thorough review of ABM-u's administrative tasks and development activities (DIFI-rapport 2008, 22-38), and presents the views of the informants.

6 In this series, ABM-u published a large number of documents directed at the LAM sector, and for educational purposes. (https://www.kulturradet.no/sok?addsearch=ABM). 
Many informants regarded the development of digital content and services as an important focus area where $A B M-u$ could have done a better job than the previous institutions (DIFI-rapport 2008, 9, 64). The report also points out that $\mathrm{ABM}-\mathrm{u}$ does not have formal authority "neither to order the LAM institutions to digitize collections, to develop good digital services, or to follow ABM-u's recommendations on how this should be done" (DIFI-rapport 2008, 37).

In the report, DIFI concludes that it is "broad support among users and partners that a common development agency for the LAM sector is appropriate" (DIFIrapport 2008, 1). DIFI further believes that “[...] ABM-u balances well between administrative tasks and development work but points out that the administrative tasks should be made more visible. To move forward with the digitization work, it becomes vital to make the actors interact” (DIFI-rapport 2008, 1).

On the question of the interfaces between actors, and whether tasks can be transferred from ABM- $u$ to other actors, most of the informants answer that it is not "tasks that should be taken over by others" (DIFI-rapport 2008, 63). Only the National Library does not consider it to be useful with a joint body for the LAM sector, while the informants from the National Archives are more positive now than they were at the establishment in 2003 (DIFI-rapport 2008, 40).

\section{New LAM Policy Signals: ABM-u - a Dead End?}

The White Papers on the digitalization of cultural heritage and on library policy both signal that the discontinuation of $\mathrm{ABM}-\mathrm{u}$ is in the making (St.meld. nr. 23 (2008-2009); St.meld. nr. 24 (2008-2009)).

\section{The Digitalization Council Replaces ABM-u as a Coordination Body}

Both the White Papers highlight "the digital perspective" in the LAM policy. The White Paper on libraries assumes that "[a] digital perspective [...] will characterize all future development of library services” (St.meld. nr. 23 (2008-2009), 19) and that:

The potential for collaboration and coordination across the archive, library and museum sectors is great, and digitalization is a force that more than anything else draws the sectors together, and which makes it necessary and natural with close collaboration (St.meld. nr. 23 (2008-2009), 118).

However, ABM- $\mathrm{u}$ have had an unclear mandate and had been too ambitious so that the significance of ABM- $u$ for the LAM field has also been unclear (St.meld. nr. 23 (2008-2009), 118). A future organization of the LAM field must, therefore, 
emphasize measures and activities that motivate implementing bodies to offer better user services (St.meld. nr. 23 (2008-2009), 119). The recognition that digitalization is the major change "agent" in the LAM context means that there was a need for a unifying LAM body to be able to take out the overall synergy effects for the LAM field believed to be created by digitalization. Such a body composed of key LAM players would be set up through the establishment of a new council for coordination of the digitalization activities in the LAM area (St.meld. nr. 24 (20082009), 103; St.meld. nr. 23 (2008-2009)). The Council will "continually assess the overall strategies for digitalization with a view to making proposals that contribute to healthy digital collection management" (St.meld. nr. 23 (2008-2009), 119). In the report Cultural Heritage for All (2006), the Working Group on digitalization had proposed the establishment of a governing body for digitalization efforts in the LAM field in the form of a Digitalization Council with representatives from the sectors and the various levels of government to anchor the initiative across the sectors (Gausdal 2006, 52), as well as a national digitalization program for the LAM sectors. The central role of the National Library as a digitalization agent is highlighted in the report (Gausdal 2006, 64), and in particular, that the National Library from 2006 had implemented a large-scale digitization program for the entire collection $(27,64)$. The report gives ABM- $u$ a coordinating role in most of the digitalization measures proposed.

For the 2007 fiscal year, the National Library, the National Archives and the $\mathrm{ABM}-\mathrm{u}$, as mentioned, were each awarded an extra NOK 3 million for digitization programs, and the Ministry writes that $\mathrm{ABM}-\mathrm{u}$ should concentrate its digitization efforts on the museum sector (St. prp. No. 1 (2006-2007), 47). In the Digitalization in LAM field White Paper, this is followed up by specifying that the responsibility for the implementation of the digitization effort must be clearly linked to the sectors: the National Library will be responsible for the library area, the National Archives for archives, and ABM- $u$ for the museums (St.meld. nr. 24 (2008-2009), 102). For the National Library and the National Archives, this meant responsibility for the direct digitization work, while ABM- $u$ is assigned coordination tasks for the museum sector, but not for the operational digitization activities (St.meld. nr. 24 (2008-2009), 102-103).

\section{From ABM-u to the National Library}

The Library White Paper outlines a possible future transfer of responsibility for the development of the state library policy and for administrative tasks from ABM- $\mathrm{u}$ to the National Library (St.meld. nr. 23 (2008-2009), 119). The purpose of such a reform is to delineate the boundaries between ABM- $u$ and the collections managing institutions within the field, probably primarily in relation to the National 
Library, as the National Archives' tasks are not included in the ABM-u portfolio. The detailed argumentation for a reorganization is not easily found in the White Paper, but we can read that "clear and robust national frameworks" must be established, and digitalization, in particular, is highlighted (St.meld. nr. 23 (20082009), 118). Furthermore, the ABM-u has spread its business on too many tasks, thus giving unclear policy signals to the sector. Additionally, it is referred to comments from the National Library and the Librarians' Association (Bibliotekarforbundet) to the DIFI 2008 evaluation report on ABM- $u$ in which both argue that $A B M-u$ negatively influences the library field. Troms county municipality proposes that $A B M-u$ is given the status of a directorate, or that $A B M-u$ is abolished, and its portfolio is transferred to the county municipalities. The DIFI evaluation of $\mathrm{ABM}-\mathrm{u}$ concluded that $\mathrm{ABM}-\mathrm{u}$ largely had worked well in relation to the cultural policy expectations and professional expectations in the sectors, expressed at the time of its creation.

\section{Reorganization and Liquidation}

The Ministry of Culture's assessments in the White Papers on Digitalization in the LAM field (St.meld. nr. 24 (2008-2009)), and on Library policy (St.meld. nr. 23 (2008-2009)), are followed up one year later when a new reorganization of the LAM central government administration is proposed, which means the end of ABM- $\mathrm{u}$ and with it the end of a state coordinating body for LAM policy.

In the White Paper Omorganisering av ABM-utvikling (Reorganization of $\mathrm{ABM}-\mathrm{u}$ ), the Ministry of Culture proposes "changes in the division of labor between the state institutions in the field of archives, libraries and museums" (Meld. St. 20 (2009-2010), 1). With reference to previous White Papers concerning the archive, library, and museum sectors, a reorganization is proposed in which "the National Library is given responsibility for the library tasks ABM- $\mathrm{u}$ has taken care of" (Meld. St. 20 (2009-2010), 3). The remaining part of ABM-u was to be co-organized with the Art Council Norway's administration. While 19 ABM- $\mathrm{u}$ positions were transferred to the National Library as of July 1, 2010, and six to the Norwegian Science Index (NVI), the remaining 40 full-time equivalents were transferred to the Arts Council Norway as of January 1, 2011.

The reorganization meant that $\mathrm{ABM}-\mathrm{u}$ ceased to be an institution with effect from 1 January 2011. It is still emphasized that there will be a need for increased cooperation between the LAM sectors, not least to be able to target the cooperation on digitalization: 
In the future, therefore, the cross-cutting perspective will be clarified in the objectives of both the National Library, the National Archives, and the Museum sector. Not least, better and more targeted cooperation on digitization issues must be facilitated, as is also envisaged in the Digitalization White Paper (Meld. St. 20 (2009-2010), 4).

As part of the implementation process, on 15 February 2010, the Ministry of Culture sends a letter to the National Library asking it to "actively participate in the further process of designing a good and appropriate model for the government's efforts in the library field" (Brev fra Kulturdepartementet til Nasjonalbiblioteket av 15. februar 2010). On March 2, 2010, a similar letter is sent to the National Library and ABM- $u$ in which the Ministry asks the two institutions to present their specific proposals for the transfer of tasks and resources (Brev fra Kulturdepartementet til ABM-utvikling og Nasjonalbiblioteket av 2. mars 2010). The proposal was to include a detailed and reasoned assessment of how joint resources and resources for development tasks and Digital LAM should be distributed.

While the Library White Paper and the processing of this in the Storting in the summer and autumn of 2009 considered a possible transfer of tasks, the letter from the Ministry in March 2010 states that “[all] pure library tasks must be moved out of ABM-u” (Brev fra Kulturdepartementet til ABM-utvikling og Nasjonalbiblioteket av 2. mars 2010, our italics). The White Paper on the reorganization of $\mathrm{ABM}-\mathrm{u}$ refers to this process: "In the period following the Storting's processing of the ABM White Paper, there has been a dialogue between interested parties about the library tasks. Based on this process, the Ministry wants the library tasks to be gathered in the National Library" (Meld. St. 20 (2009-2010), 1).

We assume the dialogue referred to is an exchange of letters between the Ministry, the National Library, and ABM-u. The National Library replies in an undated letter with an attached note which was prepared following a request from the Ministry of 19 August, 2009 (Brev fra Nasjonalbiblioteket til Kulturdepartementet, undated). The letter shows a wish for the transfer of development tasks while saying no to taking over purely administrative tasks. It is problematized

whether it is possible to establish a clear distinction between the tasks of ABM- $u$ and the National Library according to the division suggested in the White Papers. If the distinction is not clear, the danger of unclear lines of responsibility increases, unclear communication with the library sector from the government and inappropriate distribution of resources and expertise.

$\mathrm{ABM}-\mathrm{u}$ responds on March 10, 2010, and emphasizes the distribution of the number of person-years and funds. The following are suggested:

- Transfer of delegated measures with a total frame of NOK 57 million, calculated in relation to the 2010 budget framework. 
- Transfer of project funds of an estimated NOK 14 million, calculated in relation to the 2010 budget framework.

- Transfer of all employees in the library department, as well as the former director of the National library inspection, a total of 19 person-years.

- Transfer of three full-time positions in support functions (Brev fra ABMutvikling til Kulturdepartementet av 10.03.2010).

While the National Library had for several years and on several occasions expressed an intention to do something regarding the ABM- $\mathrm{u}$ library tasks, $A B M-\mathrm{u}$ adopts a passive role. It accepts the transfer and is most concerned about not losing more person-years than necessary.

When the Storting dealt with the Whitepaper on the reorganization of ABM$\mathrm{u}$ in late November 2010 (Meld. St. (2009-2010)), the Cultural Affairs standing committee was divided. The members of the ruling coalition, the Labor Party, the Center Party, and the Socialist Left supported the reorganization, while the nonsocialist opposition was sharply critical:

These members believe it is striking that the government has done this without any thorough process with employees and with very little consultation with the relevant professional communities. [...] These members would point out that the discontinuation of ABM-u was a very important decision that should have been the subject of wider treatment, where the concrete solutions had been better discussed than what these members believe is the case for the barely four pages long White Paper. [...] These members have noted that the reasons for some solutions refer, among other things, to the processing of the Library White Paper, Meld. St. 23 (2008-2009) and the recommendations to the Digitalization White Paper from the Standing Committee for Family and Cultural Affairs (Innst. S. nr. 321 (2008-2009)). These members would emphasize that these documents were dealt with by the Storting without the discontinuation of ABM- $\mathrm{u}$ being considered relevant and that important issues related to this eventuality were therefore not discussed. (Inst. 91S (2010-2011) our italics).

This may indicate that the policy signals in the Library White Paper regarding $\mathrm{ABM}-\mathrm{u}$, in particular, were not perceived clearly by many politicians and this appears to be the case for most of the public as well. One comment by Odd Letnes in Bok og bibliotek - an independently edited library magazine funded by the government - indicates that also the library sector at large did not react:

What will become of the innovation of ABM- $u$ and especially in relation to the National Library, was the major theme in the Library White Paper that has been bypassed in silence in the library sector. The White Paper was, in reality, clear in its message. The Minister for Culture, Trond Giske, announced the split of ABM-u, but without concluding. By expressing himself in the future tense, he created an open situation. There was no serious objection to this in the public debate on the White Paper preceding the passage in the Storting before the summer (Letnes 2009). 
Only in the fall of 2009 did some debate arise in the newspaper Klassekampen and in the Bok og Bibliotek, ${ }^{7}$ where the National Library's digitalization project and the lack of transparency in the ALM change processes are discussed. For example, Jannicke Røgler, in Bok og Bibliotek, states that "the monopolizing of power by adding most of the state library tasks to the National Library is not necessarily the best solution for the library sector" (2009). On November 7, 2009, Klassekampen published an article by three library directors with the headline "Lack of transparency about important changes”. The library directors miss a professional justification for the change and openness about the process. Finally, it is pointed out that "the reasoning must be based on something else than the fact that the National Library wants this result”. In November of 2009, the County Librarians, in a statement printed in Bok and Bibliotek, ask that

\footnotetext{
[t]he Storting's Standing Committee for Family and Cultural Affairs considers our views in the processing of the state budget and the proposal in the White Paper for the distribution of tasks between ABM- $u$ and the National Library. A strengthening of the municipal public library system requires a central government institution independent of the National Library. (https://www.bokogbibliotek.no/aktuelt/aktuelt/stopp-nedbyggingen-av-ABM--utvikling)
}

The short existence of $A B M-u$ is marked by the two reorganization processes following extensive evaluation processes shortly after one another. The responsibility for libraries was transferred to the National Library as is described in the Library White Paper, while the archive and museum tasks were transferred to the Arts Council Norway. As late as 2015, the responsibility for archive development was transferred to the National Archives. Thus, the pre-ABM-u-era institutional order was restored along sectoral lines, but not along the former institutional lines, the National Library had added the central government public library policy area to its weight - the question of resurrecting the National Library Inspection agency was never raised.

\section{Discussion: Convergence and Divergence}

In 1999 the LAM White Paper proposed to create a separate government agency for policy development and for coordinating the activities in the LAM sectors for archives, libraries, and museums (St.meld. nr. 22 (1999-2000)). This institution, ABM- $u$ (The Norwegian Archive, Library, and Museum Authority), was anchored

7 An overview of all contributions in Bok og bibliotek can be found here: https: //www.bokogbibliotek.no/aktuelt/aktuelt/bok-og-bibliotek-og-debatten-om-ABM-utvikling-ognasjonalbiblioteket. 
in the notion of synergies flowing from innovations in digital technology, primarily through the convergence and digitization of documents (St.meld. nr. 22 (19992000)).

Furthermore, it was held, almost as a law of nature, that the convergence of types of documents meant the complementary convergence of document institutions (institutions organized around different document types, e.g. libraries, archives, and museums). The ABM- $u$ resulted from the merger of several LAM institutions, but with the National Library Inspection and Norwegian Museum Authority as the principal institutions. ABM- $\mathrm{u}$ was to develop one common LAM policy and coordinate its activities in the archive, library, and museum fields with the sector institutions - with the National Archives and the National Library as principals.

\section{Resistance to ABM-u}

At the first opportunity, during the consultation round of the report detailing the organizational structure of $A B M-u$ before the establishment of the organization, $\mathrm{ABM}-\mathrm{u}$ met strong opposition from the most central institutions in the LAM sector, the National Library and the National Archives (Ministry of Culture 2001b). Both agencies were under the remit of the Ministry of Culture and were to be included in LAM collaboration on the digitalization of cultural heritage. The very need for $A B M-u$ was called into question: the National Library considered itself to be a mini-ABM- $\mathrm{u}$, and the National Archives considered that the arguments for new national superstructures were weak.

Both the Digitalization White Paper and the Library White Paper, both from 2008, strongly indicate that the closure of ABM-u was imminent. The following year, the Ministry proposes the shutdown, and from the start of $2011 \mathrm{ABM}-\mathrm{u}$ is history. However, it is still emphasized that collaboration is much needed in the LAM field, especially when it comes to digitalization.

Especially the National Library's reluctance toward ABM- $u$ is persistent through the timeline of ABM-u. In the end, The Ministry of Culture concluded with the National Library and discontinued ABM- $\mathrm{u}$. What factors can best explain the winding-up of $A B M-u$, and thus the winding-up of the attempt at creating one coordinating LAM institution by the merger of the archive, library, and museum agencies in central government? 


\section{ABM-u Closure}

The LAM White Paper involved an interweaving of two policy areas - digitalization policy and LAM policy. The digitalization policy was in large measure a policy for digitizing material from the three LAM sectors. The LAM policy for the central government administration was a policy for the institutional integration of the LAM sector bodies and policy areas subject to the Ministry of Culture, except for the National Archives and the National Library (and the Arts Council Norway), but including the National Library Service from the Ministry of Education, Research and Church Affairs. In the LAM White Paper, the digitalization of the three LAM sectors was considered almost a prerequisite and the main impetus for convergence between the LAM institutions. For the National Library, digitalization has been a focus area since the 1990s; it still is and will stay for years to come. The same probably goes for the National Archives, although the digitalization efforts have followed a different course.

$A B M-u$ was intended to be the coordinator of the LAM sector while at the same time, the two key national players in the sector were outside the organization. In this lies a source of conflict of interest. Additionally, the digitization of documents was primarily the domain of the National Library and the National Archives. Overall, the probability of another outcome than the closure of ABM-u seems small, especially given the institutional configuration of the central government LAM policy area. ABM- $u$ was never able to claim a dominant role in central government LAM policymaking. Finally, ABM-u was discontinued, and the National Library assumed the role of the state's body for the library sector. The National Library's “victory" could hardly have been more substantial. The National Library consolidated its role as the key player in digitalization in the LAM sector, but it also formally assumed the status as the dominant institution in the library field. From Schattschneider's theory, the most rewarding thing that can be achieved is the establishment of institutional structures that safeguard policy interests over time (Hacker and Pierson 2014). The National Library won not just one prize, but two: the control of the digitalization activity in the LAM field, and of the central government library sector.

\section{Alternative Development Paths?}

Explaining the outcomes of change in LAM policy and institutions is important for policy development and interesting for research, but perhaps more challenging and probably with even greater impact on learning is asking what policy change and institutional change did not happen, why it did not happen, and what could 
have happened. Reviewing alternative trajectories of policies and institutional development and researching the conditions for alternative outcomes is important for future policymaking and for research and theory building within studies of institutional development and as a basis for comparative studies.

The establishment of ABM-u expressed expectations that the body would coordinate the state LAM sector. The National Library and the National Archives were still directly subject to the Ministry, and at the same level of the government hierarchy as was ABM-u. ABM-u's entry into the LAM sector and the cultural policy field meant the establishment of a new cultural policy government body for LAM policy development and coordination but without a clarification of the relationships with the most important state actors in the sector. ABM-u became a new institution, placed beside existing institutions, not on top of the existing structures in the sector. This meant that the formal organizational structure was kept unchanged except that a new horizontally placed entity was added to the existing institutions, the National Archives and the National Library. Thus, the National Library and the National Archives had to agree with ABM-u on how the LAM sector should be coordinated. Such a placement of ABM-u was an invitation to conflict or inaction. Given any resistance and use of blocking strategies from one or more of the actors, this set-up for cooperation becomes difficult to make work. Put differently, ABM-u's ability to coordinate measures in the LAM field, such as the digitalization policy and digitalization processes in the sector, was limited.

The creation of ABM- $u$ meant that a new horizontally placed institution was added to the portfolio of the Ministry of culture. This is different from a strategy of layering where the new institution is added on top of the existing entities that hopefully would disintegrate as separate institutions and integrate with the new institution with time. The organizational placing of ABM- $u$ makes a sectoral institution of the prospective integrative component, of the institution intended for coordination purposes, continues and increases specialization, and the number of central sectoral institutions from two to three. The structural placement of ABM- $u$ does not signal its purpose as an institution for coordination. It signals that ABM$\mathrm{u}$ is a sector institution as the National Archives and the National Library, and as such, becomes an institution with its specific sectoral interests, just the opposite of coordinating role intended for the organization. This means that a layering strategy would have been unworkable and impossible to implement. ABM-u was not placed on top of the National Library and the National Archives.

The structural organization of the state LAM sector was not the responsibility of $\mathrm{ABM}-\mathrm{u}$ but belonged to the Ministry of Culture. In principle, the Ministry of Culture could have merged the National Library and the National Archives with ABM$\mathrm{u}$ or have clarified the relationship between the bodies in another way. At the same 
time, the National Library and the National Archives are actors with strong historical and national roots that make them nearly untouchable.

Alternatively, the Ministry could have implemented a strategy of policy drift an approach implying that the strength of protests from the National Library and the National Archives would dampen over time and that demands for coordination of digitalization efforts in the LAM area would be pushed forward, for example, by the international wave of convergence between LAM institutions. However, internationally, after the 2000s, the expectations for the convergence of archives, libraries, and museums at both the state and local levels weakened, partly due to unclear and weak results (Vårheim, Skare, and Lenstra 2019).

Another factor regarding alternative outcomes is the role of ABM- $u$ itself. Could ABM- $u$ have been more proactive in its relationships with the Ministry, the National Library, and the National Archives? In addition to the awkward organization of the relationship with the Ministry and the two sector institutions, also in the position as a newcomer, it was, of course, challenging to fight, as we have seen, formidable opponents such as the National Library and the National Archives. Accommodating three professions and three different LAM sectors within $\mathrm{ABM}-\mathrm{u}$ was difficult and weakened the ability to stand up against the opponents. Also, the persistent externally initiated organizational reviews and reorganization seem never to have allowed the institution to put its house in order. There seem to be very few alternative trajectories that could have produced an alternative outcome for the ABM-u. Still, institutional terrains can change. The future, even in the LAM area of the central government, is not carved in stone. New technology, international trends, and stubborn losers can bring forward expectations of new policies.

\section{Epilogue: Libraries, Archives and Museums Post-ABM-u}

Factors connected to digitalization processes were strong arguments both for the creation and the closure of $A B M-u$. The White Paper Reorganization of $A B M-u$ emphasized increased future cooperation in the archive, library, and museum sectors and "a better and more targeted collaboration on digitization issues" (Meld. St. 20 (2009-2010), 4). The Digitalization Council, which was proposed the first time in 2006 (Gausdal 2006, 52) and repeated in the Library White Paper (St.meld. nr. 23 (2008-2009), 119) two years later, only became operational from 1 January 2016.

In 2017, the Office of the Auditor General presented an investigation of the digitization of cultural heritage (Dokument 3: 4 (2016-2017)). The report stated that a large part of the cultural heritage was still not digitized. The report emphasizes 
that the National Archives and large parts of the museum sector, in particular, have not given sufficient priority to the digitization work. Also, much of the digitized material was not available to the public. The National Library's commitment to digitization is emphasized as successful and is the only central government LAM institution where progress was in line with the intent of the Digitalization White Paper. Thus, by 2017, the National Library had further consolidated its position as the leader in digitalization and digitization, the leader in the library sector, the leader in the LAM sector and a leader in the cultural sector. The development after 2017 does not weaken this impression.

The investigation by the Auditor General has led to a greater focus on the progress of digitization work in the archive and museum sector, and it appears to have enforced a higher degree of cooperation between the sectors, now with the National Library in the leading role. The White Paper Diversity and Arm's Length. Media Politics in a New Era describes the upcoming expansion of the National Library's digitization activities at its primary digitization plant in the city of Mo i Rana:

Therefore, the government has assessed and concluded that parts of the financial savings by the closing down of the national broadcasting company's license collection department should be used to expand the activities of the National Library, which today has about 200 employees in the city of Mo i Rana. Here, new workplaces can be created that will make it possible to digitize a significant amount of cultural heritage material, and thus contribute to the realization of the cultural policy goal of preserving and disseminating cultural heritage (Meld. St. 17 (2018-2019), 54-55).

In an interview with the Librarians' Association (Bibliotekarforbundet) in June 2019, National Librarian Aslak Sira Myhre discusses how to use the 70 new positions: "The National Library hereby becomes responsible for not only its own collection but for digitization in the entire LAM sector. At the same time, a doubling of digitization capability enables us to develop even more efficient production lines for all types of materials.” (Bergan 2019). 


\section{References}

“ABM-utvikling årsmelding”. Oslo, 2007. Accessed August 6, 2019. https://www.kulturradet. no/vis-publikasjon/-/ABM--utvikling-arsmelding-2007.

Audunson, R. "Between Professional Field Norms and Environmental Change Impetuses: A Comparative Study of Change Processes in Public Libraries". Library \& Information Science Research, 21, no. 4, 523-552, 1999.

Bergan, E. “Aslak Sira Myhre om de 70 nye stillingene”. Accessed August 12, 2019. https:// www.bibforb.no/aslak-sira-myhre-om-de-70-nye-stillingene/, 2019.

Brev fra Nasjonalbiblioteket til Kulturdepartementet av 16.11.01, ref. 1999/295 AS. TVERRSAMBAND - uttalelse fra Nasjonalbiblioteket.

Brev fra Riksarkivaren til Kulturdepartementet av 10.07.01, ref. 01/3593 A. 008 JH. TVERRSAMBAND. Riksarkivarens høringsuttalelse.

Brev fra Kulturdepartementet til Nasjonalbiblioteket av 15. februar 2010, ref. 2009/03742 KV KSR:amb. Oppgavefordeling på bibliotekfeltet.

Brev fra Kulturdepartementet til ABM-utvikling og Nasjonalbiblioteket av 2. mars 2010, ref. 2010/00265 KV KSR:amb. Oppgavefordeling mellom ABM-utvikling og Nasjonalbiblioteket.

Brev fra Nasjonalbiblioteket til Kulturdepartementet, udatert. Oppgavefordeling mellom ABMutvikling og Nasjonalbiblioteket.

Brev fra ABM-utvikling til Kulturdepartementet av 10.03.2010, ref. 09/577-I0. Vedr. oppgavefordeling mellom ABM-utvikling og Nasjonalbiblioteket.

Byberg, L. "Public Library Development in Norway in the Early Twentieth Century: American Influences and State Action". Libraries \& Culture, 28, no. 1, 22-34, 1993.

Cyert, R. M. and J. G. March. A Behavioral Theory of the Firm. Englewood Cliffs, NJ: Prentice-Hall, 1963.

DIFI-rapport 8. Evaluering av ABM-utvikling. Difi-rapport 8. Accessed February 5, 2019. https: //www.difi.no/sites/difino/files/2008-09_g06eq.pdf, 2008.

Dokument 3:4. Riksrevisjonens undersøking av digitalisering av kulturarven (Office of the Auditor General report.). 2016-2017. Accessed August 6, 2019. https://www.riksrevisjonen.no/ globalassets/rapporter/no-2016-2017/digitaliseringkulturarv.pdf.

Duff, W. M., J. Carter, J. M. Cherry, H. MacNeil, and L. C. Howarth. "From Coexistence to Convergence: Studying Partnerships and Collaboration Among Libraries, Archives and Museums”. Information Research, 18, no. 3, 2013. paper 585 [http://InformationR.net/ir/183/paper585.html].

Egeland, L. “Interview”, January 31, 2019.

Evjen, S. "The Image of an Institution: Politicians and the Urban Library Project". Library \& Information Science Research, 37, no. 1, 28-35, 2015.

Fagerjord, A. and T. Storsul. "Questioning Convergence”. In Storsul, Tanja and Dagny Stuedah (eds), Ambivalence Towards Convergence, pp. 19-31. Göteborg: Nordicom, 2007.

Frenander, A. and J. Lindberg. Styra eller stödja? Svensk folkbibliotekspolitik under hundra år. Borås: Valfrid, 2012.

Gausdal, R. L. (red.). Kulturarven til alle - digitalisering i abm-sektoren. Oslo: ABM-utvikling, 2006. (ABM-skrift 32).

Given, L. M. and L. McTavish. "What's Old is New Again: The Reconvergence of Libraries, Archives, and Museums in the Digital Age". Library Quarterly, 80, no. 1, 7-32, 2010. 
Hacker, J. S. "Privatizing Risk Without Privatizing the Welfare State: The Hidden Politics of Social Policy Retrenchment in the United States". The American Political Science Review, 98 , no. 2, 243-260, 2004.

Hacker, J. S. and P. Pierson. “After the 'Master Theory': Downs, Schattschneider, and the Rebirth of Policy-Focused Analysis". Perspectives on Politics, 12, no. 3, 643-662, 2014.

Hess, T., C. Matt, A. Benlian, and F. Wiesböck. "Options for Formulating a Digital Transformation Strategy”. MIS Quarterly Executive, 15, no. 2, 123-139, 2016. https://doi.org/10.7892/ boris.105447.

Høring. “Evaluering av ABM-utvikling”, 2008. Accessed February 19, 2019. https://www. regjeringen.no/no/dokumenter/horing --evaluering-av-ABM--u/id520613/.

Innst. S. nr. 46. Innstilling frå familie-, kultur- og administrasjonskomiteen om Kjelder til kunnskap og oppleving - Om arkiv, bibliotek og museum i ei IKT-tid og om bygningsmessige rammevilkår på kulturområdet. 2000-2001. Accessed August 6, 2019. https://www. stortinget.no/no/Saker-og-publikasjoner/Publikasjoner/Innstillinger/Stortinget/20002001/inns-200001-046/? lvl=0.

Innst. $91 \mathrm{~S}$. Innstilling fra familie- og kulturkomiteen om omorganisering av ABM-utvikling. 2010-2011. Accessed August 6, 2019. https://www.stortinget.no/no/Saker-ogpublikasjoner/Publikasjoner/Innstillinger/Stortinget/2010-2011/inns-201011-091/? lvl=0.

Kann-Christensen, N. “At trække på samme hammel: formål og indsatsområder for to udviklingspuljer i Danmarks biblioteksvæsen”. Dansk Biblioteksforskning, 2, no. 2, 31-42, 2006.

Kann-Christensen, N. “Institutionel teori: Rationalitet, isomorfi og løse koblinger i biblioteksvæsenet”. In Andersen, J., H. Jochumsen, and C. Hvenegaard Rasmussen (eds), At forstå biblioteket: en introduktion til teoretiske perspektiver, pp. 139-157. Copenhagen, Denmark: Danmarks Biblioteksforening: Danmarks Biblioteksskole, 2008.

Letnes, 0. “Når vil regjeringen splitte ABM-utvikling?”. Bok og Bibliotek. https://www. bokogbibliotek.no/aktuelt/aktuelt/nvil-regjeringen-splitte-ABM--utvikling (accessed 06.08.2019), 2009.

Mahoney, J. and D. Rueschemeyer. Comparative Historical Analysis in the Social Sciences. Cambridge, UK; New York: Cambridge University Press, 2003.

Mahoney, J. and K. Thelen. Explaining Institutional Change: Ambiguity, Agency, and Power. Cambridge; New York: Cambridge University Press, 2010.

Marty, P. F. "An Introduction to Digital Convergence: Libraries, Archives, and Museums in the Information Age". Library Quarterly, 80, no. 1, 1-5, 2008.

Meld. St. 20. “Omorganisering av ABM-utvikling.” 2009-2010. Accessed February 5, 2019. https://www.regjeringen.no/no/dokumenter/Meld-St-20-20092010/id608202/.

Meld. St. 17. Mangfald og armlengds avstand. Mediepolitikk i ei ny tid. 20182019. Accessed August 9, 2019. https://www.regjeringen.no/contentassets/ 7dec1c0ee86149bda8f69b256beaa202/nn-no/pdfs/stm201820190017000dddpdfs.pdf.

Ministry of Culture. “Evaluering av Statens bibliotektilsyn og Norsk museumsutvikling”. Oslo: Rapport fra et evalueringsutvalg oppnevnt av Kulturdepartemente, 2001. Accessed August14, 2019. https://www.regjeringen.no/globalassets/upload/kilde/kd/rap/2001/ 0003/ddd/pdfv/135327-evaluering.pdf.

Ministry of Culture. "TverrsAMBand. Rapport fra Arbeidsgruppe for IT og andre sektorovergripende spørsmål innenfor bibliotek, arkiv og museum - mars 2001”. Oslo, 2001. Accessed August 6, 2019. https://urn.nb.no/URN:NBN:no-nb_digibok_2013082724012. 
Ministry of Culture. “Act Relating to Public Libraries (The Public Libraries Act)”. LOV-1985-12-20108. LOV-2013-06-21-95 on January 1, 2014. https://kunnskapsbase.bibliotekutvikling.no/ ressurser/lovverk/bibliotekloven-pa-engelsk/.

Museums and libraries formally transfer to Arts Council England - IFACCA, the International Federation of Arts Councils and Culture Agencies (November 25, 2011). https: //web.archive.org/web/20111125223941/http://ifacca.org/national_agency_news/2011/ 10/03/museums-and-libraries-formally-transfer-arts-counc/.

Museums, Libraries and Archives Council. In Wikipedia. https://en.wikipedia.org/w/index.php? title=Museums,_Libraries_and_Archives_Council\&oldid=918647080, 2019.

Nielsen, P. O. Kulturarvsstyrelsen. Den Store Danske. Gyldendal. Accessed August 2, 2019. http://denstoredanske.dk/index.php?sideld=112091.

Pierson, P. Politics in Time: History, Institutions, and Social Analysis. Princeton, NJ: Princeton University Press, 2004.

Pressman, J. L. and A. Wildavsky. Implementation: How Great Expectations in Washington Are Dashed in Oakland; Or, Why It's Amazing that Federal Programs Work at All, This Being a Saga of the Economic Development Administration as Told by Two Sympathetic Observers Who Seek to Build Morals on a Foundation. Berkeley, CA: University of California Press, 3rd edn, 1984.

Rasmussen, C. H. "Is Digitalization the Only Driver of Convergence? Theorizing Relations Between Libraries, Archives, and Museums". Journal of Documentation, 75, no. 6, 12581273, 2019. https://doi.org/10.1108/JD-02-2019-0025.

Rayward, W. B. "Electronic Information and the Functional Integration of Libraries, Museums, and Archives”. In Higgs, Edward (ed.), History and Electronic Artefacts, pp. 207-226. Clarendon Press, 1998.

Røgler, J. “Trenger bibliotekene ABM-utvikling?”. Bok og Bibliotek, no. 3, 2009. Accessed August 6, 2019 https://www.bokogbibliotek.no/arkiv2/tidligere-utgaver/nr-3-2009/trengerbibliotekene-ABM--utvikling29.

Røvik, K. A. “Trender og translasjoner: Ideer som former det 21. århundrets organisasjon”. Oslo, 2007.

Schattschneider, E. E. Politics, Pressures, and the Tariff. New York: Arno Press, 1935.

Schickler, E. Disjointed Pluralism. Institutional Innovation and the Development of the US Congress. Princeton: Princeton University Press, 2001.

Simon, H. A. Administrative Behavior: A Study of Decision-making Processes in Administrative Organization. New York: The Macmillan Company, 1947.

Skare, R., S. Stokstad, and A. Vårheim. "ABM-utvikling og avvikling: Institusjonell konvergens og divergens i kulturpolitikken”. Nordisk Kulturpolitisk Tidsskrift, 22, no. 2, 231-256, 2019. https://doi.org/10.18261/.

Statskonsult. "Evalueringen av organiseringen av ABM-utvikling". Statskonsult rapport 14, 2006. Accessed February 5, 2019. https://www.difi.no/sites/difino/files/2006-14.pdf.

St.meld. nr. 22. Kjelder til kunnskap og oppleving. Om arkiv, bibliotek og museum i ei IKT-tid og om bygningsmessige rammevilkår på kulturområdet. 1999-2000. Accessed February 2, 2019. https://www.regjeringen.no/no/dokumenter/stmeld-nr-22-1999-2000-/id192730/.

St.meld. nr. 27. Gjør din plikt - Krev din rett. Kvalitetsreform av høyere utdanning. 2000-2001. Accessed February 22, 2019. https://www.regjeringen.no/no/dokumenter/stmeld-nr-272000-2001-/id194247/. 
St.meld. nr. 49. Framtidas museum - Forvaltning, forskning, formidling, fornying. 2008-2009. Accessed February 19, 2019. https://www.regjeringen.no/no/dokumenter/stmeld-nr-492008-2009-/id573654/.

St.meld. nr. 23. Bibliotek. Kunnskapsallmenning, møtestad og kulturarena i ei digital tid. 2008-2009. Accessed February 19, 2019. https://www.regjeringen.no/no/dokumenter/ stmeld-nr-23-2008-2009-/id555516/.

St.meld. nr. 24. Nasjonal strategi for digital bevaring og formidling av kulturarv. 2008-2009. Accessed February 19, 2019. https://www.regjeringen.no/no/dokumenter/stmeld-nr-242008-2009-/id555254/.

St.prp. nr. 1. Kultur- og kirkedepartementet. 2006-2007. Accessed April 30, 2019. https://www. regjeringen.no/no/dokumenter/stprp-nr-1-2006-2007-/id213084/.

Streeck, W. and K. Thelen. "Introduction: Institutional change in Advanced Political Economies". In Streeck, Wolfgang and Kathleen Thelen (eds), Beyond Continuity: Institutional Change in Advanced Political Economies, pp. 1-39. New York: Oxford University Press, 2005.

Thelen, K. and J. Mahoney. "Comparative-historical Analysis in Contemporary Political Science". In Mahoney, James and Kathleen Thelen (eds), Advances in Comparative-Historical Analysis, pp. 3-36. Cambridge: Cambridge University Press, 2015.

Tilson, D., K. Lyytinen, and C. Sørensen. "Research Commentary - Digital Infrastructures: The Missing IS Research Agenda”. Information Systems Research, 21, no. 4, 748-759, 2010. https://doi.org/10.1287/isre.1100.0318.

Vårheim, A. "Paradigmeskiftet i distriktspolitikkens tekster på 1990-tallet: omgivelsesdrevet punktering eller institusjonelt valg?”. Norsk Statsvitenskapelig Tidsskrift, 17, no. 1, 76103, 2001.

Vårheim, A. "Evolving and Devolving Institutions: A Perspective on Norwegian Public Policy Towards the IT-industry 1945-2000”. In Skare, R., N. W. Lund, and A. Vårheim (eds), A Document (Re)turn: Contributions from a Research Field in Transition, pp. 287-298. Frankfurt/M.: Peter Lang, 2007.

Vårheim, A., R. Skare, and N. Lenstra. "Institutional Convergence in the LAM Sector: a Contribution Towards a Conceptual Framework”. Information Research, 24, no. 4, 2019. paper Colis 1918. http://InformationR.net/ir/24-4/colis/colis1918.html (Archived by the Internet Archive at https://web.archive.org/web/20191217173326/http://informationr.net/ir/244/colis/colis1918.html).

Warren, E. and G. Matthews. "Public Libraries, Museums and Physical Convergence: Context, Issues, Opportunities: A Literature Review Part 1". Journal of Librarianship and Information Science, 51, no. 4, 1120-1133, 2019. https://doi.org/10.1177/0961000618769720.

Warren, E. and G. Matthews. "Public Libraries, Museums and Physical Convergence: Context, Issues, Opportunities: A Literature Review Part 2". Journal of Librarianship and Information Science, 52, no. 1, 54-66, 2020. https://doi.org/10.1177/0961000618769721.

Warner, K. S. R. and M. Wäger. "Building Dynamic Capabilities for Digital Transformation: An Ongoing Process of Strategic Renewal”. Long Range Planning, 52, no. 3, 326-349, 2019. https://doi.org/10.1016/j.lrp.2018.12.001.

Yoo, Y., O. Henfridsson, and K. Lyytinen. "Research Commentary - The New Organizing Logic of Digital Innovation: An Agenda for Information Systems Research". Information Systems Research, 2, no. 4, 724-735, 2010. https://doi.org/10.1287/isre.1100.0322. 
Part II: Professions 



\title{
Ragnar Audunson, Hans-Christoph Hobohm, and Máté Tóth 8 LAM Professionals and the Public Sphere
}

\author{
How do Librarians, Archivists and Museum Professionals \\ Conceive the Respective Roles of their Institutions \\ in the Public Sphere?
}

\section{Introduction}

The role of archives, libraries and museums is changing. During the last decades all three professional fields are witnessing profound paradigm changes. At least on a programmatic and theoretical level, New Librarianship, New Museology and New Archival Thinking are being developed (see for example Buschman 2003; Lankes 2011; Vergo 1989; McCall and Gray 2013; Ross 2015; Simon 2010; Huvila 2008; MacNeil and Eastwood 2017; Theimer 2018). In the light of digitalization and other global developments all three institutions revisit their role as platforms, increased participatory interaction with their potential communities and their effective mission in the society. The transformations in the digital society seem to foster similar changes in the three fields which are not only digital and not only technology triggered (Rasmussen 2019). They emphasise new roles beyond the mere information collection and dissemination function for all three of these institutions (Smiraglia 2014).

In addition to the traditional roles of preserving and promoting the cultural heritage and being arenas for learning, there is an increased focus upon their role as meeting places and arenas underpinning the public sphere with the mission of sustaining democratic values in societies (see for the field of libraries Buschman 2018; Hobohm 2019; Rivana Eckerdal 2017; Widdersheim and Koizumi 2016). How do professionals in the respective LAM fields perceive the challenges related to this new focus on their role as meeting places and arenas for promoting the public sphere? We will investigate this question in this paper.

Two trends are of particular importance regarding the topic of our research. One trend can be termed the social turn, Söderholm and Nolin's (2015) assertion that we are in the middle of what they call the third community wave, the start of which dates from the turn of the century and continues to the present day. Klinenberg's perspective on libraries as important parts of the social infrastructure can

Note: An earlier version of the chapter was presented at the CoLIS10 conference in June 2019 in Ljubljana (see Audunson, Hobohm and Tóth 2019).

2 Open Access. (C) 2020 Ragnar Audunson et al. (c) BY-NC-ND This work is licensed under a Creative Commons Attribution-NonCommercial-No-Derivatives 4.0 License. 
be subsumed under this category (Klinenberg 2018). We are, for example, witnessing an upsurge in physical meetings, such as discussions and debates, reading circles and game nights. Community pubs and cafes frequently have such programs. The other trend is digitalization with the explosive growth in social media platforms, blogs, Internet-based news media and streaming of cultural content. How have the LAM professions adapted to these trends?

We will elicit the following research questions based on surveys undertaken in winter 2018/ spring 2019 among librarians, archivists and museum professionals in Norway, Sweden, Denmark, and Hungary:

RQ1: Do we find indications that the digital and social developments referred to above have led to the development of new services and new forms of working, particularly the development of services related to the social turn and services based on digital technologies? Are there differences between the three fields with respect to taking digital technologies into use and are there differences between the countries?

RQ2: How do librarians and archivists define their role as professionals underpinning the public sphere in a digital age? Do professionals from the three fields think in similar or different ways and are there differences between the six countries?

\section{Research Methods, Sampling and Organisation of the Survey}

Drawing the samples from the three professional groups proved to be a major challenge. None of the partner countries has a register of librarians, archivists or museum professionals from which we could draw samples. In addition, the definition of what librarians, archivists or museum professionals are is ambiguous. One of the authors of this paper undertook a survey among Norwegian librarians in 2000 (Audunson 2001) and, at that time, a librarian for all practical purposes could be defined as a person with a diploma in librarianship from a school in library and information science. This is not the case anymore. For the current study, the three target groups, or professions, are defined as follows: 1 . Librarians are defined as all employees in public libraries with a diploma in librarianship or any employee, no matter the educational background, with a professional responsibility for developing and mediating library services to the public; 2 . Archivists are defined as employees with a responsibility for archival appraisal, archival and historical outreach programmes within archives, collection management, curating exhibitions, mediation and archival pedagogics and/or research. Directors of archives are included; 3. Museum professionals are defined as employees with a respon- 
sibility for collection management, curating exhibitions, mediation and museum pedagogy and/or research. Leaders of museums are also included.

The data were collected as follows: in Denmark, Sweden, Norway and Hungary directors in local government libraries, archives and museums were approached and asked to distribute the electronic questionnaire to employees falling within the respective professions defined above. In Hungary, professional mailing lists were used to reach librarians and museologists. In Germany, the questionnaire was distributed via relevant mailing lists and newsletters for the three professions.

This resulted in the following datasets:

Tab. 8.1: Number of respondents - professional field and country

\begin{tabular}{lrlllr}
\hline & Den & Swe & Nor & Ger $^{*}$ & Hun \\
\hline Librarians & 817 & 782 & 332 & 1014 & 812 \\
Archivists & 69 & 173 & 135 & 302 & 44 \\
Museum professionals & 229 & 193 & 138 & 209 & 141 \\
\hline
\end{tabular}

* total $\mathrm{N}$ of respondents at least partially answering the survey

We see that in all the countries we were far more successful in reaching librarians compared to archivists and museum professionals. This is probably related to the fact that the departments and researchers in question are first and foremost library researchers working in library and information science departments and, therefore, more closely affiliated to and better known among library professionals than among archivists and museum professionals.

The social turn dimension of RQ 1 was measured via a set of questions asking the respondents if open meetings and seminars, user participation and creative and collective activities such as social reading and makerspace are parts of the service portfolio of the respondents' institutions. The questions were not identical - it was necessary to adapt them to librarianship and archival and museum practice. Adaptation to the technological turn was elicited by asking the respondents if they offered a set of technological services in addition to traditional ones, for example digital access to materials, web-based exhibitions and hybrid exhibitions in museums. These questions were not included in the archival survey.

Research question 2 was elicited via a short questionnaire asking the respondents to evaluate different statements regarding justifications for using scarce public resources to uphold library, archival or museum services.

As we were not able to obtain a randomised sample, we cannot generalise our results to the national populations of public librarians, archivists or museum 
professionals. Some of the differences reported may also have resulted from translating the original questionnaire formulated in English into the various languages of the partner countries.

\section{The Technological and Social Turn}

\section{Libraries}

The questionnaire respondents were asked if certain services are offered by their institutions and, if yes, if these services play an important or a marginal role within the service portfolio of the library or museum. The listed services were categorised as relating to the social or digital turn. In the tables below the first value indicates the percentage of the respondents who reported having that particular service in the library or museum, while in the brackets the value indicates the percentage of respondents who considered that it plays an important role within the service portfolio.

In the case of libraries activities realised in a physical space like outreach services, special events, community building or creative programs were considered part of the so-called social turn, while those services that are related to the new digital responsibilities of libraries were categorised into the digital turn. The providing of digital material (e.g. e-books, audio-visual material, other electronic content) and those kind of activities that are related to supporting users with special knowledge necessary for being successful in the digital era (e.g. computer classes, digital literacy initiatives) were placed in this category.

Tab. 8.2: "Services the library offers apart from providing access to traditional media." (Percentage of answers: yes; in brackets: yes, important role)

\begin{tabular}{llllll}
\hline & Den & Swe & Nor & Ger & Hun \\
& $\mathbf{N = 5 9 5}$ & $\mathbf{N = 7 8 2}$ & $\mathbf{N = 3 3 2}$ & $\mathbf{N = 6 3 7}$ & $\mathbf{N = 8 1 2}$ \\
\hline Activities outside the library & $94(44)$ & $81(11)$ & $62(14)$ & $69(12)$ & $66(28)$ \\
Social reading & $98(78)$ & $87(34)$ & $72(35)$ & $55(14)$ & $82(34)$ \\
Meetings and events in the library & $98(86)$ & $99(72)$ & $99(91)$ & $92(68)$ & $99(82)$ \\
$\begin{array}{l}\text { Conversational programming } \\
\text { (e.g. language cafés) }\end{array}$ & $52(16)$ & $82(50)$ & $80(65)$ & $47(14)$ & $21(4)$ \\
$\begin{array}{l}\text { Creative activities } \\
\text { Game nights }\end{array}$ & $91(45)$ & $84(25)$ & $78(49)$ & $56(17)$ & $77(41)$ \\
\hline & $41(5)$ & $31(2)$ & $52(21)$ & $32(6)$ & $50(10)$ \\
\hline
\end{tabular}


Meetings and events in the library is by far the most important service category belonging to the social turn. Almost all respondents in the respective countries report that their library is involved in such activities and that it is an important part of their service portfolio. Social reading is also an activity a clear majority report being involved in; however, Denmark and Germany deviate from the other countries. A much larger proportion in Denmark report that social reading plays a central role compared to the other countries, whereas a significantly lower proportion in Germany report being involved in social reading. We also see that most respondents report being involved in activities outside the library, with the exception of Denmark where these activities are clearly marginal.

Conversational programming (language cafés) is extremely important in Sweden and Norway and has very little importance in Hungary. These kinds of events are mainly organised for immigrants who would like to develop their language skills to more easily integrate into the society of the receiving country (Johnston 2018). As Hungary has a very low ratio of people with a non-European background these programs also have less importance in the country's libraries.

Tab. 8.3: "Services the library offers apart from providing access to traditional media." (Percentage of answers: yes; in brackets: yes, important role)

\begin{tabular}{lllllll}
\hline & Den & Swe & Nor & Ger & Hun \\
& $\mathbf{N = 5 9 6}$ & $\mathbf{N = 7 9 2}$ & $\mathbf{N = 3 3 2}$ & $\mathbf{N = 6 3 7}$ & $\mathbf{N = 8 1 2}$ \\
\hline Lending of ebooks & $99(69)$ & $99(50)$ & 96 & $(54)$ & $89(65)$ & $15(2)$ \\
Digital meeting places & $44(5)$ & $33(4)$ & 26 & $(9)$ & $33(8)$ & $35(8)$ \\
Digital literacy initiatives & $83(31)$ & $79(30)$ & $75,8(37)$ & $55(16)$ & $71(39)$ \\
$\begin{array}{l}\text { Citizen services related to } \\
\text { e-government, internet banking }\end{array}$ & $92(48)$ & $52(17)$ & 62 & $(24)$ & $13(2)$ & $75(42)$ \\
etc. & & & & & & \\
$\begin{array}{l}\text { Computer classes } \\
\text { Helping individuals with }\end{array}$ & $82(38)$ & $63(17)$ & 66 & $(30)$ & $24(5)$ & $78(38)$ \\
electronic devices & $91(33)$ & $89(35)$ & 77 & $(35)$ & $88(37)$ & $94(60)$ \\
\hline
\end{tabular}

The results indicate, as shown in Table 8.3, two major differences between the participating countries. The first is the low proportion of Hungarian libraries that report lending e-books. In the four other participating countries a clear majority report that they lend e-books and that this service plays a central role. The reason is probably that Hungary has not launched a national e-book lending system, whereas the other countries have such systems in place.

The other main difference is the extremely low value for (digital) "citizens services", i.e. helping users with e-government and digital banking, but also for 
"computer classes" in German libraries. This may indicate that there is no demand for these services, that competing services are functioning well or that there is still some catching up to be done in terms of basic service orientation. In view of the backlog in digitality in Germany, the reason is certainly a mixture of these aspects. A clear majority in all the other countries report having such services and significant number report that they play a central role.

As for the technological turn in libraries, the lending of e-books dominates. With the exception of Hungary, this is the only service that a clear majority of the respondents report their libraries are involved in and that it constitutes a central service.

\section{Archives}

Tab. 8.4: The social turn - archivists: "In what kind of external arrangements/events is the archive you are working in involved?" (Percentage of answers)

\begin{tabular}{llllll}
\hline & $\begin{array}{l}\text { Den } \\
\mathbf{N = 6 9}\end{array}$ & $\begin{array}{l}\text { Swe } \\
\mathbf{N = 1 7 3}\end{array}$ & $\begin{array}{l}\text { Nor } \\
\mathbf{N = 1 3 5}\end{array}$ & $\begin{array}{l}\text { Ger } \\
\mathbf{N = 2 4 1}\end{array}$ & $\begin{array}{l}\text { Hun } \\
\mathbf{N = 4 4}\end{array}$ \\
\hline $\begin{array}{l}\text { Exhibitions in the premises of the } \\
\text { archive }\end{array}$ & 73 & 71 & 67 & 43 & 77 \\
$\begin{array}{l}\text { Open lectures, seminars, debates } \\
\text { Classes (genealogical research) }\end{array}$ & 58 & 65 & 64 & 40 & 73 \\
$\begin{array}{ll}\text { Classes (other topics) } \\
\text { Inviting user }\end{array}$ & 54 & 41 & 59 & 13 & 48 \\
contributions/participation & 68 & NA & 49 & 24 & 64 \\
\hline
\end{tabular}

Respondents were asked about what kind of external arrangements or events their archive is involved in and to select from the above options. The exhibitions are the most important services in all countries, even more important than open lectures and meetings. This suggests that archives generate their own interpretations rather than allowing users to generate new knowledge through more interactive means. The relatively low figures regarding user contribution further suggests that archives rely much less on user contribution than their museologist and librarian counterparts.

The low percentages of all data in the German survey indicate the strong legal establishment of archival practice in this country, which has a strong focus on the long-term preservation of documents, including extended protection periods regarding the public accessibility of the material. 


\section{Museums}

Museum professionals were given the same question in which new museum services were listed. Different ways of presenting artefacts ranging from the provision of digital access to the curation of digital or hybrid exhibitions represented the digital turn.

Tab. 8.5: The digital turn - museums: "Does your museum offer the services and activities listed below?" (Percentage of answers: yes; in brackets: yes, important role) ${ }^{1}$

\begin{tabular}{llllll}
\hline & Den & Swe & Nor & Ger & Hun \\
& $\mathbf{N = 2 2 9}$ & $\mathbf{N = 1 9 3}$ & $\mathbf{N = 1 3 8}$ & $\mathbf{N = 8 6}$ & $\mathbf{N = 1 4 1}$ \\
\hline Digital access artefacts & 43 & $90(68)$ & 83 & $31(27)$ & $87(37)$ \\
Digital exhibitions & NA & $70(21)$ & 28 & $18(7)$ & $52(11)$ \\
Hybrid exhibitions & 40 & NA & 50 & $39(13)$ & $65(18)$ \\
\hline
\end{tabular}

Ensuring digital access to content means a lower level of process and does not require curatorship. It can be accomplished with use of aggregation services or by uploading digitised items to the institutions' website. More respondents offer digital artefacts on their websites than those who create digital exhibitions. Hybrid exhibitions are an emerging trend that incorporate digital elements so that visitors can interact with digital content relating to the displayed physical items. Hybrid exhibitions are more widespread throughout the participating countries than exclusively digital exhibitions.

Germany and Denmark had the lowest number of respondents who reported that digital artefacts or digital or hybrid exhibitions are accessible or play an important role within the institutions' service portfolios. The reason for this difference may be the lack of representation of our sample. The bigger national or regional institutions are more likely to work with digital content than the ones having only local responsibility.

As shown in Table 8.2, open meetings and organised programs have become very significant for libraries in the last few decades and in Table 8.6 we see that this is also the case for museums. Both librarians and museologists attribute higher importance to these kinds of services. Concerning user participation, such as inviting the public to take part or plan exhibitions, helping groups present their

1 In the Danish and Norwegian questionnaires to museum professionals it was only asked if the service is offered or not - the respondents were not invited to distinguish between a marginal or important role. 
Tab. 8.6: The social turn - museums: "Does your museum offer the services and activities listed below?" (Percentage of answers: yes; in brackets: yes, important role)

\begin{tabular}{|c|c|c|c|c|c|}
\hline & $\begin{array}{l}\text { Den } \\
\mathrm{N}=\mathbf{2 2 9}\end{array}$ & $\begin{array}{l}\text { Swe } \\
N=193\end{array}$ & $\begin{array}{l}\text { Nor } \\
N=138\end{array}$ & $\begin{array}{l}\text { Ger } \\
N=86\end{array}$ & $\begin{array}{l}\text { Hun } \\
N=141\end{array}$ \\
\hline Open meetings/lectures & 65 & $92(62)$ & 88 & $22(75)$ & $97(72)$ \\
\hline $\begin{array}{l}\text { Inviting the public take part or } \\
\text { plan exhibitions ("co-creation") }\end{array}$ & 18 & $74(24)$ & 36 & $45(16)$ & $50(10)$ \\
\hline $\begin{array}{l}\text { Help groups present their own } \\
\text { history }\end{array}$ & 24 & $66(27)$ & 43 & $45(16)$ & $79(33)$ \\
\hline Makerspace, creative activities & 51 & $72(37)$ & 54 & $35(19)$ & $62(39)$ \\
\hline
\end{tabular}

own history, or offering makerspaces, there are significant differences between the countries' responses and they are generally attributed less importance than open meetings and organised programs.

\section{Perceptions of LAM-institutions as Public spaces: What Legitimises Libraries, Archives and Museums?}

We presented the questionnaire respondents with a battery of questions that aimed to measure their perception of the fundamental social mission of their institutions. We were particularly interested in eliciting the priority given to the traditional role of the institutions, which includes the collection, preservation and mediation of cultural heritage, compared to the new role(s), which includes the provision of meeting places, promotion of public debate and facilitation of democracy and democratic processes. The categorisation into "traditional" and "new roles" was done only after the survey for analytical purposes and was not present in the questionnaires.

The statements aiming at catching the traditional roles of libraries were:

- The library provides people with information they need in their everyday lives.

- The library promotes learning, supporting informal as well as formal learning.

- The library promotes contemporary literary and cultural expressions of high quality.

- The library promotes the literary and cultural heritage.

- The library provides their users with experiences and meaningful leisure time, e.g. by providing entertainment and popular reading material. 
The parallel questions for archives were:

- Archives support research.

- Archives are arenas for learning.

- Archives promote the cultural heritage.

For museums the statements aiming at covering the traditional roles were:

- The museum collects, documents and preserves the cultural heritage/natural history.

- The museum mediates within its subject area, e.g. cultural heritage or natural history, or both.

- The museum is an arena for learning.

- The museum promotes the qualitatively best in the cultural heritage, e.g. the cultural canon.

The following statements elicited the new socio-political and meeting place-roles: For libraries:

- The library promotes democracy by being an arena for public discourse.

- The library is an important social meeting place in the community.

- The library promotes creativity and innovation by giving their users options for performing different activities independently or jointly, e.g. knitting clubs, reading circles, hip-hop laboratories, poetry labs, or makerspaces.

- The library promotes integration and social cohesion by being a meeting place across ethnic and cultural belongings.

For archives:

- Archives promote transparency, making it possible for media and citizens to obtain information about the activities of public bodies and institutions.

- Archives provide citizens with information they need for leisure time activities.

- Archives provide citizens with information they need to exercise their rights as citizens.

- Archives provide citizens with information they need to participate actively in democracy and society.

- Archives are arenas for public debate.

- Archives are arenas where minorities and other marginalised groups can present their histories and cultural expressions, as well as build their identities.

- Archives promote integration by including the history of minorities and other marginalised groups in the common cultural heritage.

- Archives promote equality by making archival material digitally accessible.

- Archives facilitate public debate by means of digital discussion forums. 
For museums:

- The museum's exhibitions and mediation promote democracy by giving the users access to knowledge and information they need to be active citizens.

- The museum promotes democracy by being an arena for public discourse.

- The museum promotes creativity and innovation by giving its users the possibility to engage in different activities individually or together with others, e.g. makerspaces.

- The museum promotes the cultural heritage of everyday life/ordinary people.

- The museum promotes integration and social cohesion by being a meeting place across ethnic and cultural belongings.

We invited our respondents to evaluate each of these statements by using a scale from 0 to 10, where 0 indicates very low importance and 10 indicates the reason in question is of vital importance in legitimising the institution. In Tables 8.7, 8.8 and 8.9 below, the mean values for all statements are presented.

Tab. 8.7: Traditional and new reasons for upholding a library service: "How do you as a library professional evaluate these different dimensions of the role the library has in your community." (Mean scores on a scale from 0 to 10)

\begin{tabular}{|c|c|c|c|c|c|}
\hline & $\begin{array}{l}\text { Den } \\
N=564\end{array}$ & $\begin{array}{l}\text { Swe } \\
N=773\end{array}$ & $\begin{array}{l}\text { Nor } \\
N=330\end{array}$ & $\begin{array}{l}\text { Ger } \\
N=595\end{array}$ & $\begin{array}{l}\text { Hun } \\
\mathrm{N}=812\end{array}$ \\
\hline Traditional: Everyday life information & 8,9 & 8,2 & 7,3 & 8,5 & 8,6 \\
\hline Traditional: Provide an arena for learning & 8,6 & 8,7 & 8,5 & 8,9 & 8,9 \\
\hline $\begin{array}{l}\text { Traditional: Promoting contemporary } \\
\text { quality literature }\end{array}$ & 8,4 & 9,2 & 8,4 & 6,3 & 8,3 \\
\hline $\begin{array}{l}\text { Traditional: Promoting the cultural } \\
\text { heritage }\end{array}$ & 8,8 & 7,9 & 8,4 & 7,0 & 9,1 \\
\hline $\begin{array}{l}\text { New: Promoting democracy as an arena } \\
\text { for public debate }\end{array}$ & 7,3 & 7,3 & 7,3 & 8,3 & 6,0 \\
\hline New: Community meeting place & 8,8 & 9,0 & 8,3 & 9,0 & 8,6 \\
\hline $\begin{array}{l}\text { New: Makerspace, creativity and } \\
\text { innovation }\end{array}$ & 7,3 & 6,9 & 6,3 & 6,2 & 8,3 \\
\hline New: Integration & 7,9 & 8,4 & 8,1 & 8,4 & 8,0 \\
\hline Total "traditional roles for libraries" & 8,7 & 8,5 & 8,1 & 7,7 & 8,7 \\
\hline Total "new roles for libraries" & 7,8 & 7,8 & 7,5 & 8,0 & 7,7 \\
\hline
\end{tabular}

Overall, it can be observed that traditional views regarding the tasks of libraries continue to prevail, while in some cases the difference is considerable. Interestingly, Germany is the only country where the new roles tend to be given more importance than the traditional roles. There is a high consensus (expressed by a low 
standard deviation of results) regarding the "learning" and "meeting place" roles, which could converge as a "place of learning”. There is relatively little acceptance, as well as little disagreement, regarding high culture, but also regarding the topic "Makerspace and Creativity", which has been intensively discussed in the German library community and for which a strong weakening of the hype-status can already be observed. The topic of integration, on the other hand, is "still" very relevant for libraries in Germany, as is their (increasing) role in "democracy and public opinion formation". In this respect, the differentiated picture provided by the data from Germany is perhaps politically significant in contrast to the other four countries. Is there a greater political awareness among German librarians? Recently, the fostering of "third places" and the taking on of community orientated approaches have been strongly promoted by the official German cultural policy and corresponding campaigns and support programmes.

Tab. 8.8: Traditional and new reasons for upholding an archival service: "How do you as a professional evaluate these different dimensions of the role of the archive where you work?" (Mean scores on a scale from 0 to 10)

\begin{tabular}{|c|c|c|c|c|c|}
\hline & $\begin{array}{l}\text { Den } \\
N=61\end{array}$ & $\begin{array}{l}\text { Swe } \\
N=169\end{array}$ & $\begin{array}{l}\text { Nor } \\
N=135\end{array}$ & $\begin{array}{l}\text { Ger } \\
N=192\end{array}$ & $\begin{array}{l}\text { Hun } \\
\mathrm{N}=44\end{array}$ \\
\hline $\begin{array}{l}\text { Traditional: Support public } \\
\text { administration }\end{array}$ & 8,9 & 7,1 & 5,1 & 6,4 & 7,27 \\
\hline Traditional: Support research & 8,8 & 9,3 & 4,3 & 9,1 & 8,2 \\
\hline Traditional: Provide an arena for learning & 7,7 & 8,0 & 7,0 & 7,8 & 6,7 \\
\hline $\begin{array}{l}\text { Traditional: Preserve and promote } \\
\text { cultural heritage }\end{array}$ & 9,1 & 9,2 & 5,8 & 9,0 & 8,1 \\
\hline $\begin{array}{l}\text { New: Ensure public administration } \\
\text { transparency }\end{array}$ & 8,6 & 8,0 & 3,8 & 8,2 & 6,5 \\
\hline $\begin{array}{l}\text { New: Support leisure time and hobby } \\
\text { activities }\end{array}$ & 5,1 & 5,4 & 7,5 & 4,4 & 4,1 \\
\hline $\begin{array}{l}\text { New: Access to information on citizens' } \\
\text { rights }\end{array}$ & 7,7 & 7,9 & 3,4 & 7,8 & 6,4 \\
\hline $\begin{array}{l}\text { New: Information supporting citizen } \\
\text { participation }\end{array}$ & 7,8 & 7,3 & 6,2 & 6,7 & 6,9 \\
\hline New: Serving as arenas for public debate & 5,9 & 5,3 & 8,0 & 6,6 & 4,8 \\
\hline $\begin{array}{l}\text { New: Serving as arenas where minorities } \\
\text { can present themselves }\end{array}$ & 5,8 & 6,5 & 7,8 & 5,6 & 5,5 \\
\hline $\begin{array}{l}\text { New: Promote equality by making } \\
\text { archival material digitally accessible }\end{array}$ & 7,8 & 6,5 & 7,5 & 6,0 & 7,3 \\
\hline $\begin{array}{l}\text { New: Support public opinion building } \\
\text { through digital discussion forums }\end{array}$ & 5,4 & 3,4 & 7,7 & 3,7 & 4,4 \\
\hline Total "traditional roles for archives" & 8,6 & 8,4 & 5,6 & 8,0 & 7,6 \\
\hline Total "new roles for archives" & 6,7 & 6,3 & 6,5 & 6,1 & 5,7 \\
\hline
\end{tabular}


The figures indicate again that the traditional roles are generally perceived as more important than the new roles when it comes to legitimising archives; however, the Norwegian responses deviate from the other countries in this respect. The Norwegian respondents generally regard the new roles to be more important than the traditional ones. We see that the Norwegian respondents also deviate significantly by perceiving some reasons, both traditional and new, that are seen by respondents from the other four countries as very unimportant; for example, providing research data and access to information needed for citizens to exercise their rights as citizens, as well as ensuring public administration transparency.

The results once again demonstrate the special role of the German archives, which by law are primarily oriented towards long-term historical research and the preservation of archival material. Virtually all new roles for archives are assessed very differently by the German archivists surveyed (high standard deviation), but tend to be rejected. Digital aspects in particular are not well received by German archivists. This roughly corresponds to the relatively low digital affinity of German museums (Table 8.5).

Tab. 8.9: Traditional and new reasons for upholding a museum service: "How do you as a museum professional evaluate these different dimensions of the role of the museum where you work concerning the following statements?" (11-point scale: Mean scores on a scale from 0 to 10$)$

\begin{tabular}{|c|c|c|c|c|c|}
\hline & $\begin{array}{l}\text { Den } \\
N=151\end{array}$ & $\begin{array}{l}\text { Swe } \\
N=187\end{array}$ & $\begin{array}{l}\text { Nor } \\
N=135\end{array}$ & $\begin{array}{l}\text { Ger } \\
\mathrm{N}=86\end{array}$ & $\begin{array}{l}\text { Hun } \\
\mathrm{N}=141\end{array}$ \\
\hline $\begin{array}{l}\text { Traditional: Collect/document the } \\
\text { cultural heritage }\end{array}$ & 9,4 & 9,0 & 6,4 & 9,4 & 8,6 \\
\hline Traditional: Mediate the cultural heritage & 9,4 & 9,2 & 9,4 & 9,5 & 8,5 \\
\hline $\begin{array}{l}\text { Traditional: Facilitate cultural heritage } \\
\text { research }\end{array}$ & 8,8 & 6,4 & 8,4 & 8,5 & 8,3 \\
\hline Traditional: Provide an arena for learning & 8,7 & 9,0 & 9,0 & 9,1 & 8,2 \\
\hline $\begin{array}{l}\text { Traditional: Preserve the cultural } \\
\text { heritage, cultural canon }\end{array}$ & 5,9 & 6,2 & 5,6 & 6,7 & 7,5 \\
\hline $\begin{array}{l}\text { New: Provide access to citizenship } \\
\text { information }\end{array}$ & 8,0 & 8,1 & 8,0 & 8,3 & 7,7 \\
\hline New: Serve as an arena for public debate & 6,9 & 6,8 & 7,8 & 7,7 & 4,6 \\
\hline $\begin{array}{l}\text { New: Offer makerspaces and } \\
\text { opportunities for creativity and } \\
\text { innovation }\end{array}$ & 6,2 & 6,3 & 6,6 & 6,9 & 6,7 \\
\hline New: Facilitate participatory heritage & 7,0 & 7,1 & 7,2 & 7,0 & 7,9 \\
\hline New: Foster integration & 6,2 & 6,8 & 8,6 & 7,5 & 6,9 \\
\hline Total "traditional roles for museums" & 8,4 & 8,0 & 7,7 & 8,6 & 8,2 \\
\hline Total "new roles for museums" & 6,9 & 7,0 & 7,6 & 7,5 & 6,8 \\
\hline
\end{tabular}


We see that the average of means for the traditional roles are higher than the average of means for the new roles in all the countries except Norway, where there is no difference. The German museum professionals who responded to the questionnaire tend to be the most conservative whereas the Norwegian respondents give less priority to collecting cultural heritage. The results for Germany may have been influenced to some degree by the data collection method, which may have caused small, community-oriented museums (e.g. museums that incorporate participatory heritage practices to a greater degree) to be underrepresented in the sample.

Summarising and comparing the results for all three institutions, we find that:

- Librarians in the five countries perceive the library's role as a learning arena and the library's role as a meeting place as the two most important reasons legitimising libraries. The mean for all the countries is 8.7. The library as an arena for public debate and the creative/makerspace role are the least important, with an average mean score of 7.2 and 7.0 respectively.

- Archivists also give a low value to public debate as a reason for upholding archives. The average mean score is 6.1 for physical meetings and 4.9 for promoting public debate on digital platforms. Promoting the cultural heritage and supporting research are the two most important legitimations. We must add, however, that the results for the archival field are affected by the extremely low scores for some of the items from the Norwegian respondents, for example providing research data, which has an average score of 8.9, up from 7.9, if we take the Norwegian respondents out.

- Museum professionals are similar to librarians by giving a very high value to the importance of the museum as an arena for learning (average mean 8.8) and ranking public debate and makerspace at the bottom with average scores of 6.8 and 6.5 .

\section{Contributions to Upholding a Sustainable Public Sphere}

We see from Table 8.10 that librarians give top priority to providing people with knowledge that they need to make informed choices, closely followed by helping people keep generally updated and helping them know their rights and obligations as citizens. The average of the means is 8.8 for providing knowledge for informed choices, 8.4 for helping people keep generally updated and 8.3 for knowledge on rights and obligations. There are no big differences between the countries. Being an arena for physical meetings and discussions scores considerably lower, in particular providing platforms for digital discussions. Whereas the average of means for Denmark, Sweden, Germany and Hungary is 7.4, the Norwegian librar- 
Tab. 8.10: "How can libraries contribute in building a sustainable public sphere?" (Mean scores on a scale from 0 to 10 )

\begin{tabular}{|c|c|c|c|c|c|}
\hline & $\begin{array}{l}\text { Den } \\
N=564\end{array}$ & $\begin{array}{l}\text { Swe } \\
N=767\end{array}$ & $\begin{array}{l}\text { Nor } \\
N=330\end{array}$ & $\begin{array}{l}\text { Ger } \\
N=594\end{array}$ & $\begin{array}{l}\text { Hun } \\
\mathrm{N}=812\end{array}$ \\
\hline $\begin{array}{l}\text { Provide knowledge people need to make } \\
\text { informed choices }\end{array}$ & 9.0 & 8.8 & 8.8 & 9.0 & 8.5 \\
\hline $\begin{array}{l}\text { Provide knowledge people need to know } \\
\text { about rights and obligations as citizens }\end{array}$ & 8.5 & 8.5 & 8.3 & 8.4 & 7.8 \\
\hline $\begin{array}{l}\text { Help people keep generally updated and } \\
\text { politically informed }\end{array}$ & 8.6 & 8.6 & 8.6 & 7.9 & 8.4 \\
\hline $\begin{array}{l}\text { Serve as arenas for physical meetings } \\
\text { and discussions }\end{array}$ & 7.6 & 7.8 & 8.4 & 7.3 & 6.7 \\
\hline Provide digital platforms for discussions & 6.0 & 5.9 & 5.8 & 5.6 & 6.7 \\
\hline $\begin{array}{l}\text { Develop civic skills related to traditional } \\
\text { media }\end{array}$ & 7.4 & 7.4 & 7.8 & 7.8 & 7.1 \\
\hline $\begin{array}{l}\text { Develop civic skills related to digital } \\
\text { media }\end{array}$ & 7.3 & 7.6 & 7.8 & 8.0 & 7.3 \\
\hline Develop community partnerships & 8.3 & 7.7 & $\mathrm{~N} / \mathrm{A}$ & 8.3 & 7.9 \\
\hline
\end{tabular}

ians deviate from their colleagues in the other four countries with a score of 8.4 for arranging public meetings.

The museum professionals perceive creating engagement and emotional involvement regarding the issues and exhibition deals as their most important contribution for keeping up a public sphere, which is slightly more important than providing knowledge to support informed choices. The average of means is 8.5 for creating emotional engagement and 8.2 for providing knowledge. The Norwegian museum professionals have particularly high scores on both these dimensions compared to their colleagues in the other four countries. The Norwegian respondents also have a much higher score than respondents from the other countries when it comes to the importance of having physical meetings and discussions in the museum and providing digital platforms for discussion. Norwegian museum professionals give arranging physical meetings and discussions the same score as Norwegian librarians, a result that is somewhat surprising given the high focus on meetings in Norwegian libraries as a result of the change in library legislation. Norway's museum professionals also give the provision of digital platforms for debate and discussion a significantly higher score than Norwegian librarians. 
Tab. 8.11: "How can museums contribute in building a sustainable public sphere?" (Mean scores on a scale from 0 to 10 )

\begin{tabular}{llllll}
\hline & $\begin{array}{l}\text { Den } \\
\mathbf{N = 1 4 1}\end{array}$ & $\begin{array}{l}\text { Swe } \\
\mathbf{N = 1 8 5}\end{array}$ & $\begin{array}{l}\text { Nor } \\
\mathbf{N = 1 3 8}\end{array}$ & $\begin{array}{l}\text { Ger } \\
\mathbf{N = 8 4}\end{array}$ & $\begin{array}{l}\text { Hun } \\
\mathbf{N = 1 4 1}\end{array}$ \\
\hline $\begin{array}{l}\text { Provide access to knowledge people } \\
\text { need to make informed choices via } \\
\text { exhibitions }\end{array}$ & 8.2 & 7.8 & 9.2 & 8.2 & 7.7 \\
$\begin{array}{l}\text { Create engagement and emotional } \\
\text { involvement }\end{array}$ & 8.2 & 8.1 & 9.7 & 8.5 & 7.8 \\
$\begin{array}{l}\text { Provide arenas for physical meetings and } \\
\text { discussions }\end{array}$ & 7.3 & 7.9 & 9.0 & 8.0 & 6.0 \\
\begin{tabular}{l} 
Provide digital platforms for discussions \\
\hline
\end{tabular} & 5.5 & 6.5 & 7.8 & 5.9 & 5.7 \\
\hline
\end{tabular}

\section{Basic Professional Attitude in Archives and Museums: Neutrality or Professional Activism?}

To tap the professional attitude of archivists, we formulated a question focusing on the archivist's role as a neutral guardian of the material submitted to the archive versus his or her independent responsibility for taking an active stand as to how society best can be documented or even actively strive to secure and make visible marginalised histories.

Tab. 8.12: "Which basic professional attitude do you think is the best in order to make the archive a public arena/ arena for the public sphere?" (Percentage of answer chosen)

\begin{tabular}{llllll}
\hline & $\begin{array}{l}\text { Den } \\
\mathbf{N}=\mathbf{6 1}\end{array}$ & $\begin{array}{l}\text { Swe } \\
\mathbf{N}=\mathbf{1 7 3}\end{array}$ & $\begin{array}{l}\text { Nor } \\
\mathbf{N}=\mathbf{1 3 5}\end{array}$ & $\begin{array}{l}\text { Ger } \\
\mathbf{N}=\mathbf{1 9 2}\end{array}$ & $\begin{array}{l}\text { Hun } \\
\mathbf{N}=\mathbf{4 4}\end{array}$ \\
\hline $\begin{array}{l}\text { A neutral guardian of the material } \\
\text { submitted to the archive }\end{array}$ & 10 & 34 & 13 & 19 & 25 \\
$\begin{array}{l}\text { Take an active stand as to how society } \\
\text { best can be documented }\end{array}$ & 42 & 28 & 47 & 38 & 16 \\
$\begin{array}{l}\text { Actively strive to secure and make visible } \\
\text { easily marginalized histories }\end{array}$ & 48 & 38 & 40 & 43 & 59 \\
\hline
\end{tabular}

In all the five countries, those who define their professional role as being neutral guardians of the material submitted to the archives are in a clear minority and, in all the countries except Norway, the largest group consists of those maintaining that the archivists should actively strive to document easily marginalized histories. Given the impact of identity politics in Sweden, it is a bit surprising that we 
find the largest group of neutral guardians, as well as the smallest group of minority activists, among Swedish archivists.

In Germany there is a long running academic debate about the role of archives, which is triggered by the first two possible answers. It is all the more surprising that a large number of German archivists participating in the survey choose option three and prefer an active role for minorities.

The museum professionals were also presented with three sets of dichotomous statements. There was one question regarding building national (or regional or local) identity versus promoting critical reflection on history and identity; one counterposing neutrality versus creating involvement, if necessary by provoking and taking a stand; and one counterposing the professional responsibility for presenting the history and heritage of minorities versus offering minorities a platform and professional help for telling their stories themselves.

Tab. 8.13: The museum professional's attitude regarding basic professional role 1: "Which of the two statements below do you agree with most (without necessarily agreeing completely with any of them)." (Percentage preference chosen)

\begin{tabular}{llllll}
\hline & $\begin{array}{l}\text { Den } \\
\mathbf{N}=\mathbf{1 3 8}\end{array}$ & $\begin{array}{l}\text { Swe } \\
\mathbf{N}=\mathbf{1 8 5}\end{array}$ & $\begin{array}{l}\text { Nor } \\
\mathbf{N}=\mathbf{1 3 8}\end{array}$ & $\begin{array}{l}\mathbf{G e r} \\
\mathbf{N}=\mathbf{8 4}\end{array}$ & $\begin{array}{l}\text { Hun } \\
\mathbf{N}=\mathbf{1 4 1}\end{array}$ \\
\hline $\begin{array}{l}\text { Contribute to a common national, } \\
\text { regional or local identity }\end{array}$ & 54 & 16 & 33 & 21 & 44 \\
$\begin{array}{l}\text { Promote critical reflection on national, } \\
\text { regional or local identity }\end{array}$ & 47 & 84 & 67 & 79 & 56 \\
\hline
\end{tabular}

Tab. 8.14: The museum professional's attitude regarding basic professional role 2: "Which of the two statements below do you agree with most (without necessarily agreeing completely with any of them)." (Percentage preference chosen)

\begin{tabular}{llllll}
\hline & Den & Swe & Nor & Ger & Hun \\
& $\mathbf{N = 1 3 8}$ & $\mathbf{N = 1 8 5}$ & $\mathbf{N = 1 3 8}$ & $\mathbf{N = 8 4}$ & $\mathbf{N = 1 4 1}$ \\
\hline $\begin{array}{l}\text { Strive for neutrality } \\
\text { Promote engagement }- \text { if necessary by }\end{array}$ & 47 & 61 & 30 & 46 & 89,4 \\
taking a stand and provoking & & 39 & 70 & 54 & 10,6 \\
\hline
\end{tabular}

We find that an overwhelming majority of museologists are of the opinion that museum professionals should promote critical reflection on national identity. A majority, but far from an overwhelming one, seem to be of the opinion that museum professionals should not necessarily strive for neutrality, but for engage- 
Tab. 8.15: The museum professional's attitude regarding basic professional role 3: "Which of the two statements below do you agree with most (without necessarily agreeing completely with any of them)." (Percentage preference chosen)

\begin{tabular}{llllll}
\hline & $\begin{array}{l}\text { Den } \\
\mathbf{N}=\mathbf{1 3 8}\end{array}$ & $\begin{array}{l}\text { Swe } \\
\mathbf{N}=\mathbf{1 8 5}\end{array}$ & $\begin{array}{l}\text { Nor } \\
\mathbf{N}=\mathbf{1 3 8}\end{array}$ & $\begin{array}{l}\text { Ger } \\
\mathbf{N}=\mathbf{8 4}\end{array}$ & $\begin{array}{l}\text { Hun } \\
\mathbf{N}=141\end{array}$ \\
\hline $\begin{array}{l}\text { A professional responsibility to tell the } \\
\text { stories of minorities, marginalized } \\
\text { groups }\end{array}$ & 69 & 57 & 56 & 41 & 50,4 \\
$\begin{array}{l}\text { Offer a platform for minorities so that } \\
\text { they themselves can present their } \\
\text { stories. }\end{array}$ & NA & 43 & 44 & 59 & 49,6 \\
\hline
\end{tabular}

ment, if necessary by provoking and taking a stand. Here the Swedish and particularly the Hungarian respondents deviate by believing much more strongly in the ideal of neutrality than their colleagues in the other countries. When it comes to presenting the history of minorities, respondents in all the countries, with the exception of Germany, believe that this is a professional responsibility of museologists and that the task should not be left to the minorities themselves, but by offering them a platform, help and professional guidance.

\section{Conclusion}

\section{Which Conclusions can we Draw Regarding our Two Research Questions?}

$\mathrm{RQ} 1$ asked if the social and digital turns have led to new forms of working and new services in archives, libraries and museums. All the institutions seem to have adapted to the social turn. A clear majority of the respondents from all three fields report they are engaged in arranging meetings, seminars and public debates. In the cases where we asked if such events constitute a marginal or central part of their service portfolio the tendency in all three fields is that these services are central. For libraries, the social turn is evident in all countries. As for museums and archives there are some significant differences. The proportion of museum professionals from Germany who report being involved in arranging public meetings is low compared to the other countries. The same is the case for Danish museum professionals. German archivists also have considerably lower scores on the questions measuring the social turn in archives compared to their colleagues in the other countries.

When it comes to the technological turn in libraries, the lending of e-books is the only service, with Hungary as an exception, which almost all respondents re- 
port that their libraries are involved in and which has a central role in the service portfolio. Helping people with digital devices apparently has developed into an important service in all the countries. A majority report being involved in it and a substantial proportion in all the countries report that such services play a central role. A majority in all the countries report being involved in digital literacy initiatives and, with Germany as an exception, substantial proportions report that such initiatives play a central role in Denmark,

In Sweden, Norway and Hungary, helping people with e-government, electronic banking and offering computer classes are services in which a majority report being involved. Providing platforms for digital discussion and communication scores low in all countries.

Libraries, then, seem to have adapted to the digital turn via a varied set of services. If our respondents reflect the generalised reality, most of the services, with the exception of lending of ebooks, are services based on physical encounters between librarians and users in the library, such as computer classes, helping users with devices, helping them with e-government and e-banking. Services based on communication on digital platforms are more seldom.

Our findings relating to adaptation to the digital turn in museums are more difficult to interpret. The variations between the countries are large. The proportion reporting that they provide digital access to artefacts in their museum varies from 31 per cent in Germany to 43 in Denmark and 80, 87 and 90 per cent in Norway, Hungary and Sweden respectively. If our data reflects reality, they seem to indicate that:

- Providing digital access to artefacts in the collections is becoming common practice, although with some variations.

- A substantial proportion report that they offer hybrid exhibitions.

- Curating web-based exhibitions is still relatively marginal.

RQ 2 is related to perceptions of the legitimacy of the LAM-institutions and the role of traditional legitimations versus new ones related to the social and digital turn. Generally, the traditional legitimations related to for example the cultural heritage and learning are more important than the new ones in all the professional fields and in all the countries. One exception is German librarians, who tend to perceive the new legitimations as more important than the traditional.

Librarians and archivists tend to be of the opinion that their role as professionals is to be critical of what they present, not uncritical and neutral promoters of the cultural heritage and national identity or neutral guardians of the documents submitted to archives, whereas museums tend to be less critical and more neutral guardians of their cultural heritage. 


\section{References}

Audunson, R. "Folkebibliotekenes rolle I en digital framtid. Publikums, politikernes og bibliotekarenes bilder (The role of public libraries in a digital future. The perceptions of the public, the politicians and the librarians)". In Audunson, Ragnar and Niels Windfeld Lund (eds), Det sivilserte informasjonssamfunn, pp. 206-224. Berger: Fagbokforlaget, 2001.

Audunson, R., H.-C. Hobohm, and M. Tóth. "ALM in the Public Sphere: How do Archivists, Librarians and Museum Professionals Conceive the Respective Roles of their Institutions in the Public Sphere?". Information Research 24, no. 4. http://www.informationr.net/ir/244/colis/colis1917.html.

Buschman, J. E. Dismantling the Public Sphere: Situating and Sustaining Librarianship in the Age of the New Public Philosophy. Westport, Conn. u. a.: Libraries Unlimited, 2003.

Buschman, J. “On Democracy and Libraries”. The Library Quarterly, 88, no. 1, 23-40, 2018. doi:10.1086/694871.

Johnston, J. "The Use of Conversation-based Programming in Public Libraries to Support Integration in Increasingly Multiethnic Societies". Journal of Librarianship and Information Science, 50, no. 2, 117-129, 2018. doi:10.1177/0961000616631613.

Klinenberg, E. Palaces for the People. How Social Infrastructure Can Help Fight Inequality, Polarization, and the Decline of Civic Life. New York: Crown, 2018.

Hobohm, H.-C. "Bibliotheken und Demokratie in Deutschland. Ergebnisse eines europäischen Projektes zu ihrer Rolle und ihrem Engagement für Demokratie und Gemeinwohl". o-bib. Das offene Bibliotheksjournal, 6, no. 4, 7-24, 2019. https://doi.org/10.5282/obib/2019H4S7-24.

Huvila, I. "Participatory Archive: Towards Decentralised Curation, Radical User Orientation, and Broader Contextualisation of Records Management”. Archival Science, 8, no. 1, 15-36, 2008. https://doi.org/10.1007/s10502-008-9071-0.

Lankes, R. D. The Atlas of New Librarianship. Cambridge, Mass: MIT Press, 2011.

McCall, V. and C. Gray. “Museums and the 'New Museology': Theory, Practice and Organisational Change”. Museum Management and Curatorship, 29, no. 1, 19-35, 2013. https://doi.org/10.1080/09647775.2013.869852.

MacNeil, H. and T. M. Eastwood (eds). Currents of Archival Thinking. Santa Barbara, California: Libraries Unlimited, 2nd edn, 2017.

Rasmussen, C. H. "Is Digitalization the Only Driver of Convergence? Theorizing Relations Between Libraries, Archives, and Museums”. Journal of Documentation 75. https://doi.org/ 10.1108/JD-02-2019-0025.

Rivano Eckerdal, J. “Libraries, Democracy, Information Literacy, and Citizenship”. Journal of Documentation, 73, no. 5, 1010-1033, 2017. doi:10.1108/JD-12-2016-0152.

Ross, M. “Interpreting the New Museology”. Museum and Society, 2, no. 2, 84-103, 2015. https://doi.org/10.29311/mas.v2i2.43.

Simon, N. The Participatory Museum. Santa Cruz, California: Museum 2.0, 2010.

Smiraglia, R. P. Cultural Synergy in Information Institutions. New York, NY: Springer, 2014.

Söderholm, J. and J. Nolin. "Collections Redux: The Public Library as a Place of Community Borrowing”. The Library Quarterly, 85, no. 3, 244-260, 2015.

Theimer, K. "Partizipation als Zukunft der Archive”. Archivar, 71, no. 1, 6-12, 2018.

Vergo, P. (ed.). The New Museology. London: Reaktion Books, 1989.

Widdersheim, M. and M. Koizumi. "Conceptual Modelling of the Public Sphere in Public Libraries". Journal of Documentation, 72, no. 3, 591-610, 2016. doi:10.1108/JD-06-20150079. 



\section{Perceptions and Implications of User Participation and Engagement in Libraries, Archives and Museums}

\section{Introduction}

Engagement with the citizenry is at the heart of the mission of all public institutions. Libraries, archives and museums (LAM) are no exception. What tends to be more difficult to articulate is what this engagement means in practice for LAM institutions and individual organizations. Similarly, there is hardly a consensus of what effect the engagements should have on the public - and even more so, what effect the outcomes should have on the institutions. This chapter inquires into this latter, relatively under-researched question of expectations, experiences and perceptions of the implications engaging with the public has on libraries, archives and museums in Scandinavia.

Users' motivation for contributing to cultural collections have been studied from various angles (e.g. Bonacchi et al. 2019; Roued-Cunliffe and Copeland 2016). This chapter takes a different approach. We will examine the motivations, attitudes, preparedness and willingness to make use of the users' contributions in LAM organizations, a topic that has been studied so far to a considerably smaller extent (Jansson 2017, 2018). Motivations and attitudes involve perceived effects of user contributions on enhancing the public sphere, and possibly a stance on the need for, or the possibilities for, a reorientation of curatorship for digital materials. On a more practical level, integrating user contributions into the official, professional knowledge base, such as the main catalogues of LAM organizations, raises possible concerns about quality, ownership and professional mastery (Oomen and Arroyo 2011). Our research is based on a survey exploring both attitudes and the editing policies implemented in tools that are made available for users.

When users are invited to share their knowledge, experiences or affections related to cultural heritage disseminated by LAM organizations, the context of the participatory endeavor is sometimes organized as a project of limited time and scope, and sometimes as a standing invitation to contribute knowledge to the collection catalogue. While promoting participation and engagement often is the stated, primary purpose for inviting user participation, the arrangements and the technical solutions are often merely designed for enhancing catalogue metadata 
pertaining to specific objects in a collection. The function of enhancing metadata could, as Eveleigh (2014) notes, be poorly served by conceptualizations of user participation and engagement.

However, for this study, we were interested in the durability of the contributions that users make to LAM organizations' catalogues. Instead of focusing on what the user may get out of his or her participation, we wanted to look into what the organizations do with the pieces of knowledge users have provided. This is a question consisting of two broad elements. The first main element is about attitudes and perspectives on the role of the users. Are the users' knowledge about collection objects something LAM organizations need, or even want, to be part of the enduring catalogue information? Will user contributions be perceived as a different form of knowledge, subject to other standards of quality and relevance than the professionally maintained catalogue information, or should they be held to the same standards and therefore be closely reviewed by LAM professionals? The second broad question is about practices in existing arrangements and systems for gathering user contributions. The rationale of examining practices is to learn whether user contributions are actually integrated into the main catalogues of the LAM organizations. To this aim, the survey questions on practices covered what kind of contributions the currently used technical systems are supporting, who are allowed to edit contributions and on what conditions, what the storage policies look like, and whether the organizations are performing regular assessments concerning the quality of the user assessments.

Integrating additional information into the catalogues is by no means the only possible benefit from user contributions, but there are two reasons why it is worth examining. The first one is that many existing tools and arrangements are designed in a way that convey an impression of contributing to permanent and accumulating knowledge. The second one is that catalogues, despite several differences, form a common ground for negotiating and bridging knowledge organization between the different LAM disciplines.

\section{Theoretical Approach}

Wikipedia has been characterized as a great success of user contributions through digital technology: "The true wonder of wiki-platforms is their capacity to mobilize contributors in great numbers and to incite them to write and edit articles" (Henningsen and Larsen, in this volume). LAM organizations may also profit in many ways from the potential of engaging the populace at large in contributing to their work, but widely different institutional contexts and traditions of how professionals and the public are expected to collaborate mean that LAMs cannot 
simply reproduce the success of the most eminent wiki-based collaborations, although the local history wiki under the administration of the National Library of Norway has been quite successful.

There are several competing lines of discourse focused on explicating how the very nature of scientific or cultural knowledge may be affected by user engagement. One influential strand of discussion perceives transition from hegemonial discipline-oriented scientific discoveries to more application-oriented scientific knowledge production involving larger parts of society (Nowotny, Scott and Gibbons 2001). Another approach, more narrowly applicable to cultural heritage, is the paired concepts of "heritage" and "voice" which are different rationales for using and sharing cultural heritage knowledge (Ivey 2009). As our study does not aim to explore such qualitative features of different forms of knowledge per se, they are not going to be discussed here in detail, but we assume that underlying discourses on what makes knowledge trustworthy, relevant and adequately organized will form a backdrop to the respondents' answers to the survey questions.

Ridge (2014) takes as a starting point that crowdsourcing has become increasingly popular in memory institutions as a tool for digitizing or computing vast amounts of data. Nevertheless, there are signs that indicate a certain restraint among the LAM institutions. Huvila (2015) has analyzed how "participation" is discussed in the context of archives and records management and explored practical and theoretical implications of the disclosed discursive practices. He found that there was not one notion of participation, but nine different and partly conflicting types of participation. Further, he notes that there is fairly little research on how participation is conceptualized by archives professionals and researchers.

There might be a mismatch between the values and missions of the LAM institutions and the idea of crowdsourcing. Owens has pointed at the definition of crowdsourcing, especially in terms of "outsourcing" (Owens 2014), and contributed to opening up and redefining the concept: "What crowdsourcing does (and most digital collection platforms fail to do) is to offer an opportunity for someone to do something more than consume information." (278).

Eveleigh (2014) has pointed out that crowdsourcing also harbors a hidden threat to professionalism:

Crowdsourcing initiatives in archives, as in related professional fields, are also haunted and constrained by the fear that a contributor might be wrong, or that descriptive data might be pulled out of archival context, and that researchers using collaboratively authored resources might somehow swallow all of this without question or substantiation (2015)

But this threat might also lead to a new concept of profession within the institutions that opens up for user participation. Phillips argues that a new model of 
"open authority" is required to combine effectively community contributions and museum expertise in interpreting shared heritage (Phillips 2014, 247). This also means a new role of the curator:

Stemming from this need for additional curation, the traditional role of the curator as a content provider should be augmented with that of a platform provider, gathering and dispersing information in addition to creating it.

User participation may be regarded as a means of democratizing the cultural heritage. Nevertheless, Bonacchi et al. (2019) found that crowdsourcing cannot straightforwardly be considered a democratizing form of cultural participation. The involved public cohort is not radically different in socio-demographic makeup to the one that physically visits such institutions, being for example financially better-off with high levels of formal education.

Crowdsourcing has also been proposed as an approach for promoting the convergence of LAMs (Kalfatovic et al. 2008). The LAM sector is seen as a whole, but there are obvious differences between the institutions. Theimer (2015) explores how archivists and special collections librarians in organizations of different sizes and types have approached the challenges of collection, as well as exploring opportunities to acquire new kinds of materials and conduct thoughtful reappraisal.

Another line of research has focused more generally in professional attitudes and expectations in the LAM context. Huvila $(2012,2014,2016)$ has surveyed LAM professionals' views of the future of their institutions. Similarly to participation, he found that the attitudes differ considerably even if it is possible to identify certain broad views or subject positions that can be identified across the field. In the two studies, the professionals were in favor of the idea of LAMs as promoters of civic engagement and user involvement as a key facet of how LAMs should work in the future. At the same time, it was apparent that the expectations of how LAMs should work and what they should achieve were not entirely compatible with each other, and there was a lack of clarity and even theoretical depth in the views that could be seen as a hindrance to formulating a clear "positive orthodoxy" (i.e. vision) of what LAMs should do or be in the future. As Marty (2012) underlines, there is a need to be more open towards users as contributors but also of articulating the role and contribution of professional staff.

\section{Methods and Material}

Our approach to the question of what are the implications of user participation for the LAM institutions is to investigate both attitudes and practices of LAM professionals. The combination of attitudes and practices was thought to provide 
an insight into a possible tension between professional custodians' authoritative knowledge and the perhaps more digressive and harder-to-verify contributions made by users. Attitudes and opinions related to their own field of work is something we would expect from any LAM professional, as acquired norms and values are part of what defines a profession (Wilensky 1964).

The data was collected using an online survey submitted to LAM professionals in three Scandinavian countries (Norway, Sweden and Denmark) in 2019. The survey questionnaire was developed and both linguistically and culturally translated by an international team of researchers. The survey was managed locally in the participating countries using online survey software available at the participating research institutions.

The design of the survey had all respondents $(\mathrm{N}=2443)$ answering the questions on attitudes towards crowdsourcing, regardless of whether they had any experiences with such solutions or not. Only respondents with either current or previous experiences with crowdsourcing solutions were asked the questions pertaining to practices. The number of respondents who had experiences with such solutions was 258 out of 2443 . Unfortunately, due to a misconfiguration of the survey forms sent to the Danish respondents, the questions pertaining to practices were missing. Therefore, the 90 Danish respondents out of those 258 respondents who had experiences with crowdsourcing solutions did not get the opportunity to answer questions about practices. Hence, only Norwegian and Swedish respondents $(\mathrm{N}=168)$ were asked these questions.

The questions regarding practices was also directed at LAM professionals, which proved to be a bit of a stretch, because the affordances offered by technical solutions for user contributions result from the institutions' policies and not from individual professional judgment. Hence, more precisely, the survey data on practices tell us about the LAM professionals' knowledge of their institutions' policies and practices. As our respondents are professionals in LAM organizations, it should be noted that it is their individual experiences and knowledge about their organizations' handling of user contribution that is surveyed. The organizations may have policies and mechanisms in place that our respondents are not aware of. Gaps in the knowledge of institutional policies is expressed by a fairly high number of "I don't know" answers in this part of the survey.

As mentioned above, the questions on experiences and policies were not included in the surveys answered by Danish archives or museums professionals. Therefore, this part of the survey only includes data from Norway and Sweden. This makes a total of six different survey forms, to archivists, librarians and museologists respectively, in both countries. The questions were essentially the same, though in different languages. The tools and methods for collecting data have also been slightly different. Unfortunately, this has led to two minor issues with a vari- 
able containing information on what forms of user contributions has the organization made arrangements or technical solutions for. This question has eight options, with the possibility of selecting more than one. The survey sent to Norwegian librarians missed the first option, "Adding predefined keywords or classification data", and the survey sent to Swedish museologists only allowed for one selection for each respondent on this question, thus perhaps missing out some forms of user contributions they actually have on offer.

Respondents were recruited using measures that were deemed appropriate in order to reach as many LAM professionals in each country as possible. The nonavailability of comprehensive lists of all LAM professionals in the participating countries restricted both the possibility to include complete populations in the survey and the possibility to make systematic assessment of the representativity of the samples. The measures included the use of professional mailing lists, websites, social networks and contacting national professionals associations. As a result, the data represents a convenience sample. In spite of the shortcomings of the survey approach and the presence of an unknown bias, the data is still useful for the exploratory rather than confirmatory aims of the present study.

\section{Analysis}

The data was analyzed with SPSS 25.0 using descriptive statistics and one-way analysis of variation (ANOVA).

\section{Attitudes}

The attitudes were analyzed using a set of 20 questions on an 11-point Likert-like scale. The questions listed in Table 9.1 were adapted to fit the vocabulary and conditions respectively in libraries, archives and museums and translated to Norwegian, Swedish and Danish for the survey.

\section{Country and Profession Related Variation}

The findings show that the attitudes towards user contributions and contributing in the Scandinavian LAMs have a lot of similarities in spite of some country and profession-specific variation. Profession-wise the attitudes differed in all other questions (on significance level $\mathrm{p}<0.001$ ) than $(\mathrm{e})$, a major reason for engaging people to participate in the work of LAM institutions is to get more visitors and users to the institutions. Country-wise the attitudes differed in all other cases 
Tab. 9.1: Questions on the attitudes towards user contributions

a It is very important to engage the public to work together with professionals in [libraries/archives/museums]

b The public can enrich [libraries/archives/museums] collections by providing additional information

c Engaging the public as volunteers helps [libraries/archives/museums] to deliver high quality services with smaller financial resources

d Engaging the public reduces the number of professional staff needed in [libraries/archives/museums]

e A major reason for engaging people to participate in the work of [libraries/archives/museums] is to get more visitors and users to the institutions

f Managing [libraries/archives/museums] collections in the future is impossible without contributions made by the public

g The high number of passive, non-contributing members of the public is a problem, we should expect more from our users

$\mathrm{h}$ Engaging users as contributors provides important support for the public discourse in the society

i Engaging users as contributors is a democratic responsibility of [libraries/archives/museums]

j Letting the members of the public contribute is a form of listening to them and giving them an opportunity to experience benefits of [libraries/archives/museums] from their own premises

$k \quad$ A major reason for engaging people to participate in the work of [libraries/archives/museums] is to empower them as individuals

I Many users are more knowledgeable of the collections than [libraries/archives/museums] professionals, both as subject experts and as the users of the collections

$\mathrm{m} \quad$ User engagement at [libraries/archives/museums] should be a user-driven activity (i.e. decisions should be made by users)

$\mathrm{n} \quad$ User engagement at [libraries/archives/museums] should be marshalled by professionals

o Additional information supplied by users should be re-examined by professionals

p The most important contributors are earlier owners or stakeholders of collection items

$q$ The members of the public who are contributing should be treated as equals to the professionals

$r \quad$ New digital technologies allow [libraries/archives/museums] to engage users in the management of collections

s A significant aspect of participation is to engage users within their own fields of interest, or in ways that are relevant to their own life situations

$\mathrm{t}$ Engaging the public to contribute is how [libraries/archives/museums] should work with their users today 
than (d), engaging the public reduces the number of professional staff needed in LAM institutions, and ( $n$ ), user engagement at LAM institutions should be marshalled by professionals.

The attitudes were most split regarding the questions of whether (p) the most important contributors are earlier owners or stakeholders of collection items (e.g. books, records, objects) (mean 3.47, SD 3.267). Here especially Swedish archivists (mean 7.15) and museum professionals (mean 6.48) considered it helpful whereas Danish (mean 0.00) and Norwegian (mean 2.22) librarians and Danish museum professionals (mean 2.47) thought the contrary.

Also the question whether (c) engaging the public as volunteers helps LAM institutions deliver high quality services with smaller financial resources (mean 5.10, SD 3.258) divided opinions. The Danish librarians were the most negative whereas many others, especially Danish (mean 6.96) and Norwegian (mean 6.28) archivists and Norwegian (mean 6.45) and Swedish (mean 6.55) museum professionals, were positive.

With regards to the issue of whether the (r) new digital technologies allow LAM institutions to engage users in the management of collections (mean 3.60, SD 3.189), the museum professionals (mean 5.68) and archivists (mean 5.15) were fairly optimistic whereas library (mean 2.68) professionals were pessimistic. They were also less inclined to believe (mean 3.13), together with Danish museum professionals (mean 3.15), that (l) many users are more knowledgeable of the collections than LAM professionals, both as subject experts and as the users of the collections - another issue with divergent views among the respondents (mean 3.79, SD 3.116),

Regarding the question of whether (i) engaging users as contributors is a democratic responsibility of LAM institutions (mean 5.24, SD 3.114), the Swedish (mean 5.90) respondents were more positive than the others, especially the Danes (mean 4.29). Considering if ( $\mathrm{k}$ ) a major reason for engaging people to participate in the work of LAM institutions is to empower them as individuals (mean 4.91, SD 3.114), the respondents in Denmark and Norway, especially in archives (DK mean 3.33; NO mean 3.02) and museums (DK mean 3.55; NO mean 3.99), agreed less with the statements than Swedes (mean 5.65).

The respondents showed least variation in their views that (d) engaging the public reduces the number of professional staff needed in LAM institutions (mean 1.39, SD 2.161), and that (m) user engagement at LAM institutions should be a userdriven activity (i.e. decisions should be made by users) (mean 2.64, SD 2.479).

As a whole, the respondents were inclined to consider that (o) additional information supplied by users should be re-examined by professionals (mean 7.35, SD 2.871) and (n) user engagement at LAM institutions should be marshalled by professionals (mean 6.93, SD 2.912), but that (b) the public can enrich collections 
by providing additional information (such as reviews, recommendations or supplementing catalogue data) on collection items (mean 6.72, SD 2.790) and (j) letting the members of the public contribute is a form of listening to them and giving them an opportunity to experience benefit of LAM institutions (mean 6,60, SD 2.838).

The respondents were least inclined to believe that (d) engaging the public reduces the number of professional staff needed in LAM institutions (mean 1.39, SD 2.161), (g) the high number of passive, non-contributing members of the public is a problem, we should expect more from our users (mean 2.44, SD 2.474), (f) managing collections in the future is impossible without contributions made by the public (mean 2.47, SD 2.719), and (m) user engagement at LAM institutions should be a user-driven activity (i.e. decisions should be made by users) (mean 2.64, SD 2.479).

\section{Demographic Differences}

The role of demographic factors in explaining the differences in attitudes was studied using one-way analysis of variation (ANOVA). According to the findings (at the significance level <.001), the male respondents were more inclined than females to consider that (d) engaging the public reduces the number of professional staff needed in LAM institutions $(F(3,2435)=11.462$, $p<.001)$, (f) managing collections in the future is impossible without contributions made by the public $(\mathrm{F}(3,2421)=7.511, \mathrm{p}<.001)$, $(\mathrm{g})$ the high number of passive, non-contributing members of the public is a problem, we should expect more from our users $(F(3,2422)=$ 6.870, $\mathrm{p}<.001),(\mathrm{m})$ user engagement at LAM institutions should be a user-driven activity $(\mathrm{F}(3,2404)=6.355, \mathrm{p}<.001)$, $(\mathrm{p})$ the most important contributors are earlier owners or stakeholders of collection items $(\mathrm{F}(3,2399)=12.510, \mathrm{p}<.001)$, and (r) new digital technologies allow LAM institutions to engage users in the management of collections $(F(3,2398)=20.344, p<.001)$. In contrast to these fairly instrumental questions, females scored slightly higher in questions about outreach $(e, j)$, public discourse $(h)$ and empowerment $(k)$ even if none of these differences were statistically significant.

Education is also a factor that is linked to attitudinal differences. The LAM educated were generally less enthusiastic about user contributions than others in all questions other than (k), a major reason for engaging people to participate in the work of LAM institutions is to empower them as individuals, even if this particular difference was not statistically significant. The differences are significant for questions a, b, c, d, f, g, l, m, p, q, r, and t, and non-significant for e, h, i, j, $\mathrm{k}, \mathrm{n}, \mathrm{o}$, and s. A comparison of the differences gives an impression that the LAM educated respondents were more concerned of LAMs as an actor and institutional 
implications of participation, whereas non-LAM educated focused more on users as an active primary stakeholders in the equation.

\section{Practices}

\section{Experiences With and Knowledge Of Policies and Mechanisms}

As a starting point for analyzing practices, we asked whether the organization where the respondent is employed has had any experience with digital tools for user contributions. Only respondents answering "yes" on either of the two first alternatives ("such solutions are currently in use" or "such solutions have been tested earlier") were asked to answer the remaining questions on the practical handling of the user contributions within the organizations. Table 9.2 shows distributions by country of respondents who did or did not have any experience with such solutions in their own organization.

Tab. 9.2: Have you, or the LAM organization you work for, ever planned or used a technical solution for "crowdsourcing", where external users of digital collections may contribute to the collections or the catalogue data by providing additional information?

\begin{tabular}{|c|c|c|c|c|}
\hline & \multicolumn{3}{|l|}{ Country } & \multirow[t]{2}{*}{ Total } \\
\hline & Denmark & Norway & Sweden & \\
\hline \multirow{2}{*}{$\begin{array}{l}\text { Yes, one or more such technical } \\
\text { solutions are currently in use }\end{array}$} & 67 & 74 & 61 & 202 \\
\hline & $2.7 \%$ & $3.0 \%$ & $2.5 \%$ & $8.3 \%$ \\
\hline \multirow{2}{*}{$\begin{array}{l}\text { Yes, we have tested that kind of } \\
\text { technical solution, but we are not } \\
\text { currently using it }\end{array}$} & 237 & 147 & 197 & 567 \\
\hline & $0.9 \%$ & $0.6 \%$ & $0.8 \%$ & $2.3 \%$ \\
\hline \multirow{2}{*}{$\begin{array}{l}\text { No, but I know that my organization } \\
\text { is planning or considering that kind } \\
\text { of technical solution }\end{array}$} & 347 & 487 & 367 & 1187 \\
\hline & $1.4 \%$ & $2.0 \%$ & $1.5 \%$ & $4.8 \%$ \\
\hline \multirow{2}{*}{$\begin{array}{l}\text { No, and neither am I aware that any } \\
\text { such technical solution has been } \\
\text { considered }\end{array}$} & 3527 & 3337 & 6547 & 13397 \\
\hline & $14.4 \%$ & $13.6 \%$ & $26.8 \%$ & $54.8 \%$ \\
\hline \multirow[t]{2}{*}{ I don't know } & 2417 & 1357 & 3527 & 7287 \\
\hline & $9.9 \%$ & $5.5 \%$ & $14.4 \%$ & $29.8 \%$ \\
\hline Total (Count) & 717 & 604 & 1122 & 2443 \\
\hline Total (Per cents) & $29.3 \%$ & $24.7 \%$ & $45.9 \%$ & $100.0 \%$ \\
\hline
\end{tabular}


Having planned or using a technical solution for crowdsourcing was rare in all countries even if it was more common among Danish and Norwegian respondents than Swedes. 12.3\% (74/604) of Norwegian, 9.3\% (67/717) of Danish and 5.4\% (61/1122) of Swedish respondents indicated that a such solution was planned or in place. 2.3\% (14/604) of Norwegian, 3.2\% (23/717) of Danish and 1.7\% (19/1122) of Swedish respondents indicated that such a solution had been tested. Over half indicated that no crowdsourcing was used, and in what can probably be taken as an indication of the priorities, 33.6\% (241/717) of Danish, 22.4\% (135/604) of Norwegian and 31.4\% (352/1122) of Swedish respondents did not know. A slightly larger group had tested such solutions but were not currently using them.

Of the different functions, $41.1 \%$ had or had planned giving opportunity to add information about persons, families, organizations or places represented in the collection objects, $15.6 \%$ adding keywords or classification data, $60.5 \%$ adding free text descriptions or comments, 32.4\% providing transcriptions, $37.4 \%$ correcting errors or disputable existing information and $8.6 \%$ establishing links between objects in the collection, while almost one fourth, $23.8 \%$, indicated that they did not know.

Approximately half of the respondents indicated that the users of their crowdsourcing services belong to either organized groups, or that they have a distinct field of interest.

The information users contributed could in most of the cases be edited by authorized persons within the organization (75.6\%). In $16.7 \%$ of cases external users who had entered the information could edit it, while in $7 \%$ of cases anyone could edit it.

In a slight majority of the cases, the crowdsourced information was either planned to be kept by the organization (26.6\%), or no explicit decision had been made (25.3\%). Only in a few cases had a decision actually been made to delete the information after a certain period of time (4.4\%).

The most typical procedure (42.8\%) to manage contributions, indicated by the respondents, was that organizations perform regular assessments of all (or of a significant amount of) the user contributions and incorporate them in the primary catalogues or storage systems. Fairly seldom were the edits incorporated directly (7.5\%). More often they were not incorporated at all (13.8\%).

Only a few respondents (13.1\%) indicated that their organization had conducted systematic evaluations of their crowdsourcing. Thirty-five per cent had not conducted evaluations, nor did they have immediate plans to do so. The results of the evaluations had indicated mixed impacts with most reported cases of positive impact in Sweden and least in Denmark.

The proportion of LAM professionals who reported actual experiences with technical solutions for user contributions were $9.6 \%$ (168 out of 1753 respondents) 
from Norway and Sweden. The proportion of Norwegians with such experiences are $14.5 \%$ (88 out of 605 ), while it was $7 \%$ (80 out of 1148 ) in Sweden. The main explanation for this difference is that the number of librarians responding in Sweden was quite high, while there is a small proportion of librarians who have any experience with solutions for user contributions. This does not imply that user contributions are considered less important in the library sector, but it is probably fair to assume that library professionals are more often employed in small units, and therefore less involved in such activities than archivists and museologists.

Are there any specific categories of professionals who seem to engage more in user contributions? The age group does not seem to play much into it. Out of the respondents who answer that they or their organization have experiences with solutions for user contributions, $8.6 \%$ are 34 years or younger, 9.4\% are between 35 and 49 , and $10.4 \%$ are 50 years or older. These are small differences, though it is interesting to notice a slightly higher proportion with the older age groups.

Whether the professionals work in a public institution or not seems to have a somewhat higher impact. The data on this variable has a lower $\mathrm{N}$ (1382, instead of 1753 as for the rest of the data set), because information on public or private ownership is lacking for the group of Norwegian librarians. The total portion of professionals with experience or knowledge of solutions for user contributions is $11.5 \%$ for this variable, instead of $9.6 \%$ for the rest of the data set. The proportion of these respondents who work in public LAM organizations is $9.3 \%$, while the portion working in a non-public organization is $18 \%$. This difference is consistent with the numbers that show that such solutions are most widespread in museums, as the proportion of museums that are not publicly owned is higher than for archives and libraries.

The type of educations seems to have a higher impact: $7.8 \%$ have some sort of LAM education, while $14.3 \%$ have another university degree or similar. The proportion with no higher education is zero. The difference between LAM educations and other educations comes almost solely from the library sector. While most librarians have an LAM, more specifically a LIS, education, the proportion of people involved with solutions for user contributions are mostly people with other academic backgrounds. If we look at the proportions for museum and archives in isolation $(\mathrm{N}=628)$, the proportion of respondents who have experience with or knowledge of solutions for user contributions is virtually equal for those with an LAM education (22.8\%) and those with another academic education (22.4\%).

The final independent variable to look at is gender. Generally speaking, there is a high proportion of women working in LAM institutions. The overall proportion for the data set is $74.8 \%$ women. Librarians have the highest proportion of women; for archives and museum the proportion of women is $62 \%$. However, dealing with user contributions seems to have appealed to a slightly higher share of 
male employees in the LAM organizations. 7.9\% of the respondents who have experiences with or knowledge of the organizations' solutions for user contributions are women, with $14.6 \%$ of them men. Again, librarians account for some part of the bias, but there is still a gender difference when archives and museums are seen in isolation: $21 \%$ of the women and $24.2 \%$ of the men. This appears to be a small difference, but it is worth noting a difference between Sweden and Norway as well. For archivists and museologists in Norway, $26.2 \%$ of those who deal with user contributions are women, while 33.6\% are men. In Sweden, the difference is smaller, and the proportion of women is slightly higher (17.7\% women, $15 \%$ men). This seems to indicate that working with solutions for crowdsourcing has appealed to men in Norway, while this is not the case in Sweden.

\section{Policies and Mechanisms in LAM User Contribution Arrangements}

The user contributions may be of different forms. This question was open for checking multiple boxes, thus the sum of total percentages is higher than 100 .

As noted earlier, the first out of these columns was left out of the survey form sent to Norwegian librarians, which contributes 8 out of the 168 persons in this data set. This is reflected in the percentages of the first column of Table 9.3. The second problem with this table is that the survey sent to Swedish museologists was missing the possibilities to mark more than one option. In addition to these seven columns, there was also an option for answering "I don't know”, which was only available if not combined with any of the other options. "I don't know" achieved a total of $11.3 \%$ of the answers.

The most prevalent form of user contributions is to add free text descriptions or comments to digital objects in a collection. This functionality is available in the technical solutions that $53.6 \%$ of the professionals had experience with or knowledge of in their own organization. Using predefined keywords or establishing links between objects in a collection were the least popular ones. This could be because these forms may require more professional skills.

\section{The Professionals' Perceptions of Their Users}

The question asked was "what are the most significant characteristics of the external users of the technical solution(s)"? Only one answer to the question was possible, see Table 9.4.

There is somewhat high variance on this question, but some patterns may be interesting. Librarians, both in Norway and Sweden, held the highest rates of the answer "I don't know". More than half of Norwegian archivists perceive their users to belong to an organized group, such as local historians or genealogists. An 

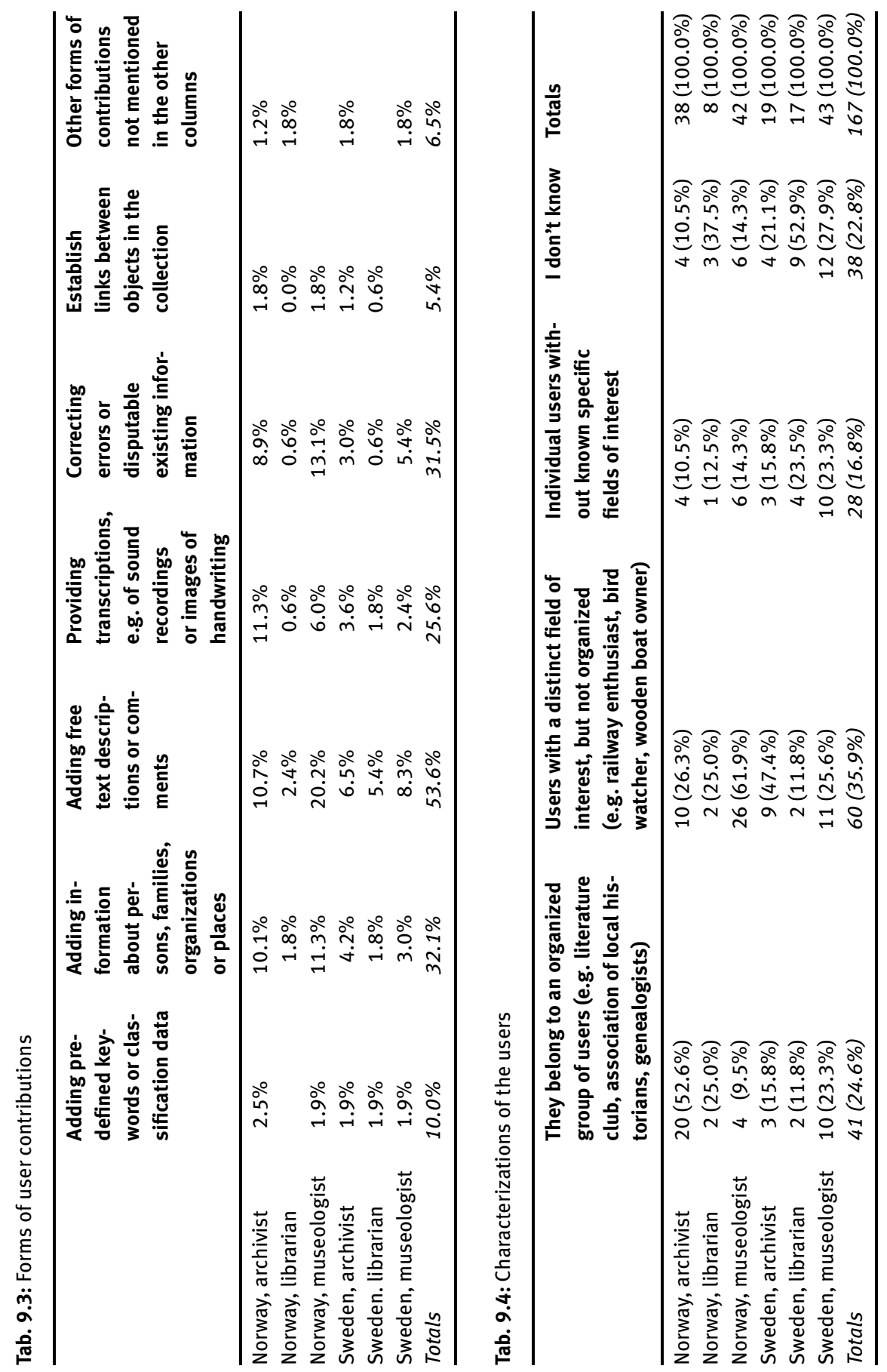
even higher proportion of Norwegian museologist, 61.9\%, perceived their users as persons with a distinct field of interest, but who are not organized.

\section{Editing Policies}

Another question about policies and mechanisms was who may edit the information that users have contributed, see Table 9.5. Again, several options could be selected.

The highest score is for the option "authorized user within my organization". Very few were pursuing policies that external users may edit contributed information themselves. It is worth noting that the option "I don't know" came out with the second highest score, 58.9\%. This probably signifies that the question of authorizations for editing information has not received sufficient attention.

\section{Retention Policies}

We also wanted to look into the questions of what happens to the user contributions after they had been collected, and - possibly - verified or checked for quality by the organization. We asked two questions related to this concern, see Table 9.6.

The first one was "for how long will the organization store information that is contributed by external users"?

This is clearly a matter that has not been settled very well, nor communicated well within the organizations. The last two alternatives, either that no decision has been made or the respondent doesn't know, got more than two thirds of the answers combined. Only a marginal number of respondents indicated there was a policy of deleting user contributions after a certain period of time. Almost one third answered that the organization intended not to delete the user contributions.

\section{Integrating User Contributions in Primary Catalogues}

The second question concerning what would happen to user contributions, see Table 9.7, was "in what way (if any) does the user contribute information incorporated into the organization's primary catalogues or storage systems”?

The answers to this question, we believe, probably indicates a low level of maturity of the policies governing user contributions. Even if user contributions remain within a specific technical solution that the users have access to for a very long time, a defined policy on if, how and when the users' knowledge or suppositions will be necessary for the contributions to survive for a long time, across technology changes and further developments of the collections. As many as $81 \%$ of the Norwegian museologists indicated their policy was to assess the user contributions regularly. This policy seems to be widespread with museologists in Swe- 


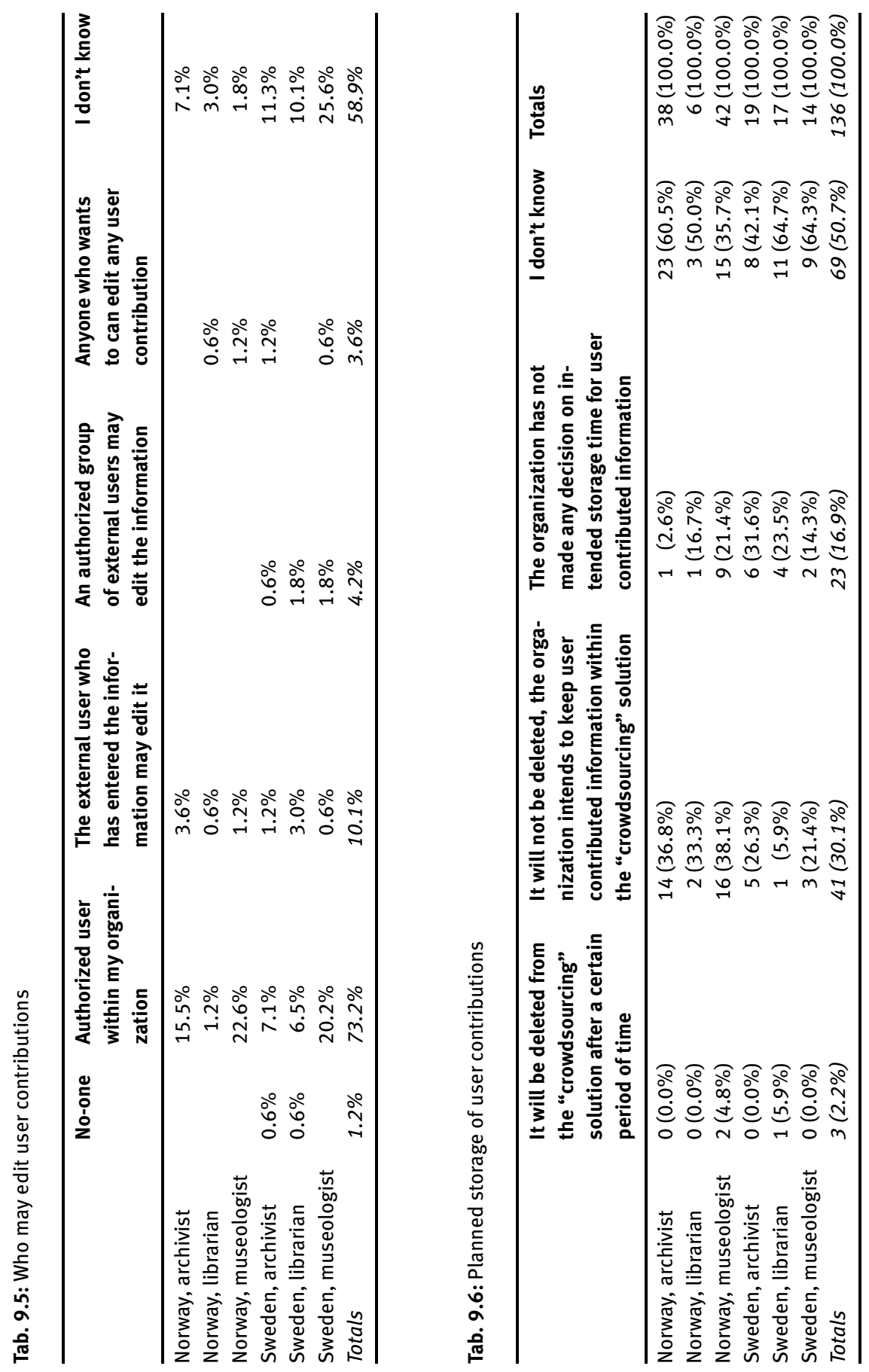




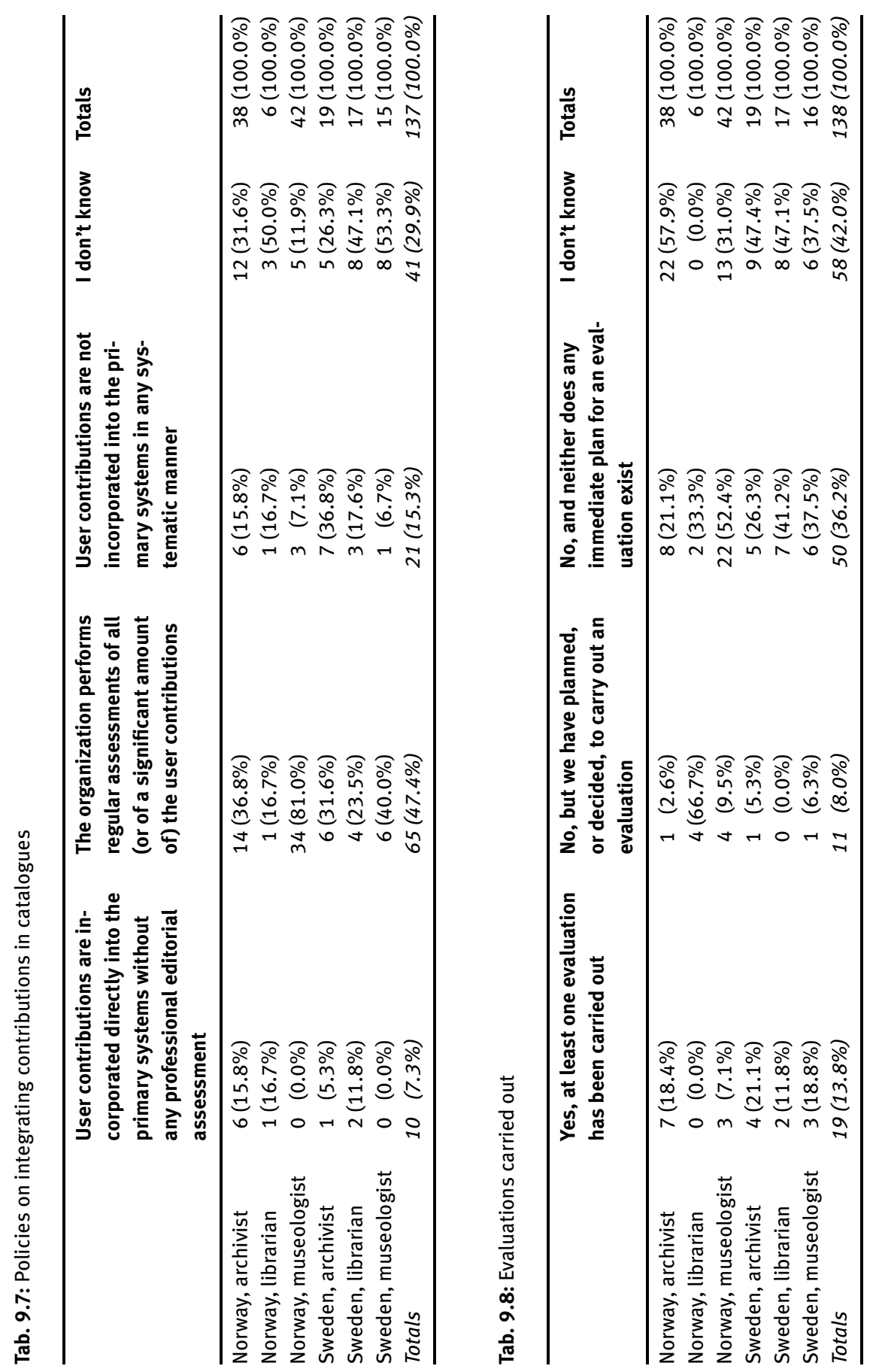


den and with archivists in both countries as well, though the rates are lower. On the other hand, the overall "I don't know"-answers were almost one third (29.9\%) also for this question. There seems to also be a need for clarifying and communicating policies within the organization on this matter.

\section{Whether the Crowdsourcing Solutions Have Been Evaluated}

The last questions in the surveys were on whether there had been evaluations of the solutions for user contributions used by the organizations.

As shown in Table 9.8, only 13.8\% answered that at least one evaluation has been carried out. Another $8 \%$ had either plans or made a decision for carrying out an evaluation. The remaining almost $78.2 \%$ were either "no" or "I don't know". It should probably not be very surprising, as many of these activities and initiatives are fairly new to the organizations. However, the unsettled, or poorly communicated, policies on how the organizations will deal with user contributions indicates that evaluation of such solutions will probably be a good idea.

The last question was on the results from an evaluation, see Table 9.9. As there were low numbers of respondents who knew of any such evaluation, there were also few answers to this question. In those few instances, however, the results were mostly positive.

\section{Discussion}

The analysis showed that there are differences in user contribution related attitudes among the respondents but that they are surprisingly small, whereas the differences in practical experiences are considerable between a small number of respondents who had such experiences, and the large majority who had not engaged users as contributors. In some country-specific attitudinal differences, there could be seen echoes of different emphases in the national LAM policies. For instance, Swedish respondents were more inclined to emphasize the democratic and empowering role of LAMs than their Danish and Norwegian colleagues. It was difficult to see similar patterns in the practical experiences.

Considering the profession-wise differences, it is hardly surprising that museum and archives professionals were somewhat more inclined to think that, for instance, experts or previous owners of collection items could be especially useful contributors. The respondents were in favor of maintaining the curatorial responsibility at the institutions. While the professionals were positive towards engaging users as contributors of additional information and engaging them in a dialogue, they did at the same time not believe that user engagement would re- 


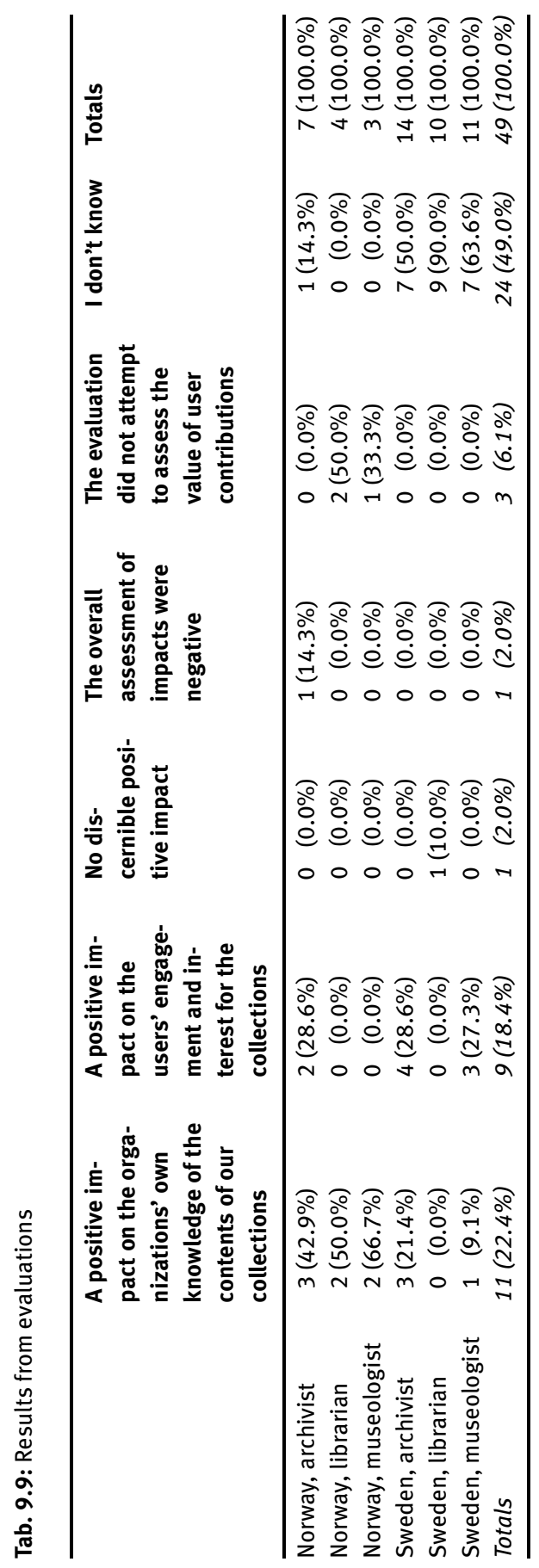


duce the number of professional staff needed in LAM institutions or that the lack of engagement of some users would necessarily be a major issue. This finding confirms earlier, not necessarily unsurprising, observations in the literature that the professionals are not inclined to believe that their role is diminishing. To a certain degree, the findings seem to suggest that the male respondents were more worried about the technical viability of user engagement, such as risks of nonengagement, whereas the female respondents were more focused on the soft (e.g. democracy, empowerment) benefits of working closer with users. The significance of the LAM professions and respondents' identification as a LAM person as a key factor that explains attitudes was visible also in the differences between LAM educated and other respondents. LAM educated individuals underlined the role of LAM professionals whereas the others were more inclined to emphasize the importance of letting users decide.

As a whole, engaging users as contributors is still very rare and in spite of the small number of success stories (e.g. Ridge 2016; Roued-Cunliffe and Copeland 2016), an average LAM professional has little or no experience of engaging users as contributors. For the same reason, the common attitudes towards user contributions are anchored on expectations and how participation has been discussed in the academic and professional literature rather than on first-hand experiences. The lack of first-hand experience on engaging users as contributors is especially striking considering the analyzed data. It would have been plausible to expect that respondents with earlier experiences would be overrepresented in the final sample as they could be assumed to be more interested in answering user contribution related questions.

While the number of respondents with experiences from crowdsourcing solutions in their own organizations was relatively low, the different questions on policies and practices seem to reveal that the LAM institutions have not yet figured out, nor implemented and communicated, policies and expectations for whether or how they will handle user contributions. Both the rates of "I don't know" answers and the rate of what could be interpreted as laissez-faire policies indicate that policies on preserving user contributions are either lacking or not well communicated to the professionals. As such, user contributions appear more as a byproduct of online outreach and exposure rather than a method of enriching collections, accumulating material, or breaking out of the traditional views of users as literal "users" of LAMs, not active co-equals to the professionals. 


\section{Conclusions}

A key practical implication of the present study is that as it is still very rare to work with user contributions in a systematic manner, it would be important to gather more experiences and work with users, and develop ideas and approaches to engaging them in a mutually productive and useful manner. Similarly to how LAMs already for some time have been suffering from being socially useful but not necessarily used that much in practice (Usherwood et al. 2005), the current relevance of user contributions is still very much on the level of their potential social usefulness rather than in their demonstrated benefits in the LAM sector as a whole.

\section{References}

Bonacchi, C., A. Bevan, A. Keinan-Schoonbaert, D. Pett, and J. Wexler. "Participation in Heritage Crowdsourcing”. Museum Management and Curatorship, 34, no. 2, 166-182, 2019.

Eveleigh, A. "Crowding out the Archivist?: Locating Crowdsourcing Within the Broader Landscape of Participatory Archives". In Ridge, M. (ed.), Crowdsourcing our Cultural Heritage, pp. 211-230. London: Routledge, 2014.

Henningsen, E. and H. Larsen. "The Joys of Wiki Work: Craftsmanship, Flow and Selfexternalization in a Digital Environment”. In Audunson, R., H. Andresen, C. Fagerlid, E. Henningsen, H-C. Hobohm, H. Jochumsen, H. Larsen, and T. Vold (eds), Libraries, Archives and Museums as Democratic Spaces in a Digital Age. Berlin: De Gruyter Saur, 2020.

Huvila, I. "Navigators, Debaters or Information Architects? How Library, Museum and Archive Professionals Perceive their Role in the Future Society". In Riekert, W.-F. and I. Simon (eds), Information in e-Motion: Proceedings of the BOBCATSSS 2012 20th International Conference on Information Science Amsterdam, 23-25 January 2012, pp. 190-194, Bad Honnef, 2012. Bock + Herchen.

Huvila, I. "Archives, Libraries and Museums in the Contemporary Society: Perspectives of the Professionals”. In Kindling, M. and E. Greifeneder (eds), iConference 2014 Proceedings, pp. 45-64, Illinois, 2014. iSchools.

Huvila, I. "The Unbearable Lightness of Participating? Revisiting the Discourses of "Participation" in Archival Literature”. Journal of Documentation, 71, no. 2, 358-386, 2015.

Huvila, I. "Change and Stability in Archives, Libraries and Museums: Mapping Professional Experiences in Sweden”. Information Research, 21, no. 1, 2016.

Ivey, B. “Expressive Life and the Public Interest”. In Jones, S. (ed.), Expressive Lives, pp. 23-33. London: Demos, 2009.

Jansson, I.-M. "Organization of User-Generated Information in Image Collections and Impact of Rhetorical Mechanisms”. Knowledge Organization, 44, no. 7, 515-528, 2017.

Jansson, I.-M. “Negotiating Participatory KO in Crowdsourcing Infrastructures”. In Ribeiro, F. and M. E. Cerveira (eds), Challenges and Opportunities for Knowledge Organization in the Digital Age: Proceedings of the Fifteenth International ISKO Conference 9-11 July 2018 Porto, Portugal, pp. 863-870, Baden-Baden, 2018. Ergon-Verlag. 
Kalfatovic, M. R., E. Kapsalis, K. P. Spiess, A. V. Camp, and M. Edson. "Smithsonian Team Flickr: a Library, Archives, and Museums Collaboration in web 2.0 Space”. Archival Science, 8, no. 4, 267-277, 2008.

Marty, P. F. "Unintended Consequences: Unlimited Access, Invisible Work and the Future of the Information Profession in Cultural Heritage Organizations". Bulletin of the ASIS\&T, 38, no. 3, 27-31, 2012.

Nowotny, H., P. B. Scott, and M. T. Gibbons. Re-thinking Science: Knowledge and the Public in an Age of Uncertainty. John Wiley \& Sons, 2013.

Oomen, J. and L. Arroyo. Crowdsourcing in the Cultural Heritage Domain: Opportunities and Challenges. In Proceedings of the 5th International Conference on Communities and Technologies (138-149). Brisbane, Australia: ACM, 2011.

Owens, T. "Making Crowdsourcing Compatible with the Missions and Values of Cultural Heritage Organisations". In Ridge, M. (ed.), Crowdsourcing our Cultural Heritage, pp. 269280. London: Routledge, 2014.

Phillips, L. B. “The Role of Open Authority in a Collaborative Web”. In Ridge, M. (ed.), Crowdsourcing our Cultural Heritage, pp. 247-267. London: Routledge, 2014.

Ridge, M. (ed.). Crowdsourcing our Cultural Heritage. London: Routledge, 2016.

Roued-Cunliffe, H. and A. Copeland (eds). Participatory Heritage. London: Facet, 2016.

Theimer, K. Appraisal and Acquisition: Innovative Practices for Archives and Special Collections. Rowman \& Littlefield, 2015.

Usherwood, B., K. Wilson, and J. Bryson. "Relevant Repositories of Public Knowledge?: Libraries, Museums and Archives in 'the Information Age"”. Journal of Librarianship and Information Science, 37, no.2, 89-98, 2005.

Wilensky, H. L. “The Professionalization of Everyone?”. American Journal of Sociology, 70, no. 2, 137-158, 1964. 


\section{Like, Share and Comment! The Use of Facebook by Public Libraries and Museums: A Case Study from Tromsø, Norway}

\section{Introduction}

Historically, libraries, archives and museums (LAMs) have been perceived as institutions providing infrastructure for an open and enlightened public discourse. While Norwegian public libraries are regulated by law that focuses on libraries being providers of knowledge and agents of popular enlightenment as well as local meeting places and arenas for debate, ${ }^{1}$ the Norwegian museum sector is governed by relatively general and open political signals about the role of museums in society. Nevertheless, diversity, inclusion, and dialogue are important key words for both institutions. ${ }^{2}$ In addition, public libraries and museums are also supposed to keep up with technological development, not only to digitize their own collections but also to offer digital services to the public. ${ }^{3}$ Most public libraries and museums do not only have official webpages offering information about their services and self-services, but are also present on social media platforms like Facebook, Twitter, Instagram or YouTube.

This article investigates how three institutions in Troms $\emptyset$ (the main branch of the Troms $\varnothing$ public library and two museums) are using Facebook. By analyzing the frequency of posts, their content and the user participation created, I seek to

1 See https://lovdata.no/dokument/NL/lov/1985-12-20-108, accessed September 192018.

2 See for instance the Norwegian government's white paper number 49 (2008-2009). Framtidas museum - Forvaltning, forskning, formidling, fornying, 102: "Museene skal gi både kunnskap og opplevelse. De skal være tilgjengelige for alle og være relevante og aktuelle samfunnsinstitusjoner som fremmer kritisk refleksjon og skapende innsikt. En aktiv formidling er derfor viktig både i et demokratiperspektiv og i et allment kulturperspektiv" (The museums will provide both knowledge and experience. They should be accessible to all and be relevant community institutions that promote critical reflection and creative insight. Active dissemination is therefore important both in a democracy perspective and in a general cultural perspective (my translation)). 3 See for instance the Norwegian government's white paper number 24 (2008-2009) about the digital preservation and dissemination of cultural heritage, and white paper number 27 (20152016) about the use of information technology to make everyday life easier. Public libraries are supposed to increase the digital skills of the inhabitants, and thus contribute to increased digital user participation (Kommunal- og moderniseringsdepartementet (2015), 116-117). 
answer the following questions: what type of posts are the institutions posting? What type of posts are the ones that engage users? What type of user engagement is most common? What similarities and differences can be observed between the three institutions? By answering these questions, I hope to show how the three institutions and their followers use Facebook. I have chosen to focus on the institutions' Facebook pages because Facebook is by far the most popular social media platform with about $64 \%$ of the Norwegian population having a Facebook account in 2017. All three institutions are in addition to Facebook also present on other social media platforms like Instagram, Twitter or Flickr, but the highest number of followers is on Facebook.

\section{Facebook in Relation to Public Libraries and Museums}

As pointed out by Carlsson, "the body of academic research studying the use of social web in public libraries" (Carlsson 2015, 632) is growing. Investigated aspects are the strategies for social media use, the perception of stakeholders, best practices, and including how libraries advertise their services through Facebook. One of the latest contributions researches public library programs through Facebook events (Mathiasson and Jochumsen 2019). Nevertheless, "empirical work that explores the consequences of social web for public libraries in situ" (Carlsson 2015, 644 ) is missing. There are some case studies from different countries about museums' use of social media, ${ }^{4}$ whereas Camarero et al. "analyze the communication strategies of 240 fan pages and the effect on engagement indicators at a fan page level” (2018, 1120). Capriotti and Losada-Díaz evaluate whether art museums are using Facebook "as a tool for dialogic communication with their publics" (2018, 644) and if the various resources offered by social media platforms are used to encourage interaction with the publics. There are almost no studies about Norwegian museums ${ }^{5}$ or Norwegian public libraries and their use of social media and no comparisons between different institutions in whether they succeed in reaching out to potential audiences by using social media or not. This article therefore presents the results from a case study where the Facebook pages of three institutions are investigated. In order to compare these three Facebook pages, I have analyzed the first six months of 2018 (January 1 until June 30) to find the total

\footnotetext{
4 See Kidd 2011, 2016 for the UK; Badell 2015 for Catalan museums; and Lazaretti et al. 2015 for the Museum of Natural History of Florence.

5 Jørgensen 2011 presents a case study about NTNU Museum of Natural History in Trondheim, Norway and its exploration of web 2.0 technologies to communicate with museum visitors with a focus on a science blog and a science wiki.
} 
number of posts, the content of the posts, and the number and kind of user involvement (like, share, comment). While the total number of posts can give us an impression on the institutions' presence and activity on FB, the content of the post will tell us about the kind of information the institutions are disseminating through FB. We can assume that public libraries and museums are using social media to disseminate information and to communicate with their audiences. As stated in Camarero et al., "measuring organizations' communication performance in SNS and level of user engagement is by no means an easy task" $(2018,1120)$. Researchers have proposed different metrics. I will in the following employ the "three consumer engagement dimensions" proposed by Camarero et al.: "popularity, generated content, and virality" $(2018,1120)$. While the number of "likes" can be related to a page's popularity, Facebook allows its members to not only be a visitor of a page, but also to become a content producer by commenting. Generated content can be seen as an indicator for the users' commitment; the number of reposts or shares can measure the virality of a post or page.

My analysis has not considered information on how the Facebook algorithm works and what consequences this might have for the visibility of posts on users' own walls. While studies like Camarero et al. have used analytical tools to analyze a large number of Facebook pages, my own analysis was conducted manually using Excel. As far as I could find there are no longer free analytical tools available, probably because Facebook's data access policy has changed lately (Camarero et al. 2018, 1130). I have used my own FB account and accessed the institutions' FB pages to register all posts during the analyzed six-month period. Therefore, this analysis is based on small numbers for only three institutions, but is nevertheless complete in the sense that all posts during that period are registered and not only posts that appeared on my own wall. The findings therefore might reveal some interesting tendencies for how public libraries and museums are using social media and how they succeed in engaging their audiences.

\section{A Short Presentation of the Institutions}

All three institutions are situated in Tromsø, a municipality with 76,649 inhabitants and a large number of tourists visiting each year. Troms $\varnothing$ public library and Perspektivet museum are located in the city center, while The Arctic University Museum of Norway (TMU) is located outside the city center and can be reached by bus or car. 


\section{Tromsø Public Library}

Troms $\emptyset$ public library is a popular institution in the heart of the city. The numbers reported for 2017 show that the library had 7.8 visits and 4.7 loans total per inhabitant. While the last number is slightly higher than the average number for Norway as a whole, the number of visits is almost double the average number for Norway. ${ }^{6}$ The library has an official webpage with self-service opportunities for patrons like searching the library database or managing loans, information about opening hours, current events, and contact information. Here we also find links to social media platforms the library is present on: Facebook, Flickr, Twitter, YouTube, and Instagram. ${ }^{7}$

\section{The Arctic University Museum of Norway (TMU)}

The museum was founded in 1872 and is North Norway's oldest research institution. In 1976 the museum was incorporated in the University of Tromsø. Today the museum is a conglomerate consisting of The Arctic University Museum of Norway, The Polar Museum, MS Polstjerna, and the Troms $\varnothing$ Arctic Alpine Botanical Garden. Each of these branches have their own webpages and social media appearance, some available in Norwegian and English. I will in the following only focus on The Arctic University Museum of Norway, which had 55,089 visitors in 2017 and 60,909 in 2018.

The museum's webpages (see https://uit.no/tmu) are part of the university's official webpages. Here we find information about exhibitions, collections, and research, outreach initiatives especially for schools, information about the employees, and latest news. On the page with contact information we find a telephone number and an e-mail-address as the only possibility for individual contact. At the top left hand side of the page we also find two icons of social media platforms: Facebook and Instagram. By clicking on these icons, we get forwarded to the museum's Facebook page and Instagram account.

\footnotetext{
6 These numbers are according to the statistics made available by the National Library of Norway (only in Norwegian), https://kunnskapsbase.bibliotekutvikling.no/statistikk/statistikk-fornorske-bibliotek/folkebibliotek/, accessed February 27, 2019.

7 See https://www.tromso.kommune.no/hjem.255743.no.html, accessed May 15, 2019. The information is available in Norwegian, Sami, and English.
} 


\section{Perspektivet Museum}

Perspektivet Museum is a foundation established in 1996. The scope and contents of the museum's collections reflect Troms $\varnothing$ and the surrounding community's history from the 1950s to today. The museum belongs to Norway's national museum network and also participates in networks for minorities and cultural diversity. One important goal for the museum is to be a part of conversations and debates about issues of today. ${ }^{8} 24,361$ persons visited the museum in 2017 and 29,534 in 2018. The growing number of tourists visiting Troms $ø$ might explain the growth in visitors, but also the number of events taking place at the museum has increased during that period. The museum has a webpage in Norwegian and English (https://www.perspektivet.no/en/) informing about exhibitions, collections, and contemporary documentations. Under the headline "About the museum" we can read about the museum's history and about the people employed at the museum. In addition to Facebook, the museum is also present on Instagram and Flickr.

\section{The Institutions' Presence on Facebook}

The number of people who like the Facebook page of an institution (by September 2019) compared to the number of inhabitants in the municipality can give an indication about the use of these pages. ${ }^{9}$ Compared to other public libraries and museums in municipalities with about the same number of inhabitants, the numbers for Troms $ø$ are about average (Table 10.1). It is impossible to know from the outside why people choose to like the FB page of an institution. We can nevertheless assume that people who for instance like the FB page of the Tromsø public library are users of the library or at least sympathetic to the institution. The number of people who like a FB page does not necessary tell anything about how involved or active these persons are on FB. However, a general observation is that the number of followers is much higher than of the people who like, share or comment on the page. Even large institutions like the Museum of Modern Art (MoMA) in NYC with over 2 million followers has not much user generated activity on its FB page. The same can be said for public libraries in large cities.

8 For more information see the museum's own presentation on its web page, https://www. perspektivet.no/en/about-the-museum/, accessed May 152019.

9 People who like a certain FB page do not need any geographical closeness to the institution. Tourists can like a FB page, as well as people who have a professional interest, for instance libraries or museums are other potential followers. 
Tab. 10.1: Number of people who like the Facebook pages

\begin{tabular}{lll}
\hline Institution & $\begin{array}{l}\text { Number of people who } \\
\text { like the FB page }\end{array}$ & $\begin{array}{l}\text { Number of inhabitants in } \\
\text { the municipality* }\end{array}$ \\
\hline Tromsø public library & 4.291 & 76.601 \\
TMU & 7.652 & 76.601 \\
Perspektivet museum & 2.108 & 76.601 \\
Fredrikstad public library & 4.360 & 82.206 \\
Østfoldmuseene & 7.665 & 82.206 \\
Drammen public library & 3.260 & 69.233 \\
Drammens museum & 3.959 & 69.233 \\
Sandnes public library & 2.958 & 77.959 \\
\hline
\end{tabular}

* These numbers are according to Statistics Norway, https://www.ssb.no/kommunefakta/ tromso, accessed September 42019.

The period analyzed is the first six months of 2018, from January 1 until June 30. Even if the time period studied is limited, the results (Table 10.2) indicate some interesting tendencies.

Tab. 10.2: Number of posts per month

\begin{tabular}{llllllll}
\hline & January & February & March & April & May & June & Total \\
\hline Tromsø public library & 21 & 25 & 24 & 24 & 17 & 22 & 133 \\
TMU & 21 & 30 & 38 & 19 & 21 & 22 & 151 \\
Perspektivet museum & 11 & 14 & 12 & 15 & 9 & 13 & 74 \\
\hline
\end{tabular}

While the university museum (TMU) has most posts during these six months (151), the library is not far behind with 133 posts in total. On average the library posts 22 posts each month and the university museum 25 . Perspektivet museum has only 74 posts during the period, a clearly lower number than the other two institutions, but the museum is still active on a regular basis with an average of 12 posts each month. TMU was most active on Facebook in February and March, while the other months have a stable number of posts (about 20). The same can be said about the Facebook presence of the public library: about 20 posts each month, with only May - a month with many holidays - having less posts.

These numbers indicate that all three institutions are present on Facebook on a regular basis during the period investigated. They are nevertheless less active than proposed by Capriotti and Losada-Díaz: "According to these reports, the adequate frequency of posting would be between 1 and 2 posts per day (around 
7 and 15 posts per week)" (Capriotti and Losada-Díaz 2018, 645). The numbers for the three Tromsø institutions are meanwhile in line with the authors' findings for museums' posting activity on Facebook that has a "low average of just over two posts per week [...]. Moreover, the average number of original posts of museums is even smaller" (Capriotti and Losada-Díaz 2018, 645), as we will see in the following analysis of the posts.

\section{Tromsø Public Library on Facebook}

In June 2019 4,392 persons followed the FB-page of the Tromsø public library. The number of followers is not especially high compared to the number of inhabitants, but distinctly higher than for other social media platforms the library is using. ${ }^{10}$

As mentioned above, the library posts on a regular basis on Facebook, between 17 and 25 posts each month, or 5.5 post per week. In order to analyze the posts, the text of each post, the number of likes, shares, and comments were registered in an Excel document. Seven categories were created: literature, event announcement, shared content, information, pictures, questions, and other. In the case of doubt, the most prominent theme was chosen; for instance book reviews published by newspapers and shared by the library were categorized as "literature" and not as "shared content".

Table 10.3 shows the number of posts per months by these categories.

A large part of the posts are events getting announced (45) and shared content (30). Posts about literature, either book reviews or suggestions for what to read, are - not surprisingly for a library - frequent. Only a few posts are formulated as questions to the patrons or as an invitation to contribute for instance by sending in a photo of one's own book shelf or asking children to make a drawing for the library. Only two of the posts ask for the patrons' opinion about literature. The large majority of posts therefore is simply informative, not trying to establish a conversation between the library and its followers.

Most of the posts - 85 out of 133 in total - have between zero and ten likes. Taking into consideration that almost 4,000 people liked the page in 2018 and were engaged in one way or another with the content of the page, this number suggests little user engagement and activity. Only very few posts seem to be much more popular. The three posts with most likes ${ }^{11}$ were also shared and commented

10 By June 2019 the library had 18 followers on Flickr, 680 on Twitter, 13 on YouTube and 1,649 on Instagram.

11 Screenshots of the library's Facebook posts were taken 26.6.2018. 
Tab. 10.3: Tromsø public library - number of posts by categories

\begin{tabular}{|c|c|c|c|c|c|c|c|c|}
\hline & $\begin{array}{l}\text { Number } \\
\text { of posts }\end{array}$ & $\begin{array}{l}\text { Litera- } \\
\text { ture }^{a)}\end{array}$ & $\begin{array}{l}\text { Event an- } \\
\text { nounce- } \\
\text { ment }\end{array}$ & $\begin{array}{l}\text { Shared } \\
\text { link/ } \\
\text { content/ } \\
\text { post }\end{array}$ & $\begin{array}{l}\text { Questions/ } \\
\text { wish for } \\
\text { response }\end{array}$ & $\begin{array}{l}\text { Infor- } \\
\text { mation }{ }^{b)}\end{array}$ & Pictures ${ }^{c)}$ & Other \\
\hline Jan & 21 & 1 & 10 & 7 & $1^{d)}$ & & 2 & \\
\hline Feb & 25 & 5 & 11 & 6 & & & 2 & $1^{e)}$ \\
\hline Mar & 24 & 4 & 6 & 5 & 2 & 5 & 2 & \\
\hline Apr & 24 & 4 & 9 & 5 & & 3 & 3 & \\
\hline May & 17 & 3 & 5 & 4 & 1 & 4 & & \\
\hline June & 22 & 6 & 4 & 3 & & 8 & 1 & \\
\hline Total & 133 & 23 & 45 & 30 & 4 & 20 & 10 & 1 \\
\hline
\end{tabular}

a) For instance, about the death of an author or the nomination of an author for a prize, but also book reviews.

b) Practical information about opening hours or problems at the library, but also about empty positions etc.

c) Pictures from events, but also pictures showing how it looks at the library right now.

d) Shared link from British newspaper about Virginia Woolf but combined with a question to the patrons.

e) Sami national day.

on. Even if the number of shares and comments was limited, these three posts succeeded in engaging the followers much more than all the other posts.

The post with by far the most likes (120) is shared content (an article from digi.no) informing about how all Norwegian books published before the year 2000

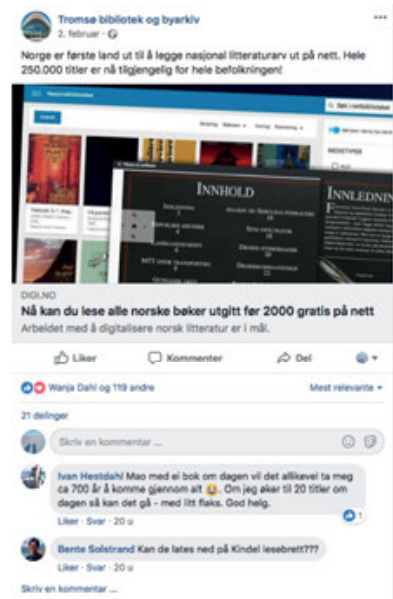

120 likes, 21 shares, 2 comments

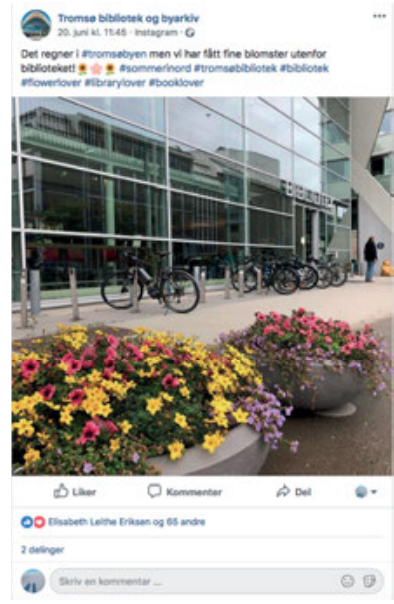

66 likes, 2 shares, no comments

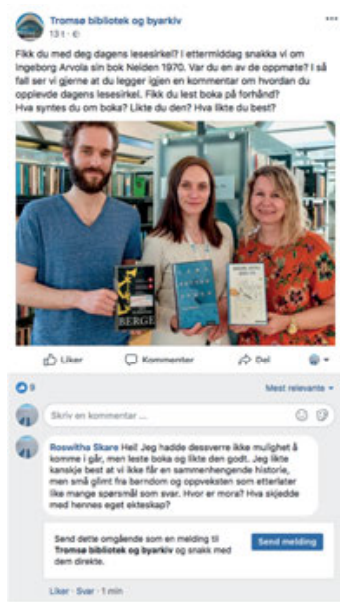

58 likes, 5 shares, 2 comments 
are accessible for free on the webpages of the National library of Norway - information that should be relevant and interesting for people interested in the library and reading. While Camarero et al. found that "external links which users need to click on seem [not] recommendable, since users prefer visual posts and short texts" $(2018,1129)$, this post did not only generate the most likes, but also a relatively high number of shares that contributes to the virality of the post and the library's Facebook page. One reason for this might be the content of the shared article, while another reason might be the way the library posts the article. The library not only posts the link, but also adds a short text that summarizes the content. The number of likes and shares indicates high popularity and a certain virality. There is nevertheless little user commitment with only two comments where one person is asking about practical issues while the other is pointing to the high number of books available online and how long it would take to read all these books. Neither the library nor the other users are reacting to these comments, not even on the practical question of whether these books can be downloaded to a kindle reader.

The post with 66 likes is about the summer weather in Tromsø. The photo used in this post is from the entrance of the library where flowers were planted. As pointed out by Camarero et al., the use of a picture might have "a positive impact on the number of likes" $(2018,1128)$. Even if the post reaches a certain popularity, it does not create content from the users or any virality. With regards to the topic of the post this is not surprising: there is not much to do about the weather, but the followers can express that they like the flowers or the image of the library together with the flowers by using the like option. Nevertheless, one might argue that the post works in connecting the library with its users and that the visitors can maintain a relationship with the institution by viewing the image of the library and by liking the post.

The third post presents an image of three persons with a book in their hands. The longer text explains that the library will start a new activity - a reading group - and how it will be organized. Users familiar to Troms $\emptyset$ public library will recognize that the picture is taken inside the main library. Some will also recognize the persons in the photo as librarians working there. Fifty-eight likes, five shares, and two comments indicate both popularity and virality, but little user engagement when it comes to creating own content. As in the case of the post with most likes, this post only generates two comments that express excitement about that initiative. There is no conversation between the library and its users or among the users about what to expect etc. 


\section{The Facebook Page of the Arctic University Museum of Norway (TMU)}

The FB-page of the Arctic University Museum of Norway (TMU) is followed by 7,632 persons (June 2019), a significant higher number of followers than the other two institutions in this study. The persons following the TMU might in addition to people living in Troms $\varnothing$ also be tourists that have visited or plan to visit Troms $\varnothing$ and the museum. In addition to FB, the museum is also present on Instagram $(1,883$ followers).

As for the library, the text of each post, the number of likes, shares, and comments were registered in an Excel document. As mentioned above, the total number of posts from TMU during these six months is higher than for the library, but here we can also observe the same tendency: a large part of posts are event announcements (60) and shared content (36).

Tab. 10.4: TMU - number of posts by categories

\begin{tabular}{lllllll}
\hline & $\begin{array}{l}\text { Number } \\
\text { of posts }\end{array}$ & $\begin{array}{l}\text { Status/ } \\
\text { activities }\end{array}$ & $\begin{array}{l}\text { Event announce- } \\
\text { ment/Shared } \\
\text { event }\end{array}$ & $\begin{array}{l}\text { Shared link/ } \\
\text { content/ } \\
\text { post/video }\end{array}$ & $\begin{array}{l}\text { Pictures/ } \\
\text { shared } \\
\text { albums }\end{array}$ & $\begin{array}{l}\text { "Fredags- } \\
\text { gløtt"c) }\end{array}$ \\
\hline Jan & 21 & 3 & 11 & 5 & 2 & \\
Febr & 30 & 5 & 12 & 6 & 4 & 3 \\
Mar & 38 & 2 & 18 & 12 & 3 & 3 \\
April & 19 & 3 & 7 & 4 & 1 & 4 \\
May & 21 & 5 & 7 & 4 & 1 & 4 \\
June & 22 & 5 & 5 & 5 & 2 & 5 \\
Total & 151 & 23 & 60 & 36 & 13 & 19 \\
\hline
\end{tabular}

a) For instance, Happy new year on January $1^{\text {st }}$, but also information about activities of the museum like exhibitions and collections or information about prizes won by employees.

b) Articles from the local newspapers (www.itromso.no; www.nordlys.no), from the university (uit.no), the Norwegian broadcaster NRK, forskning.no (about research in Norway), and forskerforbundet.no (the union most Norwegian researchers are organized in).

c) Every Friday an old photo accompanied by an explaining text is posted. In May there is one post called "Museumsgløtt"; the photo was not posted on a Friday, probably because of the many holidays in May.

The analysis of the posts led to five categories: status/activities, event announcement, shared content, pictures, and "Fredagsgløtt". While the first four categories can be compared to the library's activities on FB, "Fredagsgløtt" is a term coined by the museum itself for posts that combine old photographs with an explaining text, posted each Friday. The museum started in February 2018 with these posts 
on a regularly basis. "Fredagsgløtt" therefore is the only category with a given number of posts during the period studied here.

A little more than a third of all posts (57) had between 0 and ten likes, while another third (59) had between ten and 50 likes. Twenty-five posts had between 50 and 100 likes, while nine posts had considerably more likes, sharing, and also comments. Eight out of these nine posts had between 100 and 200 like, while one post was outstanding with 617 likes, 76 sharing and 137 comments. Five out of these nine posts with the most like included the one with over 600 likes which belongs to the category "Fredagsgløtt", published on Fridays.

I will in the following have a closer look on the three posts with most likes. Two of these three posts belong to the category "Fredagsgløtt", while the third one provides information on how to make a bee-hotel.

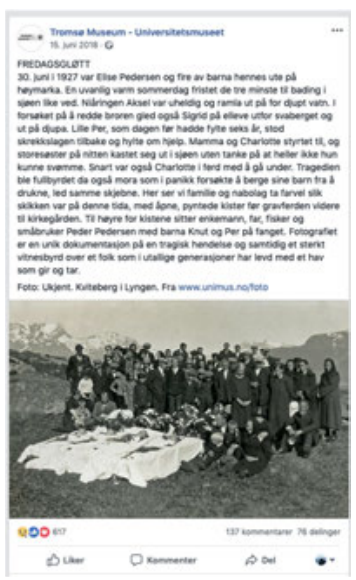

617 likes, 76 shares, 137 comments

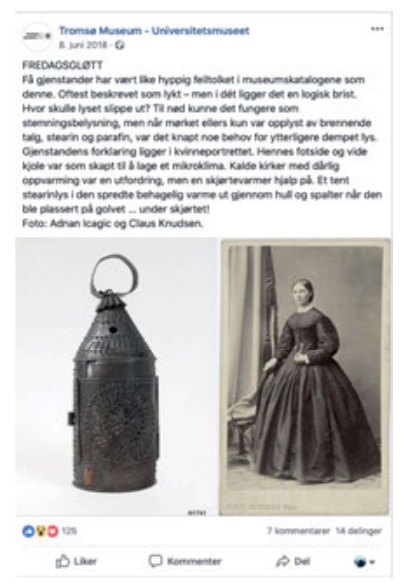

125 likes, 14 shares, 7 comments

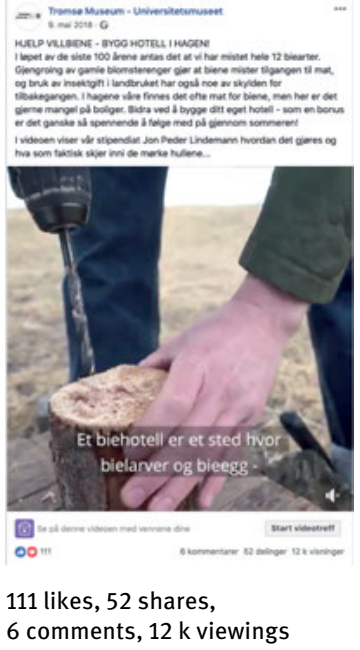

111 likes, 52 shares, 6 comments, $12 \mathrm{k}$ viewings

The post with by far most likes (617) presents an old photograph where family and neighbors are gathered around four open coffins. The accompanying text explains the tragical drowning accident that happened on a warm summer day in 1927. The name and age of the persons involved in the accident as well as the name of the place are mentioned in the text.

The high number of likes (617), shares (76), and comments (137) indicates not only high popularity but also high virality and user engagement. While Camarero et al. found that the "popularity of a post does not increase when its content increases (a longer post)" (2018, 1128), this post is actually an example with quite a long text, but all in combination with an image. The "creativity of said content 
(images and emotional tone)" (Camarero et al. 2018, 1128) seems to be the most important criterion for user engagement.

Although the content of the comments varies and some only demonstrate their feelings by posting an emoji, many of the comments are about the historical event, the persons in the photo etc. It seems that historical photos that the followers can relate to because of their geographical closeness and even familiarity with the persons in the photo create more engagement and user generated content that again contribute to the virality of the post, especially the post about the funeral which initiated a conversation between the followers of the page and also between the followers and the museum. Unlike many other posts that have comments, the comments on this post are not only articulating own thoughts but are also responses to the expressions of others. These responses transform the commentary field in a kind of meeting place for the persons involved and engaged in this historical event and create a kind of community for the time being.

While the post with the second most likes also belongs to the category of "Fredagsgløtt", combining historical images with an explaining text, the third post contains a video that shows how to build a bee-hotel. While the text invites the users to build a bee-hotel in order to help the bees find food and to survive, the video demonstrates how to build one. This post has many likes and shares and $12 \mathrm{k}$ viewings, but only six comments. Here we find people tagged in the commentary field, a way to draw other's attention to the content of the post, but not so much a way to engage in conversation with other people. This post also demonstrates that the content reaches a large number of persons but that most of them probably only watch the video without any need to express their thoughts about it.

\section{Perspektivet Museum on Facebook}

2,144 persons follow the Facebook page of Perspektivet museum (June 2019), the lowest number of all three institutions. The museum is also active on Flickr (395 followers) and Instagram (1,122 followers).

Even if Perspektivet museum has less posts during the first six months of 2018 (only three per week on average), the same tendency as for the other institutions is visible when analyzing the posts. Also, for Perpektivet museum the two categories of event announcements (23) and shared content (14) account for half of the total posts. The museum uses both pictures and videos to inform their followers about activities at the museum; videos are used more often here than the university museum.

The smaller number of posts - compared to the other two institutions studied here - can be explained by the size of the museum. The museum is probably not 
Tab. 10.5: Perpsektivet museum - number of posts by categories

\begin{tabular}{lllllll}
\hline & $\begin{array}{l}\text { Number of } \\
\text { posts }\end{array}$ & $\begin{array}{l}\text { Status/ } \\
\text { Activities/ } \\
\text { Exhibition }\end{array}$ & $\begin{array}{l}\text { Event announce- } \\
\text { ment/Shared } \\
\text { event }\end{array}$ & $\begin{array}{l}\text { Shared link/ } \\
\text { content }\end{array}$ & $\begin{array}{l}\text { Photos/ } \\
\text { shared } \\
\text { albums }\end{array}$ & Video \\
\hline Jan & 11 & 0 & 4 & 1 & 6 & 0 \\
Febr & 14 & 1 & 5 & 3 & 4 & 1 \\
Mar & 12 & 5 & 3 & 3 & 1 & 0 \\
April & 15 & 1 & 6 & 3 & 2 & 3 \\
May & 9 & 4 & 1 & 2 & 0 & 2 \\
June & 13 & 1 & 4 & 2 & 4 & 2 \\
Total & 74 & 12 & 23 & 14 & 17 & 8 \\
\hline
\end{tabular}

working with social media on a daily base, as there are periods with many posts and then periods with little or no activity. Forty-four posts, more than half of all posts, received between 0 and ten likes, 24 posts had between 11 and 30 likes and only five posts had between 31 and 50 likes. This might indicate less popularity and virality than the posts from the other two institutions. The post with most likes received 77 likes, three shares and five comments. Posts with photos and videos are the ones that receive most engagement, even if the numbers are smaller than for the "most popular" posts from TMU. As mentioned above, the Perspektivet museum does not post on Facebook on a daily basis. ${ }^{12}$ Some days they post several messages that seem to receive about the same numbers of reactions, which might indicate that fans who like one post also like all the other posts.

The post with most user engagement is a post about a product made by the museum. The post is in English, but the comments are in Norwegian, mostly expressing the wish for one of these toy bags. It also seems that the persons communicating with each other know each other already. The other two posts that created most user participation are photos from one of the events held at the open-air museum. The same person commented on both posts, expressing how much she liked that event.

12 Part of the museum is also an open-air museum situated outside the city center and some old buildings on the neighbor island. During the summer months many of the museum's activities take place in the open-air museum. 


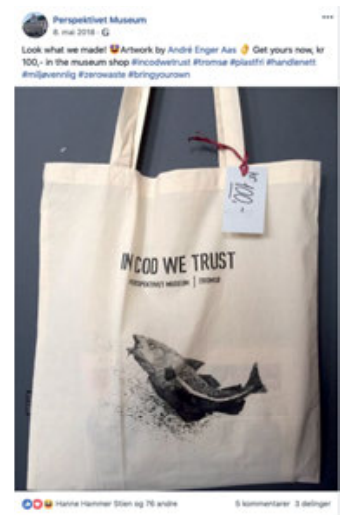

77 likes, 3 share, 5 comments

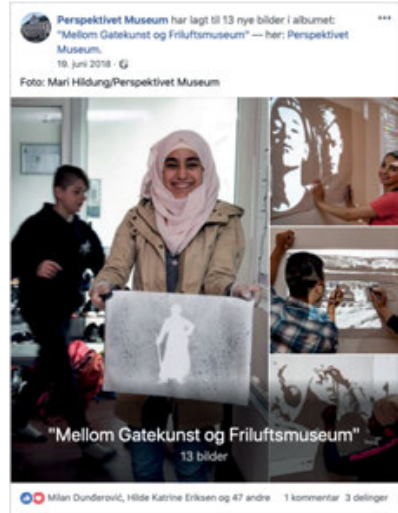

49 likes, 3 shares, 1 comment

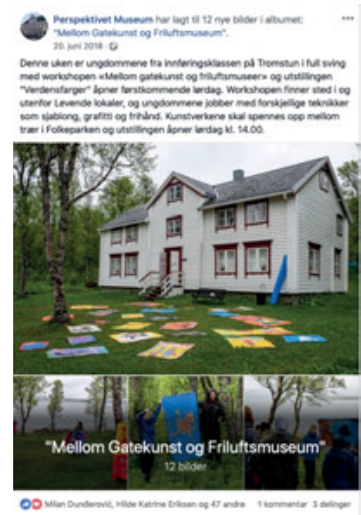

49 likes, 3 share, 1 comment

Even if the number of the museum's posts on Facebook is limited during these six months, this finding is also confirmed by Camarero et al.: a post's popularity increases when its content is presented "in a number of languages" $(2018,1128)$, and "the use of pictures [...] has a positive impact on the number of likes" (2018, 1129). "A greater total number of posts" - in the case of Perspektivet up to 4 posts on one day - reduces virality (per post)" $(2018,1129)$.

\section{Discussion of the Findings}

The comparison of the three institutions' Facebook appearance indicates many similarities: all three institutions post on a regular basis, but the frequency of posts is rather low. The posts usually combine text and images, with only Perspektivet museum using video on a more regular basis. Posts that announce events or share content are most frequent for all three institutions. Most of the posts have no or only very few likes and shares. Comments are not frequent and most of the comments are statements without any form for conversation or reaction to comments made by others. Only a few posts create a larger user engagement, not only in likes and shares, but also in the form of comments. Here the posts entitled "Fredagsgløtt" by the university museum are in an extraordinary position. Many of these posts are not only liked and shared, but create a conversation between the users and in some cases between the users and the museum, especially the one post about a tragic accident posted by the museum which has created by far the most likes, shares, and comments. The comments on that post actually also created a conversation between the followers involved and between the followers and the 
museum. This might suggest that the use of images (both still and video) is important, but even more important is emotional engaging content that connects the followers and the institution. As some of the posts of the Tromsø public library illustrate, it is not enough to ask a question to create a conversation: "At the post level, posting questions reduces virality. [...] if a [sic] organization is seeking users' active participation in its communications then the organization itself should also get involved in users' conversations” (Camarero et al. 2018, 1130).

The results from this case study seem to confirm that most Facebook users only read a post or watch an image without any need to get further engaged in the content of the post. It seems that most users are only engaged in activities that demand little commitment, such as liking and sharing of posts. While the numbers of likes and shares are indicators for a post's popularity and its virality, the number of comments might be an indication for the user's commitment. One might conclude that the users are - with the exception of the posts "Fredagsgløtt" by TMU - not very committed to these institutions, but this might only be true to some degree. From the outside it is impossible to know how many users actually read the posts, and whether they are engaged by the content or not. Since many of the posts are event announcements or contain practical information, they do not demand any kind of reaction or much engagement. This is in line with the findings by Capriotti and Losada-Díaz that Facebook often is used in "a traditional off-line one-way perspective [...], considering it as a mere tool that can be used to disseminate information about the institution and its activities, but not to stimulate interaction and two-way communication with their publics" $(2018,648) .{ }^{13}$ My own findings thus confirm what is established in other studies about the use of social media by LAMs and other organizations in the corporate world.

To meet patrons/ users where they are is one argument used by the institutions studied here to justify their presence on social media. Another argument, not explicitly mentioned, is announcing an event on Facebook is free compared to an advertisement in the local newspaper that must be paid for. ${ }^{14}$ The problem is still how to reach out to users and patrons. As far as I know, none of the institutions studied here have asked their patrons and users if they want the institution to be on Facebook or on other social media or what the users expect to find on social media. One might argue that institutions like public libraries and muse-

13 Similar findings were made by Ahorany 2012 and Lazzaretti et al. 2015.

14 Facebook is of course not for free and both the institutions and we as individual users are paying with information about ourselves and our information behavior. 
ums have to be present on social media because all others are. ${ }^{15}$ Nevertheless, it is not enough to be present on Facebook. The institutions not only need resources for posting, monitoring, and responding on social media; they also should have a clear strategy for what they want to achieve by their social media presence. In Norway, public libraries and most museums are non-commercial institutions financed by the public. Still, they depend on the number of visitors/ patrons to legitimate their existence and funding. It is therefore important to reach out to the public and to tell about activities and news. Social media can be seen as one tool to connect with the public and a place where visitors can maintain a relationship with the institution.

Discussions about the Internet and especially about Web 2.0 and social media platforms often stress their democratic potential, providing meeting places where user contribution, collective intelligence, reuse and remix (Jenkins 2006), but also empowerment and ownership have become buzzwords since the mid-2000s. Participation in terms of individuals becoming "creators and primary subjects" who communicate "effectively into the public sphere" (Benkler 2006, 213) is discussed as the Internet's democratizing potential leading to the emergence of a network public sphere (Benkler 2006, 272). While this might be true for user generated content on for instance wikis, blogs or YouTube, Facebook is obviously not the place for many of these activities, as most of the users are more or less passive consumers of the content presented by the institutions. ${ }^{16}$ Capriotti and LosadaDiaz conclude that "the museums analyzed [...] are not taking advantage of all the tools offered by Facebook as a means of interactive and dialogic communication" $(2018,647)$. The same could be said about the institutions in Troms $\varnothing$ analyzed here. This leaves the question unanswered of if users actually are interested in using social media platforms to communicate with each other or with the institution. As mentioned before, the large majority of FB-users are passive consumers not active contributors or even producers of content. If the institutions want to interact with their users by providing digital meeting places, for instance on FB, they have not only to use the opportunities provided by the social media platform, but also engage in a conversation with their patrons on a regular basis. It is obviously not enough to ask a question once in a while; a climate of dialogue, exchange

15 In the USA, "93\% of the largest libraries; 82\% of libraries serving between 25,000 and 499,999; $68 \%$ of libraries serving between 10,000 and 24,999 ; and $54 \%$ of the smallest libraries" (Hofschire and Wanucha 2014, 7) were on Facebook in 2012.

16 It would be interesting to look into commercial FB pages and the role of competitions and giveaways. Users seem to participate by writing a comment much easier when they can win something. However, these comments often are not creating any form for conversation but are only very short statements; often the company only asks for an emoji or the name of a person. 
and conversation has to be established day by day. The examples from the university museum's "Fredagsgløtt” indicate that a conversation between users and between the institution and the users is possible as long as the content is personally engaging. It seems that posts consisting of old photographs and emotionally engaging stories are the ones that engage followers the most, often also because of the follower's geographical closeness to the place and the persons involved. The use of images and videos, especially from events where followers can see and watch themselves or persons they might know, seems also to create a high user engagement in shares and likes.

There might be different reasons for people to follow the library or a museum on Facebook. Getting updates and reminders about events might be one important reason, while meeting other people might be less important in an online environment. Nevertheless, the Facebook pages of institutions like public libraries and museums are part of the public sphere, even if these digital public spheres are small and produce only little user participation. These "weak publics" (Fraser 1992, 134) exist beside all the other publics the institutions create both by their events and by being open and including institutions where people can meet and talk to each other, either planned or by chance.

\section{References}

Aharony, N. "Facebook Use in Libraries: An Exploratory Analysis”. Aslib Proceedings: New Information Perspectives, 64, no. 4, 358-372, 2012. https://doi.org/10.1108/ 00012531211244725.

Badell, J.-I. “Museums and Social Media: Catalonia as a Case Study”. Museum Management and Curatorship, 30, no. 3, 244-263, 2015. https://doi.org/10.1080/09647775.2015. 1042512.

Benkler, Y. The Wealth of Networks. New Haven, CT: Yale University Press, 2006.

Capriotti, P. and J.-C. Losada-Díaz. "Facebook as a Dialogic Communication Tool at the Most Visited Museums of the World". El Profesional de La Información, 27, no. 3, 642-650, 2018. https://doi.org/10.3145/epi.2018.may.17.

Carlsson, H. "Researching Public Libraries and the Social Web, 2006-2012". Journal of Documentation, 71, no. 4, 632-649, 2015. https://doi.org/10.1108/JD-03-2014-0046.

Camarero, C., M.-J. Garrido, and R. San Jose. "What Works in Facebook Content Versus Relational Communication: A Study of their Effectiveness in the Context of Museums". International Journal of Human-Computer Interaction, 34, no. 12, 1119-1134, 2018. https://doi.org/10.1080/10447318.2017.1418475.

Fraser, N. "Rethinking the Public Sphere: A Contribution to the Critique of Actually Existing Democracy”. In Calhoun, C. (ed.), Habermas and the Public Sphere, pp. 109-142. Cambridge, Massachusetts, and London, England: The MIT Press, 1992. 
Hofschire, L. and M. Wanucha. "Public Library Websites and Social Media”. Computers in Libraries, 34, no. 8, 4-9, 2014. https://search.proquest.com/docview/1625138478? accountid=17260.

Jenkins, H. Convergence Culture. Where Old and New Media Collide. New York and London: New York University Press, 2006.

Jørgensen, G. “Den vanskelige dialogen. Om universitetsmuseenes praktiske utfordringer i møtet med web 2.0-samfunnet”. Nordisk Museologi, 1, 81-97, 2011. http://dx.doi.org/10. $5617 / \mathrm{nm} .3147$.

Kidd, J. “Enacting Engagement Online: Framing Social Media Use for the Museum”. Information Technology \& People, 24, no. 1, 64-77, 2011. https://doi.org/10.1108/ 09593841111109422.

Kidd, J. Museums in the New Mediascape. Transmedia, Participation, Ethics. London and New York: Routledge, 2016. https://doi.org/10.4324/9781315596532.

Kommunal- og moderniseringsdepartementet. "Digital agenda for Norge. IKT for en enklere hverdag og økt produktivitet. (Meld. St. 27 (2015-2016))”. Technical report, Departementet, Oslo, 2015. https://www.regjeringen.no/no/dokumenter/meld.-st.-2720152016/id2483795/.

Kulturdepartementet. "Nasjonal strategi for digital bevaring og formidling av kulturarv. (St.meld. nr. 24 (2008-2009))”. Technical report, Departementet, Oslo, 2008. https: //www.regjeringen.no/no/dokumenter/stmeld-nr-24-2008-2009-/id555254/.

Kulturdepartementet. "Framtidas museum - Forvaltning, forskning, formidling, fornying. (St.meld. nr. 49 (2008-2009))”. Technical report, Departementet, Oslo, 2008. https: //www.regjeringen.no/no/dokumenter/stmeld-nr-49-2008-2009-/id573654/.

Lazzeretti, L., A. Sartori, and N. Innocenti. "Museums and Social Media: the Case of the Museum of Natural History of Florence". Int Rev Public Nonprofit Mark, 12, 267-283, 2015. https://doi.org/10.1007/s12208-015-0136-5.

Mathiasson, M. and H. Jochumsen. "Researching Public Library Programs Through Facebook Events: A New Research Approach”. Journal of Documentation, 75, no. 4, 857-875, 2019. https://doi.org/10.1108/JD-08-2018-0137. 


\section{Kjell Ivar Skjerdingstad \\ 11 Reading Between the Shelves - the Library as Perspective in Life and Profession}

to be in place is to know, is to become aware of one's very consciousness and sensuous presence in the world [...] place is the most fundamental form of embodied experience the site of a powerful fusion of self, space and time. (Feld and Basso, 1996, 9)

In commanding public libraries to emphasize "kvalitet, allsidighet og aktualitet" in what they provide to children and adults, the Norwegian Library Act structures professional practice. While considerable research has been devoted to the implications of quality (Oterholm 20191), and some to aktualitet (Oterholm and Skjerdingstad 2015), allsidighet has not been discussed. The Law itself does not expand on the notion, nor do the preparations apart from emphasizing that public libraries need to reflect the variety of the users' rights to choose themselves, have an obligation to inform on various subjects, and to "reflect and mediate different perspectives in the current public debate" (Kulturdepartementet 1986). The bottom line then seems to be that libraries should provide access to a broad range of literature and other media usable for all potential purposes by all potential users in all potential situations, times etc. As such, allsidighet depicts a central idea in libraries' self-descriptions, even in most other countries. One appropriate question, even in a more international context, would then be how libraries translate this political lead, or overarching ideological guideline, in their practices, and how these are experienced by the users, loaners, readers, attendees. Following up on this, my chapter then hopefully contributes both to the development of this underexplored concept in Library and Information Science, and responds to the need for continuous professional development (Nolin 2008).

Etymologically, the word allsidighet refers to an object having all or many sides, and to that which may be used for various purposes. Possible translations would be universality, multiplicity, versatility, diversity, comprehensiveness, many-sidedness or plurality. German uses Allseitigkeit. To avoid misguiding connotations, here I will stick to the initial Norwegian word.

As professional practice embeds ways of seeing, thinking, and categorizing (etc.) the world, reading one's surroundings is essential. By way of reading the public library as a text, as a web of intersecting signs, meanings, and voices,

1 See Oterholm 2019 for further references and discussions on the topic.

2 Open Access. (c) 2020 Kjell Ivar Skjerdingstad (c) BY-NC-ND This work is licensed under a Creative Commons Attribution-NonCommercial-No-Derivatives 4.0 License.

https://doi.org/10.1515/9783110636628-011 
through an in-depth heuristic method I try to uncover how allsidighet is conceptualized and realized in the public library. Contrary maybe to current trends in library and information research focusing either the digital or the social independent of the physical in situ collections (Söderholm and Nolin 2015), I equal libraries with the books, reading, and materiality of the place. This article then explicitly answers to how Söderholm and Nolin find that "wanting in discussions emphasizing the social is inquiry into the potential of the public library's already well-established traditional (infra)structure in its most concrete form: the on-site physical collection" $(2015,245)$.

The roots of the word library in English as well as its pendant in German and Scandinavian languages, Bibliotheca mercilessly point at how a library needs books and books need to be somewhere. Of course, the early history of libraries (for example Wehus 2019) confirms this. Even the coexistence of several other library functions in current practices, or the concept of digital libraries as frequently confirmed by their iconography, lend heavily on this idea. So, let that be my point of departure: first there is a collection of books. Then, of course, without people coming in, it is merely that, a collection; an invisible archive (Skjerdingstad and Tveit 2019).

Departing from one work-week of participation in the daily life of the local library of the village of Gloppen on the Norwegian west-coast in spring 2017, I have made observations, talked to staff and loaners, followed up on books or other phenomena that were given weight, such as anecdotes of what was told in meetings etc. Everyone I talked to was aware of my task as wanting to know the daily professional life so to speak from in-between the shelves. I took notes which were amplified and given thicker descriptions and rewritten at least twice a day, morning and evening.

From the onset I wanted to read the library as a text involving the observer, reader, as a phenomenologically situated embodied subject. Reading in this sense implies a decoding of signs, images, letters, but a reading experience also involves feelings and senses as when fictional reading makes us see, listen, shiver or fear (see for example Rothbauer and Skjerdingstad 2013). The idea however of bringing the concept of allsidighet to the fore came much later and made it necessary to revisit the library once more for half a day. Furthermore, I have had three conversations with the chief of staff Torill Berge on the telephone. She has also read the manuscript twice and given invaluable contributions, insights, and corrections. 


\section{The Library as a Perspective in my Mother's life - a Personal Prologue}

In libraries there should be books and materials for everyone. "Also, for auntie Mary in The Bay", says one of my informants working at the local library of Gloppen. Her loans and readings may be low-brow or high-brow, however through the books the library has become what the librarian terms "a perspective in her life. Not only the books, but the library is part of how she sees the world." On the one hand, this points at the bottom line of allsidighet. Of course, the library must offer different books and materials, but less obviously maybe, it even corresponds to the loaners', users', and attendees' ways of seeing. The library as a perspective in life implies that there are always more books available. This is the basic grammar of loaners' expectations for allsidighet.

In condensed form, as a perspective in the life of attendees, the library states this: there is always a book behind the book. And tentatively, this could be a way of looking that, putting it bluntly, not so much looks for similarities or hidden meanings as for the possibility of something else. Reading for the library then would be looking for diversity, for what is behind or besides what else may be there. Attempting to grasp where it leads one to have the library as constitutional in one's way of seeing, as a perspective in the users' life, I have made a small detour to visit my mother who has always had the library as a part of her way of looking at herself, her family, her work, and the world.

My mother, a former school teacher, born in 1938, has always read an immense amount of books of all kinds: "My goal was always to sit down and read - when doing housework, cleaning, cooking, tidying - I always aimed at the point where I could finally sit down with the book." Since before going to school, when the library in her small southern coastal home town of Grimstad was just some shelves guarded by two old Misses, she continually went to the library. I remember her taking me as a small boy, first to our local branch in the school in the outskirts of Trondheim, then Norway's third largest city, and later to the municipal city library down town. And when I ask her about this topic, she of course walked up to the "new" local branch yesterday. She is there several times a week. So, while she has made her one essential move from her hometown via some years at the seminary in the capital Oslo, to living in the same house now for over 50 years, the libraries have changed multiple times. To her, just as well, they are all the same; her library has remained The Library. The library has always been part of how she looks at and how she perceives the world - in how she reads it. She could always go to the library. I think it is fair to say that for her knowing that the library is there confirms the possibility of continuing to live and connect to a plurality of 
persons, stories, times, places, and moods, that goes far beyond reading as reading a book.

My mother reads lots of books. Always several at the same time. She needs the multiplicity of various books. Just now, this week that I am talking to her; she reads a book about the author and actor Marie Hamsun, also wife of Nobel prize winner Knut Hamsun. She remembers both of them from her childhood as they lived just outside Grimstad. She is also rereading a historical and geographical trilogy on her present region Trøndelag; rereading the local books, she says, is valuable because she now knows all the places it tells about. She says it is about recognition and places, now having been there, and then again through reading she revisits once more. She also reads a biography of St. Olav (the patron saint of Trondheim) which again makes her reread the medieval poet and historian Snorri, who tells Olav's story from yet another angle. And, she reads it all at the same time: so, in a certain sense, she never reads a book, always a library.

For the last 20 years she has written down all the books she has read in a list now covering several note books - itself a library catalog, a kind of library. When I ask her what for, she answers it is to check out whether she has read something before. It is a question of verification but maybe also of lived life; of recalling both the multiplicity of her readings, and of her life folding out and between these readings. And maybe most important to her, the echo between these two: a life with eight grandchildren and four daughters-in-law and as a schoolteacher and wife and friend, but always with this drive towards finally being able to sit down and read.

The registration of books then embodies and manifests what she looked for and all that was fulfilled and missed in-between. As Umberto Eco (2009) reminds us, a list even discloses what is not listed. For my mother that would be all that which the readings were embedded in: washings, cooking, weddings, birthdays, cake-and-coffee-gatherings. The list transforms what would elsewise disappear into the iterative narrative mode, to singular events, both those that stand out, but maybe even more what is in-between. Stretching back, the list tells and confirms that a life is lived; kind of like how family photos from the past both portray a moment and make a cut in the continuous flow of time. They make us remember that place and those persons, but also reveal the sheared edge of time and oblivion surrounding this moment. A list of life's read books as photos from the past evokes the feeling of time having passed and the paradoxical presence of what is missing, of a life lived: again this "That too!"

It is informative comparing it to how the Norwegian folklorist Moltke Moe in the nineteenth century described the folk ballad: "The high points of the action side by side, like a far-off row of mountain peaks - all the rest in mist and fog, left to be filled in by fantasy" (Johannesen 1993, 132). The look for the library, 
the program it installs in the way people like my mother see the world, partly at least, can then be identified as this look for peaks in-between: the look for the books to sit down and read after the duties. But then that look also reveals all the variations that lie behind and between: all the richness in the fog. All that is hidden in oblivion that however may reveal in a glimpse a face, place, atmosphere or smell.

The library as a perspective, or maybe better a way of seeing in life, is this gaze, or perceptive mood, this consciousness that there is always a book behind a book beside a book, this sense that there is a life behind a life, that both in and between the titles and readings and shelves there is the variety of days of lived life - sorrows and pleasures, tasks and duties. Readings, happenings, events, rituals, and the repetitions of everyday life, the duties, the same tasks over and over: finally, I can sit down with a book. There is in that a palimpsest, a transfiguration of life in the reading not only as when reading evokes memories, affects, and thoughts, but also as an act where layer upon layer of life - of present, past and hopes for the future - lends meaning to each other (Bjerg 1988; Genette 1997).

\section{Reading: From Work to Text}

According to evolutionary psychology, our ability to read stems from the need to distinguish and judge signs of danger or nutrition, to foresee the weather or understand the possibilities of certain topographies for our basic needs for survival (William-Olsson 2011, s. 75). In this sense reading is always intentional; there is a dialectic between purpose (for example the librarians' urge to mediate allsidighet) and the possibilities and restrictions of the environment (Merleau-Ponty 2000). In moving through textual as well as material and topographical environments, we read them as complex totalities of obstacles, passages, warnings or encouragements (etc.) according to our motives, needs, purposes. In reading we mobilize what we know and what we have learnt, i.e. our skills, memories, thoughts, associations, affects. Reading in this sense needs to be understood as an embodied practice involving affective and cognitive functions, sensing, perceiving, thinking, remembering etc. "In fact to read is to wander through an imposed system (that of the text, analogous to the constructed order of a city or of a supermarket)" as Michel de Certeau puts it (1988, s. 169). In the following, this is precisely what I aim to do - I will report from my walking through that imposed system not of the supermarket or the city, but of the library as if it is a text I pass through with my body: reading for the library in walking through the library would then, obviously, even enlighten how it directs me to see the world through the library. 
Roland Barthes helps me understand how this could be done. Even though his small essay "From work to text" is an effort to rethink the text as independent of its author, it also lays the foundation for a conceptual understanding of the surroundings as if being text. What Barthes does here is to unleash the text as a field we pass or work ourselves through. His semiotically grounded reflections allow me to see how the body moves to orient itself in the perceptual and semiotic surroundings considering its aims and intentions - for example to understand allsidighet.

To Barthes, a text does not contain meaning; rather it offers words, sentences, paragraphs and passages from which meanings may emerge, emanate, be drawn. Correspondingly there are always many meanings at play, and each meaning is by itself meaningless if not comprising inner conflicts. To Barthes then, literature, text, and in our context libraries offer themselves as places where further thinking is sustained, encouraged, and provoked. Where texts lead us? is therefore a more pertinent question than what do they mean. In reading the library as text, the question is where it leads us if we follow our intention to find out how it fulfils its political mandate if we look for how allsidighet is executed; how it comes to the fore and how is it hidden away, forgotten or displaced?

Barthes further specifies such an attitude to text and reading by means of the interdependent notions of signifier and signified, carrier and content. He then lays the foundation as a way of reading that echoes everyday reading of other people and signs - in a manner that more precisely

practices the infinite postponement of the signified: the Text is dilatory; its field is that of the signifier. The signifier must not be conceived as "the first stage of meaning", its material vestibule, but rather, on the contrary, as its aftermath; similarly, the signifier's infinitude does not refer back to some idea of the ineffable (of an unnamable signified) but to the idea of play; the engendering of the perpetual signifier (in the fashion of a perpetual calendar) within the field of the Text is not achieved by some organic process of maturation, or a hermeneutic process of "delving deeper", but rather by a serial movement of dislocations, overlappings, and variations; the logic governing the Text is not comprehensive (trying to define what the work "means") but metonymic; the activity of associations, contiguities, cross-references coincides with a liberation of symbolic energy (if it failed him man would die) (Barthes 1986, 59).

What Barthes here underscores in his poetic and enigmatic language is how the meanings you search, either in a text, a textual practice such as a book talk or a website, or in the library, always will and should slip away. There is always a meaning behind a meaning; "a book behind a book behind a book" as it is said in Michael Glawogger's beautiful documentary from the Russian National Library (Glawogger 2013; Norang and Skjerdingstad 2019). Searching for the meaning of the library is not looking for a hidden essence, but trying to open the plurality of 
possible, local meanings that play with and against each other. And in our context - more specifically - how it echoes allsidighet. The text is, Barthes writes, not "coexistence of meaning, but passage, traversal; hence, it depends not on an interpretation, however liberal, but on an explosion, on dissemination” (Barthes 1986, 59). Reading therefore is about discovering, finding new ways, plotting places of significance, pointing at and saying there, there and there: "Let us take a walk through that passage, because I am wondering what is on the other side." The library then seems to lend itself as a metaphor (even metonymy as the library is literally a collection of texts) for text, and Barthes gives us a method to read libraries as texts of/or passages according to our interest - as in my case allsidighet. He offers a way of reading which I will emphasize once more demands a methodological attitude to see and look also for the marginal and not so prominent as long as it matters and seems useful for the reader, practitioner or researcher that intends to see what goes on.

Barthes' way of reading is as I underscored above, in line with everyday practice, not least in that the driving force is desire, desire maybe as in Freud's sense as an urge to incorporate more, expand, and grow as that necessarily also implies to create tension, inquietude, and difference (Freud 1991). However, the way of the desire is continuous; desire always merges what comes into that which exists. Desire wants more. Desire creates and is created by tension. So, there is the tension, but also the methodological challenge for me as a researcher (as for the professional or the student) to know where and how I am following the desire. The challenge is to know and show where I come from and where I am heading when trying to recuperate my investigative reading journey through the readings/ writings of my own text. Does the journey lead to new places formerly not visited and how do these places or topoi relate in one way or another to what I am searching for; allsidighet.

\section{Library Philosophy - Careful Connections}

The local library of Gloppen is located at the fringe of the small village; just behind is the local museum of cultural history with the minor, dark, tarred timberbuildings along the creek. And behind the museum there is the forest. There is a secondary school, a primary school five minutes' walk away, a gym, a football field, and an indoor sports centre as well as an outdoor-field. Nearby is a high school, and the library localities themselves are new and joined with other institutions - the music festival, the local arts-schools for children etc.

Gloppen public library also serves as a school library. The Norwegian teacher from the secondary school underscores the importance of having a library so close 
by - precisely because it "implies the possibility of being close to books all the time". There is a necessity in this, he claims, both in the sense that young people hang around in an area where books with their varying voices are forming the place, and in the sense that here they know they can always get advice from people who know literature and have no interest in pushing them either in this direction or that. In his words the library becomes "The Other Room". It is a nice place to be; there are comfortable chairs and sofas, medium-high partitions that both allow shelter and give an overview, nice warm colours, and a large window opening the library space towards the community, the fjord, and in the faint distance one of the largest medieval barrows on the West Coast. You can see it, but you must know it is there to discover it. But if one knows, the window opens towards history beyond the everyday-activities of the sports-fields and the commercial centre which we see in the middle ground. All in all, the library becomes an open and comfortable place that establishes and verifies both the connection to the homeplace and the local community, and to time and history. As such it is also a liminal zone, a facilitator for such processes as writing, thinking, and contemplation or in-depth reading as in the liminal what is is challenged by what is not.

The librarian-in-chief Torill Berge puts it this way: "Our philosophy is publikumskontakt" - connections with the audience. She supports her argument; it concerns talking to those loaners that approach the desk about what they have read, it is being able to do small-talk as well as listen to and communicate on all that which is beyond everyday routine. It is, and I continue paraphrasing here, about being able to connect to what others say through a few sentences; either the subject is what is at hand or of a deeper more existential or abstract character, to pass with them through a short passage of words, and then continue with something else. Being there for everybody. That is one of the clues to practice allsidighet.

"Oh, how nice to see you guys again. So once more you are back home". In this informal way the young male adults are greeted, those who are home for a short visit, they who have left to study or work in nearby cities or further away. And this is precisely the bottom-line of what this local library according to its philosophy wants to be - a place where people are recognized. Berge expands:

The elderly woman who is regularly dropping by, with her brownish leather handbag with the golden lock, the bag marked by wrinkles and scars from ages of use that since the forties has been used exclusively to carry books. She who is curious and updated on what new books are coming, and who at one opportunity reveals to her who attends the front desk 'imagine, is it not incredible that we can have such a relationship without knowing each other'. She whose daughter once dropped by to borrow some books for her mother, making the librarian think what she cannot say: That you cannot take these books with you back home to her, it is under, it is below, it is outside of her taste, preferences, style, dignity. 
The point is not that the daughter hardly knows her mother, or whether the librarian knows her better, but to illustrate the obvious point that librarians may come to know the users in a particular way, namely as readers. A library reader being, one may assume, in concordance with my personal prologue, one part of the many ways-of-being that pertains to a person. A reader being, and that is what the small story above really tells us, one of the many very different personas that may imbue and constitute an individual. The reader as part of her diversity.

Next, though maybe banal and easy to overlook, my point is that these small encounters obviously matter - to the users, but such encounters also make the community, make the library: what matters most with them is maybe the simple fact that they occur. Such meetings weave people together in what linguist Roman Jakobson termed phatic communication - all we say and the ways we say it is simply, but even more importantly, to sustain community, keep the communication channels open (Jakobson 1960). Small-talk in this sense confirms that you are, and you are here, as well as that I am, and subsequently we are, here. Then what matters is that these passing encounters take place. As such they even make place. However, Berge then modifies -

concerning connection to the users as part of our philosophy: it sounds sturdy and bombastic. Neither is it quite true. There are so many people coming in that just want to be left alone. To be here without obligation. Precisely because it is not binding, non-committal. In this perspective, our task is to judge whether people want help or just want to be left alone. We must be able to sense that difference. People use the library in a plurality of ways. We do not know what they use it for, but we know that they know that we do not know that! Here people are free from being asked, often in majuscules, CAN I HELP YOU?

Beyond the philosophy of connecting, there is an understanding of connecting as including even letting go. The practical clue as how to practice this is in the capacity to read and judge situations - when to approach and how, when to stay back while also being available. Again, the librarians underscore allsidighet as the core of their philosophy; of this local library in Gloppen, as having to do with how you look upon the basics of the library - books and reading as well as people. Books, of course, work differently according to varying situations and readers: "We shall have something for he who needs a light book to be able to fall asleep in the evening, and for the old man who wakes up each morning at five o'clock and needs an audiobook till his wife awakens so that the day does not fall so all too long." The librarians emphasize that even though "these functions maybe not are so highly estimated or point at ways of reading commonly seen as less valuable, this is something we should and must consider in our work. It is an important part of our political and social mandate". The problem, they continue, is that these functions are hard to communicate or market. They easily fall into a "political and 
social shadowland" for politicians and other decision-makers: "The library has no dependents. Schools and kindergartens, teachers and pupils use and need the library, but the library is not what defines their tasks or practices.” This points of course directly at the political problem par excellence; the library hardly defines the life and activity of anyone - not even my mother or auntie Mary.

Our West Coast library is a new one. It is situated close to nearby culture and knowledge institutions. This new placement also enables new things to happen, and other local social agents to read the library differently. When the local Music theatre stages an opera based on Roald Dahl's book The Witches, the library automatically connects and makes an exhibition. One of the local cultural bureaucrats tells about a tour with a locally based storyteller, folk musician, and "world star". She performs

\begin{abstract}
popular ballads and stories from how everyday-life used to be some years ago, when people had to cooperate to make a living in more than poor rural circumstances. She sings songs from a time when songs were a tool among other tools to manage and survive, to get the work done. Therefore, we wanted to share these amazing locally based musical narratives with other communities in the region. We wanted to share it because those places were where these tunes and stories belonged; they are gone, so if they are going to survive, they need other arenas. Thus, we decided to visit other local libraries with this treasure.
\end{abstract}

The local tour had between ten and 15 listeners at each place. That is of course just a few, and it is small scale. However, the small congregation is here esteemed as a positive sur-plus value in that it contributed to a sense of reconstructing the original intimate settings of the songs. The official tells that even though it was a varying experience more than anything due to the differences in infrastructure, for example when a library had fixed shelves like in a store, and a sofa just by the door which was the one place one could perform, in one way that hindered the performance. In another, in contrast to a fixed professional scene, these "shortcomings" of the library added up to the value of the project by underscoring the original everyday nature of the songs. However, when asking for artefacts and books with local historical information to utterly underscore the local and historical atmosphere of the songs, the result was quite varying, as were the librarians' ownership of the visit. The bureaucrat continues:

It is a question of place and of people. Librarians should have a sensitivity for what happens, of what goes on and where people are. You see it here; all kinds of people drop by. And all are met with respect. The librarians meet people I never get in touch with. People who struggle with their lives and find nourishment there. It is something about what I identify as a professional attitude of librarianship emphasizing that each and one have a dignity of his own, a right to have a place of his own, and potentials that may be released. They support the activities of other people and of other institutions. 
I listen to a second teacher at a school situated a five minutes' drive away from the library. So, it is not immediately accessible in school time. To her therefore, it is important to make the school as she puts it, "slightly more library". Therefore, she has put up shelves and provides books from the library, so there is always a small collection available in the classroom. It is particularly useful when someone has finished their work or has some spare time: "At one occasion we worked with the North Pole. One of the boys found a book about it, read it and came to me, annoyed! 'Why, haven't you told me this!' That is, told him there exist books, that he should have known about." What the teacher then tells us is a story about how the library is thought of as another way of seeing. There is something, and there is something above, beyond, besides, behind. A surplus. There is more. Of, course the boy discovers a book, but his discovery is also that there are books, and therefore books behind books behind books: an actualization of allsidighet there are other ways.

\section{Double Vision}

The librarian-in-chief utters that their philosophy is to connect with the users, but as stated, contact for her even implies a respect to leave alone. As a philosophy, connection therefore demands a certain kind of double vision - an ability to see that things could always be otherwise. The eighteenth-century Norwegian poet and critic Aasmund Olavsson Vinje (1818-1870) termed it tvisyn - an ability to see both the right and the wrong side of the woven fabrics of life, to laugh with one eye while weeping with the other, as he famously said and wrote.

When attending a staff meeting - they are three, two librarians and a parttime assistant - I ask about a painting. I am told that the blue horse has become an idiom for the small community of workers. It refers to a famous poem by Brazilian poet and pater Dom Helder Camara (1909-1999) which they read aloud:

Be merciful Lord. / Care especially for / the people who are so / logical, / pragmatic, / realistic / that they are offended / when someone believes / that there exists / small blue horses.

The picture however has a story; in 2006, before moving, the library won it as part of a prize. At first it was only there, "next we came to see how it was connected to our township both because there is also a horse in the municipality coat of arms, and because it was the chief administrative officer of our community that later explained to us how the image was connected to Camara's prayer.” Torill Berge, the chief librarian continues: 
Yes, she made us aware of that. So, the picture came to connect literature and the local community and represent literature as an opening towards the world. Then we had to find out what it was, and it became a reminder - not a prayer for those that may forget the power of imagination - but a reminder to ourselves to not forget to be wondrous, curious, questioning. You know, everyday life may be quite hectic - there is a lot of to-and-fro, routines, reporting, fuss and bother, opening and closing, arranging, e-mails, meetings... So, it became kind of a proverb for us - we can tell each other that 'now we are about to forget the blue horse' and we all know what that means. It helps us recall our passion for literature. The blue horse has become a tool, a point of support in our common everyday life. When one of us identifies something worth bringing on she will say, 'I just found a small blue horse'. Abbreviations are good! The blue horse says that this is something new I will share with the others. It says I have found something I will tell you, so it even becomes part of your world and repertoire. We would easily have forgotten if we just turned the pages as we almost always do all too rapidly. The blue horse becomes a bookmark. Even in time: it reminds us that we must stop up and pause. Do not forget that this is what our work is about: literature and reading. That it demands time to read. We must facilitate that. Create openings towards this other room. As my colleague Ann-Kristin Fløtre says: 'If you do not open the book you will never know what is inside'. So, pausing, opening, taking the time needed to see whether there is something in there, the time needed to contemplate and discover. That is the challenge.

Berge further explains that now the blue horse has had its time. Thing becomes "worn-out and threadbare". As a tool it hardly works anymore, we use a different language now. But taking your time in everyday-life to turn new pages even in the large book that the library is, that is what we need to continue with. "And you do not know what is inside until you open up. That counts for the book and everything we work and struggle with."

So, there is all that which keeps people busy in the daily work, and then there are these small glimpses of something else. There are golden moments that stand out in literature and in life. An old woman came by and told the librarian that she had just been recommended the best book ever: "She was sick from cancer and died three months later. Of course, such experiences stand out and reminds us that what we are doing matters. Sometimes we see it there and then, sometimes not at all, sometimes we get to know it much later.” Berge summarizes it all in this double vision; on the on hand there is the "quotidian turning of all the pages in the book of life", all that you have to do for others and yourself that makes life deeply meaningful in itself, but which maybe first becomes meaningful when you bother to notice it, while on the other there are these golden moments that suddenly lights it all up.

In Gloppen Public Library, poet and performance artist Kurt Johannesen is presented as a kind of house poet, a "teraph". Among other sides of his multifarious works are the English titles Other Other Exercises (2012), Other Other Other 
Exercises (2015) and About the Innermost (2014). Typical examples of his work are poems like these:

Gå inn i skogen. Grav eit hol og skrik ned i det. Tet holet igjen

(Johannessen 1994)
Walk into the forest.

Dig a hole and scream down in it.

Close it again.

As a poet Johannessen gives attention to the often unseen, close, and quotidian; as a performance artist he encourages us not only to look in other perspectives and ways, but to do something about it. Drawing a bird on a note, packing it around a stone, and throwing the stone as far as you can into the forest sounds easy, but is uncomfortable: it is about crossing a border, entering a liminal zone of the unobvious. Having done it however and having thrown this, for me, mandatory look over my shoulder to see if anyone observes me as I do it also gives a sense of freedom and feeling of having taken one step further: "I did it!"

ABOUT ONE, THAT WHICH SURROUNOS ONE AND THAT WHICH IS BEYOND ONE

IN TME MIDDLE OF ONE IS THE INHERMOST. AROUND ONE IS THAT THAT WHICH SURROUDS ONE. AROUND THAT WHICH SURROUNDS ONE IS THAT WHICH IS BEYOND ONE. THAT WHICH IS BEYOND ONE IS TMAT TO WHICH ONE DOES NOT HAVE DIRECT ACCESS.

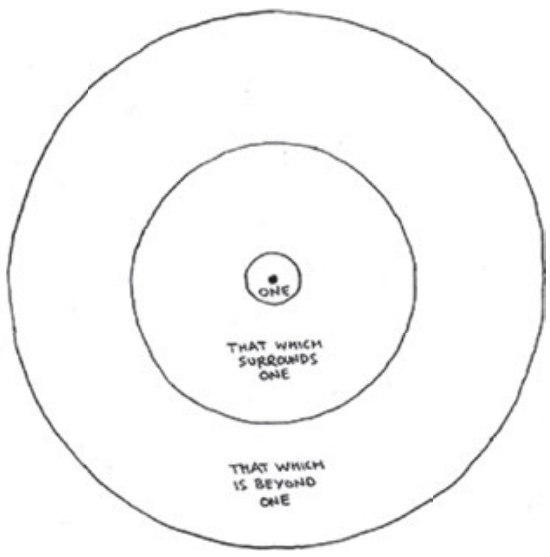

This pictorial poem from About the Innermost (2014) is both absurd and banal, but in-between the ludicrous and not understandable on the on hand and the self-evident on the other this also reflects how the library is delimited by borders that both open and shut off towards the rest of the world: walls, windows, shelves, collections, books around you, around one-s(h)elf. We cannot touch them all, but they are all potentially accessible. But then again, the pictorial poem reflects, and incarnates, the poetics of Johannessen: try it out yourself. Moreover, this is also a way of looking at the philosophy of the library - its connections to the users: this lens, gradually focusing on the One as the picture clearly draws it, reminds us that we do not have direct contact; there are borders that hinder or may be tres- 
passed, there are layers behind layers, books behind books, in readers and users too. Connection implies that borders may be crossed - sometimes yes, sometimes no. Looking at the library through this lens illuminates its borders not as "that at which something stops but, as the Greeks recognized, the boundary is that, from which something begins its presencing" (Heidegger 1971, 5). It is by the border, line, shelf, wall, that something begins to exist, that makes it be(come) and therefore also possible to overcome. The art is knowing how, but also knowing when to take another way.

The blue horse as well as Kurt Johannessen's poetry deepen and manifest the philosophy of Gloppen Public Library as one of double vision. On the one hand the horse as a reminder of the moment, the pause, the creative, the poetic, the golden moments - on the other the encouragement not only to pause and read yourself and your close surroundings, your everyday life, work and struggle, but also to do something with them: throw the paper, give it over, give in. Where it hardly can be denied that, if we read the text closer, Camara puts the spiritual above the material, culture above materiality, Johannesen denies the dichotomy in praising that which comes close to you. While Camara sees it all distanced from above, Johannesen is thrown into the world among the rest of us and all that surrounds us. However, common for both, as they are used here in the breakroom and as a house poet, is the apology for the not immediately understandable. There are "other, other, other" perspectives, ways of seeing. An affirmation of allsidighet.

\section{Rethinking Allsidighet - Six Dimensions}

Through a series or, maybe better, a network of close readings of what Roland Barthes terms passages in the text, I have displayed part of the Gloppen library as a text seen through the prism of allsidighet - a multiplicity of multiplicities that each and together transcends their antidotes; the self-sufficient, the immanent and shut-off, the closed, the limited, the authoritarianism of utterances that deny difference, that never doubt, hesitate or withdraw in shame. However, as something is clearly not allsidighet, it is also impossible to demarcate once and for all what it is as it can never escape its (immanent) utopianism. Allsidighet of course never ends, can never be fulfilled. Any phenomenon might be utterly diversified. The collection can always cover more.

All in all, what we also have discovered are possible realizations of the command to emphasize allsidighet in the mediation. So, is it then, we may ask, possible to distinguish some consistent dimensions of allsidighet when it comes to the context of what libraries stress in their mediation of literature, other media, culture? The following effort to plot out some such dimensions - in accordance 
with the way Barthes encouraged us to read in the sense of following discovering passages and following directions - cannot be traced mechanically back to the foregoing empirical elements, but rather are the theoretical, what Barthes precisely terms, aftermaths in/of these readings, six possible consequences for the practice of mediating literature according to the mandate of allsidighet.

First there is the variety in the collection. Genre, media, provenience, gender, culture etc. The variety in a collection cannot be ultimately measured by nothing, but rather measured by what it lacks. The answer to the question of whether something covers all sides is pluralistic, can never be affirmed; there is always a possible surplus, glitch. As a guideline allsidighet points at the need for more.

Second, there is a possible variety of what is taken out of the collection and displayed or used in the various situations: allsidighet in what is chosen. When the librarians choose to have a program on cities in the literature, they choose works that could of course have been others. Moreover, in presenting the works they emphasize something, not all of it: paraphrasing is always to leave something unspoken, and a quote could always have begun and ended elsewhere, and besides one may always quote something else.

Third, mediating literature (for example) implies to choose a medium and a way of speaking and articulating - this count for reading aloud, the tune an oral reply is given in, the design of the blog, the soundscape of the podcast. Thus, there are allsidighet in impartation, mediation, or form. To put it simply, there are of course always different answers to how and in what genre the chosen pieces should be mediated, presented, offered.

Fourth, there is the ability to use and read literature and cultural artefacts in a variety of ways. The expertise and craftmanship is being able to read literature and world, and attune mediation, in being able to read in various ways - reading for the plot, the atmosphere, the character or the other times in that other place. Reading for when to cross the border, and when to step back.

Fifth, there are the variety of groups and individuals which the library should be able to reach, should talk and listen to, and even provide with literature. Obviously, as mentioned above, the clue here is relevance. We could maybe think that the other and complimentary side of allsidighet is relevance. Variety does not make sense till it becomes relevant for someone in some way or another. Relevant is what one in a situation finds useful here and now or as a potential, but etymologically it can also be traced back to an old French word for "assisting": as a participle of relevõ - which means to lift up once more, to highlight, or to relieve, relevance as the reverse side of allsidighet points at that which may help to manage a situation or what is worth noticing or giving attention.

Finally, there is, as Torill Berge pointed out in one of her readings of this manuscript, a sixth dimension related to the fact that people change. Each reader 
develops over time to be a different reader, and each reader is a multiplicity of readers at the same time. That counts for Auntie Mary as well as my mother of course. Each reader moves from day to day, from each stage of life to another, from situation to situation, from morning to evening and night. "There are rooms in every reader that we of course do not know - but have to be aware of, remind ourselves that may be there. The one who enters may be another tomorrow", Berge says.

So, in reading for allsidighet, we see how it is interconnected with what is relevant. Remember how the law mentions allsidighet in a triangle with kvalitet and aktualitet; quality and relevance/ aktualitet. The latter has two sides, one meaning updated and associated with what is on in the news, the other meaning what is relevant for the subject loaner, reader, attendee (Oterholm and Skjerdingstad 2015). Thus, if the other side of allsidighet is the relevance for users, it is hard not, considering the Law's command, to see allsidighet as the ultimate quality. Elsewhere, I will try to speculate on how the three concepts of the Law form a cluster where the quality is the realization of allsidighet, or if the three of them together serve all sides.

There is, however, another problem with allsidighet: if referring to singular works allsidig would at least exclude media or literature that for example highbrow scholars might deem simple, popular, limited or precisely one-sided. Such an exclusion is hardly concordant with the intention of the law. Further, as allsidig both connotes that which sees or is seen from various perspectives, i.e. avoiding one side only singular perspectives, it tends towards meaning a total inclusion that may avoid good unilateral initiatives or specialization. And of course, if we think very concretely on what a library should prioritize, specialization versus plurality is an everyday dilemma. Concordantly, even public libraries might of course have localizations or needs that could demand certain specializations.

\section{Beyond Matter}

Trying to capture the definite features of allsidighet is of course an impossible task in contradiction both with the indeterminate "nature" of the concept and the way of reading that Barthes has taught me. Trying then to take one step back, to imagine how it would be to have the ultimate variety at hand, being always able to find what one searches for, having the ultimate multiplicity which fulfils all needs, unavoidably points at a dystopian dimension also. Of course, there is something highly pleasurable and reassuring in finding the oddity you looked for, or in someone pointing at it or drawing it out of a hidden shelf; however, there might never the less be something scary here. "Is it possible that it really existed? 
How on earth did you know? How could you reckon that was what I was looking for? Does it really work this way too?"

In an article reflecting on the boundaries of the library, literary LIS-scholar Helge Ridderstrøm (2019) has elaborated on Jonathan Basiles' digital reconstruction of Jorge Luis Borges' “The Library of Babel”. Here Basile creates a digital library based on a text-generator that in principle, theoretically, digitally contains or (re)creates all texts ever written and ever can be. All the books that will be written in the future are already there, all the things that could be said likewise and so the questions to be asked. It is all already accomplished. What this dystopian place nevertheless does not include in its vision of the omni-accessible is all that is beyond content; form and before all matter. What is not there in Basile's allencompassing library therefore, are the books, the papers and covers and all that materiality which make up things. All that which obviously add up to the multiplicity of books, libraries, and collections, not least in actually making them exist.

So, what is most scary in Basile's generator is the disappearance of physical reality, of place, matter, and the subsequent idea that spirit, ideas, contents, and utterances live a life of their own, independent of (and above) physical restrictions - and possibilities. That is also what Barthes' concept of text opposes: there is no universal meaning beyond the particular realization that this particular text offers in this particular setting. His way of reading is strongly material in presuming how the body moves through the landscape.

Thus, it may be time to reconsider what author Frode Grytten is remembered to have said, by one of the library users in Gloppen, at a reading of his own books there: "The important thing is that the library exists". That it exists. However indirectly, this statement from literature itself - from that which makes libraries happen (books, and behind books, writing and authors) - has been the simple argument of this chapter. The subject being both legitimated and complicated by the paradoxical myth of the digital era: the library is everywhere and nowhere. On the one hand everything seems immediately available on the web, as if the library has expanded to be all over. On the other hand, to delineate the presence or absence of the Internet library is impossible. In our everyday life the Internet library fulfils our information needs, while we at the same time also know that what is most relevant may be hidden behind pay walls or need expert excavation or a physical inquiry.

Moreover, phenomenologically speaking, to the user, the Internet library is embedded in images, texts, sounds; noises from all over and elsewhere. Here, on the web, materiality is radically transformed by a smaller or bigger screen, one with high or low resolution, a die-cast body good to hold or a crackling plastic case. So, if materiality has not vanished, it is reduced. "Where the paper archive 
affirmed the material differences of writing, the digital archive flattens everything into identical objects. In the digital archive, everything is reduced to the status of a document" (Piper 2012, 78-79). All the papers and formats are enforced to pass through the same electronic least denominator - the device at hand. In this sense, does the e-book fit in with the demands to mediate allsidighet? Is there not more into it?

There is more. That is the ultimate and infinite addendum that is implicit in the command to mediate allsidighet. Reading the library should also be to follow the passages outwards, as the librarians in places like Gloppen mediate books in school and class settings to overcome distance. In comparatively scarcely populated regions like Sogn og Fjordane that is even more indispensable.

So, allow me one last detour through one last passage to underscore the importance of materiality, this time from another community, although in the same region. A class of eleven-year-old children has been exposed to and involved in a project of literature mediation. In class we have this philosophically tuned discussion on what they think about the meaning of the library and the nature of reading. Their highly developed consciousness of the complexity of the two is striking. Towards the end of our conversation a girl says silently:

I found an old Bible which used to belong to my great grandfather.

It was brownish, dirty and old. He had written in it and scribbled.

I felt as if he stood beside me.

I have never met him.

She has hardly spoken till now. Then she tells this story of something that has obviously moved her. It may have to do with the content and form of the book being the Bible, but her experience is carried, enabled, and held, thanks to the materiality of the book: it is the Bible, and in it there are the signs and traces left there from her great grandfather that she herself has never met. It is an object with a physical presence. And it is thanks to this materiality that the traces in the margins and between the lines are able to arouse the great grandfather as if he is present too. Through these traces and the knowledge presumably mediated to her by her father or mother, he becomes alive. It is however not that the Bible makes her meet him, more as if he (tempting to say resurrected) emerges from the book and gets ready to walk along with her, "beside" her. We can imagine that what matters to the eleven-year-old girl is not what he has written, but that what he scribbled meant something to him. Furthermore of course it counts that it is a particular book he has used and that likely has provoked his writings and scribblings: this book is the book of books. The Bible used to be part of the interior of homes. The incarnation of God's Word, carrier of The Great Story as well as of the smaller but presumably even more existential histories of the life of the family. 
A symbol of a belief, and a strong signal to visitors. As such, the Bible was also a thing that was in use. It was part of the interior. It was radically versatile. In poor Christian homes where the fishermen were out at sea as in the whole West Coast that grounds my work here, the Bible was a concrete carrier of hope and despair. When the weather was bad, and the fishermen should have been home, the Bible was literally speaking something to hold on too. Of course, it became "brownish, dirty and old". It was that too - the ultimate quality of allsidighet.

\section{References}

Barthes, R. "From Work to Text”. In The Rustle of Language. New York: Farrar, Strauss and Giroux, 1986.

Bjerg, S. Litteratur og teologi. Transfigurasjoner - omkring Graham Greene. Aarhus: Forlaget ANIS, 1988.

de Certeau, M. “Reading as Poaching”. In de Certeau, M. (ed.), The Practice of Everyday Life. Berkeley Ca., Los Angeles Ca. \& London: University of California Press, 1988.

Eco, U. The Infinity of Lists. New York: Rizzoli, 2009.

Feld, S. and K. Basso. "Introduction”. In Feld, S. and K. Basso (eds), Senses of Place. Santa Fe NM: School of American Research Press. Lincoln, Neb: University of Nebraska Press, 1996.

Freud, S. ““Beyond the Pleasure Principle.” [Jenzeits des Lustprinzips, 1920]”. In On Metapsychology: The Theory of Psychoanalysis. Harmondsworth: Penguin Books, 1991.

Genette, G. "Palimpsests: Literature in the Second Degree”, 1997.

Glawogger, M. (Director) and W. Wenders (Producer). "The Russian National Library”. [Motion picture]. Germany: Neue Road Movies/Metronome, 2013.

Heidegger, M. “Building, Dwelling, Thinking”. In Poetry, Language, Thought. New York: Harper Colophon Books, 1971.

Jakobson, R. “Closing Statement: Linguistics and Poetics”. In Seboek, T. (ed.), Style and Language. Cambridge. Mass.: MIT University Press, 1960.

Johannesen, G. Draumkvede 1993. Oslo: Samlaget, 1993.

Johannessen, K. Øvingar. Bergen: Zeth, 1994.

Johannessen, K. About the Innermost. Bergen: Zeth, 2014.

Kulturdepartementet. “Forarbeider til bibliotekloven, Ot. Prp. Nr. 14 (1085-1986)”. Oslo, 1986.

Merleau-Ponty, M. Phenomenology of Perception. London: Routledge \& Kegan, 2000.

Nolin, J. In Search of a New Theory of Professions. Borås: Högskolan i Borås, 2008.

Norang, A. and K. I. Skjerdingstad. "Glawoggers geopoetiske blikk. Det russiske nasjonalbiblioteket”. In Skjerdingstad, K. I. and Å. K. Tveit (eds), Biblioteket i litteraturen. Oslo: Pax, 2019.

Oterholm, K. Kvalitet i praksis: en sammenliknende studie av profesjonelle leseres situerte diskusjoner av litterær kvalitet. Oslo: OsloMet, 2019.

Oterholm, K. and K. I. Skjerdingstad. "Aktualitetens fire former og lyrikken som mulighet”. In Ridderstrøm, H. and T. Vold (eds), Litteratur og kulturformidling. Nye analyser og perspektiver. Oslo: Pax, 2015.

Piper, A. Book Was There: Reading in Electronic Times. Chicago: University of Chicago Press, 2012. 
Ridderstrøm, H. “Borges’ digitale bibliotek”. In Skjerdingstad, K. I. and Å. K. Tveit (eds), Biblioteket i litteraturen. Oslo: Pax, 2019.

Rothbauer, P. and K. I. Skjerdingstad. Plotting the Reading Experience. Theory/Practice/Politics. Waterloo Ca.: Wilfrid Laurier University Press, 2016.

Skjerdingstad, K. I. and Å. K. Tveit. "Biblioteket som metafor, institusjon og sted". In Skjerdingstad, K. I. and Å. K. Tveit (eds), Biblioteket i litteraturen. Oslo: Pax, 2019.

Söderholm, J. and J. Nolin. "Collections Redux: The Public Library as a Place of Community Borrowing”. Library Quarterly: Information, Community, Policy, 85, no. 3, 244-260, 2015.

Wehus, M. “Makt, kunnskap og poesi i det antikke biblioteket”. In Skjerdingstad, K. I. and Å. K. Tveit (eds), Biblioteket i litteraturen. Oslo: Pax, 2019.

William-Olsson, M. Läsningen föregår skriften: poesins aktualitet. Stockholm: Ariel, 2011. 
Part III: Users 



\section{Andreas Vårheim, Henrik Jochumsen, Casper Hvenegaard Rasmussen, and Kerstin Rydbeck 12 The Use of LAM Institutions in the Digital Age}

\section{Introduction}

Amidst much speculation on the impact of digitalization, there have been no lack of visions for the future of libraries, archives, and museums (LAM institutions). Sometimes digitalization has been perceived as a useful tool for fulfilling the aims of enlightenment and free access to information and cultural heritage, and other times the digital development has been framed as a threat or game-changer for the LAM institutions. In this chapter, we present empirical data on the use of digital LAM services, and we elucidate how users relate to digital LAM services and LAM services in general. We think the present-day use of digital LAM services is a good indicator of where LAM institutions are heading in the coming years, and relevant for LAM-policy development in government and the institutions. This way, we bring data on digital use, and perhaps some realism to the never-ending debate on the future of LAM institutions. Important questions are: what does digitalization of user services in libraries, archives, and museums (LAMs) mean for patrons - do patrons use the digital services offered by the LAM-institutions? Which digital services are used? What are they used for?

We analyze how user characteristics, such as country, gender, age, education, income, urban/rural, immigration status, and home Internet access correlate with the digital service usage in LAM institutions. By comparing patterns of use as reported by users in six European countries, we examine variation in patterns of digital use between the countries. Do differences indicate different trajectories of development towards multiple LAM futures, or do they indicate national LAM systems on different stages of development towards a shared future of LAM use? The lack of time-series data makes it difficult to conclude on whether national systems have changed and how they have changed, and calls for future data collection, preferably at five-year intervals. At this point, we present data from a survey to representative samples of the Hungarian, Swiss, German, Danish, Swedish, and Norwegian populations conducted in June 2017. The national samples vary from 1,002 respondents up to 1,021. Altogether, we have 6,050 respondents (see Audunson et al. (2019) for more information about the data collection process). This analysis is based on quantitative and qualitative data on digital use from the survey.

First, the chapter contains a review of professional and scholarly debates on LAM institutions and digital development; second, a presentation of the findings 
from the survey on the use of digital services in LAM institutions; third, a presentation of free-text analysis of the user responses on content accessed and activities engaged through digital LAM services; fourth, based on the findings we discuss the relevance of the LAMs as digital public sphere institutions today and implications for future LAM adaptation in the digital age.

\section{Digital Debates in LAM Institutions}

The former chair of the German Library Association, Claudia Lux, wrote in 1994 a paper with the title Vom Bibliothekar zum Cybrarian - die Zukunft des Berufs in der virtuellen Bibliothek (From Librarian to Cybrarian: the Future of the Profession in the Virtual Library), where she tried to outline a virtual library in the future - a never closing library for everyone with instant access to digital books (Lux 1994). Following the same line of thought, the digital impact was discussed in the museum field. One example from 1999 is the former managing museum director Steve Dietz's text Cybermuseology: Taking the Museum to the Net/Bringing the Digital Media to the Museum (Dietz 2014). According to Dietz, the new technology could be a catalyst for the "museum's migration to the Web". On a general level, Lux and Dietz share the common notion that the physical LAM-institution more or less would dissolve in cyberspace.

Although early adopters to new technology, a certain concern connected to digitalization has been present ever since the spread of the microchip in the late 1970s. At that time, the concern was associated with the question of whether the chip would replace the librarian (Jochumsen and Hvenegaard Rasmussen 2006). Later, when the use of the Internet arrived in the early 1990s, the question was whether the Internet actually would replace the physical library. At the same time though, library professionals also recognized that digital development meant a new and significant role for public libraries. Thus, the public libraries could contribute to the digital empowerment of the citizens and thereby reduce the risk of an A- and B-team regarding IT-competencies, closing the digital divide. As we know today, neither the physical library nor the librarian was replaced by cyber services. The librarian is still in demand, and libraries are still being built all over the world. What has happened is that the role of both the librarian and library has changed and that the possibilities of the physical library have been replenished by different Internet-founded offers (Jochumsen, Hvenegaard Rasmussen, and Skot-Hansen 2012). At the same time, public libraries still play an important role as providers of access to the Internet and as supporters of the digital skills of individual citizens. 
The fear of digitalization has not been present to the same degree among professionals in the two other LAM-institutions. In a study carried out by Eva Pina Myrczik, in which she reviews and reflects on the factors defining the expected benefits that have influenced the implementation of digital initiatives in publicfunded museums over the course of the last 20 years, we see a gradual development. Myrzcik identifies three different phases. The first phase was concerned with making digitized cultural heritage accessible, the second was characterized by a more individualized museum mediation that took the visitors' background and needs into account, and the third and present phase is about including and engaging the users of the museums, or user participation (Myrzcik 2018).

Thus, it seems reasonable to state that while the digital development internally in the library field has been seen more or less as a threat to the very existence of the librarian and the physical library, in the museum field it has rather been seen as an add-on supporting the museum experience for the visitors. It might also be reasonable to assume that this difference among other factors has to do with the fact that the museum contains an original, which cannot be replaced by any Internet offering. The library, on the other hand, has services, which often can be replaced by content found on the internet. However, as stated by the British expert in library architecture Brian Edwards: "IT does not destroy the library but liberates it into providing new kinds of public services attracting a potential new audience" (Edwards 2009, xiii). On the same note, we see that lending figures are decreasing, but the number of visitors is stable in a Nordic context. In Norway, the number of visitors is slightly increasing. In Denmark, the same numbers are stable, while the figures show a slight decrease of visitors in Sweden and Finland. ${ }^{1}$

In archives, we see a development in which digitalization by many professionals is seen as a great potential for boosting the use of the archives and for developing the archives through user participation. The Canadian archivist Terry Cook (2013) argues that archival paradigms over the past 150 years have gone through

1 In Norway, between 2012 and 2017, the number of books lent per capita shrank from 4.9 to $4.1(17.2 \%)$, while visits per capita increased from 4.1 to 4.6 (11.2\%) (https://kunnskapsbase. bibliotekutvikling.no/statistikk/statistikk-for-norske-bibliotek/folkebibliotek/historisk-

statistikk-for-folkebibliotek/). In Denmark, between 2012 and 2017, the number of book lent per capita shrank from 7.5 to 5.1 (32\%), while visits per capital were approximately 6.5 in both 2012 and 2017. These figures are based on calculations from Statistics Denmark (https://www.dst.dk/da). In Sweden, between 2012 and 2017, the number of books lent per capita shrank from 7.1 to $6.1(14.1 \%)$, while visits per capita decreased from 7.0 to $6.3(10 \%)$. (https://www.kb.se/samverkan-och-utveckling/biblioteksstatistik/hamta-utstatistik/statistikrapporter.html\#item-42705879d169b8ba882a1ccf). In Finland, between 2012 and 2017, the number of books lent per capita shrank from 12.7 to 12.0 (5.5\%), while visits per capita decreased from 9.6 to 9.1 (5.2\%) (https://tilastot.kirjastot.fi/?show_year=0). 
four phases: from juridical legacy to cultural memory to societal engagement to community archiving. Especially among the later paradigms, digitalization has been perceived as a driver for the development of the archives. On the one hand, the digitization of archival documents has improved the public's access to archives (Bolick 2006). On the other hand, the public have not only been passive users of archival services, but the users have also been participating in archival activities. Crowdsourcing, where some of the archival workloads are outsourced to the public, is an example of this. It can be huge digitization projects, where volunteers are the primary workforce in transcribing physical documents or adding contextual knowledge to pictures and more (Oomen and Aroyo 2011). Concerning the archives, digitalization cannot be described as a tough challenge as for the libraries or as a supplement to the physical museum. Rather, digital development primarily has been perceived as a possibility, notably among archivists dealing with societal engagement and community archiving. One example is the book of the Nordic Archival Conference in 2015, where digitalization is described as the main driver for transforming the archives from passive collections towards more user-driven institutions (Hosar et al. 2016).

\section{Digital Development in LAM Institutions}

As shown above, the relationship between digitalization and professional development in the LAM-field seems to have varied from institution to institution. Looking at the LAM-field as a whole, the ongoing digitalization has not only been a tension between "bricks" and "clicks", where tradition-bound professionals have struggled for physical institutions and collections, while a digital avantgarde prophesied the death of the physical LAMs. Over time, digital development has proved much more diverse. However, there are some common characteristics of digital development in libraries, archives, and museums. Inspired by Myrcik (2018), we will describe the digital development departing from three headlines: Digital information about institutions, Digital access to content, and Digital participatory culture.

\section{Digital Information About the Institutions}

In the wake of the Internet, an obvious digital extension of the LAM services was to create homepages for the institutions. The Danish National Museum was the first museum to have a website in 1996, which communicated general information about the institution (Myrczik 2018). These early webpages have been de- 
nominated as "brochures" or "business cards" because the main function was to give basic information about the museum, such as types of collections and opening hours (Schweiber 2004). Among libraries (Cohen and Still 1999) and archives (Cox 1998), this kind of homepage became normal in the late 1990s. According to an IFLA-paper dealing with the Internet in everyday library use, 110 Finnish public library homepages were operative in the spring of 1997 (Jokitalo 1997). A quick overview of the research literature on LAMs' use of social media shows that libraries and museums' primary use of Facebook is as a collection of "brochures" communicating general information about the institution (Fletcher and Lee 2012; Aharony 2012; Skare 2018, 2019). Also, the use of social media in general, in relation to LAMs, is limited to a small number of users. Based on this conclusion, it is reasonable to assume that Facebook users visiting LAM-webpages mostly do it to gain information rather than participate in different kinds of activities.

\section{Digital Access to Content}

Although the LAM-institutions' first homepages primary consisted of information about the institutions, some of the websites also gave access to more or less of the institutions' collections. The Danish National Museum's website also hosts a special digital exhibition: Guder og Grave (Gods and Graves), which contains 450 selected objects from the Danish bronze age. Normally these objects were seldom accessible for users; they were kept in a storeroom with no public access.

The distribution of the Internet was a catalyst for digitization projects in all three types of LAMs. For modern libraries and museums, providing access to knowledge and cultural heritage has always been an inevitable task (Brown and Davis-Brown 1998), and digital development improves access to LAMs' collections. As mentioned, for archives, digitalization has provided a significant opportunity to reach a larger audience. In the past, archives were a caretaker of administrative and legal records, also providing citizen access to public documents, preserving historical sources for scholars. Starting with the political radicalization of the 1970s, they have sought a broader audience, and digital technology has supported the democratization of the archive as a societal resource (Bolick 2006).

Different kinds of communication or mediation of content can be perceived as an extra dimension created by digital access to the LAMs' collections. For instance, the 450 selected digitized objects in Gods and Graves were surrounded by different kinds of information about the Bronze Age and archaeological excavations. According to Myrczik (2018), this type of digital exhibition has been normal in Danish museums since the millennium. In a Danish library context, Litter- 
atursiden.dk is not a digital access point for fiction, but a website with different kinds of information on fiction, e.g. book reviews. Bokcirklar.se is a community helping readers interested in virtual book discussions to get in contact with fellow readers for organizing virtual reading communities. It is run by some of the Swedish county libraries. Digital services such as Litteratursiden.dk and Bokcirklar.se raises the question: are the users aware that they are using a library service?

\section{Digital Participatory Culture}

The third characteristic of the ongoing digitalization of LAMs is an increasingly participatory culture both outside and inside the LAM institutions. According to the American media scholar Henry Jenkins (2005), the development of the social media has been a major driver in participatory culture, because the barriers for artistic expression and civic engagement have been lowered. Today, it is easier to produce, share, remix, and comment on artistic expressions and other kinds of content. This tendency is not only identifiable on civic sites on the Internet, but there is also a participatory turn in western cultural policy (Bonet and Négrier 2018), which also appears within the LAM field. Participation has been a buzzword for more than a decade (Huvila 2008; Simon 2010; Lankes, Silverstein, and Nicholson 2007).

Furthermore, the participatory turn in LAMs is a complex phenomenon; it both takes place in a digital and physical setting, and the activities can be different. It can range from book clubs through interactive communication to crowdsourcing. In particular, the archives have used crowdsourcing for digitization projects and enriching collections. Sometimes crowdsourcing solves insurmountable digital tasks for the archives, while crowdsourcing on other occasions is a time-consuming way to reach out to new users. Also, crowdsourcing and other forms of participation are heavily discussed within all LAMs (Eveleigh 2014). Thus, seen from the inside of the LAM institutions, participation is a hot issue, but how do the users perceive and use participatory LAM activities in a digital context?

\section{The Digital Use of LAM-institutions}

\section{Visiting Libraries, Archives, and Museums in the Digital Age}

In this section, we follow up on the LAM professional and scholarly debates in the digital age, in the context of the use of digital services provided by libraries, ar- 
chives, and museums. We present findings (quantitative data) on reported digital visits versus physical visits to the institutions and display the variation in types of visits between the six countries surveyed relative to the user demographic characteristics: age, gender, immigrant or native, education, home Internet access, urban/rural, and income.

\section{Digital or Physical Library Visits?}

In 2017, 40.5\% of the survey respondents in Denmark, Germany, Hungary, Norway, Sweden, and Switzerland usually visited public libraries only by foot or on wheels; that is, they visited the library building in person (Table 12.1), while 14\% visited only digitally through connections to the Internet. However, one quarter in the sample both sometimes visit the library digitally from home and sometimes physically visit the library premises. $20.8 \%$ say they do not visit libraries.

Tab. 12.1: How do you usually visit the public libraries?

\begin{tabular}{lcrc}
\hline & Frequency & All \% & Users \% \\
\hline Physically & 2,450 & 40.5 & 51.1 \\
Internet & 847 & 14.0 & 17.7 \\
Both & 1,493 & 24.7 & 31.2 \\
Never & 1,260 & 20.8 & $\mathrm{~N} / \mathrm{A}$ \\
Total & 6,050 & 100.0 & 100.0 \\
\hline
\end{tabular}

These results mean that people at least in the six countries still physically visit public libraries for library services. Not more than $14 \%$ of all the respondents in the survey only access libraries electronically from locations outside the library itself, while $65.2 \%$ only visit physically, or visit physically and by digital devices. Library users are more frequent visitors, $17.7 \%$ visit only digitally, while $82.3 \%$ visit physically or both physically and digitally.

\section{Archives}

What about archives? From Table 12.2, we can read that more people exclusively visit archives electronically (24\%) than by paying a physical visit (12.7\%), 10.6\% visit in both ways, and 52.7\% never visit archives. Among users of archives, $73.2 \%$ either use the archive only electronically, or visit both digitally and in person.

Digital archive visits are more popular than physical visits. More than half of the users of archives visit only digitally. Archival use is more in line with the early digital age expectations compared to libraries. 
Tab. 12.2: How do you usually visit archives?

\begin{tabular}{lcrc}
\hline & Frequency & All \% & Users \% \\
\hline Physically & 767 & 12.7 & 26,8 \\
Internet & 1,453 & 24.0 & 50.8 \\
Both & 641 & 10.6 & 22.4 \\
Never & 3,189 & 52.7 & $\mathrm{~N} / \mathrm{A}$ \\
Total & 6,050 & 100.0 & 100.0 \\
\hline
\end{tabular}

\section{Museums}

Museums are visited digitally by $8.5 \%$ of people in the six country sample taken together, while $55.1 \%$ visit physically. $14.1 \%$ visit museums both digitally and physically, and 22.2\% in the sample never visit museums in either way. These relatively low scores for digital use are in line with expectations of the digital museums as an added value to physical collections; they are an add-on rather than a replacement for buildings and for experiencing physical museum objects.

Tab. 12.3: How do you usually visit museums?

\begin{tabular}{lcrc}
\hline & Frequency & All \% & Users \% \\
\hline Physically & 3,336 & 55.1 & 70.9 \\
Internet & 516 & 8.5 & 11.0 \\
Both & 855 & 14.1 & 18.2 \\
Never & 1,343 & 22.2 & $\mathrm{~N} / \mathrm{A}$ \\
Total & 6,050 & 100.0 & 100.0 \\
\hline
\end{tabular}

Comparing digital use of the three different types of institutions among all respondents (Table 12.4), 28.9\% of respondents have used public library digital services in the last 12 months, 9.9\% have used archival digital services, while $21.6 \%$ have used digital museum services.

Concluding this section on digital and physical visits to libraries, archives, and museums, we can state that:

1. Digitalization does not (at least not for now) seem to replace traditional library services, as still more than half of the library users (51.1\%) visit only through physical visits, while the percentage of users visiting libraries only physically or both physically and digitally taken together is as high as $82.3 \%$, while digital-only visitors represent $17.7 \%$ of library users. 
2. Digitalization means unleashing the potential reach of archives, more than half of users visit only digitally, 50.8\%. $73.2 \%$ of archive users visit either only digitally or visit both digitally and physically.

3. Digitalization seems to be an add-on and represents a supplemental service for museums rather than posing any threat to physical visits; still, $11 \%$ of users visit museums through digital channels only.

\section{LAM Digital Use in the Six Countries}

An important question in this chapter is if, and then how, digital use varies by country. Do we in the data see a reproduction of the general North-South cultural divide between European countries (Rokkan and Lipset 1967), which is reflected in the level of national library spending (Vårhem et al. 2008)? Are there age gaps, gender gaps, education, immigration, income, and rural/urban gaps, and if so, how do they play out?

Danes in the sample use digital library services more than the inhabitants in any of the five other countries; $39.7 \%$ of Danes used digital services at least one time during the last 12 months (Table 12.4). ${ }^{2}$ Germans respondents were the most infrequent users; $19 \%$ used digital services. The three Scandinavian countries had the highest numbers of digital users, while $26.3 \%$ of the Hungarians surveyed visited a library digitally during the last year. The divide in library spending between the north and the south is partly reproduced in these figures. The northerners are the most eager of digital users, but it is perhaps surprising that German and Swiss usage among respondents is lower than in Hungary. These three countries have the lowest usage levels for digital library services.

Norwegian respondents use archival digital services the most, some $12.9 \%$, while the Swedes, the Swiss, and the Danes follow closely. Germans are the most infrequent users of digital services in archives, 6.9\%, and Hungarians use these services marginally more often than the Germans.

For the use of digital services in museums, we see a different pattern, with the Danes (24.4\%) and the Swedes having the highest numbers, but only marginally ahead of Switzerland with $24.1 \%$. Following closely, in Hungary and Norway, about $20 \%$ of the museum visitors sampled have used digital museum services in the last twelve months, while German museum users are the least tech-savvy, when it comes to the use of digital museum services.

2 In Sweden and Norway, the survey question for libraries was formulated somewhat differently from the other countries in that it was asked for the use of digital services "in the library". In the four other countries, the question was whether the respondent had used "digital library services". However, this difference in wording does not seem to have had a significant impact on the data. 
Tab. 12.4: Use of Libraries, Archives, or Museum Digital Services during the last 12 months according to age (percentages)

\begin{tabular}{|c|c|c|c|c|c|c|c|c|}
\hline Country & Institution & $N$ & $18-29$ & $30-39$ & 40-49 & $50-59$ & $60+$ & Total \\
\hline \multirow[t]{3}{*}{ Denmark } & Library & 905 & 37.4 & 37.2 & 42.2 & 41.4 & 39.7 & 39.7 \\
\hline & Archive & 905 & 5.8 & 7.4 & 7.2 & 8.9 & 16.2 & $10.2^{b)}$ \\
\hline & Museum & 905 & 14.6 & 19.8 & 22.3 & 28.7 & 31.0 & $24.4^{b)}$ \\
\hline \multirow[t]{3}{*}{ Sweden } & Library & 894 & 29.8 & 39.1 & 30.8 & 34.3 & 35.3 & 34.0 \\
\hline & Archive & 894 & 8.8 & 8.7 & 9.9 & 16.3 & 15.4 & $11.9^{a)}$ \\
\hline & Museum & 894 & 22.8 & 19.6 & 19.8 & 26.5 & 31.3 & $24.2^{\mathrm{a})}$ \\
\hline \multirow[t]{3}{*}{ Norway } & Library & 900 & 43.1 & 25.2 & 27.5 & 31.9 & 26.1 & $30.7^{b)}$ \\
\hline & Archive & 900 & 8.5 & 5.4 & 18.1 & 8.5 & 19.4 & $12.9^{b)}$ \\
\hline & Museum & 900 & 16.0 & 19.0 & 25.7 & 20.6 & 21.3 & 20.6 \\
\hline \multirow[t]{3}{*}{ Germany } & Library & 815 & 32.4 & 22.1 & 17.7 & 10.6 & 15.9 & $19.0^{b)}$ \\
\hline & Archive & 815 & 6.9 & 7.6 & 6.1 & 2.8 & 10.8 & $6.9^{\text {a) }}$ \\
\hline & Museum & 815 & 13.1 & 13.0 & 18.3 & 12.2 & 19.0 & 15.3 \\
\hline \multirow[t]{3}{*}{ Switzerland } & Library & 858 & 32.8 & 15.9 & 20.1 & 22.7 & 21.2 & $22.3^{\mathrm{a})}$ \\
\hline & Archive & 858 & 13.7 & 4.0 & 9.0 & 12.9 & 10.6 & $10.3^{\mathrm{a})}$ \\
\hline & Museum & 858 & 19.8 & 24.5 & 18.7 & 24.9 & 29.0 & 24.1 \\
\hline \multirow[t]{3}{*}{ Hungary } & Library & 902 & 30.5 & 20.4 & 23.7 & 21.3 & 33.3 & $26.3^{\mathrm{a})}$ \\
\hline & Archive & 902 & 5.4 & 8.3 & 6.8 & 5.2 & 9.0 & 7.1 \\
\hline & Museum & 902 & 16.8 & 13.8 & 19.2 & 22.6 & 27.5 & $20.3^{b)}$ \\
\hline Total & Library & 5274 & 34.6 & 26.7 & 27.2 & 26.4 & 29.2 & $28.9^{b)}$ \\
\hline Total & Archive & 5274 & 8.0 & 7.0 & 9.6 & 9.3 & 13.9 & $9.9^{\mathrm{b})}$ \\
\hline Total & Museum & 5274 & 17.2 & 18.3 & 20.7 & 22.6 & 26.7 & $21.6^{\mathrm{b})}$ \\
\hline
\end{tabular}

Pearson's Chi-Square a) $\mathrm{p} \leq 0.05$

$$
\text { b) } \mathrm{p} \leq 0.01
$$

For archives and especially for museums, the North-South Europe divide in use of digital services is less pronounced than for public libraries, while Germany consistently lags behind the other countries for digital service usage.

\section{LAM Digital Use in the Six Countries According to Age Distribution}

In the sample of the six countries, the youngest, the 18-29, age group are the most frequent users of digital library services, with 34.6\% having used digital services in the last year, while the 50-59 age group are the most infrequent users, some $26.4 \% .^{3}$ There are statistically significant differences in reported use of LAMs be-

$312.3 \%$ (776) of respondents have not answered the questions on digital use of the three services. Also, for the other variables some values are missing. This explains the variation in $\mathrm{N}$ between countries. 
tween age groups in Norway, Germany, Switzerland, and Hungary (Pearson's ChiSquare Test). For example, in Germany, 32.4\% of the youngest age group use digital services, compared to $10.6 \%$ of the $50-59$-year-olds.

Among users of digital services in archives, the differences between age groups are greatest in the Scandinavian countries, for example in Norway where $8.8 \%$ in the youngest group are users, while 19.4\% are users in the oldest age group, 60+. Switzerland shows the opposite pattern of all the other countries, where $13.7 \%$ of the youngest use digital services in archives, while this is only $10.6 \%$ in the oldest age group. For the use of digital services in museums, we see the same pattern of age distribution in all countries; seniors use digital museum services significantly more than juniors.

Tab. 12.5: Use of Library, Archives, or Museum Digital Services during the last 12 months according to gender (percentages)

\begin{tabular}{|c|c|c|c|c|c|}
\hline Country & LAM-institution & $N$ & Male & Female & Total \\
\hline \multirow[t]{3}{*}{ Denmark } & Library & 905 & 31.3 & 47.5 & $39.7^{b)}$ \\
\hline & Archive & 905 & 12.8 & 7.7 & $10.2^{\text {a) }}$ \\
\hline & Museum & 905 & 22.1 & 26.4 & $24.4^{b)}$ \\
\hline \multirow[t]{3}{*}{ Sweden } & Library & 892 & 26.6 & 41.9 & $34.0^{b)}$ \\
\hline & Archive & 892 & 10.4 & 13.5 & 11.9 \\
\hline & Museum & 892 & 22.5 & 26.0 & $24.2^{\mathrm{a})}$ \\
\hline \multirow[t]{3}{*}{ Norway } & Library & 898 & 25.8 & 35.5 & $30.7^{b)}$ \\
\hline & Archive & 898 & 14.9. & 10.7 & 12.8 \\
\hline & Museum & 898 & 18.6 & 22.4 & 20.5 \\
\hline \multirow[t]{3}{*}{ Germany } & Library & 814 & 17.9 & 20.1 & 19.0 \\
\hline & Archive & 814 & 8.6 & 5.2 & $6.9^{\text {a) }}$ \\
\hline & Museum & 814 & 17.4 & 13.3 & 15.4 \\
\hline \multirow[t]{3}{*}{ Switzerland } & Library & 858 & 19.4 & 25.3 & $22.3^{\text {a) }}$ \\
\hline & Archive & 858 & 11.4 & 9.1 & 10.3 \\
\hline & Museum & 858 & 23.7 & 24.6 & 24.1 \\
\hline \multirow[t]{3}{*}{ Hungary } & Library & 901 & 24.0 & 28.2 & 26.3 \\
\hline & Archive & 901 & 6.2 & 7.9 & 7.1 \\
\hline & Museum & 901 & 16.9 & 23.5 & $20.3^{b)}$ \\
\hline Total & Library & 5268 & 24.3 & 33.4 & $28.9^{b)}$ \\
\hline Total & Archive & 5268 & 10.8 & 9.0 & $9.9^{\text {a) }}$ \\
\hline Total & Museum & 5268 & 20.3 & 22.9 & $21.6^{\mathrm{b})}$ \\
\hline
\end{tabular}

Pearson's Chi-Square a) $p \leq 0.05$

b) $p \leq 0.01$ 


\section{LAM Digital Use in the Six Countries by Gender}

In the sample, women are much more active digital users than men in libraries, 33.4 compared to $24.3 \%$; in museums, women are slightly more active, but in archives, men are marginally more frequent digital users (Table 12.5). For digital library use, women take a strong lead, except in Germany and Hungary. The male dominance in archives is strongest in Denmark, but there is a majority of women users of digital archives in Hungary and Sweden. In museums, women use digital services more in all countries except Germany, and particularly so in the Scandinavian countries and Hungary.

\section{LAM Digital Use in the Six Countries by Immigration Status}

Almost consistently, immigrants use LAM digital services more than natives, most in Hungary and Switzerland, with the only exceptions being Sweden and Den-

Tab. 12.6: Use of Library, Archives, or Museum Digital Services during the last 12 months according to immigration status (percentages)

\begin{tabular}{|c|c|c|c|c|c|}
\hline Country & LAM-institution & $N$ & Native & Immigrant & Total \\
\hline \multirow[t]{3}{*}{ Denmark } & Library & 905 & 39.5 & 42.1 & 39.7 \\
\hline & Archive & 905 & 9.9 & 14.0 & 10.2 \\
\hline & Museum & 905 & 24.6 & 21.1 & 24.4 \\
\hline \multirow[t]{3}{*}{ Sweden } & Library & 894 & 34.1 & 33.9 & 34.0 \\
\hline & Archive & 894 & 10.7 & 17.3 & $11.9^{\mathrm{a})}$ \\
\hline & Museum & 894 & 24.0 & 25.0 & 24.2 \\
\hline \multirow[t]{3}{*}{ Norway } & Library & 900 & 30.1 & 37.3 & 30.7 \\
\hline & Archive & 900 & 12.6 & 16.0 & 12.8 \\
\hline & Museum & 900 & 19.9 & 28.0 & 20.5 \\
\hline \multirow[t]{3}{*}{ Germany } & Library & 815 & 18.7 & 25.7 & 19.0 \\
\hline & Archive & 815 & 6.7 & 11.4 & 6.9 \\
\hline & Museum & 815 & 14.9 & 25.7 & 15.4 \\
\hline \multirow[t]{3}{*}{ Switzerland } & Library & 858 & 21.8 & 30.6 & 22.3 \\
\hline & Archive & 858 & 9.8 & 18.4 & $10.3^{a)}$ \\
\hline & Museum & 858 & 23.2 & 38.8 & $24.1^{\text {a) }}$ \\
\hline \multirow[t]{3}{*}{ Hungary } & Library & 902 & 20.0 & 35.0 & $26.3^{\text {a) }}$ \\
\hline & Archive & 902 & 6.6 & 30.0 & $7.1^{b)}$ \\
\hline & Museum & 902 & 16.9 & 23.5 & 20.3 \\
\hline Total & Library & 5274 & 28.4 & 34.9 & $28.9^{\mathrm{b})}$ \\
\hline Total & Archive & 5274 & 9.3 & 16.8 & $9.9^{b)}$ \\
\hline Total & Museum & 5274 & 21.1 & 27.3 & $21.6^{\mathrm{b})}$ \\
\hline
\end{tabular}

Pearson's Chi-Square ${ }^{\text {a) }} \mathrm{p} \leq 0.05$

b) $\mathrm{p} \leq 0.01$ 
mark, where natives are on par with immigrants in libraries, and again Denmark, where immigrants only use digital museum services on par with the natives. In this context, immigrants include migrants having moved to another country and their children (first and second generation immigrants).

\section{LAM Digital Use in the Six Countries by Educational Level}

LAM digital services are used significantly more by the highly educated in all six countries. For archives, this tendency is weaker, and in Hungary, respondents without tertiary education visit archives digitally slightly more than respondents with tertiary education.

Tab. 12.7: Use of Library, Archives, or Museum Digital Services during the last 12 months according to education (percentages)

\begin{tabular}{|c|c|c|c|c|c|}
\hline Country & LAM-institution & $N$ & Primary and Secondary & Tertiary & Total \\
\hline \multirow[t]{3}{*}{ Denmark } & Library & 890 & 34.0 & 49.8 & $39.8^{b)}$ \\
\hline & Archive & 890 & 8.8 & 12.7 & 10.2 \\
\hline & Museum & 890 & 20.6 & 31.6 & $24.6^{b)}$ \\
\hline \multirow[t]{3}{*}{ Sweden } & Library & 885 & 28.1 & 42.1 & $34.0^{\mathrm{b})}$ \\
\hline & Archive & 885 & 9.8 & 14.7 & $11.9^{\mathrm{a})}$ \\
\hline & Museum & 885 & 18.9 & 30.6 & $24.2^{b)}$ \\
\hline \multirow[t]{3}{*}{ Norway } & Library & 884 & 25.1 & 35.6 & $30.8^{\mathrm{b})}$ \\
\hline & Archive & 884 & 10.9 & 14.6 & 12.8 \\
\hline & Museum & 884 & 15.6 & 25.2 & $20.8^{\mathrm{b})}$ \\
\hline \multirow[t]{3}{*}{ Germany } & Library & 796 & 15.9 & 25.1 & $19.1^{\mathrm{b})}$ \\
\hline & Archive & 796 & 5.8 & 9.3 & 6.9 \\
\hline & Museum & 796 & 13.7 & 19.0 & $15.4^{a)}$ \\
\hline \multirow[t]{3}{*}{ Switzerland } & Library & 849 & 17.7 & 29.9 & $22.4^{b)}$ \\
\hline & Archive & 849 & 9.9 & 10.8 & 10.3 \\
\hline & Museum & 849 & 20.0 & 30.9 & $24.1^{b)}$ \\
\hline \multirow[t]{3}{*}{ Hungary } & Library & 902 & 22.4 & 35.0 & $26.3^{b)}$ \\
\hline & Archive & 900 & 7.2 & 6.9 & 7.1 \\
\hline & Museum & 900 & 18.9 & 24.6 & $20.3^{a)}$ \\
\hline Total & Library & 5274 & 23.9 & 36.3 & $28.9^{\mathrm{b})}$ \\
\hline Total & Archive & 5244 & 8.6 & 11.8 & $9.9^{\mathrm{b})}$ \\
\hline Total & Museum & 5204 & 21.1 & 27.3 & $21.6^{b)}$ \\
\hline
\end{tabular}

Pearson's Chi-Square ${ }^{\text {a) }} \mathrm{p} \leq 0.05$

b) $\mathrm{p} \leq 0.01$ 
Tab. 12.8: Use of Library, Archives, or Museum Digital Services during the last 12 months according to home internet access (percentages)

\begin{tabular}{llllll}
\hline Country & LAM-institution & $\boldsymbol{N}$ & No Internet & Internet at home & Total \\
\hline Denmark & Library & 905 & 24.5 & 41.4 & $39.7^{\mathrm{b})}$ \\
& Archive & 905 & 11.7 & 10.0 & 10.2 \\
& Museum & 905 & 16.0 & 25.4 & $24.4^{\text {a) }}$ \\
\multirow{5}{*}{ Sweden } & Library & 894 & 21.8 & 35.2 & $34.0^{\text {a) }}$ \\
& Archive & 894 & 10.3 & 12.0 & $11.9^{\text {a) }}$ \\
& Museum & 894 & 19.2 & 24.6 & 24.2 \\
Norway & Library & 900 & 18.6 & 31.3 & 30.8 \\
& Archive & 900 & 11.6 & 13.0 & 12.9 \\
& Museum & 900 & 9.3 & 21.1 & 20.6 \\
Germany & Library & 815 & 19.0 & NA & 19.0 \\
& Archive & 815 & 6.9 & NA & 6.9 \\
& Museum & 815 & 15.3 & NA & 15.3 \\
Switzerland & Library & 849 & 13.0 & 22.9 & $22.3^{\text {a) }}$ \\
& Archive & 849 & 5.6 & 10.6 & 10.3 \\
& Museum & 849 & 11.1 & 25.0 & $24.1^{\text {a) }}$ \\
Hungary & Library & 902 & 27.7 & 26.1 & 26.3 \\
& Archive & 902 & 8.0 & 7.0 & 7.1 \\
& Museum & 902 & 17.0 & 20.8 & 20.3 \\
Total & Library & 5274 & $N A$ & $N A$ & $N A$ \\
\hline Potal & Archive & 5244 & $N A$ & $N A$ & $N A$ \\
\hline
\end{tabular}

Pearson's Chi-Square a) $\mathrm{p} \leq 0.05$

b) $\mathrm{p} \leq 0.01$

\section{LAM Digital Use in the Six Countries by Internet Access}

In the sample, in all countries, except Hungary, patrons with home Internet access use digital library services and digital museum services considerably more than people without home Internet access (Table 12.8). The use of digital archive services shows little variation with home access or not in Scandinavia and Hungary, while twice as many Swiss respondents with home Internet access use digital archive services compared to people without home Internet access.

\section{LAM Digital Use in the Six Countries by Urban/Rural and Income}

LAM digital use does not vary significantly with respondents' income. We also find few differences in digital use between rural and urban areas, except for Norway, 
where the use of digital archival services is significantly higher in the peripheral areas, and in Hungary and Switzerland we see the same for public library digital services.

To summarize, our quantitative analysis of survey data has shown there are significant differences in the use of digital LAM-resources based on gender, age, and immigration status. The analysis also showed that digital services are used significantly more by the highly educated in all six countries, although there were less or no significant variations in usage patterns regarding rural and urban areas, or the respondents' income, and their access at home or not to the Internet.

In the following section, we analyse free-text data, where the respondents described their use of LAM-institutions' digital resources more closely.

\section{The Use of Digital LAM-resources: Qualitative Results}

How did survey respondents use the digital resources of the LAM-institutions? And which resources did they use? The free-text responses of our respondents are presented in Table 12.9. However, it has to be emphasized that relatively few of the respondents filled in free text information. The highest response rate was for the use of library resources, something which probably has to do with the fact that many of the library's basic services are digital. The Danish respondents reached the highest score with a response rate of $36 \%$, and the German respondents the lowest with 15\%. A great majority of the free-text respondents had used the local digital library system to search the catalog for books, make reservations, renew loans, and more. In some cases, they had downloaded e-books or audiobooks through the library, and there were also some digital suggestions about purchases of new books. There was no difference between the six countries in this respect.

The answers show that the use of LAM-institutions' digital resources is often connected to the search on the website or social media for basic information such as contact information, opening hours, and upcoming activities. It confirms the assumption that Facebook users visiting LAM-profiles primarily do it to gain information rather than to take an active part in different kinds of digital LAM-related activities. In particular, this was the case for the museums, where this category formed the far largest group, and very few respondents had tried to gain digital access to content, for example, by looking at virtual exhibitions or material in virtual collections. Sometimes the communication was about booking tickets to guided tours. The response rates for museums were, generally speaking, slightly lower than for the libraries with $22 \%$ as the highest (Sweden and Denmark) and $15 \%$ as the lowest (Germany) score. 
Tab. 12.9: Use of digital LAM services. Analysis of free-text answers (percentages by country)

\begin{tabular}{|c|c|c|c|c|c|c|c|}
\hline \multicolumn{2}{|c|}{ Institution/Activity/ Country } & Swe & Nor & Den & Ger & Swi & Hun \\
\hline \multicolumn{2}{|c|}{ Total number of survey respondents } & 1005 & 1021 & 1004 & 1017 & 1002 & 1001 \\
\hline \multicolumn{2}{|c|}{$\begin{array}{l}\text { Used digital public library resources, } \% \\
\text { of total number }\end{array}$} & 30 & 27 & 36 & 15 & 19 & 24 \\
\hline \multicolumn{2}{|c|}{$\begin{array}{l}\text { Used digital museum resources, \% of } \\
\text { total number }\end{array}$} & 22 & 18 & 22 & 12 & 21 & 18 \\
\hline \multicolumn{2}{|c|}{$\begin{array}{l}\text { Used digital archival resources, \% of } \\
\text { total number }\end{array}$} & 10 & 11 & 9 & 6 & 9 & 6 \\
\hline \multirow{6}{*}{$\begin{array}{l}\text { Public } \\
\text { libraries } \\
\text { Categories } \\
\text { of use } \\
\text { in \% of } \\
\text { total } \\
\text { number of } \\
\text { responses }\end{array}$} & $\begin{array}{l}\text { 1. Checked the library's web- } \\
\text { site for contact info, opening } \\
\text { hours, info about activities } \\
\text { etc. }\end{array}$ & 6,2 & 7,4 & 5,7 & 2,8 & 3,6 & 3,6 \\
\hline & $\begin{array}{l}\text { 2. Checked social media of } \\
\text { the library (FB, Instagram, } \\
\text { blogs, Twitter, Pinterest etc.). }\end{array}$ & 1,1 & 2,1 & 0,9 & 0,5 & 0,6 & 3,6 \\
\hline & $\begin{array}{l}\text { 3. Used the library system in } \\
\text { order to digitally search for } \\
\text { books, make reservations, } \\
\text { renew loans etc. }\end{array}$ & 14,9 & 14,4 & 19,6 & 6,7 & 8,4 & 7,4 \\
\hline & $\begin{array}{l}\text { 4. Downloaded e-books or } \\
\text { other digital media, includ- } \\
\text { ing streamed audio books, } \\
\text { movies etc., which the library } \\
\text { gives access to. }\end{array}$ & 5,0 & 2,6 & 5,0 & 2,9 & 3,1 & 3,4 \\
\hline & $\begin{array}{l}\text { 5. Digitally given active re- } \\
\text { sponse to the library, e.g. } \\
\text { suggestions about purchases } \\
\text { of new books, communica- } \\
\text { tion with the library staff, } \\
\text { paid fines for delayed books, } \\
\text { booked meeting rooms at the } \\
\text { library. }\end{array}$ & 0,9 & 0,6 & 0,1 & 0,5 & 0,2 & 0,9 \\
\hline & $\begin{array}{l}\text { 6. Activities probably related } \\
\text { to the use of computers dur- } \\
\text { ing IRL-visits and references } \\
\text { to commercial services for } \\
\text { e-books ed. }{ }^{\text {b) Information }} \\
\text { difficult to understand or not } \\
\text { usable. }\end{array}$ & 4,6 & 2,4 & 3,5 & 2,4 & 3,3 & 4,4 \\
\hline
\end{tabular}


Tab. 12.9: (continued)

\begin{tabular}{|c|c|c|c|c|c|c|c|}
\hline \multicolumn{2}{|c|}{ Institution/Activity/ Country } & \multirow{2}{*}{$\begin{array}{r}\text { Swe } \\
9,9\end{array}$} & \multirow{2}{*}{$\frac{\text { Nor }}{9,2}$} & \multirow{2}{*}{$\frac{\text { Den }}{11,4}$} & \multirow{2}{*}{$\frac{\text { Ger }}{6,6}$} & \multirow{2}{*}{$\frac{\text { Swi }}{12,6}$} & \multirow{2}{*}{$\frac{\text { Hun }}{8,9}$} \\
\hline \multirow{6}{*}{$\begin{array}{l}\text { Categories } \\
\text { of use } \\
\text { in \% of } \\
\text { total } \\
\text { number of } \\
\text { responses }\end{array}$} & $\begin{array}{l}\text { 1. Checked a museum's web- } \\
\text { site for contact info, opening } \\
\text { hours, info about exhibitions } \\
\text { and other activities, entrance } \\
\text { fees, guided tours, menu of } \\
\text { the restaurant etc. }\end{array}$ & & & & & & \\
\hline & $\begin{array}{l}\text { 2. Checked social media of } \\
\text { a museum (FB, Instagram, } \\
\text { blogs, Twitter, Pinterest etc.) }\end{array}$ & 1,8 & 1,8 & 0,7 & 6,9 & 1,4 & 3,8 \\
\hline & $\begin{array}{l}\text { 3. Looked at virtual exhibi- } \\
\text { tions or material in virtual } \\
\text { collections of a museum. }\end{array}$ & 1,1 & 1,2 & 0,7 & 2,9 & 1,4 & 3,1 \\
\hline & $\begin{array}{l}\text { 4. Actively communicated } \\
\text { with a museum, e.g. through } \\
\text { digital booking of guided } \\
\text { tours or buying of tickets dig- } \\
\text { itally. Digital communication } \\
\text { with the staff. }\end{array}$ & 0,7 & 0,2 & 0,3 & 0 & 0,5 & 0,3 \\
\hline & $\begin{array}{l}\text { 5. Participated in } \\
\text { crowdsourcing-like activi- } \\
\text { ties (published documents or } \\
\text { given information about doc- } \\
\text { uments in the collections of a } \\
\text { museum). }\end{array}$ & 0,2 & 0,1 & 0 & 0 & 0,1 & 0,3 \\
\hline & $\begin{array}{l}\text { 6. Activities probably related } \\
\text { to the use of computers dur- } \\
\text { ing IRL-visits. }{ }^{\text {c) Information }} \\
\text { difficult to understand or not } \\
\text { usable. }\end{array}$ & 3,6 & 3,2 & 4,1 & 2,4 & 2,6 & 3,0 \\
\hline $\begin{array}{l}\text { Archives } \\
\text { Categories } \\
\text { of use }\end{array}$ & $\begin{array}{l}\text { 1. Checked an archival institu- } \\
\text { tion's website for contact info, } \\
\text { opening hours, info about } \\
\text { activities etc. }\end{array}$ & 2,6 & 2,4 & 1,8 & 0,9 & 1,9 & 1,7 \\
\hline $\begin{array}{l}\text { in } \% \text { of } \\
\text { total } \\
\text { number of } \\
\text { responses }\end{array}$ & $\begin{array}{l}\text { 2. Checked social media of } \\
\text { an archival institution (FB, } \\
\text { Instagram, blogs, Twitter, } \\
\text { Pinterest etc.) }\end{array}$ & 1,0 & 0,9 & 0,5 & 0,4 & 0,5 & 0,9 \\
\hline
\end{tabular}


Tab. 12.9: (continued)

\begin{tabular}{|c|c|c|c|c|c|c|}
\hline Institution/Activity/ Country & Swe & Nor & Den & Ger & Swi & Hun \\
\hline $\begin{array}{l}\text { 3. Used digital documents } \\
\text { from an archival institution, } \\
\text { researched genealogy with } \\
\text { help from digital resources. }\end{array}$ & 2,4 & 4,4 & 2,8 & 1,3 & 2,7 & 2,0 \\
\hline $\begin{array}{l}\text { 4. Participated in } \\
\text { crowdsourcing-like activi- } \\
\text { ties (published documents or } \\
\text { information about documents } \\
\text { in the stacks of an archival } \\
\text { institution). }\end{array}$ & 0,3 & 0,1 & 0 & 0 & 0 & 0 \\
\hline $\begin{array}{l}\text { 5. Actively sent requests digi- } \\
\text { tally to the staff of an archival } \\
\text { institution. }\end{array}$ & 0,1 & 0,1 & 0 & 0 & 0 & 0,5 \\
\hline $\begin{array}{l}\text { 6. Activities probably related } \\
\text { to the use of computers dur- } \\
\text { ing IRL-visits, answers refer- } \\
\text { ring to "archive" in a broader } \\
\text { sense and references to com- } \\
\text { mercial archival services. } \\
\text { Information difficult to under- } \\
\text { stand or not usable. }\end{array}$ & 3,5 & 2,7 & 2,8 & 2,4 & 3,0 & 0,9 \\
\hline
\end{tabular}

a) Free-text respondents saying he/she didn't use any digital services at all are counted as no answers.

b) E.g., answers as: Internet, Google, Netflix, Amazon, cd, laptop, Pc, Ipad, MeineStadt.de, Thalia, Windows.docs, e-mail, Ex Libris, Aldiko, Audible, iBooks, iPhone, Buch pluss, Gemeindeblatt, Zalando, Borger.dk, Adlibris bookshop, computer, mobile phone, hotels.com, Kivra, Ligimus, Media, spicy memes, Swish, TV, habbo, snapchat, genealogy.

c) For example: Internet, Google, Library, iPad, Kivra, Hotmail, Media, surfplatta, Nüremberg, Online, Suchmaschine, Windows Writer, Email, City Guide, MEG, Online-Bibliothek, Tablet, Wikipedia, Readbooks, Telenor, NBs nettsidor.

d) For example: Internet, Google, Library, iPad, Amazon, Meinestadt.de, My Amnesty, e-book, VHS, Zeitungsartikel, Archive.de, Adressänderung, BCU, Deepweb, online Schalter, Passausstellung, Postfinance, You Tube, Borgerservice, Pdf, Biblioteket, Arkiv Digital.

However, the fewest responses were for the use of archival resources. Considering the results reported in Table 12.4 on the respondents' digital use of the three ALM institutions, the lower number of free-text responses, for the use of archives is to be expected. The Norwegians scored the highest with $11 \%$, and the German and Hungarian respondents the lowest with $6 \%$. Still, the results in Table 12.2, showing that digital visits to archives are twice as popular (24\%) as phys- 
ical visits (12\%) among the respondents, it is somewhat surprising that according to the free-text responses few had used digital archival documents. This applied to $4.4 \%$ of the Norwegian respondents, but only for $1.3 \%$ of the Germans. Some respondents had ordered legal documents of different kinds. Though, the respondents interested in genealogy formed an important group, using digital resources to find information about their ancestors. But it has to be emphasized that in many cases, those resources were not directly connected to the archival institutions but services such as the international Ancestry and My Heritage or the Swedish Arkiv Digital, in other words, Internet-based companies that digitize and give access to archival material through subscriptions.

When analyzing the free text answers, we realized that many answers were not about the use of digital resources of the LAM-institutions, but apparently about the respondents' use of any digital resource during the visit to the library, museum or archive. The general use of digital resources was most evident in libraries, which is not surprising because in all countries covered by this study computers with Internet access are available in public libraries for the visitors' personal use. In many LAM institutions, there is also a free wi-fi service so that the visitors can get access to the Internet using their own devices. But it confirms that the users do not reflect much about whether the digital resources they use are connected to a LAM institution or not. In many cases, their use was just about googling, checking personal email, or social media. Sometimes it was related to the search for city guides or maps, and sometimes it had to do with issues connected to personal finances, bank transactions, or the user's mobile phone service.

In some cases, it was the use of national platforms for citizens' information or digital briefcases for documents from authorities or companies. Some respondents had used databases and other types of digital material that the institution subscribed to, such as digital newspapers, databases, or software. And sometimes it was about watching streamed TV shows or about Internet shopping. Interestingly, there were quite a few references to commercial services for e-books, audiobooks and online bookshops such as Amazon or Adlibris.

The survey tells us that the users do not think about whether the digital resources they use are connected to a LAM institution or not. Often, the use was googling, email, or social media. The participation in crowdsourcing activities was extremely rare among the respondents concerning all three LAM institutions.

Thus, no obvious signs of an increasing digital participatory culture connected to the LAM institutions were found. However, the results indicate to some degree that the LAM institutions, and especially the public libraries, provide services where people use digital resources of many different kinds to get access to 
information related to their rights and obligations as citizens, and where users take part in digitally mediated cultural expressions.

\section{Summary and Discussion}

As we have seen, museum usage seems to be the least affected by digital services; they are an add-on to the collection of physical objects. Libraries are in the middle position, but still heavily dominated by physical usage. In archives, on the contrary, digital visits are more popular than physical visits. Digital archive services seem to remove the barrier of physical travel to archival collections, and thereby can make physical access to collections seem less important to decision makers. We find that the European north-south cultural divide exists for the use of digital library services. Still, it is the geographically in-between German respondents that are the most infrequent users of all three types of LAM digital services. Germany consistently trails behind the Nordic countries, Switzerland, and Hungary.

Women dominate the use of LAM-digital services, except for archives that men use slightly more. Library digital services are used most frequently in the youngest age group, the 18-29-year olds, while the 50-59 age group is the most infrequent users; Germany especially has high numbers for the young. For archives and museums, we find the opposite pattern; in all the six countries, digital use increases with age. In the total sample, immigrants use all LAM digital services more than natives, and the most in Hungary and Switzerland. LAM digital services are used more by the highly educated in all six countries. Except for Hungary, patrons in all countries with home Internet access use digital library services and digital museum services substantially more than people without home Internet access, while the use of digital archive services shows little difference between countries.

From the qualitative data, we see that the use of LAM institutions' digital resources is still often connected to searching on the website or on social media for basic information such as contact information, opening hours, and upcoming activities. In particular this was the case with the museums, where this category formed the far largest group, and very few informants had tried to gain digital access to content, for example, by looking at virtual exhibitions or material in virtual collections. Regarding digital access to content in archives, an important group was the respondents interested in genealogy, using digital resources to find information about their ancestors, although in many cases those resources were not directly connected to the archival institutions but subscription-based commercial digital services. 
The survey revealed that participation in crowdsourcing activities was extremely rare among the respondents for all three LAM institutions. The conclusion from that is that there are still no strong signs of an increasing digital participatory culture connected to the LAM institutions involving the digital resources provided specifically by those institutions. But at the same time, the results seem to indicate that the ALM institutions, and especially the public libraries, work as community platforms for digital communication and participation, where people use digital resources of many different kinds to access information related to their rights and obligations as citizens, to digitally mediated learning resources, cultural expressions, and entertainment, such as literature, film, music, computer games, or to communicate digitally, share information with other users, and actively participate in activities on all conceivable topics.

When comparing the results of the survey with the professional and scholarly debate concerning digitalization that has characterized the LAM institutions since the early days of the Internet, we see a certain connection between the different assumptions and predictions, from representatives of the respective institutions, and the findings from the survey. Although heavily dominated by physical usage, a large percentage of patrons uses the library either digitally or both digitally and physically. But digitalization does not (at least not for now) pose an immediate threat to physical libraries as still more than half of the library users only visit the library through physical visits.

For museums, digital services can be seen as an add-on to the traditional physical activities based on the collection of physical objects but not as something that replaces the physical visit. Archives are the only LAM institution visited digitally more than physically. The digital transformation has opened up new opportunities for access and use of archival data and thereby has unleashed the potential reach of the archives.

The findings presented in this chapter contributes to the limited literature on the topic of the use of digital LAM-services - especially in that in addition to public libraries, the digital use of archives and museums is examined, and in a comparative perspective regarding both document institutions and national systems.

Concerning the LAM institutions as public-sphere infrastructure in a broader sense, including, for example, the support of participation, social cohesion, and civil society, the role of the physical LAM institutions does not seem to have been significantly reduced in the digital age.

Apart from archival digital services, digital LAM-services still seem to be in early adolescence. The contribution of digital services to digital participation in cultural and civic activities connected to libraries and museums is minor, more than a decade after the social media revolution. It is questionable whether digi- 
tal services will contribute considerably to the public sphere role of libraries and museums.

The physical and spatial dimensions of library and museum buildings and collections that are open to individuals and communities, creating public engagement and activities for both minds and bodies, are seemingly unbreakable institutional traits extending beyond the public sphere (see also Freeman and Blomley 2018). Taking the liberty of recontextualizing Stein Rokkan, The Norwegian Political Scientist, digital services count, but physical services decide.

Acknowledgment: The authors thank Roswitha Skare for organizing the Norwegian free-text answers and reviewers for constructive and helpful comments.

\section{References}

Aharony, N. “Facebook Use in Libraries: An Exploratory Analysis”. Aslib Proceedings, 64, no. 4, 358-372, 2012. https://doi.org/10.1108/00012531211244725.

Bolick, C. M. "Digital Archives: Democratizing the Doing of History". International Journal of Social Education, 21, no. 1, 122-134, 2006.

Brown, R. H. and B. Davis-Brown. "The Making of Memory: The Politics of Archives, Libraries and Museums in the Construction of National Consciousness". History of the Human Sciences, 11, no. 4, 17-32, 1998. https://doi.org/10.1177/095269519801100402.

Audunson, R., S. Aabø, R. Blomgren, H.-C. Hobohm, H. Jochumsen, M. Khosrowjerdi, R. Mumenthaler, K. Schuldt, C. H. Rasmussen, K. Rydbeck, M. Tóth, and A. Vårheim. "Public Libraries as Public Sphere Institutions: A Comparative Study of Perceptions of the Public Library's Role in six European Countries". Journal of Documentation, 75, no. 6, 1396-1415, 2019. https://doi.org/10.1108/JD-02-2019-0015.

Bonet, L. and E. Négrier. "The Participative Turn in Cultural Policy: Paradigms, Models, Contexts”. Poetics, 66, 64-73, 2018. https://doi.org/10.1016/j.poetic.2018.02.006.

Cohen, L. B. and J. M. Still. "A Comparison of Research University and Two-Year College Library Web Sites: Content, Functionality, and Form”. College \& Research Libraries, 60, no. 3, 275-289, 1999. https://doi.org/10.5860/crl.60.3.275.

Cook, T. "Evidence, Memory, Identity, and Community: Four Shifting Archival Paradigms". Archival Science, 13, no. 2-3, 95-120, 2013.

Cox, R. J. "Access in the Digital Information Age and the Archival Mission: The United States". Journal of the Society of Archivists, 19, no. 1, 25-40, 1998. https://doi.org/10.1080/ 00379819809514420.

Dietz, S. "Cybermuseology: Taking the Museum to the Net/Bringing the Digital Media to the Museum". http://www.yproductions.com/cybermuseology/toc.html, 2014.

Eveleigh, A. "Crowding out the Archivist? Locating Crowdsourcing Within the Broader Landscape of Participatory Archives". Crowdsourcing Our Cultural Heritage, pp. 211-212, 2014.

Edwards, B. Libraries and Learning Resource Centres. Amsterdam: Elsevier, Architectural Press, 2nd edn, 2009. 
Fletcher, A. and M. J. Lee. "Current Social Media Uses and Evaluations in American Museums". Museum Management and Curatorship, 27, no. 5, 505-521, 2012. https://doi.org/10. 1080/09647775.2012.738136.

Freeman, L. M. and N. Blomley. "Enacting Property: Making Space for the Public in the Municipal Library”. Environment and Planning C: Politics and Space, 2399654418784024. https://doi.org/10.1177/2399654418784024.

Hosar, M., E. Røsjø, and B. Jensen (eds). \#arkivdag: Relevans, medvirkning, dialog. Oslo: ABMmedia AS, 2016.

Huvila, I. "Participatory Archive: Towards Decentralised Curation, Radical User Orientation, and Broader Contextualisation of Records Management”. Archival Science, 8, no. 1, 15-36, 2008. https://doi.org/10.1007/s10502-008-9071-0.

Jenkins, H. Confronting the Challenges of Participatory Culture: Media Education for the 21st Century. Mit Press, 2009.

Jochumsen, H. and C. Hvenegaard Rasmussen. Folkebiblioteket under forandring: Modernitet, felt og diskurs. København: Danmarks Biblioteksforening og Danmarks Biblioteksskole, 2006.

Jochumsen, H., C. Hvenegaard Rasmussen, and D. Skot-Hansen. "The Four Spaces - a New Model for the Public Library”. New Library World, 113, no. 11/12, 586-597, 2012. https: //doi.org/10.1108/03074801211282948.

Jokitalo, P. “Internet in Every day Public Library Use”. 63rd IFLA General Conference - Conference Programme and Proceedings (31 Agosto-5 Septiembre 1997).

Lankes, R. D., J. Silverstein, and S. Nicholson. "Participatory Networks: The Library As Conversation”. Information Technology and Libraries, 26, no. 4, 17, 2007. https://doi.org/10. 6017/ital.v26i4.3267.

Lux, C. "Vom Bibliothekar zum Cybrarian - Die Zukunft des Berufs in der virtuellen Bibliothek". BuB - Forum Bibliothek Und Information, 46, no. 10/11, 860-866, 1994.

Myrczik, E. P. “Cultivating Digital Mediation: The Implementation of Publicly Funded Digital Museum Initiatives in Denmark”. International Journal of Cultural Policy, pp. 1-16, 2018. https://doi.org/10.1080/10286632.2018.1495714.

Oomen, J. and L. Aroyo. "Crowdsourcing in the Cultural Heritage Domain: Opportunities and Challenges". In Proceedings of the 5th International Conference on Communities and Technologies - C\&T'11, p. 138, 2011. https://doi.org/10.1145/2103354.2103373.

Lipset, S. M. and S. Rokkan. Party Systems and Voter Alignments: Cross-national Perspectives. New York: Free Press, 1967.

Schweibenz, W. “The Development of Virtual Museums”. ICOM News Magazine, 3, no. 3, 2004. Simon, N. “The Participatory Museum. Museum 2.0", 2010.

Skare, R. "The Public Library and Social Media. A Case Study from Troms $\varnothing$, Norway". In Proceedings from the Annual Meeting of the Document Academy, vol. 5, no. 2, 2018.

Skare, R. Chapter in this anthology, 2020.

Slots og kulturstyrelsen. Folkebiblioteker i tal 2015. København: Kulturministeriet, 2015.

Vårheim, A., S. Steinmo, and E. Ide. "Do Libraries Matter? Public Libraries and the Creation of Social Capital”. Journal of Documentation, 64, no. 6, 877-892, 2008. 



\section{Libraries and Democracy in Germany. As Perceived by the Public in Contrast to the Professionals}

\section{Research Questions}

This study in the context of project ALMPUB "Archives, Libraries, Museums as Public Sphere Institutions in the Digital Age" takes as its starting point the fundamental criticism voiced by Paul Jaeger and others (2013), namely that discussions on the relationship between libraries and democracy lack empirical evidence.

This takes into account the Nordic approach that considers the three key institutions of knowledge - libraries, archives and museums - together. Project partner Håkon Larsen provides an overall conceptual explanation of why these three institutions are comparable as public spaces and arenas of political discourse (Larson 2018).

The current research landscape has been explained in a report published in the Journal of Documentation and the results of representative population surveys in six countries are given in another recent article in the same journal (Audunson et al. 2019a, 2019b). The initial analyses of the survey of occupational fields were presented at CoLIS 10 (the conference "Conceptions of Library and Information Science" taking place every three years) in Slovenia in June 2019 (Audunson, Hobohm, Tóth 2019, see also Audunson, Hobohm and Tóth, this volume).

The starting point of the European project with partners from more than six countries was to establish the extent to which national populations attribute different roles to libraries in comparison to other countries, but also in comparison to the self-perceptions of library professionals in each respective country. The project is explained in more depth in the present volume. The starting points are similar projects by Ragnar Audunson and his team who for over two decades have dedicated themselves to understanding the role of the public library as a place in society (cf. e.g. Audunson 2005). The European network "Libraries in Urban Space" can be traced back to an interdisciplinary conference in Potsdam in 2012 with the title "The City of Flows - Interdisciplinary Perspectives on the Digital City in Analogue Spaces”. 
The basic research questions for the present chapter were as follows:

- How is digitalisation changing the role of libraries, archives and museums as infrastructure institutions which support open and enlightened discourse within society?

- Is there a difference between the professional self-perception and the public image of the library regarding the new roles?

It takes the German library field as the focus of investigation.

\section{Survey Methodology}

In 2017, an English-language master questionnaire was designed for a population survey, with versions for each country being prepared and translated by the project partners: Norway, Sweden, Denmark, Hungary, Germany and Switzerland. The questionnaire comprised around 30 questions which were partially designed in accordance with the European Social Survey ${ }^{1}$ (ESS) scales and tested in different environments. The survey itself was conducted in the six countries by the Norwegian social and market research company Sentio Research. Contact to the sample was achieved by means of existing panels and thus partly by self-recruitment. However, a check based on socio-demographic control variables (age cohorts, education level) showed that the sample surveyed achieved an acceptable level of representativeness of $\mathrm{N}=6050$ in all countries.

Taking the population questionnaire as a template, further 36-question English-language master questionnaires seeking to compare the role of perception and self-awareness of staff and management in the three institutions (i.e. archives, libraries and museums in each country) were developed for all three occupational fields and translated into the respective national languages with slight adjustments depending on the country and occupational field. In some cases, it was not possible to transfer the wording of individual questions and response scales directly from the population questionnaire and adapt it to match the target group. This time project partners initiated their own data collection. In Germany, the three institution surveys were conducted in summer 2018 (libraries) and spring 2019 (archives and museums). Contact to the sample was achieved via professional nationwide mailing lists or using the snowball method (self-recruitment). The librarian occupational field survey in Germany described

1 European Social Survey - European Research Infrastructure Consortium ESS-ERIC: https:// www.europeansocialsurvey.org. 
here was administered by Limesurvey Professional ${ }^{2}$ at the Potsdam University of Applied Sciences and resulted in a response rate of $N=1014$. A number of questions were optional, meaning that the full sample size was not always achieved. Even if the survey procedure did not result in a representative sample in a strict statistical sense, the socio-demographic variables surveyed (type of librarian training, catchment area of one's own library, extent of management responsibility in one's own range of tasks etc.) show a wide dispersion and no conspicuous bias.

\section{Results}

\section{Library Visits: Comparisons Within Europe}

The indicator "Market penetration" - i.e. number of library visits undertaken by a population - obviously represents an important question in comparisons between European countries. Responses to the question "How often did you physically visit a public library, a museum or an archive in the last year?" were largely in line with expectations, but nevertheless revealed a usage rate of approx. 50\% for Germany and Switzerland, which is fairly high compared to other German studies $^{3}$ (see Table 13.1, Figure 13.1). This might be an effect of the sampling method of the Sentio panel in German-speaking countries or even a bias triggered by the political climate at the time of the survey. This figure is interesting in light of the widely perceived leadership of Nordic countries: at the very least the library usage

Tab. 13.1: Library visits in the last 12 months (ALMPUB: V23, $N=6050$ ) in per cent, rounded

\begin{tabular}{llllllll}
\hline & Denmark & Sweden & Norway & Germany & Switzerland & Hungary & Total \\
\hline Never & 29 & 30 & 36 & 52 & 53 & 32 & 38 \\
$1-3$ times & 32 & 35 & 30 & 25 & 26 & 40 & 31 \\
$4-9$ times & 18 & 17 & 17 & 12 & 10 & 14 & 15 \\
$10-20$ times & 11 & 10 & 10 & 6 & 8 & 9 & 9 \\
$20+$ & 11 & 8 & 7 & 5 & 4 & 5 & 7 \\
\hline
\end{tabular}

2 https://fh-potsdam.limequery.org.

3 E.g. the representative survey commissioned by DBV and Stiftung Lesen in 2012 ("Ursachen und Gründe für die Nichtnutzung von Bibliotheken in Deutschland" = "Causes and reasons for the non-use of libraries in Germany") shows that the use of libraries (all types) "in the last 12 months" was 37\% (public libraries alone = 29\%) (see http://www.stiftunglesen.de/ bibliothekstudie). 


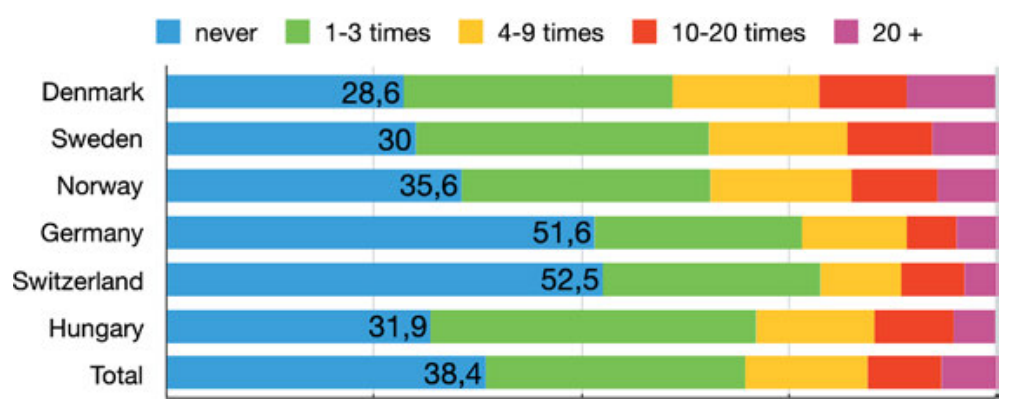

Fig. 13.1: Library visits in the last 12 months in six countries (2017) in per cent

in Germany is not as bad as often suggested, and might ultimately be at the level of other countries (any statistical artefact omitted). This difference in observed usage of libraries seems not to have an effect on the following parts of the survey because most of the following questions were overall attributions on a fixed scale which can be estimated by users as well as non-users.

\section{Social Significance of Libraries}

In order to determine the general social value attributed to LAM institutions in the countries surveyed the following item was presented in the questionnaire:

To what extent do you think libraries, archives and museums contribute in realising the following social values? Use the scale from 0 to 10, where 0 indicates not at all and 10 indicates very good. Please enter your answer in each row/column.

As far as libraries are concerned, the results tend to be relatively similar across Europe. On average, the promotion of "solidarity and a sense of community" and "democracy" is the function least ascribed to libraries (see Table 13.2, Figure 13.2). On the scale from 1 to 10, however, responses still reach national averages of 7 to max. 7.5. The highest scores in this respect are achieved by the responses of the Norwegian and German populations on the subject of "democracy", with values of 7.56 and 7.53 respectively. Germany's score of 8.34 also leads for the function ranked next in terms of importance, namely that libraries should promote "social value", "a liveable community". These statistical differences may be relatively minor, but it is interesting to note that the function least ascribed to libraries by German respondents (compared with other European countries) was the promotion 
of "knowledge and interest in history". One might have thought that the German sensitivity to history would be much higher - but perhaps this is not attributed to the library as a democratic institution. The promotion of lifelong learning, knowledge acquisition and access to culture is most likely to be ascribed to libraries by all respondents, although precisely these more traditional functions seem to predominate, particularly in Germany (i.e. they are usually higher than the Nordic countries for examples).

Tab. 13.2: To what extent do you think libraries contribute to promoting the following social values? (ALMPUB Q19A, N = 3729, response options from 0 to 10, mean values on an 11-figure scale)

\begin{tabular}{|c|c|c|c|c|c|c|}
\hline & Denmark & Sweden & Norway & Germany & Switzerland & Hungary \\
\hline $\begin{array}{l}\text { Interest in literature } \\
\text { and culture }\end{array}$ & 7.7 & 7.86 & 8.24 & 8.08 & 8.17 & 8.6 \\
\hline Lifelong learning & 7.85 & 8.04 & 8.21 & 8.24 & 8.37 & 8.62 \\
\hline $\begin{array}{l}\text { Knowledge/interest in } \\
\text { society around us }\end{array}$ & 7.8 & 7.8 & 8.13 & 8.02 & 7.94 & 8.18 \\
\hline $\begin{array}{l}\text { Solidarity and commu- } \\
\text { nity }\end{array}$ & 6.94 & 7.07 & 7.49 & 7.18 & 7.07 & 7.43 \\
\hline $\begin{array}{l}\text { Equal access to infor- } \\
\text { mation and knowledge }\end{array}$ & 8.17 & 8.14 & 8.66 & 8.48 & 8.46 & 8.64 \\
\hline $\begin{array}{l}\text { Equal access to cul- } \\
\text { tural experiences }\end{array}$ & 7.62 & 7.79 & 8.21 & 8.03 & 8.08 & 8.52 \\
\hline Democracy & 7.22 & 7.27 & 7.56 & 7.53 & 7.08 & 7.15 \\
\hline $\begin{array}{l}\text { Knowledge of other } \\
\text { cultures }\end{array}$ & 7.66 & 7.57 & 7.94 & 8.19 & 8.24 & 8.44 \\
\hline $\begin{array}{l}\text { Knowledge of and } \\
\text { interest in history }\end{array}$ & 8.05 & 8.08 & 8.36 & 7.65 & 7.8 & 8.74 \\
\hline A liveable community & 7.54 & 7.52 & 8.02 & 8.34 & 7.67 & 7.58 \\
\hline
\end{tabular}

Figure 13.2 shows the striking similarities between the six countries but also reveals some interesting country characteristics, especially in the dimensions of "democracy" and "liveable community". Any cultural explanation will be left to the reader and cannot be expanded upon here further. For the sake of clarity, the following analysis will focus on the German scores compared to the combined values of the five remaining countries. 


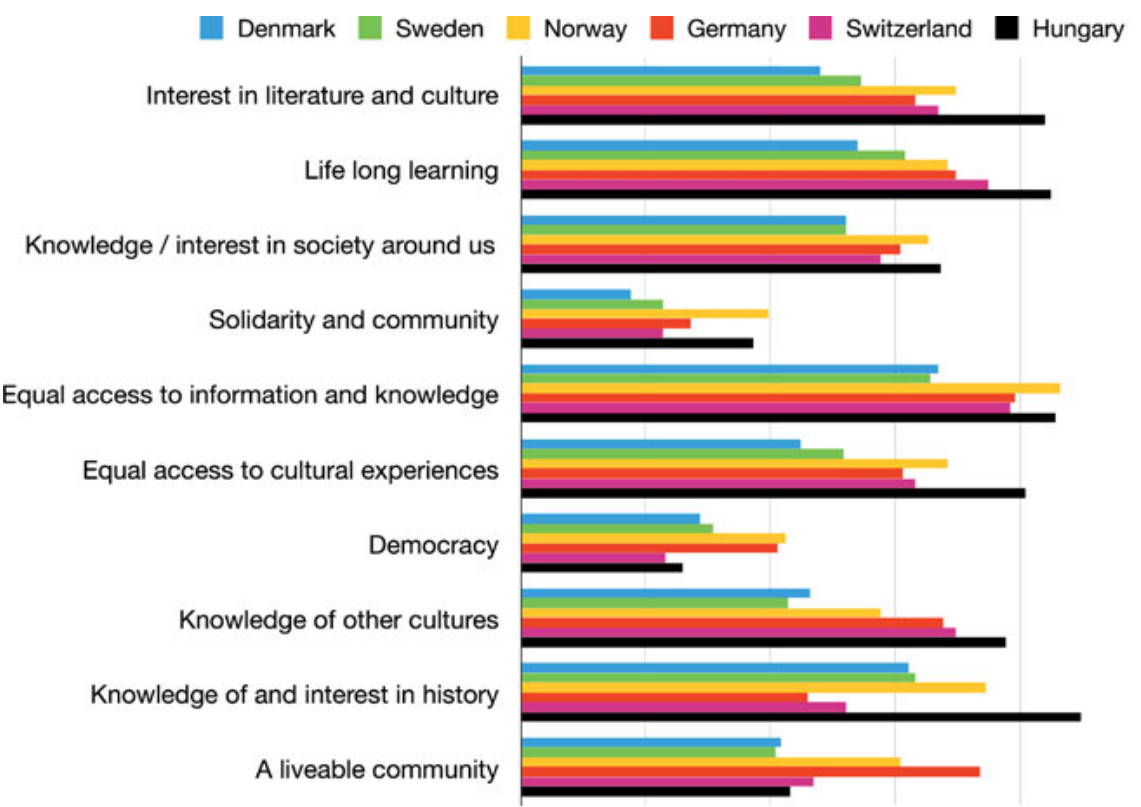

Fig. 13.2: Libraries and social values in six countries

\section{Functions of Public Libraries in Society}

Panel participants were asked specifically about the roles of libraries with the following stimulus:

A public library has many roles and there can be many reasons for upholding a public library service. A number of different reasons are given below. Could you for each of these indicate the importance on a scale from 0 to 10 as a reason for upholding a library service in your community, where 0 indicates very little important and 10 indicates of very high importance.

Here, "traditional" functions primarily promoting culture and support knowledge acquisition were also rated higher in Germany (see Table 13.3 and Figure 13.3). The values are above the country average, particularly for these aspects perceived as "traditional" by the population. Cultural heritage (item "J"), meaningful leisure activities ("K") and knowledge and everyday information ("A", "B") are given comparatively high priority for German libraries. "Democratic public discourse" (“C”) and "library as a meeting place" ("D") are also rated positively in line with the research hypothesis of the project - especially compared with other countries. It is noticeable that all aspects involving creativity, innovation ("H", "I") and "active 
involvement" (as well as "informal learning" "E"4) have lower values in Germany. The German population does not yet - at least according to this survey from 2017 perceive the library as a creative place. In terms of social integration, the role of the library as a "meeting place transcending ethnic and cultural origins" ("L") is also underestimated comparatively.

\section{Germany \\ 5 other countries \\ German librarians}

A) Information ... everyday lives

B) promotes democracy ... access to knowledge

C) promotes democracy ... public discourse

D) social meeting place

E) promotes learning

F) equal access to knowledge

G) digital devides

H) creativity and innovation ... joint activities

I) cultural expressions

J) cultural heritage

K) meaningful leisure activities

L) Integration and social cohesion
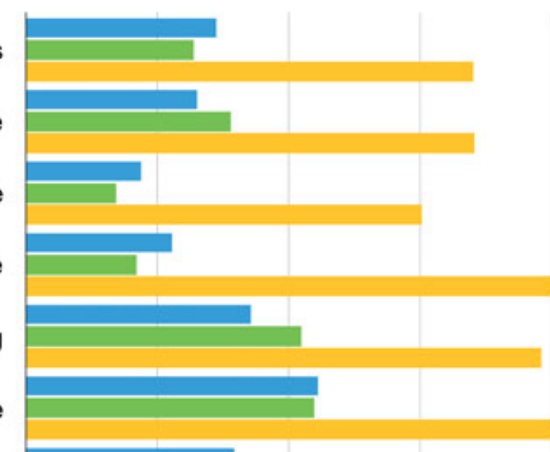

\section{$-$}

-
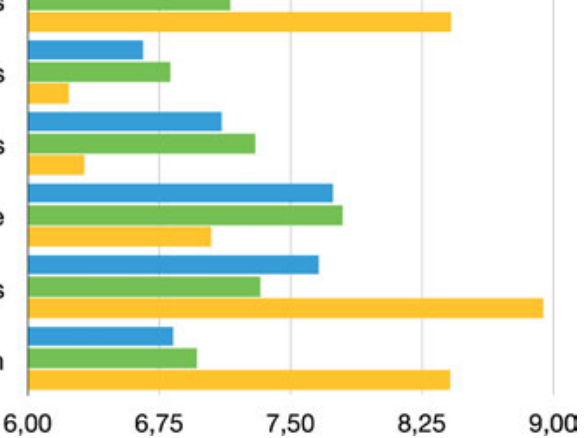

Fig. 13.3: Comparison of functions assigned to public libraries

When comparing responses from the library professionals to the same questions (third column "German librarians" in Table 13.3), it is noticeable that many social (and democratic) and information functions are rated higher by those in the profession than by the population in the representative survey. ${ }^{5}$ German library

4 This could be a problem relating to the formulation of the questions: the concept of "informal learning" may not be easy to understand.

5 See yellow bars in Figure 13.3. Note that this is a scale section with the same questionnaire scales. 
Tab. 13.3: Functions of public libraries in Germany $(N=1017$, answer options from 0 to 10 , mean values on a 11-figure scale) compared to Denmark, Sweden, Norway, Switzerland and Hungary $(\mathrm{N}=5033)$ and compared to the occupational field survey librarians $(\mathrm{N}=595)$.

\begin{tabular}{|c|c|c|c|}
\hline & Germany & $\begin{array}{l}5 \text { other } \\
\text { countries }\end{array}$ & $\begin{array}{l}\text { German } \\
\text { librarians }\end{array}$ \\
\hline $\begin{array}{l}\text { A) The library provides people with information } \\
\text { they need in their everyday lives. }\end{array}$ & 7.09 & 6.96 & 8.55 \\
\hline $\begin{array}{l}\text { B) The library promotes democracy by giving } \\
\text { citizens access to knowledge and information } \\
\text { they need to be active in their communities. }\end{array}$ & 6.98 & 7.17 & 8.56 \\
\hline $\begin{array}{l}\text { C) The library promotes democracy by being an } \\
\text { arena for public discourse. }\end{array}$ & 6.66 & 6.52 & 8.26 \\
\hline $\begin{array}{l}\text { D) The library is an important social meeting } \\
\text { place in the community. }\end{array}$ & 6.84 & 6.63 & 9.01 \\
\hline $\begin{array}{l}\text { E) The library promotes learning, supporting } \\
\text { informal as well as formal learning. }\end{array}$ & 7.29 & 7.57 & 8.94 \\
\hline $\begin{array}{l}\text { F) The library promotes equality by giving equal } \\
\text { access to knowledge resources and literary and } \\
\text { cultural experiences. }\end{array}$ & 7.67 & 7.65 & 9.09 \\
\hline $\begin{array}{l}\text { G) The library promotes equality by evening out } \\
\text { digital divides. }\end{array}$ & 7.19 & 7.16 & 8.42 \\
\hline $\begin{array}{l}\text { H) The library promotes creativity and innovation } \\
\text { by stimulating their users' spaces, opening up } \\
\text { for individual or joint activities (maker spaces). }\end{array}$ & 6.66 & 6.82 & 6.24 \\
\hline $\begin{array}{l}\text { I) The library promotes contemporary literary and } \\
\text { cultural expressions of high quality. }\end{array}$ & 7.11 & 7.30 & 6.33 \\
\hline $\begin{array}{l}\text { J) The library promotes the literary and cultural } \\
\text { heritage. }\end{array}$ & 7.74 & 7.80 & 7.05 \\
\hline $\begin{array}{l}\text { K) The library provides their users with experi- } \\
\text { ences and meaningful leisure activities, e.g. by } \\
\text { providing entertainment and popular reading } \\
\text { material. }\end{array}$ & 7.66 & 7.33 & 8.94 \\
\hline $\begin{array}{l}\text { L) The library promotes integration and social } \\
\text { cohesion by being a meeting place transcending } \\
\text { ethnic and cultural origins. }\end{array}$ & 6.83 & 6.97 & 8.41 \\
\hline
\end{tabular}


professionals are comparatively pessimistic with regard to aspects of high culture and cultural heritage ("I", "J") - this is very likely due to the focus on public libraries. The aspect "creativity and innovation ... makerspace" ("H") is rated even lower by professionals working in the institution than by the general population.

Despite the concept being repeatedly enshrined in law, the perception of the dimension "The library promotes democracy because it is a place for forming public opinion" is still comparatively underdeveloped in all countries surveyed. More widespread is the perception of the aspect of freedom of opinion and equal access to knowledge and information. In Germany, it can be noted that despite the predominance of traditional perceptions, sensitivity for these "new" roles of libraries is already quite pronounced, especially in comparison with the Nordic countries assumed to be pioneering these new approaches.

\section{Public Library as a Promoter of Democracy?}

In order to assess possibilities for promoting the postulated democratic roles of libraries, the same question was asked in the population survey and institution survey in all participating countries:

Public libraries should be institutions that promote the free formation of opinion and thus democracy. The library can perform this role in several ways and below we have specified some. How do you think your local library should prioritise these? Use the scale from 0 to 10 , where 0 indicates very low priority and 10 very high priority in relation to the goal of promoting democracy and the free formation of opinion.

Here too, the information function of libraries continues to prevail in all countries - and with particular emphasis in Germany. "Well-founded decisions" ("A") and "rights and obligations" ("B") are certainly the questionnaire-specific triggers that produce the high values in this context (see Table 13.4 and Figure 13.4). It remains difficult for all country populations to perceive libraries as an arena for public discourse, even though responses in Germany indicate they are already perceived as event venues ("D"), which in this survey were associated with the promotion of democracy due to the formulation of the question. Library professionals follow this assessment but also attach particular importance to civic skills ("F"). In particular, digital media literacy ("G") is seen here as an instrument that promotes democracy. However, the offer of libraries' own digital platforms ("E”) for the debate of municipal topics tends to be rejected in practice. 
Tab. 13.4: Priorities of options for democracy promotion by libraries (population survey $\mathrm{N}=1017$, response options from 0 to 10 , mean values of the 11-figure scale) compared to Denmark, Sweden, Norway, Switzerland and Hungary $(\mathrm{N}=5033)$ and compared to the German library occupational survey $(\mathrm{N}=594)$

\begin{tabular}{|c|c|c|c|}
\hline & Germany & $\begin{array}{l}5 \text { other } \\
\text { countries }\end{array}$ & $\begin{array}{l}\text { German } \\
\text { librarians }\end{array}$ \\
\hline $\begin{array}{l}\text { A) Provide knowledge and information which the } \\
\text { citizens need to make informed choices. }\end{array}$ & 7.78 & 7.37 & 8.99 \\
\hline $\begin{array}{l}\text { B) Provide information which the citizens need to } \\
\text { know about their rights and obligations as citizens. }\end{array}$ & 7.79 & 7.28 & 8.39 \\
\hline $\begin{array}{l}\text { C) Provide information helping citizens to keep gen- } \\
\text { erally updated and informed on community issues. }\end{array}$ & 7.32 & 7.22 & 7.89 \\
\hline $\begin{array}{l}\text { D) Be an arena for public meetings and discussions, } \\
\text { i.e. physical meetings. }\end{array}$ & 6.82 & 6.65 & 7.37 \\
\hline $\begin{array}{l}\text { E) Provide digital arenas for discussing community } \\
\text { issues. }\end{array}$ & 6.48 & 6.55 & 5.66 \\
\hline F) Develop civic skills related to traditional media. & 6.74 & 6.74 & 7.82 \\
\hline G) Develop civic skills related to digital media. & 6.64 & 6.68 & 8.03 \\
\hline
\end{tabular}

Germany 5 other countries German librarians

A) Information ... informed decisions

B) Information ... rights and obligations

C) informed on community issues

D) arena for physical meetings

E) digital arena

F) skills for traditional media

G) skills for digital media
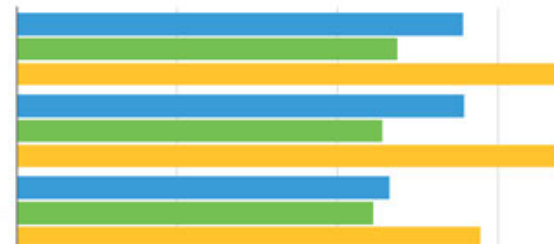

\section{$\sqrt{-1}$}




\section{Roles and Competences of Librarians}

In addition to a number of other questions, the librarians surveyed were finally asked whether they ascribe to themselves a role in promoting democracy, or whether they feel the competences required are lacking in their specific context. The question was as follows:

The role as a library professional is a complex one. How similar do you perceive your role as a library professional in the community you work are to the roles listed below. Place yourself on a scale from 0 to 5 , where 0 means that the role is not similar to the roles you play at all and 5 means very similar. The library role is similar to the role of a...

The different roles mentioned above represent different competences. Are there any of the competences listed in the roles that you feel your library is missing in order to fulfil its role in the community? Mark up to five roles which you feel represent competences lacking in your library/ which cannot be fulfilled.

The result is an interesting ranking of the roles assigned to those working in libraries (see Figure 13.5). After the classic job descriptions such as "information, knowledge and literature mediator", the relevant roles of an "agent for enlightenment and education" and an "agent for freedom of expression and information" follow very closely, also closely followed by "facilitators", "teachers" and "event managers”. In the first areas, competence deficits in respondents' own libraries were relatively seldom identified. Deficits were identified in the pedagogicalpsychological field but also in the field of social and youth work and especially in the role as "integration consultant" and as "community developer" (in the entries to the open question "Other", several respondents noted that the roles "change manager" and "media pedagogue" were missing from the questionnaire). Finally, it comes as no surprise that gaps in competence were also identified in IT, social media and web design.

Above all this means that librarians, in addition to their traditional role as information and knowledge mediators, actually do perceive themselves as guarantors of freedom of opinion, education and training for the public sphere as defined by Habermas (1989, see introduction of the present volume), and also ascribe these competences to themselves. This is to say that they - at least in Germany do accept their role in democracy and are able to fulfil it. 


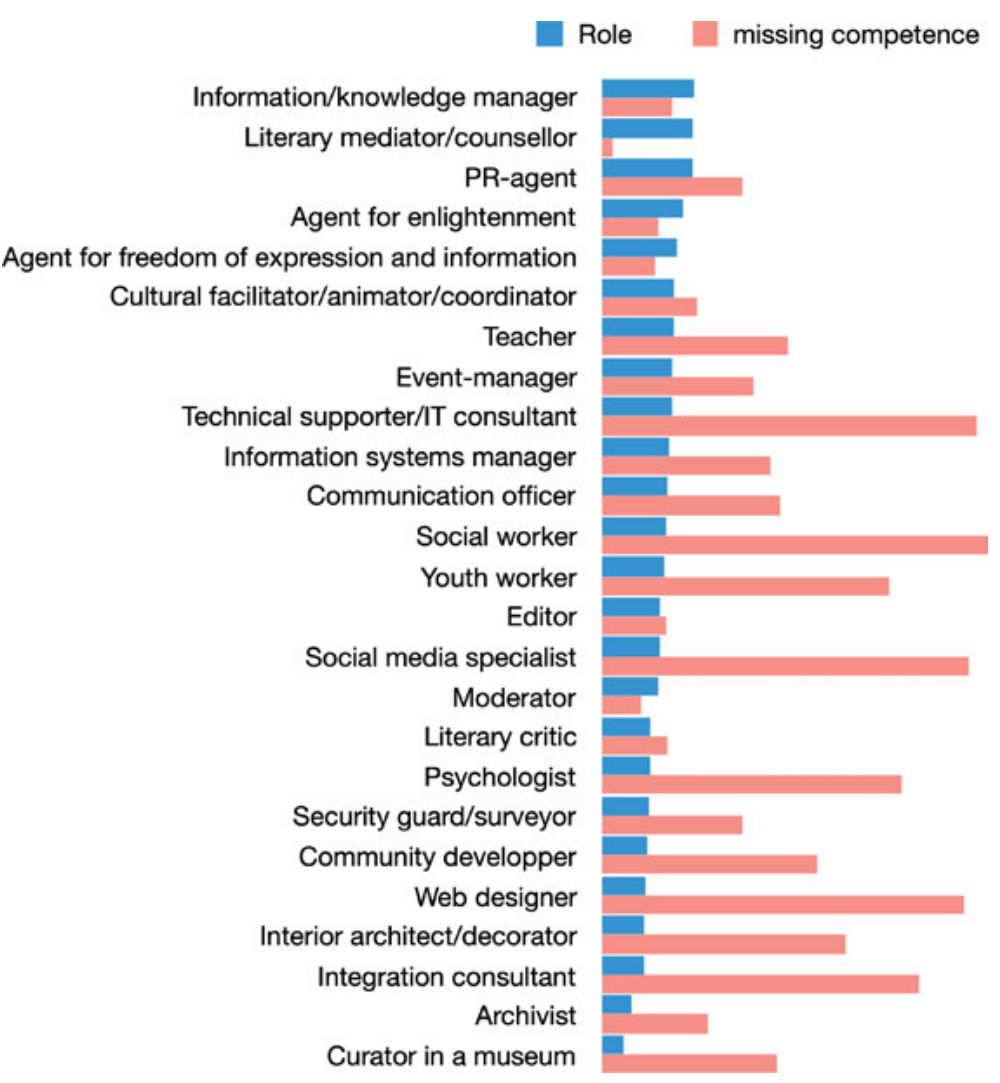

Fig. 13.5: Role self-attributions and perceived competence deficits - German library field survey, $\mathrm{N}=579$, scale of $0-5$ (V14), or multiple answers, max. 5 (V15)

\section{Conclusion}

Overall, it is clear that libraries (and here the public libraries as pioneers) exhibit the kind of social responsiveness postulated by Widdersheim (2018). In an intraEuropean comparison, different social and infrastructural conditions can be seen to result in differences in use and the attribution of functions. For example, the digital use of libraries is clearly lower in countries with less developed digital infrastructures (such as Hungary). Many of the variables observed in the ALMPUB network surveys can be linked to cultural and structural differences. However, the fact that the library and cultural laws of Nordic countries draw more profound and explicitly links between libraries and democracy does not have as strong an effect as might be expected. A number of more in-depth analyses of the avail- 
able data are still pending. Initial inferential evaluations of the statistics suggest that the factor "trust in social institutions" is significant (Audunson et al. 2019b), which may be an important aspect of the relation to modern political theory as discussed in the introductory chapter (Audunson et al., this volume). Following elaborate quantitative surveying, further analyses of the collected data material must now follow and, if necessary, qualitative methods must be used to identify further consequences and requisite conditions for librarian initiatives undertaken for the benefit of democratic society.

While the data obtained so far should be treated with caution, a positive tendency can be observed throughout Europe, but especially in Germany: on the one hand there is (some) support among the population for the political function of libraries, and on the other library professionals themselves view this role quite positively in principle. Perhaps it would help to go on the offensive here, and also to participate actively in discourse around the role and form of democracy in our time. Should rationalism's orientation towards a neutral consensus in which libraries "only" contribute to the generation of knowledge for rational discourse suffice? Or does an "arena” or "agora” not imply much more debate, involvement and dialogue face to face - as French political theorists suggest (Huzar 2013, see introductory chapter)? Perhaps - in the spirit of David Lankes' (2011) dictum that knowledge only comes from conversation - we should initiate talk. And in times of disruptive renewal, democracy needs a lot of knowledge and conversation.

Acknowledgment: Translated by Steve Mortimer, Berlin. A first version of parts this chapter has been presented at the German National Library Congress, march 2019 in Leipzig (cf. Hobohm 2019).

\section{References}

Audunson, R. “The Public Library as a Meeting-place in a Multicultural and Digital Context”. Journal of Documentation, 61, no. 3, 429-441, 2005.

Audunson, R., S. Aabø, R. Blomgren, et al. "Public Libraries as an Infrastructure for a Sustainable Public Sphere”. Journal of Documentation, 75, no. 4, 773-790, 2019.

Audunson, R., S. Aabø, R. Blomgren, H.-C. Hobohm, et al. "Public Libraries as Public Sphere Institutions. A Comparative Study of Perceptions of the Public Library's Role in Six European Countries". Journal of Documentation, 75, no. 6, 1396-1415, 2019. doi:10.1108/JD-022019-0015.

Audunson, R., H.-C. Hobohm, and M. Tóth. “ALM in the Public Sphere. How do Archivists, Librarians and Museum Professionals Conceive the Respective Roles of their Institutions in the Public Sphere?”. Information Research, 24, no. 4, 2019. papercolis1917.

Audunson, R., H.-C. Hobohm, and M. Tóth. "ALM Professionals and the Public Sphere: How do Librarians, Archivists and Museum Professionals Conceive the Respective Roles of their 
Institutions in the Public Sphere?". In Audunson, R., H. Andresen, C. Fagerlid, E. Henningsen, H-C. Hobohm, H. Jochumsen, H. Larsen, and T. Vold (eds), Libraries, Archives and Museums as Democratic Spaces in a Digital Age. Berlin: De Gruyter Saur, 2020.

Audunson, R., H. Andresen, C. Fagerlid, et al. "Introduction - Physical Places and Virtual Spaces: Libraries, Archives and Museums in a Digital Age”. In Audunson, R., H. Andresen, C. Fagerlid, E. Henningsen, H-C. Hobohm, H. Jochumsen, H. Larsen, and T. Vold (eds), Libraries, Archives and Museums as Democratic Spaces in a Digital Age. Berlin: De Gruyter Saur, 2020.

Habermas, J. The Structural Transformation of the Public Sphere: An Inquiry into a Category of Bourgeois Society. Cambridge: Polity Press, 1989.

Hobohm, H.-C. "Bibliotheken und Demokratie in Deutschland. Ergebnisse eines europäischen Projektes zu ihrer Rolle und ihrem Engagement für Demokratie und Gemeinwohl". o-bib. Das offene Bibliotheksjournal, 6, no. 4, 7-24, 2019.

Huzar, T. J. "The Public Library Democracy and Rancière's Poetics of Politics”. In Information Research 18 (Proc. of CoLIS 8), paper C15, 2013. http://InformationR.net/ir/18-3/colis/ paperC15.html.

Jaeger, P. T., U. Gorham, J. C. Bertot, et al. “Democracy, Neutrality, and Value Demonstration in the Age of Austerity”. The Library Quarterly, 83, no. 4, 368-382, 2013.

Lankes, R. D. “The Atlas of New Librarianship”. Cambridge, Mass, 2011.

Larsen, H. "Archives, Libraries and Museums in the Nordic Model of the Public Sphere”. Journal of Documentation, 74, no. 1, 187-194, 2018.

Widdersheim, M. M. “A Political Theory of Public Library Development”. Libri, 68, no. 4, 269289, 2018. 


\section{Cicilie Fagerlid}

\section{Democratic Coexistence, Tiny Publics and Participatory Emancipation at the Public Library}

\section{Introduction: Democratic Coexistence in a Digital Age}

This chapter analyses situations and events at public libraries where being together creates, on the one hand, individual social and civic awareness, and on the other, various kinds of relations between strangers. I suggest calling this double process democratic coexistence. Democratic coexistence means becoming aware of and having a minimum of interaction with the variety of people constituting a society, not only with kin, peers and members of your personal online echochamber. This understanding of democracy highlights its experiential and functional aspects, rather than formal governance (see Sennett 2006). It relates thus to library scholar John Buschman's call for a renewed understanding of the relationship between democracy and the library: "[D]emocracy takes place directly and indirectly in venues not commonly thought of as sites for it but where everyday life is negotiated and played out (e.g. libraries), thereby constructing the culture" (2018a, 34; see also Buschman 2018b). Similarly, sociologist Eric Klinenberg (2018) emphasizes how spending time in our "social infrastructure" teaches us to deal civilly with "small shared problems" and negotiate differences typically - or even particularly - present at the public library. Social infrastructure is Klinenberg's term for "the physical places that allow bonds to develop" $\left(2018^{1}\right)$ and is thus fundamental for a democracy. This processual and situational approach to daily life democracy is in line with social anthropological analyses of how interaction constitutes social reality. ${ }^{2}$

1 Online source without pages. Klinenberg 2018, "Social infrastructure is not..." Paragraph 3.

2 Despite my emphasis on democratic coexistence, I do not imply that situations at the library cannot also foster intolerance, disrespect, discord and unresolved conflicts, as I will briefly touch upon. However, the processes creating democratic coexistence are no less real just because other - far less prominent, as I will argue -practices, interactions and interpretations have different results. Neither does my perspective imply that social reality is congruent and perceived identically, independent of previous experience, gender, age, socioeconomic and cultural background (see Haraway 1988). 
A characteristic of everyday life in the public library is the extent to which the different spheres of contemporary life blur (Aabø and Audunson 2012). Not only do people create a room of their own, paradoxically, among strangers (Fagerlid 2016, 2017). The complex space affords varied needs and activities. It thus dissolves analytical dichotomies between the individual and communal; the practical and existential; the emotional and rational; and the sensorial, communicative body and reflective mind. A holistically experienced social reality appears, accompanied perhaps, by a fuller, less alienated sense of being human (see Skjerdingstad, this volume). This chapter describes and analyses events and situations at the public library that produce and reproduce experientially complex and holistic social realities connected to democratic coexistence between strangers. ${ }^{3}$

\section{Methodological Notes}

The chapter is based on one year of observation, participation and experience at ten public libraries situated in different areas of the Norwegian capital Oslo. The neighborhoods' differences comprise - simplistically put, and partly overlapping - financial affluence (Røa) and sociocultural and educational advantage (Majorstuen, Lambertseter, Oppsal); centrality (Grünerløkka, Torshov) and periphery (Bjerke); heterogeneity and rapid gentrification (Tøyen); and socioeconomical disadvantage (Furuset, Stovner, Holmlia).

In addition to numerous literary events and public talks, I have attended around 30 meetings in eight different book clubs and five "shared reading" sessions. I have had small conversations with users and my library worker husband, conducted group interviews with five book clubs and in-depth semi-structured individual interviews - lasting from one to three, but usually around two hours with 30 users in the age-range 15 to 88 and six members of staff and middle managers.

In line with the anthropological dictum to "grasp the natives' points of view" (the plural emphasized by Narayan 1993; see also Malinowski 1922), the aim of my overall postdoctoral project was deliberately open and explorative. It concerned the local public library's meanings and functions in the life of different users and how the different user categories coexisted at the physical public library. An inter-

3 At the same time as having democratic dimensions and dynamics, many of the events and situations have strong therapeutic elements, soothing and negotiating individual existential worries and traumas. There is likely a close link between democratic participation and individual healing, which this chapter touches upon without going into detail about (see also Fagerlid 2012 for a similar double process). 
est in coexistence, more than interaction, and the library as a room of one's own among strangers, more than a meeting place, crystallized during my first three months of fieldwork in 2012 (Fagerlid 2016), thus before I formulated the research questions for the ALMPUB project.

Fieldwork observation consisted of gaining an overview of the social composition of the library space, activities, comportments and interactions, and noting down as much as possible, both of the bigger picture and of micro-processes. I have spent time in all sections of the various libraries, at all times of ordinary opening hours, from August throughout June 2017-18. During observant participation, I have engaged in ordinary library activities, such as reading, writing and attending events, at the same time as noting down features of the environment and my own experiences. By participant experience, I mean the sensory affects and effects of being, working and attending events side by side others at the library, but also of raising one's hand and voicing one's opinions - as different from merely observing - in literary discussions, and, as in the last scene in this chapter, of being mesmerized by a moving performance at a Meet the Author event.

Lastly, and evidently, all knowledge production is partial and situated (but not relative), and a result of an embodied and positioned researcher's engagement with the world, as pointed out by historian of science Donna Haraway (1988).

\section{A Brief Note on the Role of Staff}

This chapter analyses democratic coexistence from a user perspective. It therefore lacks a systematic analysis of the staff's role in the creation of a convivial ambience (scene two below contains a brief, but typical example; see also Skjerdingstad, and Evjen and Vold, this volume). I acknowledge, however, the importance of the staff's calm and considerate presence, their ceaseless assistance and overtly neutral and equal treatment, yet also special care for young and old in particular need of a kind word and acknowledgement. Many experienced library workers show great understanding of, and actively contribute to, the minutiae of human psychosocial needs and everyday coexistence in their creation of a convivial library atmosphere. The library is, much due to the staff's way of working, still a sanctuary of humane slowness in an increasingly hectic - indeed overheated (Eriksen 2016) - contemporary life and world.

Finally, it should be noted that as I have mainly spent time in libraries during ordinary opening hours, I presume that the library as collections without "the social processes” initiated and stimulated by staff (Audunson and Aabø 2013) would function quite differently, although I so far lack sufficient comparative data (see however Engström 2019). 


\section{The Socialization of People and Citizens}

As Buschman continues, "good people or good democratic citizens are fostered by sites and institutions that socialize them to democratic interactions, practices, and participation" $(2018,34)$. A range of situations at the public library - from flimsy physical co-presence by the PC or printer or in the toilet queue to mutual epiphanies and shared sparks of the sublime at literary events - reminds us of the differences and similarities, nonetheless fundamental equality, of our fellow human beings. In various situations, most people pragmatically realize that their own convenience ends where another fellow human being's convenience begins: keep it tidy and clean, don't mess up books and newspapers, keep reasonably quiet, respect the queue and the loan period - in short, be a decent citizen. If not, this place will not be very agreeable (see also Klinenberg 2018).

"Look at all the other people who sit quietly and work," parents typically point out to their children with a soft voice when entering the library. Staff also use a range of techniques for instilling in children, and other visitors, the respect of the equal rights and needs of all patrons: equal loan and use periods for books, PCs and other resources. Queues and lists ensure first come, first served principles. Library norms and rules, its institutionalized culture, thus direct users towards attentive, respectful and egalitarian democratic interaction and practices. ${ }^{4}$

Norms, etiquette and sociability are however never clear-cut, but contested, changing - and ignored. The number and composition of visitors - accordingly also tolerated practices and behavior - vary in the course of the day, week and season; from library to library; and according to architectural and structural changes. Nevertheless, I rarely observe instances of dispute or open conflict (compared to certain academic libraries where socially regulated codes of conduct are stricter, see Fagerlid 2017). Rather than directly addressing deviating behavior - usually noise or someone taking up limited space with the "wrong" task, e.g. working in the newspaper section - a few people will cast a glance and perhaps move away if a disturbance seems to last; air their discord quietly to staff members; or come in

\footnotetext{
4 These pragmatic lessons in how my liberty stops where yours begins is a basic premise for democratic coexistence. The self-disciplining into self-governing subjects (Foucault 1997) has a long tradition in western history (Aristotle $350 \mathrm{BCE}$ ) and modern forms of government (Foucault 1982). Through everyday techniques of the self and body in public institutions, people learn to govern and educated themselves into subjects. The library traditionally inculcates self-education, self-surveillance, cleanliness, orderliness and timekeeping (see Fagerlid 2017 for self-disciplining in an academic library). This self-subjectification has recently taken one step further with the extended, unstaffed opening hours introduced at many public libraries. Lisa Engström (2019) has written an enlightening analysis in her PhD thesis on governmentality and its transcendence in libraries with staff-less opening hours.
} 
only at certain times of the day. It is therefore hard to quantify to what extent divergent behavior increases or impedes tolerance. Methodological cautions taken, very few people I have spoken to explicitly complain about the behavior of other library visitors. Some, however, say they are disturbed by noise. Most find ways of dealing with it - to come early to get a seat in the reading room (if there is one), earplugs or headset - but a handful say they visit a particular library less or not at all because of noise.

Although open conflicts erupt very rarely in Oslo Libraries, in particular two recently refurbished and de-zoned libraries have generated debate and complaints related to increasing noise. The two so-called "social libraries" are situated in socioeconomically deprived parts of Oslo, where a mix of crammed living conditions, lack of buying power and of neighborhood facilities create the incongruous need for both public meeting places and quiet spaces for concentration. The refurbishments have been highly successful in terms of substantially increasing the number of visitors, though notably without proportionally increasing the number of employees and square meters. However, some former visitors have left, in favor of other, quieter libraries or even cafés. Users' own analyses of the development in the revamped libraries are of interest to this essay. Rather than generational, class or ethnic lines of division, interpretations seem to follow political rifts: some (for instance an ambitious school girl recently immigrated to Norway from an African country and two middle-aged Norwegian as a Foreign Language teachers) blame unfortunate architectural designs - the continuous floor plan and loss of quiet areas - and misguided laxing of norms in these two "social libraries." One library user in my material and some voices in the media present a different interpretation. The increased noise at certain libraries reinforces their perception of the "failed 'integration' of 'foreign cultural' people (fremmedkulturelle)" and even conspiracy theories of a Muslim take-over of Europe aided by naïve left-wing politicians. ${ }^{5}$ Although the more extreme views represent a tiny minority of library visitors, it is worth noting that everyday inter-

5 This latter view appeared in a long conversation with an elderly frequent library user. In a reader's letter (Klassekampen February 18, 2019), a library user made similar associations between the increasing noise levels at his library and how "small children in hijabs", police presence and "teachers who learn self-defence" at the local school and a "woman with niqab outside the mosque" replaced "Norwegian [i.e. white] families" in the neighbourhood. In the wake of this letter being posted on two alt right or far right - however right wing government sponsored - web periodicals similar views surfaced (https://www. document.no/2019/02/24/utdrivelsen-fra-stovner/, https://www.rights.no/2019/02/utdrivelsenfra-stovner-en-journalists-beretning/ [both accessed November 1, 2019]).The polarised political climate in Norwegian political debate and at discussion forums before but particularly after the July 22, 2011 right-wing extremist terror attack (Bangstad 2014) also affects library debates. 
actions and practices at local libraries also can reinforce hostile opinions towards strangers, thus the opposite of convivial and democratic coexistence.

\section{Empirical and Theoretical Overview}

This chapter analyses six different situations of coexistence in everyday library life. I argue that these situations, at the same time as somehow connecting people, affect individuals as sentient, social and civic beings. Or as Buchman writes, the situations foster "good people or democratic citizens" (2018, 34). In the first situation, we will sense a subtle human warmth of being among long-time regular strangers in the newspaper section. Here, the rational act of staying updated interweaves with the emotional needs of being together (see Bakhtin 1981; Gardiner 2004). Secondly, from the playmat in the children's section we will overhear a long chat between seemingly opposites. These two situations are instances of what Paul Gilroy (2004) terms "everyday conviviality" where you interact in disregard of identity markers. The safe, neutral library space constitutes also a "cosmopolitan canopy" (Anderson 2011). Here, categories of people you perhaps knew only as media stereotypes transform into fellow humans, reading the newspaper or looking after a child, just like yourself. In the third situation, at the knitting café, gossip translates to micropolitics of people with different needs from yourself, negotiating their daily life. While identification across different identity markers occurs in the first two situations, the conversation among knitters broadens the participants' understanding of difference. All three dynamics promote an understanding of sociocultural diversity, which is a basic requirement for a democracy (Aristotle; Sennett 1998; Soja 2003).

Furthermore, in the fourth situation, we see how participatory events generate "tiny publics", which promote civic engagement with ripple effects elsewhere in the public sphere (Fine and Harrington 2004). The mutual respect and recognition which characterize interaction in book clubs and "shared reading" events also set in motion an emancipatory potential (Debord 1957; Bourriaud 2002) which can lead to active citizenry as well as a fuller participation in one's own life (Bishop 2006). The fifth situation at a "shared reading" meeting explores the balancing act of sincerity and anonymity in public. Finally, in the mundane environment of a small neighborhood library, we experience a spark of the sublime and are reminded of our shared predicament of being human. All the events and situations testify to the messy quality of everyday life, where sentiment and reflection, the individual and the communal and various life-spheres merge (Gardiner 2004, 30; Bakhtin 1981). 


\section{A Space for Democracy}

"Democracy supposes people can consider views other than their own," according to Aristotle (in Sennett 1998, 19). To accept differences aids the ability to appreciate and evaluate differing views and conflicting interests, which is a fundamental skill in representative democracy. In The Spaces of Democracy, Sennett (1998) shows how the Athenian city square - agora - facilitated and formed this capacity and outlook among citizens. The city draws together people of different backgrounds, occupations and interests (Aristotle; Soja 2003). In the physical space of the agora commerce, religious rituals, juridical hearings and casual hanging out occurred at the same time. Simultaneously experiencing these divergent activities, which do not always fit together, lays the foundation for Aristotle's notion of an open, democratic outlook (Sennet 1998, 19).

In the colonnaded walkways (stoa) around the agora, people could withdraw from the bustle, yet still observe life at the square (Sennett 1998, 18-19). The architecture and social space of the agora function thus similarly to modern public libraries. As with the stoa, the library's corners and shelves - enabling partial withdrawal and seclusion - encircle open vistas and spaces of divergent, sometimes incongruous, activities. This back-and-forth between social exposure to the variety of different people and activities and personal withdrawal into self-reflection mirrors the back-and-forth between deep and shallow play, or involvement in rituals studied by anthropologists (Geertz 1973). Deep engagement in the bustle creates affect, emotions and experience. Withdrawal and observation at a distance enable reflection (see Kapferer 1984; Middleton 2010; Fagerlid 2012, 244).

The democratic space of the public library can thus be seen as part of a two thousand years long history of multifunctional public spaces. Their very multifunctionality is central in the effect they have on individuals, society and democracy (see Aabø and Audunson 2012). In these complex public spaces, different life spheres mix and blur in what the philosopher Mikhail Bakhtin would call a heteroglossia of different social languages (1981; see Gardiner 2004, 38). Human thinking and reasoning take place in the embodied experience of these real-life situations, charged with simultaneous concerns from one's private, professional and civic life. Bakhtin (1981) brings attention to how the mind and body, the rational and emotional, and the private and public are indistinguishable in everyday life. In the newspaper corner, we will see how the simple act to stay informed also has existential and psychological importance. 


\section{The Comforting Community of Regular Strangers in the Newspaper Corner}

The sociability in the newspaper corner is generally polite but reserved. Jens, ${ }^{6} \mathrm{a}$ regular for 20 years, tells of no conversations but the casual "I'm finished with this paper, do you want it?" Or they might touch upon library etiquette when "someone has torn out the betting or filled out the crossword." As a single, rather introverted person on disability benefit, the nods of recognition, familiar faces and silent presence of others "who also reads the paper, who do the same thing as me, right then" are important in Jens' everyday life. He visits the newspaper corner several times a week to keep updated on social affairs - which he likes to comment on in discussion forums on the Internet - but also to fulfil another basic human need. With a timid laughter he explains how the library is a quite good place to "be seen," like the church:

Many go to church in order to be seen. "Here I come to church. I too sit here!” That's very well, of course. Nothing shameful in going to church in order to be seen, or to go to the library to be seen. [...] When you sit there and read the newspaper, there are many others who do that, too. You notice who they are. The ones who read the papers are seen. But if you sit by the PCs you turn your back to the others. Then you're not seen. That is not social, in that respect.

He adds that he probably writes and participates in online forums, too, in order to say "Hello! I'm alive!" (Fagerlid 2016, 117; Henningsen and Larsen, this volume, for a deeper analysis of online engagement). Jens estimates he visits his local library for at least an hour three times a week. Half of the time he spends in the circle of newspaper readers, the rest with his back to the physical library facing the Internet. He laughs a little at himself for not having Internet access at home. From the perspective of a timid, single person without close family or a job to go to, it seems however emotionally and psychologically sound. ${ }^{7}$ At his local library, Jens enjoys being among familiar faces, and admits with his shy laughter that he also likes to watch the "beautiful Pakistani women". His suburb is a good place to live because of the "beautiful gangster cars" and the library.

The particular seating arrangements in newspaper corners invite different degrees of coexistence. Sitting in a circle, as previously in Jens' local library, the readers face and thus see each other, although are usually silent. Personalities seem also to make a difference. Apart from one exception, discussions are uncommon

6 All names are pseudonyms.

7 Various ways of tactically limiting the ubiquity of the digital is common among young people as well, as Astrid Anderson and I found in our research in an academic library (Anderson 2017; see also Fagerlid 2017). 
in the newspaper sections in Oslo Libraries. This fact might relate to how the library functions as a public realm. A public realm is according to Sennett (20098) "a place where strangers meet." "Anonymity”, "impersonality" and "incomplete knowledge" characterize the behavior, actions and interactions constituting public social space (2009). It is “low intensive” in Ragnar Audunson's terms, in the sense that many of the people you are exposed to will have different interests and values from yourself $(2005,436)$. The subtle friendly familiarity Jens experiences in the newspaper corner could be shattered by a political debate exposing different interests. We shall see similar dynamics of selected anonymity, impersonality and incomplete knowledge in literary discussion. In the next scene at the playmat, however, different dynamics take place.

\section{Encounters: the "Hipster" Man and the "Chador" Woman"}

The man enters the library hurriedly, slightly distressed. He is around 40, a trimmed beard and greying hair, short by the ears longer on top, the hipster haircut, wearing neat, knee-long shorts and an ironed short-sleeved shirt. He holds a baby, perhaps eight months, in his arms. The librarian at the counter quickly resolves his problem, reassuring him that "the person responsible for the textbooks is really kind. We are patient here. I know, this often happens when you move houses. Usually it turns up after a while. What was it about, by the way?" He tells about perennials, relaxed now, and explains how practical it is with flowers you don't have to replace every year. I imagine the new family moving from this inner-city area to a terraced house with a little garden. He continues to smalltalk with the librarian before he sits down on the floor in the children's section, putting the baby on the playmat.

One of the three young women in the ankle-long black chador I have seen here every day lately is already sitting there with her baby. The two babies are about the same age. She starts talking. Her almost accent-free Norwegian indicates that she has grown up in Oslo, yet her full-body dark cloak stands out from the local colorful hijabs and long dresses. She compliments "the big beautiful eyes" of the other

8 Online source without pages (Sennett 2009: “The point of departure”, para.1). All citations in this section is from the same online paragraph.

9 I know very little about these two people and have only the superficiality of their appearance to build my simplistic labelling on. This is the way they appeared to me and my particular bias. Other people who noticed them together in the library might perceive them differently. Still, my point is, that the two of them appearing in a convivial and long-lasting chat in public contribute to a sense of coexistence not only for their own sake but also for the atmosphere of the library. 
baby girl and goes on: “They don't need much, except love.” The subject of starting nursery ignites an exchange. "We have applied from October 1 and have got a spot," she says. Their babies move around on the floor, as the conversation flows freely. The difference between dads and mums, between men and women. About female prime ministers and housework. My attention moves elsewhere. After 30 minutes I notice that they are still talking.

In many ways this accidental meeting between strangers epitomizes the local area, Tøyen, as well as library children's sections in general. Tøyen is a deprived inner-city area undergoing rapid gentrification. The library has succeeded in retaining or even enhancing its role as an overwhelmingly mixed and cosmopolitan space, in the midst of the encroaching predominantly white and middle-class cafés and bars. While increasingly attracting students, writers and freelancers of all creeds, the library has kept its old multi-ethnic patronage of working-class elders, school children with immigrant background and parents with babies. ${ }^{10}$

The informal architecture and the noise of the children and dispersed attention of their accompanying adults seem to make it acceptable to engage in conversations between strangers in library children's sections. Many of the accidental meetings which happen between strangers in libraries take place here. Conversations here tend to last longer and are more personal than accidental exchanges by the borrowing automats, another social, but more superficial, spot.

The notion of cosmopolitanism acknowledges and appreciates cultural difference. In contrast, the sociologist Paul Gilroy (2004) coins the term "everyday conviviality" for situations and places where difference and identity politics (maybe even identity per se) are irrelevant. Rather, interaction and coexistence take place across, and in disregard of, difference:

The radical openness that brings conviviality alive makes a nonsense of closed, fixed and reified identity and turns attention toward the always-unpredictable mechanisms of identification. (Gilroy 2004, xi)

The concept of everyday conviviality hones Richard Sennett's (2009) understanding of the public realm as an open system characterized by anonymity, impersonality and incomplete knowledge. The two strangers at the playmat, representing two (stereo)typical, but apparently very different, Tøyen inhabitants, felt free to draw on particular aspects of their life, initially connected to their common status as a baby's parent, and seemingly without carrying any extra luggage of precon-

10 All Norwegian public libraries have good nappy changing facilities. The approximately one year long parental leave, longer if you are a single parent, can be lonely for many men and women without a local social network. Many use the children's section in public libraries. 
ceived identity categories. In the conversation, beyond looking enjoyable for its own sake, they - and people in their vicinity - learnt about the needs and perspectives of fellow parents and citizen, knowledge, which is important to a wellfunctioning democracy (Sennett 1998).

\section{The Knitting Café - the Private, the Public and the Political}

Libraries increasingly facilitate social knitting as "Knit \& Listen" where people sit together in silence to knit and listen to someone reading poems, short stories or chapters from a novel. I participated in Knit \& Listen in a newspaper section, where 50 mostly, but not exclusively, pensioner women and one man (a regular newspaper reader) sat on chairs spread out facing the person reading. Before it started, some discussed their tasks at hand. Afterwards people dispersed quite quickly, among which I later noticed a group of five having coffee together at a nearby café. At Knit \& Listen and other kinds of listening events ("Sit \& Listen"), the focus is inwards, in quiet concentration. At knitting cafés, in contrast, the handicraft and verbal exchange take central stage.

Various people had described to me the knitting café as a "local central for gossip”. The random anecdotes I overheard from a table nearby, amid discussions on knitting, patterns and the treatment of woolen garments, were stories of people's lives; their own and those of other locals. A small remark from Liv, a recently retired woman I know from the library book club, changed my perspective on the stories I had only heard bits and pieces of. Besides being an avid reader, Liv has a long history of political engagement as a labor unionist with a trained eye for the micropolitics of everyday life within power structures. In her interpretation, personal anecdotes become eyeopeners into everyday consequences of larger sociopolitical processes: she had no idea, she told me, how to negotiate an everyday life with a disability from one's twenties and become dependent on subsidized transport. Now, rules of entitlement to transport were changing and rights curtailed.

Liv is an outdoor and trekking person but had met a neighbor by chance and been invited along to the circle of knitters. Now, she comes every week. In addition to the sociability, she likes the mix of people. While the local book club is smaller, exclusively white and pensioner-dominated (but not middle-class, in contrast to the one in the next scene), the ten to 15 knitters are far more diverse, in terms of age and ethnic background. There are usually at least a couple of elderly Pakistani women joining. The choice of language erupts once in a while as a point of explicit negotiation, where the opinions are divided (Liv, always in favor of diversity and married to polylingual Egyptian Copt, frowns. For her, people can speak whatever they want). While the women knit, among other things, small woolen garments 
for the premature baby ward and socks for the Salvation Army charity shop, they share stories of everyday struggle and much more. The public realm of knitters teaches participants of the different needs of fellow citizens (see Sennett 1998).

\section{Book Clubs as a Tiny Public and as Participatory Art with Emancipatory Potential}

The children's section seems close to gender neutral, and the newspaper corner has a slight male dominance. Norwegian library book clubs, however, are as female as the knitting events.

The intensity has fallen as the book club meeting draws to a close. Amid a string of contemporary novels, this month we read Hemingway's The Sun Also Rises. Points of view, endorsements and polite and respectful disagreements have for 50 minutes shuttled back and forth across the table, between the seven retired women plus me, several decades younger. We have jumped from the lost generation and the unruly life of artists; brazen anti-Semitism and racism; Hemingway's powerful style of writing; his psychology and masculinity, and whether the reader has or has not changed her perspective on him since 40-50 years ago; the portrayal of the main female character (is she "easy" or "liberated"?); the narrator's "platonic" relationship with a prostitute; a comparison with Scott Fitzgerald and Knut Hamsun's early novels; and finally bullfighting and animal welfare. All issues seem to have been sufficiently covered when the conversation, as it often does at this point at the meetings, springs associatively from the book in question to wider socio-political themes.

“There weren't any 'lost generation' after the Second World War. Why this difference?” The comment pierces the lull. The neat, discreetly dressed woman speaks mildly. Amalie always wrings her hands as she speaks, as if hesitant. Her queen's English, ${ }^{11}$ reminiscent of her days in Oxford as an au pair in the 1960s, hides her western Norwegian rural and formerly strongly stigmatized (stril) dialect. I find the contrasts, between her English and Norwegian and her wringing hands and perceptive readings, intriguing. As often, her remark opens a new horizon in the discussion. "No, on the contrary!" Hedda, a woman in her mid-eighties concedes with her usual sharpness. Her urban western dialect breaks into her Eng-

11 Most libraries have book clubs in Norwegian. In addition, there exists one evening and one afternoon group in English, both at Majorstuen, a communication hub nearby the University and National Broadcasting. All but two of the around 15 regulars at the afternoon group are Norwegians. The evening group is considerably younger, smaller and with a majority of non-natives. 
lish. "We were the luckiest generation known in history. During the war we had nothing, and afterwards we got all the free education we wanted. We all got jobs. It was no question about me not getting a job. We were the luckiest..." Amalie re-joins. "Yes! A lucky generation! I was born in 1945, we've never experienced unemployment." A third woman, Halldis, who also has higher education, from the inland valleys, concurs: "No, never on a great scale."

The library is situated in the western, wealthier part of Oslo and many of the women live nearby or in other affluent neighborhoods. They come from various backgrounds from literally all over Norway, and their lives are, as they underline in this discussion, to a large extent product of the social democratic equalizing policies of postwar Norway.

The oldest - almost 90, and often quiet, due to her hearing impediment, yet exceptionally well-read, even in this company of lifelong readers - brings in a new element: "The slowness of improvement after World War II was healthy. It was a nice climb." A fifth woman, the only one originating from Oslo, agrees: "That's what happened in Norway." Several of the women concur. The slow, but steady climb in living conditions after the Second World War was healthy, in contrast to the rapid rise of the last decades: "We didn't demand more and more and more." Part of the discussion centers on the difference between a slow and a rapid rise in standards of living, between their generation and the children growing up now. Part of it sticks to the improvement of welfare they benefited from. A sixth woman, from northern Norway, who has been quiet for a while, brings the discussion back to their luck and sense of gratitude for the remarkable improvement of health and welfare: "They call us, born during the Second World War, the dessert generation. We got the Norwegian State Education Loan Fund, which was a breakthrough for education". Halldis nuances the picture some of the women paint of today's children: "We're forgetting something now. It's not any child. There are 100,000 children growing up in poor families. You have the 'haves' and the 'have nots.' The gaps are growing”.

The discussion has not solved the initial puzzle of the different conditions after the First and Second World War, nor reached any agreement, which rarely if ever is the aim of conversations in book clubs. Rather, the exchange of points of view on the same book and same issues between people from different walks of life bring in new perspectives and open horizons for the individual reader, thus somehow constituting a multifaceted, but common reality. When reflecting on the effects of war (one of this group's recurrent topics), they have effectively analyzed the political and economic conditions of their own world and their place within it.

Neither in book clubs do the participants comment on party politics, despite usually knowing each other better than the newspaper readers. Controversial 
issues, like immigration, "integration" and Islam, are likewise avoided, except from sporadic remarks, which are either ignored or followed up with an apolitical anecdote.

\section{Tiny Publics and the Emancipatory Potential of Participation: The Creation of Active Citizens}

The highly complex micro-interaction in book club discussions can be analyzed from several angles. In addition, the dynamics change whether or not there is a professional leader present, or to what extent the leader intervenes and directs the discussion, and whether he or she emphasizes the literary or the sociopolitical and historical aspects of the book. In self-led groups and groups where the leader follows the flow, which comprise a majority of my material, it is the social, political and historical aspects of literature that take central stage. ${ }^{12}$

When discussing social issues in literature, no one seems to presume that some have better answers than others. People thus interact in a strikingly egalitarian way. In forming their points of views and lines of argument, all participants feel free to draw conclusions from personal experience, general knowledge and their often quite long lists of devoured literature, as we saw examples of in the discussion. They frequently express disagreements - as Halldis' nuancing the description of today's children - but rarely challenge each other's viewpoints directly. Instead they encourage each other to explain and expand on their perspectives. Nods, smiles and repetition of others' phrases, also when disagreeing, weave the participants together convivially.

The sociologists Fine and Harrington (2004) analyze the relationships between civil society and the micro-interaction and face-to-face relations in small groups. These "tiny publics" are simultaneously the "origin, arena and outcome of civic engagement and civil society", they conclude. In tiny publics, the group dynamics create desire and means for public action. Furthermore, tiny publics provide the very arena and discursive space where public engagement is explored and enacted (Fine and Harrington 2004, 353). Most of the book club participants I have spoken to take part in other cultural activities at the library and elsewhere in Oslo. Many also do voluntary and humanitarian work. They thus actively par-

12 In literary oriented groups participants speak with more varied levels of confidence, and in the bigger groups several members come only to listen and learn. Although the leader might say that there are no right or wrong answers, only different interpretations, I'm not sure the participants are convinced. The discussion sometimes become more hierarchical, with the leader standing out as the most knowledgeable. 
ticipate in creating a functional civil society. The book clubs thus conform well to Fine and Harrington's analysis of the close relationship between tiny publics and civil society in general.

Another micro-interactional perspective from art theory suggests that participation and relational forms of artistic creation can initiate emancipation in individual everyday lives, and also spill over to active civility elsewhere. Artistic practices, from the 1920s' Dada movement and Brechtian theatre to Guy Debord (1957) and the Situationists in the 1960s, have sought to spark emancipation and de-alienation through creative participation. In the 1990s, curator and art critic Nicholas Bourriaud (2002) introduced the concept of relational art to account for the tendency of contemporary artists to attempt creating social relations through artworks. Situations constructed around works of art can generate processes inside and between the participants (see also Fagerlid 2012). Similarly, within the convivial environment of the book club, novels set in motion processes with emancipatory and relational potential. Professor in Art History, Claire Bishop (2006, 12) sums up three agendas of participatory art which can be translated into emancipatory potentials of book club discussions. First, the creation of an active subject "who will be empowered by the experience of physical or symbolic participation [... and] find themselves able to determine their own social and political reality" (12). Expressing your thoughts, being listened to and receiving a response foster a sense of acknowledgement, not only of your opinions, but also of you as a person. Second, as practical exercises in equal exchange of views, book clubs are egalitarian and democratic models of and for the co-creation of meaning and coexistence, which can be transposed to other arenas in one's life. Third, a collective however not necessarily consensual - interpretation of meaning reinforces social bonds. To convey one's own experiences in front of strangers in a comprehensible way, and to listen to the experiences of strangers with respect, can nurture dialogue and sympathy, rather than monologues and segregated echo-chambers. Book clubs thus create and reinforce social bonds between people who are more or less strangers to each other. Everyday conversations between members of a society create shared perceptions of reality. Not agreement, but an understanding that others can perceive the same reality differently.

\section{The Interplay of Sincerity, Anonymity and Acknowledgement at Shared Reading}

Shared reading is a specific approach to reading aloud and discussing particularly chosen pieces of prose and poetry. The nature of the texts, the primed pauses and the presence and perceptive interventions of a trained leader, create a special environment for discussion. There are several similarities in the participatory and 
emancipatory processes of book clubs and shared reading. In this chapter, I will however focus on the slightly different dynamics of coexistence the two kinds of communal interpretive events produce.

In contrast to the social analyses at book clubs, the discussions at the shared reading events I have attended veer towards the psychological dimensions of social relationships. ${ }^{13}$ The reasons for the difference might relate to the microscopic approach to the shorter texts in shared reading, which invites the listeners to scrutinize the details of the fictional events. A consequence is though that the event becomes quite intimately charged, a sensation that is heightened by the leader's comment at the start that "what is said in this room will remain here".

When analyzing the literary characters' actions and thoughts, I sensed on behalf of myself and the others present that we simultaneously were analyzing ourselves, our own patterns of behavior and intimate relationships. Sometimes we explicitly draw on our personal experiences. Not, as in the previous example from the postwar generation, in order to relate personal life to wider forces, but rather to relate personal life to psychological forces. At the same time, the formal setting, in a public library with strangers, tend to bring forth a detached presentation and enhanced analytical and self-reflective points of view. The balancing act where I had to provide sufficient basis for my analysis at the same time as not crossing the boundary into privacy intrigued and troubled me. It felt like being trained in public sincerity.

Shared reading concerns verbal sharing on a personal, however not private, level. At a particular Meet the Author event I experienced another basic human way of being together and sharing a moment, which might be called a collective spark of the sublime, in the most commonplace of surroundings.

\section{A Moving Moment as a Spark of the Sublime}

The performance starts gently, to be confused with spontaneous small-talk. We, the audience, have no idea of how it will seize us. The novelist Niels Fredrik Dahl says he is very happy to be here. That he, as all authors, has a very special relationship to the public library, but that his relationship is particularly special because both his parents were librarians, and several of his relatives. People smile, some nod. Then he says that the mother in the book is also a librarian. And the son is an author. Many have probably read his book beforehand, but I haven't,

13 I have only attended five shared reading events, with the same leader, compared to several dozen meetings in eight different book clubs, with and without leaders. 
and only slowly do I realize the power of the performance in front of me. Who the son is. About the diary the mother gives the son, and which the son reluctantly and scornfully accepts, but does not read, and does not talk about. Before it is too late. The diary, which would have explained to him the mother's deep and long-lasting depression, the heartrending 1960s' therapy she submitted to which prescribed withdrawal and lack of engagement with her closest, the great love she felt for her little son - but thoughts there could come no good from. "They were strangers to each other. They closed each other out". "Mmm”, I hear around me. "He never said a true word to his mother. Now, he misses her, and he never thought that would happen." Many nods.

The sentences Dahl performs are sincere and poetic. They have the generic force of literature to crack open existential horizons, which is what happens in this little audience of around 20 persons. At a Thursday morning in September, in a small library between a 24/7 gym and a Chinese restaurant, and a motorway and a trotting track. How ordinary can it get? And how sublime?

When Dahl reads from his book, a man, around 50, removes his glasses, closes his eyes and presses his fingers at the root of the nose, forcing back tears, undoubtfully. He is not the only one. I see people, young and old, blink away their tears. We are all daughters or sons, and many of us are mothers or fathers, too. "Do we know our closest ones?" the author asks. Someone sighs. "The whole life, I have not wanted to see the other. I did not see my parents." More nodding. "To have the diary is bittersweet. It is good, but too late. Can we only be together with our parents when they are dead?" People nod. The man with the glasses nods, too. "And what about my own children?" Our thoughts seem parallel, shuttling up to parents, down to children. Up and down the generations.

At this rare occasion, I seem to know what the others are thinking about. The author knows, too. "Everybody is touched by the relationship between parents and children," he says afterwards when I ask him if this is a common reaction (without having to explain what I mean, as few seem unmarked by what happened).

The performance inspires an unusually large amount of questions. When Dahl answers, the audience nods and nods: concerning self-medication with alcohol; the anecdotes about suicide the mother would tell the son; the inherited lack of joy of life; the mother's favourite poet, Hjalmar Gullberg, and his suicide. We are sharing a silent moment of our innermost feelings as parents and children, and some also of the taboos of mental illness, suicide and alcoholism. I interpret from the faces, the questions, comments and longer conversations afterwards that the moment was for a large part shared between old and young, and people of various backgrounds, but naturally with some exceptions. My company at the time, a retired woman I knew from the local book club who had read all of Dahl's 
novels, started immediately to talk about something else afterwards, before I had summoned myself. The moment is thus not shared by all, but sufficiently many to create a communal experience of the predicaments of being human, in the mundane location of a small library branch.

\section{Conclusion}

This chapter has analyzed everyday situations at public libraries producing various forms of democratic coexistence. I have presented instances of conviviality (see Gilroy 2004) in a newspaper corner and at a children's playmat, and the micropolitics of different needs at a knitting café (see Sennett 1998). By scrutinizing the generous and equal participation at a book club, I have shown how readers negotiate a multifaceted common reality (see Bishop 2006) through - among other lines of argument - situating their own historic experiences socioeconomically and politically. "Shared reading” sessions, I have argued, train participants in public sincerity, compelling them to balance their speech up against (appreciated and liberating) anonymity, impersonality and incomplete knowledge of the library's public realm (see Sennett 2009). Finally, I have recalled how a sublime moment exposed our common human predicament at a Meet the Author event. Like in a traditional town square, these ways of being together enhance awareness of differences and different needs, and glimpses of identification, community and shared humanity - acknowledgements and sentiments vital in a democracy.

Library coexistence consists thus as much of emotions, affect, embodied reactions and non-verbal communication as of reason, rational reflections and deliberation. People seek as much recognition, acknowledgement and communion as knowledge and information. The library is therefore perhaps as much an infrastructure of everything human, as it is of information and the social (see Klinenberg 2018). While you might think you just dropped by at your local library, you in fact did much more. You negotiated everyday situations as a citizen and a full human being, which slightly shaped you and created human relations at the same time. 


\section{References}

Aabø, S. and R. Audunson. "Use of Library Space and the Library as Place". Library \& Information Science Research, 34, no. 2, 138-149, 2012. https://doi.org/10.1016/j.lisr.2011.06. 002.

Anderson, A. "Kunnskapens hus: et antropologisk perspektiv på universitetsbiblioteket som sted”. In Anderson, A., C. Fagerlid, H. Larsen, and I. Straume (eds), Det åpne bibliotek: Forskningsbibliotek i endring, pp. 147-170. Oslo: Cappelen Damm Akademisk, 2017.

Anderson, E. The Cosmopolitan Canopy: Race and Civility in Everyday Life. New York: W.W. Norton \& Company, 2011.

Aristotle. "Nicomachean Ethics", 350 B.C.E.

Aristotle. "Politics". https://www.gutenberg.org/files/6762/6762-h/6762-h.htm, 1912.

Audunson, R. "The Public Library as a Meeting-place in a Multicultural and Digital Context: The Necessity of Low-intensive Meeting-places”. Journal of Documentation, 61, no. 3, 429441, 2005.

Audunson, R. and S. Aabø. "From Collections to Connections: Building a Revised Platform for Library and Information Science”. Information Research, 18, no. 3, 1-10, 2013. https:// eric.ed.gov/?id=E]1044628 [accessed November 1, 2019].

Bakhtin, M. The Dialogic Imagination: Four Essays. Austin: University of Texas Press, 1981.

Bangstad, S. Anders Breivik and the Rise of Islamophobia. London: Zed books, 2014.

Bishop, C. “Introduction”. In Bishop, C. (ed.), Participation, pp. 10-17. Boston: MIT Press, 2006.

Bourriaud, N. Relational Aesthetics. Dijon: Les presses du reel, 2002.

Buschman, J. “On Democracy and Libraries”. Library Quarterly, 88, no. 1, 23-40, 2018.

Buschman, J. "Everyday Life, Everyday Democracy in Libraries: Toward Articulating the Relationship”. The Political Librarian, 4, no. 1, 18-28, 2018. https://openscholarship.wustl.edu/ pollib/vol4/iss1/10 [accessed June 5, 2019].

Debord, G. "Report on the Construction of Situations and on the International Situationist Tendency's Conditions of Organization and Action. Translated from French by Ken Knabb". http://www.cddc.vt.edu/sionline/si/report.html [accessed August 5, 2019], 1957.

Engström, L. Att skapa självstyrande individer; effektivitet och motrörelser: Styrningsrationalitet och icke-rationalitet i bibliotek med obemannade öppetider. PhD thesis, University of Copenhagen, Faculty of Humanities, 2019. https://static-curis.ku.dk/portal/ files/216972954/Ph.d._afhandling_2019_Engstrom.PDF, [accessed October 31, 2019].

Eriksen, T. H. Overheating: An Anthropology of Accelerated Change. London: Pluto Press, 2016. https://www.jstor.org/stable/j.ctt1cc2mxj.

Evjen, S. and T. Vold. "Being, Learning, Doing: A Palace for the Children? A Tween's Library Seen from the Users' Perspectives”. In Audunson, R., H. Andresen, C. Fagerlid, E. Henningsen, H-C. Hobohm, H. Jochumsen, H. Larsen, and T. Vold (eds), Libraries, Archives and Museums as Democratic Spaces in a Digital Age. Berlin: De Gruyter Saur, 2020.

Fagerlid, C. The Stage is all the World, and the Players are mere Men and Women. Performance Poetry in Postcolonial Paris. Unpublished Ph. D. Thesis, University of Oslo, 2012. https: //www.duo.uio.no/handle/10852/37519.

Fagerlid, C. "Skjermet sammen - sameksistens på folkebiblioteket”. Norsk Antropologisk Tidsskrift, 27, no. 2, 108-120, 2016. 
Fagerlid, C. “Et godt sted å arbeide. Drømmer og disiplinering på biblioteket”. In Anderson, A., C. Fagerlid, H. Larsen, and I. Straume (eds), Det åpne bibliotek: Forskningsbibliotek $i$ endring, pp. 171-192. Oslo: Cappelen Damm Akademisk, 2017.

Fine, G. A. and B. Harrington. "Tiny Publics: Small Groups and Civil Society". Sociological Theory, 22, no. 3, 341-356, 2004.

Foucault, M. "Technologies of the Self”. In Rabinow, P. (ed.), Ethics. Subjectivity and Truth. Essential Works of Foucault 1954-1984, pp. 223-251. London: Penguin, 1997.

Foucault, M. "The Subject and Power”. Critical Inquiry, 8, no. 4, 777-795, 1982.

Gardiner, M. E. "Wild Publics and Grotesque Symposiums: Habermas and Bakhtin on Dialogue, Everyday Life and the Public Sphere”. The Sociological Review, 52, (1_suppl.), 28-48, 2004.

Geertz, C. “Deep Play. Notes on the Balinese Cockfight”. In The Interpretation of Cultures, pp. 412-454. New York: Basic Books, Inc, 1973.

Gilroy, P. After Empire: Melancholia or Convivial Culture? Abingdon: Routledge, 2004.

Haraway, D. "Situated Knowledges: The Science Question in Feminism and the Privilege of Partial Perspective”. In Feminist Studies, 14, no. 3, 575-599, 1988.

Henningsen, E. and H. Larsen. "The Joys of Wiki Work: Craftsmanship, Flow and Selfexternalization in a Digital Environment”. In Audunson, R., H. Andresen, C. Fagerlid, E. Henningsen, H-C. Hobohm, H. Jochumsen, H. Larsen, and T. Vold (eds), Libraries, Archives and Museums as Democratic Spaces in a Digital Age. Berlin: De Gruyter Saur, 2020.

Kapferer, B. "The Ritual Process and the Problem of Reflexivity in Sinhalese Demon Exorcisms". In J. J. MacAloon (ed.), Rite, Drama, Festival, Spectacle, pp. 179-207. Philadelphia: Institute for the Study of Human Issues, 1984.

Klinenberg, E. "Worry Less About Crumbling Roads, More About Crumbling Libraries". The Atlantic, 2018. https://www.theatlantic.com/ideas/archive/2018/09/worry-less-aboutcrumbling-roads-more-about-crumbling-libraries/570721/ [accessed October 31, 2019].

Malinowski, B. Argonauts of the Western Pacific. London: Routledge, 1922.

Middleton, P. “Poetry's Oral Stage”. In Kemal, S. and I. Gaskell (eds), Performance and Authenticity in the Arts, pp. 215-253. Cambridge: Cambridge University Press, 2010.

Narayan, K. “How Native Is a “Native” Anthropologist?”. American Anthropologist, 95, no. 3, 671-686, 1993.

Sennett, R. The Spaces of Democracy. Raoul Wallenberg Lectures. Michigan: University of Michigan, Ann Arbor, 1998.

Sennett, R. “Quant. The Public Realm”. https://www.richardsennett.com/site/senn/templates/ general2.aspx?pageid=16\&cc=gb [accessed March 19, 2019], 2009.

Sennett, R. "Housing and Urban Neighbourhoods. The Open City". Newspaper essay Berlin, November. http://downloads.Isecities.net/0_downloads/Berlin_Richard_Sennett_2006The_Open_City.pdf [accessed February 5, 2019], 2006.

Skjerdingstad, K. I. "Reading Between the Shelves - the Library as Perspective in Life and Profession”. In Audunson, R., H. Andresen, C. Fagerlid, E. Henningsen, H. C. Hobohm, H. Jochumsen, H. Larsen, and T. Vold (eds), Libraries Archives and Museums as Democratic Spaces in a Digital Age. Berlin: De Gruyter Saur, 2020.

Soja, E. “Writing the City Spatially". In City, 7, no. 3, 269-280, 2003. https://doi.org/10.1080/ 1360481032000157478. 


\title{
Tonje Vold and Sunniva Evjen
}

\section{Being, Learning, Doing: A Palace for the Children?}

\author{
A Tween's Library Seen from the User's Perspectives
}

\section{Introduction}

The connection between democracy, empowerment, and participation at the political level is clear: without an empowered citizenry that are willing and able to shape their own future and the future of their country through participation, democracy and democratic processes are compromised. Working towards a participating an empowered public could in other words strengthen democracy. But what measures are needed to do so? In recent years public libraries have emphasized both empowerment and participation as objectives for their activities. Several of the Nordic countries have library acts incorporating public libraries' role in democratic infrastructure. Casper Hvenegaard Rasmussen posits participation as the absolute "buzzword" in cultural politics and cultural mediation $(2016,39)$. Research investigating how public libraries - being free and open democratic public spaces - support democracy has also developed over the past decade (Buschman 2019).

At the core of the UN Convention on the Rights of the Child is child participation. According to Hart (1997), participation is important both for individual children, participating in decision-making affecting their lives, but also for children to be involved in decisions affecting the larger community where they live. Hart goes on to call participation "the means by which a democracy is built, and it is a standard against which democracies should be measured" (Hart 1997). In other words, efforts to strengthen empowerment and participation should include both adults and children. Designing library space for children and youth implies that the users themselves are involved in the process of developing and maintaining it. Equally important is the ongoing development of empowerment among the younger library users. Williams and Edwards (2011) investigate in an Australian case study how public libraries, by providing youth with space and resources, can contribute lasting benefits for them and their capacities for citizenship, for their families, and the wider community.

In this chapter we investigate the library's empowering aspects within the context of Biblo Tøyen, a library designed and open only for children between 
ten and fifteen. It is unique in a Norwegian context, but inspired by TioTretton in Stockholm, and the Library of 100 talents in Holland. Both these libraries have been designed and developed with the involvement of users - the children themselves (Mosch and Bertrams 2009; Bayliss 2015). Most libraries put a special emphasis on creating services for children, but traditionally these have been centered around books and reading. At Biblo, the goal is to create a third place (Oldenburg 1989) for children and make them active contributors and participants in the library. Learning, knowledge, and culture still take center stage, but literature does not underpin the activities in the library. Cooking, playing games, or creating things are the most visible activities at Biblo.

Biblo is situated in Tøyen, an inner-city district of Oslo which undergoes a rapid gentrification process. This area is also known for certain social problems, among them child poverty. As part of the city's efforts to improve the area for its inhabitants, Biblo was set up as a cooperation between the city and the Oslo library system, Deichman, at the same time as the local public library was refurbished. Biblo is situated at a public square, next to cafes and restaurants and welfare service offices.

This analysis is part of a larger study, where we have examined the design and aesthetics of the library (Vold and Evjen 2016) and interviewed the staff to investigate their professional perspectives on creating a library space for this age group (Evjen and Vold 2018). From our previous published research on Biblo, the following themes and findings surfaced.

1. User participation in designing the library. The intention behind Biblo's spatial design was to provide children with a place they could feel ownership to, a place to hang out, to feel at home, to use according to their needs and desires. Serendipity was the crucial effect that the manager wanted to accomplish, when speaking about how the books and shelves were designed. Otherwise, the focus was to provide children with a place which signaled fun and creativity and smaller rooms where they could "chill" and be closed off, alone or with their friends. The collection plays a minor part in the design.

2. The staff's perception of professional identities and roles vis-a-vis the users. Interviews with the staff highlighted particularly three aspects: a) building individual relations with the users was alfa and omega for the library to work; b) they looked upon their work with the users as part of a strategy to empower children, particularly those with few opportunities to partake in the cultural life elsewhere, or through helping with homework; and c) the ideal of children's participation ruled how activities were organized (for instance that no adult could enter, "do their thing" i.e. reading from a new book, do research on the kids, and then leave). The staff's ideas of the library coincide on the one hand with old ideals of Bildung and education, and on the other with more 
modern ideals of empowerment, and of the child as in the process of being, rather than of becoming. None of the staff members are trained librarians; they have mixed professional backgrounds from arts and education but all have experience with youth work. The staff's professional identity as librarians is closer to the youth worker than with the teacher. Mediation of culture is important to the staff but mediation of literature is not prioritized as it is in the traditional library.

Historically, control has been an important motivation when developing library services for children (Tveit 2016), keeping them off the streets and providing a regulated service. Our previous research showed us that regulations and rules gradually have developed at Biblo, benefitting the children's safety within the library space. Certain frictions between autonomy and control, freedom and safety, are hence also manifest at Biblo, as it is in the wider community, where Biblo is presented as a solution to social issues in the neighborhood - an answer to the problem of children (where children are perceived as a nuisance), as well as the problems in the neighborhood (perceived as an environment which children should be protected from). To understand how Biblo works, we need the voices of the children, the ones Biblo is for. Their input allows us to explore to what extent children's libraries can support participation and empowerment, and also the interplay between autonomy and regulation that occur in this context.

We address the following questions:

- How does Biblo work as an arena for participation and empowerment for the children coming there?

- How is autonomy and freedom perceived by library users?

\section{Theoretical Framework: Studying Children's Library Use in a Public Sphere Perspective}

In his essay entitled The Public Realm (2010), Richard Sennett describes the public as "a place where strangers meet". In the urban context, a myriad of "publics" exists, recognizable as places where people are unfamiliar with each other. What makes the publics interesting and important is not the unfamiliarity, Sennett argues, it is that what takes place there cannot happen in private: "people can access unfamiliar knowledge, expanding the horizons of their information [...] In the public, people can discuss and debate with people who may not share the same assumptions or the same interests. Democratic government depends on such exchanges between strangers." Any library space can, by this perspective, be part 
of the public realm. They are open and free for all, and provide a physical space where information is available, and knowledge is shared. Sennett points to Hannah Arendt, whose ideal public realm lets people discuss and debate freely and equally, but this is only possible if they are not tied to their private circumstances. Public libraries as meeting places and arenas for participation and community engagement have been the subject of several studies during the past decade (Aabø, Audunson, and Vårheim 2010; Aabø and Audunson 2012; Johnson 2017), and one feature that sets them apart from many others is how people can come together despite their different circumstances.

Social equalizing is a goal in the politics of the welfare state, and the development of libraries and library services have been part of this objective. Public libraries are also part of city planning. In Palaces for the People the American sociologist Eric Klinenberg claims that libraries are the prime buildings among public service buildings to form the social infrastructures of the cities (2018). Shared public space is essential for such infrastructures. Klingenberg's account of the public library accentuates that being allowed into a public space without judgement, expectations to pay, fundamentally secures (marginalized) people's dignity. All these perspectives - social equalizing, urban planning and the formation of a change-making place - form the background for building Biblo. Biblo serves as a shared public space on the one hand mimicking a larger community, it is an important part of the social infrastructure of Oslo, and the library space is constructed to bring about positive change for those who participate in using and making it.

Public libraries are still negotiating and developing their capacity as democratic infrastructure. One approach is the idea of the participatory library, which has emerged as a new understanding of how libraries can meet and engage the users (Cuong Nguyen, Partridge, and Edwards 2012; Rasmussen 2016) through participation. The term "participatory library" reflects an understanding of users as more than recipients of culture and knowledge; they should also be active partners, co-creators of library activities, and content. Rasmussen shows how participation can be seen as audience development, a catalyst for cultural diversity and a competitive resource (2016). The term empowerment originates from psychology and refers to "a construct that links individual strengths and competencies, natural helping systems, and proactive behaviors to matters of social policy and social change" (Zimmerman and Rappaport 1988). It is applied within different disciplines, including Library and Information Science (LIS). Johansson and Hultgren (2018) stress the importance of creating library space for children, at the same time as operationalizing concepts like participation and empowerment.

In their four-space model (2012) Jochumsen, Rasmussen, and Skot-Hansen outline a conceptual model for public libraries, where empowerment, along with 
innovation, is listed as one of the libraries' overarching goals: "Empowerment concerns development of strong and independent citizens who are able to solve everyday problems," they say. In their model, it is particularly the library as a learning space and a meeting space that underpins this objective. Research focusing on digital competence, outreach or the social aspects of the library often use the empowerment perspective when looking at outcomes of such programming (Sandoval-Almazán, Gil-Garcia, Luna-Reyes, Luna, and Rojas-Romero 2012; Sung, Hepworth, and Ragsdell 2013; Brewster 2014).

Turning to childhood research, the concepts of "being" and "becoming" are essential in order to understand how children have been and are perceived. Are they merely "being", as independent actors, or are they in the process of "becoming”, "adults in the making”, as Uprichard describes (2008)? She suggests that it might be more fruitful to see these concepts not as mutually exclusive, but rather theorize children as both beings and becomings - not one or the other. Marianne Gullestad has advocated a shift from the study of childhood as such, to the study of specific childhoods (1996, 17). She breaks the analysis of childhood down to three different kinds of research areas: 1 ) facts in the lives of children; 2) ideas and images of childhood; and 3) experiences of childhood. Whereas the two first "research foci are explicit adult perspectives on children's lives", the "last research focus suggests studying children as children in order to grasp their perspectives of the world" (Gullestad 1996, 18). The aim is to see society from the point of view from the children. In this study, we uphold the user perspective and focus on the children's experiences of this particular public culture arena.

\section{A Task-oriented Methodology}

The study of the children's point of view in the context of research is inherently an adult perspective, as Gullestad also underscores. Using children as informants furthermore raises issues concerning ethics, planning, engagement and approach, which are different from targeting groups consisting of adults (Tinson 2009). Barriage (2018) suggests a task-centered approach, which entails engaging the young informants in activities that play into their strengths and competencies while collecting data. Our first visit to Biblo took place before the opening in March 2015, and we have up until April 2019 regularly visited and observed the activities in the library. Entering Biblo for research concerning the library user, as well as our previous observations and findings, were at the back of our minds. However, the kids' responses in this part of the study was not intended as an evaluation of the findings of our own previous research, although they chronologically follow those by the management and the staff. While we had the previous 
research in mind when meeting the kids, what we wanted was to listen to their version without asking set questions, in order to explore their narratives and not have a predetermined narrative unfold. The method we used allowed the children to set the agenda, and made possible an exploration of their preferred themes, and we could then use this material to analyze the topics of empowerment and participation.

A certain negotiation of the gap between our adult and the children's perspectives was bound to take place, and our approach reflects an attempt to bridge the gap, with the knowledge that it cannot be removed. Biblo has been the subject of much interest and attention, from researchers, librarians, politicians and the general public. The management has become increasingly restrictive about granting adults access because they want to protect the children, and not make them study objects. To be welcomed in, you must give something back. For us, this meant that our first step had to involve getting to know the children, of value for us, by providing them with something of value for them. We also knew that in order to explore the children's experiences and perspectives of Biblo, interviews would not work without establishing a common ground with the children. In order to create this, we developed a task-centered methodology.

Previous studies of the library space and interviews with the staff directed us towards the kitchen, described by them as "the heart of Biblo" (Evjen and Vold 2018). For a period of six weeks, we spent afternoons in the library cooking or baking with the kids. This period served as a type of reconnaissance of a territory we knew on the surface. We did not take detailed notes from this period, in any strict form, but our observations and experiences were important groundwork prior to formally approaching the kids with questions about their library use and experience. The main research value in this phase came from gaining a sense of place, an understanding of the context and from making us known. By being available for the kids, they became used to seeing us in the library, and when we later approached them they could make a more informed choice of whether they said yes or no to talking to us, simply by having an idea of who we were and what we represented. For us, it was easier to make our questions more open and relevant, and we had a better idea of how various groups of children used Biblo (the amount of newcomers, regulars, kids who lived in the neighborhood or came from other parts of the city, how the kids operated in pairs, groups or alone etc.). Also, it made the next phase, approaching the children, easier.

In this phase, we wanted the children to show us what they liked about the library. We gave them a Polaroid camera and asked them to take four photos. If asked for more particular instructions, we would suggest they take photos of the areas or objects they preferred, or of something that represented what they liked to do while being at Biblo. Focusing on the task, as Barriage (2018) suggests, we 
did not influence their choices in any way - although the kids themselves may have influenced each other.

Afterwards, we met up for an informal talk, mostly one by one, sometimes in pairs, and at one occasion a group of three kids talked to us. Twelve children met us in total, from the age of ten to 13 , and we taped and transcribed the conversations. We did not follow an interview guide but had a list of topics we wanted to cover and let the motives of the photos lead the way into the discussion. The photos made the base for open-ended conversations about Biblo. These also concerned various contexts of the children, their after-school activities, where they lived, homework and life in general.

The Biblo patrons form a heterogeneous group. Since we already had made contacts and were familiar with the library, it was quite easy to select a variety of informants: new and experienced users, girls and boys, different national and linguistic background. We didn't need to make these kind of categories a topic in the contact with the kids, unless they addressed these themselves.

To understand what Biblo represents to the kids within the contexts of their daily lives, without exploring the various children's family backgrounds in any detail, we posed open questions about what the kids did when they were not at Biblo. For some, this question was answered by pointing to other after schoolactivities, "arts, choir, clarinetto and piano" (Samila and Ophelia), while others would refer to their duties at home: "I do the groceries, clean the floors, and help my mum with my baby sister, so that my mum can rest" (Hanna). A third typical answer indicated what other places the kid would stay at, for instance, at the school yard and youth clubs. From the children's narratives Biblo represents an afterschool-activity, a period of leisure and a specific location. Because Tøyen, at least for Norwegians, is associated with socioeconomic issues, descriptions and discussions often include ethnicity, income and family living situation. We deliberately wanted to avoid these labels and refrained from asking questions that would highlight them. Letting the kids tell their library stories without labelling the narrator was our way of doing so.

The Polaroid pictures of the library tell their own story about which elements the children highlight, prefer and use the most. Almost all picture sets include one or more photo of where the kids like to sit, or "hang", usually the cave-like padded spaces that accommodate one or two kids and up to whole groups. They use it to retreat with their mobile phones - alone or with a friend - or, in the case of the bigger spaces - to just talk with a bigger group of friends. Many presented photos related to what they like to do, activities such as playing chess, gaming, reading, using the 3D-printer. In many cases, the activities overlap: one proceeds from relaxing alone with the phone to talking with someone who is present in the room to playing a game on the phone and relaxing etc. Table 15.1 shows the mo- 
tives the children presented. Although 12 kids were interviewed, some worked in pairs and one person took only two photos, so all in all there are nine sets of photos and 37 photos. The table also lists initials of the children who took the photos, and these initials (given name) will also be used when we present our findings. When we quote from the interviews, we do not use the children's actual names, to preserve their anonymity. The children are: Alanna, Hanna, Sara/Mindy/Mel, Samila/Ophelia, Megan, Yan, Tanya, Tambar, Tony.

Tab. 15.1: "What I like at Biblo"

\begin{tabular}{|c|c|c|}
\hline $\begin{array}{l}\text { No. of photos - } \\
\text { children }\end{array}$ & $\begin{array}{l}\text { Children's preferred areas or activities } \\
\text { (no. of photos in parenthesis) }\end{array}$ & Why I like it \\
\hline $\begin{array}{l}\text { A, T, SMM, M, } \\
\text { S\&O }\end{array}$ & $\begin{array}{l}\text { Seating area 1: Large "cave". Seats } \\
\text { up to eight persons. Round windows, } \\
\text { submarine atmosphere. (6) }\end{array}$ & $\begin{array}{l}\text { A good place to hang out, } \\
\text { relaxing, talking, being on the } \\
\text { phone }\end{array}$ \\
\hline $\mathrm{S} \& O, \mathrm{~T}, \mathrm{M}, \mathrm{Y}, \mathrm{A}$ & $\begin{array}{l}\text { Kitchen: Put in an old lorry, seats } \\
\text { eight, max four can work there at the } \\
\text { same time (5) }\end{array}$ & $\begin{array}{l}\text { Like cooking, what is served, } \\
\text { hang out }\end{array}$ \\
\hline $\mathrm{H}, \mathrm{A}, \mathrm{Y}, \mathrm{M}, \mathrm{S} \& \mathrm{O}$ & Book shelves/books (5) & $\begin{array}{l}\text { Reading. Like to read at Biblo, } \\
\text { borrow books to read at home }\end{array}$ \\
\hline A, S\&O, SMM & $\begin{array}{l}\text { Seating area } 2 \text { "motor of truck". Seats } \\
\text { max four persons ( } 3 \text { ) }\end{array}$ & $\begin{array}{l}\text { Hang out, talk, look at the phone } \\
\text { with friends }\end{array}$ \\
\hline $\mathrm{T}, \mathrm{S} \& 0$ & 3D printer (3) & Making stuff \\
\hline H, Y. T & Computers (3) & Playing games, surfing \\
\hline$M, A$ & $\begin{array}{l}\text { Seating area } 3 \text { "ski gondola", can be } \\
\text { closed. Seats max. six persons. ( } 2 \text { ) }\end{array}$ & $\begin{array}{l}\text { Like it for hang out, talking, can } \\
\text { be closed, do homework }\end{array}$ \\
\hline S\&O, SMM & $\begin{array}{l}\text { Seating area 4: “Cave/tunnel”, with } \\
\text { soft padding, seats up to three. } \\
\text { Underwater photo illustration (2) }\end{array}$ & $\begin{array}{l}\text { Hang out, talking, being on the } \\
\text { phone }\end{array}$ \\
\hline $\mathrm{Y}, \mathrm{T}$ & Chess boards ( 2 ) & Like playing chess \\
\hline T S\&O, & Lego wall (2) & Can play with it, build things \\
\hline SMM & $\begin{array}{l}\text { Seating area 5: Round table } \mathrm{w} / \text { para- } \\
\text { sol. Seats up to eight persons. (1) }\end{array}$ & Like to play, be with friends \\
\hline $\mathrm{H}$ & Sofa (1) & Hang out, relax \\
\hline $\mathrm{T}$ & Stage (1) & Text-lab \\
\hline
\end{tabular}




\section{Findings}

\section{Atmosphere and Activities}

In the four-space model (Jochumsen, Rasmussen, and Skot-Hansen 2012), the spaces designate "overlapping functions that interact in the library space both physically and virtually. The model indicates the possibilities for experiencing, discovering, participating and creating the new library must offer the users." However, the "overall task is to make all four spaces interact by incorporating them in the library's architecture, design, services, programs and choice of partnerships." Biblo as a library space comes close to presenting itself as such a new library, where the architecture underpins stimulation, relaxation, inspiration and wellbeing for kids.

The activities and the atmosphere as we observed and perceived it gave the impression of a quiet, active, yet also relaxing place. From our own observations at the library, the big library space has a remarkably calm and quiet atmosphere even when there are many people present. Children form groups, pairs and sit alone at the various tables, sofas, workspaces and move between them. Although there are activities in the kitchen area, on the stage behind the curtains or by the 3Dprinter, these attract rather small groups. Very seldom the room feels left "empty" because of such activities; very seldom the room feels crowded. At the computer section, there is some commotion and cooperation due to the games that kids play there and online phenomena shared with others, but most of the time the kids sit quietly by their computers. There is seldom observable striving to get to the most popular spaces, although certain areas and activities, like making food in the kitchen section, only provides room for up to four persons at the time.

From the photos, we could see what areas and activities that the kids liked the most about Biblo. Although we could observe some of the preferred activities and some popular spots to stay, the photos provide us with a more nuanced sense of the kids' preferences. Among the motives that recur (see Table 15.1) were a big truck which has been made into a sofa, and the kitchen placed in a lorry, among one of the cave-like sofa-rooms. The kids who have taken these pictures underline that what they like to do here is to relax and to talk with friends. They like to be there, using their mobile phones, with friends or alone. Sara, Mindy and Mel, who we interviewed as a group, took pictures only of such places. When asked about what they liked to do at Biblo, they stressed Biblo as a place to meet and talk to friends. The places they preferred were all places that made such activities possible. Equally popular were the bookshelves, although they represent reading and borrowing books. 
Zooming in on one of the most popular places, we tried to learn the attraction of the kitchen space. Most of the kids would say they like it because they like to cook. Only three or four children can help with cooking or baking because of the small kitchen, but the food is served to everyone. As it is popular, we learned the use comes with a number of rules: to eat, you need to have a bar stool to sit on, thereby securing that there is not a big crowd circling around the food, and only eight can eat at the same time. The portions of food served are small; Biblo is not responsible for feeding the users, only to give them a taste of what is cooked. Up to four people can work at the same time (this is not a rule, but due to the limited size). Among Biblo's guidelines is also the rule that all food made or consumed at the library should be sugar-free. From our baking sessions, we knew that many of these were contested, as kids would like to be served many times or have bigger portions or sit two persons at one stool, while some would often ask us to provide recipes which contained sugar and complain about the fact that what we made was too wholesome and not so sweet. In the interviews, however, differences of opinions were also expressed: "We made sugar-free waffles. They tasted nothing”, or "We made cauliflower soup. It was really good!"

Apart from these recurrent motives, the bookshelves, computer section and certain sitting areas were parts of the room many of the kids represented in their photos. Those who represented the computer section underlined gaming and the fact that everyone at the computers were playing the same game. One kid complained however that their friends spent too much time at the computers, which was boring. Photos of the bookshelves were represented in five of nine data-sets and reading as an activity was brought up by almost all the kids. The girls who mainly used Biblo as a hang out place said they liked to read, and had more than once asked the staff to read to them. Some loaned in big quantities, while others preferred the school library for loans.

From the motives, the library's functions to inspire and excite its uses and providing places to perform and create seemed well taken care of, although the emphasis on reading is perhaps not significantly mirrored in the design and services.

As we talked to the kids about the photos they had taken, we also wanted to know more, and learned about the library in the context of their daily life.

\section{The Library in the Context of the Children's Everyday Life}

Before we started this phase of the project our assumption was that Biblo provided the kids a sort of haven in an urban context, and a safe space in a neighborhood with social challenges and few areas to hang out. However, the kids said little 
about feeling unsafe in the neighborhood, and Biblo is no longer the only "haven" around.

In the group we interviewed we found out that most of them lived in the neighborhoods, but there were also some coming by subway in to Tøyen from the suburbs. Some of them came every day, and sometimes stayed until closing time. Regardless of address, all the children we talked to were introduced to the library by someone. Yan told us that his teacher introduced him to Biblo, and since then he had come back almost every day. Other kids had friends introducing them, urging them to come, and showing them around, as was the case with two girls, Ophelia and Samila. Some had parents who urged them to go.

How the kids described Biblo in the interviews suggests that even though the kids themselves did not feel insecure, security was an issue for the parents, some of whom talked about that aspect with the kids. The importance of the parents' approval for the youngest kids, who are ten, must be taken into account when speaking about the success of Biblo. The employees speak to parents at meetings at school to introduce them to the intentions of the library. The kids referred to the parents' ideas of safety and preferences for Biblo at various occasions. Megan said: "My mother prefers me to come here [Biblo]. She doesn't like me going to K1". Tambar told us that his father had started talking about wanting him to go to Biblo from when he was eight years old. Now he loved being there. Megan added that she would like to go more often to K1 because they have "many games", you are allowed to shout and run - and there are no eating restrictions. Still, "I mostly come here. Because my mum says its best that I learn to read. My mum likes that I read and, that I'm active and such things. I like reading. Reading is almost a hobby for me... Before I knew about K1, I came here every day."

When we talked to Yan about the pleasure of cooking and baking, he also brought up his parents. He said: "I like to cook... Now I can bake a cake without help from my mum." Learning to cook was framed as becoming independent from the parents, and (maybe) helping out or make his mother proud. Biblo in this regard served as empowering him, making him proud and learn to solve everyday problems.

The relationship between Biblo and the home also came up in the context of doing homework, where some of the kids wanted a social environment, some preferred to do this at home and not at Biblo and some kids wanted help from the staff.

For the kids coming to Biblo, it is put in the context of the other youth services for their age, the local youth club K1 and the after-school clubs at the various local schools. All these attract local kids, who compare Biblo to these. K1 was described as a typical youth club, with games and activities, and less access restriction. There are more rules at Biblo, both concerning access and behavior - no 
running, shouting, sugar/candy and so on. For some of our informants, the relatively calm at Biblo is part of the attraction, while one girl finds the staff and the rules somewhat strict.

As these kids move about in the city, another frame for comparison was other library branches. Those of our informants who were not local came mainly to Tøyen because of the library. Those who came to Tøyen from other parts of the city could say: "Tøyen is good.” One girl, Alanna, preferred Tøyen/Biblo to the library at Furuset, although the latter is closer to her home: "We can play, we can draw, we can do what we want. At Furuset we can't do anything. It is no fun. Sometimes the older kids are there, they can do things, they dance and play Fortnite”. Yan had a similar position: “ Biblo is the best library in the whole world! Before we used to go to the library at Furuset. So... I entered, it was a lot of noise, many kids screaming. No one says anything." For him, Biblo is calm, organized and a friendly place: "Everything is perfect!"

But Biblo is of course also an indoor meeting place, comparable to outdoor settings. Despite the good intentions behind the new activities and hangouts for teenagers and tweens at Tøyen, some had noticed drawbacks. Tony lamented on the change from outdoor to indoor activities. "Before we used to be outdoors a lot”, he said, and described to us how he used to meet his friends outside, as for instance in the school yard. Now all activities had moved inside, to K1 and Biblo, and he would move from one to the other, to find his friends and according to the preference of activities (i.e. play ping pong at K1, which is not an option at Biblo). The research shows the varied motivations for coming to the library, and the varied contexts of this particular library, when seen from the users' perspectives.

\section{Relations}

In our previous research, we found the staff's primary aim was to establish good relationships with their users. The kids generally described the staff affectionately, although how much they interact with them, varied. Some staff members are described as "strict", others with admiration for their skills, or because they are "fun". Generally, they are on a first name basis, and different kids relate to different adults among the staff. Several named their preferred members of staff, indicating their capabilities in various way, i.e. making 3D-prints, or more generally, referring to them as nice, or "I like her/ him". There seems to be an element of identifying with staff members in different ways, based on common interests, personality types, or who welcomed them and helped them at their first visit. The staff's practice of properly welcoming newcomers, giving them a tour, making in- 
troductions, is a way of starting to build relationship with the kids and familiarizing them with the library.

During our period of research, we also observed different types of interaction with the adults. Some girls made a point of "spying" on one staff member, clearly enjoying the playfulness, and feeling secure in the fact that they were within boundaries of "tolerated" behavior. Although the staff members suggest activities and remind the children of current events, they never pressure them into anything. Some children could almost always be observed using their mobile phones alone or being completely absorbed in something without any common interaction. Having one's space respected seems integral to being at Biblo.

Corresponding to the stress the staff put on making good relationships, the kids seemed unproportionally concerned about staff who were "too strict" and the ways they imposed limitations on their liberty. There were considerable variations in opinion among the kids on how strict the staff was at Biblo, and how strict they should be. While some would underline that the rules and regulations at Biblo were precisely what made them prefer Biblo to K1 or other libraries in Oslo, others, like Megan, found the staff too strict, and said that was why they preferred other places:

Let me be honest. The teachers... The adults, they get crabby quite fast. And we can't run. Before I knew about the rules here, I had some candy once. Then they made me stay outside for 15 minutes before I was allowed back. It was freezing.

Most of the kids named the adults they liked the best in conversations with us. Yan spoke very warmly about a male staff member who talked to him, told him stuff and taught him technical intricacies. They shared interests, but beyond that there seemed to be a feeling of friendship, warmth and protection. In the description Yan gave of the relationship, we could hear reminiscences of what the library staff earlier had described as children's need to "have somewhere they can ask questions, where they meet adults who are neither teachers or family, who they can talk to - this is maybe a bit diffuse, but there is an 'atmosphere', 'attitude' here" (Evjen and Vold 2018). They underlined that "we have the same rules, but different ways of understanding and connecting with various children" (Evjen and Vold 2018).

The relations to other kids came up frequently in our conversations. Some of the kids came alone, some with friends or siblings and many of them came to meet up with others. Yan had made friends with another boy at the new school and introduced him to Biblo. He told us how he helped his friend to understand the rules and possibilities he himself recently had understood and been introduced to. This group, sister, brother and friend came every day and stayed until closing 
time. They were especially fond of the computer section, the chess table and the kitchen.

\section{Activities}

When Biblo was first established, the reference group who participated in the planning process clearly wanted an "unorganized" library space, where the kids themselves decide how they spend their time, and without too many events and organized activities (Vold and Evjen 2016). Biblo has become such a space, but also offers regular, daily activities. These include homework help (maths) on Mondays, cooking on Tuesdays and Textlab on Fridays. The activities are quite different, from the low-key cooking sessions to Textlab, which is a stage event where the kids present a text, something they have made themselves, for instance in the form of a poem, a rap lyric or other prose. Usually the participant group is quite small, but through our interviews and observations it seems like many of the Biblo kids attend occasionally or regularly.

Tambar told us about his experience of participating at Textlab. It was "quite scary", and he "talked much too fast", and in the end "had to do it once more, to get it right”. But he did get it right, and he smiled from cheek to cheek telling us about the event. It was obvious he had ended up with a feeling of mastering the stage and overcoming his own nervousness. He was also very fond of the 3Dprinter. He told us how he had started using it, how the adults had helped in the beginning, but he had moved on to making his own designs. He told us how proud he was to show one of the results to his father afterwards. For most of the other children we spoke with, activities like these were less important than hanging out, chilling and meeting the friends they already knew. Sara, Mindy and Mel said they sometimes went to "movie night", but it depended on the movie. Often they preferred to just talk.

During our conversations with the kids, it came up that three of them had for various reasons lived in Norway between eight months and two years. The photos these kids took did not vary from those of the other children regarding what they liked to do at Biblo, where they liked to sit etc. But when talking about activities in the interviews, they underlined the learning aspects of the library to a greater extent than the others. Alanna said: "I do my homework here. But I prefer not to ask for help. If they [the staff] help you, you never learn anything.” Alanna expresses a clear motivation, both for learning Norwegian and for learning and educating herself in general. The other two newcomers to the country reveal no such hesitations about asking for help, but they explain that they only ask when they don't understand a question from their homework, or if there are words or expressions 
they are unfamiliar with. Yan prefers a social setting while doing homework, and the presence of the staff is important. "We talk [about different things], hang out. He [one of the staff members] doesn't help me if I don’t ask”. While some children prefer to do their homework at home, others find that Biblo is preferable, usually because of the staff members who can help or explain language or content.

Considering the results of our previous research (2018), where the staff put little emphasis on reading and promotion of literature, the fact that most of the children underline the importance of books and reading to their experience of Biblo stands out. Two examples illustrate this clearly, first, the girl Megan who says "reading is almost like a hobby", and second, the conversation with two of the younger kids:

Samira: My favourite book shelf. This is where I loan almost all of my books. I particularly like that row. It is "silly and fun" (tull og tøys)

Ophelia: It [the picture] represents mostly that we enjoy borrowing books at Biblo.

Q: Do you borrow books every time you come here?

Samira: When I do, I borrow 3-4 books, quite a lot really. I return them ... not every time. We can keep the books for a certain period. If I finish earlier, I return them. At school we can loan books, but they are not the same as here. We have more to choose from here.

Ophelia: And at school we can only have two books each. Here we can have as many as we like.

The three girls, Sara, Mindy and Mel, concurred: "We like to loan books. Also at school. If we are bored, we get books. Sometimes we ask the adults to read to us. It has happened. It went well and not so well (giggles)." It turned out that some of the kids were noisy, and there was a lot of talking instead.

Asked what she liked best at Biblo, one of the girls who was quite new to Norway, Hanna, said:

$\mathrm{H}$ : Almost everything. What I like the best is cooking and reading.

Q: Yes, you took a photo of the books.

$\mathrm{H}$ : Yes, and this book is my favorite.

Q: Do you read here? Or do you borrow the books?

H: I don't borrow books here, I do that at school. I don't have to borrow here.

Q: But you read here?

$\mathrm{H}$ : Yes, I read here.

Alanna said: "This [book] is funny. I read books every day. I read them here and I take them home. For instance, at Christmas, then I brought home books about Christmas to read. I read one hour a day, or more." Asked if she got help finding books, she said. "I find them myself. I think it is better to find them myself." She explicitly related reading to learning: "If I read Norwegian books, I learn Norwegian better”. 
Speaking with the kids about reading, it was hard to miss how all the kids who spoke to us about love of literature and books referred to the same two titles as their favorite book, which they either took home, read at Biblo or would have someone read to them. These are bestselling and hugely popular titles, and as such it is not very strange that the kids have the same preference. However, the pluralism that a library can cater for, is not visible. In independent conversations it turned out that several of the children had been asked to return books they did not have on loan. "I have had many messages about an unreturned book, and I have looked for it everywhere. So now I feel that if I try to borrow a book, they [the staff] say that I have to find the missing book, I have to read here.” In those cases, the children all concluded that they did not want to loan books anymore.

The many mentions of books are also quite remarkable when placed in the context of the interviews with the staff, who would highlight the importance of cultural experiences as drama and music, but not literary ones. For example, watching a theatre performance is regarded as more than an experience; it is a manner of building cultural skills in kids with little cultural capital (Evjen and Vold 2018). Later, such experiences and skills might make them more inclined to take part in the cultural public, because it is familiar, rather than strange. The staff look at their work as enabling kids to grow, and they voice a desire for the kids to find out in what direction and though what means they will grow, at the same time as they voice a more typical Bildung-version of growth. Homework is valued as more important than reading, and at times as two conflicting activities. One of the staff members pointed out to us that if you are struggling with your homework the last thing you want is to have a book recommendation.

The conversations with the kids make us ask ourselves if not at least one professional children's and youth librarian employed at Biblo would have made a difference for these kids who come there to seek pleasure in reading, and also for those for whom reading is a struggle. Someone who has engraved from professional training the importance of never letting a user feel ashamed or blamed, in order to promote a hospitable library culture.

\section{Discussion}

\section{Participation and Empowerment, Autonomy and Freedom}

The link between libraries and democracies is well established. Libraries give the public access to information and cultural products that enable the public to participate in the larger society. Biblo is a part of this democratic process, as an arena for participation and empowerment for its users. As of today, Biblo has received 
numerous awards and has a high standing among in the library field for having accomplished a multifunctional library space for kids in their age group. When we look back on our research projects, what can librarians, library developers and city planners learn from Biblo?

Firstly, it is a good idea to include the users in setting up the library, making them feel the library is theirs from the start. From the photos, the children's preference of places at Biblo were quite consistent. Maybe the many functions that the room was created to enhance can be used more. The rotating shelves, for instance, that should give kid opportunities to see new books even when they sit at their favorite spot, do not move.

But to copy the architecture and initial process will not in itself guarantee success, as participation and empowerment at Biblo rather seems to rely on creating stable relations between the staff and users.

Contributing to empowerment among the children requires a safe environment. The experience Tambar shared with us, when he overcame his initial fear and performed at Textlab, is one of coping and accomplishment. Biblo can in other words be an arena where children can feel safe enough to challenge themselves, outside of school or organized activities. Examples of mastering new activities are many and diverse at Biblo: Yan learning to bake a cake, Alanna learning Norwegian, Tambar decoding the 3D-printer - all these seemingly small instances of accomplishment are big for the individual and have the potential of contributing to empowerment. Homework, cooking or rapping are all activities where one can learn, understand and challenge oneself outside the private realm, together with "strangers", albeit in a familiar setting. Having someone (staff members) available to ask carries different meaning for different children. No doubt for those who - for different reasons - do not have parents who can easily answer questions about schoolwork or Norwegian society, this aspect of Biblo is very important in order to make sense of the new context of one's life. Such moments also mark Biblo as a place for integration.

Secondly, no single space or service can cater for all. While some kids find Biblo too rigid and quiet, this atmosphere is the main reason others prefer the library. We know from earlier interviews that the unruliest kids have been banned from Biblo and can only re-enter after the parents have had a conversation with the staff. While some kids come in search of a place to hang out, others come to do their homework, to read and to borrow books. The photos and the conversation with the kids show us a discrepancy in the way the collection has a limited significance in the view of the staff, and in the room as such, and a higher significance in the regards of the kids. If those who come to Biblo to read and borrow books cease to come because the library services are poor in this regard, Biblo will lose some of their clientele. For these kids, there are few obvious alternatives in the 
neighborhood. This shows that a library should never be the singular hang out option for kids in one neighborhood.

Thirdly, the users are of a loving but unfaithful kind. They move about in the city. They are therefore able to compare Biblo with other library branches in Oslo. Some will come to Biblo from other parts of the city. Others in the age group will come a few times, then the cease to come, even if they live in the vicinity, and then they may return. The distinctiveness of Biblo, may in this context be a success factor: the library has a brand which is well communicated. The many and particular rules of Biblo are well communicated, understood and recognized, and are possible for the regulars to teach newcomers. The kids know what to expect. The unfaithful behavior is also a consequence of the library's aim to present itself as a low intensity meeting-place. This is not a club with a costly membership that requires particular use; on the contrary, Biblo is free to use and leave as you wish. As we see it, the space works as safe and hospitable, as a joint effort by staff and users, to welcome newcomers and communicate the expected behavior.

And lastly, in the way kids use the library, the "library"-word is important. Perhaps not for the users themselves, but our study shows that for kids in this age group, what the parents mean, is very important. Developing Biblo in the direction of a regular youth club is therefore also limiting the place's attractiveness to some of their users.

The experience of autonomy and freedom are crucial for the kids' ownership of the library. Turning to the children's responses, the kids do not perceive the adults as forcing through any distinct cultural or educational program on their behalf. They view the space as open to them, somewhere they can do what they want, what they prefer. If something is boring, or irrelevant, then they just skip it. The kids value this autonomy and are very sensitive to having it reduced or limited. If they are hindered too much in what they like to do, they cease coming. If they are treated unfairly (as in the case of the borrowed books), they avoid the activity that triggered that treatment. The stress on relations that the staff conveyed has its counterpart here and the kids are in general very happy about the staff, some are very fond of them, while others have minor complaints.

An ideal public arena allows for discussion, exchanging views, being familiarized with the standpoint of others. However, making sure the possibility exists does not mean that this is what usually happens or something users want. As a public sphere for kids, Biblo is in addition marked on the one side as familiar and welcoming, and on the other as a space where one encounters strangers. Both the staff and the design contribute to this balance. A catch phrase in the library community in recent years has been to move "from collection to connection" (Jochumsen 2017). Biblo's spatial design has underscored the value of the collection in favor of activities (Vold and Evjen 2015). The staff members are not librarians and 
are not necessarily interested in the mediation of literature and reading, for instance because they see that many of the kids who come are not good readers (Evjen and Vold 2018). Therefore, it is quite remarkable that many of the children headed towards the shelves when asked to take pictures of what they particularly liked about Biblo. In the interviews, they articulated that this was because they liked reading.

Klingenberg (2018) stresses the important effect the public library has, as endowing its users with dignity. In some respects, this perspective is relevant to the kids at Biblo. Although they, as most Norwegian kids, occupy public space as a most natural thing, some of them may have experienced exclusion from (adult) society as they have been perceived as noisy, out of place as big children and met the judgement that adult immigrants and poor people also regularly address. The way the kids spoke about the library, even sometimes naming it "the best library in the world", show us that Biblo has this quality of making children feel welcome, at home, and experience ownership of their library.

\section{References}

Aabø, S., R. Audunson, and A. Vårheim. “How do Public Libraries Function as Meeting Places?”. Library \& Information Science Research, 32, no. 1, 16-26, 2010.

Audunson, R. "The Public Library as a Meeting-place in a Multicultural and Digital Context: the Necessity of Low-intensive Meeting-places”. Journal of documentation, 61, no. 3, 429-441, 2005.

Barriage, S. "Task-centered Activities as an Approach to Data Collection in Research with Children and Youth". Library \& Information Science Research, 40, no. 1, 1-8, 2018.

Brewster, L. "The Public Library as Therapeutic Landscape: A Qualitative Case Study". Health \& place, 26, 94-99, 2014.

Cuong Nguyen, L., H. Partridge, and S. L. Edwards. "Towards an Understanding of the Participatory Library”. Library Hi Tech, 30, no. 2, 335-346, 2012.

Evjen, S. and T. Vold. ““'It's all About Relations.” An Investigation into the Youth Librarian's Role and Proficiency". Nordisk Tidsskrift for Informationsvidenskab og Kulturformidling, 7, no. 3, 59-73, 2018.

Gullestad, M. “Modernity, Self, and Childhood in the Analysis of Life Stories". In Gullestad, M. (ed.), Imagined Childhoods. Oslo: Scandinavian University Press, 1996.

Hart, R. Children's Participation: The Theory and Practice of Involving Young Citizens in Community Development and Environmental Care. New York: UNICEF, 1997.

IFLA. https://www.ifla.org/node/59413, 2018.

Jochumsen, H. “Biblioteket gjennom 100 år - Indhold, rammer og relationer”. In Tolstrup, C. R. (ed.), Biblioteksdidaktikk. Copenhagen: Hans Reitzels Forlag, 2017.

Jochumsen, H., C. H. Rasmussen, and D. Skot-Hansen. "The Four Spaces-a New Model for the Public Library”. New Library World, 113, no. 11/12, 586-597, 2012. 
Johansson, B. and F. Hultgren. Att utforma ett barnbibliotek tillsammans med barn: Delaktighetsprocesser på Malmö stadsbibliotek. [Developing a children’s library with kids - participatory processes at Malmö city library]. Borås: Høgskolan i Borås, 2018. http://hb.diva-portal.org/smash/get/diva2:1182398/FULLTEXT01.pdf.

Johnson, C. A. "Do Public Libraries Contribute to Social Capital?: a Preliminary Investigation into the Relationship". Library \& Information Science Research, 32, no. 2, 147-155, 2010.

Klinenberg, E. Palaces for the People: How Social Infrastructure can Help Fight Inequality, Polarization, and the Decline of Civic Life. Crown, 2018.

Oldenburg, R. The Great Good Place: Café, Coffee Shops, Community Centers, Beauty Parlors, General Stores, Bars, Hangouts, and how they get you Through the Day. Paragon House Publishers, 1989.

Rasmussen, C. H. “The Participatory Public Library: the Nordic Experience”. New Library World, 117, no. 9/10, 546-556, 2016.

Rasmussen, C. H. Formidlingsstrategier: en introduktion til kulturinstitutionernes formidling. Copenhagen: Samfundslitteratur, 2016.

Rasmussen, C. H., H. Jochumsen, and D. Skot-Hansen. Biblioteket i byudviklingen: oplevelse, kreativitet og innovation. Danmarks biblioteksforening, 2011.

Sandoval-Almazán, R., J. R. Gil-Garcia, L. F. Luna-Reyes, D. E. Luna, and Y. Rojas-Romero. “Open Government 2.0: Citizen Empowerment Through Open Data, Web and Mobile Apps”. In Proceedings of the 6th International Conference on Theory and Practice of Electronic Governance, pp. 30-33. ACM, 2012.

Sennett, R. “The Public Realm”. In The Blackwell City Reader, pp. 261-272, 2010. https://www. richardsennett.com/site/senn/templates/general2.aspx? pageid $=16 \& c c=g b$.

Sung, H. Y., M. Hepworth, and G. Ragsdell. "Investigating Essential Elements of Community Engagement in Public Libraries: An Exploratory Qualitative Study”. Journal of Librarianship and Information Science, 45, no. 3, 206-218, 2013.

Söderholm, J. and J. Nolin. "Collections Redux: the Public Library as a Place of Community Borrowing”. The Library Quarterly, 85, no. 3, 244-260, 2015.

Tinson, J. Conducting Research with Children and Adolescents. Design, Methods and Empirical Cases. Oxford: Goodfellow Publishers Ltd, 2009.

Tveit, Å. K. Rom for barn: Norske barnebibliotek i perioden 1914-35 og på 2000-tallet. Ph.D. Dissertation, OsloMet - storbyuniversitetet, 2016.

Uprichard, E. “Children as 'Being and Becomings': Children, Childhood and Temporality”. Children \& Society, 22, no. 4, 303-313, 2008.

Vold, T. and S. Evjen. "How Children Find Their Way: Access, Adaptability and Aesthetics in the Organisation and Design of a New Children's Library". In Creating Knowledge, Enhancing Lives through Information \& Technology, no. (30) in Proceedings of the 79th ASIS\&T Annual Meeting. American Society for Information Science, 2016.

Williams, P. and J. Edwards. "Nowhere to go and Nothing to do: How Public Libraries Mitigate the Impacts of Parental Work and Urban Planning on Young People”. Australasian Public Libraries and Information Services, 24, no. 4, 142, 2011.

Zimmerman, M. A. and J. Rappaport. "Citizen Participation, Perceived Control, and Psychological Empowerment”. American Journal of Community Psychology, 16, no. 5, 725-750, 1988. 


\section{Geir Grenersen}

\section{Libraries and the Sámi population in Norway - Assimilation and Resistance}

\section{Libraries, Assimilation and the Germ of a Sámi Public Sphere}

In this article I will ask the question: what role did libraries play during the early assimilation period towards the Sámi population in Norway? I will focus at the epoch from the late 1800s and up to the beginning of 1900, when the first organized political movements among the Sámi population were formed (Zachariassen 2013; Jernsletten 1986). This is an empirical question, and the methodological challenges are many, with the sources hard to find. In standard works on Norwegian library history the Sámi are not mentioned at all (Grenersen 2015). We must turn to the archives and see what can be found there. What we find in the archives are pieces of a puzzle that no one has tried to solve, yet. My findings in the archives fall into two categories. The first is related to the Directors of Education, Killengreen and Aas, and their reports from their inspection travels to Finnmark. The Director of Education was responsible for the implementation of the State's policy for primary and secondary education, and from 1904 to establish the boarding schools in Finnmark. Altogether 49 boarding schools were built over the next 40 years ("Internatskole for samiske barn" n.d.). In the directors' detailed "Inspection Reports" they also discussed the role of libraries in the assimilation policy towards the Sámi and Kven. ${ }^{1}$ The reports focused on the public and school libraries' potential as agents of assimilation and how reading Norwegian books could contribute to this (Killengreen 1887; Aas 1899).

Then there are sources that point in an opposite direction: could it be that Sámi political "forerunners" or entrepreneurs used libraries - and the reading of books and periodicals - as mediums that gave them new and radical ideas on the Sámi condition and that libraries contributed to a Sámi public field where political and cultural issues were discussed? The sources are complete book lists and borrowing catalogues from Tromsø Teaching College (“Udlånsprotokol”). There we find borrower accounts for the two Sámi political pioneers, Anders Larsen and

\footnotetext{
1 Kven is the Finnish-speaking population in Finnmark. In this article I will limit my discussion to the Sámi population. I will, though, use a few examples related to the Kven, where I feel it is necessary for the understanding of the case. The Kven was as much a target for the assimilation policy as the Sámi.
}

Ә Open Access. (C) 2020 Geir Grenersen (c) BY-NC-ND This work is licensed under a Creative Commons Attribution-NonCommercial-No-Derivatives 4.0 License. 
Isak Persen (later Saba), from their student years between 1895 and 1899. These accounts show that the two students borrowed many books in the categories of history, ethnography, social critique and novels and plays from the Modern Breakthrough in Scandinavian and European literature (Fulsås and Rem 2017).

Did the reading of modern books open up a public sphere for the Sámi where an open debate could take place and radical ideas circulate and lead to political action (Jernsletten 1986; Zachariassen 2012, 52-58)? From the 1880s Norwegian writers like Henrik Ibsen, Knut Hamsun, Alexander Kielland and Amalie Skram, together with other Scandianvian and European writers, created a new literary trend called the Modern Breakthrough. Did the Sámi public borrow, and read, this literature, in addition to non-fiction books? Did the modern turn in literature, and the political radicalization of the European literary public, influence the general Sámi public?² To give a tentative answer to this question I would have to have proof of how many of, and to what degree, the Sámi population used the libraries. Here my sources are meager. In the National Library, and with the help of professional archivists, I found a few complete book catalogues for public libraries in Finnmark and Troms, but no borrower accounts. The libraries had rich book collections, but we cannot identify the loaners. There are a few exceptions; from a few school library catalogs and borrower accounts from the Sámi areas in the 1920s we can see that school children in some schools were eager book-loaners. We can assume that those who were motivated among the Sámi public used the libraries, and we have some indication that this can be the case. I will return to this.

\section{The Sámi}

The Sámi are the indigenous population of the middle and Northern part of Scandinavia and the Kola peninsula in Russia. Traditionally they have lived by nomadic reindeer herding, farming, fishing and hunting. They were organized in small, decentralized units (called “Siidas” in Sámi) regulated by unwritten agreements very different from the centralized and hierarchical political structure in the Scandinavian countries (Hansen and Olsen 2004). There are approximately 50,000 Sámi living in Norway and about 80,000 to 100,000 in Scandinavia and Russia, but official censuses have not been carried through, meaning the numbers might be higher. Today around three percent of the Sámi population in Norway

\footnotetext{
2 I want to thank Narve Fulsås for discussions where he pointed to the possible connection between reading books from "the Modern Breakthrough" and political mobilization among the Sámi.
} 
have their occupation in the reindeer industry, the rest with a pattern of employment, education and income mainly in line with the majority of the population (Grenersen 2012; Samisk statistikk 2018). After the Sámi were given status as an indigenous population in Norway, the Sámi Parliament (1989) was established. The Parliament is democratically elected by a Sámi electorate and deals with all matters concerning the Sámi people. It works in cooperation with the Norwegian Parliament, and in certain areas such as language, culture, and education it has taken over administrative responsibility and policy instruments from the Norwegian Parliament (Sámediggi 2019). In the assimilation period, between 1850 and the 1970s, the Sámi language was suppressed and as a consequence many Sámi could not read or write their own language. Today the Sámi language has been revitalized, and the percentage of younger Sámi that speaks, reads and writes Sámi fluently is increasing. Between 15,000 and 20,000 persons speak Sámi today in Norway. The Sámi language is recognized as one of two (Norwegian) official languages in Norway.

\section{Religious and Cultural Assimilation}

From 1720 the Danish-Norwegian state allocated considerable economic resources into the mission. The aim was to turn the Sámi from their traditional beliefs and into "good" Christians (Hansen and Olsen 2004). The Sámi shaman drum with its pictogram writings were seen by the protestant missionaries as the main symbol of a pagan worldview. The drums were also connected to the Noide - the Sámi shaman - and the missionaries targeted the drums as the one most important cultural and material symbol of the paganism of the Sámi. By attacking the drums, they could also neutralize the Shaman, the spiritual leader of the "Siida" - the Sámi concept for the organizing principle among the different family groups. The drums were physically destroyed or burned; only a few survived, to be shipped to cabinets of curiosities among the European nobilities (Rydving 1995, 63-64). ${ }^{3}$ The protestant mission wanted the Sámi to read the Bible and other religious books in the "language of the heart". Religious books were translated into Sámi and printed in large numbers. School books, mostly with religious content, were also printed in large numbers, often with double text, Sámi on one page, Norwegian on the other (Tvete 1955).

\footnotetext{
3 Many of the drums had included pictures and ideographs of churches, crosses and other Christian symbols alongside the symbols for the Sámi religion. Through commercial activities, and the earlier Catholic mission, the Sámi were already well introduced to the main elements of the Christian faith at the time when the Protestant mission intensified.
} 
But to print religious books in Sámi was not enough; the Sámi had to read them. Throughout the seventeenth century the mission established over 20 Sámi primary schools in the counties of Nordland, Troms and Finnmark. As a consequence of this, the Sámi population in large parts of Northern Norway came to learn to read - and for the cleverest pupils to write - some 20 to 30 years before the Norwegian population in general (Hansen and Olsen 2004, 337). In 1827 the first teacher education college, Trondenes Seminarium (later moved to Troms $\emptyset$ and called Tromsø Teaching College), was established outside the town of Harstad, in the middle part of Northern Norway. Its primary goal was to educate teachers to work in the Sámi districts. From the beginning it had a quota of two Sámi students each year (Willumsen 2014, 50-51). When the Læstadian awakening started around 1830, reading of religious literature and Læstadius' sermons were one important "driver" in the success of the awakening. ${ }^{4}$ The Sámi came to love their religious books, but their "information universe" was confined to religious reading (Tvete 1955).

From 1850 onward, the policy and general view from the Norwegian government concerning the Sámi population gradually shifted into a more nationalistic attitude. The Norwegian Parliament initiated a policy of assimilation, and Sámi language in schools and congregations lost ground (Dahl 1957; Eriksen and Niemi 1983). Eriksen and Niemi define assimilation as a policy "where the state and the majority population try, by using the institutions of the state, to diminish the feeling of identity and unity of the minority" (24, my transl.). The strongest symbol of this policy was an instruction approved by the government in 1862, Sproginstrux, for teachers in the Lappish ${ }^{5}$ and Kven districts (Kjerschow et.al. 1880). It demanded the use of Sami and Kven (Finnish) languages in the classroom to be kept to a minimum (Dahl 1957; Grenersen 2016). Towards the end of the nineteenth century the authorities became almost obsessed by these "foreign nationalities" as they were called (Killengreen 1887, 37). Government officials began to look at the Sami as foreigners that should be assimilated into the modern, industrialized society that emerged (Killengreen 1887, 39-42). The government intensified the assimilation policy and the Director of Education for Finnmark was given the main responsibility for the implementation of the policy. From 1906 scholarships to Sámi students at Tromsø Teaching College were removed, and the Director of Education openly declared that he preferred Norwegian and not Sámi teachers

\footnotetext{
4 The Laestadian awakening was a major pietistic movement initiated by the Sámi priest Lars Levi Laestadius. The movement had a clear social profile against the use of alcohol among the Sámi population. The Laestadianism is still today a vital religious movement in the northern areas of Scandinavia.

5 The word “Lapp”, used for Sámi up to the 1960s, is today looked upon as derogatory.
} 
to fill vacant positions in the schools (Eriksen and Niemi 1982; Jernsletten 1986, 29). This policy was met with resistance in some of the municipalities where the Sámi and Kven were in the majority, and in some instances the local school boards appointed Sámi teachers. But mostly the government, and their official representatives in Finnmark, imposed their assimilation policy through a succession of measures, backed by increased economic support from the government (Eriksen and Niemi 1982).

The assimilation policy between 1850 and the 1970s led to a stigmatization of Sámi identity and belonging, that even today cast long shadows into the lives of many Sámi.

\section{The Establishment of a Sámi Public Sphere: Newspapers and Libraries}

Towards the end of the 1800s and the beginning of the 1900s organized resistance and political mobilization against the assimilation policy came to the surface. ${ }^{6}$ In 1873 Muitalægje (The Narrator) was established, the first newspaper in Sámi. The editor, Peder Larsen, argued that the Sámi needed their own newspaper in their own language in order to be informed on political issues, to fight assimilation, and “partake in the benefits of enlightenment" (Dahl 2016, 93). The newspaper found little support and only 33 issues were published. In 1898 the Nuorttanaste, a religious paper, came with its first number. The paper is still in print and for a long period it was the only newspaper in the Sámi language. Nuorttanaste also published secular articles and approximately 30 percent of its articles was of a secular nature (Dahl 2016). In 1906 another Sámi newspaper, Sagai Muittalægje (The News Reporter) was established by the teacher Anders Larsen. Dahl points out that the editorial content was similar to that of other local Norwegian newspapers at the time (2016, 93-94). The paper received over 500 letters to the editor during the seven years it was in print, most of them on political issues (Jernsletten 1986, 55). The symbolic and practical value of a newspaper in Sámi was huge. When the assimilation policy was at its hardest, Sagai Muittalægje showed the Norwegian authorities that the Sámi people would fight for their language and human and political rights. It was a symbol of resistance, as Anders Larsen wanted it to be, and it

6 I keep the Kautokeino upheaval in 1852 outside of the discussion. This violent upheaval against Norwegian authorities (The priest, the merchant) is still much debated, and evoke strong emotions, even today. Most scholars agree that the upheaval came as a reaction against social, economic, and cultural suppression of the Sámi (see Zorgdrager 1997). 
contributed to the establishment of a Sámi political public field. This was a prerequisite for what the Norwegian historian Ketil Zachariassen (2012) labels the "Sámi counterhegemonic project”. Zachariassen writes that from its first issue the paper was filled with critical political articles and readers' letters, written in Sámi. He writes that "Through Sagai Muittalægje Anders Larsen created a Sámi public that formed the basis of an ethno-political mobilization" (2012, 57). In 1906, when Isak Saba was elected as the first Sámi to the Norwegian Parliament, Sagai Muittalægje was the news platform that built support for Saba. Its editor Anders Larsen was a longtime friend and political ally of Saba. Sagai Muittalægje was filled with letters from the public from the very beginning. This indicates that there must have been a Sámi political public sphere, with the knowledge and competence to engage in political discussions, even when the paper started. This can be explained by the Sámi relationship with the emerging socialist movement (Jernsletten 1986, 171187). Most of the Sámi worked as small-scale fishers, farmers, and many found work on plants, building roads, in mining, and in trade. They identified themselves as workers, fishers, socialists, but also with a Sámi identity (Zachariassen 2012, 47-52). Through public meetings and debates, posters, pamphlets, and also Norwegian papers, the Sámi working population became informed and motivated for political action. But I will ask an additional question: could libraries, and the reading of books, have played a role in the establishment of a political public sphere among the Sámi? (Grenersen 2018). I will return to this question.

With the expansion of libraries in Norway from the 1850s and onward, the hegemony of religious reading among the Sámi were broken. Now the motivated Sámi reader could choose books from public libraries and a few institutional libraries, among them the library at Tromsø Teaching College. The County of Finnmark had at least 12 public libraries around 1880, and the county of Troms over 20 (Fisher, Heiberg, and Nyhuus 1901).

\section{Research Literature and Method}

When I started my research on the role of libraries during the assimilation period, the greatest challenges were the lack of primary sources (Maliniemi 2009, 2010) and that the Sámi are not mentioned in standard works on Norwegian library history (Grenersen 2016). I soon realized that if I was going to find any material concerning the role of libraries among the Sámi during the assimilation period, I had to do the archival work myself. I spent months searching for sources in local, regional, and national archives. Mostly with negative results, and every time I found any material of relevance, it felt like finding a small piece in a larger puzzle: did the Sámi really use the libraries, and if yes, who were those persons, and what 
group did they belong to? What kind of books did they borrow? And what was the relationship between libraries and the establishment of a Sámi public sphere? The last question is the hard one, because we can never prove how reading and thinking is related to actions. But the pieces I found make it possible to say that there is a probable connection between a Sámi public field and library reading.

I started my archival search at National Library in Oslo. I sent a request and asked for all material with relevance for my question. When I got the overview from the archivists at the National Library I spent three days in their archives. The results were meager. But we found a few book catalogs for public libraries from the last half of the nineteenth century in Sámi areas, among them Hammerfest Public Library in Finnmark County (1909) and Skjervø Public Library (1894), and Tromsø Public Library (1885) in Troms County ("Ukatalogisert småtrykk"). These tell about surprisingly rich books and well-equipped collections, with a good many from "the Modern Breakthrough" in Scandinavian and European literature. However, no borrower accounts were found so we know nothing about who borrowed the books.

I then continued my search for archival material at the National Archive and the University Library in Tromsø, where I spent weeks searching for relevant material. At the National Archive I found (with the help of professional archivists) a few Annual Reports on School Book Collections from eight schools in Finnmark from 1924-1925 (“Årsberetninger om skoleboksamlinger 1925-25"). These schools were in the Sea-Sámi areas in the western part of the county with an average of 30-40 pupils in each, classes with a mix of Sámi, Norwegian, and Kven (Finnish) pupils. The book stock varied from only 10-15 books up to 75 . In every report the teacher (in the report often called librarian) had to give the titles of the five most borrowed books for the last year. None of the books had any relation to Sámi conditions, but were standard children and youth books, stories about national heroes, such as Nansen's Journey over Greenland, and also English and American books in translation: David Copperfield, Uncle Tom's Cabin etc. From the reports from the schools in Finnmark, one could also see that, although the numbers varied, at many schools the pupils were eager book loaners ("Karlebotten skoleboksamling"). The most useful finding in the National Archive was a report from the Director of Education for Finnmark J. A. Killengreen on the status of the assimilation policy in the primary schools in Finnmark in 1886 (Killengreen 1887). He writes about the role of all public and school libraries in Finnmark County with regard to this policy. The report is stored in the School Directors' Archive (52 meters with archive boxes) at the National Archive in Tromsø, and cannot be identified as having valuable information on libraries, unless you (or an archivist) read through it. This goes for some of the sources I have found; in the National Library in Oslo all the relevant material was in the Non-Catalogued Collection for 
Small Prints (My translation) ("Ukatalogiserte småtrykk, Småtrykksamlingen"). You learn to appreciate the skilled archivist in those situations. In other cases the sources were easy to find; in the National Archive the complete book catalogs and borrower accounts from the library at Tromsø Teaching College from 1827 up to present ("Udlånsprotokol”; "Tilvekstprotokol”) can be found. The borrower accounts give us a complete list of who borrowed, the titles of the books or journals, and when they were borrowed. Through these we can identify the loans of Anders Larsen and Isak Persen through their years at Troms $\varnothing$ Teaching College between 1895 and 1899. Part of the book stock from this period is still intact and stored at the magazines at the University Libraries in Tromsø.

I also requested the Inter-kommunalt arkiv for Finnmark (http://www.ikaf.no) to go through their magazines and identify everything concerning libraries and the Sámi population. Archives more than 30 years old from the municipalities of Finnmark are stored here. Only one local archive from a public library in the period before 1930 was found, from 1898 from the municipality of Kistrand. In this municipality the Sámi and Kven (Finnish) population was in the majority. The library had 350 books in stock, a good many novels from writers belonging to "the Modern Breakthrough", history works, and many books related to local and regional conditions. I also called the municipal archives in the ten largest municipalities in Finnmark and asked for older archival material concerning the public library, but got no positive answers.

Why is the archival material concerning the Sámi and libraries in Norway so limited? The main reason seems to be the burning of Finnmark by the German army in November 1944. Nearly all buildings in the counties of Finnmark and Northern Troms were burned, and most of the archival material in the region was lost. Another factor can be the silencing of minority voices in archives, museums, and libraries. Kaisa Maliniemi has shown in her research that Sámi and Kven documents in regional and municipal archives in Troms and Finnmark have not been properly registered. They have not been categorized as documents written in Sámi or Kven, and in some instances they have just been put aside in folders with no proper name on them (Maliniemi 2009, 2010). She found hundreds of documents written in the Kven and Sámi languages stuffed away in the municipal archive for Kistrand municipality in Finnmark. ${ }^{7}$ She proves that in this municipality there was a writing Kven and Sámi public towards the end of the nineteenth century, and that the Kven and Sámi languages were used both when the public communicated with the municipality administration and in the administration's contact with the public. These archives had been studied both by local and pro-

7 Kistrand is now a part of Porsanger municipality. 
fessional historians, but no one had paid attention to the surprising fact that the Kven language was used in official municipal correspondence during the hardest assimilation period. This leads Maliniemi to ask the question: "How was it possible that the researchers using these records, and the archival professionals processing and describing them, had overlooked these materials" $(2009,16)$ ? Did the archivist consciously omit information about minority language records? Maliniemi does not believe so, and rather the main reason that these documents are not mentioned in the archival catalogues seem to be that:

\footnotetext{
regulations and guidelines for archival description were formulated in the central administration in the other end of the country. There appears to have been little if any consideration that archives in Northern Norway should reflect the special local cultural, historical and linguistic conditions, or that minorities should be regarded as relevant. Therefore, we find marginalization in all areas of record management - from record creation and keeping to record appraisal, arrangement and description (20).
}

The mechanism of silencing is complicated, and in my research in the archives I cannot prove that "silencing", the way Maliniemi defines and describes it, was the reason for the meager results. But the way Sámi culture was made invisible in its contact with the majority culture is well-known and described (Eidheim 1970; Grenersen 2002; Grini 2016), and we can assume that this has had its effect also on the way archives material were originally categorized and organized in Sámi and Kven areas.

\section{Libraries as Agents of Assimilation}

In his role as Director of Education in Troms County, J. A. Killengreen had the supreme regional responsibility for the authorities' assimilation policy in Finnmark and Troms County towards the end of the 1800s. Killengreen had been the leader of a reading circle in Tromsø in the 1870s and 1880s. He was a central figure when the public library in Troms $\emptyset$ was renovated in the 1880s. As director of education, he also was the man who approved the financial allocation letters to the 15-20 public libraries in Troms county in the 1880s. Killengreen was well acquainted with the regional library system, and we should not be surprised that he was concerned with the use of the libraries by the Sami and Kven public. Killengreen assumed that by reading Norwegian books and periodicals the Sami and the Kven population would more easily assimilate into the mainstream Norwegian society (Killengreen 1887).

In 1886, Killengreen made a three-month "inspection trip" to Finnmark. The purpose was to report to the Ministry of Church and Education on the assimila- 
tion policy. The schools were his main concern, but in his report he also systematically discussed the use of the 12 public libraries in the county by Sami and Kven. He observed that the Sámi and Kven did not visit the public libraries in the larger cities and towns (Vadsø, Vardø, Hammerfest). In the rural areas some of the libraries were visited "quite often by younger Lapps who have learnt Norwegian in the schools" (Killengreen 1887, 19).

Library use is connected to literacy. In Norway in the nineteenth century the Sámi, Kven, and Norwegian population went to the same schools and followed the same curriculum, and the use of Kven and Sámi languages in the classrooms was strictly regulated by formal language instructions. Along the coast Sámi reading proficiency in the Norwegian language seemed to be on an equal level among Sámi, Kven, and Norwegians in general. In the inner parts of Finnmark, where the nomadic Sámi (living from reindeer nomadism) were in the majority, Norwegian was spoken and read by fewer, according to Killengreen. In Varanger deanery, where the portion of Sámi, Kven, and Norwegians equaled a third each (respectively 421, 591 and 460 persons), Killengreen reported that three quarters of the children read well, while one quarter read "with difficulties", and also reported that two thirds of the children "write well" while one third "struggles". Killengreen's observations must be interpreted carefully, but he based his report on the teachers and clergymen reporting to him, and we can take the numbers as an estimate (Grenersen 2015).

Killengreen did not problematize the Sami and Kvens' reading skills, for example if they just learned the language (Norwegian) mechanically, or if they had a deeper understanding of the language. He assumed that the modernization of the school system in Finnmark through increased schooling hours, the employment of several Norwegian teachers (he wanted to limit the appointments of Sámi and Kven teachers), increased focus on both small children schools (one year's earlier start in school, i.e. from six years) and the upstart of several new eveningand county schools for specially gifted pupils, would lead to better skills in Norwegian. As the Sami and Kvens' Norwegian skills increase, they would start using the libraries, according to Killengreen. Therefore, Killengreen wrote, "the public libraries must be systematically developed" (63). Killengreen concluded his extensive report from the inspection trip in eight main points. He connected the activities in the public library directly to the assimilation policy and took the library as a proof that the policy worked better in some school districts than in others: 
f. Public libraries. It is important to have well-equipped libraries in order to support the school's work for Norwegianization. The foreign nationalities ${ }^{8}$ do not often attend the public libraries; but we might hope, however, as the knowledge of Norwegian language gains ground, more people will use the libraries. There are already indications that the foreign nationalities are beginning to understand the importance of libraries; for example in Næsseby, where the Lappish youth quite often visit the library and read Norwegian books. (...). (p. 62). (My translation, I have translated it from the original, rather archaic version.)

The libraries should lend a hand in this assimilation policy, according to Killengreen. Sami and Kven should read Norwegian books, with "Norwegian reading" to strengthen the assimilation policy. Not once does Killengreen suggest books in Sámi or Kven languages in the public libraries' collections (Grenersen 2015, 2018).

\section{Libraries, Books and the Establishment of a Sámi Public Sphere?}

How many Sámi and Kven used the libraries in Finnmark towards the end of the nineteenth century? What books, periodicals, and papers did they read? Killengreen gives us no answer to these questions. And these are difficult questions to answer since no lending protocols and only a few book lists have been found from this period. We know that the Kven population in the midst 1890s organized a reading society and established a library in Vadsø, the largest town in Finnmark county. They also established a newspaper in the Finnish language (Ryymin 2002; Larsen 2012, 77, 264). These efforts were all short-lived, since Norwegian authorities systematically worked against them. In the same town the "Finnmark Library" ("Finmarksbibliotheket") was established in 1895 by the county governor and the local priest, with the aim to collect scientific and fictional books, manuscripts, paintings, and pictures about the people and nature of Finnmark (Larsen 2012, 144-145, 193). Over the years it accumulated large numbers of books on Sámi and Kven conditions and in the Sámi and Kven languages. We still do not know if, and how, this library was used by the Sámi and Kven since nearly all the archival material is lost.

How did political ideas, that spread among the central European public throughout the second half of the nineteenth century, reach a Sámi and Kven public far north? My hypothesis is that the libraries transferred new and modern ideas of emancipation to the Sámi and Kven, both to the laymen and to those

8 "Foreign nationalities” was Killengreen's term for the Sámi and the Kven population, a term used by many Norwegian officials visiting Finnmark. 
who became political forerunners (Barth 1972; Grenersen 2015). I will discuss this hypothesis by looking at two Sámi political pioneers and their book loans at the Tromsø Teaching College Library. Anders Larsen (1870-1949) from Kvænangen and Isak Persen (1875-1921) from Nesseby (later he took the surname Saba) were students at Tromsø College between 1895 and 1899. Isak Persen was granted a scholarship, ${ }^{9}$ while Anders Larsen entered the school on ordinary terms. Isak Persen was the first Sámi to be elected to the Norwegian Parliament in 1906, and re-elected in 1909 with the support of the socialist and Sámi votes. Anders Larsen established the Sámi paper Sagai Muittalægje in 1904 where he supported Persen in his political campaign to be elected to the Parliament. Larsen also wrote and published the first Sámi novel in the Sámi language in 1912. Both wrote extensively on Sámi political, social, economic, and cultural issues throughout their lives.

The library catalogs and borrower accounts for Tromsø Teaching College are preserved at the State Archive in Troms $\varnothing$, and they give us a complete picture of the library's book collection and the students' loans. The library collection at Troms $\emptyset$ Teaching College had many books from the leading authors behind the "Modern Breakthrough" (Fulsås and Rem 2017). It also contained historical works and books covering science, humanistic, and pedagogical subjects. There were also many books on religion, some on ethnography and mythology, and books of more frivolous character such as popular life stories, travels and biographies. The journal collection contained approximately 30 journals in subscription. ${ }^{10}$ Most of the books were in Norwegian, a few in Finnish, and some religious and linguistic books in the Sámi language (Tilvekstprotokoll Bibliotek 1881; Dahl 1954).

When I started reviewing the loan records from the college library I identified every book and magazine the two men borrowed, the date they borrowed the books, and the literary profiles of their books, especially whether they borrowed literature within the "Modern Breakthrough" in Scandinavian and European literature (Fulsås and Rem 2017). Their loans of books within "the Modern Breakthrough" indicate that their political orientation and work was motivated - among other things - by reading critical social literature. Did reading help them to see the parallels between the Sami struggle against assimilation and the wider social and political awakening in the European countries? The problem is, of course, that we

\footnotetext{
9 The scholarship had existed at the seminar since it was established in 1826 in order to strengthen the recruitment of Sami and Finnish-speaking (Kven) teachers to the Sami and Kven school districts (Dahl, 203). In 1906, the free scholarship was abolished, as part of the assimilation policy.

10 Part of the book collection is still intact and located in the magazines of the University Library in Tromsø.
} 
cannot know, or prove, how much the reading of books from the Library in Troms $\emptyset$ College influenced them, relative to other factors. ${ }^{11}$ Did they also borrow books from Troms $\emptyset$ Public Library with its 3,500 books in stock, or did they buy books in bookstores? How did discussion about politics, culture, and language in the many forums at the College influence them (Jernsletten 1986; Zachariassen 2012)? I will argue that the profile and frequency of their loans give us an indication of their literary and intellectual taste. I have looked through and identified the content in every book they borrowed. ${ }^{12}$ We can see some patterns in their borrower accounts: they tended to borrow some authors (like Jonas Lie and Henrik Ibsen) repeatedly, which indicates that some authors were more attractive to them than others, while reading one book by an author seems to have motivated more reading of the same author. We can see this pattern in their loans of authors from the "Modern Breakthrough". They borrowed historical works over longer periods, which might indicate that these books were part of their syllabus, or that they were motivated to read history and see if there were lessons to be learnt in their own struggle for political and cultural recognition. Both were interested in ethnography, Persen also in mythology and folklore. They borrowed some books that debated religion's role in society, and Larsen borrowed some light reading in connection with summer and Christmas holidays. Larsen borrows more books than Persen about Northern Norway written by local authors and ethnographers. Persen's loans are to a greater extent focused on geography, archeology, and ancient history.

They borrowed in average two to three books a week, sometimes more, during their years at the college. In sum Persen borrowed 100, and Larsen 67 books. The collection at the Seminar Library consisted of around 2,800 books. I have ordered Larsen's and Persen's loans into four categories:

Anders Larsen: books borrowed in the Tromsø Teaching College Library, September 1897-June $1899^{13}$.

\begin{tabular}{llll}
\hline Novels/Plays & Historical works & $\begin{array}{l}\text { Ethnography/Science/ } \\
\text { Travels }\end{array}$ & $\begin{array}{l}\text { Religion/Mythology/ } \\
\text { Miscellaneous }\end{array}$ \\
\hline 24 books & 16 books & 11 books & 15 books \\
\hline
\end{tabular}

11 Thanks to Kerstin Rydbeck for her comments related to this question.

12 I have used the website Bookhylla.no at the National Library, where nearly all books published in Norway before 1990 are digitized and available for Norwegian IP addresses.

13 Both Persen and Larsen borrowed a few books more than once. The total numbers of original titles are therefore slightly less than the total numbers of loans. 
Isak Persen: books borrowed in the Tromsø Teaching College Library, October 1895-June 1898.

\begin{tabular}{llll}
\hline Novels/Plays & Historical works & $\begin{array}{l}\text { Ethnography/Science/ } \\
\text { Travel }\end{array}$ & $\begin{array}{l}\text { Religion/Mythology/ } \\
\text { Miscellaneous }\end{array}$ \\
\hline 32 books & 24 books & 22 books & 22 books \\
\hline
\end{tabular}

Larsen and Persen in sum

Fiction/Plays

Historical works/Social critique

Science/Ethnography/Travelogue

Religion/Mythology/Misc.
56 books (34\%)

41 books $(24 \%)$

33 books (20\%)

37 books $(22 \%)$

Persen's first loan was Naturen - et illustreret maanedsskrift for populær naturvidenskab ("Nature - an Illustrated Journal for Popular Natural Science"). (Reusch 1878). The journal is still running (it is Norway's oldest scientific journal) and was established at the University of Bergen. Its main purpose was to inform the reading public of the latest breakthrough in the natural sciences, and the articles were written by the leading researchers in their field. From the beginning the journal was an arena for the leading scientific debate of the time concerning Darwin's theories on evolution. Persen's loan of Naturen, and his other loans of science and ethnographic books, show us that he early on had an interest both for natural and, what we today call, social sciences. Three weeks after Naturen he borrowed Bjørnstjerne Bjørnson Paa Gud Veie ("Walking the Road of God", my transl.) where Bjørnson, the leading public debater in Norway and later Nobel laureate, discusses the relationship between the current theories on evolution and the Christian faith. Persen's loan of Naturen and Paa Gud Veie give us a hint of his interests in the great debate of his time between science and faith. He participated in different clubs at the college through his student years, where current political, scientific, and cultural topics were debated. He took part in these debates, and his skills as a public debater were nourished in this milieu and through the books he read (Zachariassen 2012, 44-47).

Persen also borrowed the Finnish national epos Kalevala, kept it for a long time, and read it in Finnish, its original language (Grenersen 2018). During his student years he collected Sámi fairytales and place names as an assistant to professor Just Qvigstad, who was the head of Tromsø College and the leading Sámi linguist and ethnographer in Scandinavia. In Qvigstad's comprehensive work on Sámi fairytales, Larsen collected around 100 stories (Qvigstad 1927-1929). In 1905 Persen wrote: "Every people that will avoid to be swallowed by another people must take care of its folksongs, fairytales and legends based on the foremoth- 
ers and -fathers' language and customs” (Jensen 2009, my translation). In 1906 Persen wrote Sámi soga lávlla ("A Song for the Sámi People," my transl.), which today has a status as a national anthem for the Sámi. Maybe Larsen's reading of Kalevala and reading of historical and mythological works at the library gave him an early inspiration to write Sámi soga lávlla some years later.

In the category History and social critique, the two students read historical works that covered Norway, ancient world history, the French revolution, and the development in Europe during the decades that followed. Some of the books on history they borrowed more or less continuously through their student years. Leading historians of the time like A. Ræder, L. Munthe Kaas, F. Granzow, and $K$. Erslev presented new thoughts on the political rights of smaller nations. In these books one could read about peoples' and nations' struggle for emancipation and liberation from colonial powers, and a growing critique of colonialism. The works have probably made an impression on Larsen and Persen, and inspired their political agitation and approval of the socialist movement some years later (Zachariassen 2012, 77-78; Jernsletten 1986, 61-67).

Of the 56 books that Persen and Larsen borrowed in the category "Fiction and plays", around 50 were written by authors representing "the Modern Breakthrough”, like Bjørnstjerne Bjørnson, Jonas Lie, Henrik Ibsen, Alexander Kilelland, and Arne Garborg. Persen borrowed 19 books by these authors, Larsen 10. They also borrowed a good many books by writers that were strongly influenced by the "Modern Breakthrough", but not with the same international reputation, like Johan Bojer and Annette Ihle. How did the reading of plays and fiction influence the two young Sámi students? This is a question that cannot be answered with any certainty. Their borrower accounts indicate that they were inspired by these authors and read many of them with enthusiasm. The literary fabric in fiction and plays works in a more indirect way than historical and ethnographic works. There is no clear political formula in fiction; it evokes emotions and often points to conflicts in the protagonists' personalities, lives, and milieu.

\section{Larsen's and Persen's Loans in Comparison}

Larsen reads more books than Persen with themes from Northern Norway and the relationship between Sámi and Norwegians. Some of these had a clear ethnocentric angle, like A. Hagemann's Blandt Lapper and Bumænd (“Among Lapps and Norwegians," my transl.), where the Sámi is portraited as inferior to Norwegians. Maybe Larsen read this book because it revealed the thoughts of Norwegians with a racist attitude towards the Sámi. He also borrowed Carl Lumholtz's Blandt Menneskeædere - Fire Aars reise i Australien ("Among Cannibals. An Ac- 
count of Four years' Travels in Australia and of Camp Life with the Aborigines of Queensland”). In the book Lumholtz expresses sympathy with his object of study - the indigenous population - but the book is imbued with his (maybe unconscious) attitude of the aboriginals as "a race (...) on level with the stone age man" and doomed to "disappear in a couple of generations" (Foreword, II-III, my transl.). Both Larsen and Persen borrowed several books by J. A. Friis, professor in Sámi languages and ethnographer. Friis also published short stories and popular ethnographic pieces about the Sámi way of living; one of these books Skildringer fra Finnmarken ("Tales from Finnmarken," my transl.) - is preserved in the magazines of the University Library of Troms $\emptyset$. Inside the cover two students have written: "Hurray for Friis, he writes very well about the Sámi condition!" (my translation). It could have been written by Larsen or Persen, but also by other Sámi students. Professor Friis' works on the Sámi language are still much valued, but his short stories with themes from Sámi daily life had a slight ethnocentric tendency. The students also read books about Northern Norway by regional writers, tales about fishermen, workers, and the daily life of common people. In these books current, societal issues were put on the agenda. Larsen's last loan is A. E. Eriksen's Dansk og Norsk litteraturhistorie ("A Danish and Norwegian History of literature", my transl.); maybe his ambition to write the first Sámi novel, and play a part in the Norwegian literary history, was born among the bookshelves at the library of Tromsø Teaching College.

\section{Conclusion}

In this article I have discussed the relationship between the use of libraries, the assimilation policy, and the Sámi political public sphere that opened up towards the end of the nineteenth century. My discussion of them is based on extensive field work in many archives. This have been a sort of puzzle solving where I have found pieces here and there, tried to put them together, and, based on the incomplete pattern that emerged, give a fair interpretation and ask some relevant questions.

First, what role did the libraries play for the director of educations (Killengreen and Aas), whom were responsible for the implementation of the assimilation policy in the schools? Killengreen's report from his four month "inspection travel" in 1886 tells us that he wanted to use the school and public libraries as places where the Sámi (and Kven) population could read books and magazines in Norwegian. The thought behind it is rather simple; if the "foreign nationalities" read Norwegian, this would be one step in their assimilation to Norwegian identity. 
This is connected to my second question: in what ways did Larsen's and Persen's reading of books, mainly in Norwegian, ${ }^{14}$ in the Troms $\emptyset$ College Library, influence their attitude towards the assimilation policy? This was another setting than the one Killengreen and Aas described, and their radical political attitude was nurtured by many different factors. I cannot prove that their reading and use of the library contributed to their political engagement, but their preference for books from "the Modern Breakthrough" and their reading of historical and ethnographic books make this probable.

The third question is related to the observation that a Sámi political public already was established when the Sámi paper Sagai Muittalægje came with its first number in 1904 (Zachariassen 2013). This is based on the fact that from its first number the paper received lots of letters of a political nature (Jernsletten 1986). Could libraries, and the reading of books and magazines, have played a role in the establishment of the political public sphere among the Sámi? This is a hard question, and my empirical findings and the scope of my research is too narrow to give a satisfying answer. But the question is worth asking because the two book lists that I have found from the public libraries in Finnmark - both from Hammerfest (the second largest town) and Kistrand (a small municipality with Sámi and Kven in the majority) - tell us about rich collections of "modern" books and periodicals from Scandinavia and Central Europe. The relatively large book stocks in the public libraries were a consequence of an offensive Norwegian library policy in the second half of the nineteeenth century (Vestheim 1997). We can conclude that books from "the Modern Breakthrough" and other books with critical social perspectives were available for a Sámi public in many towns and municipalities in Finnmark. We know that Larsen and Persen read them, but we do not yet know if they were read by a broader Sami public.

\section{References}

Aas, K. “Udtalelse om forskjelllige skoleforhold i Tromsø og Finnmarkens amter”. Kristiania: Rapport til det kongelige kirke- og undervisningsdepartement, 1899.

“About the Sámi Parliament”. https://www.sametinget.no/Om-Sametinget/About-the-SamiParliament.

Aubert, V. “The Lappish population in Northern Norway”. Oslo, 1978. Artikler fra Statistisk sentralbyrå, no. 107.

Barth, F. The Role of the Entrepreneur in Social Change in Northern Norway. Bergen: Universitetsforlaget, 1972.

Bjørklund, I. and H. Gaski. “Anders Larsen. Om sjøsamene og andre skrifter”. Karasjok, 2014.

14 They also read Sámi books, mostly grammar (Stockfeldt) and a few religious books. 
Dahl, H. Språkpolitikk og skolestell i Finnmark 1814-1905. Oslo: Universitetsforlaget, 1957. Dahl, H. "Samiske og kvenske (finske) bøker i Trondenes og Troms $\emptyset$ seminars boksamlinger 1826-1906”. Håløygminne, B., 9, årg. 35, hefte 2, 227-232, 1954.

Dahl, H. F. A History of the Norwegian Press; 1660-2015. New York: Palgrave Macmillan, 2016.

Eidheim, H. "When Ethnic Identity is a Social Stigma”. In Barth, F. (ed.), Ethnic Groups and Boundaries: the Social Organization of Culture Difference, pp. 39-58. Oslo: Universitetsforlaget, 1970.

Fulsås, N. and T. Rem. Ibsen, Scandinavia and the Making of a World Drama. Cambridge University Press, 2017.

Eriksen, K. E. and E. Niemi. Den finske fare. Sikkerhetsproblemer og minoritetspolitikk i nord 1860-1940. Oslo-Bergen-Tromsø: Universitetsforlaget, 1981.

Fisher, K., J. V. Heiberg, and H. Nyhuus. Folkebogsamlinger i Norge. Kirkedepartementet: Kristiania, 1901.

Grenersen, G. "Biblioteket ved Tromsø Seminarium og de samiske pionerene Isak Persen og Anders Larsen”. In Bok og Bibliotek, nr. 2 - 2019, 2019. https://www.bokogbibliotek. no/news-page/news-bibliotek/biblioteket-ved-tromso-seminarium-og-de-samiskepionerene-isak-persen-og-anders-larsen.

Grenersen, G. “Libraries and the Establishment of a Sámi Political Sphere”. In Proceedings from the Document Academy, 5, iss. 2, 2018. https://doi.org/10.35492/docam/5/2/7.

Grenersen, G. “Finnefondet - et fornorskningsinstrument eller et ekstra lønnstillegg? En gjennomgang av fondets midler til lærerne 1901-1902". Historisk tidsskrift, bind, 94, 2016, 609-633, 2016. Oslo: Universitetsforlaget.

Grenersen, G. "The Role of the Libraries in the Norwegianization Policy 1880-1905". In Proceedings from the Document Academy, 2, iss. 1, 2015. https://doi.org/10.35492/docam/2/ $1 / 11$.

Grenersen, G. "What is a Document Institution? A Case Study From the South Sámi Community". Journal of Documentation, 68, no. 1, 127-133, 2012. http://dx.doi.org/10.1108/ 00220411211200356.

Grenersen, G. Ved forskningens grenser. Oslo: Spartacus, 2002.

Grini, M. "Samisk kunst i norsk kunsthistorie: Historiografiske riss". http://hdl.handle.net/ 10037/10019, 2016. (Doctoral dissertation).

Hansen, L. I. and B. Olsen. Samenes historie - fram til 1750. Oslo: Cappelen, 2004.

Hansen, L. I. “Just K. Qvigstad Contribution to the Study of Sámi culture”. Acta Borealia, 9, no. 2, 47-68, 1992. https://doi.org/10.1080/08003839208580416.

“Internatskole for samiske barn. Universitetet i Oslo (n.d.)”. https://www.norgeshistorie.no/ hvordan-blir-historie-til/velferdsstat-og-vestvending/K1806-internatskole-for-samiskebarn.html.

Saba, Isak. “Norsk biografisk leksikon”. https://nbl.snl.no/Isak_Saba.

Jernsletten, R. "Samebevegelsen i Norge: ide og strategi 1900-1940”. Hovedoppgave i historie, University of Troms $\emptyset, 1986$.

Jensen, L. A. Isak Saba. Norsk biografisk leksikon, 2009. https://nbl.snl.no/Isak_Saba.

Killengreen, J. Indberetning om en Inspektionsreise til Finmarken - foretaget i Tiden fra 2den Februar til 7de Juni 1886. Kristiania: Kirkedepartementet, 1887.

Kjerschow, C., J. Killengreen, and J. Smitt. Instrux for Lærerne i de samiske og kvænske Overgangsdistrikter i Troms Stift. Tromsø: Stiftsdirektion, 1880.

Larsen, A. Bæivve-Alggo - Dagen Gryr. Karasjok: Forfatternes Forlag, 2013.

Larsen, A. “Om sjøsamene”. Tromsø Museums Årshefter, 70, no. 2, 1950. 
Larsen, R. I. Religion og fiendebilde. Læstadianismen, statskirken og kvenene 1870-1940. PhD thesis, Institutt for historie og religionsvitenskap, University of Tromsø, 2012.

Maliniemi, K. Arkivdokumentene forteller. Oslo: ABM-Utvikling, 2010.

Maliniemi, K. "Public Records and Minorities: Problems and Possibilities for Sámi and Kven". Arch Sci, 9, 15-27, 2009. doi:10.1007/s10502-009-9104-3.

Rolfsen, N. Centralstyret for de norske folkeskolers barne- og ungdomsbiblioteker. Aktstykker. Kristiania: Det Mallinske Bogtrykkeri, 1910.

Rydving, H. The End of Drum-Time. Uppsala University, 1995.

Ryymin, T. “Kvenene - en taus minoritet? Kvenske kulturelle mobiliseringsfors $ø$ k i Vads $\emptyset$ ca. 1880-1910”. Heimen, bind, 39, no. 3, 147-165, 2002. Trondheim: Landslaget for lokalhistorie.

Sámediggi. “About the Sámi Parliament”. https://www.sametinget.no/Om-Sametinget/Aboutthe-Sami-Parliament, 2019.

Samisk statistikk. "Statistics Norway". https://www.ssb.no/befolkning/artikler-ogpublikasjoner/samisk-statistikk-2018, 2018.

Tvete, B. "Skolebøker for samebarn i Norge fra Thomas von Westen til i dag". (Unpublished master's thesis), University of Oslo, 1955.

Qvigstad, J. Lappiske eventyr og sagn. Oslo: Aschehoug, 1927-1929.

Vestheim, G. Fornuft, kultur, velferd. En historisk-sosiologisk studie av norsk folkebibliotekpolitikk. Oslo: Det Norske Samlag, 1997.

Willumsen, L. H. “Trondenes Seminarium: Et lærdomsmiljø grunnlegges”. I Nordic Journal of Educational History, 1, no. 1, 45-58, 2014.

Zachariassen, K. Samiske nasjonale strategar. Karasjok: ČálliidLágáus, 2012.

Zorgdrager, N. De rettferdiges strid: Kautokeino 1852: samisk motstand mot norsk kolonialisme. Nesbru: Samiske Samlinger, 1997.

\section{Archival sources}

Fortegnelse over Tromsø Almuebiblioteheks Bøger x2, Tromsø 1885. In Ukatalogiserte småtrykk, Småtrykksamlingen. Boks: Bibl.kat.: Tr-Tø. Oslo: The National Library.

Katalog over bøker tilhørende Hammerfest herreds folkeboksamling. Hammerfest 1909. In Ukatalogiserte småtrykk, Småtrykksamlingen. Boks: Ham-Hø. Oslo: The National Library.

Katalog over Skjervø folkebibl. bøger, Tromsø 1894. In Ukatalogiserte småtrykk, Småtrykksamlingen. Boks: SI-Sk. Oslo: The National Library.

Karlebotten skoleboksamling. Årsberetning for budgettåret 1923-1924. In Årsberetninger om skoleboksamlinger 1925-25. Boks 162. Skoledirektørens arkiv. Tromsø: The National Archive.

Porsanger skolestyre. Arkivserie: Folkeboksamlingen korrespondanse 1886-1904. Inter-kommunalt Arkiv for Finnmark.

Udlånsprotokol for Tromsø seminar-bogsamling 1881. Utlånsprotokoller. Kirke, utdanning, forskning, skoleverket. Skoledirektøren i Troms, boks 304. Tromsø: The National Archive.

Tilvekstprotokoll Bibliotek. Seminarsamlingen, Boks 304. Tromsø: The National Archives of Norway, 1881.

Årsberetninger om skoleboksamlinger 1925-25. Boks 162. Skoledirektørens arkiv. Tromsø: The National Archive. 



\section{The Joys of Wiki Work: Craftsmanship, Flow and Self-externalization in a Digital Environment}

\section{Introduction}

Public discussions on digital technology and the Internet tend generally to be framed in epochalist terms and to be rife with utopian and dystopian projections of our imminent digital futures (Du Gay 2003; Henningsen and Larsen, this volume). As many observers have noted, in recent years a shift in the tone of such discussions has occurred, as the optimism that accrued to the Web 2.0 and social media 10-15 years ago has waned, with darker visions being brought to the fore. Today, a probing of the role of social media as vehicles of misinformation, commoditization, and mass surveillance looms large in popular and scholarly discussions alike (Fuchs et al. 2012; Van Dijck 2013). However, there is one notable exception to this trend in the current flora of social media: since the turn of the century, Wikipedia and platforms based on the wiki-technology have been a constant source of positive wonder among commentators. This relates to the democratic nature of the Wikipedia organization, to the deliberative aspect of content production, and to the platforms' persistent avoidance of commercialism (FirerBlaes and Fuchs 2014; Van Dijck 2013; Wright 2010). ${ }^{1}$

Prosumers (Ritzer et al. 2012; Toffler 1980) have contributed millions of articles for Wikipedia and other wiki-platforms. The true wonder of wiki-platforms is their capacity to mobilize contributors in great numbers and to incite them to write and edit articles. Based on a case study of the Norwegian local history wiki platform lokalhistoriewiki.no, we seek to understand what motivates contributors to engage in wiki work, and how this can be specified theoretically. We argue that wiki work is an avenue for the exertion of craftsmanship (Sennett 2009), and that it involves psychological processes of flow (Csikszentmihalyi 2008[1991]) and social processes of self-externalization (Elster 1989).

1 Others present accounts of Wikipedia in a less enchanted tone, pointing to the challenges posed by “Wikipedia trolls" (Shachaf and Hara 2010) and “editorial wars” on the site (Yasseri et al. 2012). 


\section{Literature Review}

While there is an extensive research literature on Wikipedia and wiki-platforms emanating from the social sciences, media science, information science, education science, and other academic fields, surprisingly few of these studies are devoted specifically to questions of the drivers of the prosumers' engagement. The ones that tend to be of a quantitative and deductive nature are in most cases based on surveys of Wikipedia-contributors in various countries (Anthony et al. 2009; Baytiyeh and Pfaffman 2010; Cho et al. 2010; Kuznetsov 2006; Lund 2015; Nov 2007; Prasarnphanich and Wagner 2009; Schrorer and Hertel 2009; Xu and Li 2015; Yang and Lai 2010).

The drivers of wiki-contributors' engagement that are highlighted in the studies can be grouped into two clusters of motivations. The first cluster can be described as sociality-oriented, in that it relates to social relations and bonds persons enter into as wiki-contributors, and the norms, values, and ideologies associated with the wiki community. Thus, Kuznetsov (2006) argues that contributors to Wikipedia are motivated by altruism (the desire to share information and knowledge with others), reciprocity (the moral obligation of mutuality in gift exchange), community (the identification with and belonging to the group of self-asserted "wikipedians"), and reputation (the recognition and moral standing persons earn in the community through voluntary efforts). Other studies affirm the importance of these motivations (Anthony et al. 2009; Baytiyeh and Pfaffman 2010; Cho et al. 2010; Prasarnphanich and Wagner 2009; Schrorer and Hertel 2009; Xu and Li 2015), as well as the importance of contributors' allegiance to an ideology of free knowledge (Nov 2007).

The second cluster of motivations that is discussed in the research literature can be termed task-oriented, because it relates directly to the experience of writing and editing on wiki-platforms and the satisfaction contributors derive from this. Thus, in addition to the abovementioned motivations, Kuznetsov (2006) points to autonomy (the freedom to decide how and when to work) as a motivation for wiki contributors. Other studies highlight desires for learning and understanding and the exercise of competence as motivations for contributors (Baytiyeh and Pfaffman 2010; Nov 2007; Schrorer and Hertel 2009). Anthony et al. (2009) note how certain contributors to Wikipedia attach a purely intrinsic value to the efforts they put into the site. Similarly, other studies highlight the intrinsic motivations of contributors, as indicated by task-enjoyment or having fun (Baytiyeh and Pfaffman 2010; Nov 2007; Schrorer and Hertel 2009). In a related manner, Yang and Lai (2010) point to "internal self-concept motivation" as particularly important to contributors, whereas Lund (2015) highlights contributors' submission to a logic of gaming. 
The drivers of contributors' engagement that emerged from our interviews with contributors to the local history wiki fall well within the register of motivations described in the research literature and underscore the importance of what we have referred to as task-oriented drivers. However, our aim in this chapter is not to assess the relative importance of variously classified motivations of wiki-contributors in quantitative terms. Rather, it is through a qualitative indepth study to deepen the analytic understanding of such motivations and how these relate to the experiences of wiki-contributors. The purpose of this investigation is to construct a thick description (Geertz 1973) of the motivations of wikicontributors, which is premised on their own accounts of their involvement on the wiki-platform and sensitive to their own conceptualizations and legitimations of this engagement. This exploration of the motivations and experiences of wikicontributors provides a basis for theoretical specifications of wiki-contributors' engagement, in accordance with abductive analysis (Timmermans and Tavory 2012).

\section{Case Description}

lokalhistoriewiki.no was established in 2007-2008 by The Norwegian Institute of Local History (NILH), which for half a century has been a publicly financed national organization for professional historians involved in local history (Sprauten 2006, 5). As of 2017, the institute NILH is part of the National Library of Norway. A longstanding objective of the institute has been to promote amateur local history activities in Norway and to support the numerous local history associations that are found across the country. Since the 1990s, NILH has increasingly sought to make use of digital technology and the Web for these ends. Here, the institute found a common interest with members of the Norwegian Wikipedia community, who had been looking to establish a platform for writings on topics that are deemed too specific to be accepted on Wikipedia (Wiig 2018). ${ }^{2}$ From the outset, it has been an explicit policy of the lokalhistoriewiki.no that "no subject is too small" for publication on the site. Initially, the NILH wanted to develop a wiki-site on a dual model, with a section reserved for contributions from professional historians and another that invited amateur contributions. Eventually, it was decided on a model that is open to both categories.

2 A criterion for publication of articles on the Norwegian Wikipedia is that they should be of national or global interest. 
lokalhistoriewiki.no is based on the wiki software and is similar to Wikipedia in many respects. This includes the layout of articles with headlines and pictures, the systems of categories and of hypertext links for cross references as well as the policy of collective ownership of articles. As in Wikipedia, articles feature public records of editions and discussions of articles. In conformity with the encyclopedic genre, the content on lokalhistoriewiki.no is organized in an itemized structure and articles are usually couched in a reporting style, dominated by constative assertions and dense with factual information. Like Wikipedia, articles vary in size from several thousand words to only a few sentences. However, in addition to the "no subject is too small" policy, the local history wiki features several modifications of the Wikipedia model. One of these is that the local history wiki allows and encourages the contribution of articles with original research. Another is that the wiki is owned and operated by a publicly funded organization. All administrators on lokalhistoriewiki.no are employees at the NILH. Some of them are also among the most prolific contributors to the wiki. In light of these features, Sveum $(2010,245)$ notes that the local history wiki appears to be unique in so far as it seems to have no parallel in other countries.

As the activities on lokalhistoriewiki.no have grown over the years, it has come to play an important role in the NILH and parts of the institute's funding from the Ministry of Culture is now earmarked for the wiki. According to the former director of the institute:

During the last decade, the wiki has been the main activity for the institute in promoting knowledge-production, knowledge-dissemination and knowledge-exchange... The wiki should be an arena for co-creation. It should function as a laboratory, where professionals and amateurs with a magnitude of skills can contribute (Sprauten 2017, 303).

From 2008 to 2017, the number of registered contributors on lokalhistoriewiki.no grew from 240 to 2919. In 2017, 47,782 articles and 167,487 pictures had been published on the wiki and the yearly number of visits on the site was in excess of 1.3 million (Wiig 2018, 567). Although from time to time the NILH recruits individuals or groups from active local history communities, and provides professional assistance, most contributors do not have any formalized relationship with the institute.

A survey we carried out among all registered contributors to lokalhistoriewiki. no suggests that the typical contributors are men aged above 50 and with a high level of education. ${ }^{3}$ Three quarters of the respondents to the survey were male.

3 The survey was distributed by the NILH through e-mail to the registered users of lokalhistoriewiki.no in October 2018. There were 2,660 recipients of the survey. Out of these, 740 persons responded to the survey, a response rate of 28 percent. 
Three quarters were aged 51 years or older. More than 80 percent of the respondents had university education (36 percent at bachelor level, 41 percent at master level and 5 percent at $\mathrm{PhD}$ level). As was pointed out to us by administrators from the NILH, while there are about three thousand registered contributors to the wiki, the majority of these are active on an irregular basis only, while a small group contribute articles and editions on a continual basis. One administrator estimated this group to consist of about 80 to 100 persons.

\section{Data Collection}

The informants in our case study were drawn from the group of highly active contributors. ${ }^{4}$ We carried out 14 interviews with 15 informants. Among these, 11 contributors were formally unaffiliated to the NILH and four were administrators employed by the institute. The gender-, age- and education profile of our informants conforms to that of the total population of contributors of lokalhistoriewiki.no. Out of the 15 informants, only two were female. With a few exceptions, the informants were aged above 50 and several were pensioners or semi-retired from work. Most of the informants can be described as amateurs, in the sense that their local history writing was done on a volunteer basis, and in the sense that they had not held formal employment as historians, academic researchers or in related occupations. However, most of the informants had university-level education and several held master's degrees in history, some of which had been obtained at a late age, after working with local history on a volunteer basis for many years. During our last couple of interviews viewpoints from earlier interviews were frequent, and we were certain that we had reached a saturation point, where additional interviews would most likely confirm our impressions from interviews already conducted.

Although we had formulated an interview guide with a battery of questions related to overarching themes prior to conducting our interviews, we let the interviews develop according to their own internal dynamic, in line with the semistructured approach to qualitative interviews (Kvale and Brinkman 2009). The interviews took place either in the home or the office of the informants, or at a conference room at our university. The interviews lasted between 30 and 90 minutes. The recordings from the interviews comprise a total of 915 minutes, and 202 single spaced pages of interview transcripts. Most of the interviews were conducted with both researchers present as interviewers, taking turns in asking questions related to topics being discussed.

4 On two occasions in 2018, we selected persons from the top-ten list of active contributors and contacted these with requests for interviews. 
We allowed the informants to control the topicality of the conversation (Sanjek 2014) and we would ask them to elaborate on experiences, concerns, and viewpoints they brought on the table. By talking to the informants about their motivations for producing wiki articles, we wanted to unravel how they give meaning to their own actions. For some informants it has been difficult to give an account of their motivations, which may be due to the fact that they spend several hours a day producing articles for the wiki; as the wiki work is experienced as an everyday activity, anchored in one's life-world, it is a challenge to make explicit the reasons for one's actions. Our job as researchers has been to interpret the meanings that the informants ascribe to their actions. Through our study, we have investigated the vocabularies of motives available to the informants in this particular time and place (Mills 1940, 913), motives being "accepted justifications for present, future, or past programs or acts" (Mills 1940, 907). With our study, we have seeked to understand the motivations for wiki work on the grounds of in-depth interviews with highly active contributors to the local history wiki, in combination with the engagement of a broad spectre of social sicence literature. Such an abductive approach (Timmermans and Tavory 2012) helped us get a grip on the importance of craftsmanship, flow, and self-externalization for wiki work.

\section{Findings}

\section{Joys of Wiki Work}

The most striking finding from our interviews concerns the informant's strong engagement in activities related to the local history wiki. With respect to many of our informants, it can be stated without exaggeration that this was an engagement of a life-defining character. One measure of this was the amount of time and effort they put into the wiki. Most would do wiki work daily and usually for several hours. For some, a normal day would consist of little other than working on the wiki. Thus, one informant told us that: "During the last six months, I have spent every waking hour on this. I do this from when I wake up in the morning, until I go to bed". This person had been working on a historical dissertation on and off for decades and was euphoric that he had found an outlet for getting his writings published. His statement was echoed by several other informants. In many cases, it appears that the informants alternated between periods where they devote all their available time to the wiki and periods where the activity slows down for some time. As one informant told us: 
Now, I don't spend more than 3 hours a day [on the wiki] [laughs]. Earlier - and I am not joking here - I could eat breakfast and then go into my home office and start working on articles for the wiki and I would keep going until 11 PM. My only interruptions would be lunch, dinner, and the evening news broadcast.

Another informant explained: "Last fall I spent an enormous amount of time on this. I think I have spent 1,000 hours so far. I don't watch a lot of TV, to put it that way. I would say that I spend around 3 hours a day on producing material for the wiki. If you multiply that by 365 , well..." Here, one must take into account that the men who made these statements were retirees, or out of work for other reasons, and therefore had ample opportunities to indulge in these activities. However, this does not by itself provide an explanation as to why they come to devote so much of their time to this particular activity.

A second way in which the informants' engagement as contributors to the wiki was revealed was in their stated disregard for incentives and rewards that are exterior to the work experience itself, what we referred to above as sociality-oriented motivations. While lokalhistoriewiki.no encourages contributors to contribute original research, it is similar to Wikipedia in that contributors do not have individual property rights to articles they produce. The informants had little to gain from their engagement in terms of making an income or furthering a career as a professional researcher or writer. As noted, the research literature on Wikipedia highlights altruism, reciprocity, identification with wiki-communities, and reputation and standing in these communities as motivations for user involvement. None of these elements featured prominently in the accounts of motivations we gathered from the contributors to the local history wiki. lokalhistoriewiki.no is presented officially as an arena for "co-creation" and several informants welcomed the collective aspect of the wiki. However, in actuality it appears that the degree of collective writing on the local history wiki was quite limited compared to Wikipedia and informants rarely made use of the talk-pages on the articles (which on Wikipedia plays an important role as an arena of public deliberation and consensus formation on the content of articles (Wright 2010)). Apart from editions and advisory comments from the administrators at the NILH, contributors were in most cases the sole authors of articles. None of the informants appeared to attach much importance to the local history wiki as a social field in which to compete for positions. It was also notable in the interviews that informants downplayed the gift-giving aspect of the wiki work, making it clear that the desire to share information and knowledge to the public was a concern of secondary importance. When we pushed informants to explicate their motives for contributing to the wiki, the recurring answers was that they did this "for their own sake" or for "the fun of it". As one informant put it: 
I do it because it is fun! The process in itself is fun... but I also have to defend the amount of time I spend on this to my wife. Then I say things like 'it is important for our society, for our local society, that this information is preserved and presented'... and stuff like that she doesn't always buy into it though [laughs].

This statement is symptomatic of our interviews, in the sense that the informants would acknowledge that there are many reasons for wanting to contribute to the local history wiki, including altruistic motives. However, the principal reason for their engagement was found in the joy of the work experience itself. Similar findings appear in psychological research on the motivations of contributors to Wikipedia (see Loveland and Raegle 2013, 1297). More generally, this falls into place with the register of motivations described in the research literature on Wikipedia that we referred to as "task-oriented" in the literature review at the start of the chapter.

A third way in which the informants' engagement in the local history wiki was brought to light in our interviews was in their reflections on the obsessional qualities of these activities. Once they had started working on the wiki, several informants explained, the activity became almost like an obsession. There are always articles that need to be written, material that needs to be put online, research that needs to be done for an upcoming article. "All the red links must become blue!" one of the informants declared, referring to the system of hypertext on the wiki (blue links direct to published articles, red links to articles yet to be written). From our interviews, it appears that the obsessional pull wiki work exerted on informants had grown in tandem with their acquisition of skills and mastery of these writing tasks. As one informant put it:

I felt that it was important to get this work up and going. I felt that I was pushing a big rock, but I could not get it rolling. But then 'person X' [refers to another user on the wiki with whom he has been collaborating] came along, and then I thought: if it has started rolling, it will never stop.

Another informant referred to the work related to the wiki as a form of mental hygiene and that he needed to check in on the site many times every week.

In other interviews, the obsessional quality of wiki work was foregrounded as a form of collector mania. Several informants spontaneously described themselves as "collectors" and others agreed when we suggested this to them. Elaborating on the self-description as a collector, an informant talked about a series of articles he had written on a waterway system in Southern Norway. First, he wrote articles about all the rivers, lakes, and canal locks it consists of, moving on to articles about the timber industry and paper mills that were found along the waterway, turning to the railway line that connected to the waterway with all of its 
train stations etc. One of the great joys of wiki work, the informant explained, was this process of "complementing and completing the picture", as ever new threads of writing emerged. Over the years, this person had devoted himself to a variety of topics for shorter or longer periods of time. Many of these interests, he explained, had come about in accidental fashion, as he had stumbled on subjects he found fascinating, e.g. when he was travelling for work or vacation. From our interviews, it appears that several contributors to the local history wiki would similarly devote themselves over time to a random variety of topics.

Other informants would rather concentrate all their contributions to the wiki on a singular topic. Thus, another self-declared collector among the informants had written exclusively on a town in Northern Norway, where he for many years had been the head of the public library. As he was approaching the end of his leadership tenure, he had initiated a project of public dissemination of historical material from an archive that was kept at the library. After several years of experimenting, he decided that the project should focus on making the history of the houses and buildings in the town centre available online. Eventually, this led him to produce articles for the local history wiki, which he continued to do also after going into semi-retirement. At the time of our interview, he had been writing on the wiki for eight years and had produced near to one thousand articles, covering all the buildings in the town centre. Reflecting on the satisfaction this work gave him as a "collector", he noted that when accessing previously unknown sources of information, this process could take the form of intellectual discovery: “... it is very satisfying to see patterns emerge. Then you just - 'Wow! Yes!'”.

A fourth way in which the informants' engagement in the local history wiki was revealed was through the emphasis they placed on the quality of the products they and others made on the wiki. When informants affirmed that the time and efforts they spent on the local history wiki was for "fun" only, this should not be taken as a sign of a frivolous attitude to the quality of the articles they published on the wiki or a downgrading of the importance of these texts. On the contrary, in interviews it was made clear that the quality of the articles that feature on the wiki mattered a great deal to the informants and that this was an important premise for their engagement. Most obviously, this took the form of a concern that information presented on the wiki should be reliable and based on proper source-work. Several informants pointed out that they were grateful that the administrators from the NILH reviewed all articles, making suggestions for improvement and making sure that unserious articles were removed from the site. Some even indicated that they wished the institute would exert an even stricter quality regime in the wiki. The informants' concern with the quality of the wiki articles also tied in with an expressed appreciation of the encyclopedic genre or style of writing. Several informants talked with excitement about the use of hypertext links for making cross- 
references in the wiki and highlighted the opportunities this created for turning local history into national or even global history.

The emphasis informants placed on the quality of their writing products became particularly apparent when conversations steered onto the topic of Facebook groups dedicated to local history, which have mushroomed in Norway over the course of the past decade. Most of the informants were members of such groups or were otherwise familiar with them. When asked to compare these groups to the local history wiki, they all made it clear that, even though they sometimes found pictures and other information on the Facebook groups, these did not belong to the same category as the wiki. This was due not only to the lack of quality mechanisms at the Facebook groups, or their appeal to nostalgic sentiments; postings on the Facebook groups, it was pointed out, were evanescent and momentary occurrences. Wiki articles, by contrast, enter into a medium that they perceived as more permanent and a site for the cumulative growth of knowledge. An informant's project had been to transcribe an old paper record of the farm estates in the municipality where he lived into wiki articles. In the interview, it became apparent that the informant viewed this project as a form of salvage operation. The wiki articles were of a rudimentary nature, with basic historical information about the farms only. Now that he had completed this job, the informant indicated, it would be left to others to add substance to the articles in the years to come. Foregrounded here was a trust in the local history wiki as a durable technological platform and a store of knowledge that would continue to grow in the foreseeable future. The librarian we referred to above, who had written articles about all the buildings in his hometown, similarly highlighted the permanence and solidity of the local history wiki, pointing to the fact that it was owned and operated by the NILH and the National Library. "It will not be deleted", he noted.

\section{Discussion}

In our interviews, we were struck by the enormous amounts of time and effort contributors put into the wiki-platform, despite the apparent lack of pay-offs in the form of economic income, furthering of careers, status, prestige etc. The reasons for their engagement in the wiki-platform, emerging from our interviews, fall within the register of motivations we have referred to as task-oriented. To gain a deeper understanding of this engagement, we argue, one must recognize that the activities wiki-contributors devote themselves to is a form of unpaid intellectual work, and hence a socially mediated and culturally codified production of useful objects. Like Wikipedia, the lokalhistoriewiki.no platform has the form and am- 
bition of an encyclopedia and its contributors view wiki work as a serious knowledge production, characterized by permanence and cumulative growth of knowledge. In order to get an analytical grip on the joys of wiki work, one must recognize that the striving to get their writings "right" in accordance with the requirements of this cultural form is a concern of paramount importance to contributors.

On this background we argue that wiki-contributors exhibit craftsmanship, in Sennett's (2009) sense of skilled workers' desire to do good work for its own sake. The craftsman, Sennett notes, "represents the special human condition of being engaged (...), practically but not necessarily instrumentally” (2009, 20, italics in original). Elaborating on Sennett's concept of craftsmanship, we specify two distinct yet interrelated types of processes that are drivers of wiki-contributors' engagement. One of these relates to the satisfaction wiki-contributors attain from mastering the challenges involved in wiki work. To account for this theoretically, we draw on positive psychology of flow experiences (Csikszentmihalyi 2008[1991]). A prerequisite for such experiences, Csikszentmihalyi makes clear, is that persons' skills are adequate to the challenges at hand. Elster (1989) makes a similar assertion in his theoretical account of work as a vehicle of self-realization. Much like Csikszentmihalyi, Elster stresses that activities must involve mastery of suitable challenges in order to become vehicles of self-realization. However, in Elster's discussion of self-realization in work these psychological processes are incorporated into a broader theoretical framework, which includes the concept of self-externalization. This concept allows us to specify a second type of process that serves as a driver for wiki-engagement, namely the satisfaction that derives from making publicly available products. Whereas experiences of flow are essentially of a psychological nature, processes of self-externalization are essentially of a social nature. In wiki work, these processes tie into an integrated experience.

\section{Wiki Work and Craftsmanship}

In Sennett's rendering, craftsmanship "names an enduring, basic human impulse, the desire to do a good job for its own sake" $(2009,9)$. It is predicated on the application of complex, slowly acquired, skills of working and points to a much broader register of activities than its conventional meaning as manual labor. Essential to craftsmanship, Sennett notes, is the engagement (or what he alternatively terms commitment) of the craft worker - "if the craftsman is special it is because he or she is an engaged human being" (Sennett 2009, 21). This engagement, Sennett makes clear, is directed at the objects produced and the objective standards that apply in various domains of craftsmanship. It is a commitment to getting the product "right", an aspiration for quality. To the craftsman, 
therefore, work becomes a reward in itself rather than a means to another end. Sennett also makes frequent notice of the obsessional nature of craft work in his writing on this topic.

As such, our case study of the contributors to the local history wiki can be seen as an exemplary illustration of the exertion of craftsmanship. At the same time, the case of the local history wiki serves as an invitation to refine the notion of craftsmanship as a theoretical concept. In his writings on craftsmanship, Sennett recounts his assertions regarding the engagement of the craft worker and the inherent rewards of craft work to the point of mantras. However, when it comes to explaining how and by what specific processes this craft engagement and the satisfactions it confers on workers is brought about, his account has little to offer. In this regard, our study of contributors to the local history wiki can be a source of furthering understanding, by allowing for a specification of the processes that are at work in craftsmanship. In the sections that follow, we will argue that the power of wiki work to facilitate engaged craftsmanship is derived from its potency as a vehicle for experiences of flow and self-externalization.

\section{Wiki Work as a Vehicle for the Experience of Flow}

One way of understanding the obsessional pull wiki work exerts on our informants is to say that it is a channel for the experience of flow, as a form of optimal experience. Psychic entropy is the normal state of consciousness, Csikszentmihalyi asserts. It is a state we experience in everyday situations, e.g. at work or in the home, where we are subjected to multiple and contradicting impressions, demands, and emotions. Moreover, he notes that when not occupied, “...the mind is unable to prevent negative thoughts from elbowing their way to center stage" (2008[1991], 169). Flow is the opposite of entropy in that it “... creates order in consciousness, and strengthens the structure of the self" (Csikszentmihalyi 2008[1991], 57). Based on empirical studies of a number of activities, he summarizes how people describe the characteristics of optimal experiences:

a sense that one's skills are adequate to cope with the challenges at hand, in a goal-directed, rule-bound action system that provides clear clues as to how well one is performing. Concentration is so intense that there is no attention left over to think about anything irrelevant, or to worry about problems. Self-consciousness disappears, and the sense of time becomes distorted (Csikszentmihalyi 2008[1991], 71).

The accounts of wiki work we were offered by our informants clearly fits this description, as many reported that they tend to lose track of time while engaged in this work, and that it is hard to stop working once they're "in the zone". When 
talking about their experiences as contributors to the wiki, informants in effect described a "state in which people are involved in an activity that nothing else seems to matter; the experience itself is so enjoyable that people will do it even at great cost, for the sheer sake of doing it” (Csikszentmihalyi 2008[1991], 4).

What this suggests is that the wiki work of local history enthusiasts can become a vehicle for flow and that the desire for such optimal experience can be a powerful motivating factor. In fact, Csikszentmihalyi has himself written about the joy of producing history as an avenue for the experience of flow. Contrary to how persons can think of history, as a "dreary list of dates to memorize", when producing history for one's own amusement, through deciding "which aspects of the past are compelling... and... focusing on the sources and details that are personally meaningful... then learning history can become a full-fledged flow experience" (Csikszentmihalyi 2008[1991], 134).

A prerequisite for the experience of flow is that a person is performing a task of a nature that makes it a challenge, and that there are standards by which this performance can be assessed as more or less successful. Implied here is that if a task is experienced as trivial rather than a challenge, this may result in boredom or distraction. If, on the other hand, a task is experienced as an overwhelming challenge, this may result in paralysis or frustration. In both cases, this precludes the experience of flow. For flow to occur, a person must take on a challenge of suitable complexity, or a "challenge that can be met", as Elster $(1989,130)$ puts it. Compared to many other forms of writing, the wiki-format can be said to be conducive to sustained experiences of flow among writers. Opinions voiced in our interviews provide us with clues as to the reasons for this.

Reflecting on the reasons for his dedication as a contributor to the local history wiki, one informant highlighted his curiosity and desire for learning. Part of the attraction of writing articles on the wiki, he told us, was that it was a way of learning about subjects he was curious about. This points to an immediacy between the acts of acquiring sources of information and knowledge and of completing written products. As the informant dug deeper into the various subjects he was interested in, he would constantly add published wiki-articles to his stock.

A professional historian from the NILH, who was an administrator on the wiki, told us that he would probably continue to produce articles for the wiki after his retirement, because it is possible to write contributions in a relatively short span of time. The thought of producing a book as a retired historian was much less appealing, he said. When we asked another informant, who also had authored books on local history, if he was planning to write more books, he made it very clear that he would never take on a project like that again, as this would keep him preoccupied perhaps for as long as a year and a half. He much preferred to busy himself with writing for the local history wiki, in addition to short pieces for the 
local newspaper. If one considers the time spent and the amount of pages he has produced as a wiki-user, it probably exceeds that of a book by far. The crucial difference is that when writing the book, he was grappling with a singular task of daunting proportions and complexity, while the effort channelled into the local history wiki takes the form of small and independent writing tasks that are likely to provide him with an instant sense of mastery. ${ }^{5}$

We have noted that the articles that feature in the local history wiki are usually relatively short texts. To understand why the writing of such articles invites mastery, one must also consider the standards of assessment that apply in a wiki, and the flexibility of writing tasks that follow from this. It is in the nature of wiki articles that they are never finished (even though they tend to stabilise when consensus is reached among contributors), and that they always invite contributors to make revisions and additions to the text (cf. Wright 2010). In the wiki-format, it is acceptable for contributors to publish articles that are incomplete, so called "stub" articles, which serve as invitations to provide content. The task of writing a wiki article is usually of a limited scope compared e.g. to that of writing a book or journal article and the risk of being overwhelmed by this challenge is comparatively low. Adding to this is the itemized organization of knowledge on a wiki. To a local history wiki user who commits to a large project, say, of producing an account of all the school buildings in a municipality, this project may in effect dissolve into the writing of a host of separate small articles. Over time, this can provide the user with a constant supply of writing tasks, which each on their own are agreeable challenges and sources of flow.

\section{Wiki Work as a Vehicle for Self-externalization}

In a section above, we referred to an informant who, over a period of about a decade, had written nearly one thousand wiki articles, covering the history of all the buildings in his hometown. Two books have previously been written on the town's history, both published before the turn of the century. When we asked the informant if he in effect had produced the third edition of the town history with his contributions to the wiki, he confirmed that this was indeed how he thought of his writings. He confirmed also that he drew great satisfaction from having completed the project. This underscores the importance of self-externalization as another driver of wiki contributors' engagement.

5 Many authors do of course experience flow also when writing a book. Nevertheless, the wiki format can provide additional satisfaction through short-term gratification from rapid selfexternalization. 
While our informants clearly acknowledged the collective authorship principle that applies on the local history wiki, they also conveyed a clear subjective sense of authorship to their articles and talked frequently about "their" articles. Their insistence that they were not motivated by a search for prestige and position among the contributors to the wiki (or in other circles) did not mean that they were indifferent to the publication of their writings or that they did not take pride in this. It clearly mattered a great deal to see one's writings published on the site. In interviews, informants talked about the pleasure they gained from knowing that their articles featured on the wiki and from viewing these articles. When posting an article, an informant explained, he would look forward with excitement "to see the [published] product" and from time to time would enjoy himself looking through old articles that he was happy with.

In accordance with Sennett's (2009) discussion of craftsmanship, this can be interpreted as an affirmation by the informant of his "presence" in the objects he has produced. Thereby, the objects become a source of pride to him and serve as an "anchoring" in the real world, as Sennett puts it. A more precise theoretical account of this matter is found in Elster's (1989) discussion of the Marxist conception of self-realisation in work. An important part of self-realisation, for Elster, is self-actualisation, which points to the development and deployment of a person's abilities and powers in dealing with challenges. It corresponds to the concept of flow discussed in the previous section. Much like Csikszentmihalyi, Elster highlights the importance that challenges are of a complexity that is suitable to individuals' abilities. For self-realisation to occur, Elster argues, self-actualisation is not sufficient; it must be coupled with self-externalization. As used by Elster, the concept of self-externalization points to the public manifestation of individuals' productive activities. It points also to the necessity of objective, or publicly agreed upon, standards by which these products can be assessed by others, in order to become potential sources of recognition and self-esteem to the individual producer. Invoking Hegel's (1977) arguments on the centrality of the value of self-esteem to human beings, Elster notes that:

Esteem requires something that can be esteemed, some form of externalisation of one's inner self. It is of no avail to be a 'beautiful soul' if the soul remains ineffable and mute; the self must be made part of the public domain. (...) Other people form the indispensable function of assessing, criticising and praising one's performance; they provide the 'reality control' without which self-actualisation would be like a 'private language', a morass of subjectivity (Elster 1989, 136-137).

Applied to the case of the local history wiki, this means that if the reality and value of the efforts put into the site is to be affirmed, it is essential that these efforts be converted into public objects, i.e. wiki-articles. Without the published results, 
the efforts would be reduced to an idiosyncratic game of dubious value and reality. In this sense, the satisfaction wiki-contributors attain through the psychological process of flow can be said to be inseparable from the social process of self-externalization. If their wiki work was not converted into public objects, this would be a private game only which, probably, would reduce its potency as a vehicle for experiences of flow.

Even though the informants were not overtly concerned with the community of wiki contributors or the social character of their wiki work, its character as selfexternalization was an important premise for their engagement. The validity of this assertion was confirmed directly or indirectly in all our interviews, including an interview with a user who talked consistently about his wiki work as a form of personal amusement. This led us to ask the informant whether he would have produced these writings if they were not intended for publication on the wiki, but rather for "your desk drawer". He replied that:

No, then I would not have had the same drive... For me, the local history wiki is actually a way to move things from my drawer and into the public domain. When it is out there, it doesn't have to be used by anyone. But suddenly, one day someone will be looking for this or that and that someone can find the stuff I have published to be useful.

Again, this statement is symptomatic of our interviews. Here, informants were emphatic that they did not seek any immediate attention and praise for their articles. What was important to them, it emerged, was that the articles should be "out there", available to people in the future. Moreover, as we have pointed out above, it was important to them that the articles would be available on a serious platform, which is built to last.

One way of interpreting the emphasis on the quality, permanence, and cumulative character of the local history wiki that was voiced by our informants is to say that this affirms the wiki's weight and importance as a medium of selfexternalization. Adding to this is the visitation numbers of the local history wiki (1.3 million per year), which are unnoticeable compared to Wikipedia, but quite substantial in the Norwegian local history context. Like Wikipedia, lokalhistoriewiki.no is open to all competent contributors. For our informants, this meant that they could write articles with the assurance that, while these texts may be subject to revisions by others and perhaps altered in ways they did not wish, they will not have their writing products rejected from publication and thus be deprived of self-externalization. To persons who are more bent on getting the products of their writing "out there" in the public than building a career as a professional writer, this can be a major incitement for engaging in wiki work. Reflecting on this feature of the local history, one informant turned to a religious vocabulary 
and told us that "I still thank the Lord for letting me discover this wiki". Another informant resorted to similar language, saying that: "It was like a gift from heaven. There are no restrictions, it is open. That was like a revelation to me”.

\section{Conclusion}

There are plenty of joys associated with wiki work that foster engagement among contributors. Our aim in this chapter has been to analyse the accounts contributors to a local history wiki provides for their involvement with the platform. Based on this data we have put forward an approach for understanding contributors' engagement in wiki work, in the sense of a dedication to do good work for its own sake. To fully understand the accounts offered by the wiki contributors, we turned to psychological theories of optimal experiences and sociological theories of individual motivations for work. Our study shows that wiki work is a strong vehicle for psychological experiences of flow and an easily accessible platform for self-externalization, and that these processes in turn come to facilitate engaged craftsmanship. This combined theoretical approach will most likely prove fruitful also for studies of contributors' motivations on other forms of user generated content platforms.

\section{References}

Anthony, D., S. W. Smith, and T. Williamson. "Reputation and Reliability in Collective Goods: the Case of the Online Encyclopedia Wikipedia”. Rationality and Society, 21, no. 3, 283-306, 2009.

Baytiyeh, H. and J. Pfaffman. "Volunteers in Wikipedia: Why the Community Matters". Educational Technology \& Society, 13, no. 2, 128-140, 2010.

Cho, H., M. Chen, and S. Chung. "Testing an Integrative Theoretical Model of Knowledge-sharing Behavior in the Context of Wikipedia". Journal of the American Society for Information Science and Technology, 61, no. 6, 1198-1212, 2010.

Csikszentmihalyi, M. Flow: The Psychology of Optimal Experience. New York, NY: Harper Perennial, 2008 [1991].

du Gay, P. "The Tyranny of the Epochal: Change, Epochalism and Organizational Reform”. Organization, 10, no. 4, 663-684, 2003.

Elster, J. "Self-realisation in Work and Politics: the Marxist Conception of the Good Life". In Elster, J. and K. O. Moene (eds), Alternatives to Capitalism, pp. 127-158. Cambridge: Cambridge University Press, 1989.

Firer-Blaess, S. and C. Fuchs. "Wikipedia: an Info-communist Manifesto". Television \& New Media, 15, no. 2, 87-103, 2014.

Geertz, C. The Interpretations of Cultures. New York, NY: Basic Books, 1973. 
Hegel, G. W. F. Phenomenology of Spirit. New York, NY: Oxford University Press, 1977.

Henningsen, E. and H. Larsen. "The Digitalization Imperative: Sacralization of Technology in LAM Policies”. In Audunson, R., H. Andresen, C. Fagerlid, E. Henningsen, H-C. Hobohm, H. Jochumsen, H. Larsen, and T. Vold (eds), Libraries, Archives and Museums as Democratic Spaces in a Digital Age. Berlin: De Gruyter Saur, 2020.

Kvale, S. and S. Brinkmann. Interviews. Learning the Craft of Qualitative Interviewing. Los Angeles, CA: Sage Publications, 2009.

Kuznetsov, S. "Motivations of Contributors to Wikipedia”. ACM SIGCAS Computers and Society, 36, no. 2, 1-7, 2006.

Loveland, J. and J. Raegle. “Wikipedia and Encyclopedic Production”. New Media \& Society, 15, no. 8, 1294-1311, 2013.

Lund, A. Frihetens rike. PhD Thesis, Uppsala University, Sweden, 2015.

Mills, C. W. "Situated Actions and Vocabularies of Motive". American Sociological Review, 5 , no. 6, 904-913, 1940.

Nov, 0. “What Motivates Wikipedians?". Communications of the ACM, 50, no. 11, 60-64, 2007.

Prasarnphanich, P. and C. Wagner. "The Role of Wiki Technology and Altruism in Collaborative Knowledge Creation”. Journal of Computer Information Systems, 49, no. 4, 33-41, 2009.

Ritzer, G., P. Dean, and N. Jurgenson. "The Coming of Age of the Prosumer”. American Behavioral Scientist, 56, no. 4, 379-398, 2012.

Sanjek, R. Ethnography in Today's World: Color Full Before Color Blind. Philadelphia, PA: Univiversity of Pennsylvania Press, 2014.

Shachaf, P. and N. Hara. "Beyond Vandalism: Wikipedia Trolls". Journal of Information Science, 36, no. 3, 357-370, 2010.

Schroer, J. and G. Hertel. "Voluntary Engagement in an Open Web-based Encyclopedia: Wikipedians and Why They do it”. Media Psychology, 12, no. 1, 96-120, 2009.

Sennett, R. The Craftsman. New Haven: Yale University Press, 2009.

Sprauten, K. Forord. Råd, Ressurser og rettleiing. NLI gjennom 50 år. Oslo: Norsk lokalhistorisk institutt, 2006.

Sprauten, K. “Norsk lokalhistorisk institutt (NLI) i perioden 2006-2016. Noen hovedtrekk”. Heimen, 54, no. 4, 302-318, 2017.

Sveum, T. "Local Studies Collections, Librarians and the Norwegian Local History Wiki”. New Library World, 111, no. 5/6, 236-246, 2010.

Timmermans, S. and I. Tavory. "Theory Construction in Qualitative Research: From Grounded Theory to Abductive Analysis". Sociological Theory, 30, no. 3, 167-186, 2012.

Toffler, A. The Third Wave. New York, NY: William Morrow \& Co, 1980.

Van Dijck, J. The Culture of Connectivity. A Critical History of Social Media. New York, NY: Oxford University Press, 2013.

Wiig, M. "Historien om hvordan NLI ble fanget i nettet. Rapport fra en vevkjerring". In Alsvik, O., H. P. Hosar, and M. Wiig (eds), I dørtrekken fra Europa. Festskrift til Knut Sprauten $i$ anledning 70-årsdagen 22. juni 2018, pp. 549-585. Oslo: Nasjonalbiblioteket, 2018.

Wright, E. O. Envisioning Real Utopias. London: Verso, 2010.

Xu, B. and D. Li. "An Empirical Study of the Motivations for Content Contribution and Community Participation in Wikipedia”. Information \& Management, 52, no. 3, 275-286, 2015.

Yasseri, T., R. Sumi, A. Rung, A. Kornai, and J. Kertész. "Dynamics of Conflicts in Wikipedia”. PLoS ONE, 7, no. 6. e38869, 2012. https://doi.org/10.1371/journal.pone.0038869.

Yang, H.-L. and C.-Y. Lai. “Motivations of Wikipedia Content Contributors". Computers in Human Behavior, 26, no. 6, 1377-1383, 2010. 


\section{The Authors}

Herbjørn Andresen is Associate Professor of Archival Science at the Department of Archivistics, Library and Information Science at Oslo Metropolitan University. He holds a doctoral degree in Legal Informatics from the University of Oslo.

Ragnar Audunson is Professor of Library and Information Science at Oslo Metropolitan University. Over the last 25 years he has done extensive research on the social role of public libraries. He holds a doctoral degree in Political Science from the University of Oslo.

Roger Blomgren is Professor of Library and Information Science at the University of Borås. His primary research focus is on how reforms and objectives in cultural policy fields are implemented in policy making and what role organization, steering, and professions have in this work. He holds a doctoral degree in Political Science from Gothenburg University.

Sunniva Evjen holds a PhD in Library and Information Science from the University of Copenhagen and her research interests include the social role of public libraries, the professional role of librarians and the library institution. She is currently an Associate Professor at Oslo Metropolitan University.

Cicilie Fagerlid was a Postdoctoral Fellow at the ALMPUB-project, Oslo Metropolitan University. Previously, she has studied performance poetry in cosmopolitan and working-class Paris and the creation of new ways of being British South-Asian in London, both at the Department of Social Anthropology, University of Oslo. Currently, she writes an ethnography from Oslo's public libraries.

Geir Grenersen is Professor of Documentation Studies at the University of Troms $\emptyset$ - the Arctic University of Norway. He holds a doctoral degree (dr.polit) from the same institution. His research interest is first and foremost related to Sámi culture and living conditions, and particularly the role of libraries as connected to assimilation and resistance of Sámi culture and language.

Erik Henningsen is Research Director at the Department for Welfare, Democracy and Governance at the Norwegian Institute for Urban and Regional Research, Oslo Metropolitan University. He holds a PhD in Social Anthropology from the University of Oslo and has worked extensively on issues related to cultural policy.

Hans-Christoph Hobohm is Professor of Library and Information Science and head of the master's program "Information Sciences" at the University of Applied Sciences in Potsdam, Germany. His main teaching and research interests are library management and information behavior as well as the foundations of information sciences. He recently published the German translation of David Lankes' Expect more.

Isto Huvila is Professor of Information Studies at the Department of ALM (Archival Studies, Library and Information Studies and Museums and Cultural Heritage Studies) at Uppsala University in Sweden. He also is lecturer (Adjunct Professor) at Åbo Akademi University. His research interests range from information and knowledge management and information work to professional and participatory information practices in libraries, archives, and museums. Huvila holds a doctoral degree in Information Studies from Åbo Akademi University, Finland. 
Henrik Jochumsen is Associate Professor at the Department of Communication, University of Copenhagen. From a sociological point of departure, he has done research on the development of the public library and the relationship between the library and the surrounding society. He holds a doctoral degree in Documentation Science from the University of Troms $\varnothing$.

Jamie Johnston is an Associate Professor of Library and Information Science at Oslo Metropolitan University. Her research interest lies in the role public libraries and information play in relation to international migration, settlement and integration, and citizenship. She holds a doctoral degree in Library and Information Science from Oslo Metropolitan University.

Håkon Larsen is Professor of Library and Information Science at Oslo Metropolitan University. His main research areas are cultural sociology, cultural policy studies and public sphere theory. He holds a PhD in Sociology from the University of Oslo.

Casper Hvenegaard Rasmussen is an Associate Professor of Library and Information Science at the University of Copenhagen. Over the last 20 years he has done research on public libraries, cultural mediation, and cultural policy. He holds a doctoral degree in Media and Documentation Studies from the University of Tromsø.

Kerstin Rydbeck is Professor of Information Studies at Uppsala University, and holds a doctoral degree in Literature. Her research has focused on the sociology of literature and on the history of popular education. She is currently writing a book about reading communities in contemporary Sweden.

Roswitha Skare is a Professor of Documentation Studies at the University of Troms $\varnothing$ - The Arctic University of Norway. Her research interests include documentation theory, the impact of paratexts on literature and film, the performance practices of silent films, as well as the LAM-field and social media. She holds a doctoral degree in Documentation Science from the University of Tromsø.

Kjell Ivar Skjerdingstad is a Professor of Library and Information Science at Oslo Metropolitan University. His main research interests is in the mediation of literature and the reading experience. He holds a doctoral degree from the University of Agder in Scandinavian literature.

Sigrid Stokstad works as a Senior Researcher at the Norwegian Institute for Urban and Regional Research, Oslo Metropolitan University. She holds a PhD in Public Law from the University of Oslo. The legal framework for multi-level governance, and specifically local implementation of national policies, is her main research interest.

Máté Tóth is head of the Research Department at Hungarian Library Institute, National Széchényi Library of Hungary and Assistant Professor at the Library and Information Science Department at the University of Pécs. His present research focuses on digitization and policy development in public libraries. He holds a doctoral degree in Library and Information Science from the Loránd Eötvös Science University of Budapest.

Tonje Vold is Associate Professor at the Institute of Archistics, Library and Information Studies at Oslo Metropolitan University. She holds a PhD in Comparative Literature on South African Literature, and does research connected to mediation of literature, sociology of literature and postcolonialism. In 2019, she published the monograph $\AA$ lese verden. Fra imperieblikk og postkolonialisme til verdenslitteratur og økokritikk (Reading the World. From Imperial Eyes and Postcolonialism to world literature and Ecocriticism). 
Andreas Vårheim is Professor of Media and Documentation Studies at the Department of Language and Culture at the University of Troms $\emptyset$ - The Arctic University of Norway. His present research focuses on information policy development and LAM institutions. He holds a doctoral degree in Political Science from the University of Troms $\varnothing$. 



\section{Index}

Aabø, Svanhild 286, 287, 291

Aas, Karl 325, 340, 341

ABM-utvikling 44

age $247,253,255,256,261,266$

aggregator $117,118,120,121,124,126,128$, 129

agora 291

Alexander, Jeffrey C. 68

Allseitigkeit 225

allsidighet 225-227, 229-233, 235, 238-240, 242, 243

American Society of Archivists 39

analogue 91, 92, 94-97, 102, 107

archival law 37, 39, 42

archival legislation 37,40

archival statistics $39-41,44$

archive $74,75,77,82,84,92,96,97,100$, 101, 103, 105-107

archivist 166, 167, 170, 176, 177, 179, 181, 182

Arendt, Hannah 308

Aristotle 288, 290, 291

assimilation 325, 327-331, 333, 336, 340

attitude 185, 186, 188-190, 192, 193, 202, 204

Audunson, Ragnar 286, 287, 291, 293

Bakhtin, Mikhail 290, 291

Barthes, Roland 230, 238

Basiles, Jonathan 241

Berge, Torill 226, 232, 235, 239

Bible, the 242, 243

Bildung 306, 320

Bjørnson, Bjørnstjerne 339

Bojer, Johan 339

book 297

book club 286, 290, 295-302

border 237, 238

Börjesson, Angelica 75

born-digital 91, 92, 95-98, 105, 106, 108

bottom-up 94, 102, 107

Buschman, John E. 165, 285, 288 catalogue 185, 186, 195, 199

Central and Eastern Europe 111, 123, 125, 128, 129

children $305,306,308,310,314,315,317$, 321-323

club 297

coexist $285-287,290,292,294,299,300$, 302

collaboration 157

collection 185, 188, 192-194, 199, 204

competence center 116, 117, 122, 123, 128, 129

connection 231-233, 235, 238

contribution 186, 188-190, 193-197, 199 , 202, 204, 205

convergence $133-137,142,145,146$, 153-155, 157

conversation 213, 215, 218, 220, 222

conversion 140

convivial 287, 290, 293, 294, 298, 299, 302

country 247, 255, 259, 262

craftsmanship 345, 350, 355, 359, 361

crowdsourcing 187-189, 194, 195, 197, 202, 204, 250, 252, 265, 267

Csikszentmihalyi, Mihaly 355-357, 359

cultural heritage 276,279

cultural policy $54,76-78,83,86,87$

culture sector 53

curatorship 185

Czech Republic 111, 113, 116, 118, 119 , 125-129

Dahl, Hans Fredrik 55

de Certeau, Michel 229

Debord, Guy 290, 299

democratic public discourse 276

democratic value 165

Denmark 166, 167, 169, 171, 177, 182, 189, 192, 195, 272, 278, 280

deterministic force 86

dialogic communication 222

Digisam 83-85

digital access 250-252, 261, 266

digital empowerment 248

2 Open Access. (C) 2020 Ragnar Audunson et al. (c) BY-NC-ND This work is licensed under a Creative Commons Attribution-NonCommercial-No-Derivatives 4.0 License. https://doi.org/10.1515/9783110636628-019 


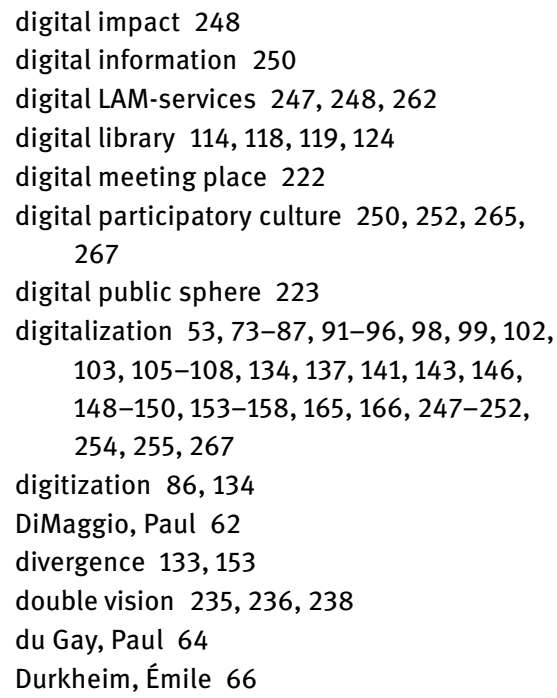

European Union Structural Funds 121, 122

Europeana 114, 116, 125, 126, 128

everyday 285

everyday information 276

everyday life 229, 236, 238, 241

experience 195

Facebook 207-213, 215, 221-223, 251, 261

fear of digitalization 249

Finnmark Library 335

flow 345, 350, 355, 356, 359, 361

formal framework 105, 106

framing 63

frequency $207,212,220$
Friis, J. A. 340

funding $111-119,125,126,128,129$

Garborg, Arne 339

gender 247, 253, 255, 258, 261

generated content 209

Germany 167, 169-171, 174, 177, 180-182, 272-274, 276-279, 281, 283

Gilroy, Paul 290, 294, 302

Gloppen 226, 227, 231, 233, 236, 238, 241, 242

Graeber, David 67

Gray, Clive 165

Gullestad, Marianne 309

Habermas, Jürgen 11-13, 281

hard means of implementation 93, 94, 96, 98, 102, 106

Helseth, Tore 55

historical institutional theory 135

historical institutionalism 75

home Internet access 247, 253, 260, 266

Hungary $111-114,116,119-121,125-129,166$, $167,169,170,177,181,182,272,278$, 280, 282

Huvila, Isto 165

Ibsen, Henrik 339

IFLA 25, 28

Ihle, Annette 339

immigration status 247, 258, 261

imperative $91,94,96,105,107$

implementation 91-93, 97-103, 105-108

income 247, 253, 255, 260, 261

information society 73

institutional isomorphism 61

interaction 208, 221

interest in history 275

International Council of Museums (ICOM) 31

ISO standard 28, 34, 39, 40

Jaeger, Paul T. 4, 271

Johannesen, Kurt 236

Kilelland, Alexander 339

Killengreen, J. A. 325, 328, 331, 333-335, 340,341

Klinenberg, Eric 165, 285, 288, 302, 308 
LAM-field 55, 134, 136-138, 140, 148-150, 154-156

LAM-organization 54

LAM-policy 54

LAM-sector 91, 93-95, 97, 98, 106, 108

Lankes, R. David 16, 165

Larsen, Anders 325, 330, 336-341

law 93, 98-103, 105

layering and drift 140

leisure activities 276

librarian $166,167,182$

library $74,75,77,80-82,85,87,88,92,97$,

$98,101,103,107,210,213,215,216,223$

library law 26, 28, 42, 43

library legislation 25,42

Library of 100 talents 306

library philosophy 231

library services 307

library space 305-308, 310, 313, 318, 321

library statistics 28,29

library users 305,307

Lie, Jonas 339

liveable community 274,275

lokalhistoriewiki.no 347, 348, 351, 354, 360

Lumholtz, Carl 339, 340

MacNeil, Heather 165

mass digitization $117,119,123$

materiality 226, 238, 241, 242

matter 241

McCall, Vikki 165

mediation of literature 238

meeting place $165,276,277$

Metha, Jal 75

Mierzecka, Anna 48, 52

Modern breakthrough 326, 332, 336, 337, 339,341

motivation 185, 346, 350, 351, 354, 361

museum $74,75,77,80,82,84,88,92$, 95-98, 100-103, 107, 207, 209-212, $216,218,222,223$

museum law 33, 42

museum legislation 31, 42

museum professionals $166,168,171,177$, $178,180,181$

museum statistics $34-36$ national archive $120,122,124,141,142,144$, 147-150, 153-157

national budget $91,92,99,103,105,108$

national gallery 124,125

national library $119,121-125,127,140-144$, 147-158

National Library of Norway 347

national museum 120

New Archival Thinking 165

New Librarianship 165

New Museology 165

"new" roles of libraries 279

Nordic Council of Ministers 34

Norway $166,167,169,177-179,182,187$, $189,192,196,197,272,278,280$

Norwegian Archive, Library, and Museum Authority 153

Norwegian Institute of Local History 347

Norwegian Library Act 225

number of library visits 273

one-way perspective 221

organization 111-116, 118, 125, 128, 129

Pálsdóttir, Ágústa 48, 52

paradigm changes 165

paradigmatic ideas 75

participation $187,204,286-288,290,298$, 299, 302, 305-308, 320, 321

participatory interaction 165

participatory library 308

participatory turn 42,43

Persen, Isak 326, 336-341

physical collection 226

physical LAM-institution 248

place 226, 233

Poland 111-114, 116, 121-123, 125, 126, 128, 129

policy imperative 73

popularity 209

population survey $271,272,279,280$

Powell, Walter W. 62

professional identities 306

professional practice 225

public library 207-211, 221, 223, 225, 226 , 236, 238, 240, 308

public sphere 106, 108, 165, 166, 222, 223 
public-private partnership 119, 121, 123

publics 307

Rasmussen, Casper Hvenegaard 305, 308, 313

relevance 239,240

reorganization $134,138,142,145,147$, 150-153, 157

resistance 325,329

roles and competences of librarians 281

Ross, Max 165

rural/urban 255

sacralization 55

Sagai Muittalægje 329, 330, 336, 341

Sámi Parliament 327

Sámi population 325, 326, 328, 332

Sámi public sphere 325, 329, 331, 335

Schuldt, Karsten 48, 52

self-externalization $345,350,355,356,358$, 361

Sennett, Richard 285, 290, 291, 293, 294, 296, 302, 355, 359

Simon, Nina 165

situation 285, 286, 288, 290, 291, 294, 299 , 302

Slovakia 111, 113, 116, 123, 125-129

social media 207-210, 213, 219, 221, 222

social turn 165

social value attributed to LAM-institutions 274

soft means of implementation 93, 94

square 291, 302

strategy $113,118-122,125,126$ structural funds $115-117,123,125-127,129$

survey $247,253,261,265,267$

Sweden $166,167,169,177,179,182,189$, 195-197, 202, 272, 278, 280

Swedish National Library Strategy 80

Switzerland 272, 273, 278, 280

task-centered approach 309

Theimer, Kate 165

third community wave 165

TioTretton 306

top-down 93, 99, 107

transformative change 138,139

two-way communication 221

urban/rural 247, 253, 260

user commitment 215

user engagement 213, 215, 217, 219, 220

user involvement 209

user participation 207, 223, 306

users $185,186,188,190,192-195,197,199$, 202, 204

Vergo, Peter 165

virality 209, 215, 217, 218, 220, 221

Visegrád countries 111, 113, 118, 126-129

white papers $56-60,91,93,96,107$

Widdersheim, Michael 282

wiki 346

Wikipedia 345, 346

Zachariassen, Ketil 330 